
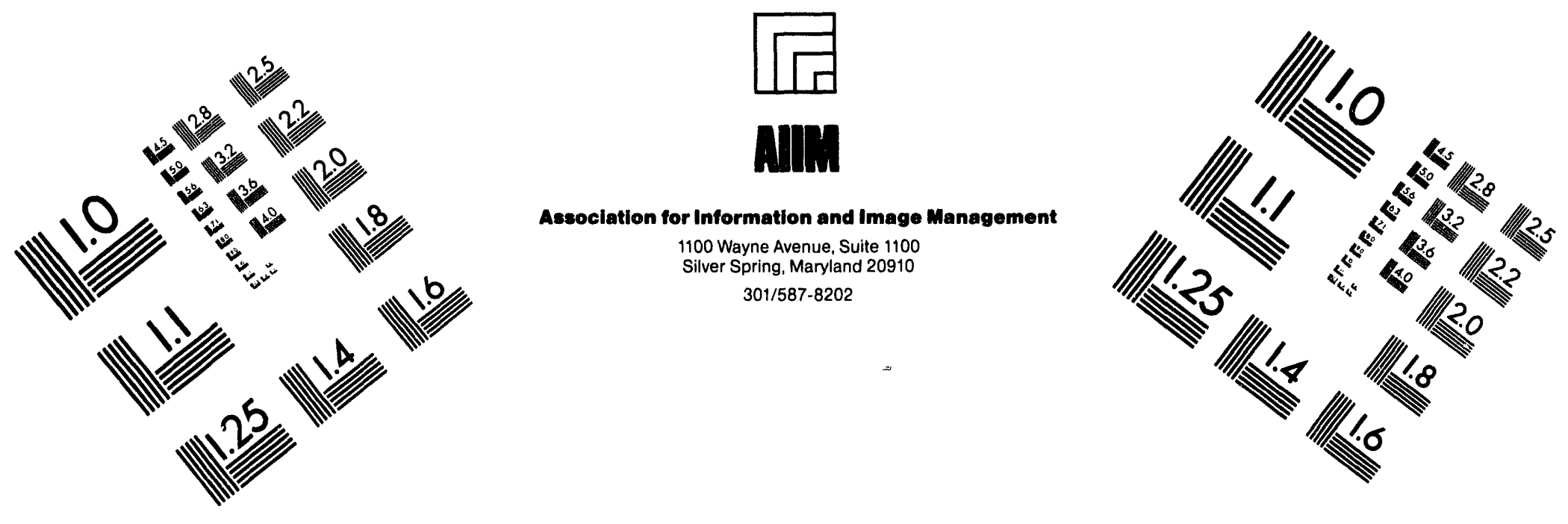

Centimeter

$\begin{array}{llllllllllllllll}1 & 2 & 3 & 4 & 5 & 6 & 7 & 8 & 9 & 10 & 11 & 12 & 13 & 14 & 15 & \mathrm{~mm}\end{array}$

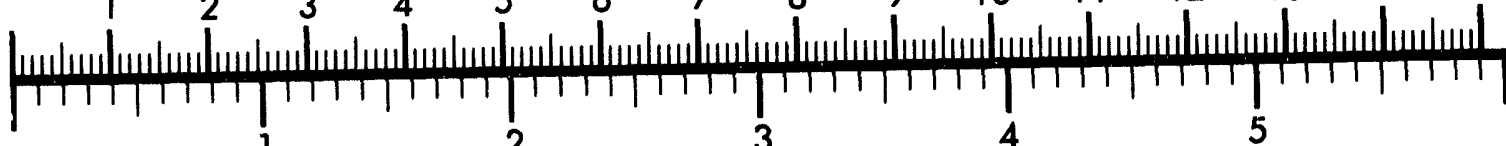
Inches
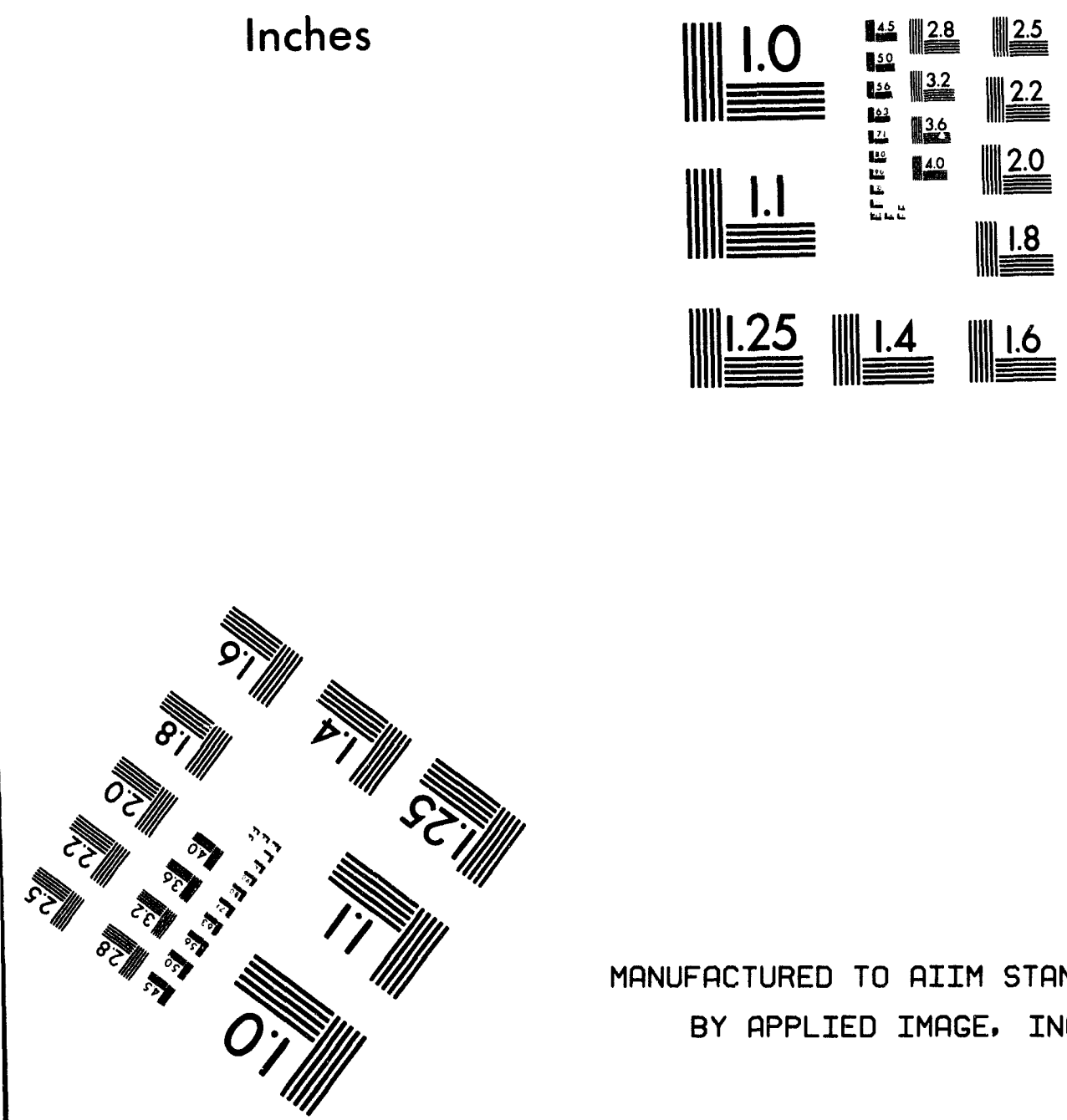

MANUFACTURED TO AIIM STANDARDS

BY APPLIED IMAGE, INC.

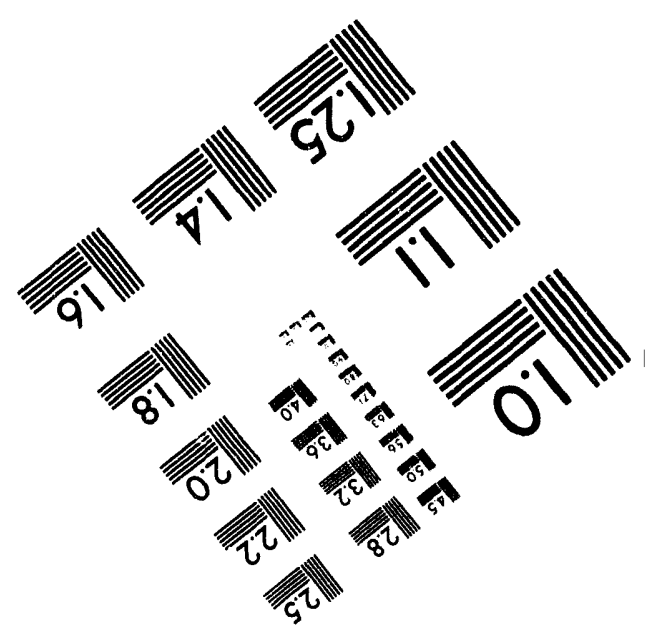



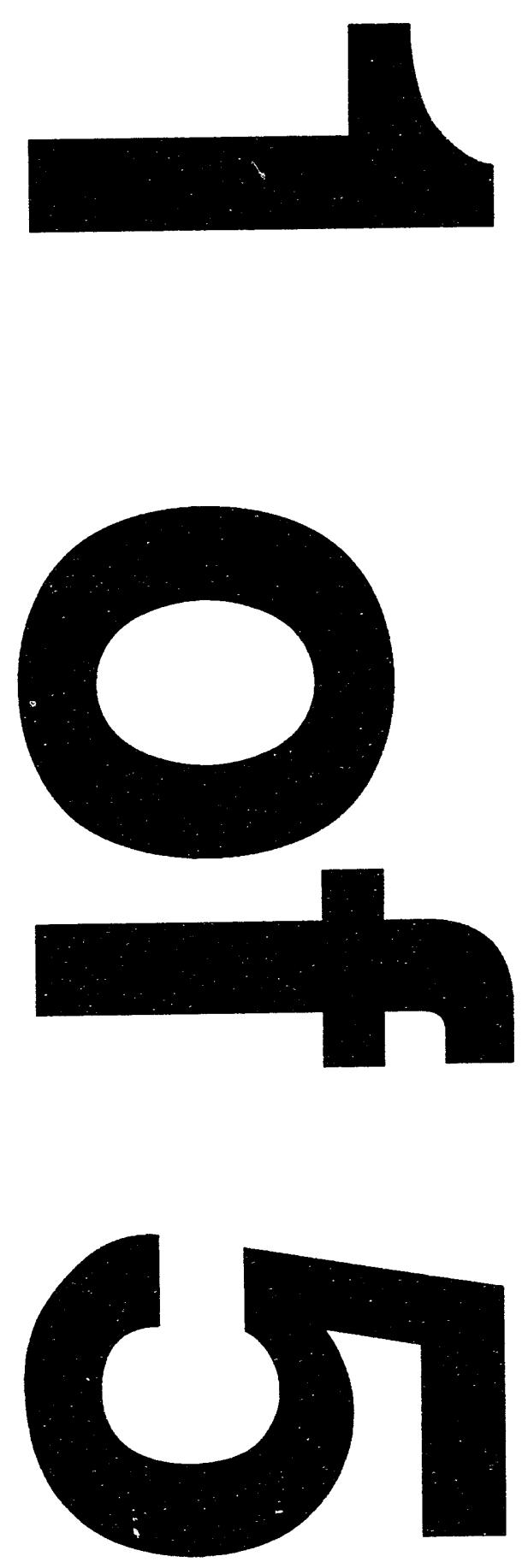
ORNL/TM-12674

\author{
Metals and Ceramics Division \\ CERAMIC TECHNOLOGY PROJECT \\ SEMIANNUAL PROGRESS REPORT FOR \\ APRIL 1993 THROUGH SEPTEMBER 1993
}

D. R. Johnson

Project Manager

Date Published: April 1994

NOTICE: This document contains information of a preliminary nature. It is subject to revision or correction and therefore does not represent a final report.

\author{
Prepared for \\ U.S. Department of Energy \\ Assistant Secretary for Energy Efficiency and Renewable Energy \\ Office of Transportation Technologies \\ Materials Development Program \\ EE 5101000
}

Prepared by the

OAK RIDGE NATIONAL LABORATORY

Oak Ridge, Tennessee 37831-6285

managed by

MARTIN MARIETTA ENERGY SYSTEMS, INC.

for the

U.S. DEPARTMENT OF ENERGY

under Contract DE-AC05-840R21400

Oromineution of THIS DOEUMENT is UMLIMITEO 
ORNL/TM-9325

ORNL/TM-9466

ORNL/TM-9497

ORNL/TM-9673

ORNL/1M-9947

ORNL/TM-10079

ORNL/TM-10308

ORNL/TM-10469

ORNL/TM-10705

ORNL/TM-10838

ORNL/TM- 11116

ORNL/TM-11239

ORNL/TM-11489

ORNL/TM- 11586

ORNL/TM-11719

ORNL/TM- 11859

ORNL/TM-11984

ORNL/TM-12133

ORNL/TM-12363

ORNL/TM-12428
Period March 1983-September 1983

Period October 1983-March 1984

Period April 1984-September 1984

Period October 1984-March 1985

Period Apri1 1985-September 1985

Period October 1985-March 1986

Period Apri1 1986-September 1986

Period October 1986-March 1987

Period Apri1 1987-September 1987

Period October 1987-March 1988

Period April 1988-September 1988

Period October 1988-March 1989

Period April 1989-September 1989

Period October 1989-March 1990

Period April 1990-September 1990

Period October 1990-March 1991

Period April 1991-September 1991

Period October 1991-March 1992

Period April 1992-September 1992

Period October 1992-March 1993

Research sponsored by the U.S. Department of Energy, Assistant Secretary for Energy Efficiency and Renewable Energy, Office of Transportation Technologies, as part of the Ceramic Technology Project of the Materials Development Program, under contract DE-AC05-840R21400 with Martin Marietta Energy Systems, Inc. 
CONTENTS

SUMMARY . . . . . . . . . . . . . . . . . . . . . . 1

0.0 PROJECT MANAGEMENT AND COORDINATION . . . . . . . . . . . . . 3

1.0 MATERIALS AND PROCESSING . . . . . . . . . . . . . . 5

INTRODUCTION . . . . . . . . . . . . . . . . . . 5

1.1 MONOLITHICS . . . . . . . . . . . . . . . . 7

1.1.2 Silicon Nitride ................ 7

Characterization of Attrition Milled Silicon

Nitride Powder (NIST) . . . . . . . . . . 7

Microwave Sintering of Silicon Nitride (ORNL) . . . 14

Development of a High Quality, Low Cost Silicon

Nitride Powder (The Dow Chemical Company) . . . . 19

Cost Effective Sintering of Silicon Nitride

Ceramics (SIU-C) .............. 33

Cost Effective Process Silicon Nitride Engine

Components (Golden Technologies Company, Inc.) . . 38

1.1.4 Processing of Monolithics ............ . 47

Improved Processing (Norton) .......... . 47

Improved Processing (ORNL) . . . . . . . . 56

1.2 CERAMIC COMPOSITES . . . . . . . . . . . . . . . 63

1.2.2 Silicon Nitride Matrix ............. 63

Optimization of Silicon Nitride Ceramics

(University of Michigan) ........... 63

Characterization of Grain Boundary Phases in

Silicon Nitride Ceramics (University of

Michigan) ................. 68

Reaction Sintering of $\alpha^{\prime} / \beta^{\prime}$ SIAION Ceramics

(University of Michigan) ..... . . . . . 73

Hot Pressed a-SiAION Ceramics (University of

Michigan) ..................... 
In-Situ Reinforced Silicon Nitride (GCCD) . . . 80

1.2.3 0xide Matrix .............. 85

Dispersion-Toughened Ceramic Composite (ORNL) . . . 85

1.2.4 Silicate Matrix . . . . . . . . . . . 95

Characterization and Testing of Low-Expansion

Ceramic Materials (ORNL) ......... 95

1.3 THERMAL AND WEAR COATINGS ....................... 99

Fabrication and Testing of Corrosion-Resistant

Coatings (ORNL) ............... 99

Development of Adherent Coatings to Reduce Contact

Stress Damage of Ceramics (Boston University) . . 110

Wear-Resistant Coatings (Caterpillar) . . . . 123

Development of Wear Resistant Ceramic Coatings

for Diesel Engine Components (Cummins Engine

Company, Inc.) ............ 126

Thick Thermal Barrier Coating (TTBC) Systems

for Low Heat Rejection Diesel Engines

(Caterpillar) .............. 134

1.4 JOINING ............................ 139

1.4.1 Ceramic-Metal Joints ............ 139

Joining of Ceramics for Heat Engine Applications

(ORNL) .................. 139

1.4.2 Ceramic-Ceramic Joints ........... 145

Analytical and Experimental Evaluation of Joining

Silicon Carbide to Silicon Carbide and Silicon

Nitride to Silicon Nitride for Advanced Heat

Engine Applications (Norton) ........ 145

1.5 CERAMIC MACHINING . . . . . . . . . . . 153

Cost-Effective Ceramic Machining (ORNL) . . . . 153

Grinding Optimization for Advanced Ceramics

(NIST) ................ 157

Chemically Assisted Machining of Ceramics

(NIST) ............... 168 
High-Speed, Low-Damage Grinding of Advanced

Ceramics (Eaton Manufacturing Technologies

Center) ..................

Laser Scatter Methods for Detection of

Subsurface Machining Damage in Ceramics

(Argonne National Laboratory) .......... 203

2.0 MATERIALS DESIGN METHODOLOGY . . . . . . . . . . . . 207

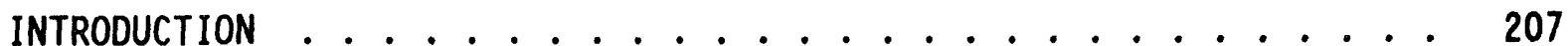

2.2 CONTACT INTERFACES .................. 209

2.2.2 Dynamic Interfaces . . . . . . . . . . . 209

Development of Standard Test Methods for

Evaluating the Wear Performance of Ceramics

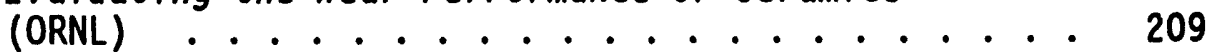

2.3 NEW CONCEPTS ..................... . . 214

Advanced Statistical Concepts of Fracture in

Brittle Materials (GE) ............ 214

3.0 DATA BASE AND LIFE PREDICTION . . . . . . . . . . . . . 219

INTRODUCTION . . . . . . . . . . . . . . . . . . . . 219

3.1 STRUCTURAL QUALIFICATION ............... 221

Microstructural Analysis of Structural

Ceramics (NIST) ............... 221

Mechanical Properties and Microstructural

Characterization of $\mathrm{Si}_{3} \mathrm{~N}_{4}$ Ceramics (ORNL) . . . . 225

Project Data Base (ORNL) . . . . . . . . . 238

3.2 TIME-DEPENDENT BEHAVIOR . . . . . . . . . . . . . 242

Fracture Behavior of Toughened Ceramics (ORNL) . . 242

Cyclic Fatigue of Toughened Ceramics (ORNL) . . . . 248

Rotor Data Base Generation (ORNL) . . . . . . . 261

Toughened Ceramics Life Prediction (NASA Lewis

Research Center) ............... 271

Life Prediction Methodology (Allison) . . . . . 289 
3.3 ENVIRONMENTAL EFFECTS . . . . . . . . . . . 313

Environmental Effects in Toughened Ceramics

(University of Dayton) .......... 313

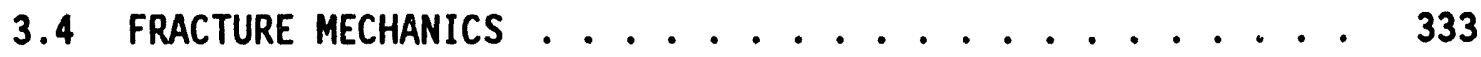

Testing and Evaluation of Advanced Ceramics at

High Temperature (North Carolina A\&T State

University) ............... 333

Standard Tensile Test Development (NIST) . . . . 343

3.5 NONDESTRUCTIVE EVALUATION DEVELOPMENT . . . . . . . . 351

Nondestructive Characterization (ORNL) . . . 351

$X$-ray Computed Tomographic Imaging (ANL) . . . . 374

Nuclear Magnetic Resonance Imaging (ANL) . . . 378

NDE Standards for Advanced Ceramics (ORNL) . . . 381

4.0 TECHNOLOGY TRANSFER .................. 383

.1 TECHNOLOGY TRANSFER ................ 383

4.1.1 Technology Transfer ............ . 383

Technology Transfer (ORNL) . . . . . . . . 383

IEA ANNEX II Management (ORNL) . . . . . . . 385

Characterization of Ceramic Powders (NIST) . . . 390

Ceramic Mechanical Property Test Method

Development (NIST) ......... . . 394 


\title{
CERAMIC TECHNOLOGY PROJECT SEMIANNUAL PROGRESS REPORT \\ FOR APRIL 1993 THROUGH SEPTEMBER 1993
}

\author{
SUMMARY
}

The Ceramic Technology Project was originally developed by the Department of Energy's Office of Transportation Systems (OTS) in Conservation and Renewable Energy. This project, part of the OTS's Materials Development Program, was developed to meet the ceramic technology requirements of the OTS's automotive technology programs.

Significant accomplishments in fabricating ceramic components for the Department of Energy (DOE), National Aeronautics and Space Administration (NASA), and Department of Defense (DoD) advanced heat engine programs have provided evidence that the operation of ceramic parts in high-temperature engine environments is feasible. However, these programs have also demonstrated that additional research is needed in materials and processing development, design methodology, and data base and life prediction before industry will have a sufficient technology base from which to produce reliable cost-effective ceramic engine components commercially.

An assessment of needs was completed, and a five-year project plan was developed with extensive input from private industry. In July 1990, the original plan was updated through the estimated completion of development in 1993. The original objective of the project was to develop the industrial technology base required for reliable ceramics for application in advanced automotive heat engines.

During the course of the Ceramic Technology Project, remarkable progress has been made in the development of reliable structural ceramics. However, further work is needed to reduce the cost of ceramics to facilitate their commercial introduction, especially in the highly costsensitive automotive market. To this end, the direction of the Ceramic Technology Project is now shifting toward reducing the cost of ceramics to facilitate commercial introduction of ceramic components for near-term engine applications. In response to extensive input from industry, the plan is to extend the engine types which were previously supported (advanced gas turbine and low-heat-rejection diesel engines) to include near-term (5-10 years) applications in conventional automobile and diesel truck engines. To facilitate the rapid transfer of this technology to U.S. industry, the major portion of the work is being done in the ceramic industry, with technological support from government laboratories, other industrial laboratories, and universities.

A systematic approach to reducing the cost of components is envisioned. The work elements are as follows: economic cost modeling, ceramic machining, powder synthesis, alternative forming and densification processes, yield improvement, system design studies, standards development, low-expansion ceramics, and testing and data base development.

This project is managed by ORNL for the Office of Transportation Technologies, Office of Transportation Materials, and is closely coordinated with complementary ceramics tasks funded by other DOE offices, NASA, DoD, and industry. A joint DOE and NASA technical plan has been established, with DOE focus on automotive applications and NASA focus on aerospace applications. A common work breakdown structure (WBS) was developed to facilitate coordination. The work described in this report is organized according to the following WBS project elements: 
0.0 Project Management and Coordination

1.0 Materials and Processing

1.1 Monolithics

1.2 Ceramic Composites

1.3 Thermal and Wear Coatings

1.4 Joining

1.5 Ceramic Machining

2.0 Materials Design Methodology

2.2 Contact Interfaces

2.3 New Concepts

3.0 Data Base and Life Prediction

3.1 Structural Qualification

3.2 Time-Dependent Behavior

3.3 Environmental Effects

3.4 Fracture Mechanics

3.5 Nondestructive Evaluation Development

4.0 Technology Transfer

\subsection{Technology Transfer}

This report includes contributions from all currently active project participants. The contributions are arranged according to the work breakdown structure outline. 


\subsection{PROJECT MANAGEMENT AND COORDINATION}

D. R. Johnson

Oak Ridge National Laboratory

\section{Objective/scope}

This task includes the technical management of the project in accordance with the project $p l$ ans and management $\mathrm{plan}$ approved by the Department of Energy (DOE) Oak Ridge Operations Office, and the Office of Transportation Technologies. This task includes preparation of annual field work proposals, initiation and management of subcontracts and interagency agreements, and management of ORNL technical tasks. Monthly management reports and bimonthly reports are provided to DOE; highlights and semiannual technical reports are provided to DOE and program participants. In addition, the program is coordinated with interfacing programs sponsored by other DOE offices and federal agencies, including the National Aeronautics and Space Administration (NASA) and the Department of Defense (DOD). This coordination is accomplished by participation in DOE and NASA joint management meetings, annual interagency heat engine ceramics coordination meetings, DOE contractor coordination meetings, and DOE Energy Materials Coordinating Committee (EMaCC) meetings, as well as special coordination meetings. 


\title{
1.0 MATERIALS AND PROCESSING
}

\author{
INTRODUCTION
}

This portion of the project is identified as project element 1.0 within the work breakdown structure (WBS). It contains five subelements: (1) Monolithics, (2) Ceramic Composites, (3) Thermal and Wear Coatings, (4) Joining, and (5) Ceramic Machining. Ceramic research conducted within the Monolithics subelement currently includes work activities on low cost $\mathrm{Si}_{3} \mathrm{~N}_{4}$ powder, green state ceramic fabrication, characterization, and densification, and on structural, mechanical, and physical properties of these ceramics. Research conducted within the Ceramic Composites subelement currently includes silicon carbide, silicon nitride, and oxidebased composites. Research conducted in the Thermal and Wear Coatings subelement is currently limited to oxide-base coatings and involves coating synthesis, characterization, and determination of the mechanical and physical properties of the coatings. Research conducted in the Joining subelement currently includes studies of processes to produce strong, stable joints between zirconia ceramics and iron-base alloys. As part of an expanded effort to reduce the cost of ceramic components, a new initiative in cost effective machining has been started.

A major objective of the research in the Materials and Processing project element is to systematically advance the understanding of the relationships between ceramic raw materials such as powders and reactant gases, the processing variables involved in producing the ceramic materials, and the resultant microstructures and physical and mechanical properties of the ceramic materials. Success in meeting this objective will provide U.S. companies with new or improved ways for producing economical, highly reliable ceramic components for advanced heat engines. 


\subsection{MONOLITHICS}

\section{1 .2 Silicon Nitride}

Characterization of Attrition Milled Silicon Nitride Powder

S. G. Malghan, P. T. Pei and D. B. Minor

(National Institute of Standards and Technology)

\section{Objective/Scope}

Currently, the starting materials in the manufacture of silicon nitride ceramic components are fine powders. These fine sized powders tend to form agglomerates due to the van der Waals attractive forces. For improved reliability in the manufacture of ceramic components, the agglomerates in the powders should be eliminated since they form defects. In addition, the powders should have an appropriate range of size distribution and specific surface area for achieving a neartheoretical density of the ceramic after densification. These factors necessitate the use of powder milling as one of the major powder processing unit operations. Therefore, milling of powders is an integral unit operation in the manufacture of silicon nitride components for advanced energy applications. The production and use of these powders require the use of efficient milling techniques and understanding of characteristics of the milled powders in a given environment. High energy attrition milling appears to offer significant advantages over conventional tumbling and vibratory mills.

The major objectives of this project are: 1. establish repeatability of particle size distribution and other relevant characteristics of slurries milled in a high energy agitation mill (HEAM); 2. determine processing and densification characteristics of powders milled in HEAM; and 3 . compare properties of powder, and resulting ceramic obtained by milling in the HEAM vs. vibratory ball mill in a collaborative project with Norton Company.

\section{Technical Progress}

The focus during this reporting period was on completion of first stage tests on repeatability and data evaluation. One of the issues we have been addressing in this series of tests is more than expected variation of particle size distribution and specific surface area of milled slurries. The unmilled slurry shows significantly better repeatability than the milled slurries, as measured by particle size distribution and specific surface area. However, as milling proceeds, the divergence begins to enlarge. Results presented in previous reports have shown that most of the milling takes place in the first $20 \mathrm{~min}$. For example, in a typical test, the $d_{50}$ decreases from $1.05 \mu \mathrm{m}$ to 0.75 $\mu \mathrm{m}$ in the first $20 \mathrm{~min}$. of milling. Subsequent decrease to $0.65 \mu \mathrm{m}$ after milling to $80 \mathrm{~min}$. is much smaller. The underlying size reduction mechanism in the initial period is primarily deagglomeration of softly held agglomerates. Some amount of size reduction of primary particles cannot be ruled out. As milling proceeds, intergranular fracture of primary particles is expected to dominate. Since the kinetics of intergranular fracture process is extremely slow, the generation of fine particles by size reduction is also slow. If we accept this argument, then the variability in crystalline structure, especially the number of 
primary crystallites in a given primary particle, can lead to the variation of size reduction kinetics. In addition, the strength of bond between the primary crystallites can play a significant role in the size reduction process. Hence, any variation in the number of primary crystallites in a primary particle and the strength of bond between these crystallites can lead to repeatability related problems during milling. Though we have not obtained any direct evidence of this hypothesis, a close examination of the process of synthesis of Ube silicon nitride powders gives credence to this argument. The synthesis process constitutes crystallization and grain growth of amorphous silicon nitride powders produced by a proprietary process. Therefore, the production of SNE-03, SNE-05 and SNE-10 constitutes the use of primarily an amorphous powder which is treated at different time and temperature profiles to produce crystalline powders of different size distribution. This process is likely to produce different degrees of crystallites aggregation. We will continue to study this behavior, especially to mask these variations so that the product size distribution can be controlled within a small range.

A number of measurements, based on primary and secondary properties of powders, have been used in this study to evaluate the variability associated with the milling data. The primary properties included particle size distribution and specific surface area at $0,20,32,50$ and 80 min milling period. Secondary properties of powders included electrokinetic sonic amplitude (ESA), $\mathrm{pH}$ at which the isoelectric point occurs $\left(\mathrm{pH}_{\mathrm{iep}}\right)$, and green density of slip cast green body. All of these data are being examined by statistical techniques. In the following, we will describe the particle size distribution and ESA as two representative primary and secondary measurements, respectively, for three tests for which most data are available. Following these data, specific surface area data are discussed.

The particle size distribution results in Figure 1 show that, at 80 min miliing, while the data of two tests ( 54 and 55) are fairly reproducible, the third test (53) shows a fairly significant difference. Since no measurable difference has taken place in the starting material, measurement process parameters, and milling parameters for these tests, one can attribute most of the observed difference to the milling process. However, as we have tried to explain in the past, this interpretation may not be entirely correct. The reason for this is that though at time zero of milling the particle size distributions do not show a significant difference, within 20 min of milling the differences are visible (Figure 2). These differences appear to be small at $20 \mathrm{~min}$ milling. However, as milling proceeds, these differences continue to become larger. Two primary reasons for such a difference could be testto-test change in breakage behavior of particles and effect of change in milling system (media size distribution, mill rotor speed, flow rate of slurry, etc.). In addition, an interaction between these two effects cannot be ruled out. We are examining all these parameters in a greater detail to provide both qualitative and quantitative influence on particle size distribution.

Figures 3 shows the ESA and $\mathrm{pH}_{\mathrm{iep}}$ data of these three tests for 80 min milled samples. The data of 50 min milled samples showed similar behavior. Though the $\mathrm{pH}_{\text {iep }}$ values show significantly better 


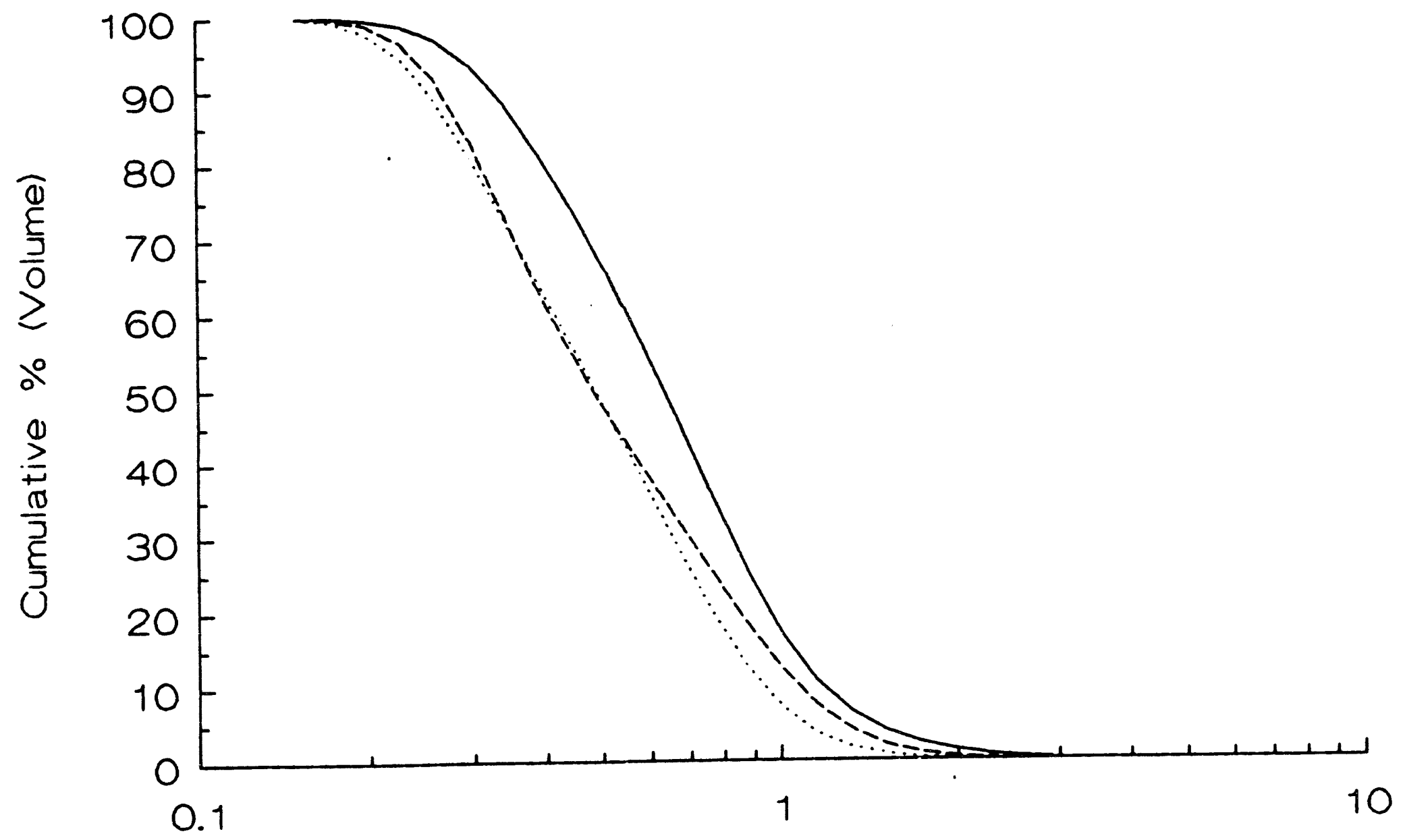

Diameter, micrometers

Figure 1. Particle size distribution of $80 \mathrm{~min}$. milled sample of silicon nitride as determined using Horiba LA-900. These data are presented for tests 53, 54, and 55. 


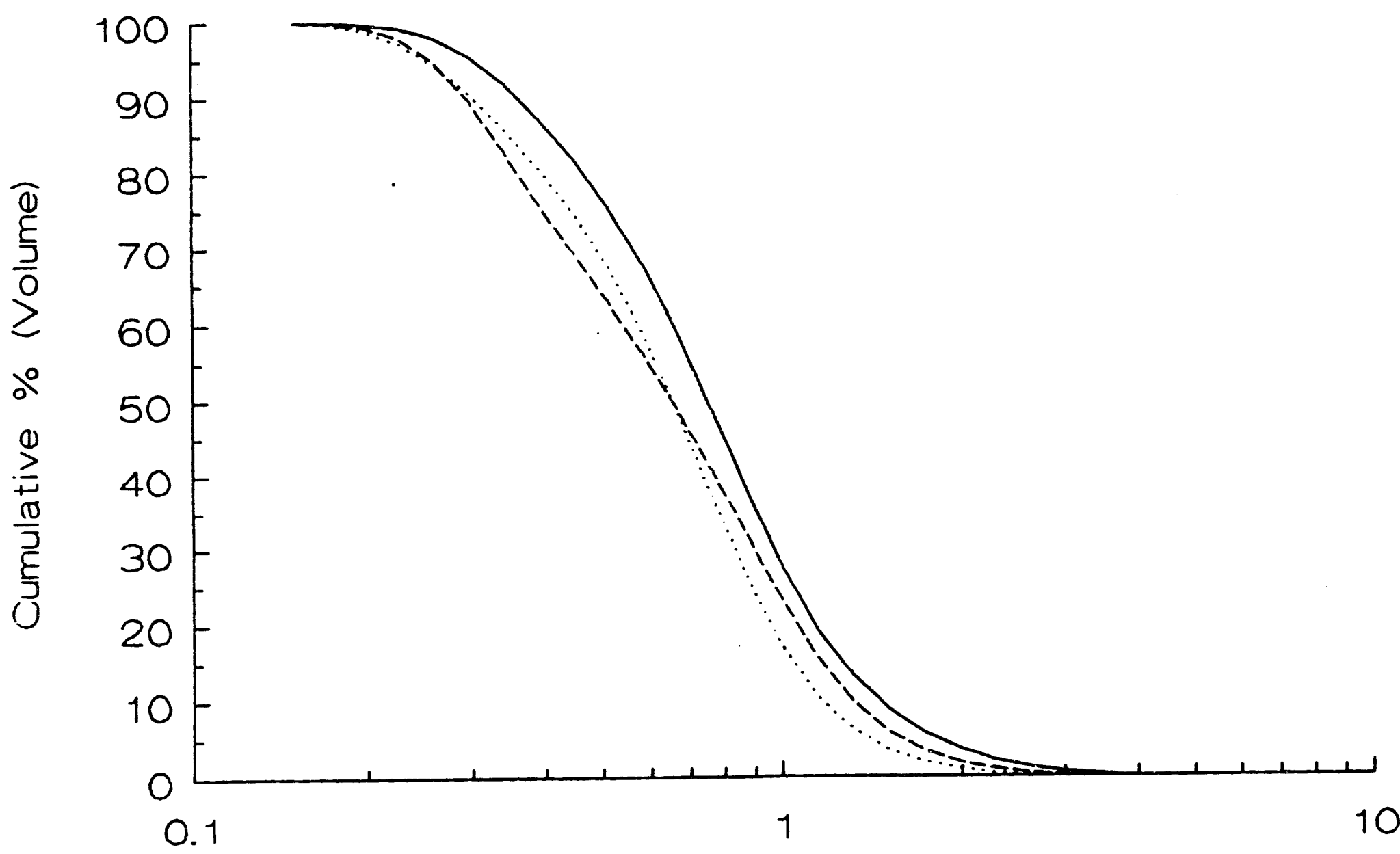

Diameter, micrometers

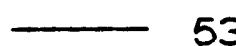

Figure 2. Particle size distribution of $20 \mathrm{~min}$. milled sample of silicon nitride as determined using Horiba LA-900. These data are presented for tests 53, 54, and 55. 


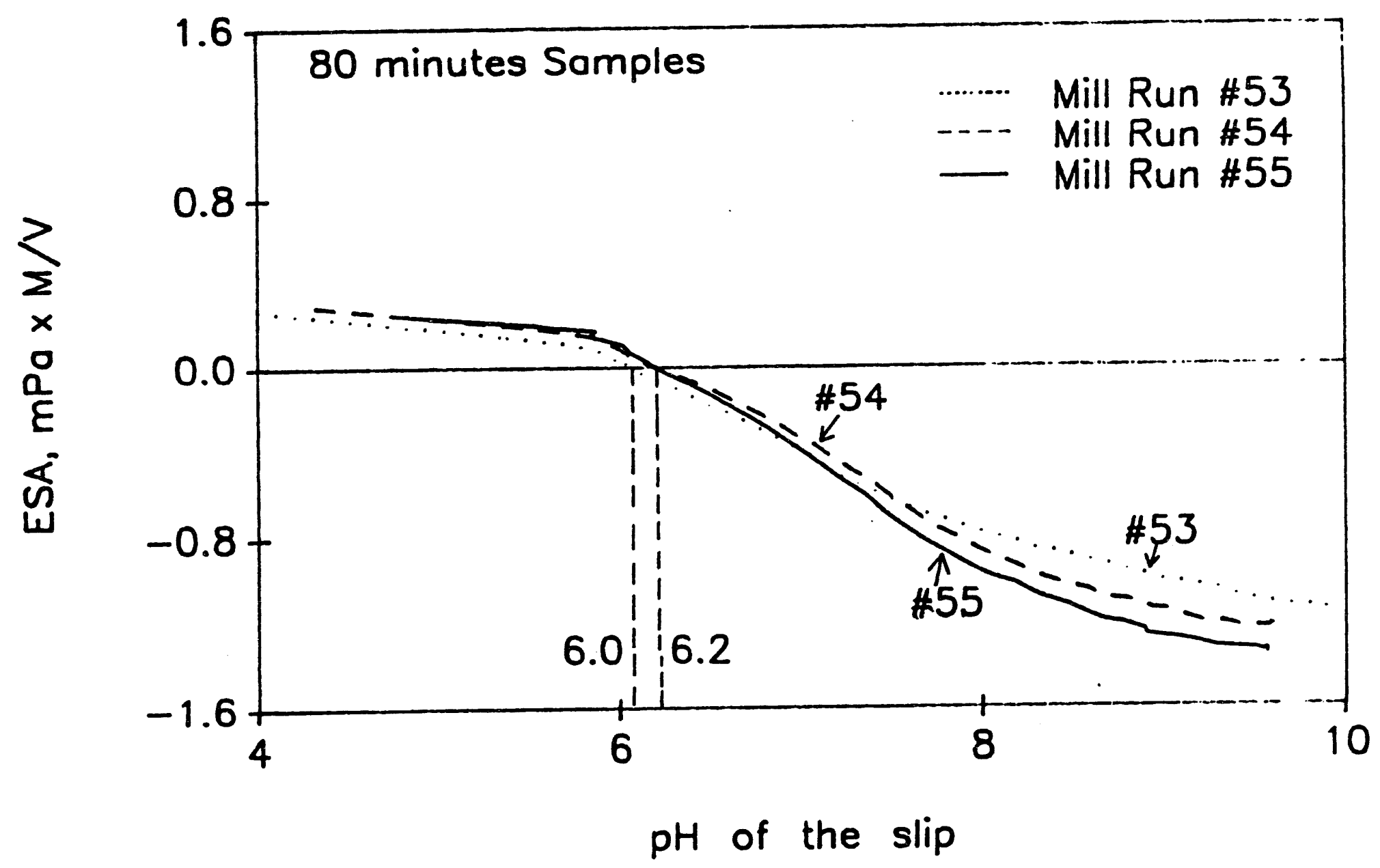

Figure 3. The ESA and $\mathrm{pH}_{\text {iep }}$ of $80 \mathrm{~min}$. milled samples as determined by Matec 8000 apparatus. 
reproducibility, the ESA values show test-to-test variation. This is expected since the $\mathrm{pH}_{\text {iep }}$ values are mostly dependent on specific adsorption of potential determining ions while the ESA values are a function of a large number of parameters such as particle concentration and size distribution, ionic strength and composition of slip, and dynamics of adsorption-desorption process at the particle interface. These parameters can influence local conditions at the particle interface, therefore can affect the ESA values. The $\mathrm{pH}_{\text {iep }}$ values lie in a narrow range of $\mathrm{pH}$ between 6.2 and 6.3 which shows that no significant changes are evident with respect to change in the adsorption of polymethacrylate dispersant.

The specific surface area data were obtained using BET multipoint method, and the procedure used is that recommended in the IEA Subtask 6 project. Our long term repeatability data on the measurement of specific surface area of silicon nitride powders shows a standard deviation of the mean of $0.3 \mathrm{~m}^{2} / \mathrm{g}$ for powders in the range of $10.0 \mathrm{~m}^{2} / \mathrm{g}$.

The specific surface area data from seven milling tests at five sampling periods are summarized in $z$ able 1 . The specific surface area data were measured on three independent milling samples at each milling period. The measurement order was randomized within the batch of samples from each test. These data showed statistically significant differences among the data from each test. At all milling times, the specific surface area increased as a function of test number. In the past series of tests, we had observed an opposite trend. Therefore, at least for the time being, we have ascribed this trend to chance.

Table 1. Statistical Data of Specific Surface Area of Milling Experiments

$\begin{array}{ccccc}\text { TIME(min) } & \begin{array}{c}\text { Average } \\ \text { SSA }\end{array} & \begin{array}{l}\text { Relative SD } \\ \text { of a Single } \\ \text { Measurement }\end{array} & \begin{array}{l}\text { Lower } 95 \% \\ \text { CI SD Single } \\ \text { of Seasurement } \\ \text { Me }\end{array} & \begin{array}{l}\text { Upper } 95 \% \\ \text { CI on SD } \\ \text { of Single } \\ \text { Measurement }\end{array} \\ 0 & 5.50 & 7.48 \% & 4.82 \% & 16.54 \% \\ 20 & 6.04 & 10.24 \% & 6.65 \% & 21.95 \% \\ 32 & 7.38 & 14.28 \% & 9.05 \% & 33.26 \% \\ 50 & 8.52 & 14.78 \% & 9.26 \% & 35.76 \% \\ 80 & 9.91 & 15.71 \% & 9.83 \% & 38.13 \%\end{array}$

The observed variance of specific surface area (SSA) data within each test was found to be not significantly different from within time variance for the control measurements on the calcined kaolin Reference Material (NIST RM 8570). Assuming that the RM 8570 kaolin is very homogeneous material, the data suggest that the within-test variation is due to the measurement process rather than the material variability between the samples within a run, and that the measurement error variance is about constant for the range of specific surface areas observed in these experiments. In the above table, CI and SD refer to confidence interval and standard deviation, respectively. 
Since the measurements were obtained in the same order as the miliing experiments, the variation between the tests could be due to either differences in the milled material or to the differences in the measurement process. The between-test variance observed in these tests is significantly larger than the between-time variance for the control data which suggests that the measurement process is not the primary source of variance. Moreover, the between-test variation is comparable to the results from the pasi year. Therefore, we believe that the differences observed in the milling test are due to differences in the milled material rather than the measurement process itself.

The relative standard deviation of a single measurement, which includes both within- and between-test variability has been estimated. In addition, the $95 \%$ confidence bounds for this relative standard deviation has been provided in Table 1 . This estimate gives an idea about how variable one can expect future results to be due to the milling and measurement process. The statistical analysis was conducted by Susannah Schiller of the Statistical Engineering Division at NIST.

\section{Status of Milestones}

On target.

Communications/Visits

Vimal Pujari, St. Gobaj.n/Norton Industrial Advanced Ceramics visited NIST to discuss milling results.

\section{Publications}

None 
Microwave Sintering of Silicon Nitride

T. N. Tiegs, J. O. Kiggans, M. Golla, and J. Maria

(Oak Ridge National Laboratory)

\section{Objective/scope}

The objective of this research element is to identify those aspects of microwave processing of silicon nitride that might (1) accelerate densification, (2) permit sintering to high density with much lower levels of sintering alds, (3) lower the sintering temperature, or (4) produce unique microstructures. The investigation of microstructure development is being done on dense silicon nitride materials annealed in the microwave furnace. The sintering of silicon nitride involves two approaches. The first approach comprises heating of silicon nitride and sialon powder compositions in the 2.45- or $28-\mathrm{GHz}$ units. The second approach deals with using reaction-bonded silicon nitride (RBSN) as the starting material and is done entirely in the $2.45-\mathrm{GHz}$ microwave furnace.

\section{Technical highlights}

Sintered Reaction-Bonded Silicon Nitride (SRBSN) - During the current reporting period, experiments were performed to optimize the powder processing conditions and composition for SRBSN. The experimental array and results are shown in Table 1. For these samples, since there were so many material variables, nitridation was done by conventional heating. The powder processing conditions and composition will be optimized for both maximum nitridation weight gain and $\alpha-\mathrm{Si}_{3} \mathrm{~N}_{4}$ content. The sintering behavior of the samples will also be determined.

In addition to the tests described above, experiments to optimize the microwave processing conditions for nitridation of silicon for SRBSN were also performed. The experimental array and results are shown in Table 2. One batch of material was used having a final composition of $\mathrm{Si}_{3} \mathrm{~N}_{4}-9 \mathrm{wt}$. $\% \mathrm{Y}_{2} \mathrm{O}_{3}-3 \mathrm{wt}$. \% $\mathrm{Al}_{2} \mathrm{O}_{3}$ after nitridation. Samples of this composition have shown good mechanical properties in previous tests. Every thermal cycle consisted of a temperature ramp up to $1100^{\circ} \mathrm{C}$ at $5^{\circ} \mathrm{C} / \mathrm{min}$, followed by a series of holds and temperature ramps as indicated in Table 2. The conditions were optimized for maximum nitridation weight gain and a confirmation run performed as shown in Table 2. Analysis of the results indicated that the important parameters were the ramp rate 3, hold times 1 and 3 , and the sample thickness. The samples will also be examined for $\alpha-\mathrm{Si}_{3} \mathrm{~N}_{4}$ content and the process optimized for maximum content. The sintering behavior of the samples will also be determined.

Cooperative Research and Development Agreements - Norton RBSN - Additional samples of Norton RBSN have been processed and the mechanical properties examined as shown in Table 3. As indicated, the microwave-processed materials exhibited higher strengths in most cases and higher toughness in all cases.

Samples of Norton RBSN have been tested for oxidation as shown in Table 4. As indicated, the microwave-processed materials exhibited lower weight gains in two of the three cases. 
Table 1. Taguchi experimental design array for optimizing the powder processing conditions and composition for sintered reaction-bonded silicon nitride. Nitridation was done by conventional heating. The design

is ar: $L_{12}\left(2^{11}\right)$ with 11 variables at 2 levels

\begin{tabular}{|c|c|c|c|c|c|c|c|c|c|c|c|c|}
\hline $\begin{array}{l}\text { Test } \\
\text { No. }\end{array}$ & $\begin{array}{c}\text { Mill } \\
\text { time } \\
\text { (h) }\end{array}$ & $\begin{array}{l}\text { Sintering } \\
\text { aids }\end{array}$ & $\begin{array}{l}\text { Sinter } \\
\text { aids } \\
\text { amounts } \\
\text { (wt \%) }\end{array}$ & $\begin{array}{c}\text { Metal } \\
\text { additive }\end{array}$ & $\begin{array}{l}\text { Metal } \\
\text { additive } \\
\text { content } \\
\text { (wt \%) }\end{array}$ & $\begin{array}{l}\alpha-\text { seod } \\
\text { content } \\
\text { (wt \%) }\end{array}$ & $\begin{array}{l}\text { Binder } \\
\text { burnout } \\
\text { atmosphere }\end{array}$ & $\begin{array}{l}\text { Bisque } \\
\text { fire } \\
\text { atmosphere }\end{array}$ & $\begin{array}{l}\text { Nitriding } \\
\text { gas }\end{array}$ & $\begin{array}{l}\text { Sample } \\
\text { thickness } \\
\text { (in.) }\end{array}$ & $\begin{array}{l}\text { Green } \\
\text { density } \\
\text { (\% TD) }\end{array}$ & $\begin{array}{l}\text { Silicon } \\
\text { weight } \\
\text { gain } \\
(\%)\end{array}$ \\
\hline 1 & 1 & $\begin{array}{l}\mathrm{Y}_{2} \mathrm{O}_{3}- \\
\mathrm{AN}_{2} \mathrm{O}_{3}\end{array}$ & 12 & $\mathrm{Fe}$ & 0.5 & 10 & Argon & Argon & $5 \% \mathrm{He}$ & 0.375 & 58 & 61.3 \\
\hline 2 & 1 & $\begin{array}{l}\mathrm{Y}_{2} \mathrm{O}_{3} \\
\mathrm{~A}_{2} \mathrm{O}_{3}\end{array}$ & 12 & $\mathrm{Fe}$ & 0.5 & 0 & Air & Vacuum & $\mathrm{No} \mathrm{He}$ & 0.75 & 62 & 61.9 \\
\hline 3 & 1 & $\begin{array}{l}\mathrm{Y}_{2} \mathrm{O}_{3} \\
\mathrm{Al}_{2} \mathrm{O}_{3}\end{array}$ & 9 & $\mathrm{Cr}$ & 2 & 10 & Argon & Argon & No He & 0.75 & 62 & 60.2 \\
\hline 4 & 1 & $\begin{array}{l}\mathrm{Y}_{2} \mathrm{O}_{3}- \\
\mathrm{SiO}_{2}\end{array}$ & 12 & $\mathrm{Cr}$ & 2 & 10 & Air & Vacuum & $5 \% \mathrm{He}$ & 0.375 & 62 & 60.8 \\
\hline 5 & 1 & $\begin{array}{l}\mathrm{Y}_{2} \mathrm{\cap}_{3} \\
\mathrm{SiO}_{2}\end{array}$ & 9 & $\mathrm{Fe}$ & 2 & 0 & Air & Argon & $5 \% \mathrm{He}$ & 0.75 & 58 & 61.4 \\
\hline 6 & 1 & $\begin{array}{l}\mathrm{Y}_{2} \mathrm{O}_{3}- \\
\mathrm{SiO}_{2}\end{array}$ & 9 & $\mathrm{Cr}$ & 0.5 & 0 & Argon & Vacuum & No He & 0.375 & 58 & 61.9 \\
\hline 7 & 4 & $\begin{array}{l}\mathrm{Y}_{2} \mathrm{O}_{3} \\
\mathrm{AN}_{2} \mathrm{O}_{3}\end{array}$ & 9 & $\mathrm{Cr}$ & 0.5 & 10 & Air & Vacuum & $5 \% \mathrm{He}$ & 0.75 & 58 & 60.9 \\
\hline 8 & 4 & $\begin{array}{l}\mathrm{Y}_{2} \mathrm{O}_{3}- \\
\mathrm{AN}_{2} \mathrm{O}_{3}\end{array}$ & 9 & $\mathrm{Fe}_{\mathrm{g}}$ & 2 & 0 & Argon & Vacuum & $5 \% \mathrm{He}$ & 0.375 & 62 & 62.2 \\
\hline 9 & 4 & $\begin{array}{l}\mathrm{Y}_{2} \mathrm{O}_{3} \\
\mathrm{Al}_{2} \mathrm{O}_{3}\end{array}$ & 12 & $\mathrm{Cr}$ & 2 & 0 & Air & Argon & $\mathrm{No} \mathrm{He}$ & 0.375 & 58 & 58.3 \\
\hline 10 & 4 & $\begin{array}{l}\mathrm{Y}_{2} \mathrm{O}_{3} \\
\mathrm{SiO}_{?}\end{array}$ & 9 & $\mathrm{Fe}$ & 0.5 & 10 & Air & Argon & No He & 0.375 & 62 & 60.0 \\
\hline 11 & 4 & $\begin{array}{l}\mathrm{Y}_{2} \mathrm{O}_{3}- \\
\mathrm{SiO}_{2}\end{array}$ & 12 & $\mathrm{Cr}$ & 0.5 & 0 & Argon & Argon & $5 \% \mathrm{He}$ & 0.75 & 62 & 61.3 \\
\hline 12 & 4 & $\begin{array}{l}\mathrm{Y}_{2} \mathrm{O}_{3}- \\
\mathrm{SiO}_{2}\end{array}$ & 12 & $\mathrm{Fe}$ & 2 & 10 & Argon & Vacuum & $\mathrm{No} \mathrm{He}$ & 0.75 & 58 & 61.9 \\
\hline
\end{tabular}


Table 2. Taguchi experimental design array for optimizing nitridation of silicon in a microwave furnace. The design is an $L_{12}\left(2^{11}\right)$ with 11 variables at 2 levels.

\begin{tabular}{|c|c|c|c|c|c|c|c|c|c|c|c|c|}
\hline $\begin{array}{l}\text { Test } \\
\text { No. } \\
\end{array}$ & $\begin{array}{c}\text { Ramp } \\
1 \\
{ }^{\circ} \mathrm{C} / \mathrm{min} \\
\end{array}$ & $\begin{array}{c}\text { Ramp } \\
2 \\
{ }^{\circ} \mathrm{C} / \mathrm{min} \\
\end{array}$ & $\begin{array}{c}\text { Ramp } \\
3 \\
{ }^{\circ} \mathrm{C} / \mathrm{min} \\
\end{array}$ & $\begin{array}{c}\text { Hold } \\
\text { time } \\
1 \\
(\mathrm{~h}) \\
\end{array}$ & $\begin{array}{c}\text { Hold } \\
\text { time } \\
2 \\
(\mathrm{~h}) \\
\end{array}$ & $\begin{array}{c}\text { Hold } \\
\text { time } \\
3 \\
\text { (h) } \\
\end{array}$ & $\begin{array}{c}\text { Hold } \\
\text { temp } \\
1 \\
\left(^{\circ} \mathrm{C}\right) \\
\end{array}$ & $\begin{array}{c}\text { Hold } \\
\text { temp } \\
2 \\
\left(^{\circ} \mathrm{C}\right) \\
\end{array}$ & $\begin{array}{c}\text { Hold } \\
\text { tomp } \\
3 \\
\left({ }^{\circ} \mathrm{C}\right) \\
\end{array}$ & $\begin{array}{c}\text { Sample } \\
\text { thickness } \\
\text { (in.) }\end{array}$ & $\begin{array}{l}\text { Green } \\
\text { density } \\
\text { (\% TD) } \\
\end{array}$ & $\begin{array}{c}\text { Silicon } \\
\text { weight } \\
\text { gain } \\
(\%)\end{array}$ \\
\hline 1 & 1 & 0.5 & 0.3 & 1 & 1 & 1 & 1200 & 1325 & 1400 & 0.375 & 58 & 62.73 \\
\hline 2 & 1 & 0.5 & 0.5 & 1 & 1 & 4 & 1250 & 1350 & 1450 & 0.75 & 62 & 62.25 \\
\hline 3 & 1 & 0.5 & 2 & 4 & 4 & 1 & 1200 & 1325 & 1450 & 0.75 & 62 & 55.74 \\
\hline 4 & 1 & 2 & 0.5 & 4 & 4 & 1 & 1250 & 1350 & 1400 & 0.375 & 62 & 62.07 \\
\hline 5 & 1 & 2 & 2 & 1 & 4 & 4 & 1200 & 1350 & 1400 & 0.75 & 58 & 62.32 \\
\hline 6 & 1 & 2 & 2 & 4 & 1 & 4 & 1250 & 1325 & 1450 & 0.375 & 58 & 62.19 \\
\hline 7 & 5 & 0.5 & 2 & 4 & 1 & 1 & 1250 & 1350 & 1400 & 0.75 & 58 & 56.10 \\
\hline 8 & 5 & 0.5 & 2 & 1 & 4 & 4 & 1250 & 1325 & 1400 & 0.375 & 62 & 61.82 \\
\hline 9 & 5 & 0.5 & 0.5 & 4 & 4 & 4 & 1200 & 1350 & 1450 & 0.375 & 58 & 62.54 \\
\hline 10 & 5 & 2 & 2 & 1 & 1 & 1 & 1200 & 1350 & 1450 & 0.375 & 62 & 58.57 \\
\hline 11 & 5 & 2 & 0.5 & 4 & 1 & 4 & 1200 & 1325 & 1400 & 0.75 & 62 & 58.10 \\
\hline 12 & 5 & 2 & 0.5 & 1 & 4 & 1 & 1250 & 1325 & 1450 & 0.75 & 58 & 61.30 \\
\hline Conf. & 1 & 2 & 0.05 & 1 & 4 & 4 & 1250 & 1350 & 1400 & 0.375 & 53 & 62.24 \\
\hline
\end{tabular}


Table 3. Summary of results on microwave and conventional sintering of Norton Ceramics slilicon nitride.

\begin{tabular}{ccccc}
\hline Sample & $\begin{array}{c}\text { Sintering aid } \\
\text { content }\end{array}$ & $\begin{array}{c}\text { Processing } \\
\text { type }\end{array}$ & $\begin{array}{c}\text { Flexural } \\
\text { strength } \\
(\mathrm{MPa})\end{array}$ & $\begin{array}{c}\text { Fracture } \\
\text { toughness } \\
\left(\mathrm{K}_{\mathbf{t}}, \mathrm{MPa} / \mathrm{m}\right)\end{array}$ \\
\hline 9032 & Low & Microwave & $808 \pm 130$ & $7.4 \pm 0.1$ \\
9032 & Low & Conventional & $804 \pm 51$ & $7.0 \pm 0.1$ \\
9033 & High & Microwave & $876 \pm 33$ & $7.3 \pm 0.1$ \\
9033 & High & Conventional & $694 \pm 44$ & $6.5 \pm 0.1$ \\
9054 & Low & Microwave & $599 \pm 18$ & $5.3 \pm 0.2$ \\
9054 & Low & Conventional & $638 \pm 23$ & --- \\
9059 & High & Microwave & $925 \pm 51$ & $8.8 \pm 0.4$ \\
9059 & High & Conventional & $834 \pm 85$ & $7.7 \pm 0.4$ \\
\hline
\end{tabular}

Table 4. Oxidation study on reaction-bonded silicon nitride at $1400^{\circ} \mathrm{C}$ in air

\begin{tabular}{ccccc}
\hline Sample & Processing & $\begin{array}{c}\text { Weight gain } \\
(\%) 24 \mathrm{~h}\end{array}$ & $\begin{array}{c}\text { Weight gain } \\
(\%) 48 \mathrm{~h}\end{array}$ & $\begin{array}{c}\text { Weight gain } \\
(\%) 72 \mathrm{~h}\end{array}$ \\
\cline { 3 - 6 } 9043 & Conventional & 5.4 & 5.3 & 5.7 \\
9043 & Microwave & 3.5 & 3.4 & 5.2 \\
9044 & Conventional & 5.1 & 5.0 & 5.1 \\
9044 & Microwave & 7.9 & 7.0 & 7.8 \\
8082 & Conventional & 12.3 & 14.3 & 13.9 \\
8082 & Microwave & 7.0 & 5.3 & 6.0 \\
\hline
\end{tabular}




\section{Status of milestones}

Milestone 112406 - "Fabricate cost-effective sintered reaction-bonded sillcon nitride and determine mechanical properties. Publish progress report." This milestone was completed ahead of schedule and the results published in the semiannual progress report for October 1992 - March 1993 and bimonthly progress reports for April - May 1993 and June - July 1993.

\section{Communications/visits/travel}

Travel by T. N. Tiegs from April 18-22, 1993, to Cincinnati, Ohio, to attend the American Ceramic Society Annual Meeting and present a paper entitled "Crystallization of Grain Boundary Phases in Silicon Nitride with Low Additive Contents by Microwave Annealing."

Travel by J. O. Kiggans from April 18-21, 1993, to Cincinnatl, Ohlo, to attend the American Ceramic Society Annual Meeting and present a paper entitled "Processing of Complex Sintered Reaction Bonded Silicon Nitride Parts by Microwave Heating."

Travel by T. N. Tiegs from May 24-26, 1993, to Cincinnati, Ohio, to attend the American Society of Mechanical Engineers (ASME) International Gas Turbine Conference and present a paper entitled "Microwave Processing of Sillicon Nitride for Advanced Gas Turbine Applications."

Travel by T. N. Tiegs from June 23-24, 1993, to Washington, D.C., to attend the Ceramic Technology for Advanced Heat Engines (CTAHE) Review Meeting at DOE and present a talk entitled "Processing of Silicon Nitride by Microwave Heating."

\section{Problems encountered}

None.

\section{Publications}

None. 
Development of a High Qualing Low Cast Silicon Nitride Pouder

D. F. Carroll, G. A. Cochran, C. L. Conner, S. D. Dunmead, G. A. Eisman,

C. J. Hwang, and A. W. Weimer (The Dow Chemical Company)

\section{Objective/Scope}

The objective of this program is to scale a carbothermal nitridation process to the pilot plant level for the production of a high quality, low cost silicon nitride powder. The tasks of this program are designed to 1) determine the relationships among raw material precursors, reactor conditions and post-processing and their effect on the characteristics of carbothermal powder produced in the intermediate scale reactor; 2) scale the process to a pilot plant stage; and 3) identify those characteristics which yield a sinterable powder that can be pressureless sintered into dense, high strength components. The results of the above tasks will be utilized in the latter stages of the program when high quality, low cost silicon nitride powder is produced in our pilot plant facility.

\section{Task 1: Reference Process Flowsheet and Cost Estimate}

The objectives of Task 1 are synthesis of $3 \mathrm{~kg}$ of powder from a pre-pilot plant facility, a process flowsheet, and a preliminary cost estimate of the current process. Task 1 was completed in May of this reporting period.

\section{Task 1.1: Process Elowsheet}

A process flowsheet detailing the unit operations of The Dow Chemical Company's silicon nitride process was delivered in May. The flowsheet of proprietary engineering elements included all precursor powder handling stages, reaction operations, and all postreaction powder finishing stages.

\section{Task 1.2: Preliminary Economics}

A preliminary assessment of the costs to produce silicon nitride powder within the specifications of the contract was delivered in May. The proprietary assessment, carried out on the current process, demonstrated that the program price objectives can be met when significant volumes are met.

\section{Technical Progress}

\section{Task 1.3: Powder Synthesis}

The objective of Task 1.3 was to generate and deliver $3 \mathrm{~kg}$ of powder to the contract monitor at Oak Ridge. The powder was produced in the current facilities and was synthesized in 0.5 to $1 \mathrm{~kg}$ batches in an intermediate lab-scale reactor. Excluding the carbon removal step, all pre- and post-reactor operations were carried out in the pilot plant facility. The reactor conditions including reaction temperature, residence time, and gas flow rate were varied in order to determine their effect on product quality. During the studies, feed composition was also varied to determine the effect of precursor properties on the final powder properties. Once the conditions were established, $6 \mathrm{~kg}$ of silicon nitride powder were synthesized, 3 for the deliverable and 3 for internal evaluations. The powder was delivered in May of this year. Details of the characteristics of this powder as well as how prrcessing of the powder into parts and the resultant mechanical properties are reviev/ed below under Task 3. 
Work at The Dow Chemical Company over the course of the past three years has demonstrated that it is possible to control both the kinetics of the carbothermal reaction and the morphology of the product. The work done in this area over the past 6 months has concentrated on the optimization of morphology with respect to the sinterability of the carbothermal $\mathrm{Si}_{3} \mathrm{~N}_{4}(\mathrm{CSN})$ product. Figure 1 shows how the surface area of the product can be controlled while the scanning electron micrographs in Figure 2 represent how the morphology of CSN powder can be modified by the Dow Chemical Company process. Here, it can be seen that the morphology of the $\mathrm{Si}_{3} \mathrm{~N}_{4}$ grains can be varied from large blocky particles to a sub-micron and equi-axed product.

Using conventional densification models, a powder with a higher surface area should be easier to sinter. However, the sinterability results presented in Figure 3 indicate that this is not the case. The powder with a surface area of $11 \mathrm{~m}^{2} / \mathrm{g}$ was found to have the highest degree of sinterability. The enhanced sinterability of this powder is a result of an optimum combination of powder surface area and morphology. The data presented in Figure 3 were obtained as part of a statistically designed set of experiments comparing the relative rates of densification between carbothermal powders (see Task 3.2). Plotted in Figure 3 are the partial sintered densities after the sintering cycle was interrupted prior to the bodies reaching full density.

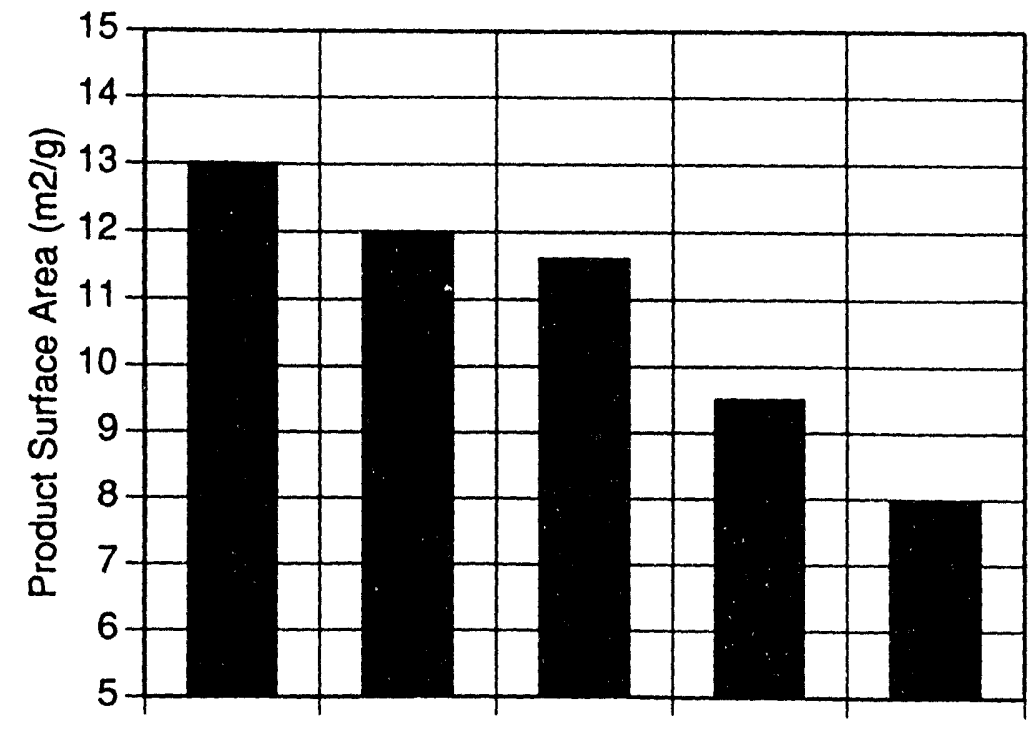

Figure 1. Effect of Proprietary Synthesis Conditions

\section{Qptimization of Carbon Removal}

Figure 4 shows a plot of final product oxygen content as a function of the oxygen content in the crude (prior to carbon removal) product. These data were obtained from materials made during the very early stages of our research with a variety of synthesis conditions. As expected, these data show that, in general, a higher oxygen content corresponds to a higher final product oxygen content. These data also show, however, that there was a large degree of scatter and lack of reproducibility in our final product oxygen even with crude materials of approximately the same oxygen content. In an effort to refine the carbon removal step in our CSN process, and develop a solution to this problem, we used a statistically designed set of experiments. The statistical design employed was a response surface central composite design considering the effects of burn-out temperature $(T)$, time $(t)$, atmosphere $(A)$, and gas flow rate $(F)$. This design included 32 experiments and was capable of developing a predictive model of the burnout process. The objective 

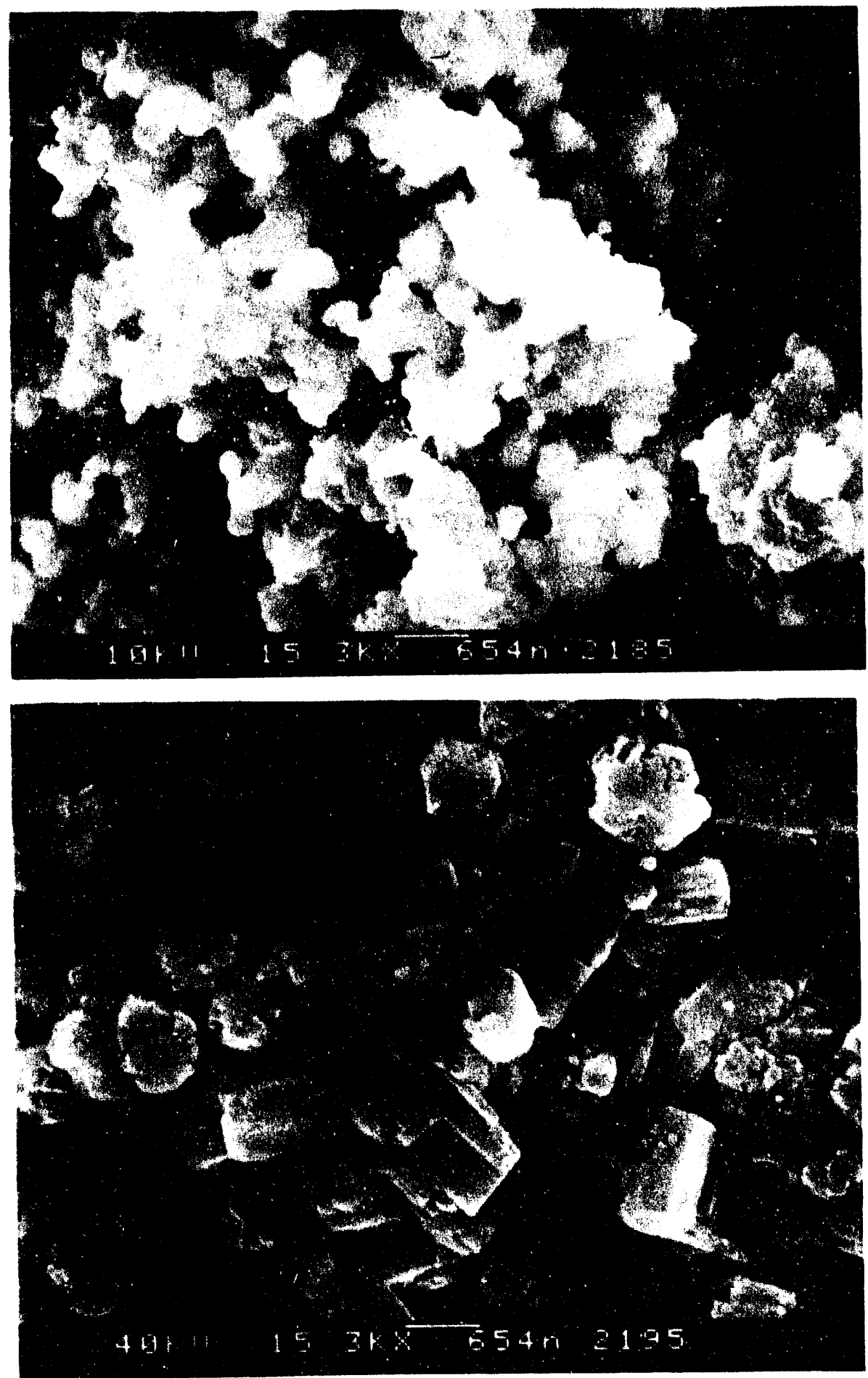

Figure 2. Scanning Electron Photomicrographs Showing Morphological Control in Dow Carbothermal Silicon Nitride Powders 


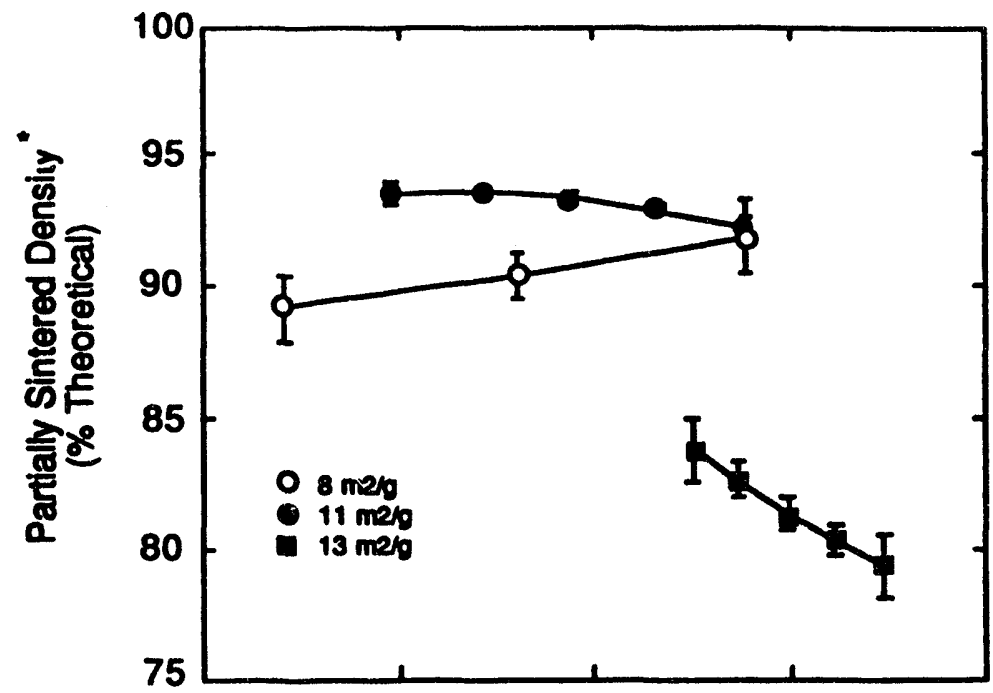

Fraction of Component $\mathbf{C}$ in Sintering Additives

- Sintering was intemupted prior to sull densliby bo examino rolative rates of donalication

Figure 3. Relotive Sinterability of Carbothermal Silicon Mitride Powders

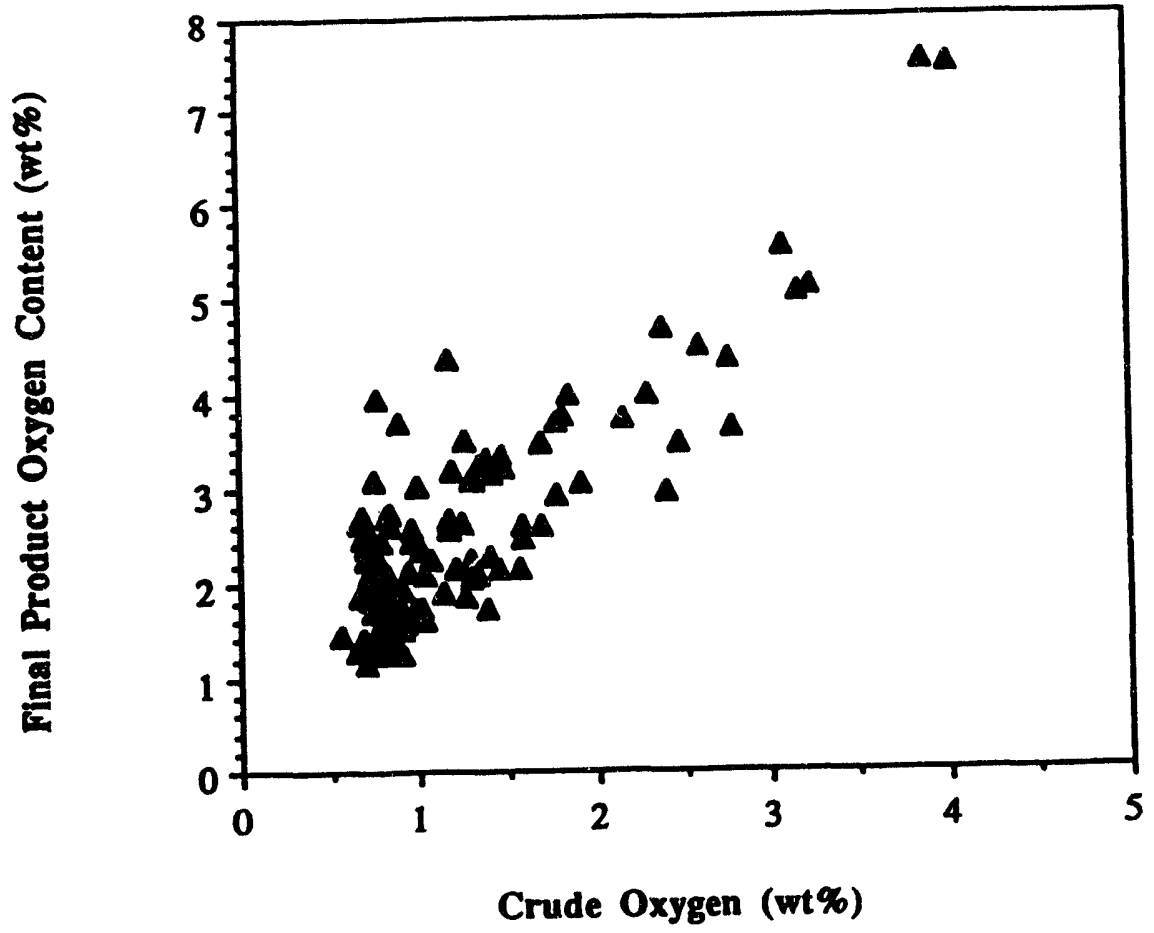

Figure 4. Final Product Oxygen Content as a Function of Crude Oxygen Content for Early Stege Runs with a Variety of Synthesis Conditions 
was to have the highest throughput (short burn-out time) as possible and yet get complete removal of the free carbon and minimize the oxidation of the $\mathrm{Si}_{3} \mathrm{~N}_{4}$ material. Table 1 shows all of the terms that were considered and their statistical significance for both the carbon removal and oxidation models.

Once we have reduced the models for the carbon removal and oxidation, we can then use these algebraic relationships to generate contour plots such as those shown in Figures 5 and 6. For example, if we decided that we wanted to operate the carbon removal step at a coded temperature of 0.28 , a coded flow rate of 0 and a coded atmosphere of 0.42 , Figure 5 would suggest that a coded residence time of approximately -0.05 is needed to get complete removal of the free carbon. Combining this information with the oxidation contour plot in Figure 6, these conditions would produce a low oxygen content product. Figure 6 also shows that at the low temperatures (i.e., $<0.67$ ) the atmosphere composition

Table 1. Terms Considered in Response Surface/Central Composite Experimental Design for $\mathrm{Si}_{3} \mathrm{~N}_{4}$ Carbon Removal Process

\begin{tabular}{|c|c|c|}
\hline Terms Considered & Carbon Model & Oxygen Model \\
\hline$T$ & Yes & Yes \\
\hline$t$ & Yes & Yes \\
\hline$F$ & No & No \\
\hline Atm & Yes & Yes \\
\hline$T^{*} T$ & Yes & Yes \\
\hline$t^{*} t$ & Yes & Yes \\
\hline$F^{*} F$ & No & No \\
\hline$A t^{*} A t m$ & Yes & Yes \\
\hline$T^{*} t$ & Yes & No \\
\hline$T^{*} \mathrm{~F}$ & No & Yes \\
\hline$T^{*} A t m$ & Yes & No \\
\hline$t^{*} F$ & No & No \\
\hline$t^{*} A t m$ & No & No \\
\hline$F^{*} A t m$ & No & \\
\hline & &
\end{tabular}

Yes = Statistically Significant

No $=$ Not Statistically Significant

$\mathbf{F}=$ Gas Flow Rate

$\mathrm{T}=$ Temperature

$\mathrm{t}=$ Time

Atm $=$ Atmosphere Composition 


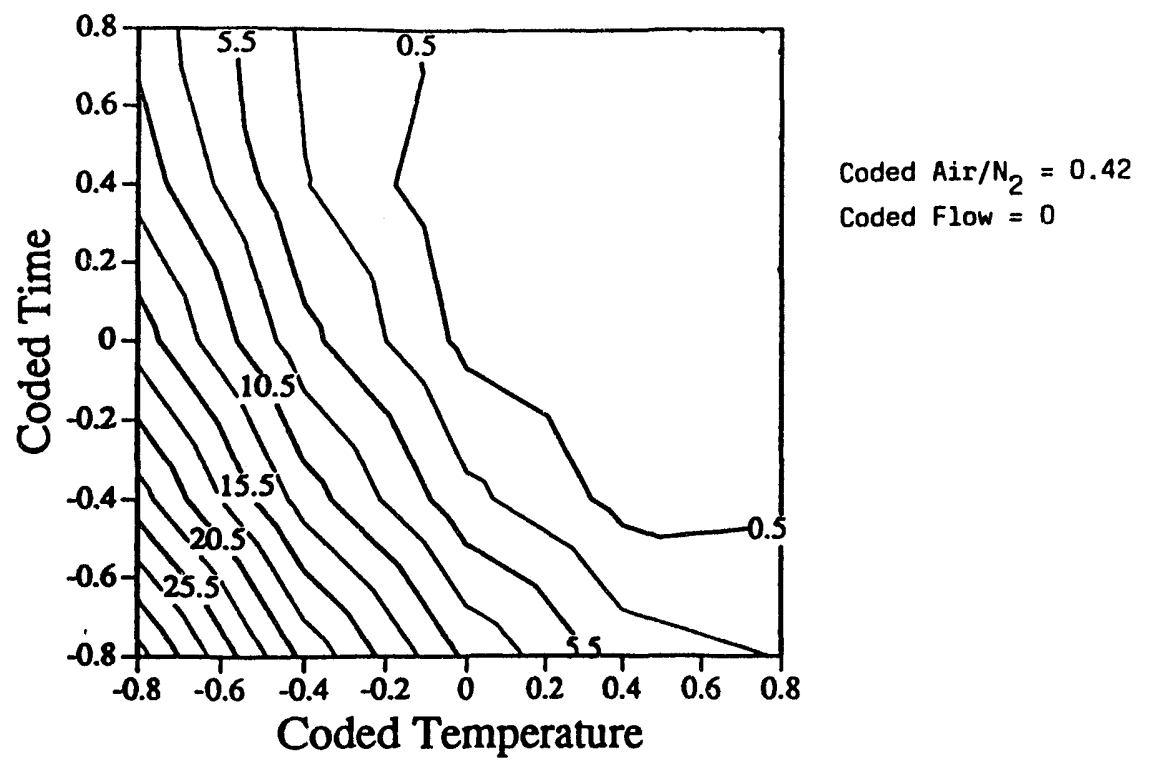

Figure 5. Contour Plot of Carbon Content in Carbothermal Silicon Nitride Powders after Burnout as a Function Time and Temperature

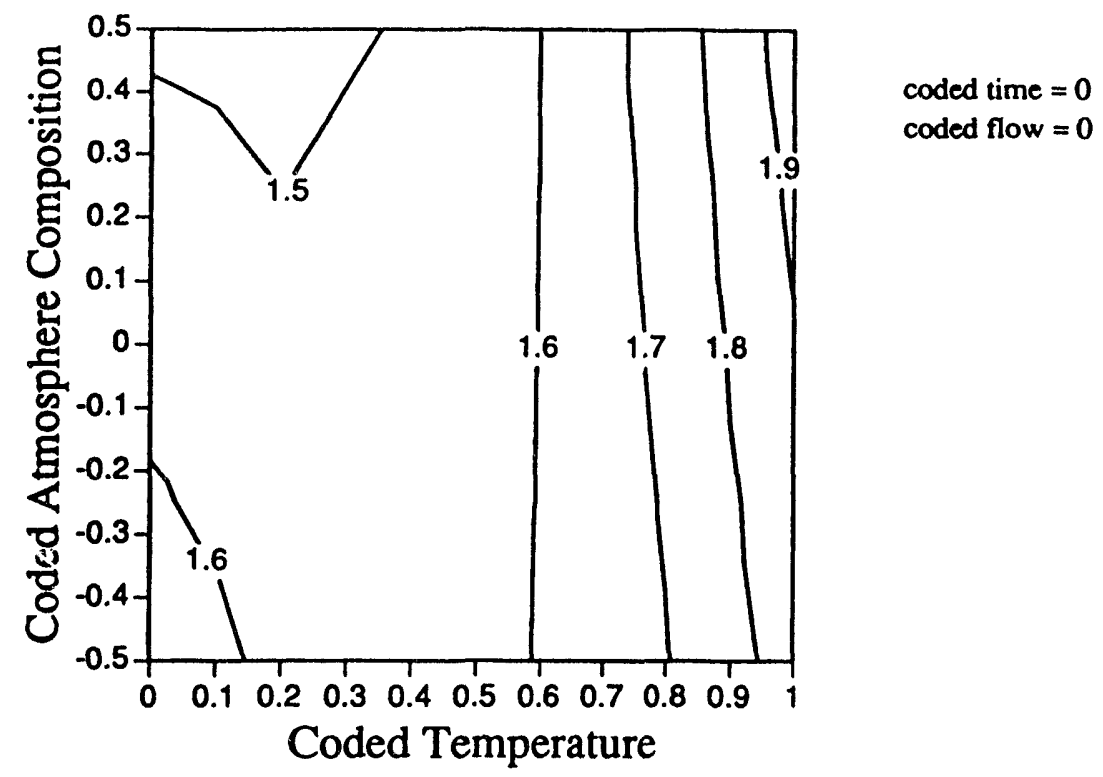

\footnotetext{
Figure 6. Contour Plot of 0xygen Content in Carbothermal Silicon Nitride Powders after Burnout as a Function of Temperature and Atmosphere Composition
}

has little effect on the oxygen content of the product. However, as the temperature increases, the oxygen contours begin to get closer together and their slope decreases, indicating an atmospheric effect. For example, if the burn-out was conducted at a coded temperature of 0.93 , an increase in the atmosphere composition from -0.5 to 0.5 would increase the oxygen content of our carbothermal powder from approximately $1.7 \%$ to $1.9 \%$.

\section{Task 2.0: Process Development and Process Scale-up}

Task 2 began in May, 1993. The primary objective of this task is to scale a process to the pilot plant level. The results of the initial efforts will be utilized in synthesizing the $10 \mathrm{~kg}$ deliverable due in November. 
Activities which took place in Task 2 concentrated on the unit operations associated with the pilot plant. The first campaigns carried out in the pilot plant were meant to identify the challenges and problems associated with moving and handling large quantities of solids specific to the silicon nitride process, determining the ease of formulating the starting materials and generating a reproducible precursor, operating the reactor to determine related engineering and chemistry issues, and lastly, developing product handling procedures. A designed experiment was generated to evaluate the reaction conditions in the larger facility to determine the scalability of the process. During the initial campaign, hundreds of pounds of powder were synthesized and evaluated. The results of the early runs provided a basiline for both powder properties as well as reactor conditions for the process. As will be detailed, under Task 3, the product powders were extensively characterized. In addition to prociss development and hardware engineering, precursor formulations developed in the intermediate reactor were scaled to the larger pilot plant facility. The product produced from the various formulations were evaluated for powder properties as well as part processing characteristics.

Based on the data generated in the pre-pilot plant study on the removal of excess carbon by a controlled oxidation reaction, a similar effort was initiated in the pilot plant postreaction calciner. During this trial, off-spec material generated in the synthesis campaigns was used for the evaluations. In the studies, key process variables such as the time and temperature of the process, gas composition, and product rate were assessed again by use of a designed experiment.

In the first few pilot plant campaigns during this reporting period, a strong emp.hasis was placed on minimization of impurities which could result from powder handling. Specifically, each unit operation was examined and modified to ensure that the product purity was impacted as little as possible. As an example, at the onset of the campaigns iron was found to be contaminating the material in one particular stage of the process. After an extensive analytical evaluation of the material in each unit operation, the problem was identified and quickly corrected. This analytical process utilized $\mathrm{x}$-ray fluorescence methods. The data presented in Table 2 shows the progress made in reducing impurities during this period.

Table 2. Characteristics of Carbothermal Silicon Nitride Powder Produced in Our Pilot Plant Facility under Task $\mathbf{2 . 0}$

\begin{tabular}{lrrrc} 
Campaign \# & \multicolumn{1}{c}{ \# } & 2 & 3 & $\begin{array}{c}\text { Program } \\
\text { Goals }\end{array}$ \\
\hline Oxygen (wt\%)-Leco & 1.88 & 1.57 & 1.69 & $<2.5$ \\
Carbon (wt\%)-Leco & 0.44 & 0.46 & 0.49 & $<0.6$ \\
Al (ppm) -XRF & 240 & nd(50) & nd(50) & $<1300$ \\
Fe (ppm) & 120 & 44 & 30 & $<2000$ \\
Ca (ppm) & 74 & 79 & 82 & $<1000$ \\
Na (ppm) & nd(10) & -- & -- & $<10$ \\
Mg (ppm) & nd(100) & -- & -- & $<50$ \\
K (ppm) & nd(5) & nd(5) & nd(5) & $<10$ \\
Cl (ppm) & nd(10) & -- & -- & $<100$ \\
S (ppm) & nd(20) & -- & -- & $<100$ \\
Surface Area (m²/g) & 7.5 & 9.4 & 11.1 & $5-20$ \\
wt.\% Alpha Si ${ }_{3} N_{4}$ & $>95$ & $>95$ & $>95$ & $>90$ \\
*nd = non detectable & & & &
\end{tabular}

As the number of campaigns increased and enhancements were made to the process and feed formulations, the run time in the pilot plant trials was extended to greater than 300 hours. During these longer tests, certain process variables specific to larger units were 
evaluated. In addition, larger quantities of crude product were generated and utilized as feed for the post-processing unit operations. As an example of the benefits of the longer run times, a determination of reactor stability could be ascertained by evaluating the wt $\%$ oxygen vs. time. These data also served the purpose of establishing operating limits for the various powder properties for quality control purposes. Figure 7 is a control chart for the product oxygen and carbon data for a trial lasting close to $450 \mathrm{hc}$. .

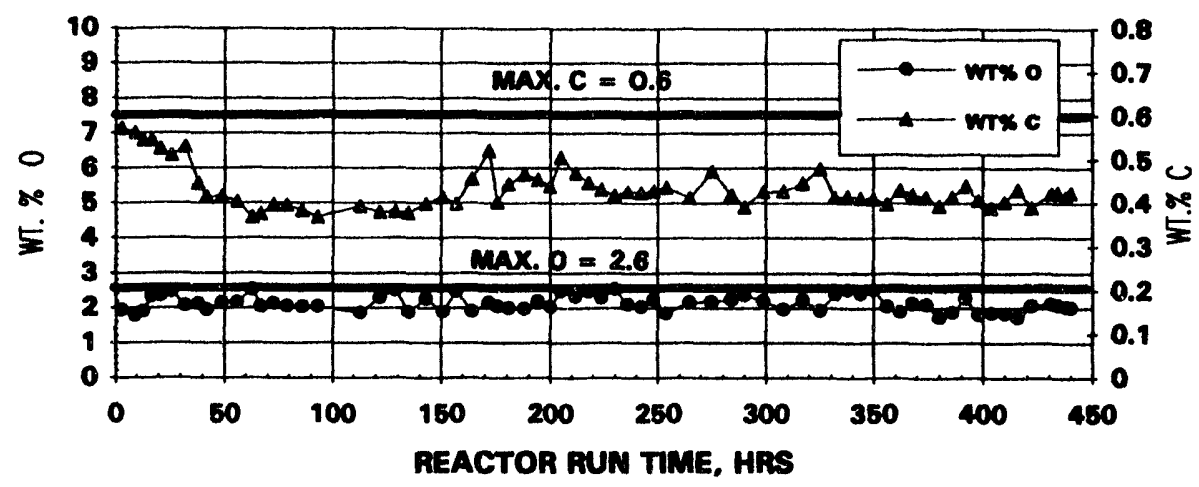

Figure 7. Pilot Plant $\mathrm{Si}_{3} \mathrm{~N}_{4}$ Product

\section{Task 3.1: Powder Characterization}

The $3 \mathrm{~kg}$ of powder produced in Task 1.3 as part of the May deliverable to MMES has been fully characterized with the results summarized below. Figures 8 and 9 are scanning and transmission electron micrographs of this carbothermal powder which was produced in reactor configuration \#1. The micrographs indicate that the carbothermal powder is a submicron, equiaxed product with no signs of whisker-like product or large agglomerates. Table 3 is a summary of the physical properties for the $3 \mathrm{~kg}$ deliverable to MMES. As

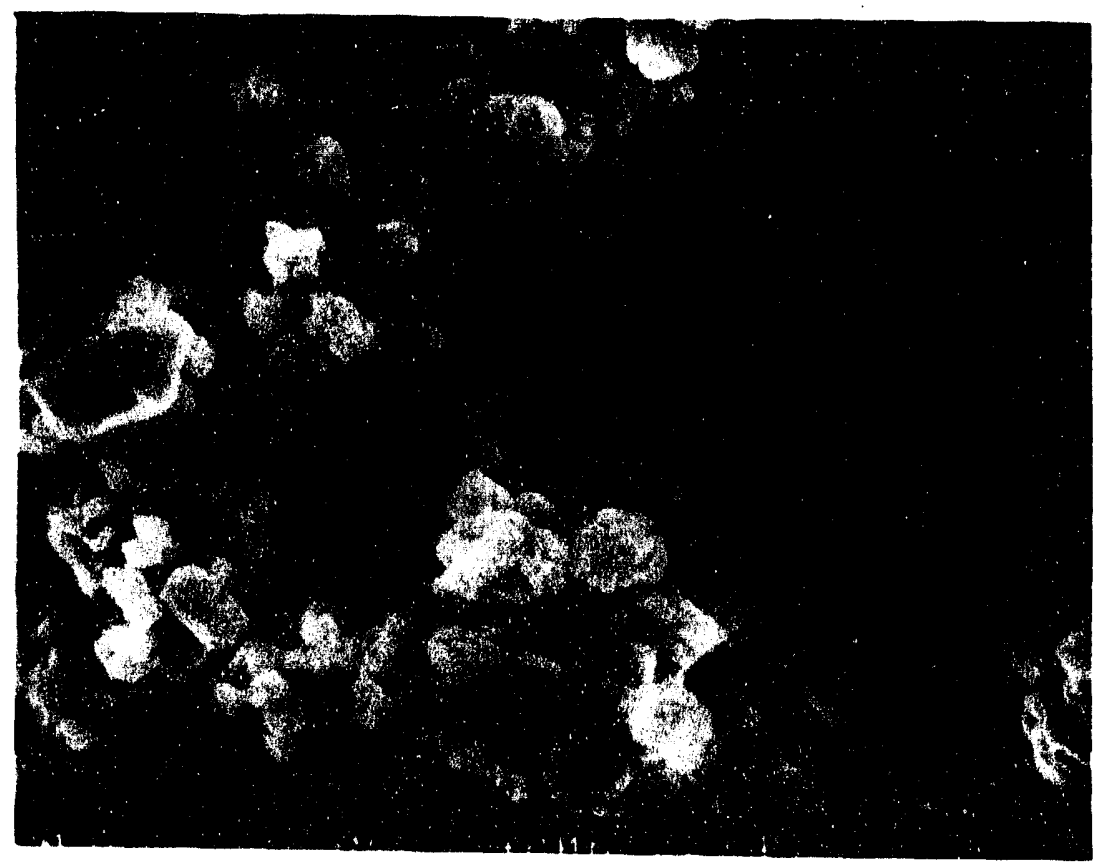

Figure 8. Scanning Electron Micrograph of the Carbothermal Powder Produced in Reactor Configuration \#1 and Delivered to MMES in May, 1993. 


\section{7}

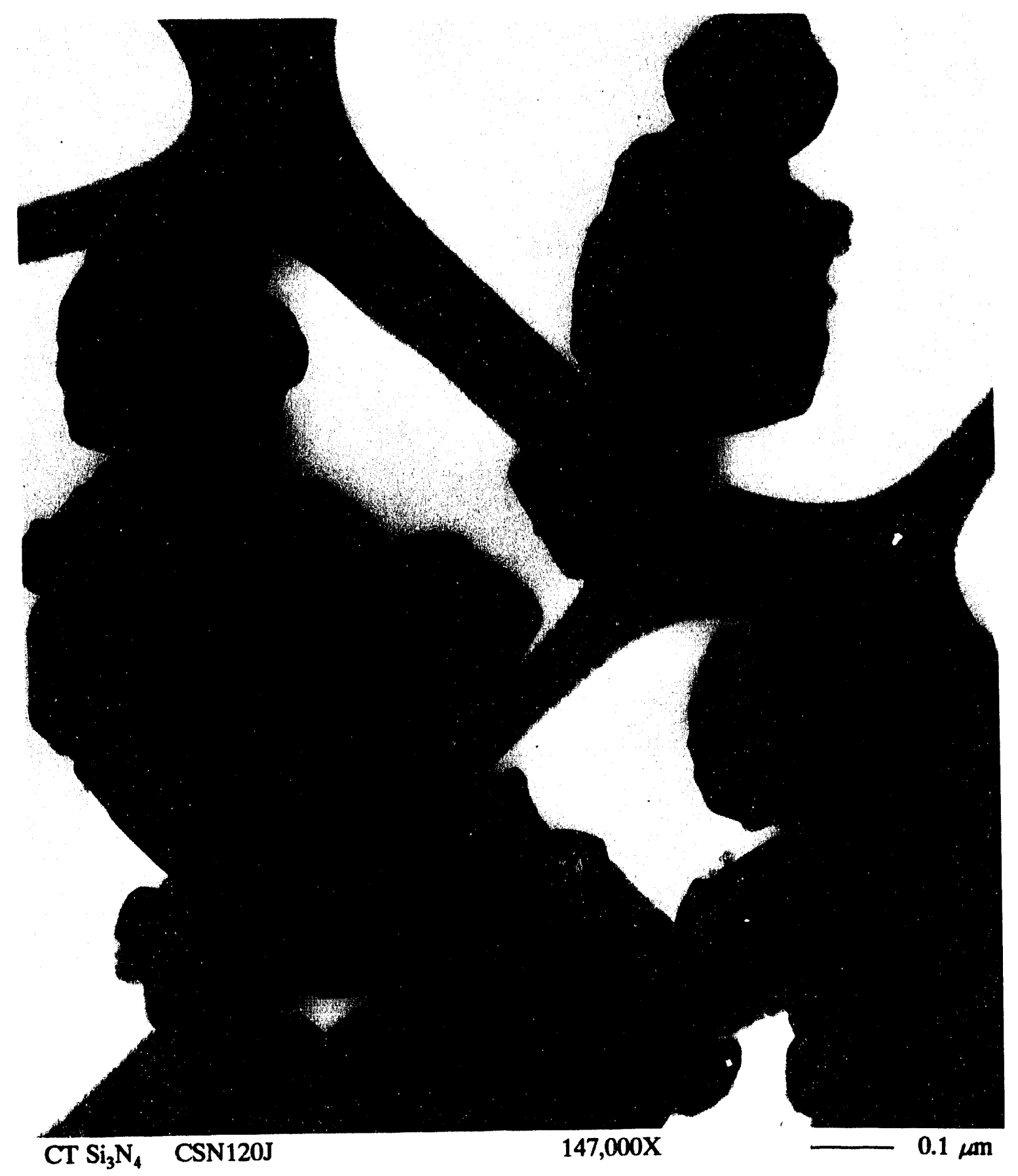

Figure 9. Transmission Electron Micrograph of the Carbothermal Powder

Produced in Reactor Configuration \#1 and Delivered to MMES in May, 1993. 
indicated, the powder has desirable characteristics of a high quality powder with an oxygen content of $2.2 \mathrm{wt} \%$, a residual carbon of $0.4 \mathrm{wt} \%$, a surface area of $10.4 \mathrm{~m}^{2} / \mathrm{g}$ and an average particle size of $0.77 \mu \mathrm{m}$. The metallic and non-metallic impurities in this powder were found to be very low and well within specifications. Figure 10 is the $x$-ray diffraction pattern for this silicon nitride product. Quantitative analysis of this pattem has indicated that the powder consists of an alpha silicon nitride content $>98 \mathrm{wt} \%$ and beta content $<2$ wt\%.

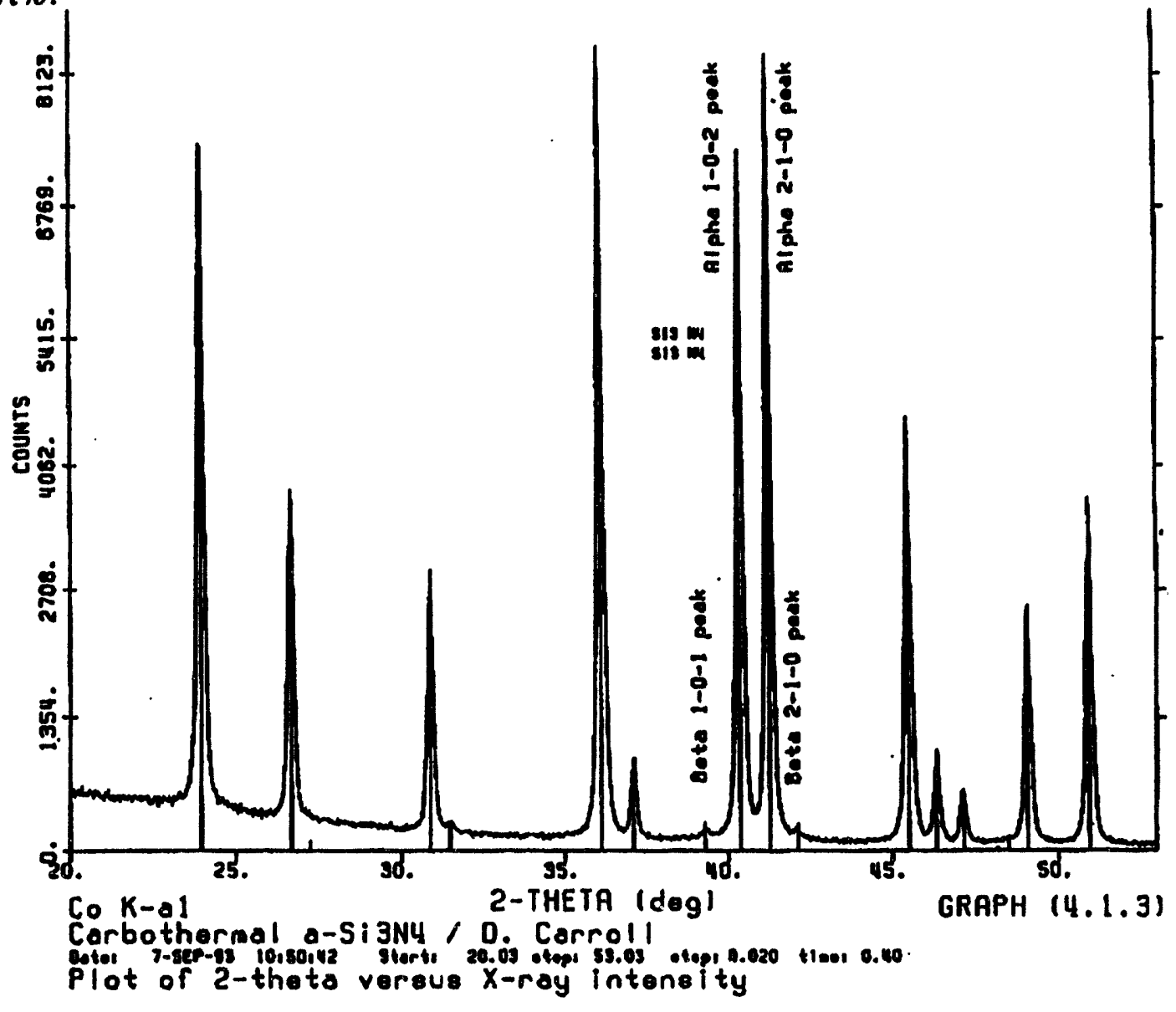

Figure 10. X-ray Diffraction Pattern of the Carbothermol Powder Produced in Reactor Configuretion $\$ 1$ and Delivered to MMES in May, 1993.

Carbothermal powder produced in our pilot plant facility under Task 2.0 was also characterized in this task to determine the physical properties. Table 2 summarizes the powder properties for three different reactor campaigns. The results indicate that the powders produced in our pilot plant facility have desirable oxygen content ( 1.6 to 1.8 wt $\%)$, residual carbon content $(-0.4 \mathrm{wt} \%)$ and surface area $\left(8-11 \mathrm{~m}^{2} / \mathrm{g}\right)$. The metallic and non-metallic impurity levels were also very low and well within specifications. $X$-ray diffraction analysis has also shown that the alpha silicon nitride content in these powders is greater than $95 \mathrm{wt} \%$.

\section{Task 3.2: Powder Sinterability}

Sinterability studies were conducted to identify the characteristics, reactor conditions and raw material precursors which yield a high quality, sinterable powder. In these experiments, carbothermal powders were mixed with a Dow sintering formulation which had a total glass content of 7.5 volume \%. The formulated carbothermal powders were 
pressed into greenware and partially sintered at elevated temperatures. This partial sintering technique facilitated comparisons between powder characteristics and relative rates of densification. The sintering formulations were also systematically varied to determine the effects of sintering composition. This experimental effort was utilized to examine the effects of raw material Additive \#1 on the powder sinterability. These results have been discussed under Task 1.3.

Table 3. Characteristics of the $3 \mathrm{~kg}$ Carbothermal Powder Produced in Our Intermediate Reactor and Delivered to MMES in May, 1993

$\begin{array}{lrc} & \begin{array}{c}\text { Dow } \\ \text { CSN Powder }\end{array} & \begin{array}{c}\text { Program } \\ \text { Goals }\end{array} \\ \text { Oxygen (wt\%)-Leco } & 2.20 & <2.5 \\ \text { Carbon (wt\%)-Leco } & 0.40 & <0.6 \\ \text { Al (ppm)-XRF } & \text { nd(50) } & <1300 \\ \mathrm{Fe}(\mathrm{ppm}) & 17 & <2000 \\ \mathrm{Ca}(\mathrm{ppm}) & 67 & <1000 \\ \mathrm{Na}(\mathrm{ppm}) & \mathrm{nd}(100) & <10 \\ \mathrm{Mg}(\mathrm{ppm}) & \text { nd }(100) & <50 \\ \mathrm{~K}(\mathrm{ppm}) & \mathrm{nd}(5) & <10 \\ \mathrm{Cl}(\mathrm{ppm}) & \text { nd }(10) & <100 \\ \mathrm{~S}(\mathrm{ppm}) & \text { nd }(100) & <100 \\ \text { Surface Area }\left(\mathrm{m}^{2} / \mathrm{g}\right) & 10.4 & 5-20 \\ \text { Ave. Particle Size }(\mu \mathrm{m}) & 0.77 & 0.1-0.8 \\ \text { wt\% Alpha Si } \mathrm{N}_{4} & >98.5 & >90\end{array}$

\section{Task 3.3: Sintering Aid Optimization}

Statistically designed experiments were utilized to determine the optimum sintering formulation that can pressureless sinter the carbothermal silicon nitride powder to greater than $98 \%$ of theoretical density. Two different sintering formulations were evaluated: a Dow formulation (total glass content of 7.5 volume \%) and a generic $\mathrm{Y}_{2} \mathrm{O}_{3}-\mathrm{Al}_{2} \mathrm{O}_{3}-\mathrm{SiO}_{2}$ formulation (total glass content of 12.1 volume \%). The carbothermal powder used for the optimization of the Dow formulation was produced in reactor configuration \#1 and had a oxygen content of $1.94 \mathrm{wt} \%$, a carbon content of $0.53 \mathrm{wt} \%$ and a surface area of 11.6 $\mathrm{m}^{2} / \mathrm{g}$. The carbothermal powder utilized for the optimization of the $\mathrm{Y}_{2} \mathrm{O}_{3}-\mathrm{Al}_{2} \mathrm{O}_{3}-\mathrm{SiO}_{2}$ formulation was produced in our pilot plant facility and had an oxygen content of 1.57 wt $\%$, a carbon content of $0.48 \mathrm{wt} \%$ and a surface area of $9.4 \mathrm{~m}^{2} / \mathrm{g}$. It should be noted that the oxygen content in the silicon nitride powder was assumed to be in the form of $\mathrm{SiO}_{2}$ and was taken into consideration in the overall sintering composition. The sintering schedule used for the Dow formulation was based upon an optimum schedule developed internally at Dow. For the $\mathrm{Y}_{2} \mathrm{O}_{3}-\mathrm{Al}_{2} \mathrm{O}_{3}-\mathrm{SiO}_{2}$ formulation, a two-step pressureless sintering schedule was utilized where the specimen was first sintered at $1700^{\circ} \mathrm{C}$ for $1 \mathrm{hr}$ in flowing nitrogen followed by an additional $2 \mathrm{hr}$ soak at $1800^{\circ} \mathrm{C}$. The results of the composition optimization for the Dow formulation and the $\mathrm{Y}_{2} \mathrm{O}_{3}-\mathrm{Al}_{2} \mathrm{O}_{3}-\mathrm{SiO}_{2}$ formulation are shown in Figures 11 and 12, respectively. The density contours as a function of the volume ratio of sintering component $\mathrm{A} / \mathrm{B}$ and the volume fraction of component $\mathrm{C}$ in the Dow sintering formulation are shown in Figure 11. From these results, it can be seen that a compositional region exists where the carbothermal powder can be pressureless sintered to greater than 98.75\% of theoretical density. The density contour plot for the $\mathrm{Y}_{2} \mathrm{O}_{3}-\mathrm{Al}_{2} \mathrm{O}_{3}-\mathrm{SiO}_{2}$ system is shown in Figure 12. The results indicate that the compositions containing a volume fraction of $\mathrm{SiO}_{2}$ ranging from $\sim 0.25$ to 0.50 and $\mathrm{a}_{2} \mathrm{O}_{3} / \mathrm{Al}_{2} \mathrm{O}_{3}$ volume ratio of $\sim 1.2$ to 2.5 can pressureless sinter the carbothermal powder to greater than $98 \%$ of theoretical density. The 
center of the $98 \%$ density contour corresponds to a composition of 87.93 vol\% $\mathrm{Si}_{3} \mathrm{~N}_{4}$, 4.77 vol\% $\mathrm{Y}_{2} \mathrm{O}_{3}, 2.55$ vol\% $\mathrm{Al}_{2} \mathrm{O}_{3}$ and 4.78 vol\% $\mathrm{SiO}_{2}$.

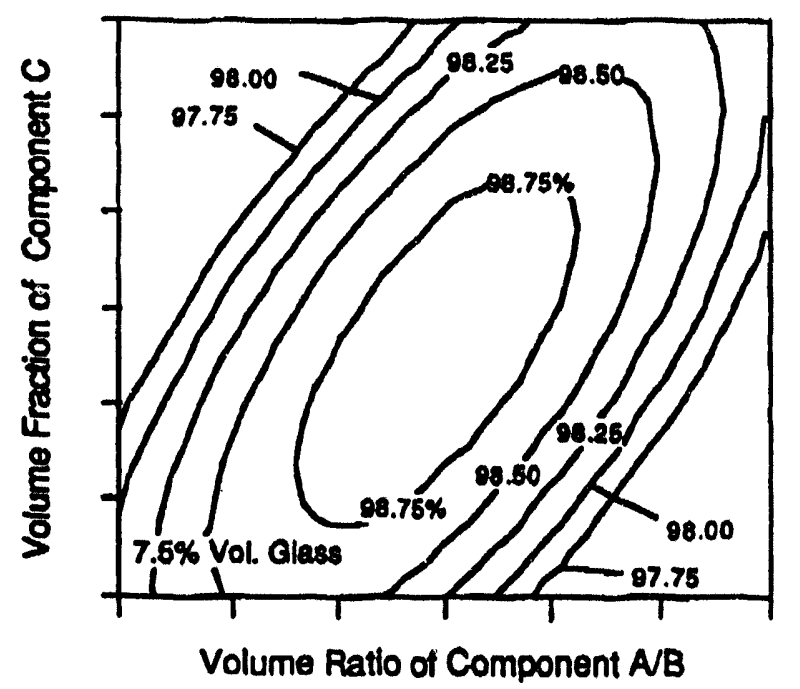

Figure 11. Percent Theoretical Density Contour Plot Showing Sintered Density as a Function of Composition for the Dow Pressureless Sintering Formulation.

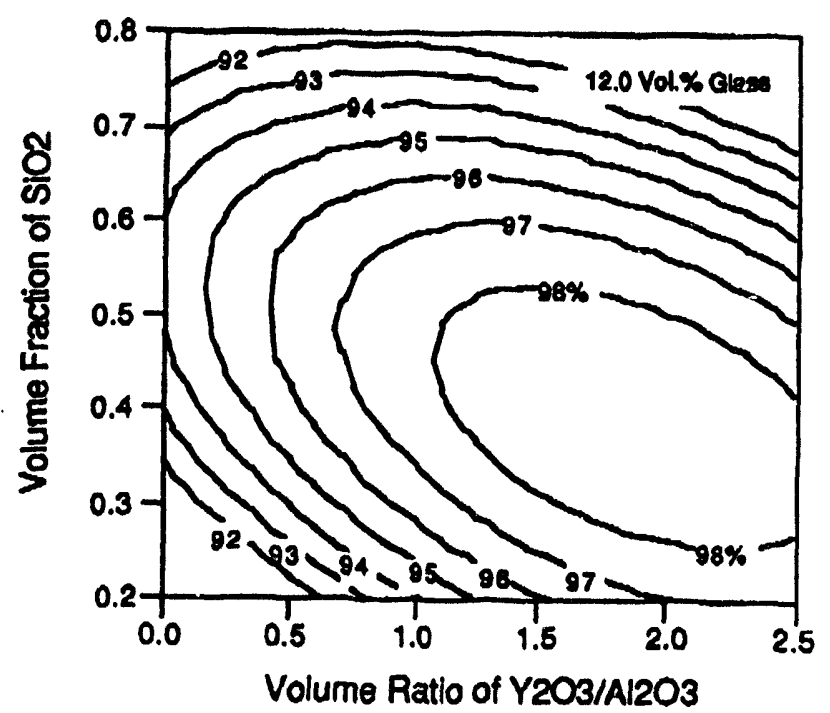

Figure 12. Percent Theoretical Density Contour Plot Showing Sintered Density as a Function of Composition for the $\mathrm{Y}_{2} \mathrm{O}_{3}-\mathrm{Al}_{2} \mathrm{O}_{3}-\mathrm{SiO}_{2}$ Pressureless Sintering Formulation

\section{Task 3.4/3.5: Suspension Development/Greenware Formation and Part Densification}

In the last six months, the efforts of Tasks 3.4 and 3.5 have focused on making high quality greenware and sintered components from carbothermal powder using both the Dow and the $\mathrm{Y}_{2} \mathrm{O}_{3}-\mathrm{Al}_{2} \mathrm{O}_{3}-\mathrm{SiO}_{2}$ pressureless sintering formulations. The sintered components produced in this task are utilized as part of a mechanical property evaluation in Task 3.7. The areas of slip preparation and casting procedure were emphasized during this reporting 
session in order to help eliminate warping and cracking that was occasionally observed in our sintered components. The first area focused on an increased solids loading in our slip using the Dow sintering formulation. New dispersants were found which enabled our solids loading to be increased from $35-37$ volume \% to $42-45$ volume \%. This increased solids loading was found to reduce our casting time and increase our greenware density. The second area dealt with improving our mixing procedures. As the solids loading of our slip increased above 39 volume \%, a dilatant behavior was observed which prevented a complete and effective mixing of the powder. Even with the new dispersant system, slips with high solids loading ( $>39$ volume \%) still exhibited a small degree of dilatancy. It was found that by altering the mixing procedure and carefully controlling the mixing variables (i.e., speed, slip to media ratio, etc.), the dilatancy behavior could be avoided allowing the preparation of slips with solids loading greater than 45 volume \%. This newly developed slip exhibited rheological behavior similar to our old slips ( 35 volume \% solids) made with the old dispersant system. The greenware obtained from the new slip system were crackfree and exhibited a two-fold increase in green strength with a green density of 57 to $60 \%$. This greenware could be pressureless sintered to greater than $98 \%$ density without cracking or warping. MOR bars were machined from these parts and supplied to Task 3.7.

The same technique was applied to preparation of greenware using the $\mathrm{Y}_{2} \mathrm{O}_{3}-\mathrm{Al}_{2} \mathrm{O}_{3}$ Sin system. Early results showed that high solid-loading slips (45 volume \%) could be obtained and cast into greenware with a density $>58 \%$. This greenware could be sintered to $96-98 \%$ of theoretical density. Occasionally, thicker slip-cast parts exhibited warping and cracking along with a bloating phenomenon after sintering. The warping and cracking was believed to be associated with density and compositional gradients in the slip cast parts. The bloating phenomenon was thought to be associated with the sintering cycle. Experimental designs have been initiated to identify the important mixing, post-mixing and sintering variables to address these issues.

\section{Task 3.7: Parts Characterization}

In order to evaluate the mechanical properties of components made from the $3.0 \mathrm{~kg}$ powder lot delivered to MMES in May, a total of 47 specimens (MIL-STD-1942A, specimen B) were machined from the billets fabricated in Task 3.5. Twenty-five of these specimens were sent to MMES as part of a July deliverable and an independent evaluation of the mechanical properties. The other twenty-two specimens were tested in-house to determine the average fracture strength and Weibull modulus for this carbothermal powder. The average fracture toughness was also measured on 3 specimens using the chevronnotched bend beam technique. The results of the mechanical property analysis are summarized in Table 4. Also, included in Table 4, are the mechanical properties measured by MMES as well as the overall program goals. The average fracture strength, Weibull modulus and fracture toughness of this material were measured to be $750 \pm 50 \mathrm{MPa}, 15$, and $7.3 \pm 0.2 \mathrm{MPa}-\mathrm{m}^{1 / 2}$, respectively. These mechanical property results compare favorably to the overall program goals. It is anticipated that with the recent improvements in our slip formulation and sintering procedures will result in improved strength beyond the program goal of $800 \mathrm{MPa}$.

Mechanical property specimens were machined from sintered billets made with the carbothermal powder produced in the second campaign of our pilot plant facility. These sintered billets were fabricated in Tasks 3.4/3.5 using the $\mathrm{Y}_{2} \mathrm{O}_{3}-\mathrm{Al}_{2} \mathrm{O}_{3}-\mathrm{SiO}_{2}$ formulation. The results of the mechanical property analysis of these specimens are summarized in Table 5. The average fracture strength, Weibull modulus and fracture toughness was measured to be $785 \pm 80 \mathrm{MPa}, 11$ and $6.45 \pm 0.2 \mathrm{MPa}-\mathrm{m}^{1 / 2}$, respectively. The mechanical properties also compare favorably to the overall program goals. Fractography of the specimens have indicated that the lower than expected Weibull modulus of 11 was due to a few specimens with machining flaws. The lower fracture toughness, as compared to the 
results in Table 4, is believe to be due to the $\mathrm{Y}_{2} \mathrm{O}_{3}-\mathrm{Al}_{2} \mathrm{O}_{3}-\mathrm{SiO}_{2}$ sintering formulation and not the nature of the carbothermal powder.

Table 4. Mechanical Property Summary for Sintered Parts Made from the $3 \mathbf{~ k g}$ of Carbothermal Powder Delivered to MMES in May.

$\begin{array}{lccc} & \begin{array}{c}\text { Dow } \\ \text { Results }\end{array} & \begin{array}{c}\text { MMES } \\ \text { Results }\end{array} & \begin{array}{c}\text { Program } \\ \text { Goals }\end{array} \\ \text { Average Strength }(\mathrm{MPa}) & 750 \pm 50 & 778 & >800 \\ \text { Weibull Modulus } & 15 & 15 & >15 \\ \text { KIC }\left(\mathrm{MPa}-\mathrm{m}^{1 / 2}\right) & 7.3 \pm 0.2 & -- & >5.0\end{array}$

Table 5. Mechanical Property Summary for Sintered Parts Made from Carbothermal Silicon Nitride Powder Produced in Campaign \#2 of Our Pilot Plant Facility

$\begin{array}{lcc} & \text { Dow } & \text { Program } \\ \text { Results } & \text { Goals } \\ \text { Average Strength }(\mathrm{MPa}) & 785 \pm 80 & >800 \\ \text { Weibull Modulus } & 11 & >15 \\ \text { KIC }\left(\mathrm{MPa}-\mathrm{m}^{1 / 2}\right) & 6.45 \pm 0.20 & >5.0\end{array}$

\section{Status of Milestones}

All milestones are on schedule.

\section{Communication/Travel}

Dr. D.F. Carroll attended the 1993 American Ceramic Society Meeting in Cincinnati, Ohio and presented a paper on "The Characteristics of a Carbothermal Silicon Nitride Powder".

A visit to the High Temperature Materials Laboratory at Oak Ridge took place on September 9 for a project review.

\section{Patent_Activity}

During this reporting period, three patent disclosures were written. All three relate to the production of silicon nitride and its related powder properties. 


\section{Cost Effective Sintering of Sillicon Nitride Ceramics (S/U-C)}

D. E. Wittmer (Associate Professor, Southern Illinois University at Carbondale, Carbondale, IL 62901

\section{Objective/Scope}

The purpose of this work is to investigate the potential of cost effective sintering of $\mathrm{Si}_{3} \mathrm{~N}_{4}$ through the development of continuous sintering techniques and the use of lower cost $\mathrm{Si}_{3} \mathrm{~N}_{4}$ powders and sintering aids.

\section{Technical Hiahliahts}

The project research goals for Phase I and II were divided into 3 major tasks. The approval of Phase III (modification IV) of this subcontract for funding has added an additional task, Task 4 . In this contract modification Tasks 2 and 3 will be continued. Task 4 involves the design, construction, and operation of a new generation belt furnace with increased capacity and the ability to exchange refractory metal and graphite hot zones.

Task 1. Refine Economic Model and Design for Chosen Furnace Configuration.

This task was completed during the previous reporting period.

Task 2. Continue Evaluation of Sintering Parameters on Properties of Selected $\mathrm{Si}_{3} \mathrm{~N}_{4}$ Compositions.

As reported previously, additional $\mathrm{Si}_{3} \mathrm{~N}_{4}$ formulations, using UBE $\mathrm{E}-10 \mathrm{Si}_{3} \mathrm{~N}_{4}$ powder were to be processed by turbomilling and pressure casting techniques described previously. The formulations were A2Y6, A2Y8 with 5 wt. $\% \quad B-\mathrm{Si}_{3} \mathrm{~N}_{4}$ seed, and $\mathrm{A} 4 \mathrm{Y} 6$ with 5 wt. $\% \mathrm{~B}_{-} \mathrm{Si}_{3} \mathrm{~N}_{4}$ seed. Due to the previously successful belt sintering of the A2Y8 compositions, the A2Y6 formulation was added to the composition matrix, in order to determine the feasibility of continuously sintering a $\mathrm{Si}_{3} \mathrm{~N}_{4}$ formulation with only $8 \%$ sintering additives. The $A 2 Y 8$ and $A 4 Y 6$ formulations with the addition of $5 w t . \%$ $\mathrm{B}_{-} \mathrm{Si}_{3} \mathrm{~N}_{4}$ seed were included to complete the data set for seeded vs. uriseeded compositions. The data generated will be used in comparing compositions sintered in the overpressure furnace with those pressureless sintering in the Centorr Model 6-BF belt furnace. 
During this reporting period, $\mathrm{Si}_{3} \mathrm{~N}_{4}$ formulations $\mathrm{A} 2 \mathrm{Y} 6, \mathrm{~A} 2 \mathrm{Y} 8, \mathrm{~A} 2 \mathrm{Y} 8$ with $5 \mathrm{wt} . \% \mathrm{~B}_{-} \mathrm{Si}_{3} \mathrm{~N}_{4}$ seed, and A4Y6 with $5 \mathrm{wt}$. $\% \mathrm{~B}_{-} \mathrm{Si}_{3} \mathrm{~N}_{4}$ seed were sintered in the belt furnace at CentorrNacuum Industries. All compositions reached near theoretical density except for the A2Y6 which was about $95 \%$ dense after sintering at $1750^{\circ} \mathrm{C}$ for $90 \mathrm{~min}$. The physical properties of these compositions are currently being determined.

As part of this task, microwave plasma etching techniques are also being developed for each of the various compositions previously sintered in the belt furnace. The parameters being investigated are power setting (with and without pulse), time, gas flow and $\mathrm{CF}_{4} / \mathrm{O}_{2}$ ratio. It appears from preliminary results, that for plasma etching $\mathrm{Si}_{3} \mathrm{~N}_{4}$ the quality of the polished surface prior to etching and the location of the specimens within the plasma chamber appear to have the greatest effect on the quality of the etch. Operating conditions have been established to obtain high quality etched surfaces on all of the $\mathrm{Si}_{3} \mathrm{~N}_{4}$ compositions studied to date. For all of these compositions, the microstructures for the polished/etched surfaces have all been examined by SEM. Figure 1 is a typical SEM photomicrograph of a plasma etched A2Y8 $\mathrm{E}-10 \mathrm{Si}_{3} \mathrm{~N}_{4}$ test bar that was sintered in the belt furnace at $1750^{\circ} \mathrm{C}$ for $90 \mathrm{~min}$.

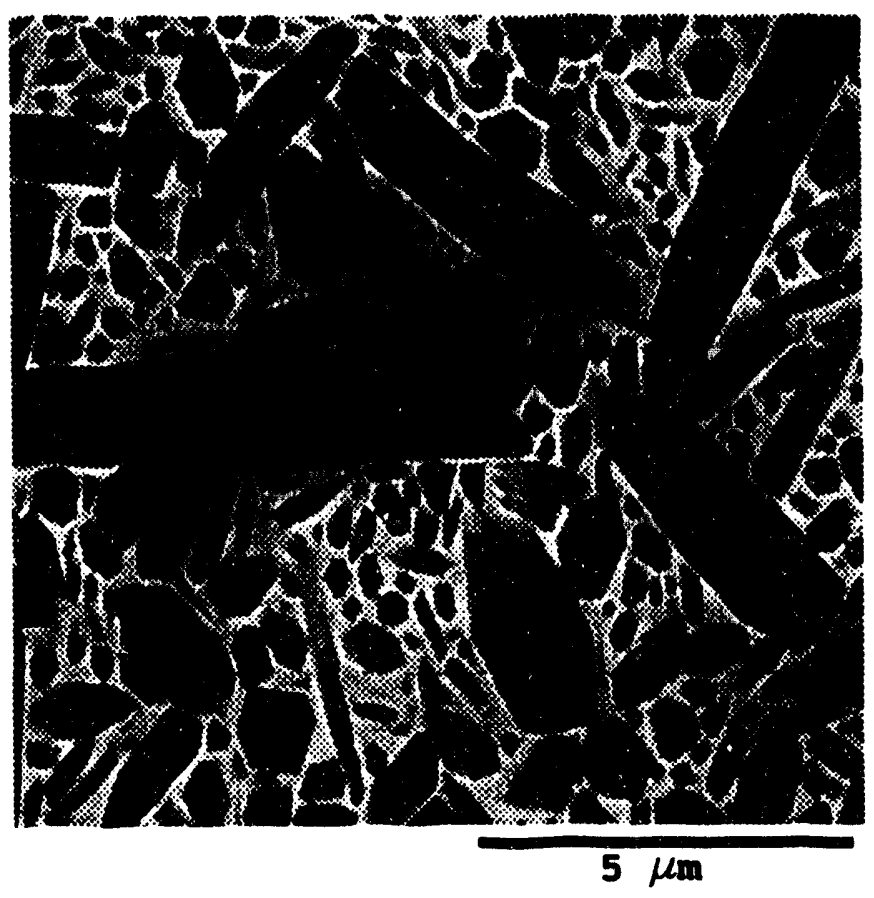

Figure 1. SEM photomicrograph of plasma etched A2Y8 E-10 $\mathrm{Si}_{3} \mathrm{~N}_{4}$

This SEM micrograph shows the presence of a significant number of elongated $\beta$ grains after sintering for only $90 \mathrm{~min}$ at $1750^{\circ} \mathrm{C}$ in the present belt furnace. 
The present belt furnace is currently being modified for a graphite hot zone in place of the refractory metal hot zone that has been used for all of the previous runs. Additional sintering in the modified belt furnace will aid in comparing the affect of hot zone type on sinterability.

Also during this reporting period, a furnace fixture for measuring hightemperature flexural strength was built for installation on the present ATS tester, and the power supply for the furnace has been received. The hightemperature test system should be on line during the next reporting period.

\section{Phase III Modification of Task 2.}

During this task, work from previous modifications will be continued. The use of reduced sintering aid additions and incorporation of $\beta-\mathrm{Si}_{3} \mathrm{~N}_{4}$ seeding to induce in-situ toughening of selected compositions will continue. The major focus will be the influence that continuous sintering has on microstructure and phase development and how the physical properties are affected by the sintering environment. Density and shrinkage data shall be used to determine the sintering kinetics and XRD shall be used to characterize the phases present as a function of sintering conditions. Microwave plasma etching techniques will continue to be optimized to allow uniform, consistent etching of the $\mathrm{Si}_{3} \mathrm{~N}_{4}$ compositions investigated. Because of the small amount of material removed by this etching technique, it allows the examination, with minimum alteration, of the as-sintered $\mathrm{Si}_{3} \mathrm{~N}_{4}$ microstructure.

The sintering mechanism of compositions containing reduced amounts of liquid phase formers is still not clear. A major portion of this task will be devoted to closer examination of the microstructure and properties as affected by the sintering environment. Both the heating rate and lack of carbon vapor pressure in the present belt furnace may be responsible for the significantly increased rates of densification and enhanced physical properties at much lower sintering temperatures and times. These effects would be addressed by sintering trials in the new prototype furnace as outline in Task 4 . The prototype furnace would be run using the graphite heating elements and shield packs and comparing the sintering behavior, surface reactions, and warpage to the same compositions sintered with the tungsten elements and molybdenum shield packs installed. Physical properties and microstructures would be compared in an effort to resolve this issue.

The addition of high temperature testing will allow for comparison of $\mathrm{Si}_{3} \mathrm{~N}_{4}$ formulations processed by continuous sintering nearer to actual use temperatures. During this task, a high temperature furnace, fixture, and test frame which was designed and constructed in the previous modifications will be utilized. The properties to be measured are elevated temperature fast fracture and stress rupture by standard techniques. 
Task 3. Continue Evaluation of Low Cost $\mathrm{Si}_{3} \mathrm{~N}_{4}$ Powders.

This tasik will be continued primarily to work with the low cost $\mathrm{Si}_{3} \mathrm{~N}_{4}$ powders presently being produced by Dow Chemical Company, under contract to DoE through Martin Marietta Energy Systems, Inc.. Samples of these $\mathrm{Si}_{3} \mathrm{~N}_{4}$ powders are scheduled to be available from Dow sometime in January. Once received, $A 2 Y 8$ and $A 2 Y 6$ formulations using these powders will be processed by turbomilling, pressure filtration, and belt sintering. The physical properties will then be determined and compared with results obtained previously from other $\mathrm{Si}_{3} \mathrm{~N}_{4}$ powders.

\section{Task 4. Design and Construct Prototype Belt Furnace}

This is a new task under the latest contract modification (Mod. IV). During this task a prototype belt furnace will be designed and constructed to make possible the sintering of a large number of $\mathrm{Si}_{3} \mathrm{~N}_{4}$ parts whose sizes and shapes are typical of those used in automotive applications, ie. small and large cam-roller followers, valve guides and seats, tappet shims, etc. This belt furnace will be constructed by Centorr Furnaces/Nacuum Industries (CVI), under subcontract to SIU-C, using concepts developed in prior contract modifications. The furnace hot-zone will be designed and constructed to allow the interchanging of tungsten or graphite heating elements and the respective shielding. This will allow for experimental verification of the effects of furnace atmosphere and construction materials on the sintering behavior of $\mathrm{Si}_{3} \mathrm{~N}_{4}$ parts. The furnace will also be designed to use either tungsten mesh, graphite fiber or SiC links interchangeably. Using a belt constructed of SiC links is based on an innovative design and will allow for maximum loading per unit volume of furnacing space. Because of the basic differences between mesh or woven belts and a SiC link belt, special mounting and drive fixtures will need to be designed to allow for thermal expansion and tensioning. Once the design parameters are established, the pilot scale furnace will be constructed and both hot zones tested prior to delivery to SIU-C. Some of the decisions that need to be made include: furnace element placement, configuration and style; furnace size (length, width, and height); power and cooling requirements, temperature controls, design and construction costs, and gas control/handling system.

During this reporting period, the design work for the furnace and power system has been initiated by $\mathrm{CVI}$ as part of their matching contribution to this program. Construction of the furnace will start as soon as the funding for construction of the furnace is in place, which will allow SIU-C to issue the subcontract to $\mathrm{CVI}$. 


\section{Status of Milestones}

1. Refine Economic Model and Design for Chosen Completed Furnace Configuration

2. Continue Evaluation of Sintering Parameters on Properties of Selected $\mathrm{Si}_{3} \mathrm{~N}_{4}$ Compositions

On Schedule Continuing

3. Continue Evaluation of Low Cost $\mathrm{Si}_{3} \mathrm{~N}_{4}$ Powders

On Schedule Continuing

4. Design and construct prototype belt furnace

On Schedule New Task

\section{Communications/Visits/Travel}

D.E. Wittmer to ORNL to discuss results of present work and contract modifications.

D.E. Wittmer, J.J. Conover and V.A. Knapp, 95th Annual ACS meeting in Cincinnati, $\mathrm{OH}$ to present paper covering work performed in this subcontract.

D.E. Wittmer to ORNL to discuss results of resent work and Phase III contract modifications.

\section{Problems Encountered}

Faulty isopress pump delayed processing.

\section{Publications}

D.E. Wittmer, J.J. Conover, V.A. Knapp, and C.W. Miller, Jr., "Economic Comparison of Continuous and Batch Sintering of $\mathrm{Si}_{3} \mathrm{~N}_{4}$ ", The American Ceramic Society Bulletin, Vol. 72, No. 6 129-137 (1993).

\section{Presentations}

D.E. Wittmer, J.J. Conover, V.A. Knapp, and C.W. Miller, Jr., "Economic Comparison of Continuous and Batch Sintering of $\mathrm{Si}_{3} \mathrm{~N}_{4}$ ", 95th Annual ACS Meeting, April 18-22, 1993, Cincinnati, $\mathrm{OH}$. 


\section{Cast Effective Process Silicon Nitride Engine Components}

Garry Garvey (Golden Technologies Company, Inc.)

\section{OBJECTIVE/SCOPE;}

The objective of this work is to develop a low-cost process for the manufacture of high quality ceramic engine components based on sintered reaction bonded silicon nitride technology. The work shall comprise three technical tasks including materials selection, process development, and property evaluation. The material property goal for this work phase is a mean RT 4-point flexure strength of $525 \mathrm{MPa}$ with Weibull Modulus equal to 15.

\section{BACKGROUND}

The commercialization of silicon nitride engine components requires that reliable, high strength silicon nitride material be available at a cost effective price. Today, many suppliers offer high strength and reliable silicon nitride. However, this material is very costly to produce due to high raw material and high processing costs. Typical silicon nitride powders range in price from $\$ 15.00$ to $\$ 70.00$ per pound. Sintering aides for silicon nitride are equally expensive. Yttria ranges from $\$ 20.00$ to $\$ 60.00$ per pound. The use of silicon as a raw material for sintered reaction bonded silicon nitride (SRBSN) can produce raw material savings, however, the current commercial practice of non-aqueous milling adds substantially to the processing costs.

In terms of the cost of thermal processing, the current practice of over-pressure sintering of silicon nitride requires substantial capitalization compared to ambient pressure sintering. It also requires a batch type approach to sintering. Both aspects of sintering add to the product costs.

Ideally, silicon nitride should be sintered at a minimum temperature at ambient pressure in a continuous mode.

Coors Ceramic Company / Golden Technologies Company has an executed License and Commercialization Agreement to license patents related to silicon nitride technology from Eaton Corporation. This technology is based on the aqueous processing of silicon metal to produce high quality SRBSN and promises to result in reducing the cost of silicon nitride parts. 


\section{APPROACH:}

The experimental plan is based on an iterative design in which silicon metal powder and other raw materials are characterized (task 1), subjected to cost effective processing (task 2), and the silicon nitride parts thus produced are evaluated (task 3). The emphasis being on identifying low cost processes capable of producing high strength, reliable parts. The program is also designed to identify low cost, reliable domestic suppliers of the requisite raw materials that can be used to produce high quality parts.

Task 1: "Raw Material Selection and Characterization" will be conducted by sampling up to five different manufacturers for each component. Ceramic raw material lots will be characterized with respect to particle size distribution, surface area, LOI, heterogeneous and homogenous compositions. Organic batch components will be analyzed for consistency of manufacturer specified parameters.

In addition to evaluation of raw materials as received from manufacturers, Task 1 will also focus on the selection of organic additives as binders, dispersants, lubricants, and electrolytes and levels required to facilitate milling, spray drying, forming, and the achievement of reliable product properties.

Task 2: "Material Processing: The point of departure of this task will be to replicate the technology licensed from Eaton Corporation. Once this facet has been completed, Coors / GTC will endeavor to develop novel proprietary and patentable technology to simultaneously improve properties, reduce costs, and limit environmental risks. Each operation in the process flow path will be investigated for opportunities for improvement. Unit operations to be examined include: milling, spray drying, forming, debindering, nitriding, sintering and machining.

Task 3: Property Testing." Property testing will be used in an iterative manner to evaluate the effects of process modifications. The primary characterizations will include quantitative microstructural analysis, strength (MOR) and Weibull analysis. In addition; hardness, phase analysis (XRD) and toughness will be determined for selected batches. All testing will be designed to obtain statistically significant results.

The following section reports the progress made during the past 6 months on these tasks. 


\section{Milestones}

\section{Task 1}

Raw Material Characterization

Samples of each of the five ceramic components of the SRBSN formulation were collected from several manufacturers. The following table outlines the scope of the study.

$\begin{array}{lcc}\text { Material } & \text { Suppliers } & \text { Total Lots Analyzed } \\ \text { Silicon } & 4 & 20 \\ \text { Ceria } & 1 & 5 \\ \text { Alumina } & 1 & 10 \\ \text { Iron Oxide } & 2 & 10\end{array}$

A minimum of five lots of material were collected from each manufacturer. Each lot of material was characterized with respect to particle size distribution, surface area and chemical composition.

Particle size distribution (PSD) was pursued by NIST. (Gratitude is extended to Dr. Subhas Malghan of NIST for his contribution.) Technically, PSD's were determined by dispersing powders in aqueous medium and evaluating the dispersions by a variety of photon scattering techniques. Surface areas were determined by nitrogen absorption technique at GTC. And chemical analyses was performed by Elemental Analysis Corporation. The technique utilized was Proton Induced X-ray Emission (PIXE).

From these results, each manufacturer was evaluated for material purity and reproducibility of physical properties. Suppliers were selected for commercialization based on these results as well as the cost to value ratio of their products.

\section{Task 2}

\section{Aqueous Milling: Surface Area \& Oxygen Content}

The relationship between milled surface area and silica content were correlated with sintered density, porosity and changes that occur during firing. This knowledge base was expanded beyond the linear surface area to oxygen content relationship that results from aqueous milling. This was achieved by two methods. First, by milling for various durations in non-aqueous media to obtain an oxygen deficient (with respect to surface area) feed stock and secondly by adding colloidal silica to obtain excess silica content. The following dependent variables were correlated with surface areas and oxygen contents:

$$
\begin{array}{ll}
- & \text { weight loss on sintering } \\
\text { - } & \text { sintering shrinkage } \\
\text { - } & \text { porosity } \\
\text { - } & \text { density } \\
\text { - } & \text { residual silicon gradient } \\
\hline & \text { porosity gradient }
\end{array}
$$

From this study a sintering process model was developed and a reproducible process that results in high strength reliable parts was identified. 


\section{Spray Drying:}

A reliable spray drying procedure has been developed and documented. Typical powder yields of $95 \%$ were noted. Batch size ranged from a current standard of $137 \mathrm{lbs}$. to $548 \mathrm{lbs}$. Current production rate is approximately $100 \mathrm{lbs} /$ hour of ready to press powder.

\section{Dry Press Binder Development}

In the report of April 1993, GTC outlined the first iteration of a binder formulation experiment that was performed during February and March, 1993. At that time, it was recognized that the binder formulation would require fine tuning once automatic dry pressing became available. The initial experiments utilizing those formulations directly in automatic dry pressing resulted in part delamination. So a fine tuning experiment was performed as follows.

The original binder formulation contained six organic components. Five of these were minor components of $1 \mathrm{wt} \%$ or less. The sixth was a major component. The experiment was designed to identify the optimal level of this major component. A production size batch (220\#) of SRBSN slip was split into six equal fractions after milling. The major binder components was varied over six levels. Each fraction was processed to sintered parts. Fractions with low levels of binder delaminated during pressing while fractions with excessive binder had low sintered densities and high shrinkage. The fraction with the optimal binder level exhibited the highest density and strength.

\section{Dry Press Development}

In parallel with iso-press/green forming, GTC has been developing dry pressing as a cost effective path to automotive ceramics. During this period, a 45 ton Hydramet hydraulic press was successfully operated in automatic mode, producing high quality parts in a disk shaped geometry. Roller geometry tooling and necessary adapters have been obtained.

A database has been establishment which documents the behavior of powders during dry press consolidation. Dry pressing pressure has been correlated with green density, firing shrinkage and sintered density. These relationships have been tabulated for a total of 22 dry press powder production samples that exist in inventory. These data will be required to develop a near net forming procedure.

\section{Eorming Technology}

A series of 250 parts have been prepared in a right round cylindrical geometry (rollers) by an isopressing/green forming procedure. This exercise was conducted for a commercial/non-contract activity. However, to evaluate the progress of this contract to develop a low cost manufacturing process these parts were characterized dimensionally and mechanically under this contract. Detailed characterization of dimensional changes during thermal processing were completed, including: cylindricity, concentricity, shrinkage heterogeneity, density, porosity, etc. Mechanical testing of the material cut from sections of the actual parts was completed and is reported in Task 3. 


\section{Nitriding: Intelligent Control}

The nitriding furnace has been equipped to control nitriding on a real time basis. This was accomplished by developing a control scheme based on a pressure derivative/temperature set point approach. The process is normally operated in a flowing gas regime. Periodically, flow is halted and the timed derivative of pressure is evaluated. This parameter is a direct measure of nitridation rate. Once the derivative has been evaluated, the furnace is returned to flowing gas condition. The derivative is used in a non-linear response algorithm to determine a new furnace temperature. In this way, nitridation rate is optimized while preventing exothermal melt-down.

\section{Sintering: Continuous}

Four continuous sintering tests have been performed. Equipment type, manufacturers and equipment location are summarized in the following table:

\begin{tabular}{|c|c|c|c|c|}
\hline \multicolumn{5}{|c|}{ Continuous Furnace Test } \\
\hline Furnace & Refractory & Flements & Location & Mánufacturer \\
\hline Type & & x. & mox & an \\
\hline Pusher & Alumina & Molybdenum & Coors Ceramics- & Lindberg \\
\hline Pusher & Tungsten & Tungsten & C.M. Furnace & C.M. Furnace \\
\hline Pusher & Alumina & Molybdenum & Eaton & C.M. Furnace \\
\hline Metal Belt & Tungsten & Tungsten & $\begin{array}{l}\text { Centorr- Nashua, } \\
\mathrm{NH}\end{array}$ & Centorr \\
\hline
\end{tabular}

A broad time/temperature optimization experiment was performed in two stages at each location (except at Eaton, optimization had been performed prior to our tests.) At least twelve timetemperature combinations were evaluated. Maximum densities as high as $97 \%$ were obtained under optimized conditions. These tests are not conclusive as we have improved our prisder quality since these tests were performed. Additional tests have been scheduled at C-M Furnaces.

\section{Near Net Shape Processing}

Toward the goal of cost effective ceramic processing, it has been recognized that near net shaping is crucial. The marginal costs of removing excessive overstock in ceramic blanks adds significantly to the price of automotive parts. A large matrix experiment has been completed which addresses the factors affecting the dimensional control of ceramic blanks.

The experimental design selected was full factorial. The forming technology was iso-press/green forming (spark plug approach). A total of 50 iso-press tube blanks were pressed. From each, an average of five cylinders were machined. All parts were serialized. Three separite firings were 
applied to evaluate the fire -to-fire variability. The levels and the positions in the furnace during firing were tabulated. The following table lists the independent variables.

\begin{tabular}{|l|c|}
\hline \multicolumn{1}{|c|}{ INDEPENDENT VARIABLE } & NUMBER OF LEVELS \\
Serial rods & 50 \\
Positions of rod (Average) & 5 \\
Firings & 3 \\
Furnace level & 5 \\
Position of parts in furnace & 20 \\
Cylinder length & 2 \\
\hline
\end{tabular}

Each cylinder was characterized before and after firing. The independent variables are listed in the following table. Several measurements were made of many variables to improve the confidence level. The following table lists the number of measurements taken of each sample.

\begin{tabular}{|l|c|}
\hline \multicolumn{1}{|c|}{ DEPENDENT VARIABLES } & MEASUREMENTS \\
SAMPLE \\
Green Density & 1 \\
Green Dimensions & 1 \\
Sintered ID Roundness, Top & 4 \\
Sintered ID Roundness, Bottom & 4 \\
Sintered OD Roundness, Top & 4 \\
Sintered OD Roundness, Bottom & 4 \\
Sintered Concentricity & 4 \\
ID Shrinkage, Top & 4 \\
ID Shrinkage, Bottom & 4 \\
OD Shrinkage, Top & 4 \\
OD Shrinkage, Bottom & 4 \\
Height Shrinkage & 4 \\
Loss on Ignition & 1 \\
\hline
\end{tabular}

An analysis of these data has been completed. Correlations have been identified. Homogenous furnace temperature zones have been identified. Fire to fire variations have been assessed and the effects of rod position have been evaluated. 


\section{Setring}

One conclusion that was drawn from the above experiment was that setter drag during firing resulted in heterogeneous shrinkage and out of roundness at the bottom of the cylinder. A follow-up experiment was performed in which seven setting techniques were studied. These included: the settering surface geometry, setter composition and part orientation during firing. The optimal settering parameters were identified that resulted in an improved shrinkage homogeneity and a twofold improvement in bottom roundness.

\section{Process Reproducibility}

In order to determine the reproducibility of the overall process, a pilot scale procedure has been developed, documented and strictly repeated a total of six times. These six powder samples were nitrided and sintered on at least three different occasions. The densiries, used as a measure of process reproducibility, are reported in the following table:

\begin{tabular}{|c|c|c|c|c|c|c|}
\hline \multicolumn{7}{|c|}{ Powder Samples } \\
\hline \multirow{3}{*}{ Sinter Run \# } & $532-103 \mathrm{~A}$ & $532-107$ & $532-109 \mathrm{~A}$ & $532-126$ & $532-128(1)$ & $532-128(1)$ \\
1 & & & & & & \\
2 & 3.31 & 3.30 & 3.31 & & & \\
3 & 3.31 & 3.33 & 3.29 & 3.30 & 3.35 & 3.33 \\
4 & 3.33 & 3.28 & 3.29 & 3.31 & 3.34 & 3.33 \\
& 3.30 & 3.30 & 3.30 & 3.31 & 3.34 & 3.34 \\
\hline
\end{tabular}

The transverse moduli of representative samples are under test and will be presented in the annual report.

\section{Task 3}

As routine procedure, processes were evaluated by studying the physical and mechanical propertied of test parts. Over 5315 physical tests (including density, porosity, shrinkage, etc.) and 1375 strength tests were performed. These test results serve the basis of selection of the above listed process development efforts and will not be repeated here. 


\section{Strength \& Reliability}

Every powder batch / thermal treatment utilized to produce parts was evaluated with respect to strength. Since the current procedure of powder processing was adopted approximately six months ago, 22 pilot scale batches ( $>125 \mathrm{lbs}$./batch) have been produced. The following is a summary of strength tests.

\begin{tabular}{|l|l|l|}
\hline minimum average batch strength & $580 \mathrm{MPa}$ & $(84 \mathrm{ksi})$ \\
maximum average batch strength & $670 \mathrm{MPa}$ & $(97 \mathrm{ksi})$ \\
maximum single sample strength & $863 \mathrm{MPa}$ & $(125 \mathrm{ksi})$ \\
minimum batch weibull modulus & 13.7 & \\
maximum batch weibull modulus & 15.7 & \\
\hline
\end{tabular}

\section{Analysis of Section Cur from Industrial Parts}

GTC manufactured parts in the geometry of a commercial cam follower geometry (1.5" OD X 0.87 " ID X 1.00 high). MOR test specimens were cut from these parts and tested for strength. Results indicated a strength of $670+/-55 \mathrm{MPa}(97+/-8 \mathrm{ksi})$. A maximum strength of $863 \mathrm{MPA}$ (125 ksi) was noted.

Comparison of these results with strength tests performed in parallel on a leading competitors silicon nitride is presented in the following table. 


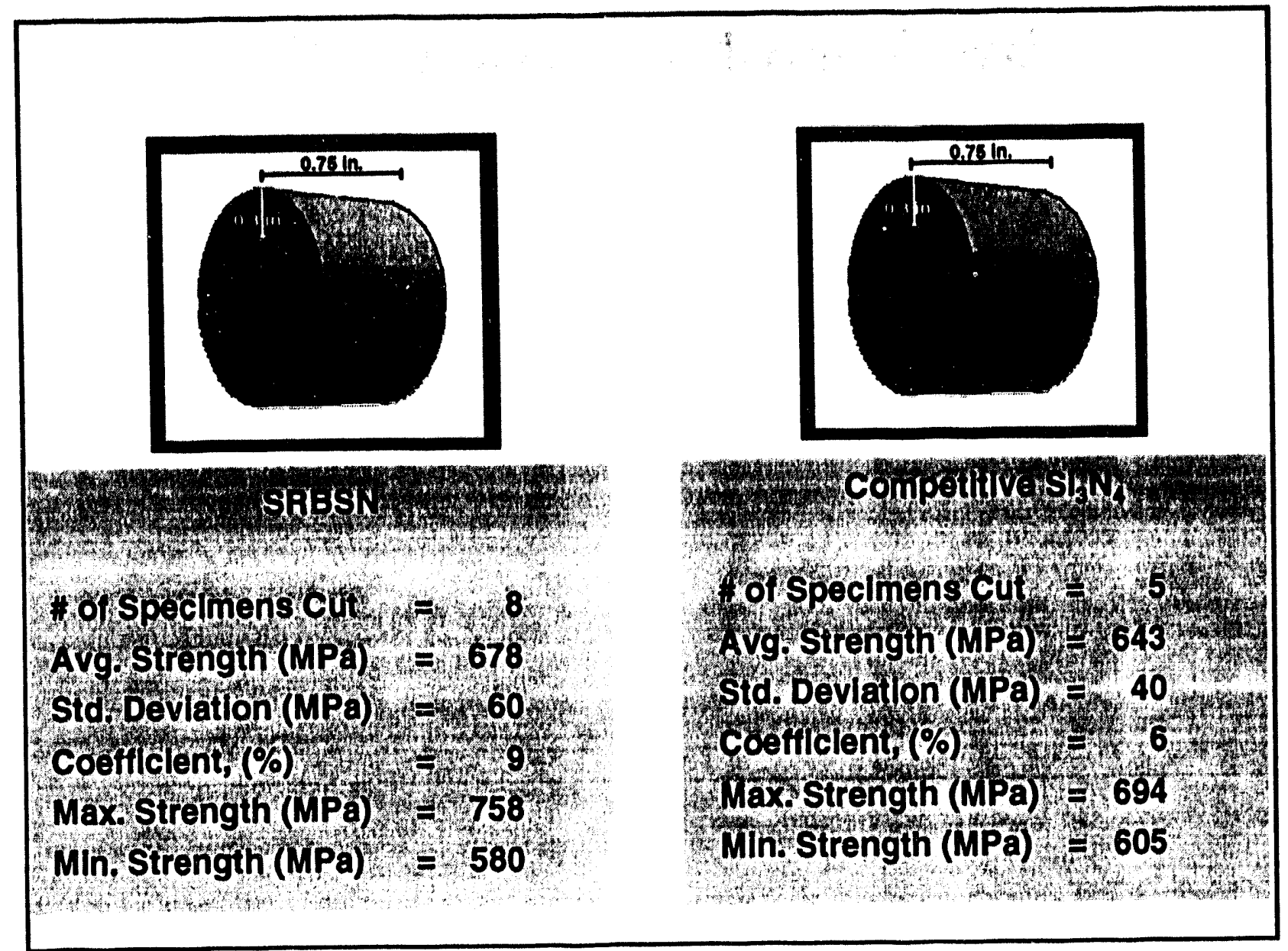

\section{CREDITS;}

Research sponsored by the U.S. Department of Energy, Assistant Secretary for Conservation and Renewable Energy, Office of Transportation Technologies, as part of the Ceramic Technology Project of the Materials Development Program, under contract \# DE-AC05-840R21400. 


\subsubsection{Processing of Monolithice}

\section{Improved Processing}

V.K. Pujari, D.M. Tracey, M.R. Foley, A.B. Hardy, S.J. Lombardo, P.J. Pelletier, L.C. Sales, C.S. White, R.L. Yeckley (Norton Company)

\section{Oblective/scope}

The goals of this contract are to develop and demonstrate significant improvements in processing methods, process controls, and nondestructive ovaluation (NDE) which can be commercially implemented to produce high reliability silicon nitride components for advanced heat engine applications at temperatures to $1370^{\circ} \mathrm{C}$. Achievement of these goals shall be sought through:

Reliability optimization of aqueous colloidal forming using highly loaded suspensions and glass encapsislated HIP'ing.

- Application of the high reliability colloidal processing technique to a gas pressure sinterable (GPS) composition.

- Demonstration of representative complex component fabrication in both the HIP and GPS systems.

\section{Technical hiahliahts}

TASK 1 Forming Using Highly Loaded Suspensions and HIP'ing

i) Powder Processing

In order to obtain high solids loading, the sedimentation behavior of Si3N4 powder with five different surfactants $(A, B, C, D, E)$ has been measured with time. As seen in Table 1, the final sedimentation density has been increased from $1.25 \mathrm{~g} / \mathrm{cm}^{3}$ in the case of no surfactant to a value of approximately $1.50-1.55 \mathrm{~g} / \mathrm{cm}^{3}$ with 3 of the surfactants.

Table 1: $\quad$ Surfactant Effects on Sedimentation Density

\begin{tabular}{||c|c||c|c||c|c||}
\hline \multicolumn{2}{|c||}{ NO SURFACTANT } & \multicolumn{3}{|c|}{ SURFACTANT A } & \multicolumn{2}{c|}{ SURFACTANT B } \\
\hline$w t \%$ & $\begin{array}{l}\text { Density } \\
\text { g/cc }\end{array}$ & $w t \%$ & $\begin{array}{l}\text { Density } \\
\text { g/cc }\end{array}$ & $w t \%$ & $\begin{array}{l}\text { Density } \\
\text { g/cc }\end{array}$ \\
\hline 0 & 1.250 & 0.1 & 1.496 & 0.2 & 1.522 \\
\hline & & 0.4 & 1.450 & 0.4 & 1.546 \\
\hline & & 0.6 & 1.523 & 0.6 & 1.367 \\
\hline & & 0.8 & 1.390 & 0.8 & 1.572 \\
\hline & & 1.0 & 1.320 & 1.0 & 1.550 \\
\hline
\end{tabular}




\begin{tabular}{||l|l||l|l||l|l||}
\hline \multicolumn{2}{||c|}{ SURFACTANT C } & \multicolumn{3}{c|}{ SURFACTANT D } & \multicolumn{2}{|c|}{ SURFACTANT E } \\
\hline$w t \%$ & $\begin{array}{l}\text { Density } \\
\text { g/cc }\end{array}$ & $w t \%$ & $\begin{array}{l}\text { Density } \\
\text { g/cc }\end{array}$ & $w t \%$ & $\begin{array}{l}\text { Density } \\
\text { g/cc }\end{array}$ \\
\hline 0.2 & 0.549 & 0.5 & 1.492 & 0.05 & 1.477 \\
\hline 0.4 & 0.524 & 1.0 & 1.454 & 0.1 & 1.488 \\
\hline 0.6 & 0.550 & & & 0.3 & 1.538 \\
\hline 0.8 & 0.548 & & & 0.5 & 1.421 \\
\hline 1.0 & 0.667 & & & & \\
\hline
\end{tabular}

ii) Density Gradient Control

From a matrix of experiments, effects of two parameters (slurry solids loading $\left(P_{1}\right)$ and powder surface area $\left(P_{2}\right)$ ) on the density and density gradient have been established. Density gradient has been indirectly measured by observing the amount of bending (runout) in cast tensile rods after HIP'ing. The higher the runout, the larger is the density gradient. The two parameters influence the casting rate (Figure 1) which in turn affects the density and its uniformity (Figure 2). As can be seen from the figures, as the powder surface area increases the casting rate decreases apparently exponentially. The casting rate goes up, however, as the slurry solids loading increases. Figure 2 indicates that as casting rate increases green density goes down and runout goes up. The control of casting rate is therefore the key to minimizing the overall density gradient in the cast part. Only low and medium solids loading slurries have been examined to date. Effect of high solids loading will be examined in the near future. As described below under NIST activity, high solids slurry is being developed using high energy attrition milling (HEAM).

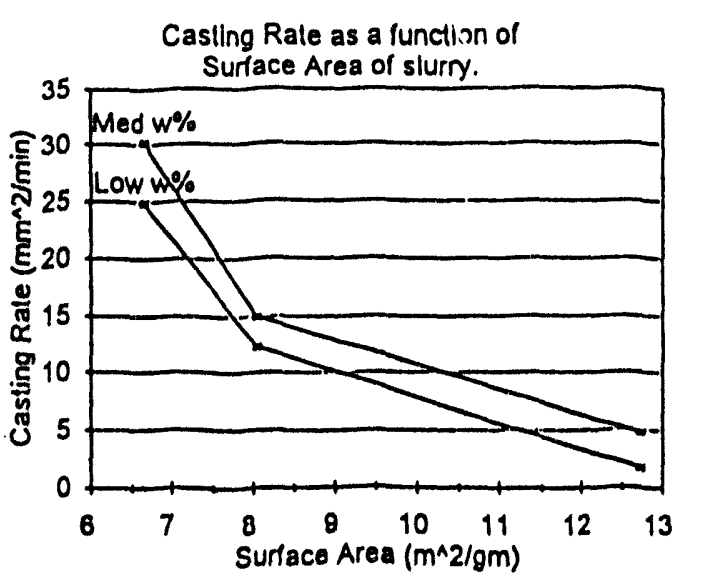

Figure 1: Dependence of Casting Rate on: a) Powder Surface Area

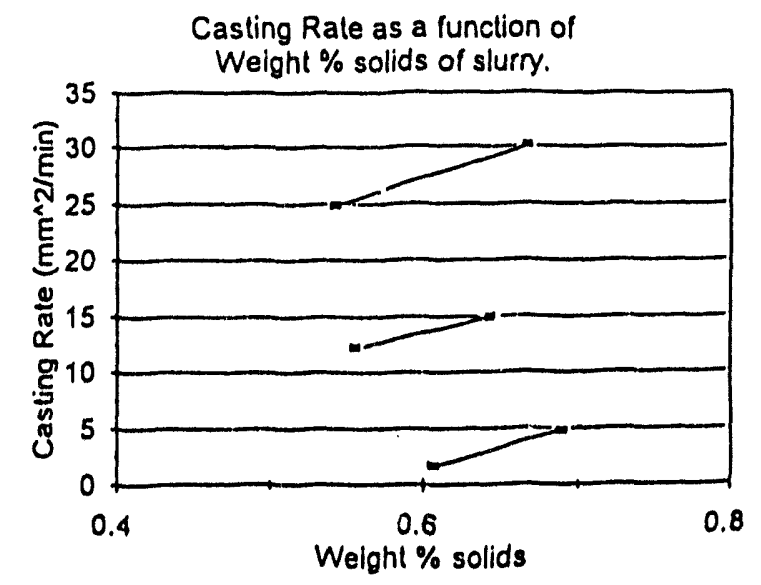

b) Slurry Solids Loading 

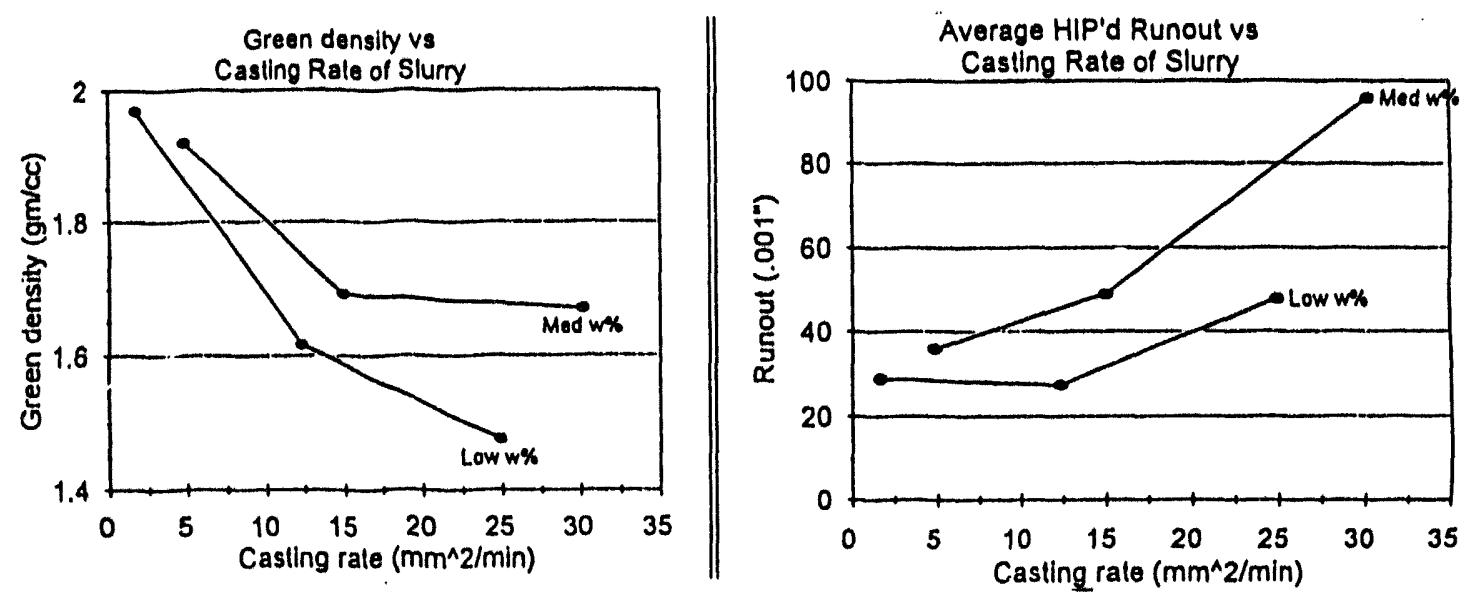

Figure 2: Effect of Casting Rate on:
a) Green Density
b) Density Gradient (Runout)

iii) Casting Process Simulation and Modelling

A casting mudel was developed which accounts for green body density gradients through the use of a porosity constitutive relationship. Experimental data suggest that the porosity that develops at the casting front, Figure 3, can be represented as a function of casting rate as follows:

$$
\epsilon=\epsilon *+\Delta \epsilon \tanh \left(\frac{d \xi}{d t} K\right)
$$

The values $\varepsilon^{\star}$ and $\varepsilon^{\star}+\Delta \varepsilon$ represent the low and high rate porosity levels, respectively. The governing equation for the casting process is given by

$$
\frac{d \xi}{d t}=\frac{x}{1-\chi-\epsilon} \frac{1}{\eta} \frac{P_{\text {eppliod }}}{\int_{0}^{e} \alpha d x}
$$

where

$x=$ solids volume fraction of slurry

$\eta=$ filtrate viscosity

$\alpha=$ cake specific resistance

Equation (2) was solved numerically subject to the porosity constitutive equation (1) for representative conditions. Solutions provide cake thickness and density (porosity) distribution as a function of time. 


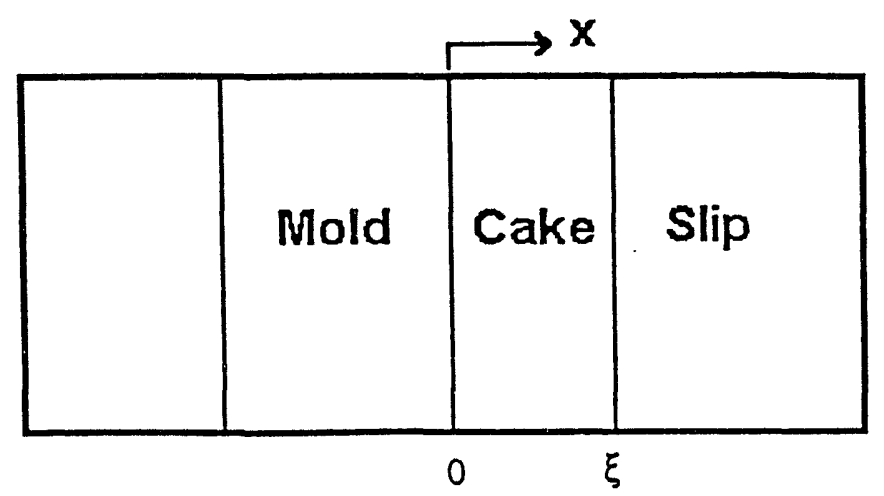

Figure 3: Geometry of Cake Growth

Results for density variations are shown in Figure 4 for the two cases of 60.6 and 68.9 w/o solids with $10 \mathrm{~m}^{2} / \mathrm{gm}$ surface area and 25 psi pressure. Notice that a low density region is predicted near the mold. This results from the very high growth rate that the cake initially experiences. With the parameters chosen here the low density region extends about 0.1 to $0.2 \mathrm{~mm}$ into the cake. The lowest density is about $5 \%$ less than the bulk value. These values are in general agreement with what has been observed in casting experiments. Figure 5 provides results which demonstrate that the density gradient at the mold can be controlled through manipulation of the pressure profile.

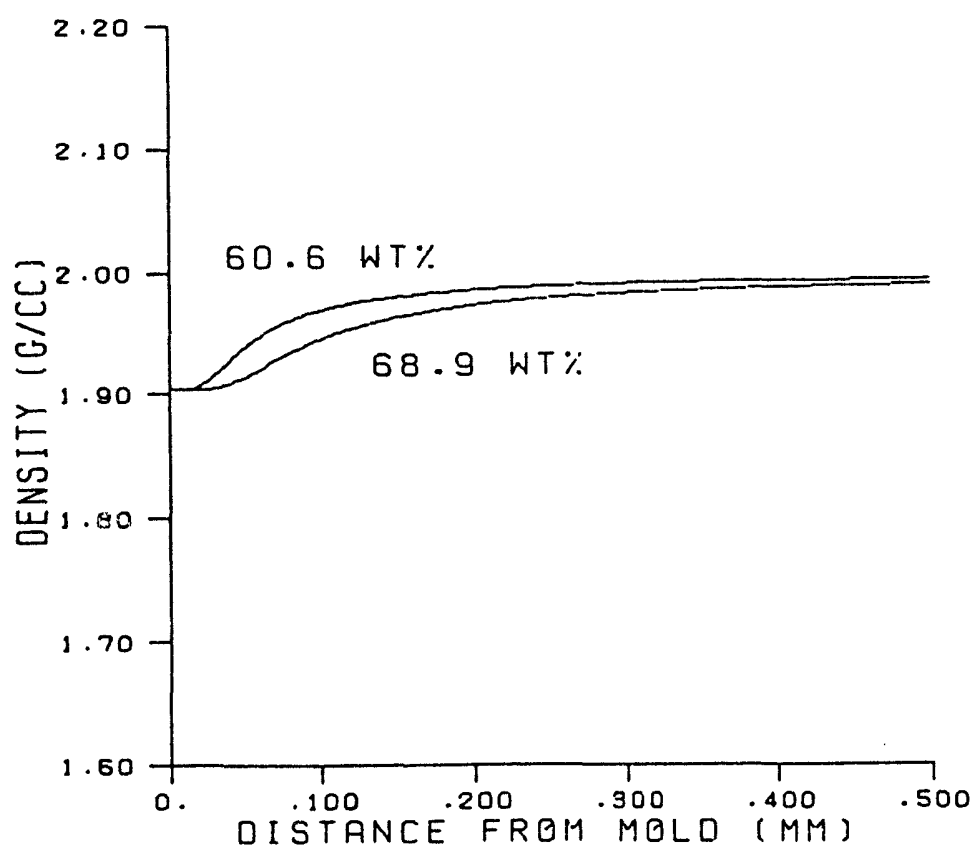

Figure 4: Prediction of Low Density Region Near Mold Interface 


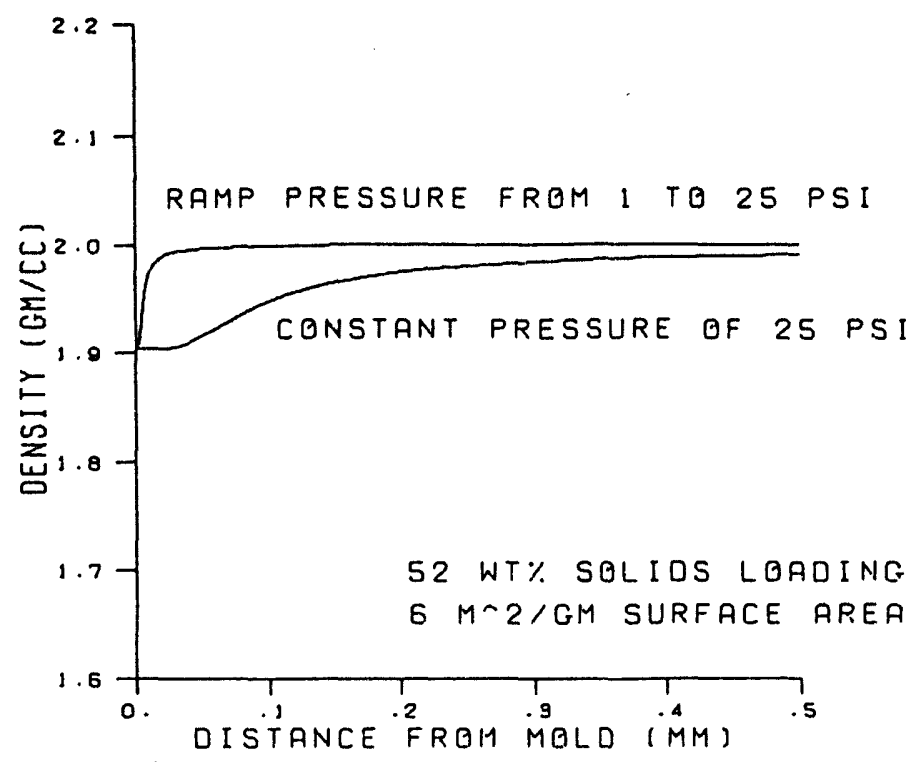

Figure 5: Density Variation for Constant and Ramped Pressure Profiles.

iv) Effect of Mold Material

Casting of aqueous silicon nitride slurries using plaster of paris molds has typically resulted with a $0.1 \cdot 1.0 \mathrm{~mm}$ high density skin, as well as a $1.3 \mathrm{~mm}$ low density cast layer at the surface of the component. It is believed that the low density layer is caused by floccing of the slurry in contact with the mold, and that the high density skin is caused by diffusion of mold material into the cast body. In order to eliminate these undesirable effects, a ceramic mold material has been investigated. In preliminary work (Phase I) density gradients were reduced by up to $75 \%$ using this material. To examine the properties of this mold in relation to a standard plaster mold, pucks were cast using a constant pressure of 30 psi. The plot of thickness vs. lime from the Kozeny-Carman model should be of the form:

$$
L=k * t^{m}
$$

where $L$ is the thickness of the cast, $t$ is the time, $m=.5$ and $k$ is a constant which depends on parameters of the slurry and the applied pressure. Fitting the observed thickness vs. time data from the two pucks to the model (Figure 6), the estimated values for $m$ were 0.485 for the plaster mold and 0.502 for the alternative mold material. This indicates that for the plaster mold we have a higher than expected initial casting rate, or a lower than expected final casting rate. This experiment will be repeated using tensile rod molds and a range of porosities for the alternative ceramic mold material. 


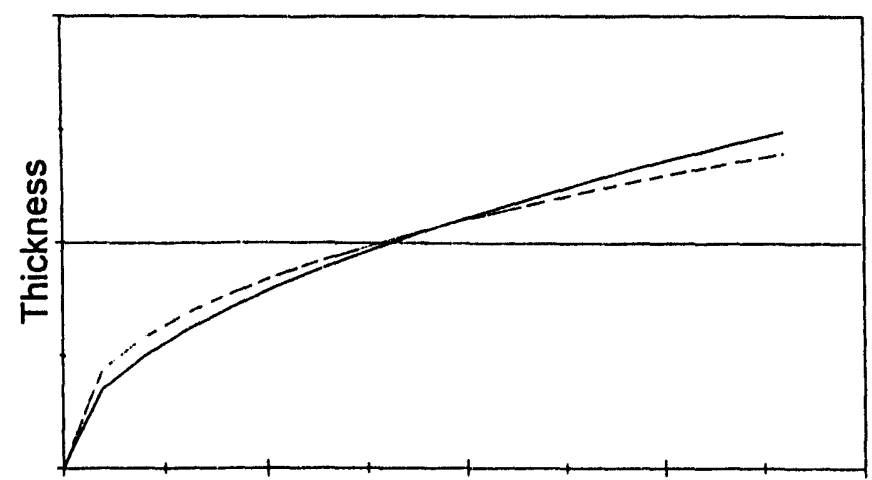

Time

- Ceramic - - Plaster

Figure 6: Effect of Mold Material on Casting Rate Profile

v) National Institute of Standards and Technology (NIST) Activity

Primary activities during this period were on the development of data for the selection of type and concentration of a polyelectrolyte dispersant for high density suspensions preparation. In addition, surface chemical characterization of constituent materials (silicon nitride, yttria and polyelectrolyte) has been completed. Five different methods were used to evaluate two potential surfactants $\left(\mathrm{S}_{1}, \mathrm{~S}_{2}\right)$ as described below:

- Interface chemistry of powder in aqueous environment

- Effect of polyelectrolyte concentration

- Particle size distribution

- Density of slip cast green body

- Adsorption isotherm

These data showed that both dispersants $\left(S_{1}, S_{2}\right)$ provided the same

amount of dispersion at $\mathrm{pH} 9.0$, while the concentrations to achieve the maximum dispersion were different due to difference in their molecular weights. Effect of type S1 polyelectrolyte concentration, for example, on dispersions is shown in Figures 7 and 8. Based on these evaluations, we have selected 300 and $640 \mathrm{ppm}$ (with respect to powder weight) as the most suitable concentration for the two surfactants to achieve the highest green density. The green densities of SNE-03 powder without milling were $61-63 \%$ theoretical.

All three powder components have been fully characterized and representative samples for milling have been prepared. The overall purpose of these milling tests is to achieve as high a solids loading as possible. Our final target is $\mathbf{8 0 - 8 5 \%}$ solids by weight. Therefore, initial tests on $75 \%$ solids as the base level and $80 \%$ as the high level have been planned. The specific surface area of the milled powder will be at 8 and $12 \mathrm{~m}^{2} / \mathrm{g}$. 


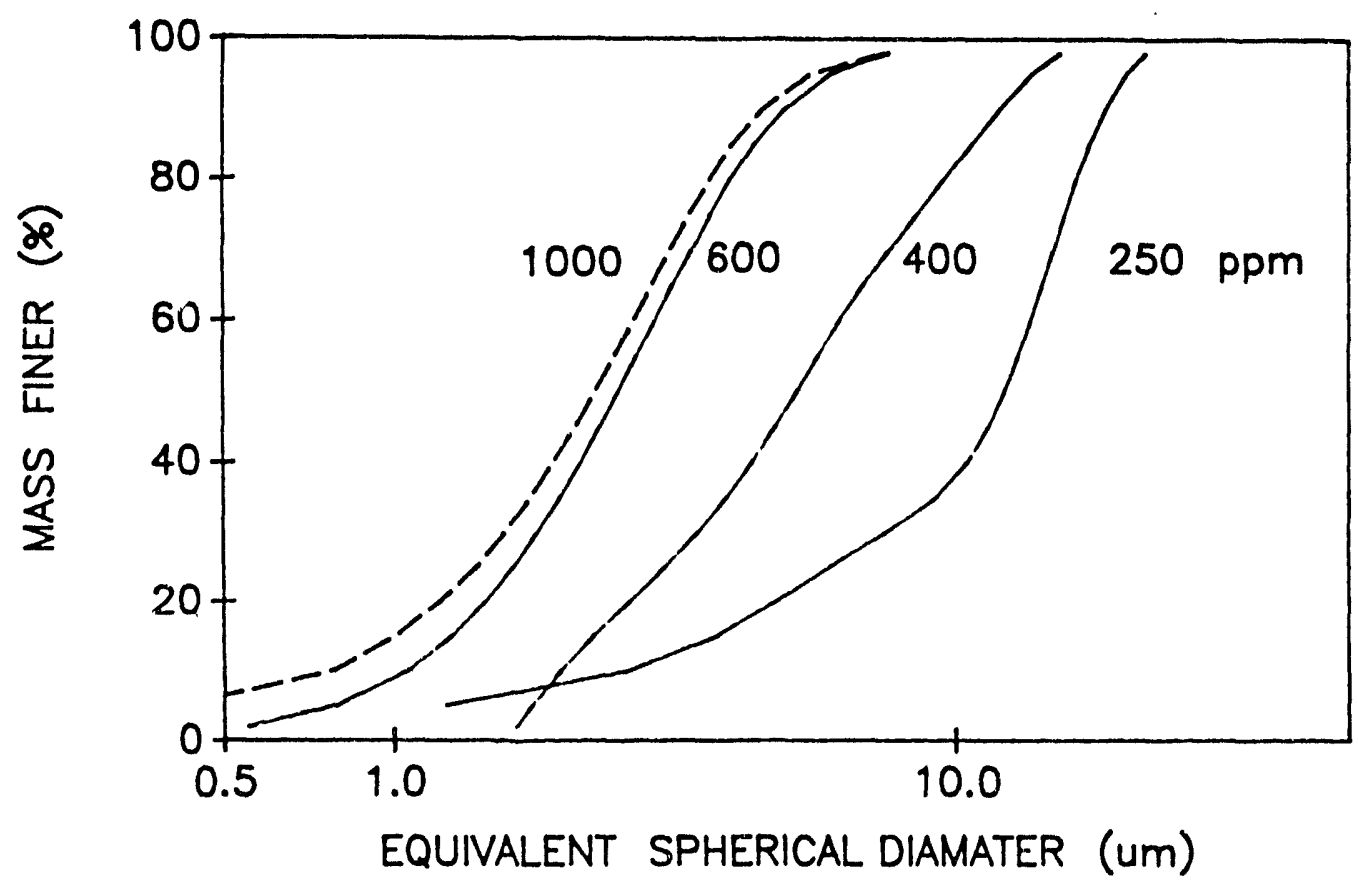

Figure 7: Concentration Effect of Surfactant $S 1$ or Yttria ( $\# 5600)$

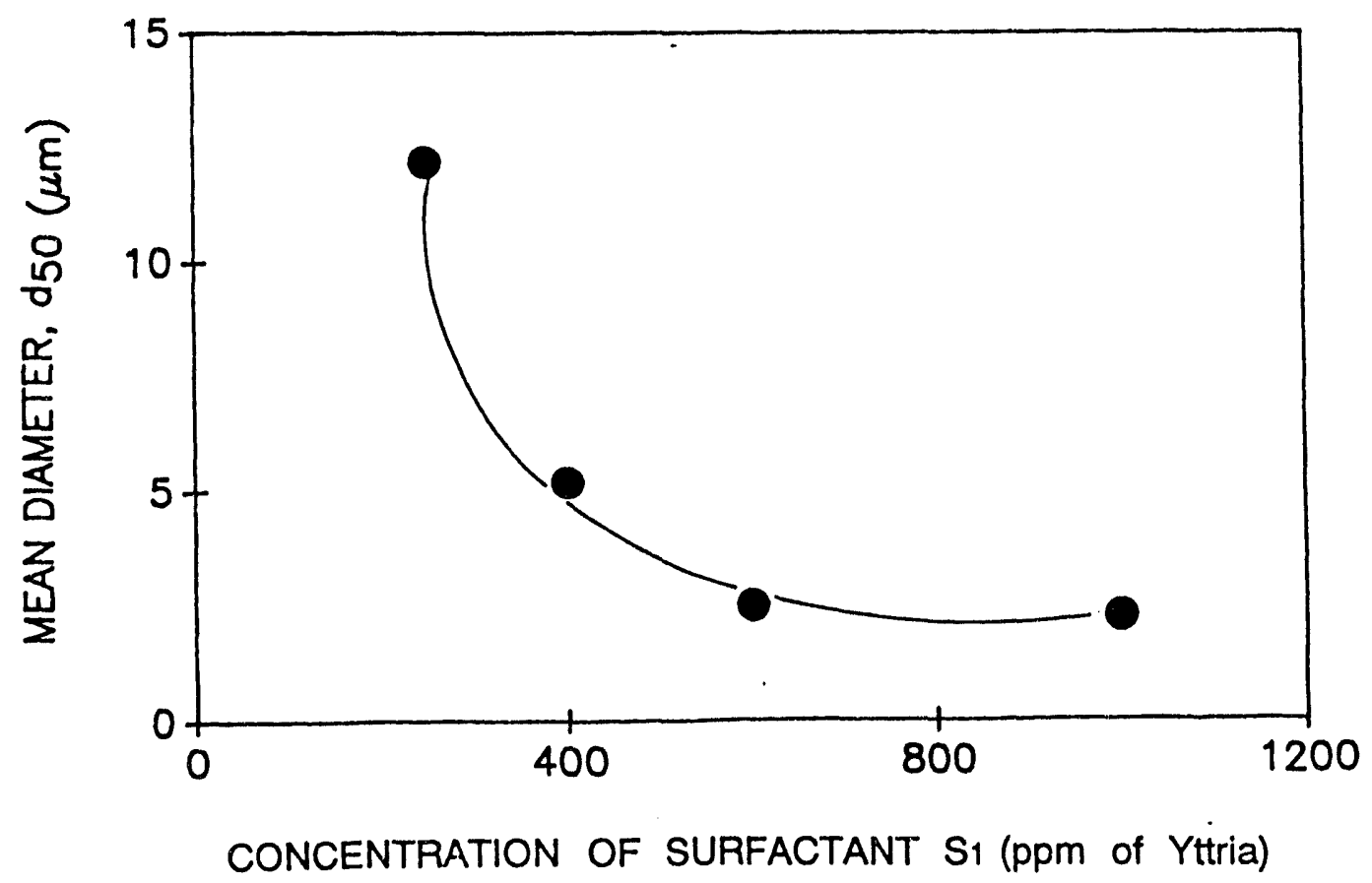

Figure 8: Concentration Effect of Surfactant S1 on Yttria ( $\# 5600)$ 
TASK 2: High Reliability Colloidal Processing of GPS Composition

The screening set of experiments to identify methods with which $\mathrm{MgO}$ hydrolysis can be limited is near completion. Based on the results of bench-top experiments, two approaches have been proven successful in limiting hydrolysis: the use of surfactants and temperature control during milling. As shown in Figure 9 , from screening tests of various surfactants, a suitable surfactant (labeled ' $C$ ') has been identified which shows control of hydrolysis up to one hundred hours. An observation made during these experiments is that the cast green densities of $\mathrm{MgO}$ based slurries have been $\leq 50 \mathrm{w} / 0$ regardless of whether hydrolysis occurs or not. It is suspected that a cause other than hydrolysis is limiting the packing during the casting process. Experiments are in progress to identify the origin of this behavior.

In spite of the low green densities obtained to date, gas-pressure sintering of these samples has resulted in a fired density of $>98 \%$ of theoretical. Evidence of a non-homogeneous microstructure was observed in these samples and is believed to arise from a gradient in sintering aid in the components. This gradient arises because of the diffusion of the sintering aids at elevated temperature. A set of experiments is being conducted to determine ways in which this inhomogeneity can be minimized.

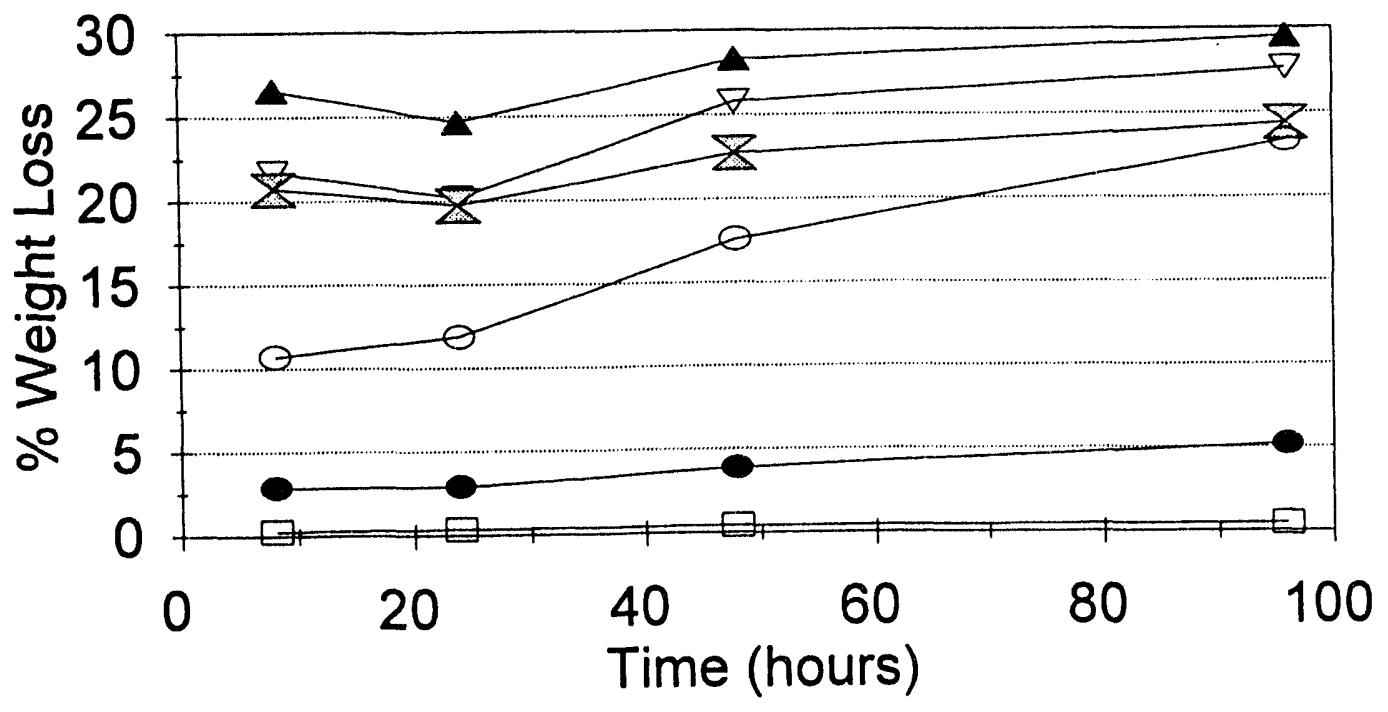

\begin{tabular}{|ll|}
\hline$-\mathrm{C} \quad \bullet \mathrm{MgO}-\mathrm{IPA}$ & $\nabla \mathrm{G}$ \\
z MgO-Water $\_\mathrm{H}$ & $\ominus \mathrm{B}$ \\
\hline
\end{tabular}

Figure 9: Effect of Surfactants on $\mathrm{MgO}$ Hydrolysis 
References

None

\section{Status of milestones}

All milestones are on schedule. Milestones $1-1$ and 2-1 (9/30/93) involving identification of suitable surfactants for the HIP and GPS compositions were met during the reporting period.

\section{Publications/presentations}

1. V.K. Pujari and D.M. Tracey, 'Processing Methods for High Reliability Silicon Nitride Heat Engine Components', presented at ASME Turbo Expo - Land, Sea \& Air, Cincinnati, Ohio, May 24-27, 1993, to appear J.Engr. for Gas Turbines and Power.

2. 'Closed Loop Colloidal Processing of High Reliability Silicon Nitride', by V.K. Pujari et al was submitted August 20,1993 for Preprints of Automotive Technology Develnoment CCM, Dearborn, MI, October 18-21, 1993.

\section{Problems encountered}

\section{None}


Improved Processing

S. D. Nunn, O. O. Omatete, C. A. Walls, D. L. Barker, and R. E. Simpson (Oak Ridge National Laboratory)

\section{Objective/scope}

To determine and develop the reliability of selected advanced ceramic processing methods. This program is to be conducted on a scale that will permit the potential for manufacturing use of candidate processes to be evaluated. The emphasis is on silicon nitride. Issues of practicality; safety, hygiene, and environmental issues; and in-process testing methods are to be addressed in addition to technical feasibility. The methodology includes selection of candidate processes and evaluation of their range of applicability to various kinds of commercially available ceramic powders.

\section{Iechnical highlights}

\section{Silicon Nitride Gelcasting}

To assess the reproducibility of the gelcasting process for producing ceramic components, a series of silicon nitride batches was prepared under identical conditions and gelcast. The batches consisted of $45 \mathrm{vol} \%$ UBE E-10 silicon nitride with $5 \mathrm{wt} \% \mathrm{Y}_{2} \mathrm{O}_{3}$ and $5 \mathrm{wt} \% \mathrm{Al}_{2} \mathrm{O}_{3}$ in a MAM/MBAM monomer solution. The 1 -kg-size batches (ceramic powder weight) were turbomilled in a 4-in.-diam vessel at 500 RPM for $1.5 \mathrm{~h}$. GAF PVP K-15 and Darvan 821A were added as dispersing aids. The initiator, AZIP, was added to the solution in the turbo mill at the completion of the milling time. Eleven batches were prepared for the repeatability study. Each batch was prepared on a different day over a period of $18 \mathrm{~d}$. Every effort was made to be consistent in the preparation method. The $\mathrm{pH}$ of the slurries was measured after milling and was consistently 8.7.

The milled slurry was cast into rod molds, plate molds, and a buttonhead tensile rod mold. The molds were then placed in an oven at $60^{\circ} \mathrm{C}$ for $1 \mathrm{~h}$ to gel the slurry. After cooling, the gelled samples were removed from the molds and placed in a controlled humidity and temperature chamber for the initial drying phase. The chamber was maintained at $25^{\circ} \mathrm{C}$ and $92 \%$ relative humidity $(\mathrm{RH})$. The samples were left in the chamber for $16 \mathrm{~h}$ before being removed to complete the drying process under ambient conditions. Samples were then placed in a desiccator for storage.

The dimensions of the dried tensile rod specimens cast from the 11 batches were measured at the points indicated in the drawing in Fig. 1. These locations were chosen because they could be precisely measured using calipers. The results of the measurements are given in Table 1. The uniformity of the castings is shown clearly by the standard deviation values which indicate a variation of only 0.1 to $0.3 \%$ about the average value for the dimensions measured.

The samples cast in the rod molds were fired at $1850^{\circ} \mathrm{C}$ for $2 \mathrm{~h}$ under $50 \mathrm{psi}$ nitrogen pressure. The diameter of the green and fired samples, and the density after firing, are shown in Table 2. The average value and standard deviation for the 
ORNL-DWG 94-5630

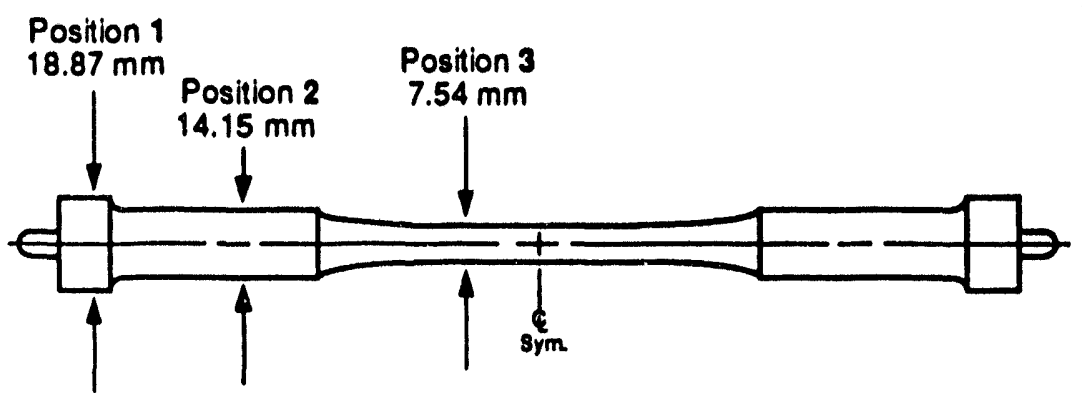

Fig. 1. Diagram of the buttonhead tensile rod specimen showing the location of the positions that were used to determine the dimensional uniformity of gelcast silicon nitride samples.

Table 1. Measured dimensions $(\mathrm{mm})$ of gelcast tensile rod specimens

\begin{tabular}{cccc}
\hline & \multicolumn{3}{c}{ Position } \\
\cline { 3 - 5 } Mold Dimension $\rightarrow$ & 1 & 2 & 3 \\
Sample: & 18.87 & 14.15 & 7.54 \\
R1 & 18.36 & 13.77 & \\
R2 & 18.44 & 13.79 & 7.26 \\
R3 & 18.44 & 13.77 & 7.32 \\
R4 & 18.36 & 13.79 & 7.26 \\
R5 & 18.36 & 13.79 & 7.29 \\
R6 & 18.36 & 13.79 & 7.29 \\
R7 & 18.42 & 13.79 & 7.32 \\
R8 & 18.36 & 13.77 & 7.29 \\
R9 & 18.47 & 13.79 & 7.29 \\
R10 & 18.42 & 13.79 & 7.29 \\
R11 & 18.34 & 13.77 & 7.24 \\
\hline & 18.39 & 13.79 & 7.29 \\
Sid. Dean:: & 0.04 & 0.01 & 0.02 \\
Variation (\%): & 0.23 & 0.09 & 0.31 \\
Shrinkage (\%): & 2.49 & 2.51 & 3.20 \\
\hline
\end{tabular}


Table 2. Measurements of repeatablity study rod samples

\begin{tabular}{|c|c|c|c|}
\hline Sample Number & $\begin{array}{l}\text { Green Diameter } \\
\text { (mm) }\end{array}$ & $\begin{array}{l}\text { Fired Diameter } \\
\text { (mm) }\end{array}$ & $\begin{array}{l}\text { Fired Density } \\
(0 / \mathrm{cm} 3)\end{array}$ \\
\hline A1.1 & 17.13 & 13.73 & 3.13 \\
\hline A1.2 & 17.13 & 13.75 & 3.13 \\
\hline R1.3 & 17.12 & 13.77 & 3.13 \\
\hline R1.5 & 17.09 & 13.70 & 3.12 \\
\hline R2.1 & 17.12 & 13.73 & 3.10 \\
\hline R2.2 & 17.12 & 13.70 & 3.13 \\
\hline R2.3 & 17.13 & 13.73 & 3.11 \\
\hline R2-4 & 17.12 & 13.60 & 3.13 \\
\hline R2.5 & 17.11 & 13.74 & 3.12 \\
\hline R3-1 & 17.07 & 13.69 & 3.14 \\
\hline A3.2 & 17.06 & 13.68 & 3.11 \\
\hline R3-3 & 17.09 & 13.70 & 3.11 \\
\hline R3.4 & 17.11 & 13.74 & 3.11 \\
\hline A3.5 & 17.08 & 13.70 & 3.12 \\
\hline R4.1 & 17.12 & 13.74 & 3.13 \\
\hline R4.2 & 17.09 & 13.78 & 3.11 \\
\hline R4.3 & 17.07 & 13.70 & 3.13 \\
\hline R4-4 & 17.12 & 13.73 & 3.11 \\
\hline 84.5 & 17.12 & 13.74 & 3.13 \\
\hline R4.6 & 17.08 & 13.70 & 3.15 \\
\hline R4.7 & 17.12 & 13.64 & 3.15 \\
\hline A5.1 & 17.13 & 13.73 & 3.12 \\
\hline A5.2 & 17.11 & 13.73 & 3.13 \\
\hline R5-3 & 17.11 & 13.73 & 3.13 \\
\hline R5.4 & 17.09 & 13.74 & 3.12 \\
\hline A5.5 & 17.09 & 13.73 & 3.13. \\
\hline R6.1 & 17.11 & 13.69 & 3.14 \\
\hline R6-2 & 17.09 & 13.69 & 3.13 \\
\hline R6-3 & 17.11 & 13.68 & 3.13 \\
\hline R6.4 & 17.13 & 13.74 & 3.13 \\
\hline R6.5 & 17.12 & 13.73 & 3.12 \\
\hline R7.1 & 17.09 & 13.70 & 3.15 \\
\hline R7.2 & 17.11 & 13.75 & 3.13 \\
\hline R7.3 & 17.09 & 13.72 & 3.13 \\
\hline R7.4 & 17.13 & 13.74 & 3.14 \\
\hline R7.5 & 17.09 & 13.68 & 3.17 \\
\hline R7. 7 & 17.09 & 13.78 & 3.11 \\
\hline R8.1 & 17.09 & 13.72 & 3.10 \\
\hline R8.2 & & 13.70 & 3.10 \\
\hline R8.3 & & 13.70 & 3.10 \\
\hline R8.4 & 17.09 & 13.70 & 3.10 \\
\hline A8.5 & 17.08 & 13.69 & 3.10 \\
\hline A8.7 & 17.12 & 13.67 & 3.00 \\
\hline R9-1 & 17.04 & 13.69 & 3.11 \\
\hline$R 9.2$ & 17.08 & 13.88 & 3.05 \\
\hline R9.3 & 17.09 & 13.78 & 3.09 \\
\hline R9-4 & 17.09 & 13.68 & 3.11 \\
\hline R10-1 & 17.06 & 1372 & 3.11 \\
\hline R10.2 & 17.09 & 13.75 & 3.09 \\
\hline A10.3 & 17.12 & 13.69 & 3.10 \\
\hline R10-4 & 17.11 & 13.69 & 3.11 \\
\hline A10.5 & 17.08 & 13.70 & 3.11 \\
\hline R11.1 & 17.09 & 13.68 & 3.15 \\
\hline R11.2 & 17.11 & 13.69 & 3.14 \\
\hline Average = & 17.10 & 13.72 & 3.12 \\
\hline St. Dev. = & 0.021 & 0.037 & 0.019 \\
\hline
\end{tabular}


54 samples are also shown in the table. As can be seen from these resuits, the gelcasting process appears to be very reproducible. The rod diameters in the green state showed a standard deviation of only $0.02 \mathrm{~mm}$ or about $0.1 \%$. In the fired state, the standard deviation of the diameters was about $0.3 \%$. This difference is probably due to the slightly higher variability of the fired density, which showed a standard deviation of $0.6 \%$. It's interesting to note, however, that the batch-to-batch variation was no greater than the typical scatter within a given batch of material as shown in Table 3. This suggests that while there is room for improvement in the uniformity within a batch, the reproducibility of the process is very good.

Samples for 4-point bend strength measurement were prepared from plates cast from the 11 batches. The plates were fired at $1850^{\circ} \mathrm{C}$ for $2 \mathrm{~h}$ under $50 \mathrm{psi}$ nitrogen pressure. The strength tests were run at room temperature. The results of these tests are summarized in Table 4. The overall strength for the batches was $583 \pm 84 \mathrm{MPa}$, giving a Weibull modulus of about 8.0. This indicates relatively low uniformity among the batches. This is probably due to the scatter in the measured densities for the plates cast from these batches, which is also shown in Table 4. This may have resulted from non-uniform heating of the samples during firing due to the arrangement of the plates in the crucibles. Further studies are planned to evaluate firing conditions.

\section{SRBSN Gelcasting}

Gelcasting of Si metal for forming sintered reaction bonded silicon nitride (SRBSN) parts was found to be unsuccessful in the MAM/MBAM gelcasting system. Several attempts at preparing gelcast batches were unsuccessful due to the reactivity of Si metal and resultant gas evolution in the basic aqueous slurry. A study indicated that gas formation was eliminated at low-solution pH levels ( pH 4). This suggested that Si gelcasting may be possible in an acidic system. Two such systems are being evaluated. One utilizes acrylic acid $(\mathrm{H} 2 \mathrm{C}=\mathrm{CHCOOH})$ as the monomer, and the other uses methacrylic acid $(\mathrm{H} 2 \mathrm{C}=\mathrm{CCH} 3 \mathrm{COOH})$. With both monomers, the crosslinking agent is a rare-earth salt of the acid. For acrylic acid, the salt is $(\mathrm{H} 2 \mathrm{C}=\mathrm{CHCOO})_{3} \mathrm{Re}$, where $\mathrm{Re}=\mathrm{Y}, \mathrm{La}$, or $\mathrm{Nd}$. An analogous salt is formed in the methacrylic acid. The salt is formed when the rare-earth oxide powder, which is used as a sintering aid, is added to the acid solution. When dissolved in the acid, the rare-earth ion reacts to form a tri-functional organo-metallic compound which can then crosslink during gel formation. The amount of crosslinker available for gel formation varies with the different rare earths and the particular acid due to differences in solubility. This was found to affect the characteristics of the gels that could be formed. The gels varied from brittle and crumbly with high levels of crosslinking agent to very flexible and rubbery with low levels of crosslinker. In forming gels with the neat acrylic acid and methacrylic acid solutions, it was found that the system consisting of an aqueous solution of acrylic acid (monomer) and the lanthanum salt of acrylic acid (crosslinker) formed the highest strength gels.

A series of solutions were prepared to determine the optimum initiator [10 wt \% ammonium persulfate (AP) in water] and catalyst [tetraethylmethylenediamene (TEMED)] additions to obtain good gels. Aqueous solutions containing $13.5 \mathrm{wt} \%$ acrylic acid and $10 \mathrm{wt} \%$ lanthanum oxide (stoichiometric additions for 
Table 3. Average and standard deviation of the rod sample measurements

\begin{tabular}{|c|c|c|c|c|c|c|}
\hline \multirow[b]{2}{*}{ Batch Number } & \multicolumn{2}{|c|}{ Green Diameter (mm) } & \multicolumn{2}{|c|}{ Flred Diametes $(\mathrm{mm})$} & \multicolumn{2}{|c|}{ Fired Dendity (alems) } \\
\hline & Averase & 8t. Dey. & Averaoe & St. Dov. & Avergose & S1. DN. \\
\hline A1 & 17.12 & 0.018 & 13.74 & 0.024 & 3.13 & 0.005 \\
\hline$m$ & 17.12 & 0.008 & 13.72 & 0.010 & 3.12 & 0.010 \\
\hline R3 & 17.08 & 0.018 & 13.70 & 0.021 & 3.12 & 0.010 \\
\hline RA & 17.10 & 0.020 & 13.72 & 0.041 & 3.13 & 0.013 \\
\hline P6 & 17.11 & 0.014 & 13.73 & 0.008 & 3.13 & 0.005 \\
\hline $\mathbf{P B}$ & 17.11 & 0.013 & 13.71 & 0.025 & 3.13 & 0.008 \\
\hline A7 & 17.10 & 0.014 & 13.73 & 0.034 & 3.14 & 0.018 \\
\hline $\mathbf{R o}$ & 17.10 & 0.014 & 13.70 & 0.016 & 3.10 & 0.008 \\
\hline $\mathbf{R}$ & 17.08 & 0.021 & 13.78 & 0.082 & 3.00 & 0.024 \\
\hline R10 & 17.09 & 0.022 & 13.71 & 0.024 & 3.11 & 0.000 \\
\hline A11 & 17.10 & 0.008 & 13.68 & 0.008 & 3.14 & 0.005 \\
\hline Overall & 17.10 & 0.021 & 13.72 & 0.037 & 3.12 & 0.019 \\
\hline
\end{tabular}

Table 4. Density, strength and Weibull modulus of samples cut from gelcast plates of silicon nitride prepared from the repeatability study batches

\begin{tabular}{cccccc}
\hline $\begin{array}{c}\text { Balch } \\
\text { Number }\end{array}$ & $\begin{array}{c}\text { Donsity } \\
\%\end{array}$ & $\begin{array}{c}\text { Number } \\
\text { of Samples }\end{array}$ & $\begin{array}{c}\text { Average } \\
\text { Strengih, MPa }\end{array}$ & $\begin{array}{c}\text { Standwd } \\
\text { Deviation }\end{array}$ & $\begin{array}{c}\text { Webull } \\
\text { Modulus }\end{array}$ \\
\hline R1 & 96.6 & 10 & 615 & 112 & 6.2 \\
R2 & 95.8 & 15 & 612 & 53 & 13.4 \\
R4 & 95.0 & 12 & 542 & 31 & 20.9 \\
R5 & 95.0 & 11 & 567 & 43 & 15.3 \\
R6 & 94.7 & 10 & 544 & 66 & 0.4 \\
R7 & 96.1 & 12 & 621 & 79 & 9.0 \\
R6 & 96.1 & 10 & 623 & 58 & 12.5 \\
R9 & 94.6 & 10 & 551 & 69 & 9.2 \\
R10 & 96.1 & 10 & 500 & 65 & 8.8 \\
R11 & 96.8 & 6 & 692 & 94 & 8.4 \\
\hline Overall & 95.7 & 106 & 583 & 84 & 8.0 \\
\hline
\end{tabular}


the complete neutralization of the acid) were prepared. Varying quantities and ratios of AP and TEMED were added to constant volumes of the rare-earth acid solution. All of the mixtures were placed in an oven at $80^{\circ} \mathrm{C}$ for $1 \mathrm{~h}$ to gel. The optimum additions were determined to be $0.5 \mathrm{wt} \%$ AP solution and $0.05 \mathrm{wt} \%$ TEMED.

A slurry was then prepared containing $45 \mathrm{vol} \%$ silicon metal powder in the rare-earth acid solution. As the AP was being added to the slurry, it rapidly thickened and began to gel at room temperature. The presence of the silicon had dramatically changed the gelling characteristics of the solution. A new series of solutions was prepared to determine the initiator addition required in the silicon slurries. Because the silicon slurry had shown such a high sensitivity to the AP addition, a 1 wt \% aqueous AP solution was used. It was found that a firm gel could be obtained with only $0.01 \mathrm{wt} \%$ AP solution gelled at 60 to $80^{\circ} \mathrm{C}$ for $1 \mathrm{~h}$.

When slurries were prepared containing additional lanthana and alumina sintering aids for an SRBSN composition, the catalyst addition needed to be adjusted again. Clearly, the reactivity of this system is extremely sensitive to small changes in the chemistry of the mixture. In addition, the oxides did not disperse easily in the acidic solution requiring the solids content to be reduced to about $35 \mathrm{vol} \%$ in order to maintain a reasonably low viscosity for milling, deairing, and casting. Further studies are under way to continue the evaluation of this system.

\section{Alternate Gelcasting Systems}

It has been demonstrated that several monomers such as MAM, NVP, M-PEG, and crosslinkers such as PEG and MBAM form gels that can be used in gelcasting. Based on some qualitative characteristics of the gel and the cost of the monomers, the MAM-PEG and MAM-MBAM systems, especially the latter, have been utilized in most of our work. However, the MAM-MBAM gels may be too weak for certain applications. The use of co-monomer systems has been shown to produce synergistic effects. Furthermore, the co-monomer system of MAM and NVP with the crosslinker MBAM can be utilized to form very hard and stiff gels because the NVP serves as a solvent to dissolve more of the crosslinker, MBAM, into the gelcasting solution. The co-monomer system will be studied for improved gelcasting properties.

An automated rheometer has been delivered by Bohlin Instruments Company. As soon as it is fully set up and operational, it will be used to characterize, quantitatively, pure gels and ceramic-loaded gels. When these quantitative values are available, it will be possible to determine the optimum monomer, comonomer, and crosslinker concentrations and concentration ratios for selected gelcasting systems.

The large controlled temperature and humidity chamber has been used for the standard drying of our gelcast parts at $25^{\circ} \mathrm{C}$ and $92 \% \mathrm{RH}$. The chamber has been very reliable for the standard drying procedure. It is to be used for the study of the reduction in the total drying time of gelcast materials. However, the instrumentation and controls necessary to carry out the study have not yet been installed. These should be ready by the next reporting period. 


\section{Garrett Cooperative Research and Development Agreement (CRADA)}

As a follow-on to the previous Collaborative Research Agreement (CRA) between Oak Ridge National Laboratory (ORNL) and Garrett Ceramic Components (GCC), work on the gelcasting of sillicon nitride components is continuing under an extension of the CRA. Research under the previous agreement demonstrated the feasibility of using gelcasting to produce complex-shaped components (automotive turbocharger rotors) using GCC's GN-10 $\mathrm{Si}_{3} \mathrm{~N}_{4}$ composition. Mechanical property testing showed that gelcast $\mathrm{Si}_{3} \mathrm{~N}_{4}$ could be produced that had mechanical properties comparable to GCC's slipcast Si3N4. Under the new agreement, ORNL is incorporating one of the new gelcasting chemical systems which has improved environmental, safety, and health ratings. (Previous work was done in the acrylamide system. The acrylamide monomer has a high toxicity rating.) Work focuses on achieving low-viscosity slips containing high-volume fractions of $\mathrm{Si}_{3} \mathrm{~N}_{4}$ powder and on complete removal of the organic materials during binder burnout. Garrett is firing gelcast samples using glass-encapsulation hot isostatic pressing (HIPing) and measuring the mechanical properties.

A batch consisting of $45 \mathrm{vol} \%$ of the GN-10 silicon nitride composition in a MAM/PEG (3:1) monomer solution was prepared. The batch was used to cast T-25 turbocharger rotors in a setup that was designed to allow the molds to be bottomfilled inside an evacuated chamber. This procedure was intended to help minimize the possibility of forming surface defects and non-filled areas in the thin sections of the rotor fins. However, it was discovered after the molds had been filled that the bases had not been adequately sealed. As a result, the molds leaked extensively, and no conclusions could be drawn regarding the effectiveness of the new casting process. Several turbocharger rotor molds that were received from GCC are being prepared for gelcasting.

Status of milestones

Milestone 114208 has been completed.

\section{Publications and presentations}

S. D. Nunn, O. O. Omatete, C. A. Walls, D. L. Barker, and K. L. Ploetz, "Improved Processing and Properties of Gelcast Ceramics," paper SXIII-96-93, presented at the Annual Meeting of the American Ceramic Society, Cincinnati, Ohio, April 18-22, 1993.

S. D. Nunn, "Gelcasting with Water-Based Additives," invited presentation at the OBES/OIT Research Assistance Task Force Meeting on Environmentally Conscious Synthesis, Processing, and Use of Ceramics, Princeton Materials Institute, Princeton University, Princeton, N.J., May 5-7, 1993. 


\subsection{CERAMIC COMPOSITES}

\subsubsection{Silicon Nitride Matrix}

Optimization of Silicon Nitride Ceramics

K. J. Lee, W. W. Yao and T. Y. Tien (The University of Michigan)

\section{Objective/Scope}

To develop processing methods to optimize strength, toughness and creep resistance of monolithic silicon nitride ceramics. Silicon nitride ceramics with fiber-like $\beta$-Si3N4 grains will have higher fracture strength and toughness and better creep resistance. The fiber-like structure can be obtained by sintering the silicon nitride ceramics at high temperature under a nitrogen over-pressure. The mechanical properties can further be improved by controlling the size and the aspect ratio of the fiber like $\beta-\mathrm{Si}_{3} \mathrm{~N}_{4}$ grains and the composition and nature of the grain boundary phase(s). The major goal of this project is to develop monolithic silicon nitride ceramics with optimum mechanical properties.

\section{Technical Highlights}

The $\alpha-\mathrm{Si}_{3} \mathrm{~N}_{4}$ to $\beta-\mathrm{Si}_{3} \mathrm{~N}_{4}$ ratio $\left(5 \% \beta-\mathrm{Si}_{3} \mathrm{~N}_{4}\right)$ and impurity content are the same in all three powders. The particle sizes of E03, E05, and E10 are 0.95, 0.70 and $0.45 \mu \mathrm{m}$, respectively. The additives used were $\mathrm{Y}_{2} \mathrm{O}_{3}, \mathrm{Al}_{2} \mathrm{O}_{3}, \mathrm{MgO}$, and $\mathrm{CaO}$, or combinations of these chemicals. The compositions studied were described by the sample designations. Two series of compositions were used To study (1) effect of particle size on grain growth, the compositions contained $92 \mathrm{wt} \% \mathrm{Si}_{3} \mathrm{~N}_{4}, 6 \mathrm{wt} \% \mathrm{Y}_{2} \mathrm{O}_{3}$, and 2 wt\% $\mathrm{Al}_{2} \mathrm{O}_{3}$. To study (2) effect of sintering additives, the samples ID 00,02 , and 20 contained the following: $90 \% \mathrm{Si}_{3} \mathrm{~N}_{4}$, $6 \% \mathrm{Y}_{2} \mathrm{O}_{3}$ and $4 \% \mathrm{MgO}$ for $00 ; 89.8 \% \mathrm{Si}_{3} \mathrm{~N}_{4}, 6 \% \mathrm{Y}_{2} \mathrm{O}_{3}, 4 \% \mathrm{MgO}$ and $0.2 \%$ $\mathrm{CaO}$ for 02 ; and $88 \% \mathrm{Si}_{3} \mathrm{~N}_{4}, 6 \% \mathrm{Y}_{2} \mathrm{O}_{3}, 4 \% \mathrm{MgO}$ and $2 \% \mathrm{CaO}$ for 20 .

Starting powders were weighed and attrition milled under isopropanol for 2 hours. Slurries were dried on a hot plate at $85^{\circ} \mathrm{C}$ under constant stirring to avoid segregation. Dried powders were isostatically pressed under a pressure of $14 \mathrm{MPa}$. Pressed pellets were sintered at different temperatures for a time period of $0.5,1,2$ and $5 \mathrm{~h}$ under a static nitrogen pressure of 10 atmospheres in a graphite furnace. The specimens were placed in a BN crucible filled with BN powders.

The surfaces were ground, polished and etched with molten salts. The grains were then disintegrated using ultrasonic vibration. Loose grains were collected on a porous medium for microscopic examination.

Figure 1 shows three photomicrographs of disintegrated $\beta-\mathrm{Si}_{3} \mathrm{~N}_{4}$ grains which illustrate the grain size differences between specimens using various starting silicon nitride powders. The length and width of these grains were measured and the results analyzed. A typical size distribution in both length and width direction are given in Figure 2. Normal distribution was observed 

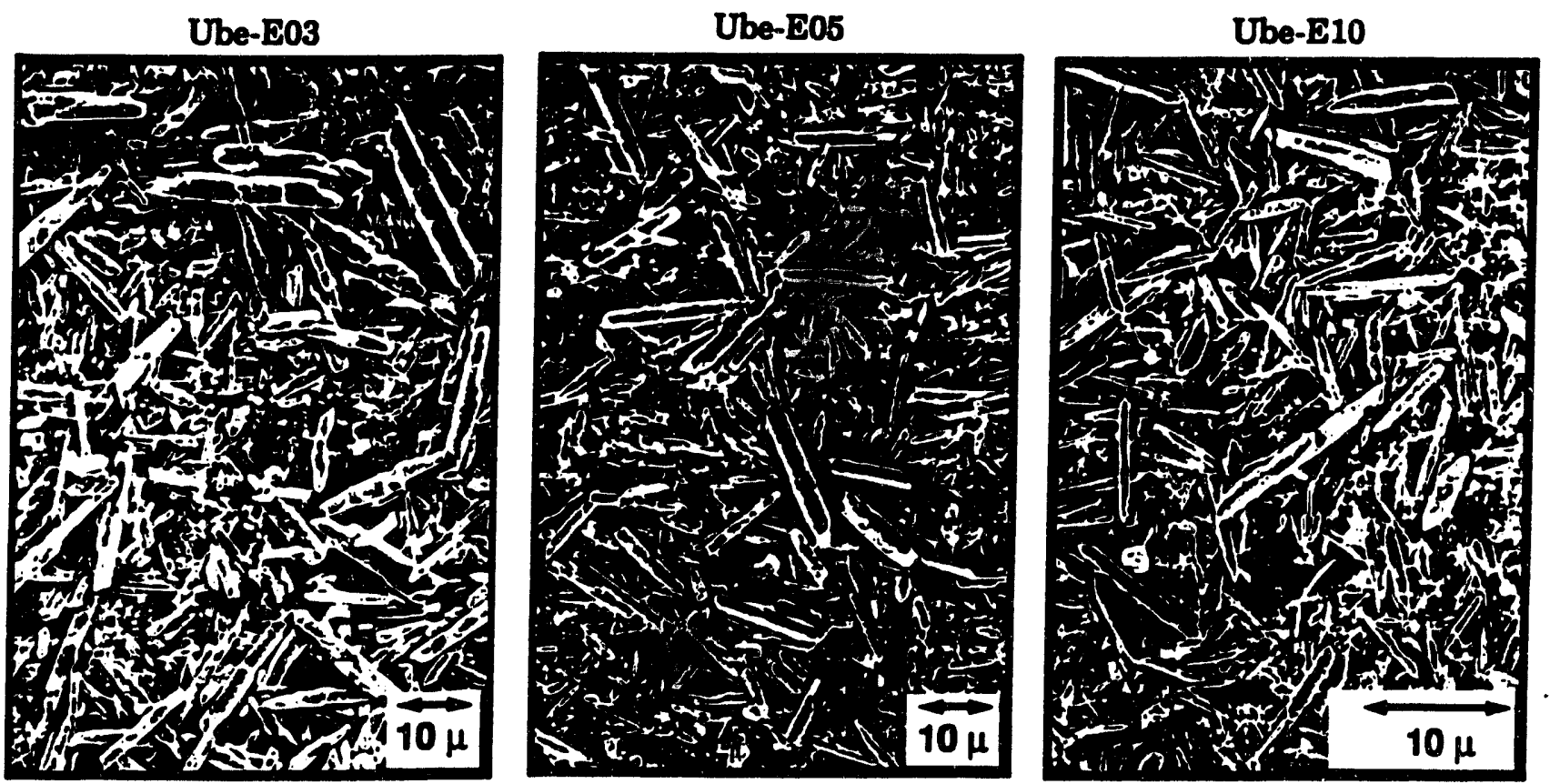

Figure 1. Micrographs of disintegrated $\beta-\mathrm{Si}_{3} \mathrm{~N}_{4}$ grains. Specimens were E03, E05, and E10 sintered at $1900^{\circ} \mathrm{C}$ for $1 \mathrm{hr}$.
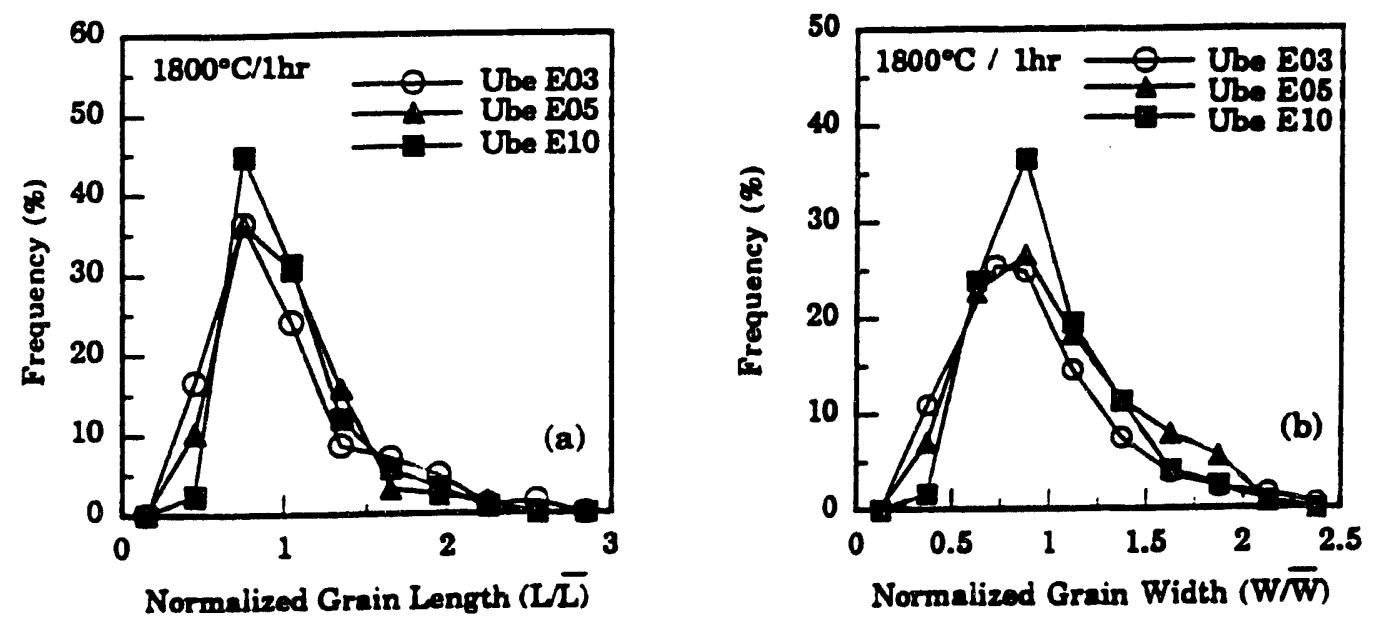

Figure 2. Size distributions of disintegrated $\beta-S_{3} N_{4}$ grains. Specimens E03, E05, and E10 sintered at $1800^{\circ} \mathrm{C}$ for $1 \mathrm{~h}$ (a) grain length, (b) grain width. 
for all sintered specimens. The mode from all of these size distribution measurements were used as the average grain size for further data treatments.

Specimens of different starting silicon nitride powders were sintered at 1800 and $1900^{\circ} \mathrm{C}$ for $0.5,1,2$ and $5 \mathrm{~h}$, and the results are given in Table 1. Table 2 gives the results of the effect on grain growth of specimens using different additives. The silicon nitride powders used for chemical effect studies were E10.

The grain size data for specimens fired at $1800^{\circ} \mathrm{C}$ for different times were plotted in a log-log scale in Figure 3. These data fit the empirical equation, $D^{n}-D_{0} n=K t$. However, because of many uncertainties, we will not discuss the results in terms of this equation. Since the value of the exponent $n$ indicates the growth mechanism, no attempt was made to assign a value to "n".

(1) Effect of Particle Size

The size of $\beta-\mathrm{Si}_{3} \mathrm{~N}_{4}$ grains in sintered specimens using E3 and E5 as starting materials grew larger in both length and width directions than those using E10 powder. This phenomenon can be explained using the relationship $\mathrm{K} \propto \mathrm{D} \gamma \mathrm{C}_{\mathrm{m}}$ where $\mathrm{K}$ is rate constant, $\mathrm{D}$ is diffusion coefficient, $\gamma$ is interfacial energy and $\mathrm{C}_{\mathrm{m}}$ is solute concentration. The above relationship applies to both diffusion-controlled and interfacelimited growth processes. The smaller grains tend to have lower angle boundaries which results in a iower mobility, i.e., slower diffusion coefficient. Therefore, the specimen with larger particles grows faster.

(2) Effect of Sintering Additives

The above relationship can also be used to explain the effect of additives on the growth of $\beta-\mathrm{Si}_{3} \mathrm{~N}_{4}$ grains. The eutectic temperature of a ternary system will be lower than that of a binary system, i.e., when one sintering additive is used, the melting temperature of the grain boundary phase is higher than when two additives are used. At the same temperature, the solubility of silicon nitride in the reactive liquid, $\mathbf{C}_{\mathbf{m}}$, is higher in the ternary system than in the binary liquid. The solubility is also higher in systems which are less refractory than in a liquid which is more refractory.

The solubility of $\mathrm{Si}_{3} \mathrm{~N}_{4}$ in the systems studied in this investigation are not known. However, the solubility of $\mathrm{SiO}_{2}$ in the $\mathrm{Y}_{2} \mathrm{O}_{3}$ and $\mathrm{Al}_{2} \mathrm{O}_{3}$ system is higher than in the $\mathrm{Y}_{2} \mathrm{O}_{3}$ and $\mathrm{MgO}$ system at the same temperatures. The grain growth results listed in Table 2 indicate that the $\mathrm{B}_{-} \mathrm{Si}_{3} \mathrm{~N}_{4}$ grains grew larger when $\mathrm{Y}_{2} \mathrm{O}_{3}$ and $\mathrm{Al}_{2} \mathrm{O}_{3}$ were used as sintering aids than when $\mathrm{Y}_{2} \mathrm{O}_{3}$ and $\mathrm{MgO}$ were used. Use of $\mathrm{CaO}$ will also promote grain growth.

Status of Milestones

On schedule 
Table 1. Measured average grain sizes and aspect ratios of $\beta-\mathrm{Si}_{3} \mathrm{~N}_{4}$ ceramics sintered under $10 \mathrm{~atm} \mathrm{~N}_{2}$.

\begin{tabular}{|c|c|c|c|c|c|}
\hline \multirow[b]{2}{*}{ Powder ID } & \multirow[b]{2}{*}{ Grain size } & \multicolumn{4}{|c|}{ Sintering time (hr) } \\
\hline & & 0.5 & 1 & 2 & 5 \\
\hline Ube E03 & $\begin{array}{l}1800^{\circ} \mathrm{C}-\mathrm{L} / \mathrm{W} \\
1900^{\circ} \mathrm{C}-\mathrm{L} / \mathrm{W} \\
1800^{\circ} \mathrm{C}-\mathrm{AR} \\
1900^{\circ} \mathrm{C}-\mathrm{AR}\end{array}$ & $\begin{array}{l}5.25 / 0.615 \\
7.55 / 1.415 \\
7.05 \\
5.70\end{array}$ & $\begin{array}{l}5.85 / 0.813 \\
8.90 / 1.84 \\
6.8 \\
4.94\end{array}$ & $\begin{array}{l}8.90 / 1.00 \\
10.02 / 1.96 \\
6.42 \\
4.65\end{array}$ & $\begin{array}{l}8.85 / 1.908 \\
10.5 / 2.33 \\
6.08 \\
4.55\end{array}$ \\
\hline Ube E05 & $\begin{array}{l}1800^{\circ} \mathrm{C}-\mathrm{L} / \mathrm{W} \\
1900^{\circ} \mathrm{C}-\mathrm{L} / \mathrm{W} \\
1800^{\circ} \mathrm{C}-\mathrm{AR} \\
1900^{\circ} \mathrm{C}-\mathrm{AR}\end{array}$ & $\begin{array}{l}4.375 / 0.578 \\
6.44 / 1.10 \\
7.3 \\
4.48\end{array}$ & $\begin{array}{l}5.25 / 0.764 \\
8.88 / 1.508 \\
6.9 \\
5.16\end{array}$ & $\begin{array}{l}8.305 / 870 \\
9.15 / 1.92 \\
6.5 \\
6.22\end{array}$ & $\begin{array}{l}8.50 / 1.26 \\
10.38 / 2.24 \\
6.4 \\
5.76\end{array}$ \\
\hline Ube E10 & $\begin{array}{l}1800^{\circ} \mathrm{C}-\mathrm{L} / \mathrm{W} \\
1900^{\circ} \mathrm{C}-\mathrm{L} / \mathrm{W} \\
1800^{\circ} \mathrm{C}-\mathrm{AR} \\
1900^{\circ} \mathrm{C}-\mathrm{AR}\end{array}$ & $\begin{array}{l}3.82 / 0.496 \\
4.38 / 0.798 \\
5.35 \\
4.80\end{array}$ & $\begin{array}{l}4.45 / 0.60 \\
6.70 / 0.988 \\
7.025 \\
5.75\end{array}$ & $\begin{array}{l}5.22 / 0.715 \\
7.55 / 1.00 \\
7.33 \\
6.02\end{array}$ & $\begin{array}{l}5.75 / 0.75 \\
9.23 / 1.215 \\
8.00 \\
6.18\end{array}$ \\
\hline
\end{tabular}

Table 2. Measured average grain sizes and aspect ratios of $\beta$-Si3 $\mathrm{N}_{4}$ ceramics sintered under $10 \mathrm{~atm} \mathrm{~N}_{2}$ with different concentration of $\mathrm{CaO}$ addition.

\begin{tabular}{llllll}
\hline Composition / & & \multicolumn{4}{c}{ Sintering time (hr) } \\
\cline { 3 - 5 } Powder ID & Grain size & 0.5 & 1 & 2 \\
\hline $\mathrm{CaO} 0 \% / 00$ & $1800^{\circ} \mathrm{C}-\mathrm{L} / \mathrm{W}$ & $2.102 / 0.563$ & $2.470 / 0.590$ & $2.775 / 0.810$ \\
& $1900^{\circ} \mathrm{C}-\mathrm{L} / \mathrm{W}$ & $2.302 / 0.675$ & $2.71 / / 0.712$ & $3.075 / 0.990$ \\
& $1800^{\circ} \mathrm{C}-\mathrm{AR}$ & 3.453 & 4.251 & 4.822 \\
& $1900^{\circ} \mathrm{C}-\mathrm{AR}$ & 3.733 & 4.551 & 4.725 \\
\hline $\mathrm{CaO} 0.2 \% / 02$ & $1800^{\circ} \mathrm{C}-\mathrm{L} / \mathrm{W}$ & $2.485 / 0.672$ & $2.902 / 0.693$ & $3.591 / 0.750$ \\
& $1900^{\circ} \mathrm{C}-\mathrm{L} / \mathrm{W}$ & $3.500 / 0.930$ & $4.375 / 1.010$ & $4.900 / 1.213$ \\
& $1800^{\circ} \mathrm{C}-\mathrm{AR}$ & 4.280 & 4.801 & 5.652 \\
& $1900^{\circ} \mathrm{C}-\mathrm{AR}$ & 4.271 & 5.003 & 5.830 \\
\hline $\mathrm{CaO} \mathrm{2.0 \% /20}$ & $1800^{\circ} \mathrm{C}-\mathrm{L} / \mathrm{W}$ & $2.450 / 0.672$ & $2.622 / 0.690$ & $4.153 / 0.783$ \\
& $1900^{\circ} \mathrm{C}-\mathrm{L} / \mathrm{W}$ & $2.625 / 0.813$ & $3.974 / 0.870$ & $5.501 / 0.931$ \\
& $1800^{\circ} \mathrm{C}-\mathrm{AR}$ & 4.721 & 5.450 & 5.903 \\
& $1900^{\circ} \mathrm{C}-\mathrm{AR}$ & 4.102 & 4.522 & 4.851 \\
\hline
\end{tabular}




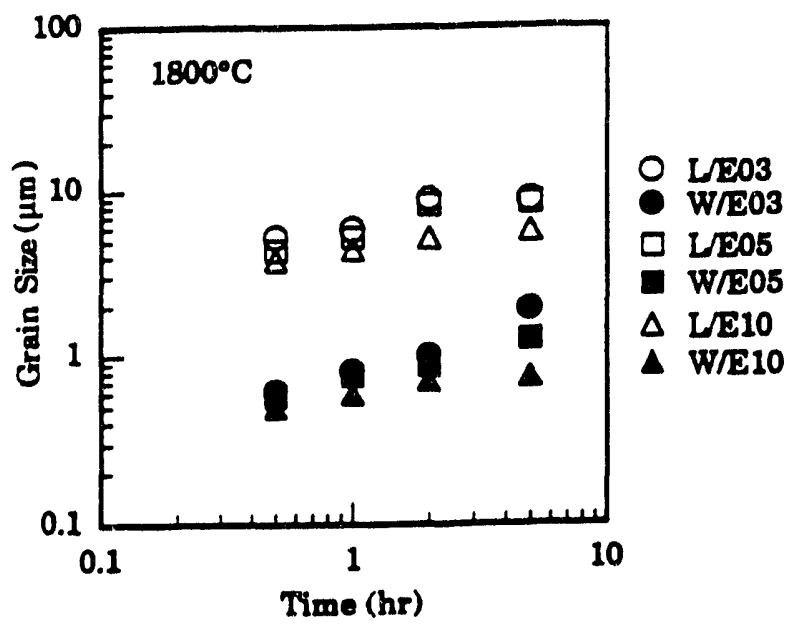

Figure 3. Growth behavior of $\beta-S_{3} N_{4}$ grains in ceramics sintered at $1800^{\circ} \mathrm{C}$ for different lengths of time. Compositions were E03, E05, and E10.

\section{Communications/Visit/Travel}

K. J. Lee attended J'MRS meeting in Tokyo, Japan on Aug. 30 - Sep. 3 for presentation of paper titled "Grain Growth of $\beta-S_{3} N_{4}$ in Silicon Nitride Ceramics". 
Characterization of Grain Boundary Phases in Silicon Nitride Ceramics

I. M. Peterson and T. Y. Tien (The University of Michigan)

\section{Objective/Scope}

The objective of this investigation is to develop silicon nitride ceramics with high flexural strength, high fracture toughness and superior creep resistance. The fiber-like structure of the $\beta-\mathrm{Si}_{3} \mathrm{~N}_{4}$ grains can be obtained by sintering the silicon nitride ceramics at high temperature under high nitrogen pressure. The composition of the sintering additives will affect the microstructural development, grain boundary characteristics, and hence, the mechanical properties. The grain boundary phases have never been synthesized separately and their properties have never been studied. The goal of this project is to synthesize and characterize the grain boundary phase and to understand the relationships between the nature of the grain boundary phase and the properties of silicon nitride ceramics. It is believed that with a thorough understanding of these relationships, ceramics with optimum mechanical properties can be obtained.

The energy required to propagate an intergranular crack depends on the residual stress present at the grain boundary, the strength of the bonding along the interface, and the intrinsic toughness of the grain boundary phase. The residual stress can be controlled by tailoring the thermal expansion coefficient mismatch between the silicon nitride and the grain boundary phase. The intrinsic toughness of the grain boundary phase is dependent on both the chemistry and the morphology of the grain boundary phase. The effect of residual stresses on the fracture toughness

was investigated by adding sintering aids containing different amounts of cordierite and YAG. The fracture toughness increased as the amount of tensile stress at the grain boundary increased. The increase in fracture toughness was correlated with a decrease $n$ bridging distance and an increase in pullout lengths, as measured from SEM photographs of the cracks.

\section{Technical Highlights}

Silicon nitride samples with 15 volume \% of four different sintering aids :YAG , cordierite , $80 \mathrm{wt} \%$ cordierite/ $20 \mathrm{wt} \%$ YAG and 60 weight percent cordierite/40 wt \% YAG in $\mathrm{Si}_{3} \mathrm{~N}_{4}$. were prepared. The oxide powders were attrition milled with silicon nitride for four hours. Different sintering heat treatments were used. One batch of samples were sintered at $1640^{\circ} \mathrm{C}$ for 3 hours under $10 \mathrm{~atm}$ of nitrogen A second batch was sintered at $1640^{\circ} \mathrm{C}$ for 3 hours, then at $1800^{\circ} \mathrm{C}$ for three hours, and then at $1640{ }^{\circ} \mathrm{C}$ for two hours to re-equilibrate the grain boundary phase. A third set was sintered at $1640^{\circ} \mathrm{C}$ for 3 hours, then at $1880^{\circ} \mathrm{C}$ for three hours, and then at $1640^{\circ} \mathrm{C}$ for two hours to re-equilibrate the grain boundary phase. One set of samples was sintered 
at $1640^{\circ} \mathrm{C}$ for three hours and then heat-treaied at $1250^{\circ} \mathrm{C}$ for 20 hours to crystallize the grain boundary phases.

The samples were quenched and the fracture toughness was measured by the indentation method. The samples were etched in a molten $\mathrm{KOH} / \mathrm{NaOH}$ solution .SEM photos were used to determine the crack lengths and distances between bridging grains. The grain sizes were measured using the disintegration method.

The fracture toughness increased with increasing residual tensile stress at the grain boundary (or compressive stress in the $\mathrm{Si}_{3} \mathrm{~N}_{4}$ matrix). The residual stress on the $\mathrm{Si}_{3} \mathrm{~N}_{4}$ grains is expressed as

$$
\mathrm{s}=\mathrm{E}_{\mathrm{Si} \mathrm{N} 4}\left(\alpha_{\mathrm{glass}}-\alpha_{\mathrm{Si3N} 4}\right) \mathrm{DT} \text {. }
$$

where DT $=1000^{\circ} \mathrm{C}$ and $\mathrm{E}_{\mathrm{Si} 3 \mathrm{~N} 4}=300 \mathrm{GPa}$.

For the samples sintered at $1640^{\circ} \mathrm{C}$, the lengths of the grains were the same for all the additives. Figure 1 shows the length distribution for the sample containing $15 \%$ cordierite. .(At higher temperatures, the mean grain length and width increased slightly with the amount of YAG in the sintering aid). The increase in fracture toughness with increasing residual stress is shown in Figure 2 for the samples sintered at $1640^{\circ} \mathrm{C}$. Results from both the quenched and the crystallized samples are shown. The increase in fracture toughness with increasing residual stress for the quenched samples is shown in Figure 3.

The fracture toughness can be correlated with the amount of bridging and the amount of crack deflection, which were measured from SEM photos. The amount of bridging is expressed as a distance between bridges, $d$, divided by the width of the grain, 1 . The decrease in normalized bridging distance $d /$, as residual stress increases is shown in Figure 4. The amount of crack deflection and pullout is expressed as a normalized crack length. The actual path length, L, and the shortest path length Lo were measured from the photos. The normalized path length is (L-Lo)/L. The increase in normalized path length with the increase in the amount of residual stress is plotted in Figure 5.

\section{Status of Milestones}

On schedule

Communications/Visits/Travel

None

Problems Encountered

None

Publications

None 


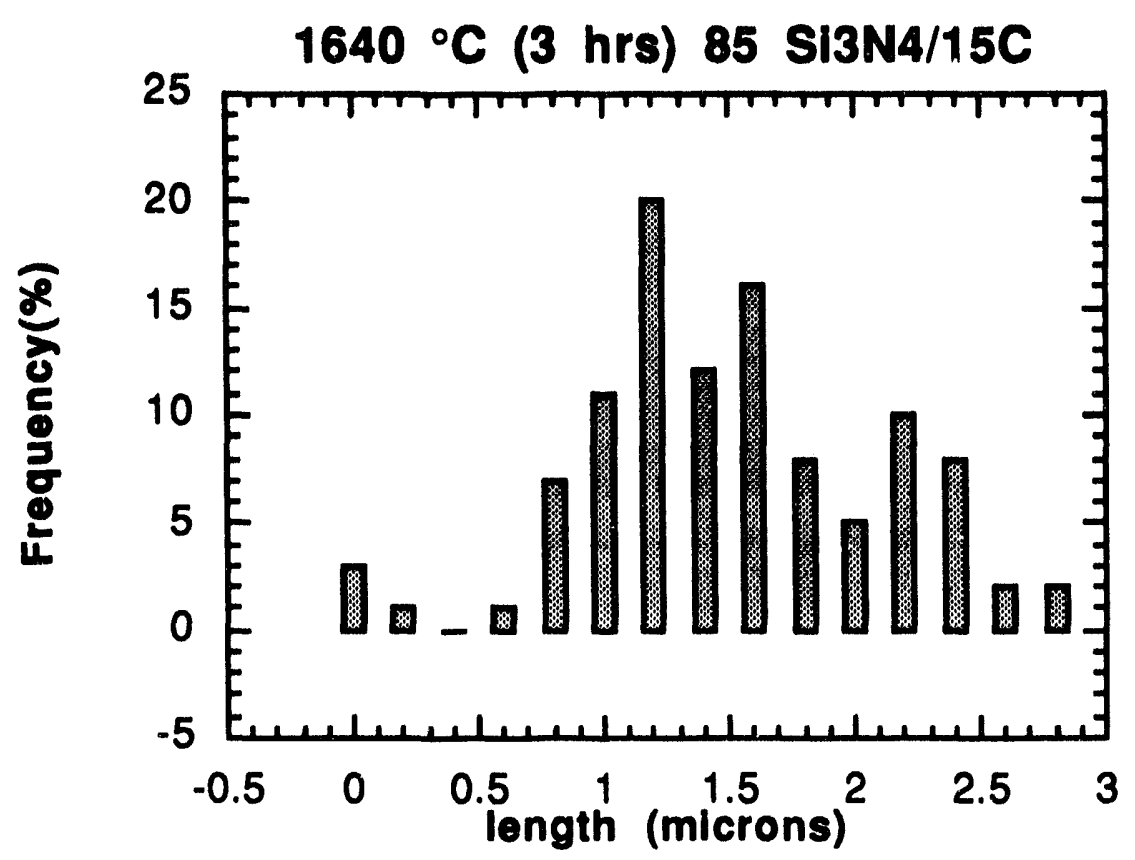

Figure 1- Grain length distribution for samples sintered at $1640^{\circ} \mathrm{C}$ for 3 hours

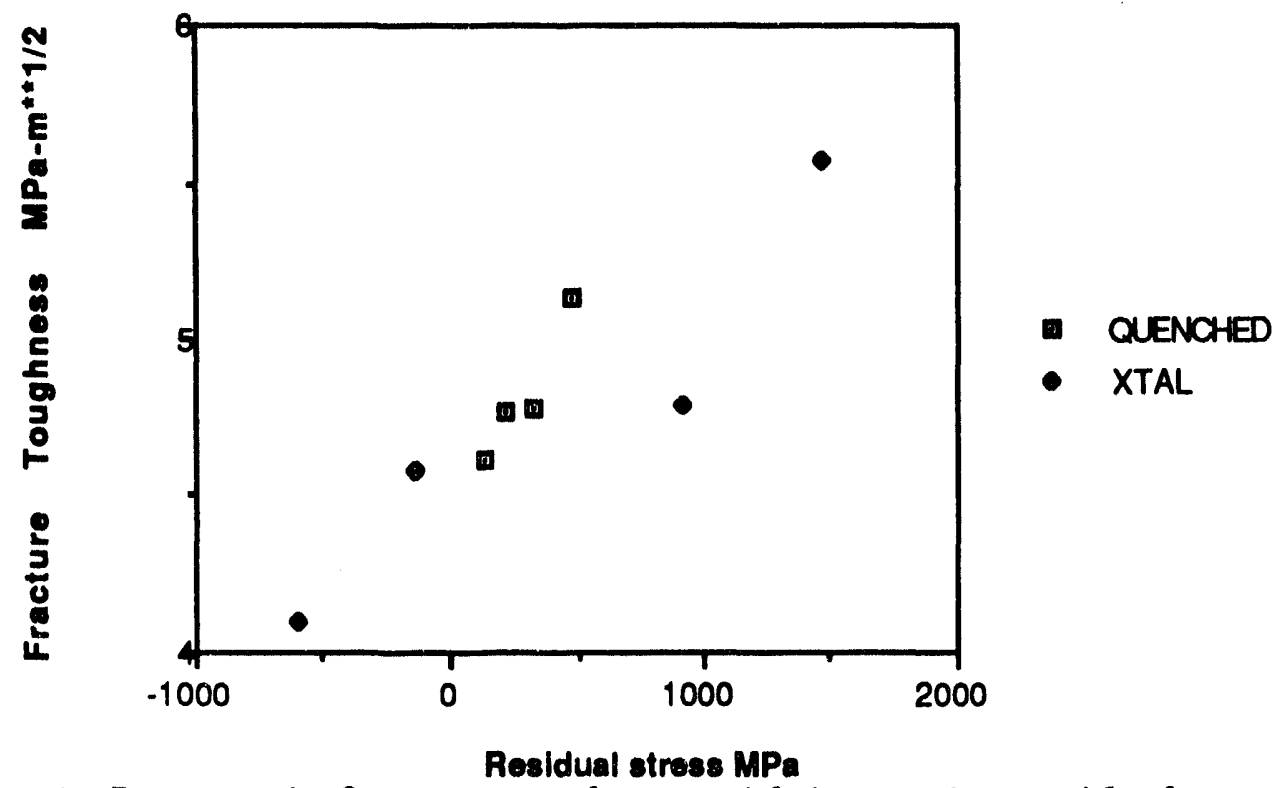

Figure 2 - Increase in fracture toughness with increasing residual stress at constant grain size 


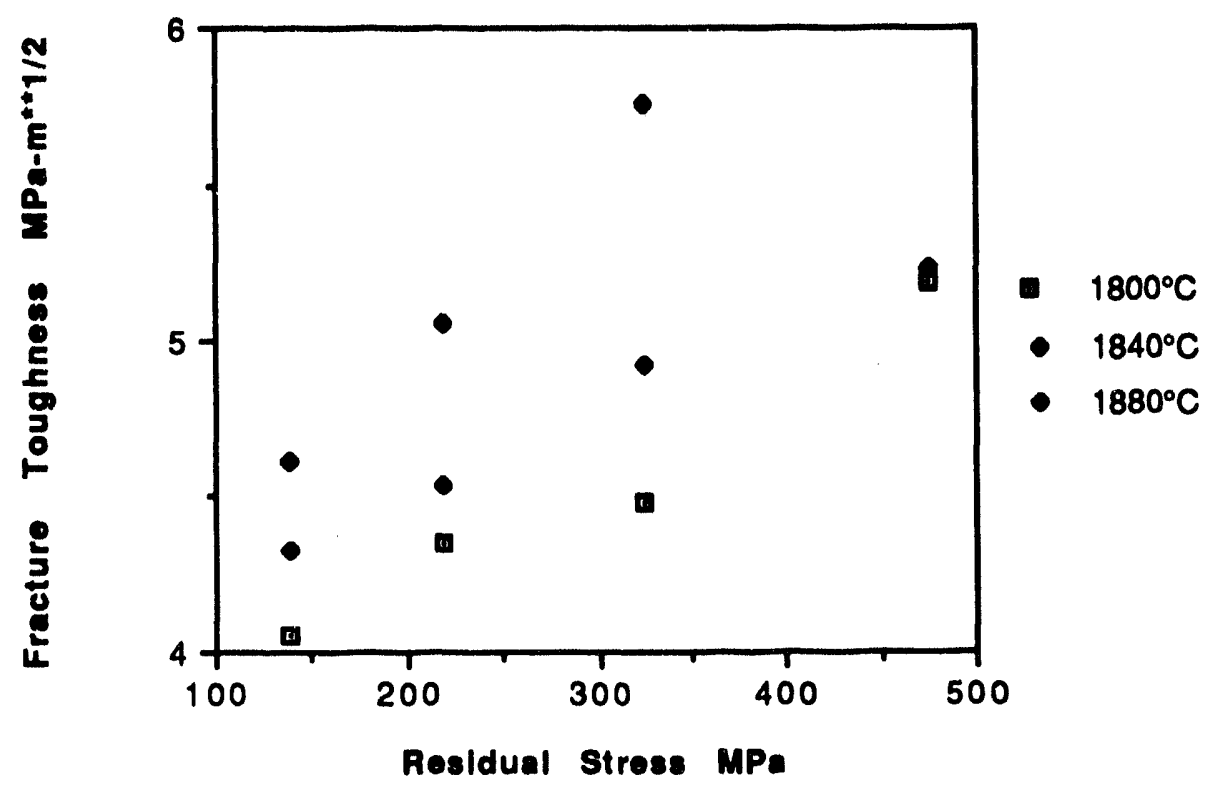

Figure 3 - Increase in fracture toughness with increasing residual stress for quenched samples

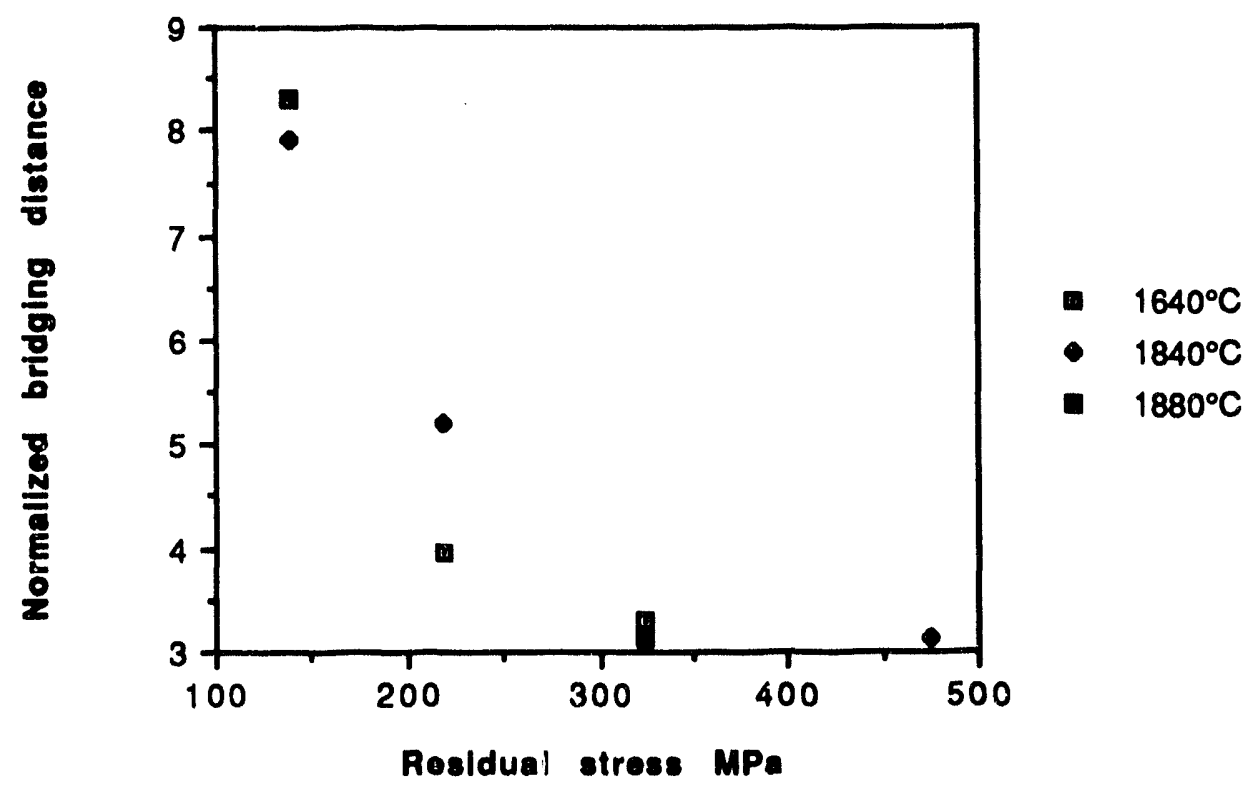

Figure 4 - Decrease in the distance between bridges with increasing residual stress 


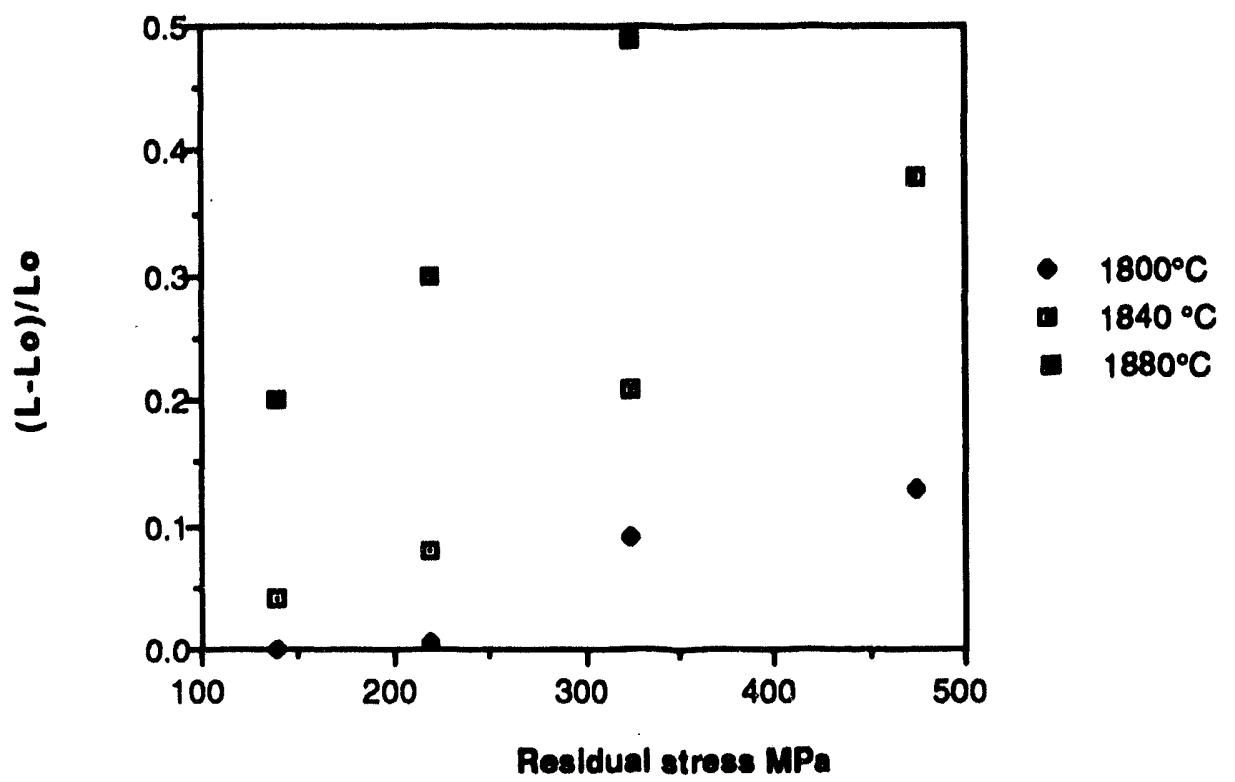

Figure 5 - Increase in the amount of crack deflection with increasing residual stress 
Reaction Sintering of $\alpha^{\prime} / \beta^{\prime}$ SiAlON Ceramics

K. Houser and T. Y. Tien (The University of Michigan)

\section{Objective/Scope}

The objective of this project is to develop processing techniques to obtain silicon nitride ceramics with a controlled grain morphology for optimum mechanical properties at room temperature as well as at high temperatures. Silicon nitride ceramics exhibit high fracture strengths and high fracture toughness when the microstructure contains fiber-like $\beta^{\prime}$-SIAION grains. Obtaining these fiber-like $\beta^{\prime}-$ SiAlON grains depends upon the temperature, nitrogen pressure and the grains' interaction with other phases present. Ideally, if the equilibrium conditions between the phases present are understood as well as the kinetics controlling the growth of these fiber-like grains, one could ultimately tailor a silicon nitride ceramic's microstructure for certain mechanical properties. This project will focus on these structure-property relationships for a range of compositions in the $\mathrm{Si}, \mathrm{Al}, \mathrm{Y} / \mathrm{N}, \mathrm{O}$ system.

\section{Background:}

This project will be working with compositions from the $\alpha^{\prime}+\beta^{\prime}$ SiAlON region on the $\alpha^{\prime}$-SiAlON plane in the Si, Al, Y/N, O system. The $\alpha^{\prime}$ plane is defined by the equation $Y_{m / 3} \mathrm{Si}_{12-(m+n)} \mathrm{Al}_{m+n} \mathrm{O}_{n} \mathrm{~N}_{16-n}$ and is illustrated in Figure 1. The $\beta^{\prime}$ phase is a substitutional solid solution where the $(\mathrm{Si}-\mathrm{N})$ is replaced by $(\mathrm{Al}-\mathrm{O})$. The $\alpha^{\prime}$ phase is a stuffed derivative of the $\alpha-\mathrm{Si}_{3} \mathrm{~N}_{4}$ phase that can incorporate some of the yttrium atoms into the unit cell as interstitials. The formation of these solid solutions reduces the amount of residual glass at the grain boundaries, which in turn allows for better high temperature mechanical properties.

There are two competing processes occurring during the sintering of these compositions; the transformation of the initial $\alpha-\mathrm{Si}_{3} \mathrm{~N}_{4}$ to $\beta^{\prime}-\mathrm{SiAlON}$ and $\alpha^{\prime}-$ SiAlON and the densification of the ceramic. Both of these processes depend upon the presence of a transitional liquid phase. If the transformation rate is faster than the densification process, the transitional liquid will be consumed by the solution/re-precipitation mechanism of transformation, and densification by liquid phase sintering will stop. Therefore understanding the kinetics of these two processes is necessary to obtain fully dense two phase $\mathrm{Si}_{3} \mathrm{~N}_{4}$ ceramics. Once fully dense ceramics have been obtained, a controlled study of the effect of temperature and time on the growth of the fiber-like $\beta^{\prime}$-SiAlON grains and the $\alpha^{\prime}-$ SiAlON grains will be performed. 


\section{Representation of the Y-SiAlON system}

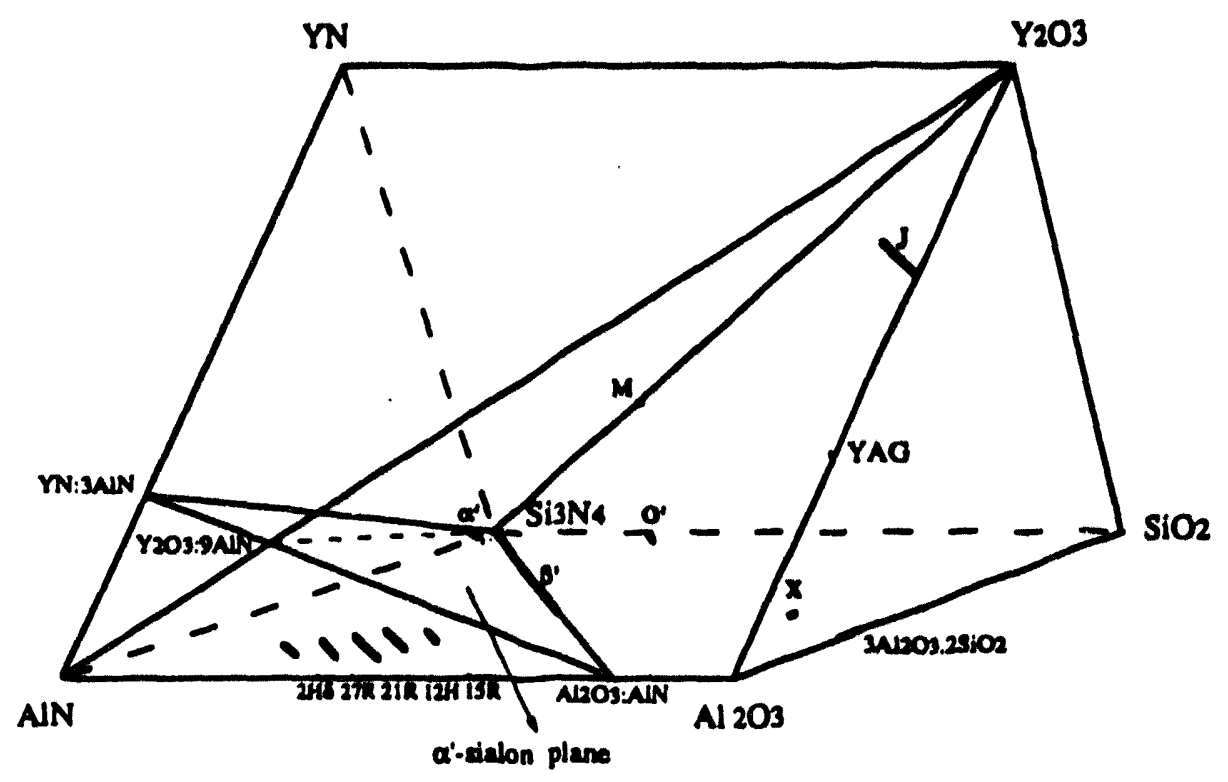

(a)

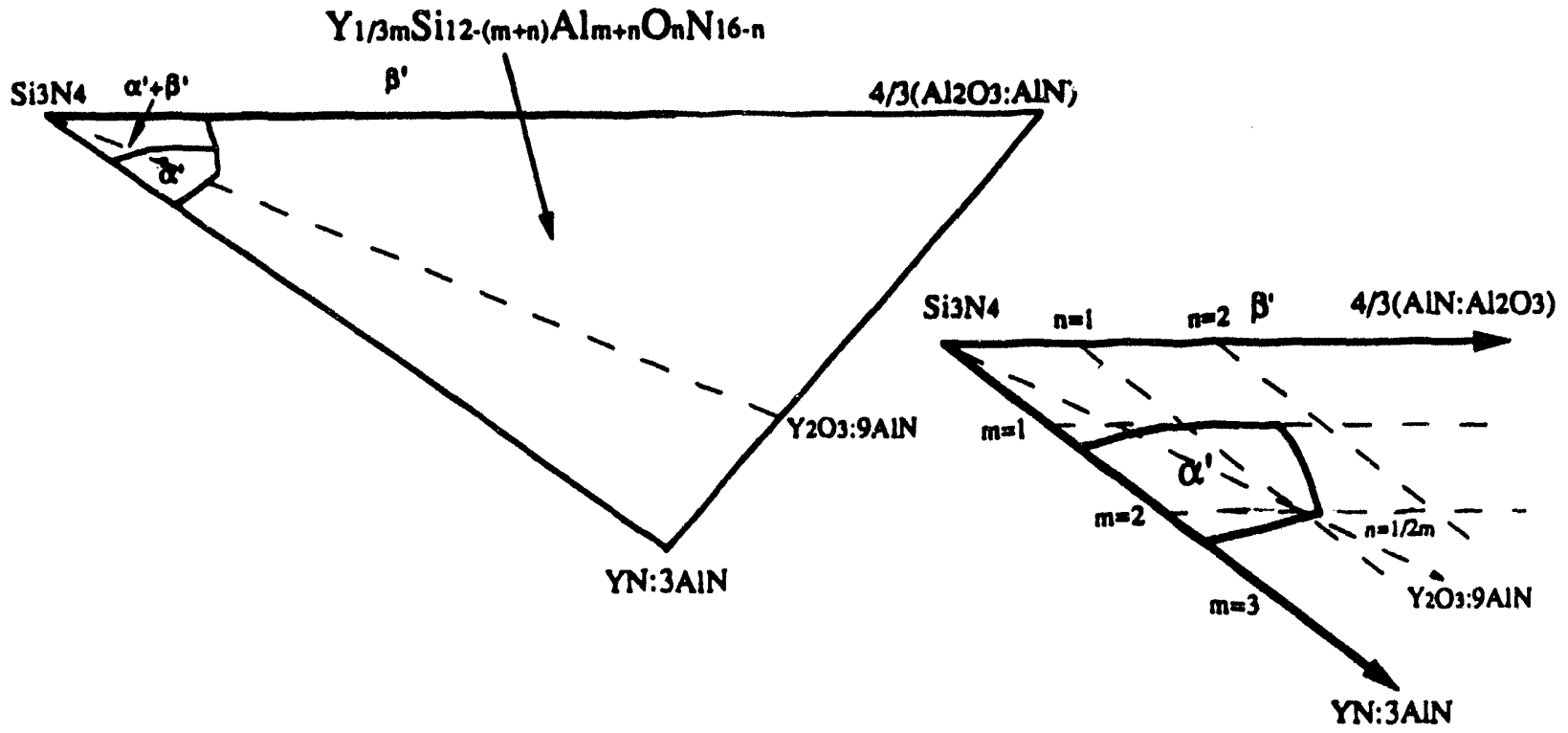

Figure 1: The $\alpha^{\prime}$-SiAION plane 


\section{Technical Highlights:}

Several composi' ions were studied in order to characterize the sintering behavior of the $\alpha^{\prime}+\beta^{\prime}$ SIAION region. These compositions were chosen based upon their ability to be gas pressure sintered to a density greater than $98 \%$ of the calculated theoretical density and are summarized in Table 1 below. The various sintering schedules are also included. X-ray diffraction (XRD) showed that all samples consisted of the desired two phase $\alpha^{\prime}+\beta^{\prime}$ SIAlONs.

\begin{tabular}{ccc}
\hline Compositions & Temperature, $^{\circ} \mathrm{C}$ & Time \\
\hline $\mathrm{m}=0.3, \mathrm{n}=2.00$ & 1900 & 2 hours \\
& 1800 & 2 hours \\
& 1700 & 2 hours \\
$\mathrm{m}=0.4, \mathrm{n}=1.75$ & $1640 / 1840$ & 2 hours at each \\
& 1900 & 2 hours \\
& 1800 & 2 hours \\
& 1700 & 2 hours \\
$\mathrm{m}=0.5, \mathrm{n}=1.75$ & $1640 / 1840$ & 2 hours at each \\
& 1900 & 2 hours \\
& 1800 & 2 hours \\
& 1700 & 2 hours \\
& $1640 / 1840$ & 2 hours at each \\
\hline
\end{tabular}

Table 1. List of compositions and sintering schedules studied. The $m$ and $n$ represent the values in the formula $Y_{m / 3} \mathrm{Si}_{12-(m+n)} \mathrm{Al}_{m+n} \mathrm{O}_{n} \mathrm{~N}_{16-n}$.

One emphasis of this study was to determine the compositional tie lines in the $\alpha^{\prime}+\beta^{\prime}$ phase region. These tie lines would establish the upper limit of the single phase $\alpha$ ' region and allow for a more accurate assessment of the composition of the $\alpha^{\prime}$ and $\beta^{\prime}$ phases present. $X$-ray diffraction methods were used to determine the lattice parameters of both of the $\alpha^{\prime}$ and $\beta^{\prime}$ SiAlON phases. Several authors have shown the dependence of $\beta^{\prime}$ SiAlON's lattice parameters on the $x$-value of substitution in $\mathrm{Si}_{6-x} \mathrm{Al}_{x} \mathrm{O}_{x} \mathrm{~N}_{8-x}$, where $x$ represents the amount of $(\mathrm{Si}-\mathrm{N})$ bonds that are replaced by (Al-O) bonds [1-4]. This relationship allows for a reasonable estimate of the final composition to be made from the determined lattice parameters. For the overall compositions studied, $\beta$-SiAlONs were found to be the range of $\beta_{10}-\beta_{15}$ (where the 10 and 15 are equivalent $\mathrm{Al}$ percents).

In order to fix the position of a particular tie line, at least three points along the tie line must be known. For each sample, the $\beta^{\prime}$ composition has been determined and the overall composition has been assumed to have remained the same. This assumption is based on the fact that the exhibited weight losses of less than 1\% could not cause substantial shifts in overall chemistry of the composition. There are two ways of obtaining the third point along the tie line. One would be to know the exact amount of the $\alpha^{\prime}$ and $\beta^{\prime}$ phases present and use 
the lever rule of phase equilibria to determine the composition of the $\alpha^{\prime}$ phase. Several methods of determining the amount of phases present in silicon nitride ceramics through the use of XRD have been presented in the literature [5-7]. In general, each method showed that the amount of the $\alpha$ ' phase was related to the $m$ value and that for $m=0.3$, the $\alpha^{\prime}$ content was approximately 20 vol\%. For $m=0.4$, and 0.5 , the amount of the $\alpha^{\prime}$ phase was 30 and 40 vol\% respectively. All of the proposed methods are still under consideration as to which one most accurately determines the percentage of phases present.

The second way of determining the third point along the tie line would be to determine the exact composition of the $\alpha^{\prime}$ phase. Several models have been proposed that attempt to fit the dependence of $\alpha^{\prime}$-SiAlON's lattice parameters to the variables $m$ and $n$, which represent the amount of substitution occurring within the $\alpha-\mathrm{Si}_{3} \mathrm{~N}_{4}$ structure [8-10]. Each of these models have been proved to be lacking in their prediction of $m$ and $n$ values from the determined $\alpha^{\prime}$-SiAlON lattice parameters. Therefore, a new model is under development.

Room temperature fracture toughness values have been determined by indentation techniques, and range from 4.5-6.0 MPa.m $1 / 2$. A grain size study has also been started, in an attempt to relate the aspect ratio of the $\beta$ ' phase along with the size distribution of the $\alpha^{\prime}$ phase to the exhibited fracture toughness and hardness.

${ }^{1}$ L.J. Gauckler, J. Weiss, T.Y. Tien, and G. Petzow, "Insolubility of $\mathrm{Mg}$ in $\beta-$ $\mathrm{Si}_{3} \mathrm{~N}_{4}$ in the System Al-Mg-Si-O-N," J. Am. Ceram. Soc., 61 [9-1.0] 397-98 (1978).

2 T. Ekstrom, P.O. Kall, M. Nygren, and P.O. Olsson, "Dense Single Phase $\beta$ Sialon Ceramics by Glass-Encapsulated Hot Isostatic Pressing," J. Mater. Scii., 24 1853-186 (1989).

3 P.L. Land, J.M. Wimmer, R.W. Burns, and N.S. Choudhury, "Compounds and Properties of the System Si-Al-O-N," J. Am. Ceram. Soc., 61 [1-2] 56-60 (1978).

${ }^{4}$ A. Takase, S. Umebayashi, and K. Kishi, "Infrared Spectroscopic Study of $\beta$ Sialons in the System $\mathrm{Si}_{3} \mathrm{~N}_{4}-\mathrm{SiO}_{2}$-AlN," J. Mater. Sci. Let., 1 529-32 (1982).

${ }^{5}$ C.P. Gazzara and D.R. Messier, "Determination of Phase Content of $\mathrm{Si}_{3} \mathrm{~N}_{4}$ by X-Ray Diffraction Analysis," J. Am. Ceram. Soc.. Bul ., 56 [9] 777-80 (1977).

${ }^{6} \mathrm{~K}$. Suzuki and Kanno, Y., "A Conventional Determination of $\alpha$-Phase Fraction in $\mathrm{Si}_{3} \mathrm{~N}_{4,}, "$ Yogyo-Kyokai-Shi, 92 [2] 101-02 (1984).

${ }^{7}$ R.G. Pigeon, and A. Varma, "Quantitative Phase Analysis of $\mathrm{Si}_{3} \mathrm{~N}_{4}$ by X-Ray Diffraction," J. Mater. Sci. Let., 11 1370-1372 (1992).

8 S. Hampshire, H.K. Park, D.P. Thompson, and K.H. Jack, " $\alpha$ '-Sialon Ceramics," Nature, 274 [5674] 880-82 (1978).

${ }^{9}$ W.Y. Sun, T.Y. Tien, and T.S. Yen, "Solubility Limits of $\alpha$ '-SiAlON Solid Solutions in the System Si,Al,Y/N,O" J. Am. Ceram. Soc., 74 [10] 2547-50 (1991). 
$10 \mathrm{M}$. Redington, K. O'Reilly, and S. Hampshire, " On the Relationships between Composition and Cell Dimensions in $\alpha^{\prime}$-Sialons," J. Mater. Sci. Let., 10 1228-31 (1991).

Status of Milestones

On schedule.

Communications/Visits/Travel None.

Problems Encountered

None. 
Hot Pressed Q-SiAlON Ceramics

P. Vlahakis and T. Y. Tien (The University of Michigan)

\section{Objective/Scope}

The objective of this project is to investigate two-phase silicon nitride ceramics whose compositions lie on the $\alpha-\mathrm{Si}_{3} \mathrm{~N}_{4}$ solid solution plane described by $\mathrm{M}_{m / 3} \mathrm{Si}_{12-(\mathrm{m}+n)} \mathrm{Al}_{\mathrm{m}+\mathrm{n}} \mathrm{O}_{n} \mathrm{~N}_{16-\mathrm{n}}$ in the $\mathrm{Si}, \mathrm{Al}, \mathrm{M} / \mathrm{N}, \mathrm{O}$ system. $M$ represents metal cations and in this project the ions are supplied by the rare earth oxides $\mathrm{Gd}_{2} \mathrm{O}_{3}$ and $\mathrm{Y}_{2} \mathrm{O}_{3}$. Compositions that lie on the $\mathrm{Si}_{3} \mathrm{~N}_{4}$ $\mathrm{R}_{2} 0_{3}: 9 \mathrm{AlN}$ join in this system have been studied. These materials, densified by a transient liquid phase during hot-pressing, showed very good mechanical properties at room temperature. However, the high temperature flexure strength exhibited a marked decrease after $1000{ }^{\circ} \mathrm{C}$ and it is thought that the presence of a glassy grain boundary phase is responsible. It is believed that additions of AlN in excess to that already in the compositions will reduce the amount of liquid produced during sintering. This should decrease or, preferably, eliminate the amorphous grain boundary phase and improve the high temperature properties. The effect of AlN additions on microstructural development and mechanical properties of hot-pressed $\mathrm{Si}_{3} \mathrm{~N}_{4}$ ceramics will be investigated.

\section{Background}

The ceramics investigated in this study are two phase materials in the B$\mathrm{Si}_{3} \mathrm{~N}_{4}+\mathrm{a}-\mathrm{Si}_{3} \mathrm{~N}_{4}$ solid solution region of the $\alpha$-SiAlON plane. The solid solution is formed by substitutions in the a-silicon nitride unit cell in which $\mathrm{Al}^{3+}$ ions replace $\mathrm{Si}^{4+}$ ions, $\mathrm{O}^{2-}$-replaces $\mathrm{N}^{3-}$, and rare earth ions of $3+$ valency are "stuffed" into interstitials to preserve charge neutrality. The solubility limits of each particular composition determine how many of the substitutions actually take place. During densification the rare earth oxides and the oxides present as thin films on the $\mathrm{Si}_{3} \mathrm{~N}_{4}$ and $\mathrm{AlN}$ particles $\left(\mathrm{SiO}_{2}\right.$ and $\mathrm{Al}_{2} \mathrm{O}_{3}$, respectively) form a eutectic liquid. This liquid assists in particle rearrangement in the first stage of sintering. More liquid forms as the sintering temperature increases and wetting of $\mathrm{AlN}$ and $\mathrm{Si}_{3} \mathrm{~N}_{4}$ causes the dissolution of these particles into the liquid. When the liquid reaches saturation $\beta-\mathrm{Si}_{3} \mathrm{~N}_{4}$ grains precipitate out and this $\alpha-\beta$ transformation continues during, and is completed after, densification has occurred. These two machanisms are competing processes and sufficient liquid must be present for both to occur. The solid solution formation also takes place during the presence of the liquid phase. The amount of each phase in the resulting microstructure is a function of the starting composition. For 
compositions in the $\alpha^{\prime}$-SiAlON plane this is determined by the $m$ and $n$ values in the solid solution formula. The morphology of the microstructure for this material typically shows high aspect ratio $\beta$ grains. This tends to give good fracture toughness values due to the tendency of these grains to weave together in an interlocking pattern. The grains formed through the solid solution ( $\alpha-\mathrm{Si}_{3} \mathrm{~N}_{4}$ s.s.) tend to be small and equiaxed. These grains yield high hardness values. The resulting microstructure produces a ceramic that has excellent mechanical properties.

\section{Technical Highlights}

For all the compositions in this study the values of $m=4$ and $n=2$ were used. Without additional amounts of AlN the compositions with these $m, n$ values lie along the $\mathrm{Si}_{3} \mathrm{~N}_{4}$ - Rare Earth:9AlN join. As the weight per cent AlN increases the compositions are pushed toward the nitrogen-rich corner of the Rare earth-Si-Al-O-N phase diagram. In practical terms this means that the amount of liquid present during sintering is reduced. It's been found that as the amount of liquid decreases, hot-pressing the powder compacts to full density becomes increasingly difficult. SEM micrographs of the compositions that did densify showed that the amount of residual liquid had apparently decreased, resulting in a smaller grain boundary phase. The micrographs also indicated that the expected morphology of elongated $\beta$ grains and smaller, equiaxed agrains did not develop. Both phases consisted of small, equiaxed grains. The reason for this occurrence will be investigated.

Compositions containing $\mathrm{Gd}_{2} \mathrm{O}_{3}$ or $\mathrm{Y}_{2} \mathrm{O}_{3}$ were hot-pressed under flowing $\mathrm{N}_{2}$. A variety of heating rates, maximum temperature, and time at maximum temperature were used in an attempt to densify the compacts. Heating rates of $25-35^{\circ} \mathrm{C} / \mathrm{min}$ were used in combination with maximum temperatures in the range $1650-1800^{\circ} \mathrm{C}$. Several hold times at maximum temperature were used. For compositions with small ( $<3$ weight\%) or no AlN additions hot press conditions of $25^{\circ} \mathrm{C} / \mathrm{min}, 1700^{\circ} \mathrm{C}$, and 1 hour at $\mathrm{T}_{\max }$ resulted in fully dense samples. Density was measured by the Archimedes' method. X-ray diffraction patterns in all samples indicated the presence of both the solid solution and $\mathrm{B}_{-} \mathrm{Si}_{3} \mathrm{~N}_{4}$ phases. Further studies will be conducted to determine the effect of AlN additions on microstructure and mechanical properties.

Status of Milestones

On schedule

Communications/Visit/Travel

None 
In-Situ Reinforced Silicon Nitride

H. Yeh and J. Pollinger (AlliedSignal Ceramic Components)

J. Yamanis and C-W. Li (Allied-Signal Research and Technology)

\section{Objective/Scope}

The objective of this program is to develop compositions and processes to obtain high fracture toughness and strength for silicon nitride $\left(\mathrm{Si}_{3} \mathrm{~N}_{4}\right)$ based ceramic materials through microstructure control. Resulting microstructures would have elongated grains that would promote crack bridging and deflection toughening mechanisms. These types of materials known as in situ reinforced (ISR) $\mathrm{Si}_{3} \mathrm{~N}_{4}$, are intended for application in advanced heat engine components. A significant amount of the improved mechanical properties must be retained to elevated temperatures. The properties should not substantially degrade over time and would thus allow the material to survive stress under extended exposures at high and moderate temperatures in oxidizing environments. The mechanical property goals of the program are listed below:

Modulus of Rupture at $25^{\circ} \mathrm{C}^{*}$

Modulus of Rupture at $1200^{\circ} \mathrm{C}^{*}$

Modulus of Rupture at $1400^{\circ} \mathrm{C}^{*}$

Stress Rupture at $1000^{\circ} \mathrm{C} \#$

Stress Rupture at $1200^{\circ} \mathrm{C} \#$

Weibull Modulus+

Fracture Toughness, $\mathrm{K}_{\mathrm{lc}}$ at room temperature**

Maximum Use Temperature

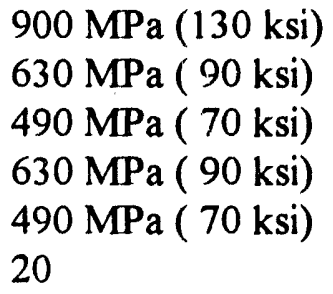

20

$10 \mathrm{MPa} \sqrt{\mathrm{m}}$ $1400^{\circ} \mathrm{C}$

The technical effort is divided into two stages. The first stage shall be a refinement stage (Tasks 1 and 2) and shall focus on the effects and interactions of the chemical composition and thermal processing variables on microstructure, mechanical behavior, and oxidation resistance. In parallel, the effects of green processing on the required amount of sintering aids, room temperature strength, Weibull statistics, and critical flaws shall be assessed. The goal for this stage shall be to identify conditions which improve the baseline material and to map composition-processing-property relationships. The second stage shall

* Four point flexure using Department of Defense MIL-STD-1942

(size B) test specification

\# Stress at which sample shall survive $100 \mathrm{~h}$ at $1000^{\circ} \mathrm{C}$.

** Measured by Chevron notch method.

+ As determined by maximum likelihood method. 
be an optimization stage (Tasks 3, 4 and 5) and shall focus on the development of ISR $\mathrm{Si}_{3} \mathrm{~N}_{4}$ with optimized microstructure and properties which meet or exceed the property goals and on the establishment of composition-processing-property correlation. In addition, a simulated engine component shall be fabricated in order to demonstrate process feasibility.

The technical effort was initiated in February 1992. In accordance with the program schedule, Task 1 - Composition and Process Development was completed end of September 1992 (Milestone 122601); Task 2 - Material Property Characterization was completed end of January 1993; Task 3 -- Composition and Process Optimization was completed during this reporting period (Milestone 122602); and Task 4-Characterization of Optimized Materials and Process, and Task 5 -- Fabrication of a Simulated Component were initiated in this reporting period.

TASK 1 - Composition and Process Development

Completed.

TASK 2 - Material Property Characterization

Completed.

TASK 3 - Composition and Process Optimization

The objective of this task js to further improve the material properties, based on results from Tasks 1 and 2 , to meet the program goals. The optimized material will then be characterized in-depth under Task 4 . The optimization effort has been completed during this reporting period, and the results are summarized below.

Compositions 2 and 4 were initially selected for further optimization. After a short period of investigation, the results led to the formulation of Composition 5 which was then included in the process optimization effort due to its potential of further improving the high temperature properties of AS800. The green forming process was already considered being near optimum, so the emphasis was focused on the optimization of sintering cycle and the effect of post sintering crystallization treatment on properties. For consistency, all experimental optimization work under this task were continued using the same laboratory scale over-pressure sintering furnace used in Tasks 1 and 2 .

A series of experiments were conducted to fine tune the sintering cycle to achieve high density as well as improved properties. A narrow sintering cycle window has been established which consistently results in near theoretical density ( $+99.5 \%$ theoretical) standard size billets for all three compositions. The typical fast fracture strengths for all 
three compositions are approximately $850 \mathrm{MPa} / 25^{\circ} \mathrm{C}, 650 \mathrm{MPa} / 1200^{\circ} \mathrm{C}$ and 590 $\mathrm{MPa} / 1400^{\circ} \mathrm{C}$. However, Composition 2 has more consistently exhibited higher room temperature strength while maintaining high toughness $(8.5 \mathrm{MPa} V . \mathrm{m})$.

It has been shown that post sintering crystallization treatment can affect the properties of AS800 materials. A standard crystallization thermal treatment cycle has been established for evaluating the effect of crystallization on the properties of Compositions 2, 4 and 5. . Following the convention used in previous reports, crystallized materials are designated Compositions $2 \mathrm{c}, 4 \mathrm{c}$ and $5 \mathrm{c}$, respectively (although the bulk chemistry did not change). The effect of crystallization is to crystallize the glassy grain boundary phase. The major grain boundary crystalline phase after crystallization is identified as $\mathrm{H}$-phase.

The response to the crystallization treatment is different for each of the three compositions. For example, the room temperature strengths for $4 \mathrm{c}$ and $5 \mathrm{c}$ are about $15 \%$ lower than the uncrystallized counterparts, but are almost the same for Compositions $2 \mathrm{c}$ and 2. The effect of crystallization on high temperature fast fracture strengths for all three compositions are not noticeable. On the other hand, the oxidation resistance and stressrupture properties at $1000^{\circ} \mathrm{C}$ can be significantly improved by the crystallization treatment, especially for composition 4 . Compositions $2 \mathrm{c}$ and $4 \mathrm{c}$ showed a weight gain of $\sim 0.05$ $\mathrm{mg} / \mathrm{cm}^{2}$ after 100 hours at $1000^{\circ} \mathrm{C}$ in air, and the weight-gain barely changed after additional 1000 hours at the temperature, suggesting that Compositions $2 \mathrm{c}$ and $4 \mathrm{c}$ are quite stable with regard to the intermediate temperature oxidation. The samples can also survive 100 hours under $\sim 480 \mathrm{MPa} 4$-pt bend stress at $1000^{\circ} \mathrm{C}$ in air. As for Composition $5 \mathrm{c}$, its oxidation weight-gain after 100 hours at $1000^{\circ} \mathrm{C}$ is higher $\left(\sim 0.12 \mathrm{mg} / \mathrm{cm}^{2}\right)$; however, its $1000^{\circ} \mathrm{C}$ stress

- rupture property is better than that of compositions $2 c$ and $4 c$. For. example, $-a$ few composition $5 \mathrm{c}$ specimens survived 100 hours at $1000^{\circ} \mathrm{C}$ under a $550 \mathrm{MPa} 4$-point bend stress, compared to $485 \mathrm{MPa}$ for Composition 2c.

The $1200^{\circ} \mathrm{C}$ stress-rupture properties of the three compositions after crystallization treatment are very similar. They all exhibit the property of surviving 100 hours at this temperature under a $\sim 590 \mathrm{MPa}$ 4-point bend stress, well above the program goal of $490 \mathrm{MPa}$. At $1400^{\circ} \mathrm{C}$, composition $5 \mathrm{c}$ showed a significantly improved stress-rupture resistance over the other two compositions. For example, several composition $5 \mathrm{c}$ specimens survived 100 hours under $400 \mathrm{MPa}$, while the stress had to be reduced to $\sim 350 \mathrm{MPa}$ for Compositions $2 \mathrm{c}$ and $4 \mathrm{c}$ for their specimens to last 100 hours. Furthermore, composition $5 \mathrm{c}$ showed a weight-gain of $\sim 0.46 \mathrm{mg} / \mathrm{cm}^{2}$ after 100 hour oxidation in air at $1400^{\circ} \mathrm{C}$. This weight gain is $\sim 50 \%$ lower compared with that of the composition $2 \mathrm{c}$ but similar to that of composition $4 \mathrm{c}$. This improved oxidation resistance of the composition $5 \mathrm{c}$ over $2 \mathrm{c}$ is most noticeable at temperatures $>\sim 1300^{\circ} \mathrm{C}$. The post-oxidation strength for composition $5 \mathrm{c}$ after the hightemperature oxidation $\left(>1300^{\circ} \mathrm{C}\right)$ is also much better than that of composition $2 \mathrm{c}$, and is slightly better than composition $4 \mathrm{c}$. 
The microstructure of the three compositions sintered under a variety of conditions are similar. Composition 2 tends to form a more uniform microstructure than the other two. Fractography results suggest that while the common fracture origin for the three compositions are super-large grains, the fracture origins for Compositions 4 and 5 tend to be larger. Therefore, future work to improve the fast-fracture strength of these compositions should focus on the understanding of the cause for the formation of these super-large grains. The fracture toughness for composition $5 \mathrm{c}$ measured by the indentation strength method ranges from 7.7 to $8.2 \mathrm{MPa} \cdot \sqrt{\mathrm{m}}$.

It should be pointed out that each of the compositions studied has its merits for a specific application. Composition 2 has the highest room-temperature strength, strongest $1000^{\circ} \mathrm{C}$ oxidation resistance, and excellent creep/slow crack growth resistance up to $1300^{\circ} \mathrm{C}$. Composition $5 \mathrm{c}$ is improved in performance in the high-temperature regime $\left(>1300^{\circ} \mathrm{C}\right)$, but its room-temperature strength is lower, and its oxidation resistance at $1000^{\circ} \mathrm{C}$ is not as good as composition 2 . However, composition $5 \mathrm{c}$ is relatively new compared to the development of the other two compositions, and its potential for further improvement in the mechanical properties, especially in the area of fast fracture strength, is high. Therefore, we recommend both Compositions 2 and $5 \mathrm{c}$ for in-depth characterization under Task 4.

TASK 4 - Characterization of Optimum Material Composition and Process

The objective of this task is to conduct a more in-depth characterization of the materials recommended under Task 3 . The test matrix includes flexural and tensile strengths and fracture toughness at room temperature, flexural and tensile strength at elevated temperatures of $1000^{\circ} \mathrm{C}, 1200^{\circ} \mathrm{C}$, and $1400^{\circ} \mathrm{C}$, elevated temperature tests to determine oxidation stress rupture and creep behavigrs. A large quantity of larger size billets are required. Work has begun to fabricate compositions 2 and 5 materials using a larger over-pressure sintering furnace. The initial focus will be to reproduce the densities, microstructures and properties achieved under Task 3 using the smaller sintering furnace. It is anticipated that fine tuning of the sintering conditions will be required.

TASK 5 - Fabrication of a Simulated Component

The objective of this task is to demonstrate the capability of the slip casting and densification processes refined under this program to fabricate a defect free heat engine component. The mixed flow ATTAP rotor has been selected for this purpose. Initial process work was initiated in this reporting period.

\section{$\underline{\text { Status of Milestones }}$}

Milestone 122601 (Refinement of baseline composition) was completed on schedule (Oct. 10, 1992). . 
Milestone 122602 (Optimization of Composition and Process) was completed on schedule during this reporting period.

The progress of all other milestone are on schedule

Communications/Visits/Travel

H. Yeh andC-W. Li visited ORNL to present an update of this program.

John Pollinger and C-W. Li visited ORNL to present an update of this program.

Problems Encountered

None

Publications

None 


\subsubsection{Oxide Matrix}

Dlspersion-Toughened Ceramic Composite

T. N. Tlegs, S. D. Nunn, P. A. Menchhofer, N. M. Gorey, and C. A. Walls (Oak Ridge National Laboratory)

\section{Objective/scope}

Initially, this work involved development and characterization of SiC whiskerreinforced ceramic composites for improved mechanical performance. To date, most of the efforts involving SiC whisker-reinforced alumina, mullite, mullite, silicon nitride, and sialon have been completed. In addition, studies of whisker-growth processes were initiated to improve the mechanical properties of SiC whiskers by reducing their flaw sizes and, thereby, improving the mechanical properties of the composites. Currently, in situ acicular grain growth is being investigated to improve fracture toughness of silicon nitride materials.

\section{Technical highlights}

\section{In situ Toughening of Sillicon Nitride by Microstructure Development}

Microstructure Development During Gas-Pressure-Sintering (GPS) - During sintering at elevated temperatures, silicon nitride materials exhibit weight losses due to decomposition and loss of $\mathrm{SI}, \mathrm{N}$, and $\mathrm{SIO}$. To minimize weight losses, samples are typically packed in powders that create a protective atmosphere. At temperatures $>1825^{\circ} \mathrm{C}$, nitrogen gas overpressures must also be used, in addition to packing powders, to suppress the decomposition of $\mathrm{Si}_{3} \mathrm{~N}_{4}$ so that materials can be densified. Pressures of 1 to $10 \mathrm{MPa}$ (10 to $100 \cdot$ atm) are usually required, and sintering additives are still needed.

The decomposition of the silicon nitride leads to a reaction layer at the surfac $\theta$ of the fired parts and is a normal occurrence. The thickness of the reaction zone can be quite variable with visible differences up to $2 \mathrm{~mm}$ from the surface common. The reaction layer is believed to form due to the interdiffusion of elements contained in the silicon nitride sample (including the sintering aids) and those present in the furnace atmosphere. This may result from the decomposition of silicon nitride during sintering, from loss of volatile sintering aid constituents, and, during GPS, from increased solublity of nitrogen in the sintering aid phase. For optimum mechanical properties, these reaction layers are machined off. It is well established that machining represents a major portion of the cost of sillcon nitride parts, and efforts are under way to reduce its impact on the economics of these materials for engine applications. Consequently, it is desirable to minimize the reaction layers and thereby minimize the machining necessary. The ultimate goal would be to eliminate the reaction zone completely and use as fabricated surfaces.

To examine the effects of processing on the formation of these reaction zones, a series of tests was performed. Important parameters affecting the reaction layers include the packing powder composition, crucible type, sintering temperature, nitrogen pressure, sintering time, use of barrier/protective coatings, and setter type. With this many variables, a Taguchi experimental array was formulated to assess the impact of each of the variables on a two-step GPS process (Table 1). For each of the conditions listed in Table 1, three compositions of silicon nitride with different intergranular phases were tested. These compositions are $\mathrm{Sl}_{3} \mathrm{~N}_{4}-6 \% \mathrm{Y}_{2} \mathrm{O}_{3}-2 \% \mathrm{Al}_{2} \mathrm{O}_{3}, \mathrm{Sl}_{3} \mathrm{~N}_{4}-\mathrm{Y}_{2} \mathrm{Sl}_{2} \mathrm{O}_{7}$ (at 5 equivalent \% oxygen) and $\mathrm{Si}_{3} \mathrm{~N}_{4}-\mathrm{Sr}_{2} \mathrm{La}_{4} \mathrm{Yb}_{4}\left(\mathrm{SiO}_{4}\right)_{6} \mathrm{O}_{2}$ (at 8 equivalent \% oxygen). 
Table 1. Taguchl experimental design array for examination of reaction layers on the surface of sillcon nitride ceramics. The design is a $L_{18}\left(6^{1} \times 3^{6}\right)$ with temperature, nitrogen pressure, time, and coating dummy-loaded to two variables.

\begin{tabular}{|c|c|c|c|c|c|c|c|}
\hline $\begin{array}{l}\text { Test } \\
\text { No. }\end{array}$ & $\begin{array}{l}\text { Packing } \\
\text { powder }\end{array}$ & $\begin{array}{l}\text { Crucible } \\
\text { material }\end{array}$ & $\begin{array}{c}\text { Sintering } \\
\text { temperature } \\
\left({ }^{\circ} \mathrm{C} /{ }^{\circ} \mathrm{C}\right)\end{array}$ & $\begin{array}{c}\text { Nitrogen } \\
\text { pressure } \\
\text { (MPa) }\end{array}$ & $\begin{array}{l}\text { Time } \\
(\mathrm{h} / \mathrm{h})\end{array}$ & Coating & Setter \\
\hline 1 & Mixture & Graphite & $1850 / 1900$ & $0.3 / 0.6$ & $2 / 1$ & No & BN \\
\hline 2 & Mixture & BN & $1900 / 1950$ & $0.6 / 3.5$ & $2 / 2$ & No & None \\
\hline 3 & Mixture & RBSN & $1900 / 1950$ & $0.6 / 3.5$ & $2 / 2$ & Yes & SIC \\
\hline 4 & Low Ox. & Graphite & $1850 / 1900$ & $0.3 / 3.5$ & $2 / 2$ & Yes & SIC \\
\hline 5 & Low Ox. & BN & $1900 / 1950$ & $0.6 / 3.5$ & $2 / 2$ & No & BN \\
\hline 6 & Low Ox. & RBSN & $1900 / 1950$ & $0.6 / 1.0$ & $2 / 1$ & No & None \\
\hline 7 & Oxidized & Graphite & $1900 / 1950$ & $0.6 / 1.0$ & $2 / 2$ & No & SiC \\
\hline 8 & Oxidized & BN & $1900 / 1950$ & $0.6 / 3.5$ & $2 / 1$ & Yes & BN \\
\hline 9 & Oxidized & RBSN & $1850 / 1900$ & $0.3 / 3.5$ & 2/2 & No & None \\
\hline 10 & BN & Graphite & $1900 / 1950$ & $0.6 / 3.5$ & $2 / 2$ & No & BN \\
\hline 11 & BN & BN & $1850 / 1900$ & $0.3 / 0.6$ & $2 / 2$ & Yes & None \\
\hline .12 & BN & RBSN & $1900 / 1950$ & $0.6 / 3.5$ & $2 / 1$ & No & Sic \\
\hline 13 & None & Graphite & $1900 / 1950$ & $0.6 / 3.5$ & $2 / 1$ & Yes & None \\
\hline 14 & None & BN & $1900 / 1950$ & $0.6 / 1.0$ & $2 / 2$ & No & SiC \\
\hline 15 & None & RBSN & $1850 / 1900$ & $0.3 / 3.5$ & $2 / 2$ & No & BN \\
\hline 16 & Mix* & Graphite & $1900 / 1950$ & $0.6 / 3.5$ & $2 / 2$ & No & None \\
\hline 17 & $M i x^{*}$ & $\mathrm{BN}$ & $1850 / 1900$ & $0.3 / 3.5$ & $2 / 1$ & No & SiC \\
\hline 18 & Mix* & RBSN & $1900 / 1950$ & $0.6 / 1.0$ & 2/2 & Yes & BN \\
\hline
\end{tabular}

${ }^{a}$ Mixture-Si $3 \mathrm{~N}_{4}-20 \%$ BN-5\% Y $\mathrm{Y}_{3}$; Low OX.-Sil $\mathrm{N}_{4}$ fired in nitrogen to $1800^{\circ} \mathrm{C}$ for $2 \mathrm{~h}$; Oxidized-Si $\mathrm{N}_{4}$ fired in air to $1000^{\circ} \mathrm{C}$ for $1 \mathrm{~h}$; BN-100\% BN; Mix $\mathrm{Si}_{3} \mathrm{~N}_{4}-20 \% \mathrm{BN}-5 \% \mathrm{Y}_{2} \mathrm{O}_{3}$ on bottom of crucible (no contact with samples). 
The differences in the packing powders allowed an assessment of the roles of $\mathrm{SI}, \mathrm{N}$, and SIO in the formation of the reaction layers. The varlous crucible types examined the typical varleties currently used to determine if there is any impact. Temperatures were elther a low or high two-stage thermal cycle. These have been used in provlous studies and showed good densification results. Different nitrogen pressures will be used only in the second stage of the sintering cycle. The lowest pressure used in the second stage was the minimum pressure to prevent excessive decomposition from taking place at that temperature (either 1900 or $1950^{\circ} \mathrm{C}$ ). In addition to decomposition, during GPS, nitrogen can be dissolved into the liquild phase, which also can contribute to the formation of a surface reaction layer. So a high-pressure second stage was used to determine if excessive nitrogen pressure adversely, affects the formation kinetics of surface reactions and the phases produced. The time variable only examined the time at the highertemperature second stage of the sintering cycle. The effect of a barrier/protective coating was assessed by painting layers of $\mathrm{BN} / \mathrm{SI}_{3} \mathrm{~N}_{4}$ (+ sintering aids) on the surfaces of the samples prior to sintering. These coatings were sacrificial and were readily removed by simply rubbing with a wire brush. The various setter types examined the typical varieties currently used to determine any effect with their use.

The tests on the reaction layer study were completed, and the results are shown in Tables 2 through 4 for the three different compositions. As shown, significant differences in weight loss, sintered density, and visible reaction layer thickness were observed at the various conditions. The $\mathrm{SI}_{3} \mathrm{~N}_{4}-6 \% \mathrm{Y}_{2} \mathrm{O}_{3}-2 \% \mathrm{Al}_{2} \mathrm{O}_{3}$ composition achieved high densities for all of the firing conditions used in the tests. On the other hand, the other two compositions with more refractory grain boundary phases showed quite variable densification. The $\mathrm{SI}_{3} \mathrm{~N}_{4}-\mathrm{Sr}_{2} \mathrm{La}_{4} \mathrm{Yb}_{4}\left(\mathrm{SiO}_{4}\right)_{8} \mathrm{O}_{2}$ composition exhibited densities from $\sim 88$ to $>100 \%$ T. D., and the $\mathrm{Si}_{3} \mathrm{~N}_{4}-\mathrm{Y}_{2} \mathrm{Si}_{2} \mathrm{O}_{7}$ composition had densities between 85 to 98\% T. D. depending on the conditions. Because of the refractory nature of the sintering additives, temperature was the most important factor affecting densification.

- Microstructure Development - An important factor in the densification and microstructure development of silicon nitride ceramics is the transformation of the original $\alpha$-phase starting powder to $\beta$-phase silicon nitride during sintering. This transformation can strongly influence the size and aspect ratio of the silicon nitride grains in the sintered material. For in situ toughening, understanding and control of the $\alpha$-to- $\beta$ transformation is of critical importance if mechanical properties are to be engineered.

Samples were prepared from a series of compositions which were being evaluated in GPS. These compositions are shown in Table 5. The samples were fired at three different temperatures $\left(1700,1750\right.$, and $\left.1800^{\circ} \mathrm{C}\right)$ and for three different times $(0.25,1$, and $5 \mathrm{~h}$ ) under conventional sintering conditions (1 atm nitrogen overpressure) to observe the rate of phase transformation which could be expected during the early stages of the GPS runs. The results of these tests are shown in Tables 6 and 7 . Since the compositions were intended to be sintered in a two-step GPS process, the densities observed for the conventionally sintered samples were relatively low. However, it was seen that for most of the compositions, the $\alpha$-to- $\beta$ phase transformation was complete after $1 \mathrm{~h}$ at $1750^{\circ} \mathrm{C}$.

Status of milestones

On schedule. 
Table 2. Prellminary results for the gas-pressure sintered samples containing sillcon nitride, alumina, and yttria

\begin{tabular}{|c|c|c|c|c|c|c|}
\hline $\begin{array}{c}\text { Test } \\
\text { condltion }\end{array}$ & $\begin{array}{c}\text { Test } \\
\text { number }\end{array}$ & $\begin{array}{c}\text { Woight loss } \\
(\%)\end{array}$ & $\begin{array}{l}\text { Density } \\
\left(\mathrm{g} / \mathrm{cm}^{3}\right)\end{array}$ & $\begin{array}{l}\text { Density } \\
\text { (\% TD) }\end{array}$ & $\begin{array}{c}\text { Reaction } \\
\text { layer } \\
\text { thickness } \\
(\mathrm{mm})\end{array}$ & $\begin{array}{c}\text { Number of } \\
\text { reaction } \\
\text { layers }\end{array}$ \\
\hline 1 & 1 & 1.16 & 3.19 & 97.6 & 2.0 & 3 \\
\hline 2 & 8 & 0.29 & 3.14 & 96.0 & 1.1 & 3 \\
\hline 3 & 7 & 0.97 & 3.24 & 99.1 & 1.2 & 3 \\
\hline 4 & 18 & 1.11 & 3.26 & 99.8 & 1.7 & - \\
\hline 5 & 9 & 0.60 & 3.24 & 99.0 & 1.5 & 3 \\
\hline 6 & 25 & 0.83 & 3.21 & 98.2 & 1.8 & \\
\hline 7 & 11 & 1.85 & 3.23 & 98.8 & 1.2 & 2 \\
\hline 8 & 4 & 0.98 & 3.12 & 95.4 & 3.0 & 1 \\
\hline 9 & 19 & -0.05 & 3.22 & 98.4 & 3.0 & - \\
\hline 10 & 10 & 2.48 & 3.24 & 99.1 & 1.4 & 4 \\
\hline 11 & 14 & 2.44 & 3.12 & 95.4 & 3.1 & 4 \\
\hline 12 & 6 & 0.70 & 3.25 & 99.4 & 1.8 & 3 \\
\hline 13 & $\dot{5}$ & $4.59^{\circ}$ & 3.25 & 99.4 & 2.5 & 3 \\
\hline 14 & 12 & 1.53 & 3.21 & 98.2 & 1.0 & 2 \\
\hline 15 & 20 & 0.0 & 3.1 & 94.8 & 1.2 & -- \\
\hline 16 & 24 & 1.06 & 3.21 & 98.2 & 1.2 & -. \\
\hline 17 & 26 & 0.77 & 3.19 & 97.6 & 0.1 & - \\
\hline 18 & 13 & 1.66 & 3.23 & 98.8 & 1.0 & 2 \\
\hline 19 & 2 & 0.74 & 3.21 & 98.2 & 1.2 & 3 \\
\hline 20 & 3 & 0.09 & 3.15 & 96.3 & 1.4 & 3 \\
\hline
\end{tabular}


Table 3. Preliminary results for the gas-pressure sintered samples containing sillcon nitride, strontla, lanthana, slica, and ytterbia

\begin{tabular}{|c|c|c|c|c|c|c|}
\hline $\begin{array}{c}\text { Test } \\
\text { condition }\end{array}$ & $\begin{array}{c}\text { Test } \\
\text { number }\end{array}$ & $\begin{array}{l}\text { Weight loss } \\
(\%)\end{array}$ & $\begin{array}{l}\text { Density } \\
\left(\mathrm{g} / \mathrm{cm}^{3}\right)\end{array}$ & $\begin{array}{l}\text { Density } \\
\text { (\% TD) }\end{array}$ & $\begin{array}{l}\text { Reaction } \\
\text { layer } \\
\text { thickness } \\
\text { (mm) }\end{array}$ & $\begin{array}{l}\text { Number of } \\
\text { reaction } \\
\text { layers }\end{array}$ \\
\hline 1 & 1 & 3.81 & 3.10 & 89.9 & 3.2 & 5 \\
\hline 2 & 8 & 1.92 & 3.08 & 89.3 & 3.5 & 4 \\
\hline 3 & 7 & 3.03 & 3.21 & 93.0 & 3.6 & 4 \\
\hline 4 & 18 & 3.25 & 3.18 & 92.6 & 4.9 & - \\
\hline 5 & 9 & 1.89 & 3.25 & 94.2 & 3.1 & 3 \\
\hline 6 & 25 & 2.12 & 3.06 & 89.3 & 6.1 & - \\
\hline 7 & 11 & 4.07 & 3.45 & 100 & 1.0 & 3 \\
\hline 8 & 4 & -0.90 & 3.30 & 95.7 & 3.2 & 4 \\
\hline 9 & 19 & 0.98 & 3.10 & 90.5 & 2.5 & -- \\
\hline 10 & 10 & 4.75 & 3.40 & 98.6 & 5.8 & 5 \\
\hline 11 & 14 & 3.86 & 3.32 & 96.2 & 1.8 & 4 \\
\hline 12 & 6 & 2.90 & 3.20 & 92.8 & 3.3 & 3 \\
\hline 13 & 5 & 8.57 & 3.30 & 96.2 & 2.1 & 1 \\
\hline 14 & 12 & 3.62 & 3.44 & 99.7 & 1.2 & 2 \\
\hline 15 & 20 & 0.53 & 3.02 & 88.1 & 1.0 & - \\
\hline 16 & 24 & 3.35 & 3.10 & 90.5 & 3.6 & -- \\
\hline 17 & 26 & 1.99 & 3.03 & 88.3 & 2.0 & - \\
\hline 18 & 13 & 3.90 & 3.45 & 100 & 1.1 & 2 \\
\hline 19 & 2 & 3.37 & 3.10 & 89.9 & 1.7 & 3 \\
\hline 20 & 3 & 0.98 & 3.07 & 89.0 & 4.5 & 6 \\
\hline
\end{tabular}


Table 4. Preliminary results for the gas-pressure sintered samples containing silicon nitride, sillca, and yttria

\begin{tabular}{|c|c|c|c|c|c|c|}
\hline $\begin{array}{c}\text { Test } \\
\text { condition }\end{array}$ & $\begin{array}{c}\text { Test } \\
\text { number }\end{array}$ & $\begin{array}{l}\text { Wolght loss } \\
(\%)\end{array}$ & $\begin{array}{l}\text { Density } \\
\left(\mathrm{g} / \mathrm{cm}^{3}\right)\end{array}$ & $\begin{array}{l}\text { Density } \\
\text { (\% TD) }\end{array}$ & $\begin{array}{l}\text { Reaction } \\
\text { layer } \\
\text { thickness } \\
\text { (mm) }\end{array}$ & $\begin{array}{c}\text { Number of } \\
\text { reaction } \\
\text { layers }\end{array}$ \\
\hline 1 & 1 & 3.75 & 3.05 & 91.6 & 1.8 & 4 \\
\hline 2 & 8 & 1.40 & 3.05 & 91.6 & 2.3 & 5 \\
\hline 3 & 7 & 2.27 & 3.24 & 97.3 & 4.6 & 8 \\
\hline 4 & 18 & 2.88 & 3.22 & 96.7 & 4.1 & -- \\
\hline 5 & 9 & 2.25 & 3.25 & 97.6 & 1.8 & 3 \\
\hline 6 & 25 & 2.24 & 2.99 & 89.7 & 1.7 & -- \\
\hline 7 & 11 & 3.66 & 3.21 & 96.4 & 2.8 & 5 \\
\hline 8 & 4 & -0.74 & 3.13 & 94.0 & 2.4 & 3 \\
\hline 9 & 19 & 1.95 & 2.97 & 89.1 & 2.0 & - \\
\hline 10 & 10 & 6.44 & 3.23 & 97.0 & 5.2 & 6 \\
\hline 11 & 14 & 4.14 & 3.10 & 93.1 & 2.8 & 5 \\
\hline 12 & 6 & 2.20 & 3.23 & 97.1 & 2.9 & 5 \\
\hline 13 & 5 & 17.8 & 3.26 & 97.9 & 3.6 & 6 \\
\hline 14 & 12 & 4.44 & 3.19 & 95.8 & 2.3 & 6 \\
\hline 15 & 20 & 0.93 & 2.84 & 85.4 & 0.3 & -- \\
\hline 16 & 24 & 2.65 & 3.03 & 91.1 & 2.0 & -- \\
\hline 17 & 26 & 3.43 & 2.93 & 88.1 & 3.0 & 3 \\
\hline 18 & 13 & 4.75 & 3.25 & 97.6 & 2.8 & 4 \\
\hline 19 & 2 & 3.10 & 3.06 & 91.9 & 3.1 & 5 \\
\hline 20 & 3 & 1.63 & 2.96 & 88.9 & 1.5 & 3 \\
\hline
\end{tabular}


Table 5. Compositions for gas-pressure sintering study and evaluation of alpha-to-beta transformation in silicon nitride

\begin{tabular}{|c|c|c|c|c|c|c|c|c|c|c|c|}
\hline \multirow[b]{2}{*}{ Batch } & \multirow[b]{2}{*}{ Additive } & \multicolumn{7}{|c|}{ Weigh $\%$} & \multicolumn{3}{|c|}{ Equivelent \% } \\
\hline & & Si3N4 & $\mathrm{SiO}$ & Y2O3 & La2O3 & $\mathrm{Nd} 2 \mathrm{O3}$ & $\mathrm{Yb203}$ & Sro & Oxygen & Sticon & $R E^{*}$ \\
\hline TRSN-1 & Y6A12 & 89.58 & 2.42 & 6.00 & $2.00(A 1203)$ & & & & 5.41 & 97.05 & 1.98 \\
\hline TRSN-2 & Sr2La8(SIO4)76O2 & 81.57 & 5.51 & : & 11.15 & & & 1.77 & 7.99 & 96.84 & 2.71 \\
\hline TRSN-3 & Sr2Y8(SiO4)6O2 & 84.50 & 5.65 & 8.02 & & & & 1.84 & 7.96 & 96.83 & 271 \\
\hline TRSN-4 & Sr2Nd8(SiO4)602 & 81.27 & 5.49 & • & & 11.48 & & 1.77 & 8.00 & 96.84 & 271 \\
\hline TRSN-5 & Lassi207 & 83.11 & 6.33 & & 10.56 & & & & 7.97 & 97.48 & 252 \\
\hline TRSNG & Y2Si207 & 85.96 & 6.47 & - 7.57 & & & & & 7.91 & 97.48 & 2.52 \\
\hline TRSN-7 & YLaSi2O7 & 84.51 & 6.40 & 3.80 & 5.29 & & & & 7.95 & 97.47 & 2.53 \\
\hline TRSN-8 & Y2Si2O7 & 91.44 & 3.29 & 5.26 & & & & & 4.39 & $\mathbf{9 8 . 2 8}$ & 1.71 \\
\hline TASN-9 & Nd2Si2O7 & 89.13 & 3.22 & $:$ & & 7.64 & & & 4.40 & 98.29 & 1.71 \\
\hline TRSN-10 & La2Si2O7 & 89.35 & 3.23 & & 7.41 & & & & 4.40 & 98.29 & 1.71 \\
\hline TRSN-11 & Sr2Y8(SiO4)602 & 90.41 & 2.73 & 5.58 & & & & 1.28 & 4.39 & 97.86 & 1.83 \\
\hline TRSN-12 & Sr2L $88(S i O 4) 602$ & 88.22 & 268 & . & 7.86 & & $\cdot$ & 1.25 & 4.40 & 97.86 & 1.83 \\
\hline TRSN-13 & SraNd8(SiO4)602 & 87.99 & 2.67 & & & 8.10 & & 1.24 & 4.40 & 97.86 & 1.83 \\
\hline TRSN-14 & Y2Si2O7 & 87.95 & 4.31 & 7.75 & & & & & 6.15 & 97.43 & 2.57 \\
\hline TRSN-15 & La2Si2O & 85.03 & 4.17 & $i$ & 10.81 & & & & 6.15 & 97.43 & 2.57 \\
\hline TRSN-16 & Nd2SizO7 & 84.72 & 4.15 & . & & 11.13 & & & 6.15 & 97.43 & 2.57 \\
\hline TRSN-17 & Sr2Y8(SiO4)602 & 86.46 & 3.46 & 8.20 & & & & 1.88 & 6.15 & 96.77 & 276 \\
\hline TRSN-18 & Sr2L $88(S i O 4) 602$ & 83.44 & 3.34 & - & 11.41 & & & 1.81 & 6.15 & 96.78 & 2.76 \\
\hline TRSN-19 & Sr2Nd8(SiO4)602 & 83.13 & 3.32 & & & 11.74 & & 1.81 & 6.14 & 96.78 & 2.76 \\
\hline TRSN-20 & Y2Si2O7 & 85.09 & 5.29 & 9.61 & & & & & 7.70 & 96.76 & 3.24 \\
\hline TRSN-21 & Sr2La8(SiO4)602 & 82.15 & 5.23 & & 10.88 & & & 1.74 & 7.65 & 96.93 & 2.63 \\
\hline TRSN-22 & Sr2La4rb4(SiO4)602 & 81.22 & 5.17 & & 5.38 & & 6.51 & 1.72 & 7.65 & 96.92 & 264 \\
\hline TRSN-23 & Yb2Si2O7 & 87.98 & 3.19 & - & & & 8.83 & & 4.40 & 98.29 & 1.71 \\
\hline TRSN-24 & Y2Si2O7 & 93.49 & 2.52 & 3.98 & & & & & 3.31 & 98.72 & 1.28 \\
\hline TRSN-25 & La2Si2O7 & 91.86 & 2.48 & & 5.66 & & & & 3.31 & 98.72 & 1.28 \\
\hline TRSN-26 & $\mathrm{Nd} 2 \mathrm{Si} 2 \mathrm{O} 7$ & $91.69^{\circ}$ & 2.48 & & & 5.83 & & & 3.32 & 98.72 & 1.28 \\
\hline TRSN-27 & Yb2Si2O7 & 90.80 & $2: 45$ & & & & 6.75 & & 3.31 & 98.72 & 1.28 \\
\hline
\end{tabular}

-RE=Rare earth 

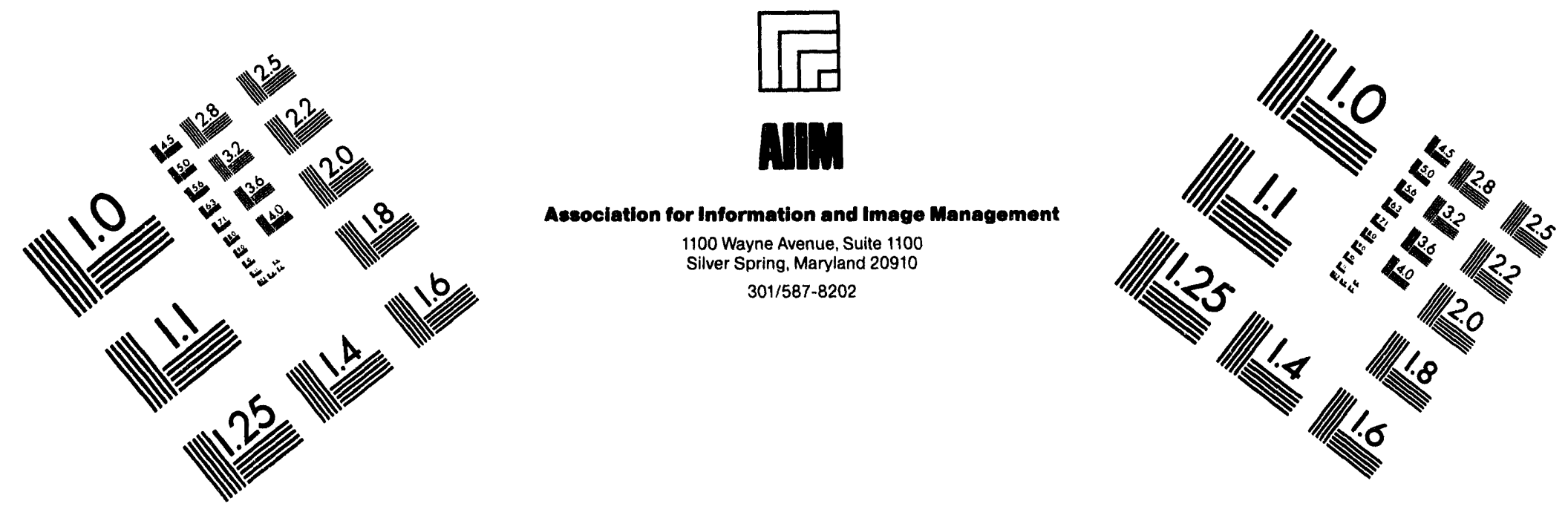

\section{Centimeter}

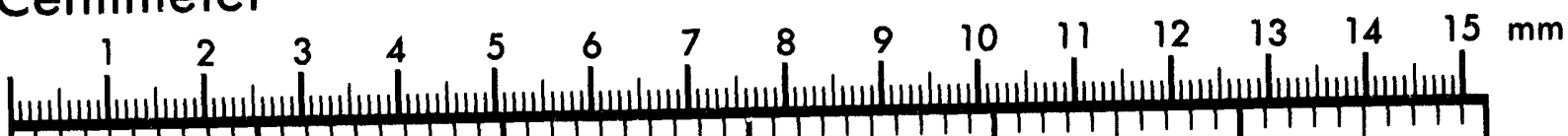

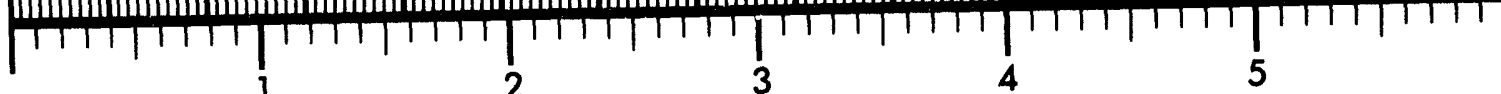
Inches
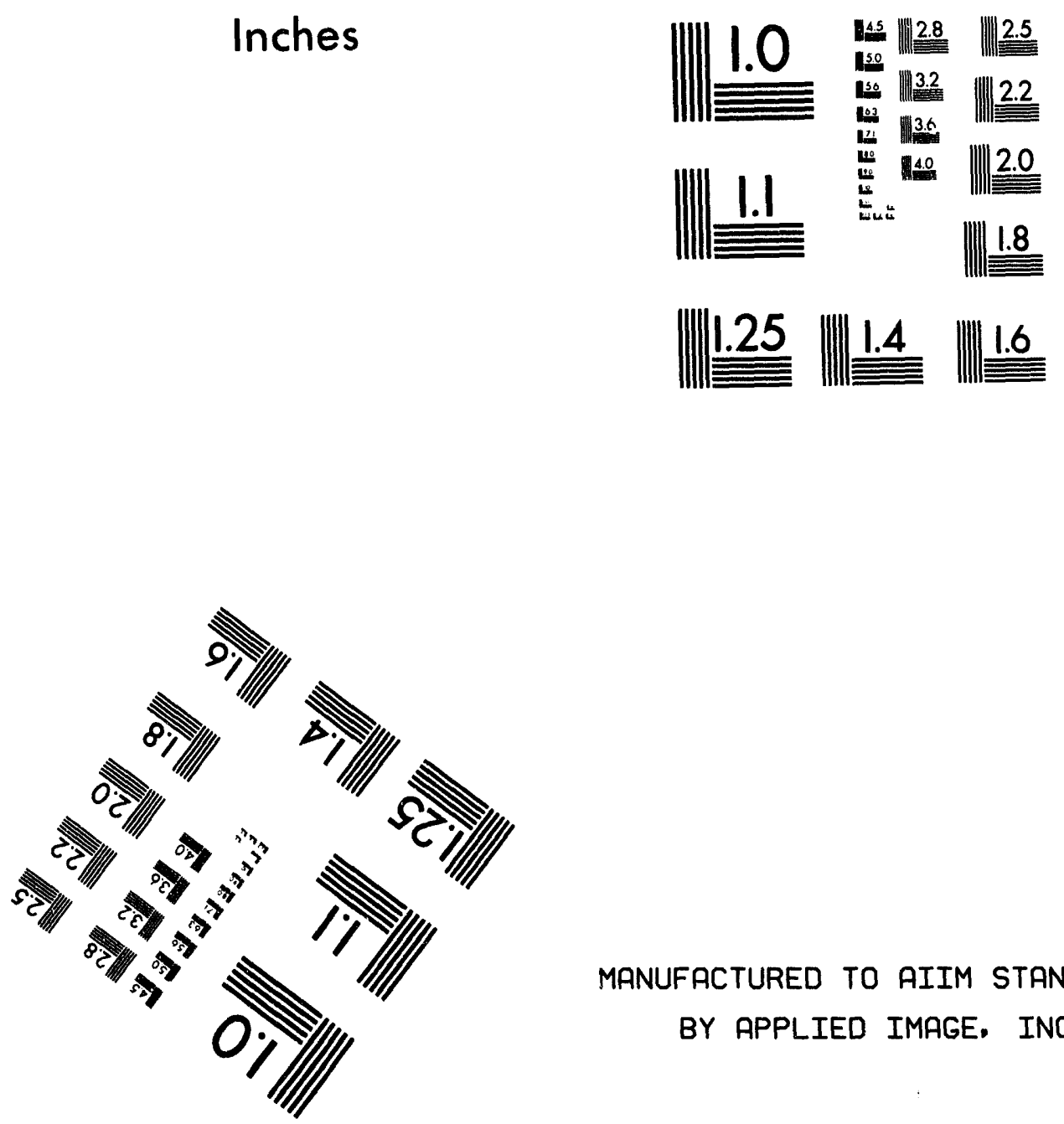

MANUFACTURED TO AIIM STANDARDS BY APPLIED IMAGE, INC.

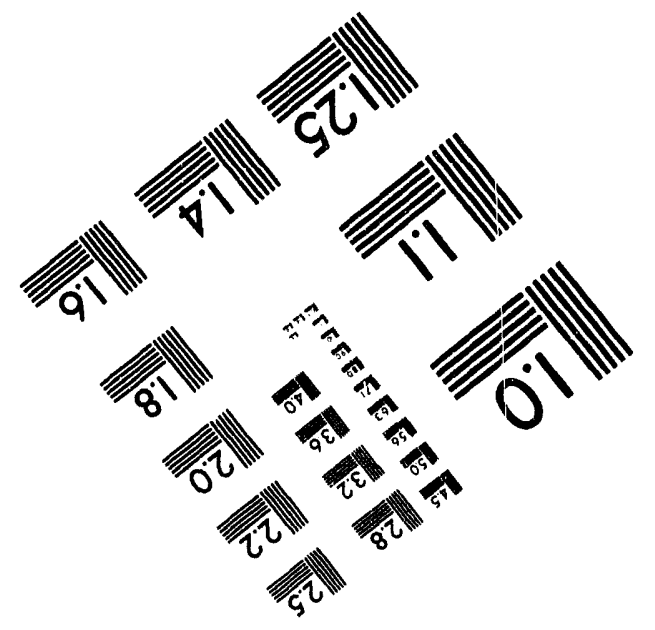



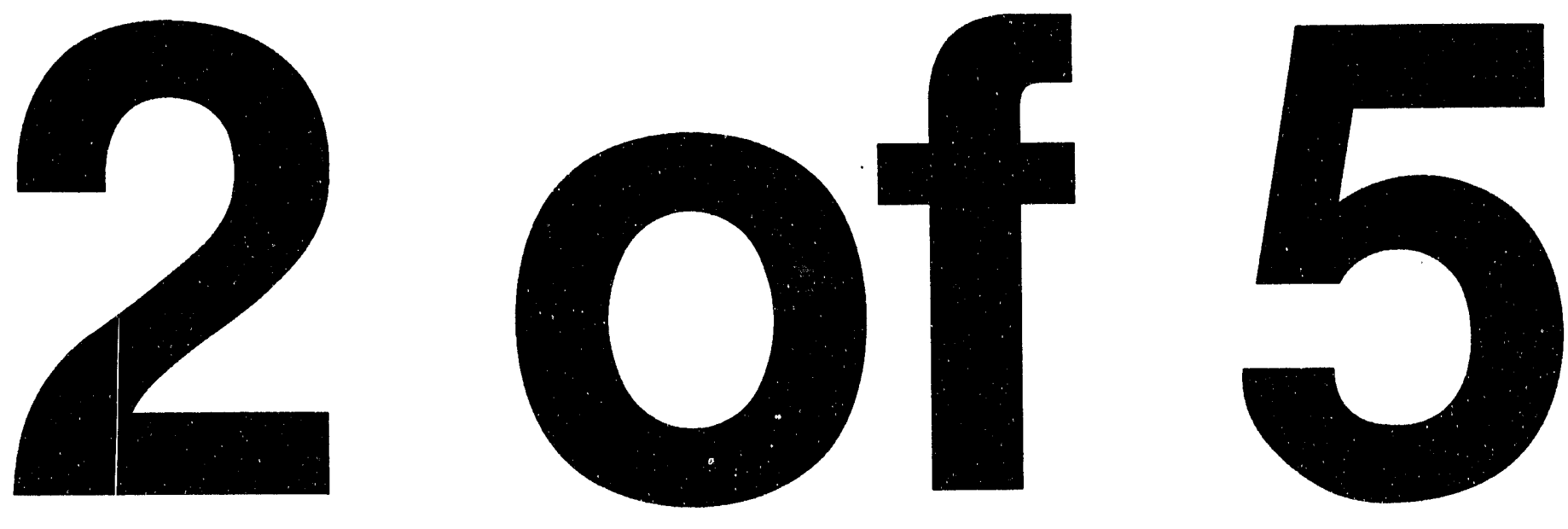
Table 6. Percent theoretical density of TRSN samples sintered at various times and temperatures

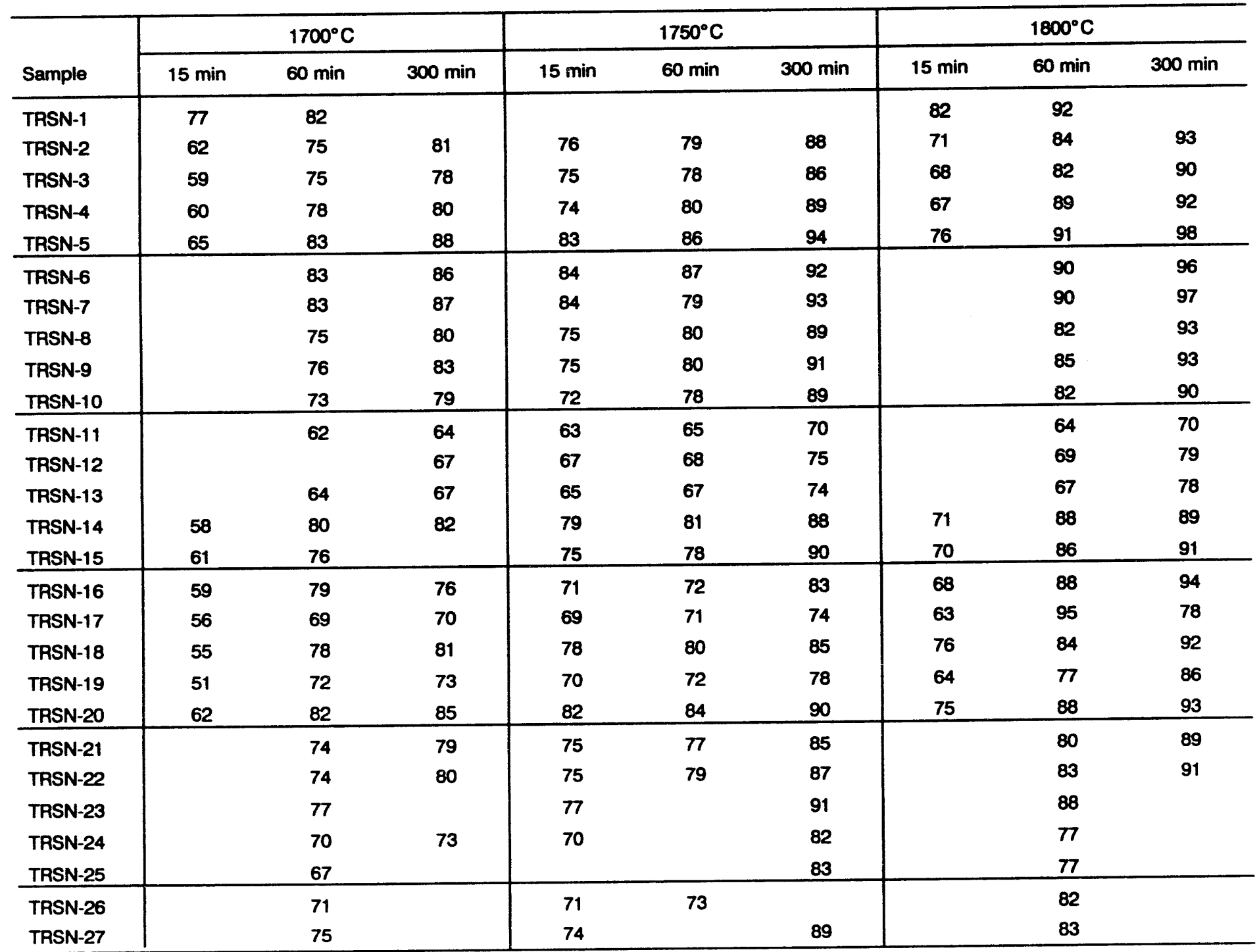


Table 7. Percent alpha phase content of TRSN samples sintered at various times and temperatures

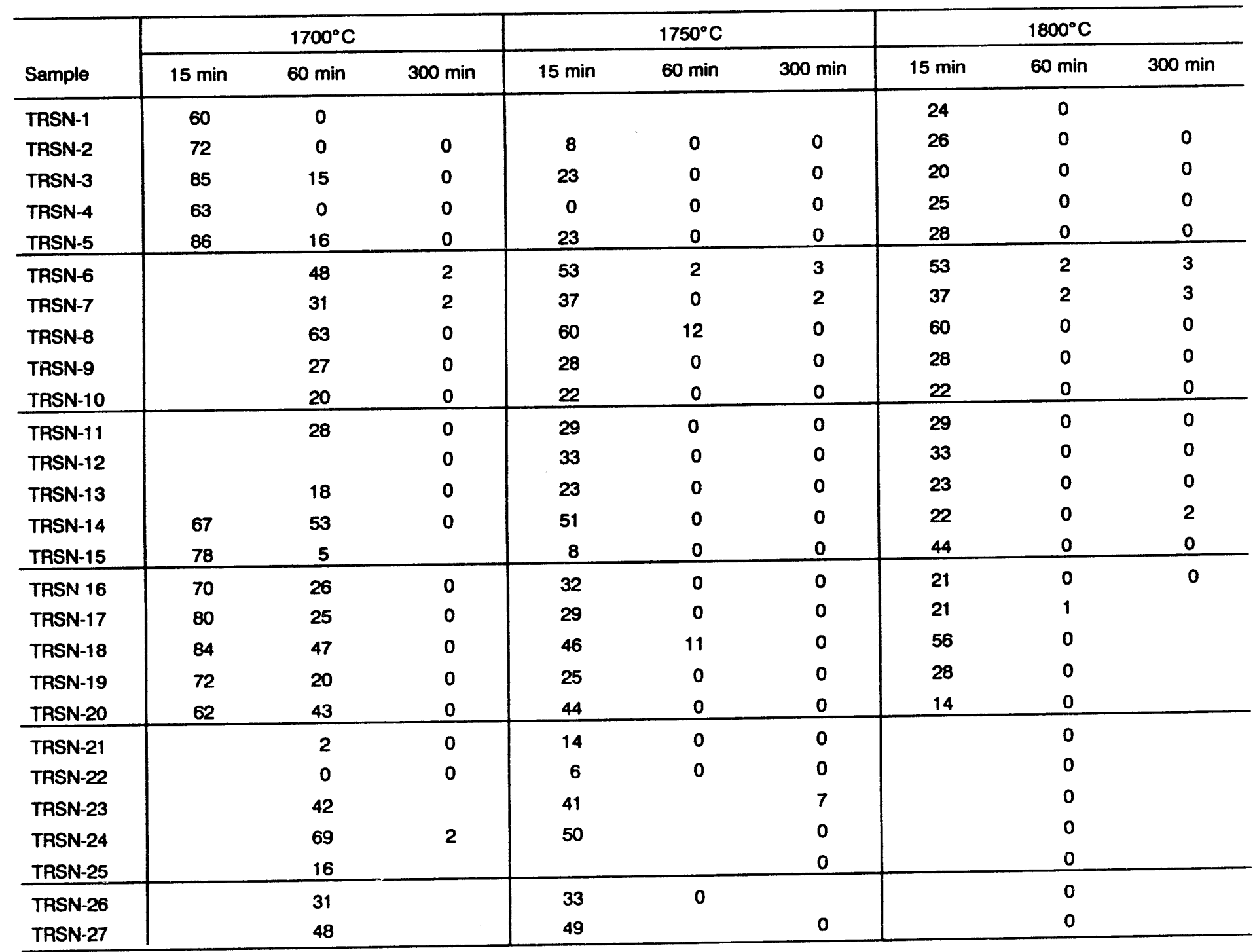




\section{Communications/visits/travel}

Travel by T. N. Tiegs from April 18-22, 1993, to Cincinnati, Ohio, to attend the American Ceramic Society Annual Meeting and present a paper entitled "Effect of Powder Characteristics on Properties of Gas-Pressure Sintered $\mathrm{Si}_{3} \mathrm{~N}_{4}$ "

Travel by T. N. Tiegs from August 31 - September 5, 1993, to Tokyo, Japan, to attend the 3rd International Union of the Materials Research Society (IUMRS) International Conference on Advanced Materials and present a paper entitled "Effect of Powder Characteristics on Gas-Pressure Sintering of $\mathrm{Si}_{3} \mathrm{~N}_{4}$ With Rare Earth Additives."

\section{Problems encountered}

None.

\section{Publications}

"Effect of Powder Characteristics on Gas-Pressure Sintering of $\mathrm{Si}_{3} \mathrm{~N}_{4}$ With Rare Earth Additives," by T. N. Tiegs, S. D. Nunn, C. A. Walls, D. L. Barker, C. Davisson, and P. J. Jones for publication in proceedings of the 3rd IUMRS International Conference on Advanced Materials. 


\subsubsection{Silicate Matrix}

Characterization and Testing of Low-Expansion Ceramic Materials

S. Subramaniam and D. P. Stinton (Oak Ridge National Laboratory)

\section{Objective/scope}

Insulated exhaust port liners are needed in advanced diesel engines to increase engine fuel efficiencies by increasing the combustion temperatures and reducing the combustion heat that is lost through the head and into the water cooling system. Lowexpansion materials have potential for this application because of their very low thermal conductivity, extraordinary thermal-shock resistar,ce, and potential to reduce attachment stresses. Thermal shock resistance is critical because the shape of the port liners requires that they be cast into the metallic cylinder head. Because functioning exhaust port liners are inaccessible after being cast into cylinder heads, they must not require maintenance for the life of the head ( $\sim 1$ million miles). Contracts have been placed with Golden Technologies Co., Inc. (GTC), formerly Coors Ceramics Co., and Low Thermal Expansion Ceramics, Inc. (LOTEC) to develop cost-effective processes for the fabrication of port liners. GTC is investigating $\mathrm{Al}_{2} \mathrm{TiO}_{5}$ and $\mathrm{Ca}_{1-x} \mathrm{Mg}_{x} \mathrm{Zr}_{4} \mathrm{P}_{6} \mathrm{O}_{24}$ while LOTEC is investigating $\mathrm{Ca}_{1-x} \mathrm{Sr}_{x} \mathrm{Zr}_{4} \mathrm{P}_{6} \mathrm{O}_{24}$ and $\mathrm{Ba}_{1+x} \mathrm{Zr}_{4} \mathrm{P}_{6-2 x} \mathrm{Si}_{2 x} \mathrm{O}_{24}$. A program has been initiated at ORNL to assist GTC and LOTEC with the characterization and evaluation of low-expansion materials.

\section{Technical highlights}

A systematic investigation of the mechanical and thermal properties of $\mathrm{Ba}_{1+x} \mathrm{Zr}_{4} \mathrm{P}_{6-2 x} \mathrm{Si}_{2 x} \mathrm{O}_{24}$ (BaZPS) ceramics as a function of composition (Si at.\%) and grain size is being carried out. Five compositions $(x=0.000,0.175,0.250,0.375$, and 0.500$)$ were synthesized from stoichiometric proportions of the reagent grade oxides using solid-state reaction method. To understand the influence of the grain size, three compositions $(x=0.000,0.175$, and 0.500 ) were additionaly sintered for 30 and 300 min to result in smaller-grain-sized samples. The densities, bulk thermal expansion coefficients, and room-temperature flexure strengths were reported in the last semiannual report. In this report, the high-temperature flexure strengths, the room-temperature Young's modulus, and the high-temperature $X$-ray diffraction $(X R D)$ results of one composition $(x=0.175)$ are reported.

Flexure strengths were measured for all five compositions $(x=0.000,0.175,0.250$, 0.375 , and 0.500 ) at room temperature, 200 , and $600^{\circ} \mathrm{C}$ (see Table 1). The flexure strengths varied from 45 to $112 \mathrm{MPa}$ for the materials measured and were essentially unaffected by temperature. The flexure strengths at all temperatures were quite low for compositions with $x=0.000$. It was observed that the flexure strength increased with increasing Si content until BaZPS with $x=0.375$, and then decreased to approximately the original value for materials with the highest silicon content $(x=0.500)$. The fracture surfaces of the sintered samples were studied by scanning electron microscopy. It was observed from the micrographs that the BaZPS compositions with $x=0.00,0.175,0.250$, and 0.375 failed predominantly by transgranular fracture, indicating that the grains were strongly interconnected. However, BaZPS with $x=0.500$ failed predominantly by intergranular fracture, suggesting the grains were not well bonded.

The room-temperature Young's modulus of each of the five BaZPS compositions was determined using a Grindo-sonic instrument (J. W. Lemmens, Inc.), which employs an 
Table 1. Flexural strength results for BaZPS compositions

\begin{tabular}{||l|l|l|l|}
\hline Composition & \multicolumn{3}{l|}{ Flexural strength $(\mathrm{MPa})$} \\
\hline (value of $\mathrm{x})$ & $25^{\circ} \mathrm{C}$ & $200^{\circ} \mathrm{C}$ & $600^{\circ} \mathrm{C}$ \\
\hline 0.000 & $55.36 \pm 4.9$ & $66.05 \pm 2.4$ & $41.43 \pm 14.4$ \\
\hline 0.175 & $84.67 \pm 12.3$ & $84.21 \pm 2.4$ & $79.32 \pm 9.6$ \\
\hline 0.250 & $98.40 \pm 5.7$ & $84.35 \pm 14.9$ & $89.82 \pm 17.1$ \\
\hline 0.375 & $112.75 \pm 10.4$ & $101.97 \pm 19.8$ & $92.67 \pm 7.05$ \\
\hline 0.500 & $49.66 \pm 7.6$ & $45.13 \pm 1.89$ & $50.94 \pm 3.50$ \\
\hline
\end{tabular}

impulse excitation technique. In this technique, the transient vibration of a test object is analyzed after excitation by means of a mechanical impulse, and an electronic circuit isolates the harmonics and determines the fundamental resonant frequency from the noise . spectrum. The Young's modulus was then determined using the prism equation, and the result is summarized in Table 2. It was observed that the Young's modulus increased with increasing silicon content to BaZPS with $x=0.175$, decreased for BaZPS with $x=0.250$, again increased for BaZPS with $x=0.375$, and then drastically dropped for BaZPS with $x=0.500$.

The high-temperature XRD results of BaZPS with $x=0.175$ (BS17) sintered for 3000 min were measured this period to determine unit-cell parameters. XRD patterns were obtained in an argon atmosphere over the scan range of 17.5 to $67.5^{\circ} 2 \theta$ at the rate of

Table 2. Young's modulus results for BaZPS compositions

\begin{tabular}{|l|l|}
\hline$x$ value in BaZPS & Young's modulus (GPa) \\
\hline 0.000 & $34.4 \pm 0.1$ \\
\hline 0.175 & $51.7 \pm 0.7$ \\
\hline 0.250 & $44.7 \pm 0.5$ \\
\hline 0.375 & $60.0 \pm 0.1$ \\
\hline 0.500 & $20.6 \pm 0.8$ \\
\hline
\end{tabular}

$0.1^{\circ} / \mathrm{min}$ at $27,200,400,600,800$, and $900^{\circ} \mathrm{C}$ during heating, and at 850 and $27^{\circ} \mathrm{C}$ during cooling. Heating and cooling rates were $10^{\circ} \mathrm{C} / \mathrm{min}$, and data collection was started after a 1-min hold at all the temperatures. The cell parameters at various temperatures were determined from the obtained XRD patterns. The unit-cell parameters, $a$ and $c$, and 
unit-cell volume variation with temperature are shown in Figs. 1-3. The cell parameters, $a$ and $c$, increased with increasing temperature to $400^{\circ} \mathrm{C}$, then decreased at 600 and $800^{\circ} \mathrm{C}$, again increased at $850^{\circ} \mathrm{C}$, and did not vary much at $900^{\circ} \mathrm{C}$. The unit-cell volume increased with increasing temperature to $400^{\circ} \mathrm{C}$, decreased at 600 and $800^{\circ} \mathrm{C}$, then increased at $850^{\circ} \mathrm{C}$, and slightly decreased at $900^{\circ} \mathrm{C}$. The axial thermal expansion coefficient at different temperatures can be calculated from the measured lattice parameters, and $\alpha_{\mathrm{a}}$ and $\alpha_{\mathrm{o}}$, the thermal expansion coefficients in the a and $c$ directions, respectively, can be computed using the following formulae:

$$
\alpha_{a}=\frac{a_{2}-a_{1}}{\left(T_{2}-T_{1}\right) x a_{1}}
$$

and

$$
\alpha_{c}=\frac{C_{2}-C_{1}}{\left(T_{2}-T_{1}\right) \times C_{1}}
$$

where $a_{1}$ and $c_{1}$ are the lattice parameters at temperature $T_{1}$, and $a_{2}$ and $c_{2}$ are the lattice parameters at temperature $T_{2}$, with $T_{2}>T_{1}$. The thermal expansion coefficients in the a and $c$ directions were found to be $2.76 \times 10^{-60} \mathrm{C}^{-1}$ and $1.35 \times 10^{-60} \mathrm{C}^{-1}$, respectively between 27 to $900^{\circ} \mathrm{C}$, and the degree of anisotropy, $\left|\alpha_{\mathrm{a}}-\alpha_{\mathrm{c}}\right|$, was found to be $1.41 \times 10^{-60} \mathrm{C}^{-1}$. Since BS17 possesses very low thermal expansion anisotropy, it is a promising candidate for thermal cycling applications.

ORNL-DWG 94-5515

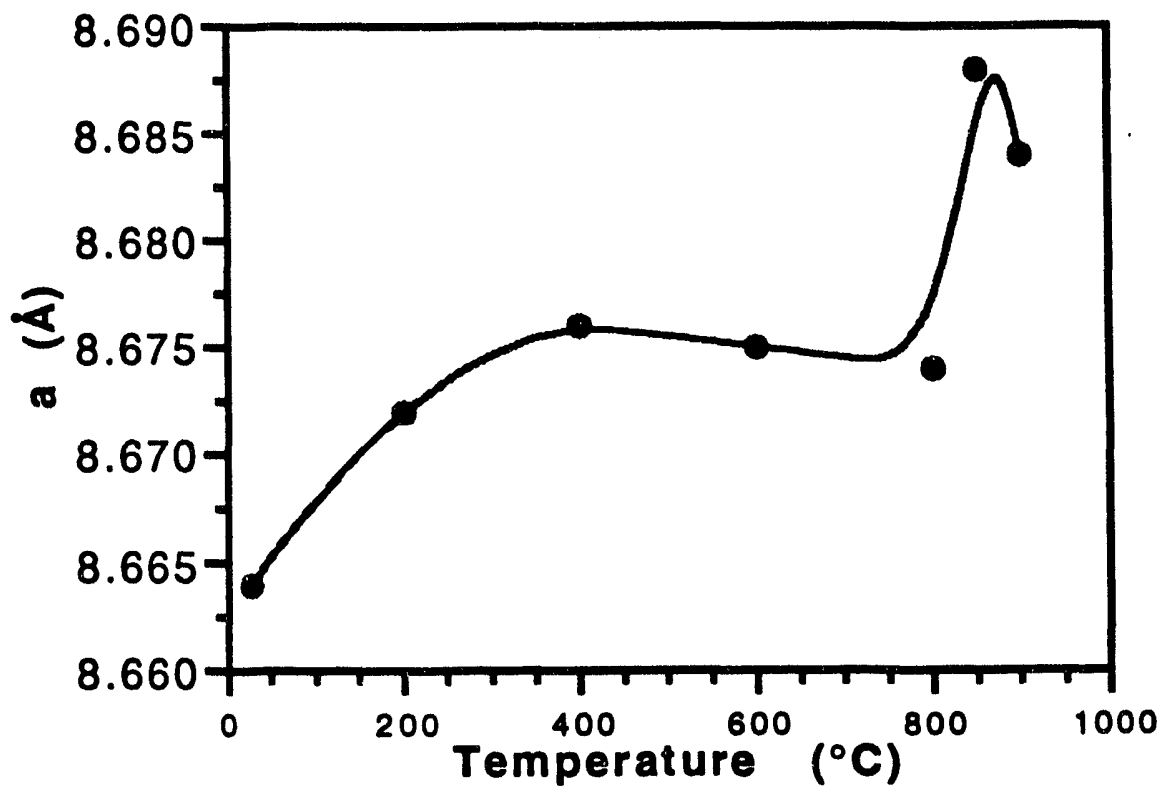

Fig. 1. Variation of unit-cell parameter "a" with temperature for BaZPS with $x=0.175$. 


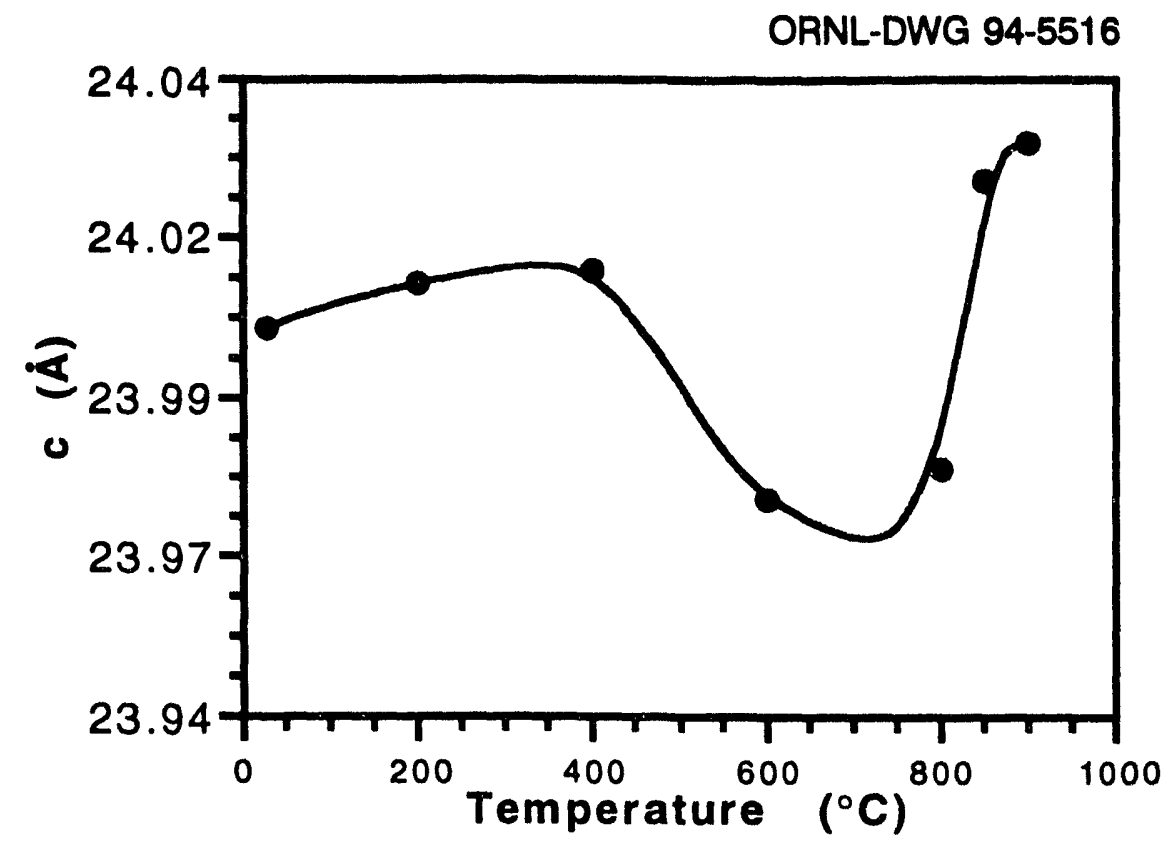

Fig. 2. Variation of unit-cell parameter $c$ " with temperature for BaZPS with $x=0.175$.

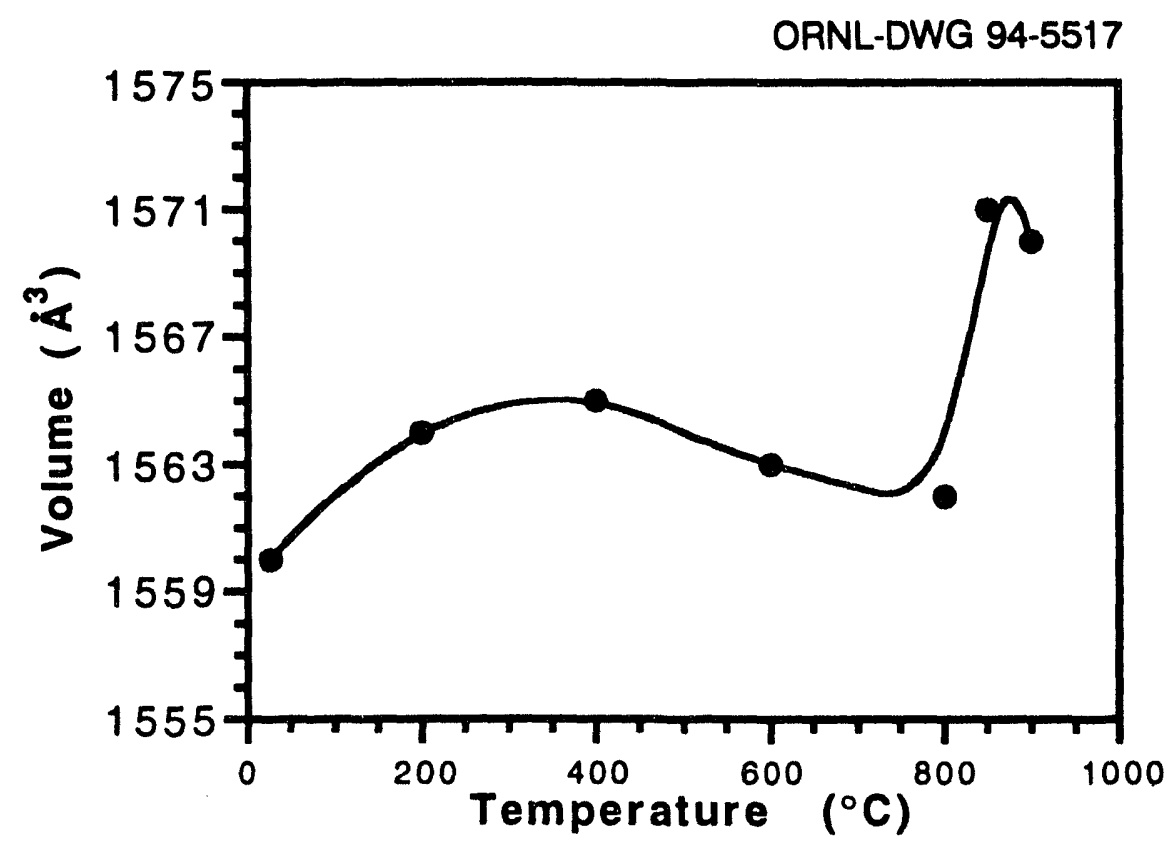

Fig. 3. Variation of unit-cell volume with temperature for BaZPS with $x=0.175$. 


\subsection{THERMAL AND WEAR COATINGS}

Eabrication and Testing of Corrosion-Resistant Coatinos

W. Y. Lee, Y.W. Bae, and D. P. Stinton (Oak Ridge National Laboraiory)

\section{Objective/scope}

Sodium corrosion of $\mathrm{SiC}$ and $\mathrm{Si}_{3} \mathrm{~N}_{4}$ components in gas turbine engines is a potentially serious problem. The outer surfaces of $\mathrm{SiC}$ and $\mathrm{Si}_{3} \mathrm{~N}_{4}$ parts oxidize at high temperatures to form an $\mathrm{SiO}_{2}$ layer that inhibits further oxidation. However, sodium which is present in high-temperature combustion atmospheres reacts with the $\mathrm{SiO}_{2}$ layer, such that it is no longer protective. The objective of this program is to develop a coating that will protect the underlying $\mathrm{SiC} \mathrm{or} \mathrm{Si}_{3} \mathrm{~N}_{4}$ from sodium corrosion and provide simultaneous oxidation protection. To evaluate the behavior of potential materials such as stabilized $\mathrm{ZrO}_{2}$ or $\mathrm{HHO}_{2}, \mathrm{TiO}_{2}, \mathrm{Al}_{2} \mathrm{O}_{3} \cdot \mathrm{TiO}_{2}$, and $\mathrm{Ta}_{2} \mathrm{O}_{5}$ in sodiumcontaining atmospheres, tha corrosion resistance of hot-pressed samples of these materials will first be evaluated. A chemical vapor deposition (CVD) process will be developed for the application of the most promising coatings. The effect of the combustion environment upon coating characteristics such as microstructure, strength, adherence, and other properties will then be evaluated.

\section{Technical progress}

The growth of a dense, void-free coating microstructure was experimentally observed with the use of $\mathrm{CO}_{2}$ and $\mathrm{H}_{2}$ as a source of oxygen for the CVD of $\mathrm{Ta}_{2} \mathrm{O}_{5}$. As described in the previous reports, $\mathrm{Ta}_{2} \mathrm{O}_{5}$ coatings deposited from $\mathrm{TaCl}_{5}$ and $\mathrm{O}_{2}$ typically consisted of highly faceted columnar grains or whiskers which did not readily coalesce during growth, resulting in the formation of undesirable open voids and pin-holes in the coating microstructure.

Figure 1 shows the morphology of $\mathrm{Ta}_{2} \mathrm{O}_{5}$ deposited on $\mathrm{Si}_{3} \mathrm{~N}_{4}$ (GN10, AlliedSignal) at a substrate temperature of $1150^{\circ} \mathrm{C}$ and a reactor pressure of 5 torr after a deposition time of $70 \mathrm{~min}$. A newly constructed dual-path, $\infty$-axial injector, which was designed to eliminate some convectionrelated problems discussed in the last report, was utilized for this experiment. The inner path $\left(1.19-\mathrm{cm}\right.$ ID) of the injector was used for the chlorination of Ta with $\mathrm{Cl}_{2}$, and the outer one $(1.91-\mathrm{cm}$ ID) was used to feed $\mathrm{CO}_{2}$ and $\mathrm{H}_{2}$ (Fig. 2). Ar was added to the inner path to help carry the $\mathrm{TaCl}_{5}$ vapor into the deposition zone. The $\mathrm{Cl}_{2}, \mathrm{H}_{2}, \mathrm{CO}_{2}$, and Ar flow rates were 4, 40,40, and $36 \mathrm{~cm}^{3} / \mathrm{min}$ at standard temperature and pressure (STP), respectively.

The coating consisted of $" 1$ - $\mu \mathrm{m}$ size grains that appeared to be relatively well coalesced during their growth. The presence of voids and pin-holes in the coating microstructure was not observed during the scanning electron microscope (SEM) analysis. The coating was identified to be orthorhombic $\mathrm{Ta}_{2} \mathrm{O}_{5}$ by X-ray diffraction (XRD) as shown in Fig. 3 . The intensity of the (001) peak was relatively high, indicating that the $\mathrm{Ta}_{2} \mathrm{O}_{5}$ grains were preferentially oriented to the [001] direction. Also, $\mathrm{Ta}_{2} \mathrm{O}_{5}$ deposited on $\mathrm{SiC}$ (Haxalloy SA) at $1105^{\circ} \mathrm{C}$ was crystalline and void free (Fig. 4). In comparison with the coating microstructures previously deposited using $\mathrm{O}_{2}$ as an oxygen source, it is evident that the use of the $\mathrm{CO}_{2}+\mathrm{H}_{2}$ mixture promotes the growth of the void-free microstructure.

The coating thickness on the $\mathrm{Si}_{3} \mathrm{~N}_{4}$ substrate decreased from 10 to $5 \mu \mathrm{m}$ along the flow direction. It was also observed that metallic Ta was deposited in a cold region located between the chlorinator and substrates. It appeared that $\mathrm{TaCl}_{5}$ and $\mathrm{H}_{2}$ preferentially reacted at the lowtemperature region, where the water-gas shift reaction between $\mathrm{CO}_{2}$ and $\mathrm{H}_{2}$ was not sufficiently activated to supply oxygen adatoms to the deposition surface. In other deposition experiments, it was found that $\mathrm{Si}(100)$ reacted with $\mathrm{TaCl}_{5}$ at 1010 to $1130^{\circ} \mathrm{C}$ to produce $\mathrm{Ta}_{5} \mathrm{Si}_{3}$ while $\mathrm{Ta}_{2} \mathrm{O}_{5}$ was being deposited.

A set of deposition experiments was performed to study the effects of temperature on the growth rate and microstructure of CVD Ta2 $\mathrm{O}_{5}$ and to assess the reproducibility of the coating process. As illustrated in Fig. 2, $\mathrm{Si}_{3} \mathrm{~N}_{4}$ substrates were placed on a $6-\mathrm{cm} \mathrm{Al} 2 \mathrm{O}_{3}$ substrate holder. The substrates and the holder were heated by a 7.6-cm-long cylindrical graphite susceptor, which was inductively coupled with an RF generator. Figure 5 shows that axial temperature variations up to 


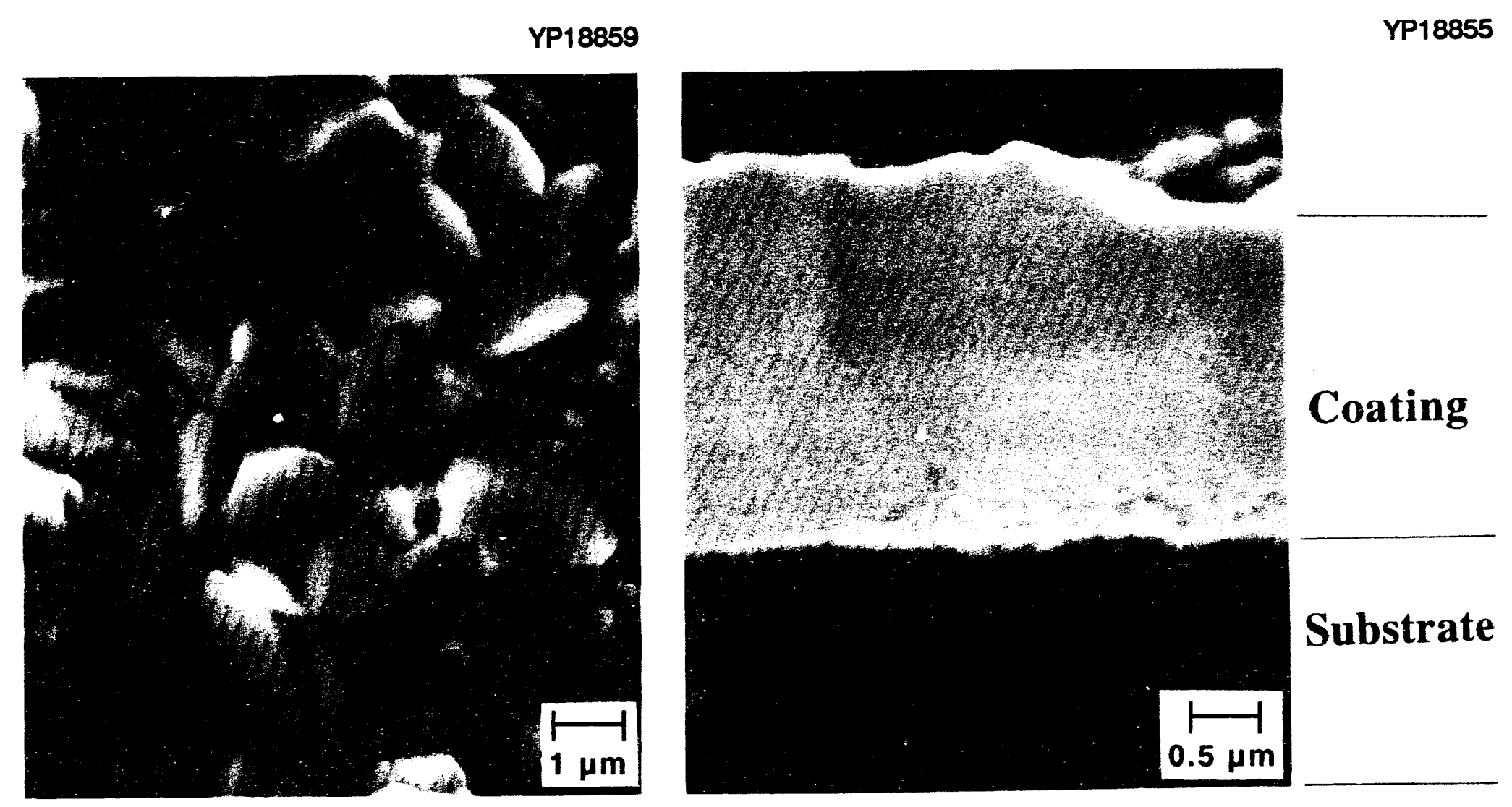

Fig. 1. SEM micrographs of $\mathrm{Ta}_{2} \mathrm{O}_{5}$ deposited from $\mathrm{TaCl}_{5}, \mathrm{H}_{2}$, and $\mathrm{CO}_{2}$ on $\mathrm{Si}_{3} \mathrm{~N}_{4}$ (GN10) at $1150^{\circ} \mathrm{C}$. 


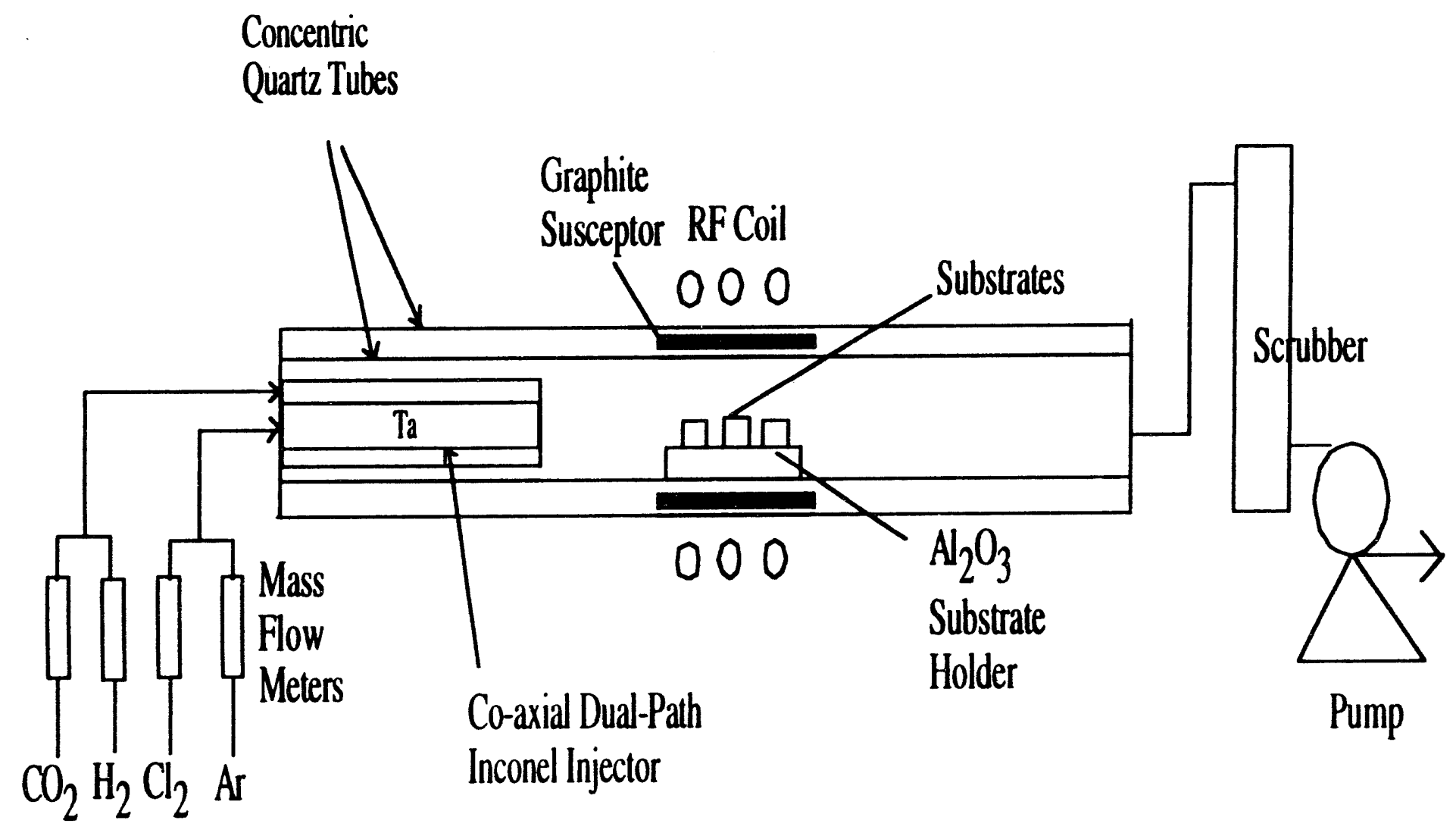

Fig. 2. Experimental apparatus used for $\mathrm{Ta}_{2} \mathrm{O}_{5} \mathrm{CVD}$. 
ORNL-DWG 94-5619

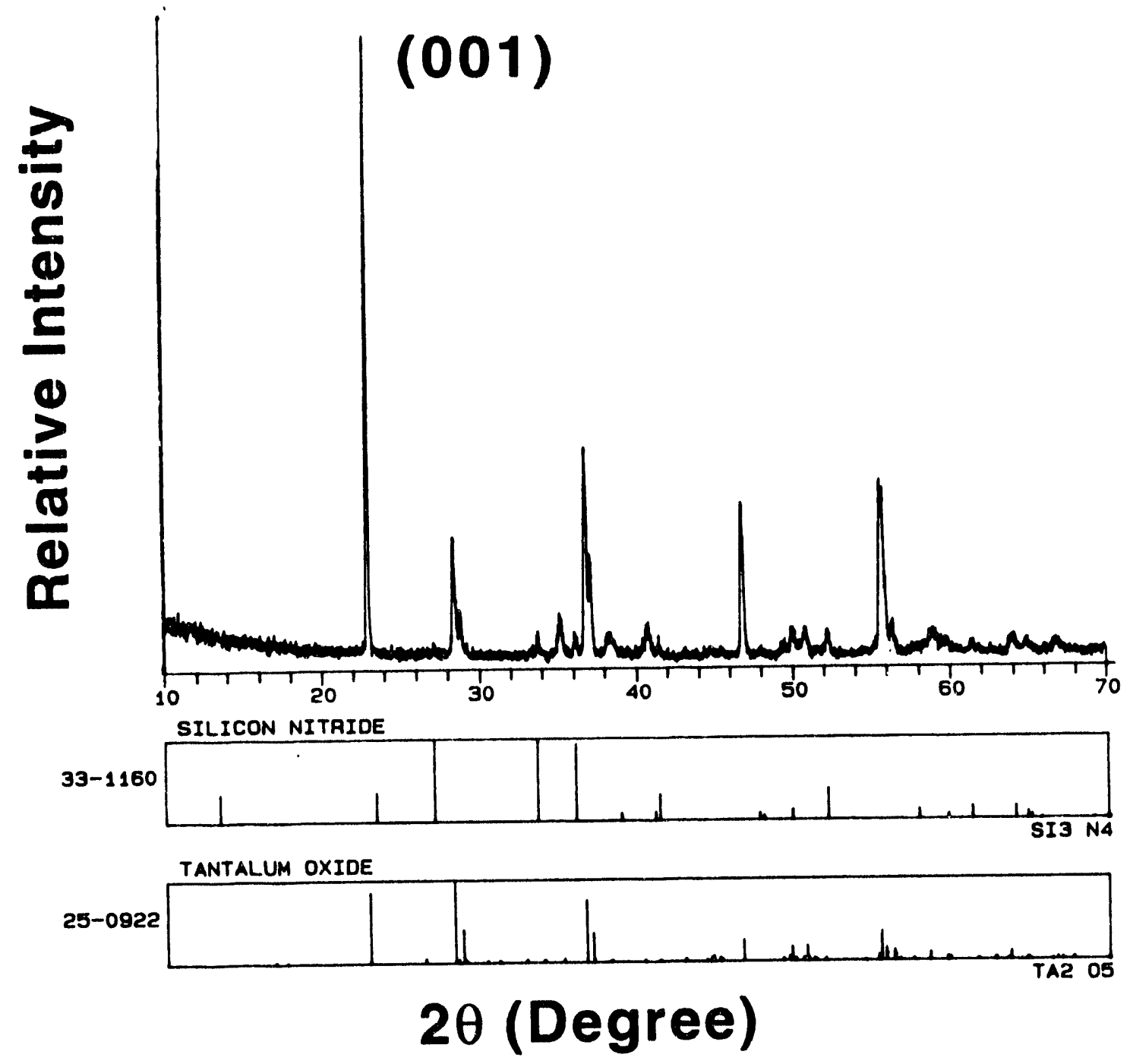

Fig. 3. XRD pattern of $\mathrm{Ta}_{2} \mathrm{O}_{5}$ deposited from $\mathrm{TaCl}_{5}, \mathrm{H}_{2}$, and $\mathrm{CO}_{2}$ on $\mathrm{Si}_{3} \mathrm{~N}_{4}(\mathrm{GN} 10)$ at $1150^{\circ} \mathrm{C}$. 


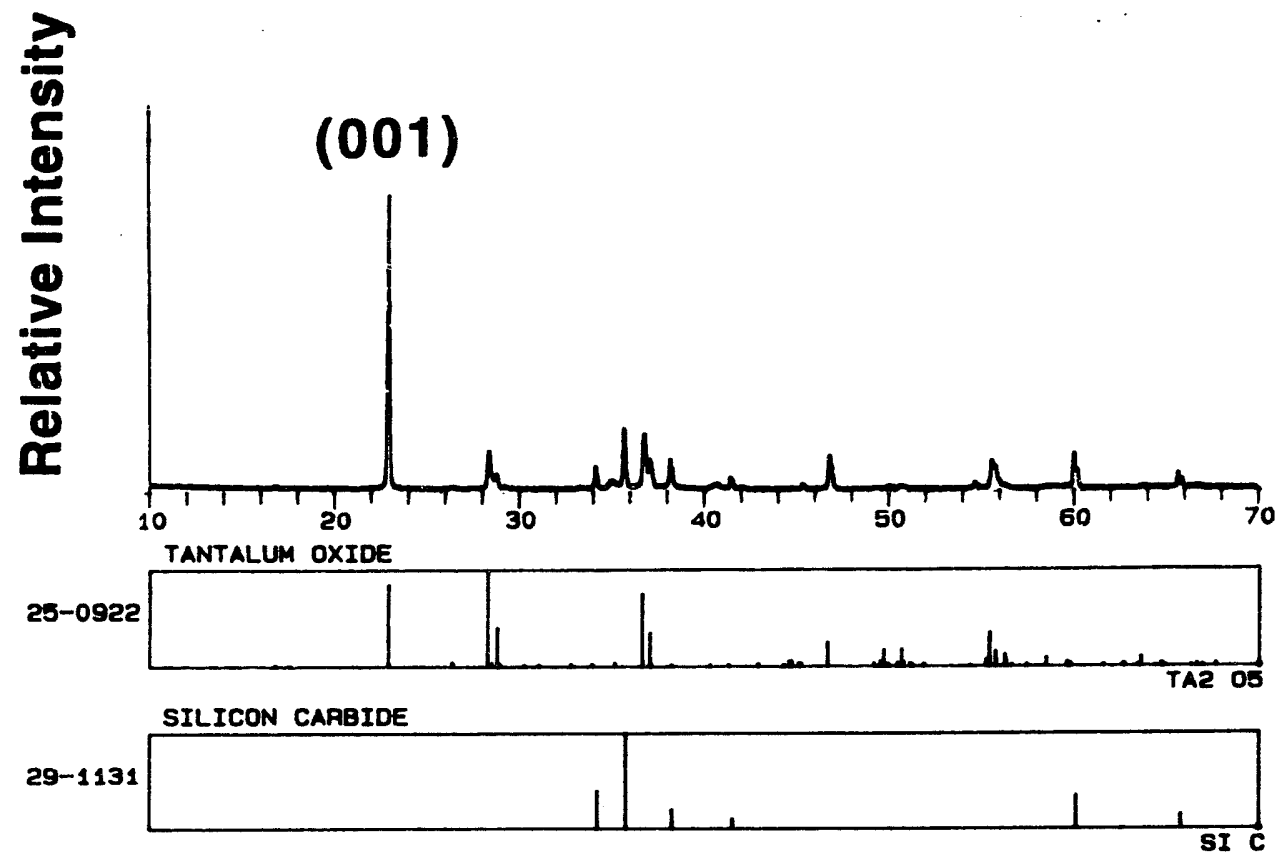

\section{$2 \theta$ (Degree)}

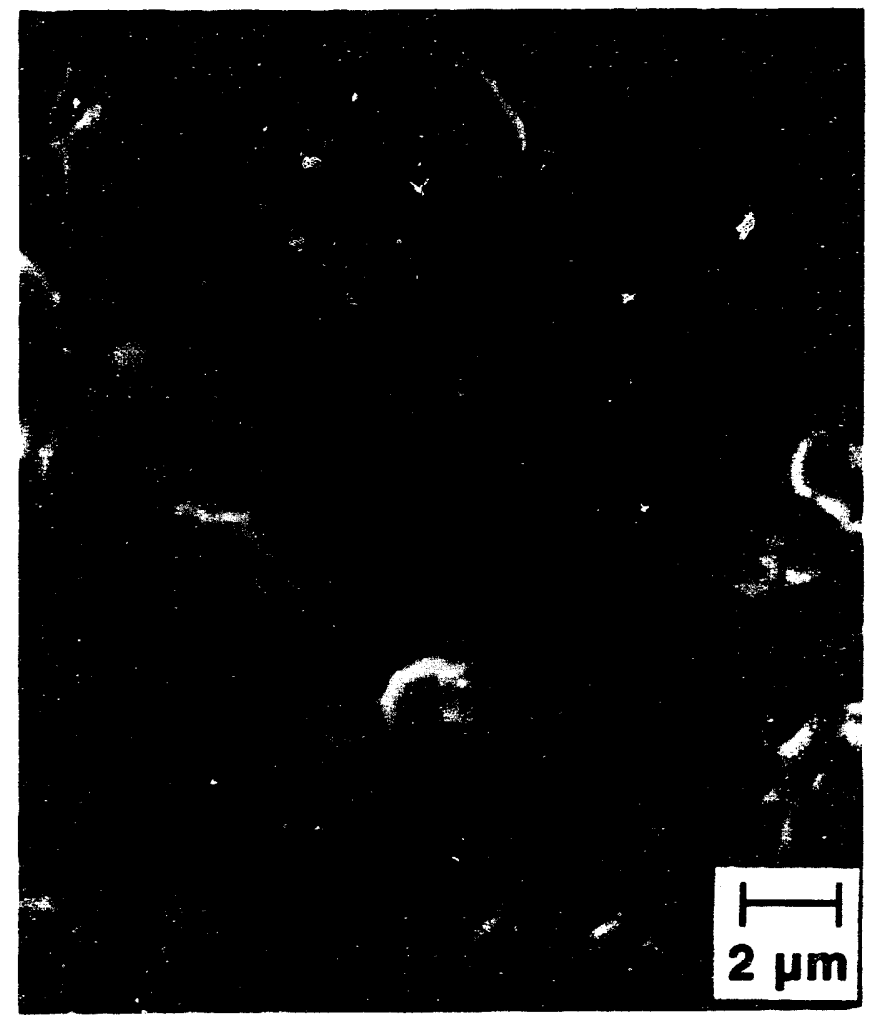

Fig. 4. XRD pattern and SEM micrograph of $\mathrm{Ta}_{2} \mathrm{O}_{5}$ deposited from $\mathrm{TaCl}_{5}, \mathrm{H}_{2}$, and $\mathrm{CO}_{2}$ on SiC (Haxalloy $\mathrm{SA}$ ) at $1105^{\circ} \mathrm{C}$. 


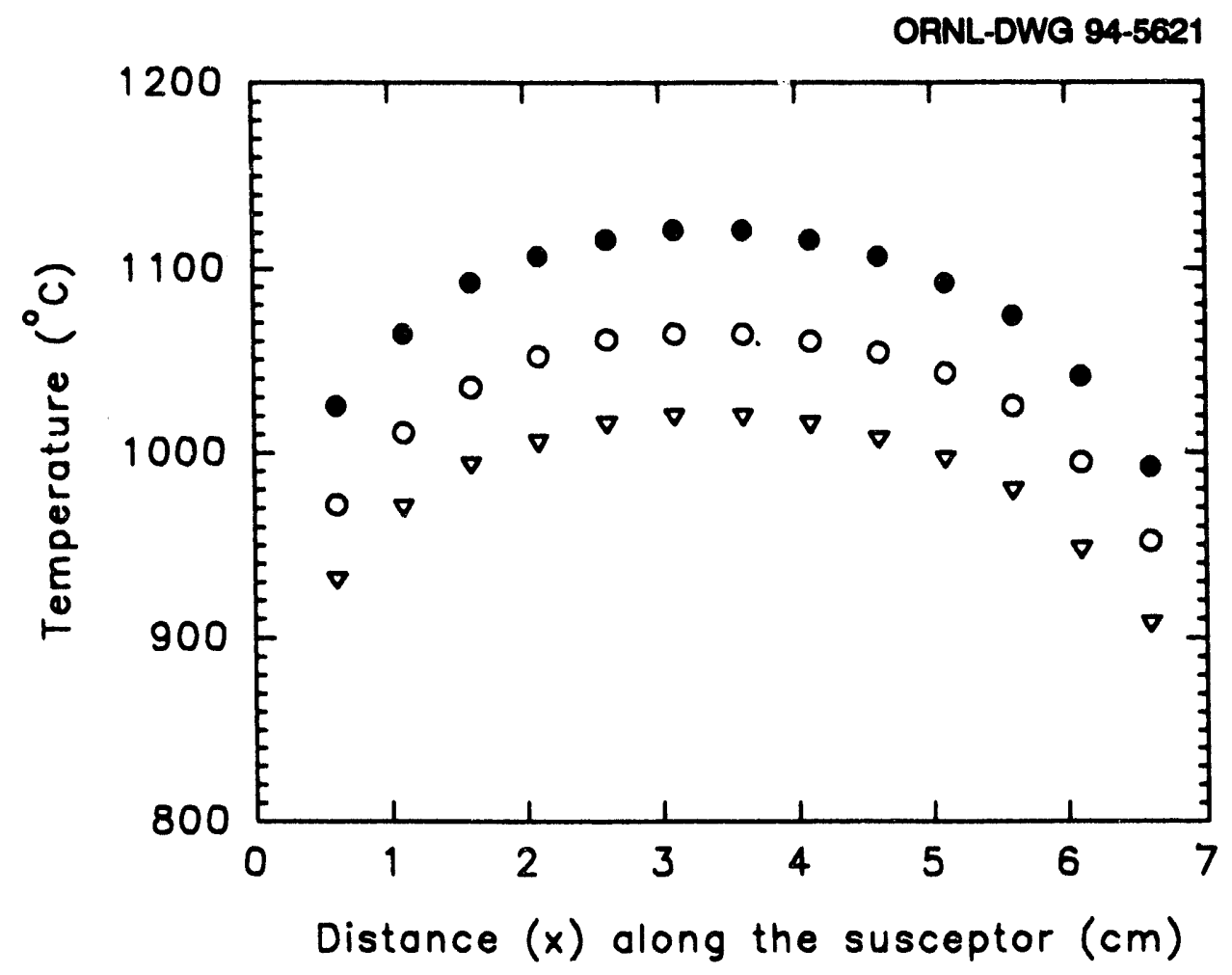

Fig. 5. Axial temperature profiles measured using a thermocouple along the centerline of the inner reactor tube while flowing $100 \mathrm{~cm} / \mathrm{min}$ of $\mathrm{Ar}$ at 5 torr. The axial distance $(x)$ was measured from the upstream end of the graphite susceptor.

$\sim 100^{\circ} \mathrm{C}$ exist along the deposition zone. A thermocouple was used to measure the temperatures along the centerline of the inner reactor tube while flowing $100 \mathrm{~cm} 3 / \mathrm{min}$ STP of Ar at 5 torr. In actual deposition runs, substrate temperatures were measured using an optical pyrometer.

Figure 6 shows that the growth rate of $\mathrm{Ta}_{2} \mathrm{O}_{5}$ generally increased with temperature. In the upstream region $(x=1.9 \mathrm{~cm})$, the growth rate increased exponentially as the temperature was increased from 1072 to $1248^{\circ} \mathrm{C}$. An apparent activation energy of $228 \mathrm{~kJ} / \mathrm{mole}$ was calculated at this location (Fig. 7). At downstream locations, the growth rate was not significantly increased by the increase in temperature, probably due to reagent depletion.

The surface morphology of $\mathrm{Ta}_{2} \mathrm{O}_{5}$ coatings deposited at various temperatures is shown in

Figs. 8 and 9. In general, the coatings consisted of 1- to 3-um size grains that appeared to be relatively well coalesced during their growth. The presence of voids and pin-holes in the coating microstructure was not observed in most coatings by the SEM analysis. As shown in Fig. 10, the coatings were identified to be orthorhombic $\mathrm{Ta}_{2} \mathrm{O}_{5}$, with preferred orientation to the [001] direction, by XRD. For some deposition experiments conducted at similar temperatures, preferred orientations to other crystallographical directions, i.e., [200] and [201], were also observed.

It appears that the $\mathrm{Ta}_{2} \mathrm{O}_{5}$ coatings have become more susceptible to microcracking (Fig. 11), as we have produced the well-coalesced and void-free microstructure through the use of the $\mathrm{CO}_{2}+\mathrm{H}_{2}$ mixture instead of using $\mathrm{O}_{2}$. At this time, it is not exactly clear as to why the microcracks form. This behavior will be studied in detail as more processing-microstructure data become available. $\mathrm{Ta}_{2} \mathrm{O}_{5}$-coated GN10 substrates $(3 \times 4 \times 10 \mathrm{~mm})$ are being tested for $\mathrm{Na}_{2} \mathrm{SO}_{4}$-induced hot corrosion at $1000^{\circ} \mathrm{C}$ in pure $\mathrm{O}_{2}$ for $100 \mathrm{~h}$. A special substrate holder was designed and constructed to simultaneously coat four GN10 bend bars $(3 \times 4 \times 50 \mathrm{~mm})$ in the reactor. 


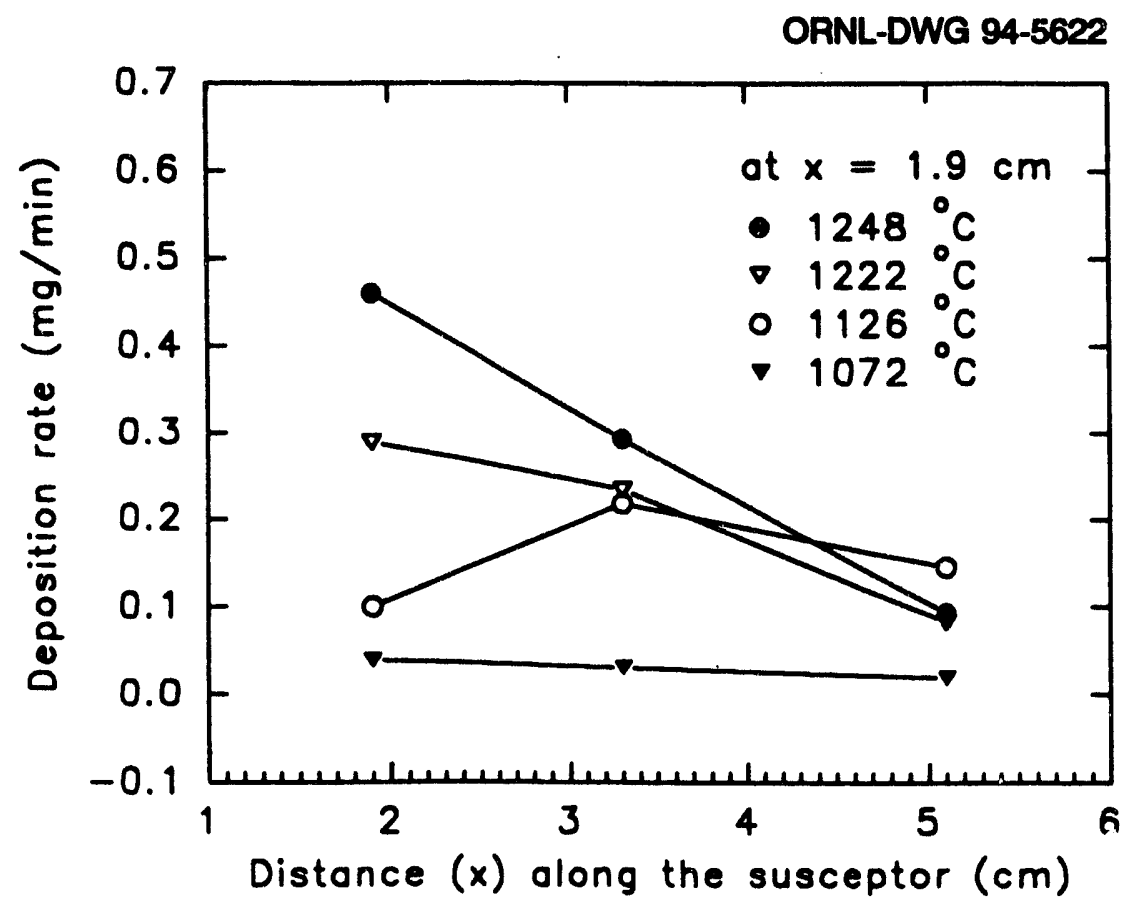

Fig. 6. Effects of temperature on axial deposition rate profiles. The temperatures at $X=1.9 \mathrm{~cm}$ were measured using an optical pyrometer.

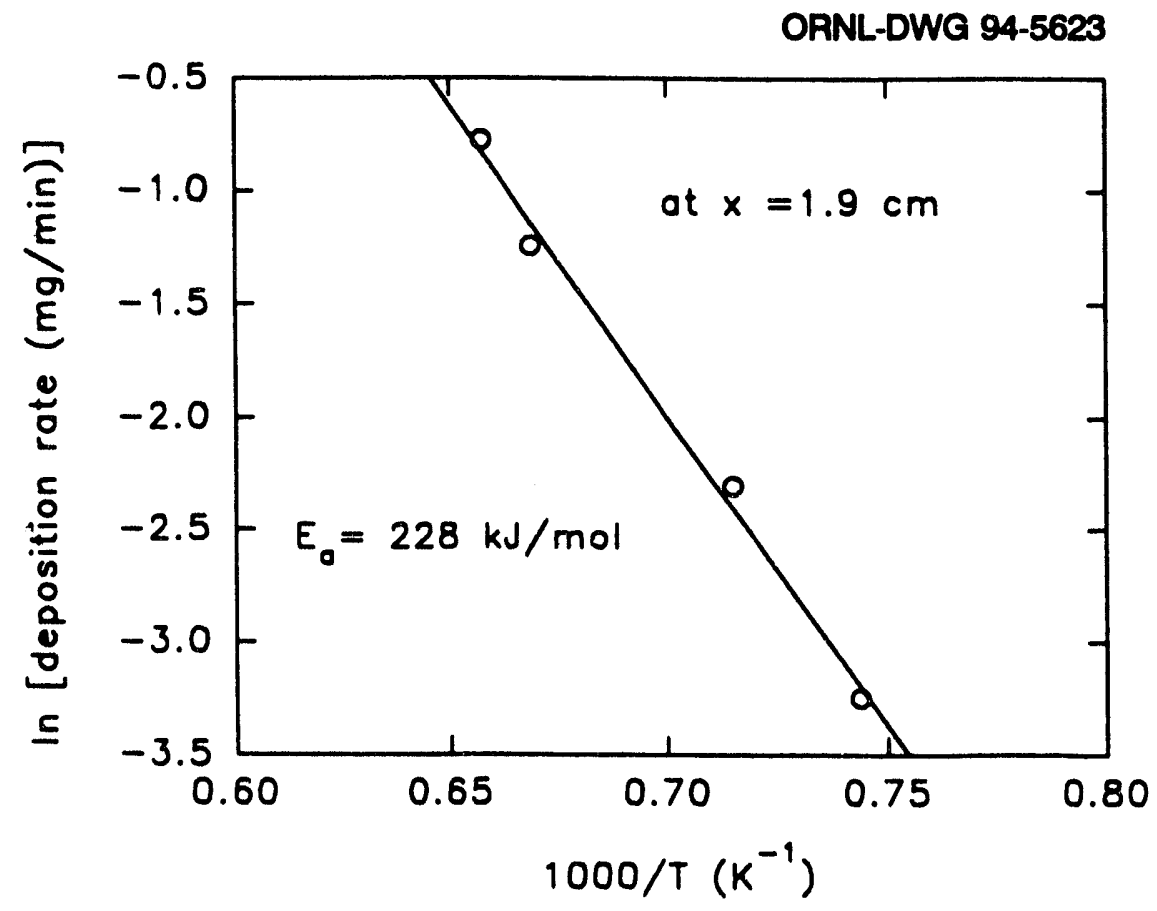

Fig. 7. Arthenius relationship between temperature and deposition rate observed at $x=1.9 \mathrm{~cm}$. 


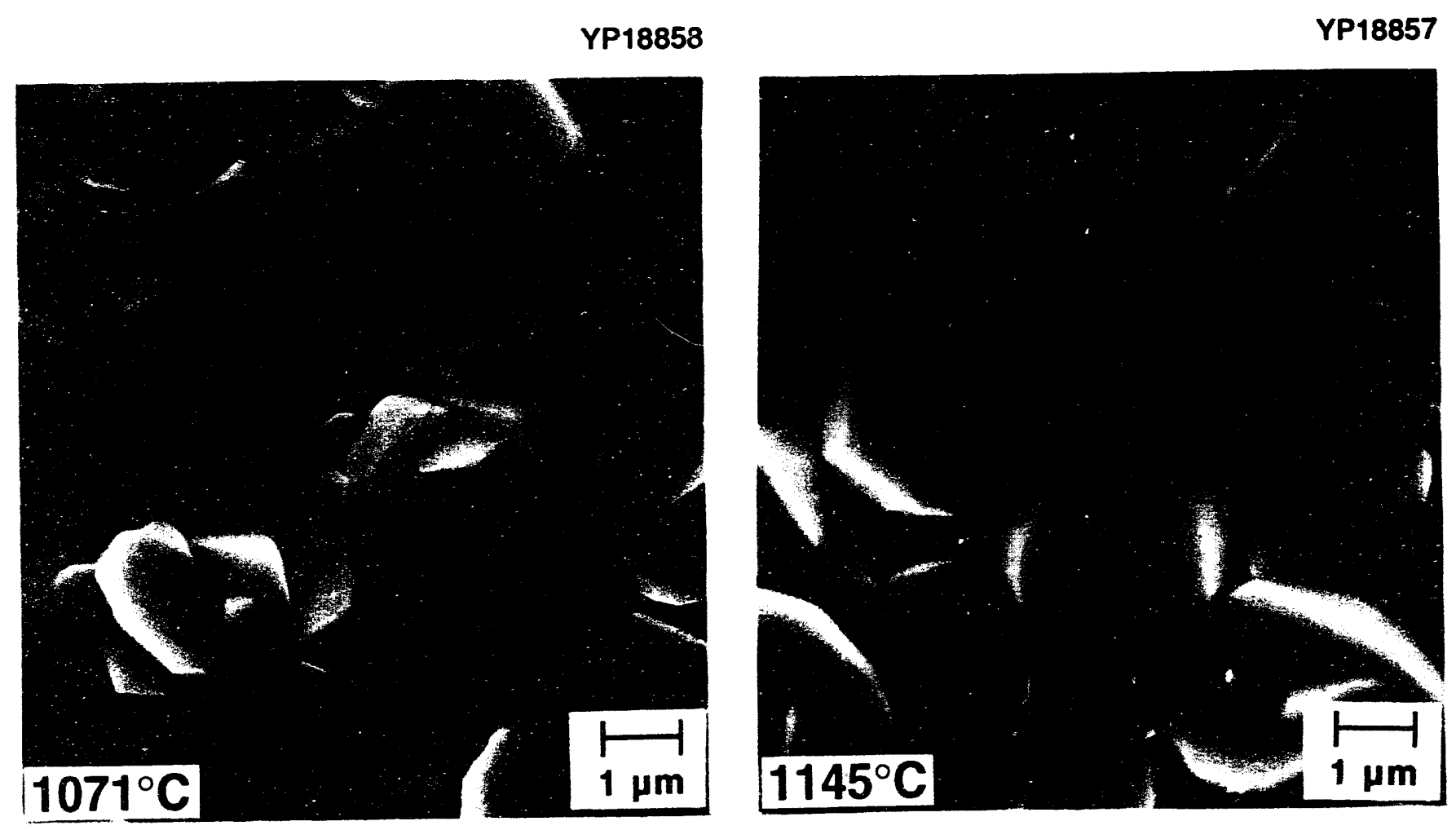

Fig. 8. SEM micrographs of $\mathrm{Ta}_{2} \mathrm{O}_{5}$ coatings deposited at 1071 and $1145^{\circ} \mathrm{C}$ at $\mathrm{X}=3.3 \mathrm{~cm}$. 


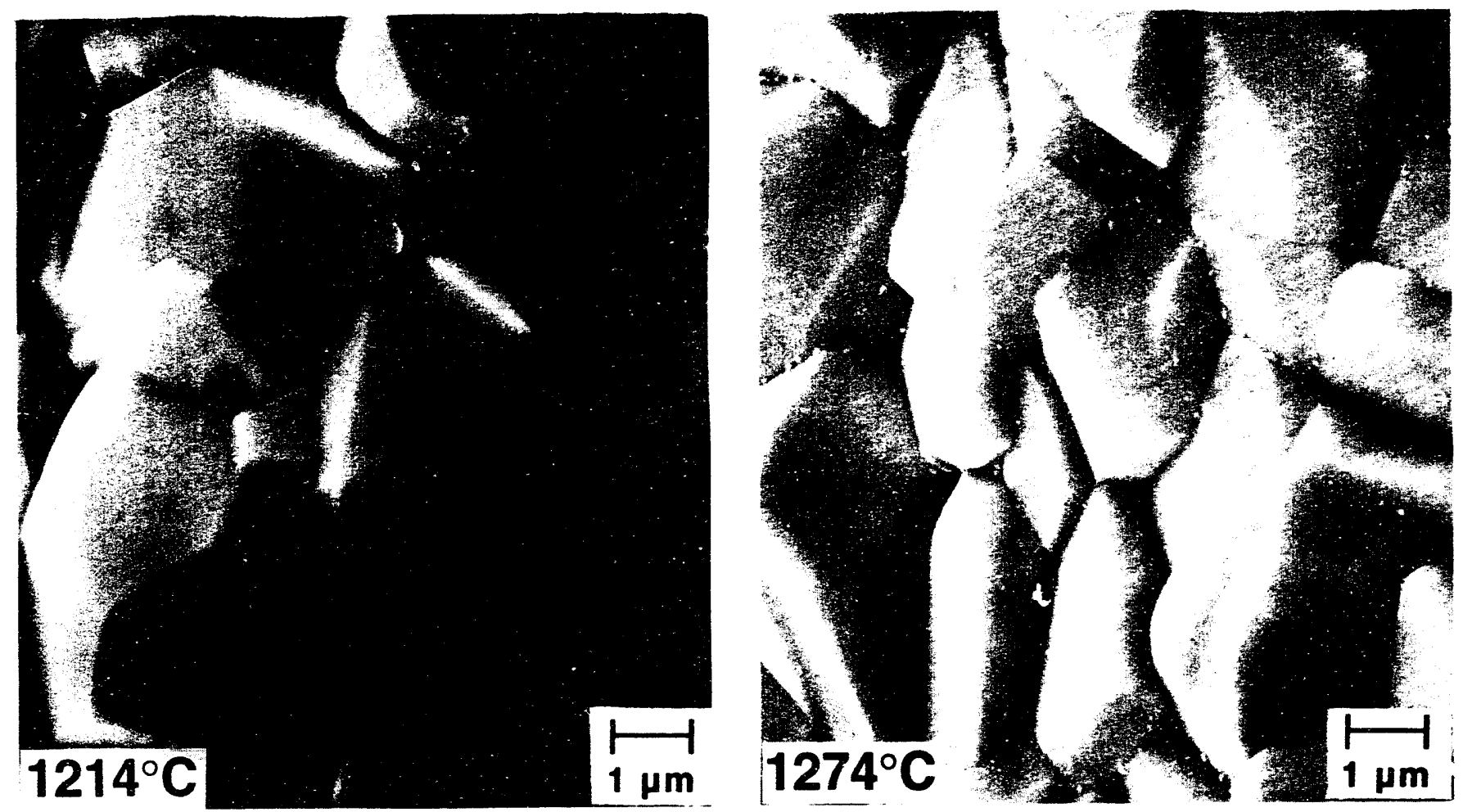

Fig. 9. SEM micrographs of $\mathrm{Ta}_{2} \mathrm{O}_{5}$ coatings deposited at 1214 and $1274^{\circ} \mathrm{C}$ at $\mathrm{X}=3.3 \mathrm{~cm}$. 


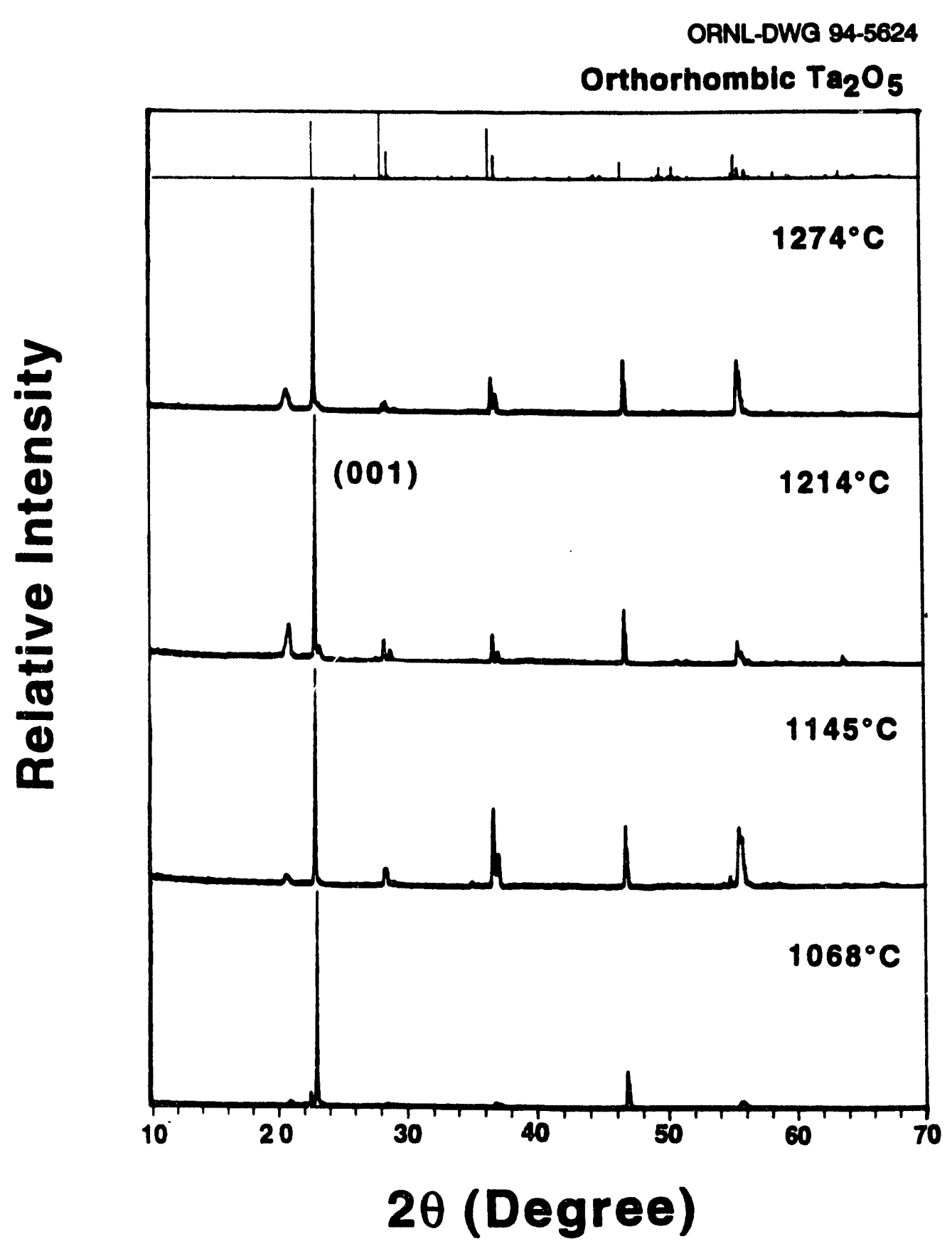

Fig. 10. XRD patterns of $\mathrm{Ta}_{2} \mathrm{O}_{5}$ coatings deposited in the temperature range of 1068 to $1274^{\circ} \mathrm{C}$ at $\mathrm{x}=3.3 \mathrm{~cm}$. 

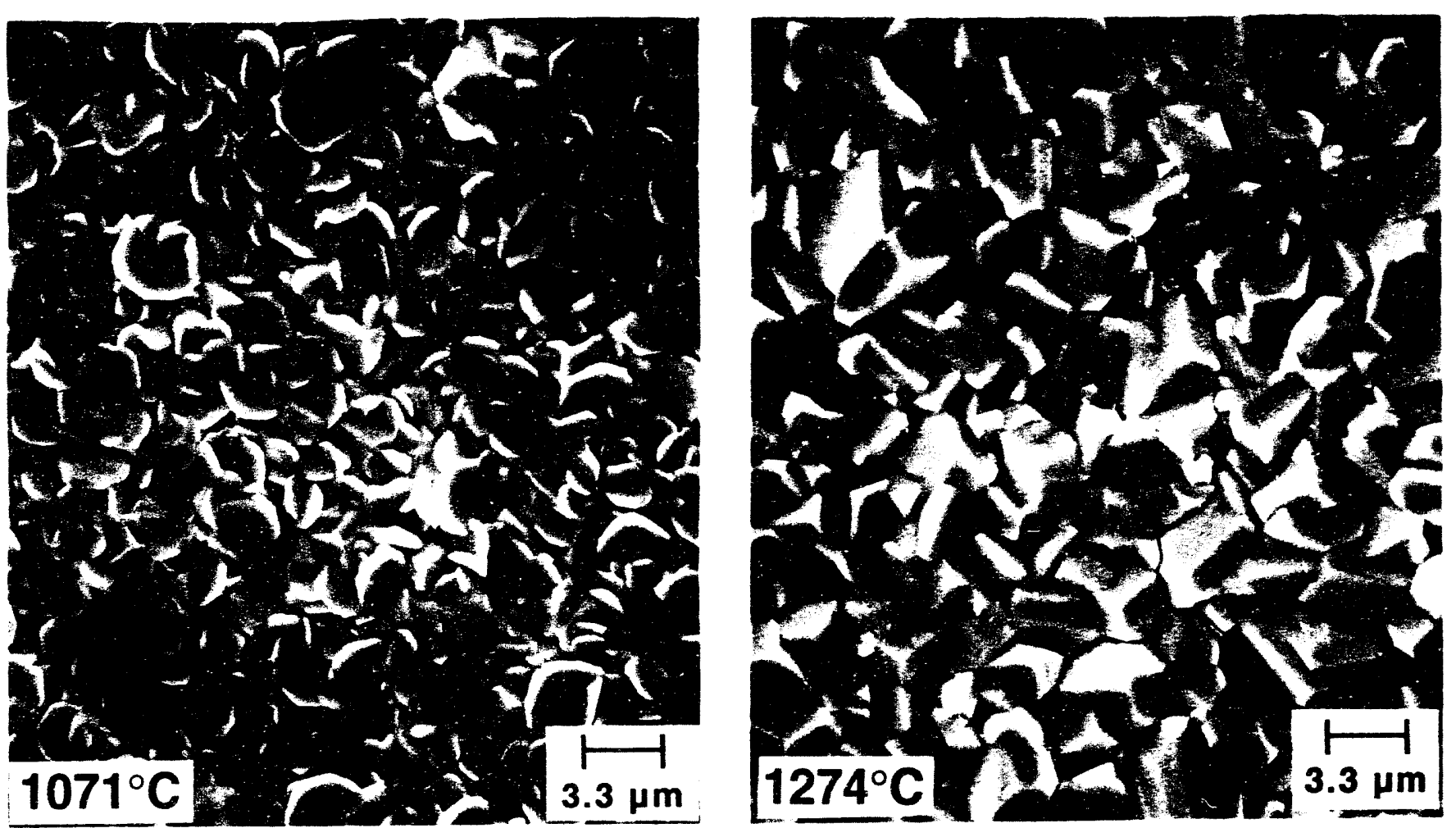

Fig. 11. The presence of microcracks on the surface of well-coalesced $\mathrm{Ta}_{2} \mathrm{O}_{5}$ coatings was frequently observed. 


\section{Development of Adherent coatings to Reduce contact Stress Damage of Ceramics V. K. Sarin (Boston University) \\ object Ive/Scope}

The development of oxidation/corrosion resistant, high toughness, adherent coating configurations for silicon based ceramic substrates for use in advanced gas turbine engines.

\section{Technical Progress}

$\mathrm{Al}_{2} \mathrm{O}_{3} / \mathrm{SiO}_{2}$ layered coatings have been grown on $\mathrm{Si}_{3} \mathrm{~N}_{4}$ and SiC substrates. These coatings have been tested at high temperatures in air. In all the coating configurations tested, no major damage to the coatings was observed up to $1200^{\circ} \mathrm{C}$ on $\mathrm{Si}_{3} \mathrm{~N}_{4}$ substrates, and up to $1400^{\circ} \mathrm{C}$ on $\mathrm{SiC}$ substrates for short times.

Two configuratiors of the multi-layered coatings have been tested: I) a total of four layers - two each of $\mathrm{SiO}_{2}$ and $\mathrm{Al}_{2} \mathrm{O}_{3}$ with $\mathrm{SiO}_{2}$ being the interfacial layer, and II) a total of three layers with $\mathrm{Al}_{2} \mathrm{O}_{3}$ layers making a sandwich with $\mathrm{SiO}_{2}$. Each of the layers is approximately $1 \mu \mathrm{m}$ thick. Figure 1 shows a SEM micrograph of the four layered coating. Iine scans were performed on the SEM to determine the phase distribution in the layered coating. Figure 1 (c) shows the line scan lmage showing the amount of $S i$ and $A I$ present across the coating/substrate interface.

Preliminary high temperature testing of these samples has been performed at 1200,1400 and $1600^{\circ} \mathrm{C}$. The samples were placed in $\mathrm{Al}_{2} \mathrm{O}_{3}$ boats and were heated to the set temperature and cooled at reasonably fast rates (approximately $1000^{\circ} \mathrm{C}$ a minute), inherently inducing a reasonable amount of thermal shock. The annealing tests were performed in a positive argon atmosphere, and the oxidation tests were done in static air.

$1200^{\circ} \mathrm{C}$ When annealed in argon atmosphere at $1200^{\circ} \mathrm{C}$ for 2 hours no significant change was observed in the coating morphology or the interfacial characteristics of these layered coatings on both $\mathrm{Si}_{3} \mathrm{~N}_{4}$ and $\mathrm{SiC}$ substrates. 
a)

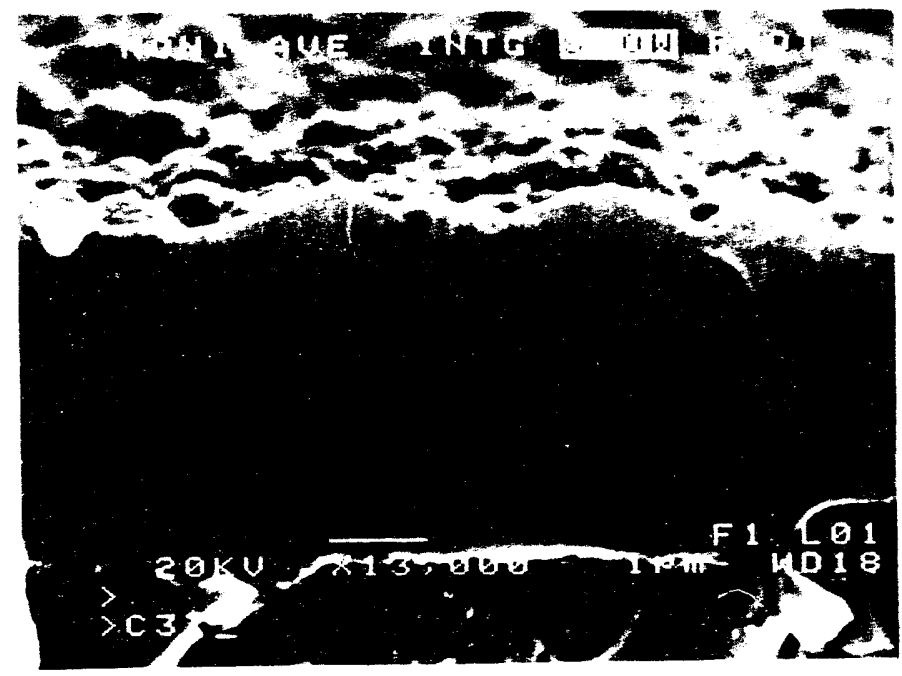

b)

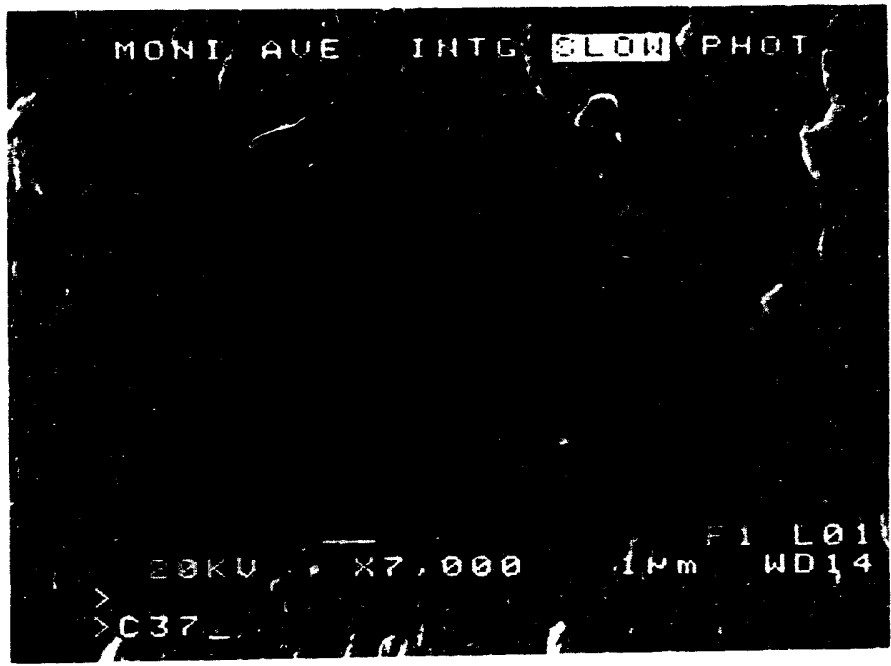

c)

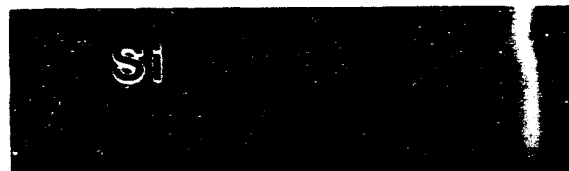

\section{19KU $\quad 8,500 \quad \overline{1 \mu_{m}}$ was}

Figure 1: SEM micrograph of a) cross section, b) surface morphology, and c) Iine scan image of the layered coating in configuration 1 on a $\mathrm{Si}_{3} \mathrm{~N}_{4}$ substrate. 
When oxidized at $1200^{\circ} \mathrm{C}$ for 2 hours the plain $\mathrm{Si}_{3} \mathrm{~N}_{4}$ substrates gained $0.113 \mathrm{mg} / \mathrm{cm}^{2}$ weight, with a possible thin native oxide formed. The coated samples gained no weight under the same conditions, though localized cracking of the coating was observed in case of the $\mathrm{Si}_{3} \mathrm{~N}_{4}$ substrates. The coating and the interface between the layers appeared to be intact. Coated SiC samples remained completely intact wien oxidized for 2 hours but developed cracks in the substrate immediate to the coating when subjected to long term oxidation for 40 hours. This effect is due to the thermal mismatch between the SiC substrate and the immediate $\mathrm{SiO}_{2}$ layer. It was observed that fracture occurred in the substrate and not at the coating/substrate interface suggesting that these coatings are extremely adherent. Figure 2 shows the SEM micrographs of the samples after the oxidation test at $1200^{\circ} \mathrm{C}$.

$1400^{\circ} \mathrm{C}$ Both the coated and the plain $\mathrm{Si}_{3} \mathrm{~N}_{4}$ substrates gained approximately the same amount of weight at this temperature when oxidized for 2 hours. The oxide film on the substrate is approximately $1 \mu \mathrm{m}$ thick, has the surface roughness of the substrate, and did not appear very dense. Figure 3 shows the oxide film. Major cracks and spallation of the coating was observed in case of configuration $I$, and localized cracking in configuration II. In both the cases the surface morphology of the coating appears to be different and glassy in nature from that before the oxidation testing (distinct round grains). This may have been due to the porous first $\mathrm{Al}_{2} \mathrm{O}_{3}$ layer allowing the diffusion of some sintering aids such as $\mathrm{Y}_{2} \mathrm{O}_{3}, \mathrm{SiO}_{2}$, and $\mathrm{Al}_{2} \mathrm{O}_{3}$ from the substrate into the coating. Additionally the $\mathrm{H}_{2}$ gas used to reduce the oxides on the $\mathrm{Al}$ chips in the $\mathrm{AlCl}_{3}$ generator may have effected the $\mathrm{SiO}_{2}$ layer already on the substrate. Experiments are being planned to study these two effects. The plain and coated Sic gained no weight, and no spalling or cracking of these coatings was observed. Figure 4 shows the SEM micrographs of these coatings after the oxidation experiment at $1400^{\circ} \mathrm{C}$.

$1600^{\circ} \mathrm{C}$ The $\mathrm{Si}_{3} \mathrm{~N}_{4}$ substrates completely failed when tested at $1600^{\circ} \mathrm{C}$ in air for 2 hours. It appears that a glassy phase diffused out of the substrate possibly for the some of the reasons stated above. It is not relevant to discuss the coating. The plain SiC sample gained $0.095 \mathrm{mg} / \mathrm{cm}^{2}$ weight with a $0.5 \mu \mathrm{m}$ thicl, oxide layer formed by the diffusion of oxygen into the SiC substrate (figure 5). The coated sample gained $0.333 \mathrm{mg} / \mathrm{cm}^{2}$. The coating blistered and completely debonded.

To better understand the structure, defects, the interdiffusion between the layers, as well as the coating/substrate interface, transmission electron microscopy work was initiated. The cross-sectional samples were 
a)
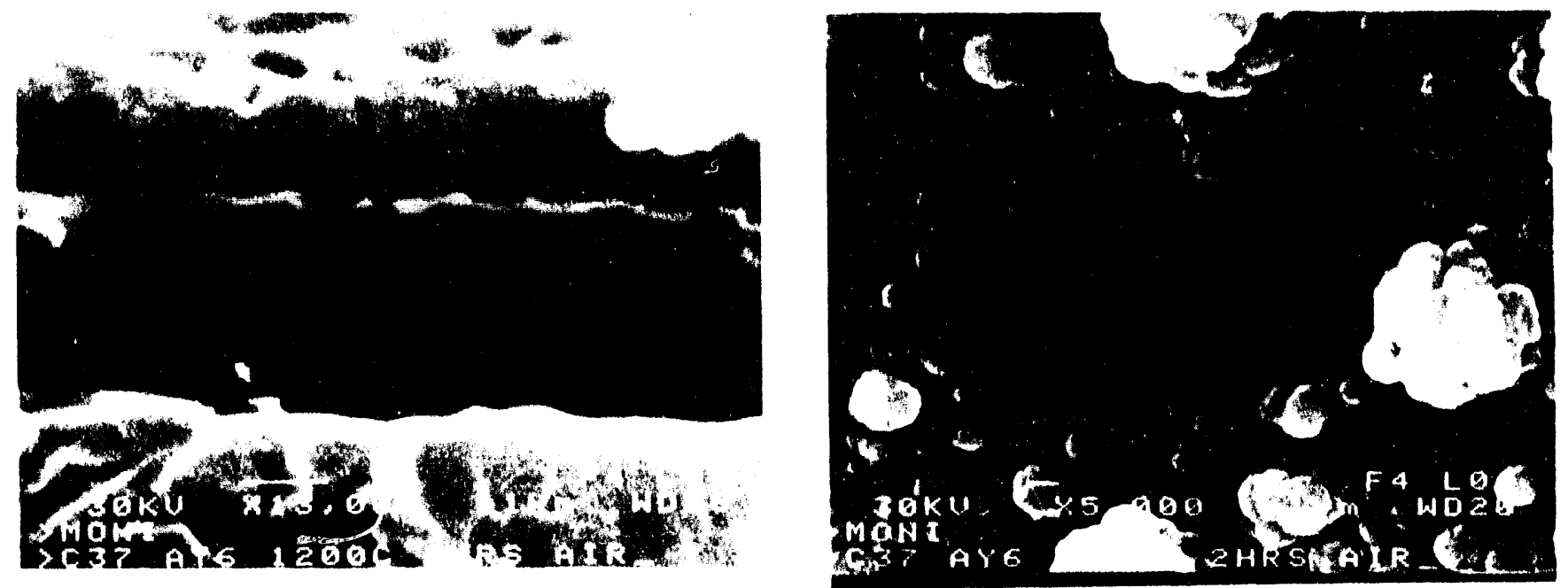

b)

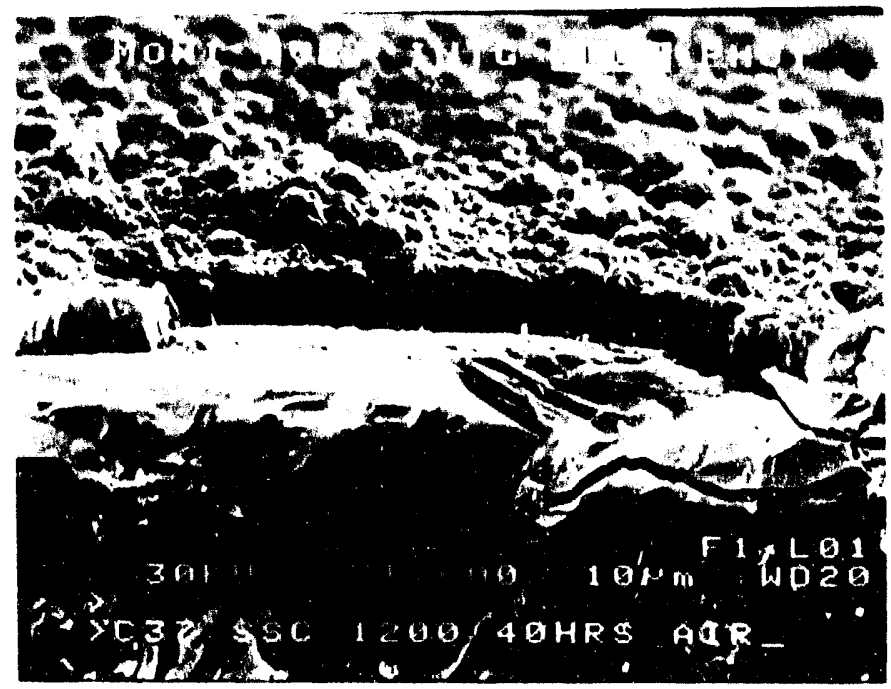

Figure 2: Results of the oxidation experiment at $1200^{\circ} \mathrm{C}$ in air a) for 2 hours showing the localized cracks generated in the coating on the $\mathrm{Si}_{3} \mathrm{~N}_{4}$ substrate -i) cross-section, ii) surface morphology, and b) for 40 hours on SiC showing cracks in the substrate immediate to the coating. 
a)

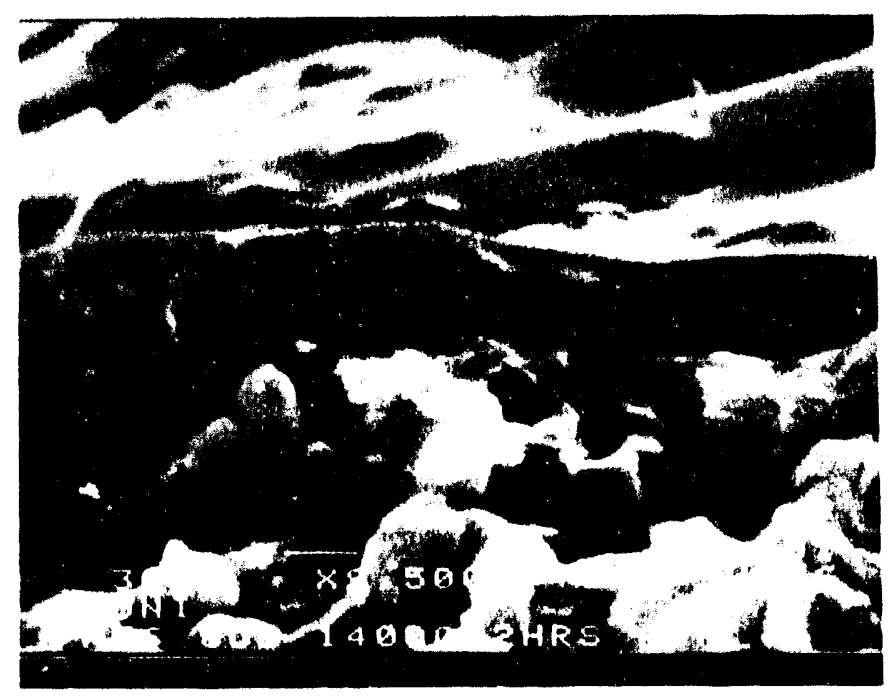

b)

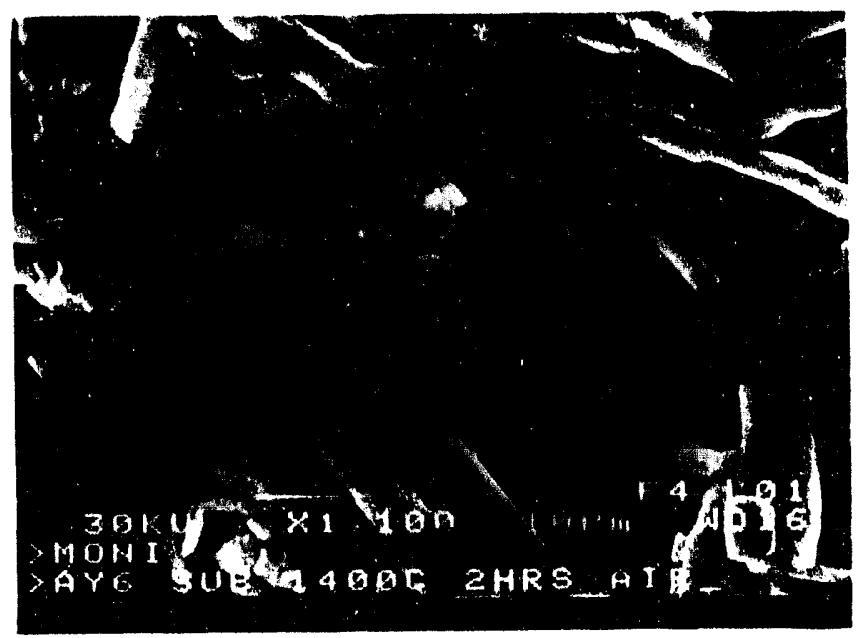

Figure 3: The native oxide film formed on the $\mathrm{Si}_{3} \mathrm{~N}_{4}$ substrate when subjected to $1400^{\circ} \mathrm{C}$ for 2 hours in air - a) crosssection, and b) surface. 
a)
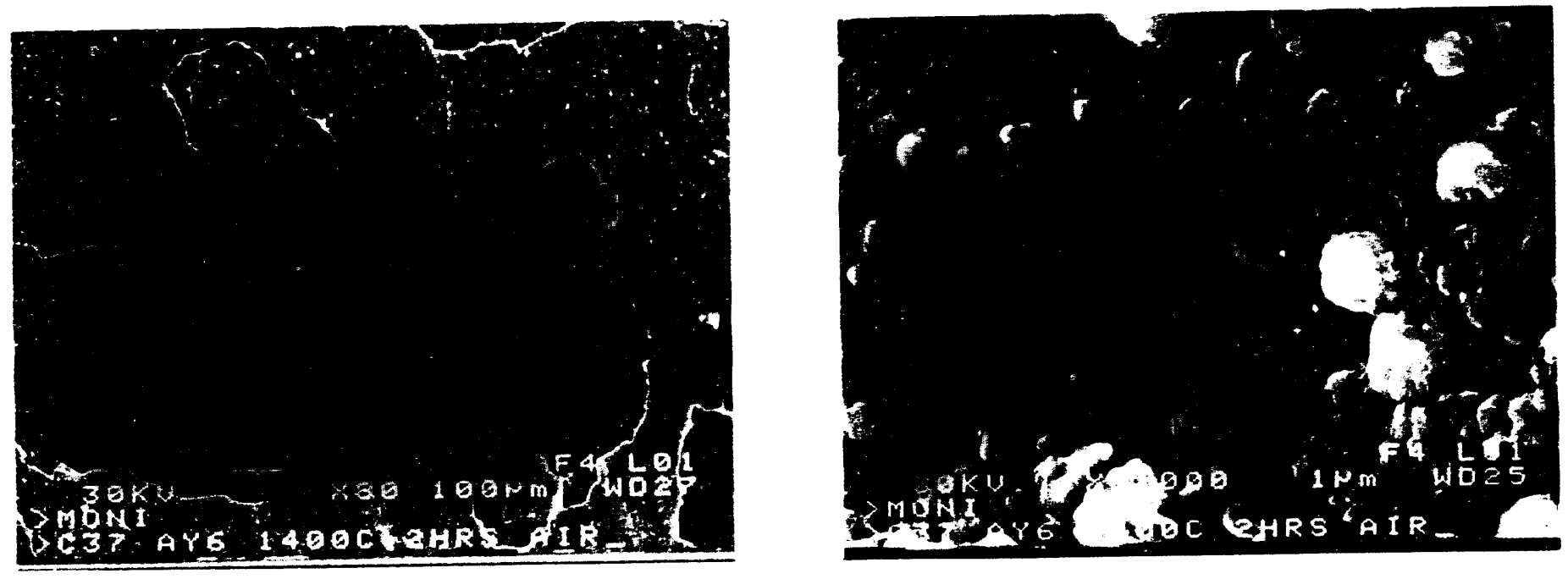

b)
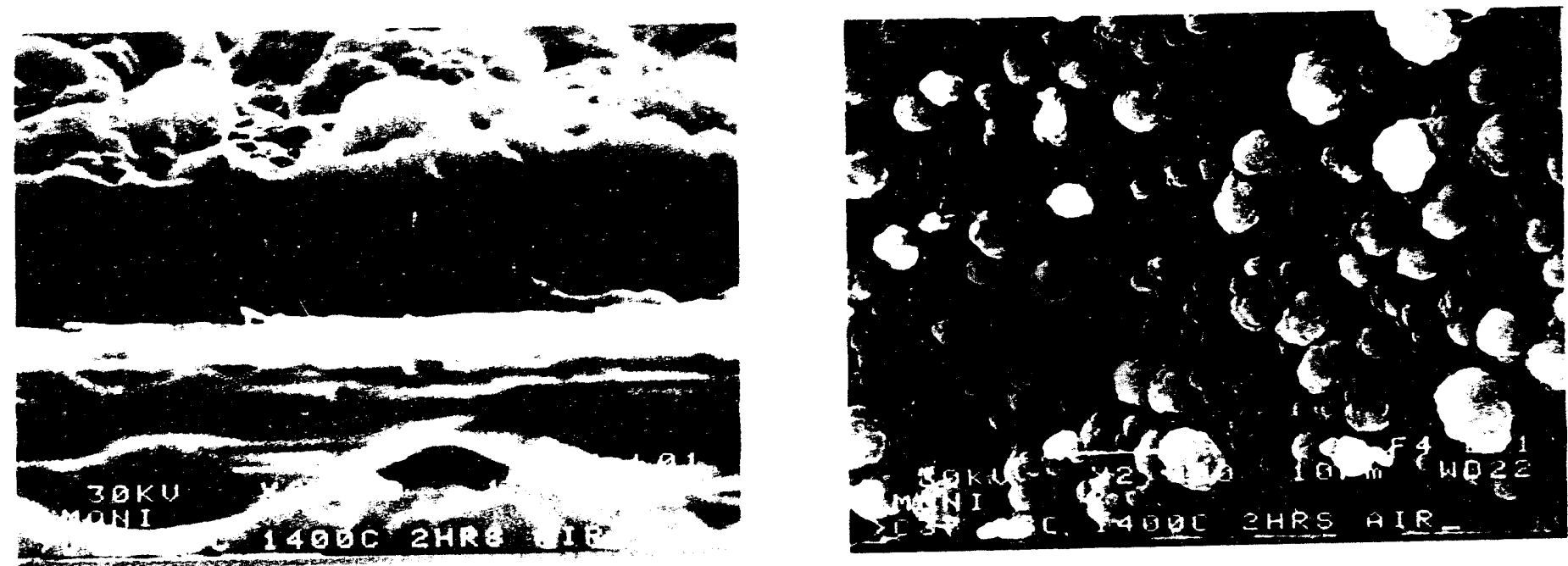

Figure 4: Results of the oxidation experiment at $1400^{\circ} \mathrm{C}$ in air for two hours showing a) major cracks and spallation of the coating on $\mathrm{Si}_{3} \mathrm{~N}_{4}$, and b) intact coating on SiC. 

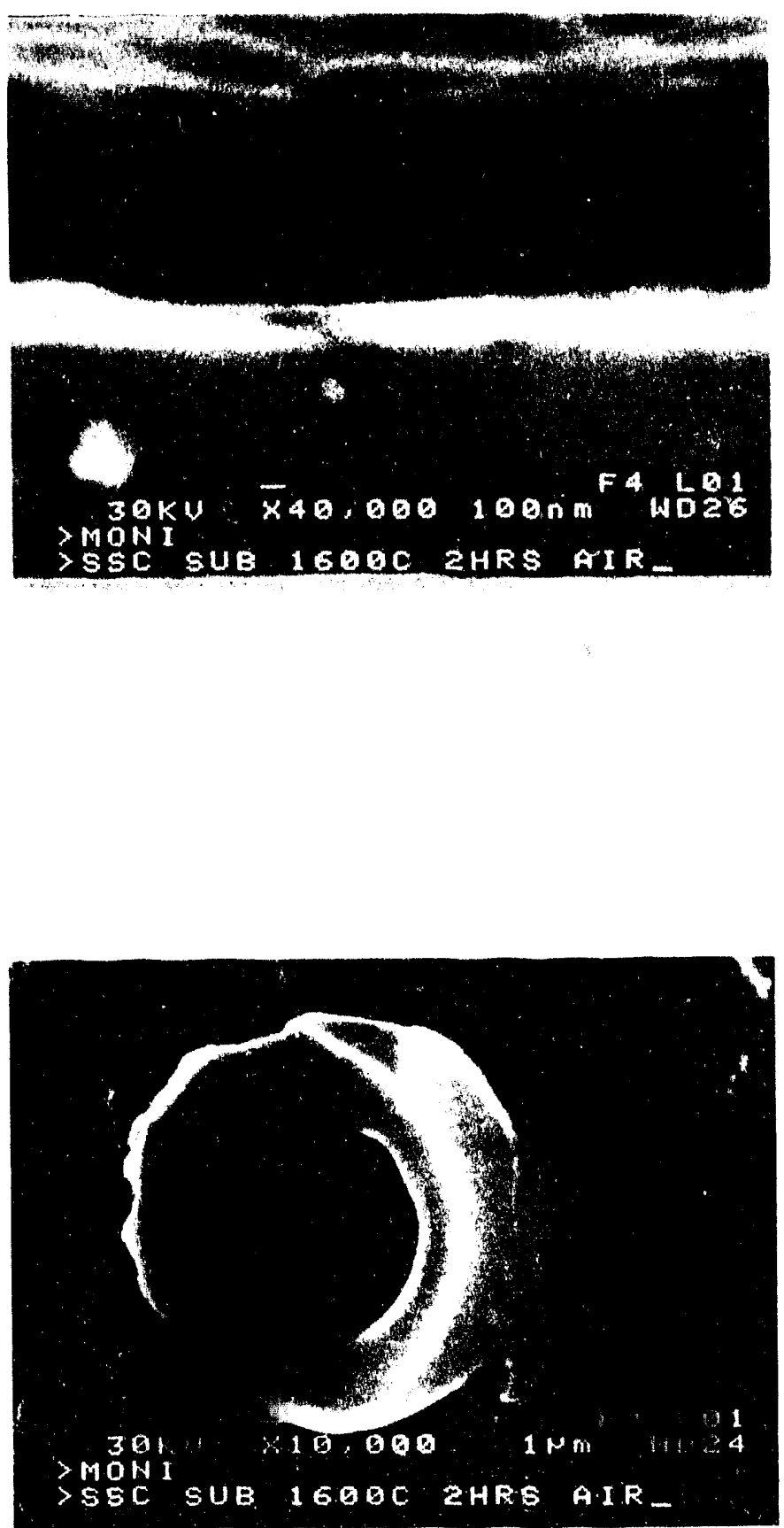

Figure 5: The oxide film formed on the SiC substrate when subjected to $1600^{\circ} \mathrm{C}$ for 2 hours in air-a) cross-section, b) surface. 
produced by gluing two films face-to-face, followed by slicing, grinding, polishing, and dimpling in the usual fashion. Special care was taken to avoid irradiation damage during ion milling by milling at low angles and by cooling the sample using liquid nitrogen.

Figure 6 shows a TEM bright field micrograph of the layered coating on $\mathrm{Si}_{3} \mathrm{~N}_{4}$. The $\mathrm{SiO}_{2}$ layer deposited at $800^{\circ} \mathrm{C}$ using the precursor TEOS $\left[\mathrm{Si}\left(\mathrm{OC}_{2} \mathrm{H}_{5}\right)_{4}\right]$ is amorphous, and the $\mathrm{Al}_{2} \mathrm{O}_{3}$ layer has a corundum $(\alpha)$ structure. This was confirmed by $x$-Ray diffraction. These coatings were heated to $1200^{\circ} \mathrm{C}$ for 2 hours in air. EDS analysis on the STEM (with a probe size of $1 \mathrm{~nm}$ ) indicates the formation of a diffusion zone between the $\mathrm{Al}_{2} \mathrm{O}_{3}$ and $\mathrm{SiO}_{2}$ at the coating interface. Figure 7 shows the diffusion zone and the energy dispersive spectra at the three different regions; region 1 showing pure $\mathrm{SiO}_{2}$, region 2 showing the mixed compound of $\mathrm{Al}_{2} \mathrm{O}_{3}$ and $\mathrm{SiO}_{2}$, and region 3 showing pure $\mathrm{Al}_{2} \mathrm{O}_{3}$. The $\mathrm{Al}: \mathrm{Si}$ (atomic) ratio in the diffusion zone is measured to be 65:35. The Al:Si atomic ratio in mullite is $60: 40$.

Annealing studies were done on $\mathrm{SiC}$ and $\mathrm{Si}_{3} \mathrm{~N}_{4}$ substrates with $\mathrm{Al}_{2} \mathrm{O}_{3}$ coatings. Figure 8 shows a TEM bright field micrograph of an as-deposited $\mathrm{Al}_{2} \mathrm{O}_{3}$ coating on $\mathrm{Si}_{3} \mathrm{~N}_{4}$. The samples were placed in a 3/8" High Purity Mullite tube placed in a $\mathrm{Al}_{2} \mathrm{O}_{3}$ tube furnace with 1 SLM Argon flowing through the Mulite tube. The samples were heated to $1400^{\circ} \mathrm{C}$ for different times. The ramping and cooling rates were reasonably high.

TEM study of the annealed specimens indicates the formation of $\mathrm{SiO}_{2}$ at the interface. An amorphous silica layer was observed immediately next to the substrate, and a crystalline silica layer was observed between the amorphous silica layer and the $\mathrm{Al}_{2} \mathrm{O}_{3}$ coating. Further investigations need to be made to determine the effect of the coating/substrate on the formation and structure of the $\mathrm{SiO}_{2}$ layers. Cracks were observed in the crystalline $\mathrm{SiO}_{2}$ layer indicating crystalline silica layer may be responsible for coating delamination. Figures 9 shows a schematic and the TEM micrograph of an annealed sample.

Preliminary studies are underway to observe the effect of an inter-layer such as $A I N$ in preventing the formation of the glassy phase at the coating/substrate interface and its effect on the adhesion characteristics. Attemps are also being made to deposit $\mathrm{SiO}_{2}$ from $\mathrm{SiCl}_{4}$ and $\mathrm{H}_{2} \mathrm{O}$ to facilitate codeposition of $\mathrm{Al}_{2} \mathrm{O}_{3}$ and $\mathrm{SiO}_{2}$ through a common precursor. 


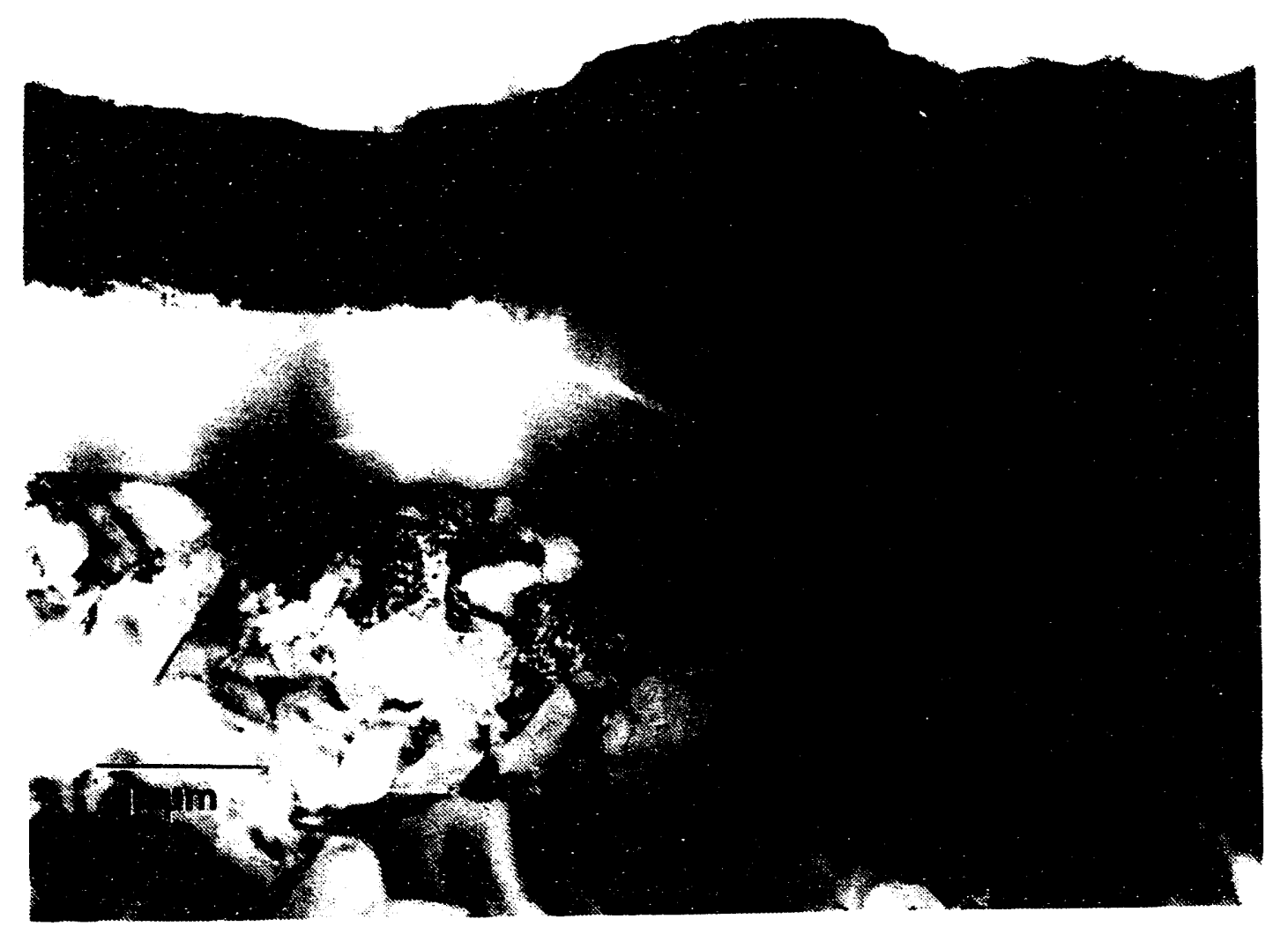


$\mathrm{Al}: \mathrm{Si}-65: 35$
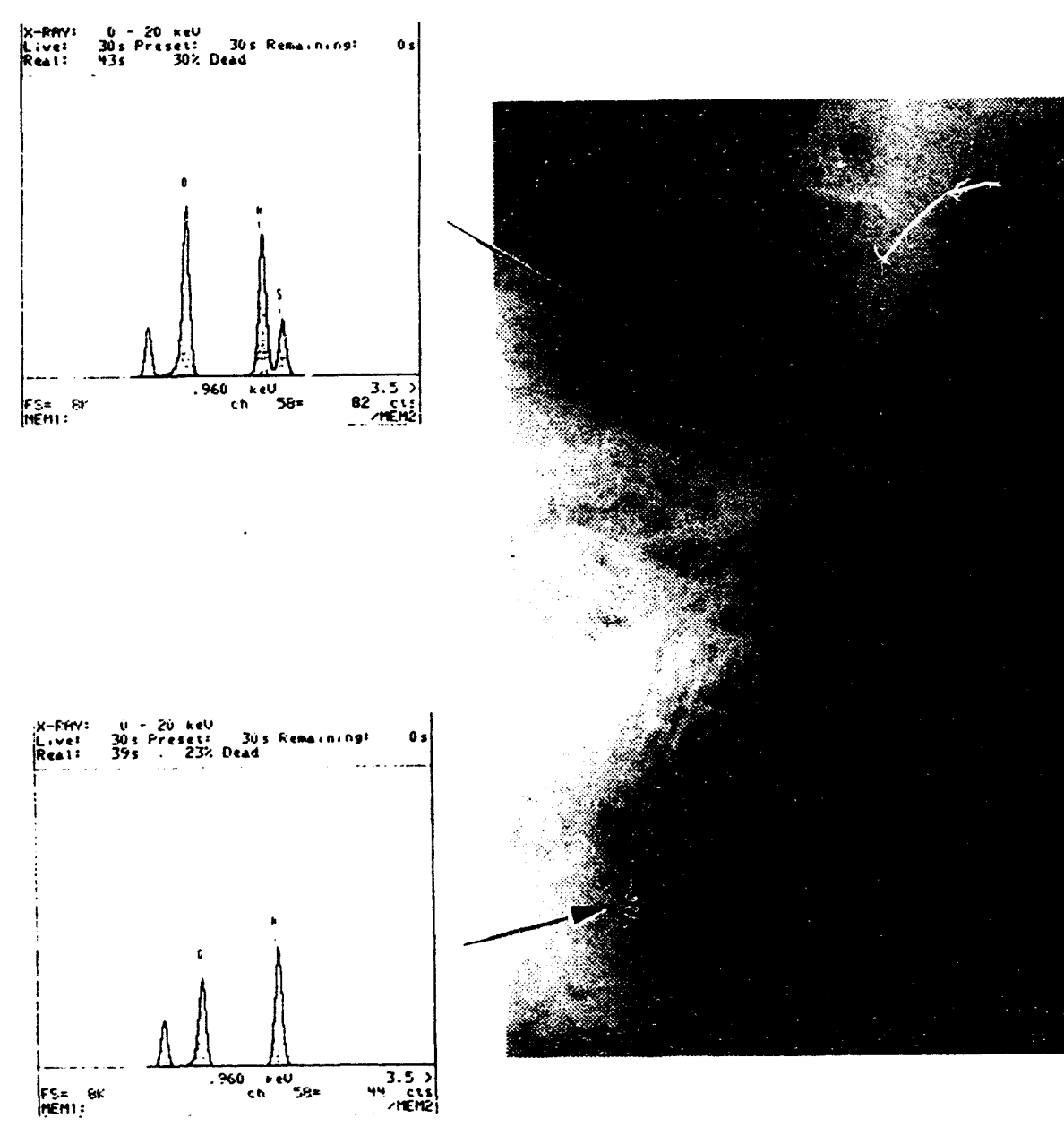

\section{$25 \mathrm{~nm}$}

Figure 7: Transmission Electron Micrograph showing the Diffused Region at the $\mathrm{Al}_{2} \mathrm{O}_{3}-\mathrm{SiO}_{2}$ interface 

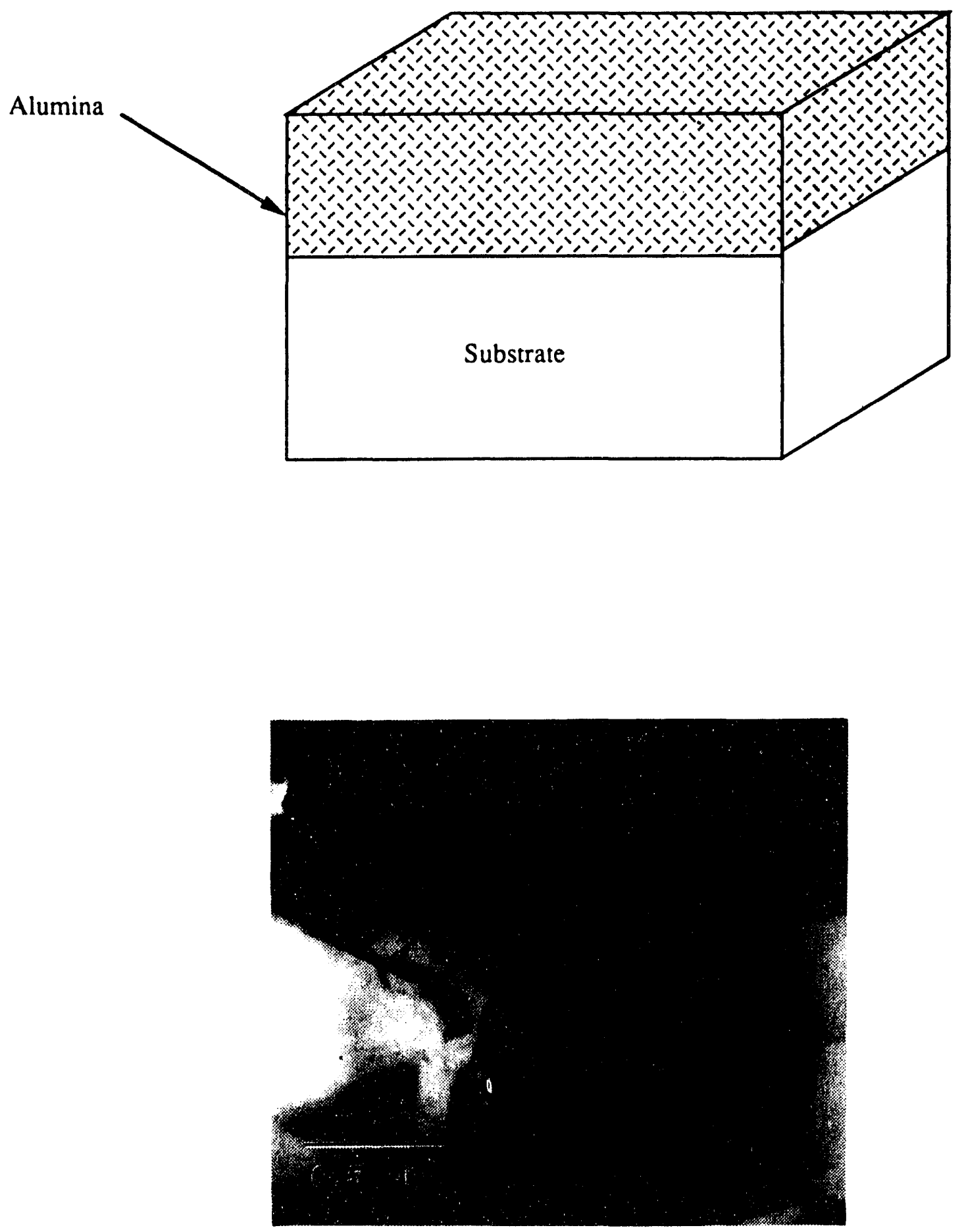

Figure 8: A schematic and a TEM micrograph of an as-deposited $\mathrm{Al}_{2} \mathrm{O}_{3}$ coating on $\mathrm{Si}_{3} \mathrm{~N}_{4}$ 

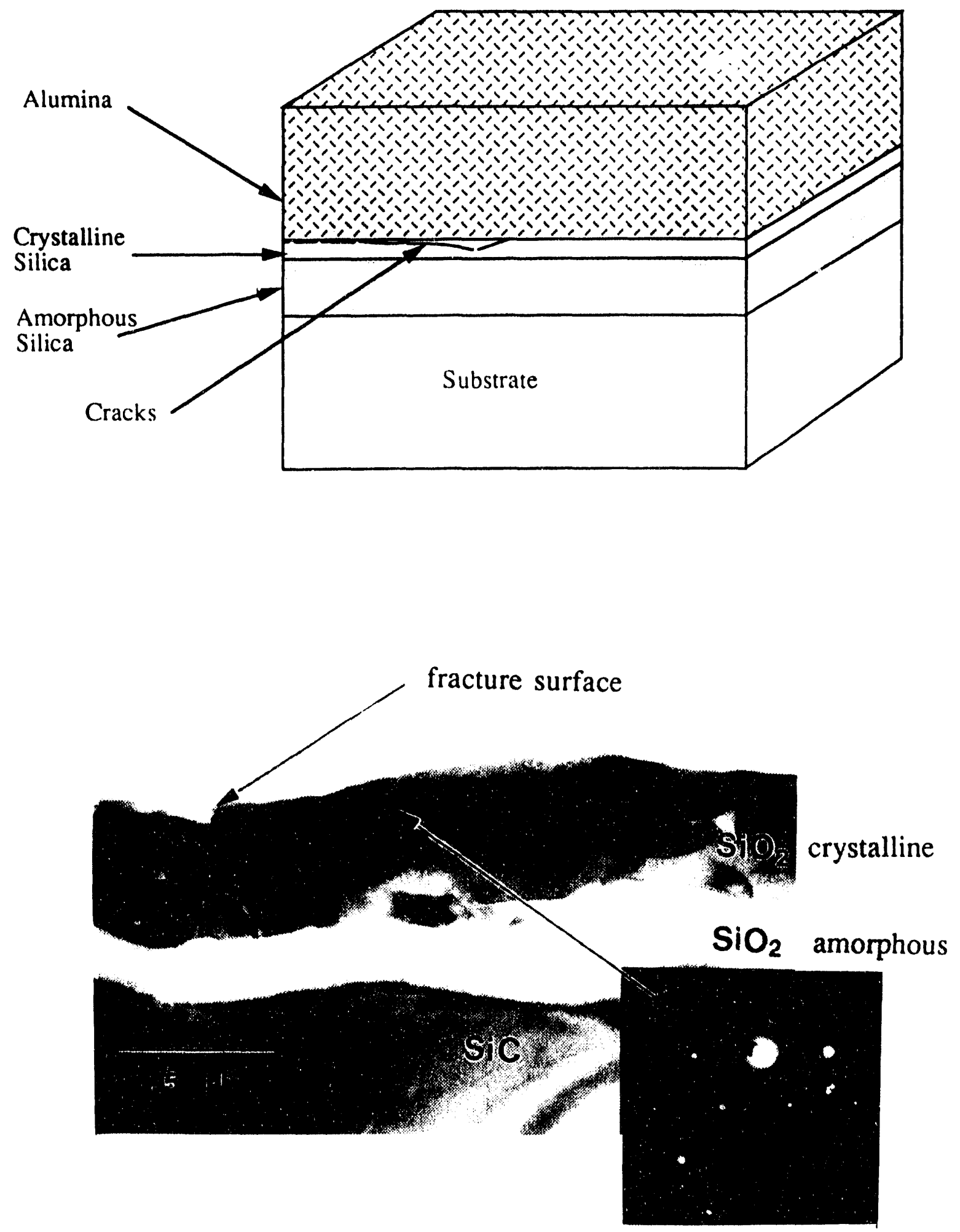

Figure 9: Schematic and TEM micrograph of an annealed sample showing the crystalline $\mathrm{SiO}_{2}$ layer causing delamination 
Status of Milestones

Schedule Status

Task 1: Development of $\mathrm{Al}_{2} \mathrm{O}_{3} / \mathrm{SiO}_{2}$

$5 / 94$

On Schedule coatings.

Task 2: Coating Characterization

$7 / 94$

On Schedule

for selection of best technique

from Task 1 .

Task 3: Development of the complete

$9 / 94$

On Schedule coating configuration for contact stress, oxidation and corrosion resistance evaluation. 
Wear-Resistant coatings

M. H. Haselkorn (Caterpillar Inc.)

\section{Objective/8cope}

The goal of this technical program is to develop wear-resistant coatings for piston ring and cylinder liner components for low heat-loss dies'el engines.

Friction and wear screening in Phase I identified plasma sprayed high carbon iron-molybdenum and chromia-silica coatings as candidate piston ring wear coatings. Plasma sprayed chromiasilica and high carbon iron-molybdenum coatings, as well as, a low temperature arc vapor deposited (LTAVD) chrome nitride coating were identified as candidate cylinder liner wear coatings. The cast iron porcelain enamel coatings exhibited unsatisfactory wear rates because of porosity in the coating.

The three main technical tasks for Phase II are further optimization of the LTAVD chrome nitride and of the cast iron porcelain enamel wear coatings and the process scale-up of wearresistant plasma coatings for cylinder liners.

The optimization of the LTAVD chrome nitride coating involves the development of an adherent 15 micron thick coating which meets the friction and wear goals of this program. The cast iron porcelain enamel process optimization centers on developing a CIPE composition with a minimum of porosity. The process scaleup of the plasma coatings will first develop I.D. plasma spray parameters for coating cylinder liners. Next, simulated cylinder liner specimens will be coated and the friction and wear properties of these coatings will be determined using reciprocating friction and wear testing using both new and "used" engine oil.

\section{Technical Progress}

Task 8, Process Scale-up of Wear-Resistant Plasma Coatings for Cylinder Liners, is completed. Statistical experiments, which determined the effect of primary gas flow, current, voltage, spray distance and carrier flow on coating microstructure and hardness and deposition efficiency, were used to build a predictive model to select three sets of I.D. plasma spray parameters for each powder. These parameters were then used to plasma spray Hohman A-6 friction and wear specimens. The coating parameters selected for each powder produced the best combination of plasma spray microstructure, coating hardness and highest deposition efficiencies. 
The Hohman friction and wear characterization showed that varying the plasma spray parameters for the chromia-silica powder had little influence on the friction and wear performance of this powder. For this reason, the plasma spray parameters selected for the application of the chromia-silica powder to the inner diameter of the simulated diesel engine cylinder liners were those which result in the highest deposition efficiency.

The friction and wear properties of the high carbon ironmolybdenum powder were influenced by the application parameters. For this reason, the plasma spray parameters selected for this powder were those which produce the coating with the best friction and wear properties.

Prior to application of the plasma spray coatings to the inner diameter of the cylinder liners, machining is required to accommodate the coating thickness. The machining of twelve cylinder liners has been completed. This procedure required the fabrication of a special fixture for holding the liners.

Using the plasma spray parameters identified in Task 8 , the chromia-silica" and high carbon iron-molybdenum powders were applied to the bores of cylinder liners (five liners were coated with each powder). The plasma coatings were then finished machined using a Heald 2EF centernal Multi-Surface horizontal O.D./I.D. grinder.

The grinding wheels selected for finishing the high carbon ironmolybdenum powder included two grit sizes, 15 and 52 micron, and two bond types, resonoid and vitreous. The wheels selected for finishing the chromia-silica powder both were vitreous bonded, but varied in grit size from 15 to 40 micron.

In Task $8 \mathrm{C}$ the machining parameters which produced the optimum surface finish and highest material removal rates were identified for coatings of each powder. Using these results as a guide, machining parameters (grinding wheel composition, feeds, speeds and depth of cut) were selected for each powder. The parameters selected included one set which would produce a high material removal rate and, one set with a lower material removal rate, but would produce a smoother surface finish. The material removal rates selected for each powder were:

Chromia-silica High carbon iron-molybdenum
- 9.04 and $0.5 \mathrm{~mm} 3 / \mathrm{min} / \mathrm{mm}$, - 10.03 and $18.08 \mathrm{~mm} 3 / \mathrm{min} / \mathrm{mm}$. 
Similar surface finishes were obtained with the chromia-silica powder irrespective of which set of machining parameters were used. The largest difference observed with the two sets of parameters was the time required to machine the liner. Using the higher material removal rates, a liner could be machined in 6 minutes, compared to 24 minutes for the lower material removal rates. It is interesting to note that even with the higher material removal rate the force on the grinding wheel was very low suggesting that even higher material removal rates can be used with this powder.

The surface finish obtained machining the high carbon ironmolybdenum powder was affected by material removal rate. The low material removal rates produced a surface finish which was within the range required for the desired tribological properties. However, the surface obtained with the higher material removal rates was unacceptable. Scanning electron photomicrographs of the surface after machining showed the reason for the unacceptable surface finishes was that the higher material removal rates caused spallation of the coating.

Plasma spraying and the final machining of plasma coated piston rings required the design and fabrication of specialized fixturing which have been completed. 
Development of Wear Resistant Ceramic Coatings for Dlesel Enaine Components M.G.S. Naylor (Cummins Engine Company, Inc.)

\section{Objective/Scope}

The objectlve of this program is to develop advanced wear-reslotant ceramic coatings for incyllinder components for future, high efficlency, low-emlssions diesel engines. Coatings and substrates (for plston rings and cyllinder liners) are to be developed to meet the following requirements:

1. Low wear as measured in laboratory ilg tests which simulate the plston ring-cylinder liner environment near top ring reversal in a heavy duty diesel engine. Test procedures developed during Phase 1 included tests with a fresh CE/SF 15 W40 lubricant at 200 and $350^{\circ} \mathrm{C}$, with a high-s0ot, engine-tested oll at $200^{\circ} \mathrm{C}$ and with no lubrication at $200^{\circ} \mathrm{C}$. Wear rates are baselined with respect to the conventional electroplated hard chromium/peariltic grey cast iron ring-liner system.

2. lower friction coefficlents than for the conventional system under all test conditions.

3. high adherence and compatiblity with substrate materials.

4. good thermal shock resistance.

5. high uniformity and reproduclbility.

\section{Technical Progress}

During Phase 1 of this effort, coating technologies and materlals were ovaluated using laboratory screening tests to simulate the tribological environment of the top compression ring in a heavy-duty diesel engine. The most promising candidates to emerge from this study were high velocity oxy-fuel (HVOF) $\mathrm{Cr}_{3} \mathrm{C}_{2}-20 \% \mathrm{NICr}$ and $\mathrm{WC}-12 \%$ Co cermets, cathodic arc physical vapor deposited (CAPVD) $\mathrm{CrN}$ and plasma sprayed $\mathrm{Cr}_{2} \mathrm{O}_{3}$. In addition, plasma sprayed $\mathrm{Cr}_{2} \mathrm{O}_{3}$ and $\mathrm{Al}_{2} \mathrm{O}_{3}-\mathrm{ZrO}_{2}$ materials were found to give excellent wear resistance at extremely high test temperatures and with no lubrication. Cylinder liner materlals giving lower system wear than pearlitic grey cast Iron were also identfiled. Thus, advanced ring coating - cyllinder liner tribological systems were developed in Phase 1. Some of these systems showed lower boundary lubricated wear coefficients at $350^{\circ} \mathrm{C}$ than conventional materials systems gave at $200^{\circ} \mathrm{C}$. In addition, these systems were much more tolerant to lubricant soot loading and oll degradation in diesel environments than the conventional electroplated hard chromium -pearlitic grey Iron system. Thus, significant improvements in wear-control technology for future, advanced low heat rejection diesel engines were demonstrated during Phase 1.

In the Phase 2 effort, processes are being developed for producing top compression ring face coatings using the best systems Identifled in Phase 1. In addition, further development and optimization of promlsing systems identified in Phase 1 is being conducted. Subcontracts are in place with three companies/institutions: Cummins Piston Ring Dlvision (CPRD), Northwestern University Basic Industrlal Research Laboratory (BIRL) and Engineered Coatings, Inc. (ECI). The following sectlon summarizes progress in each of the Phase 2 program tasks. 


\section{Iask 1 Develooment of $C_{3} C_{2}-$ Based Cermet Coatinos (ECh. BIRL CPRD)}

Athough a HVOF $\mathrm{Cr}_{3} \mathrm{C}_{2}-20 \%$ NiCr coating Identfiled in Phase 1 showed excellent wear resistance, recent engine tests showed that the ductllty of the coating needs to be improved for use as a ring coating. Three approaches are being taken to improve ductllity: (1) reducing the carbide concentration from $80 \%$ to $60 \%$, (2) reducing the 8120 of the carbldes, (3) using a more ductlle metallic blnder phase (two Hastelloy compositions) and (4) optimization of deposition parameters utllizing a broader range of thermal spray processes, including alr plasma spray, low pressure plasma spray and high veloclty oxy-fuel.

A varlety of $\mathrm{Cr}_{3} \mathrm{C}_{3}$ - based thermal spray powders is currently under imvestigation (Table 1). Development of $80 \% \mathrm{Cr}_{3} \mathrm{C}_{2}-20 \%$ Hastelloy $\mathrm{C}-22$ and $80 \% \mathrm{Cr}_{3} \mathrm{C}_{2}-20 \%$ Hastelloy $\mathrm{B}-2$ powders is in progress. A ball milling process was developed which produced powders with a $60-66 \mu \mathrm{m}$ mean particle size, but with a flattened morphology. The $\mathrm{Cr}_{3} \mathrm{C}_{2}$ - Hastelloy $\mathrm{C}-22$ powder was plasma sprayed successfully, producing a dense coating with melted carbides, but depostion rates were very low due to poor flow properties of the powder. Charactertzation of plasma sprayed coatings produced from blended $\mathrm{Cr}_{3} \mathrm{C}_{2}$ and Hastelloy powders is in progress. Clad $\mathrm{Cr}_{3} \mathrm{C}_{2}-\mathrm{Nl}$ and $\mathrm{Cr}_{3} \mathrm{C}_{2}-\mathrm{NICr}$ powders of varlous compositions and grain slzes have been ordered (Table 1).

Upon completion of the powder development work, coating process development will be undertaken using the thermal spray methods listed above. Coatings will be evaluated by means of microhardness tests, indentation fracture tests, microstructural evaluation by light microscopy and scanning electron microscopy and X-ray diffraction. In selected cases, three polnt bend tests will be conducted on free-standing thick coatings to measure strength, elastic modulus and strain-to-fallure. Wear tests will be conducted to establish relationships between microstructure and tribologlcal propertles.

\begin{tabular}{|l|l|l|}
\hline & \multicolumn{1}{|c|}{ Composition } & \multicolumn{1}{|c|}{ Process } \\
\hline 1 & $80 \% \mathrm{Cr}_{3} \mathrm{C}_{2}-20 \% \mathrm{NICr}$ (Phase I baseline) & Clad \\
\hline 2 & $60 \% \mathrm{Cr}_{3} \mathrm{C}_{2}-40 \% \mathrm{NICr}$ & Clad \\
\hline 3 & $80 \% \mathrm{Cr}_{3} \mathrm{C}_{2}-20 \% \mathrm{NICr}$ & Clad - finer carbldes \\
\hline 4 & $60 \% \mathrm{Cr}_{3} \mathrm{C}_{2}-40 \% \mathrm{NICr}$ & Clad - finer carbldes \\
\hline 5 & $80 \% \mathrm{Cr}_{3} \mathrm{C}_{2}-20 \% \mathrm{NI}$ & Clad \\
\hline 6 & $60 \% \mathrm{Cr}_{3} \mathrm{C}_{2}-40 \% \mathrm{NI}$ & Clad \\
\hline 7 & $80 \% \mathrm{Cr}_{3} \mathrm{C}_{2}-20 \% \mathrm{Hastelloy} \mathrm{C-22}$ & Blended \\
\hline 8 & $60 \% \mathrm{Cr}_{3} \mathrm{C}_{2}-40 \% \mathrm{Hastelloy} \mathrm{C-22}$ & Blended \\
\hline 9 & $80 \% \mathrm{Cr}_{3} \mathrm{C}_{2}-20 \% \mathrm{Hastelloy} \mathrm{B-2}$ & Blended \\
\hline 10 & $60 \% \mathrm{Cr}_{3} \mathrm{C}_{2}-40 \% \mathrm{Hastelloy} \mathrm{B-2}$ & Blended \\
\hline 11 & $73 \% \mathrm{Cr}_{3} \mathrm{C}_{2}-18 \% \mathrm{NI}-9 \% \mathrm{Mo}$ & Clad/blended \\
\hline 12 & $67 \% \mathrm{Cr}_{3} \mathrm{C}_{2}-17 \% \mathrm{NI}-17 \% \mathrm{Mo}$ & Clad/blended \\
\hline
\end{tabular}

Table 1. $\mathrm{Cr}_{3} \mathrm{C}_{2}$ - based cermet thermal spray powders under investigation. 
Iask 2 Development of Phyalcal Vapor Depostition Procesear (BIBL)

In Phase 1, a CrN coating applled by a cathodlc arc physical vapor deposition (CAPVD) process was found to have extremoly low wear coeficlents. In Phase 2, efforts are being focused on optimizing deposition parameters for $15 \mu \mathrm{m}$ thick CrN coatings applled by unbalanced magnetron (UBM) sputtering, minimizing the number of Cr macroparticles and maximizing coatling thickness, density, hardness and adheslon. Development of $\mathrm{CrN}$ coatings ls complicated by the existence of three potentlal phases: a $\mathrm{Cr}$ - $\mathrm{N}$ solid solution, $\mathrm{Cr}_{2} \mathrm{~N}$ and $\mathrm{CrN}$. A statistically dealgned experiment has been used to explore the effect of deposition parameters on the hardness and scratch adhesion of the coatings, using a single cathode machine. Coating parameters Included target power, total pressure, substrated blas, voltage, nitrogen partial pressure and coating thickness.

In the CiN phase range, handness was found not to be a strong function of nitrogen partial pressure (1300 - 1500 VHN), but the deposition rate decreased with increasing partlal pressure (Figure 1). Three independent varlables were used for Investlgating the CrN phase: power (kW), total pressure (mTorr) and thickness (microns) of coating. The nitrogen partial pressure and substrate blas were constant at $2 \mathrm{mTorr}\left(\mathrm{N}_{2}\right.$ ) (glving a depostion rate of approximately $300 \mathrm{~nm} / \mathrm{minut \theta}$ ) and $-125 \mathrm{~V}$, respectively. Two substrate materials were utllized: M2 tool steel, representing a traditional hard (60 HRC) substrate and $440 \mathrm{C}$ stainless sted heat treated to $38 \mathrm{HRC}$, representing the proposed plston ring substrate for this program. The scratch adhesion (critical load for coating fallure) was measured as a function of the thee varlables selected.

For M2 substrates, the adheslon maximum occurred at about $8 \mathrm{mT}$ Trr total pressure, so a single plot of adhesion against power and thickness at this pressure demonstrates the two-dimensional response (Flgure 2(a)). The maximum adheslon (6.5 kgf load) occurred at about $5 \mathrm{~kW}$ and $5 \mu \mathrm{m}$ thickness. If thicker coatings are required, then a lower power is best. If thinner coatings are desired, then higher powers are better. For the $440 \mathrm{C}$ substrates, an optimum total pressure of $10 \mathrm{inT}$ or was found. Flgure 2(b) shows the plot of adhesion versus thickness and power for this pressure. The varlation was somewhat different than for M2 substrates in that the maximum value occurred at a higher coating thickness $(>9 \mu \mathrm{m})$ and the value of the maximum was approximately $50 \%$ lower than for $M 2$ substrates. This is not surprising, since the $440 \mathrm{C}$ materlal was much softer than the M2. Two additional runs were made with the $440 \mathrm{C}$ substrates: $11 \mu \mathrm{m}$ and $15 \mu \mathrm{m}$ thick coatings were produced at $5 \mathrm{~kW}$ power and 10 mTorr pressure. Adheslon testing gave mixed results, with critcal load values ranging from 2 to $5 \mathrm{kgf}$. The reasons for this variation are under investigation. One crtical factor is thought to be the orientation of the coating.

Characterization of the $\mathrm{Cr}_{2} \mathrm{~N}$ and $\mathrm{Cr}-\mathrm{N}$ solld solution phases is summarized in Figures 3 and 4. For thls work, the substrate materlal was $\mathrm{M} 2$ tool steel only. $\mathrm{Th}_{\theta} \mathrm{Cr}_{2} \mathrm{~N}$ reglon was found to be narrow with respect to partlal pressure, 80 a value of $0.6 \mathrm{mTorr}$ was selected and held constant along with the power and total pressure. The hardness was also faily constant in this regime, at about $1300-1400$ VHN. Scratch adhesion values were found to decrease strongly with increasing coating thickness and were also a weak function of blas (Flgure 3). For the range where $\mathrm{Cr}-\mathrm{N}$ solld solutions were produced, hardness was found to be a strong function of nitrogen partial pressure and a weak function of blas (Flgure 4 (a)). For $5 \mu \mathrm{m}$ thick coatings, a maximum in coating adhesion occurred within the range of blas and nitrogen partlal pressure values investigated (Flgure 4 (b)). Adhesion was found to decrease with increasing coating thlckness (Figure 4 (c)).

The coating program is being transferred to a dual cathode UBM machine which will be used to depostt a range of coating compositions using parameters identlfied in the above work. The coatings will be $15 \mu \mathrm{m}$ thick and will be deposited onto $440 \mathrm{C}$ stainless steel wear test coupons. These samples will be used to obtain correlations between friction and wear properties and phase content, hardness and adherence. A subsequent task will be to develop a $15 \mu \mathrm{m}$ thick lamellar coating comprising alternating layers of $\mathrm{CrN}$ with elther $\mathrm{Cr}_{2} \mathrm{~N}, \mathrm{Cr}-\mathrm{N}$ solld solution or $\mathrm{Cr}$. The initial deposition parameters will be selected based on the above results for the single phases and the wear data. 


\section{$\mathrm{CrN}_{\mathrm{x}}$ Deposition Rate vs. Nitrogen Partial Pressure}

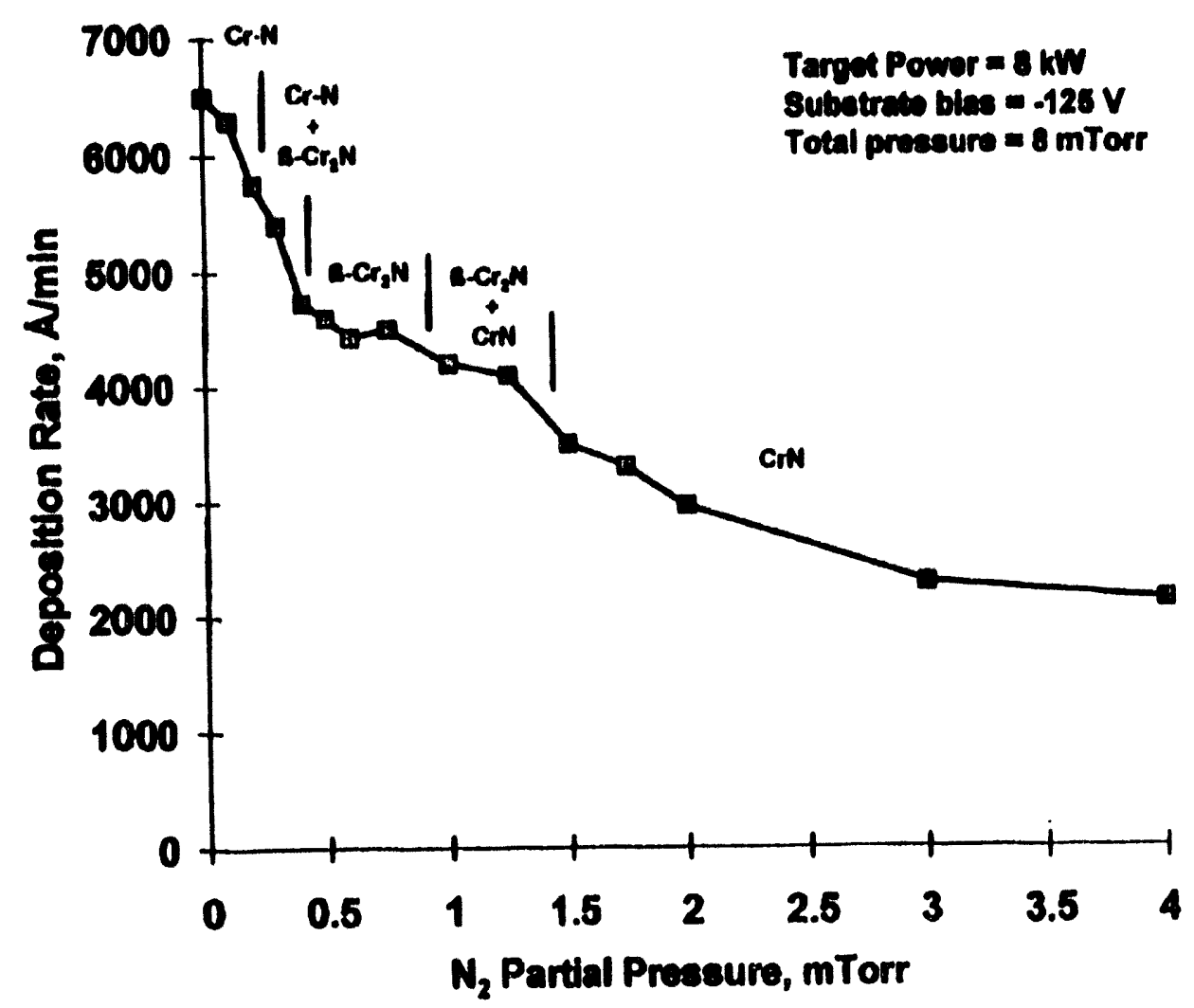

Flgure 1. Coating deposition rates as a function of nitrogen partial pressure.

Task 3 Development of Plasma Sorayed Ceramic Systems (BIRL)

Recent wear tests performed at Cummins have shown that monolithic zirconla-based systems have considerable potentlal for low wear in diesel engine environments, and it is proposed to try to reproduce these wear-resistant features using plasma spray processes. Five $\mathrm{ZrO}_{2}-\mathrm{N}_{2} \mathrm{O}_{3}-\mathrm{Y}_{2} \mathrm{O}_{3}$ powder samples have been obtained from four vendors of sintered and crushed or plasma processed powders. Characterization of coatings produced from the five powders is in progress and one powder will be selected for preparation of wear test coupons. 


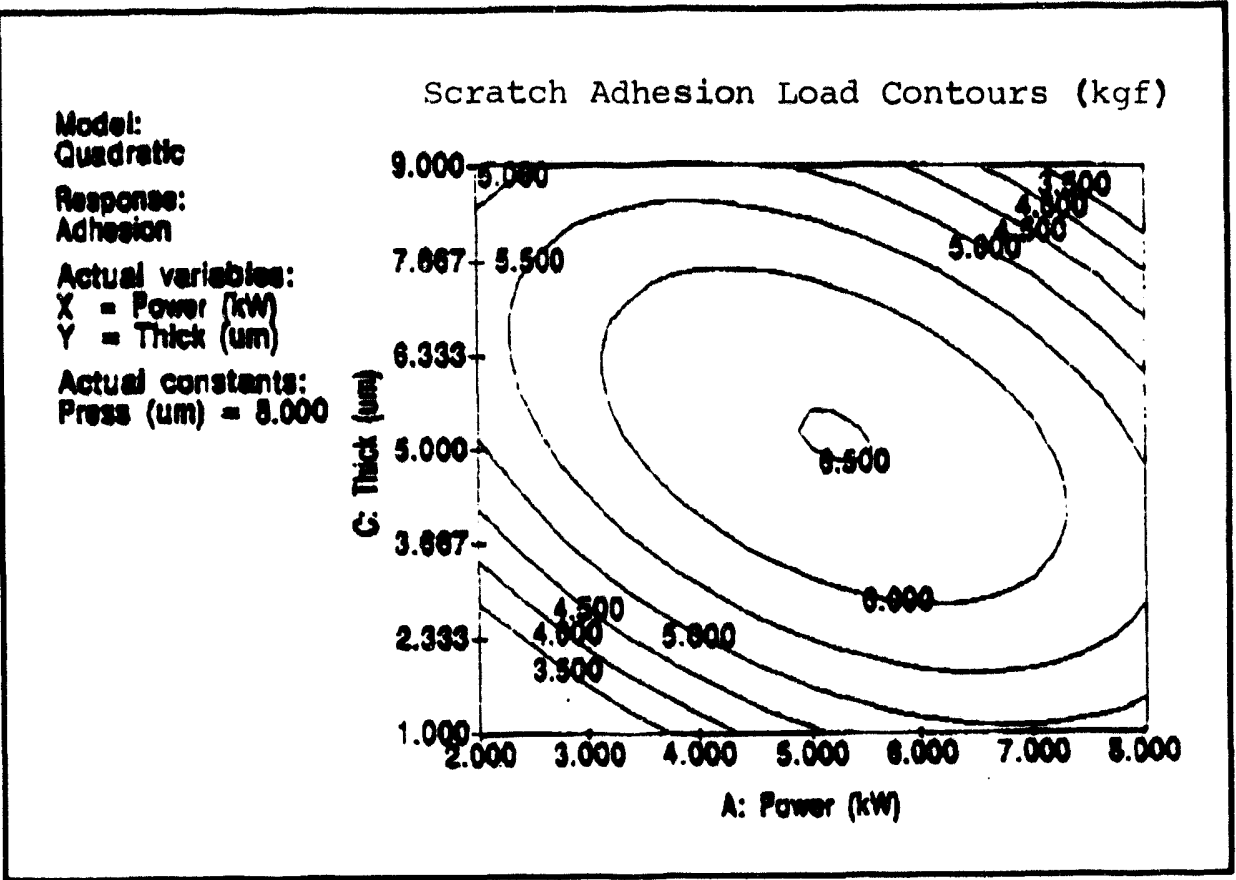

(a)

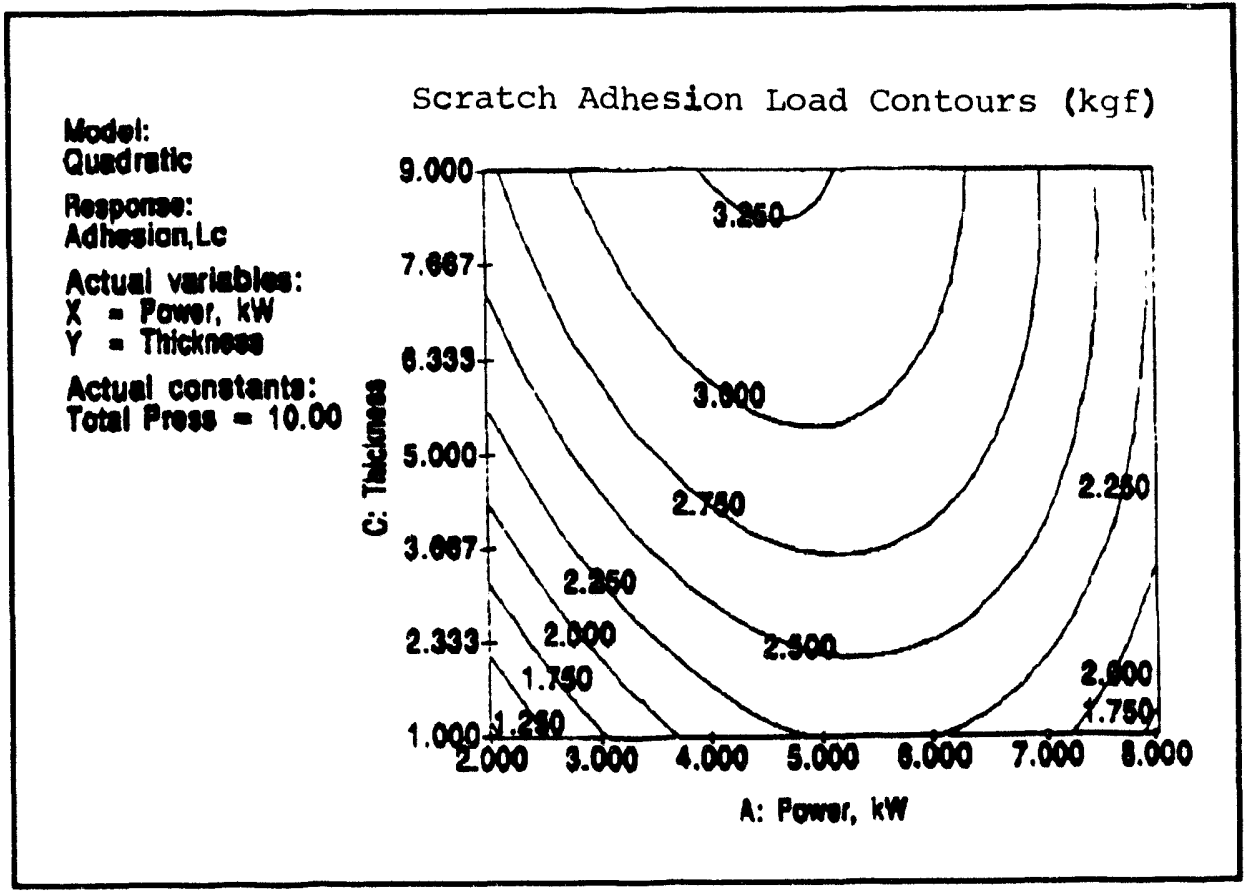

(b)

Figure 2. Scratch adhesion load (kgf) versus coating thicknes and power for $\mathrm{CrN}$ coatings:

(a) M2 tool steel substrates

(b) $440 \mathrm{C}$ stainless steel substrates. 


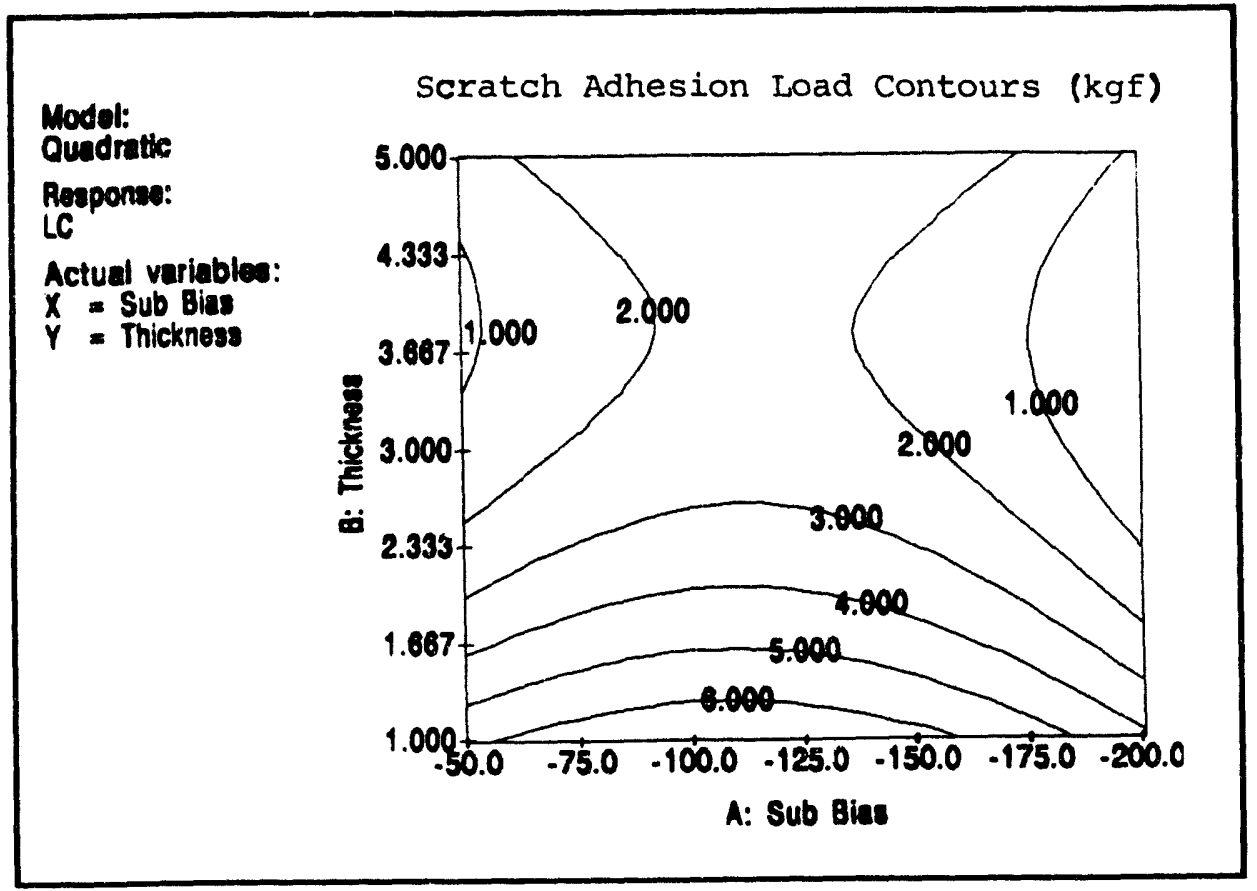

Figure 3. Scratch adhesion load (kgf) vs coating thickness and blas for $\mathrm{Cr}_{2} \mathrm{~N}$ coatings.

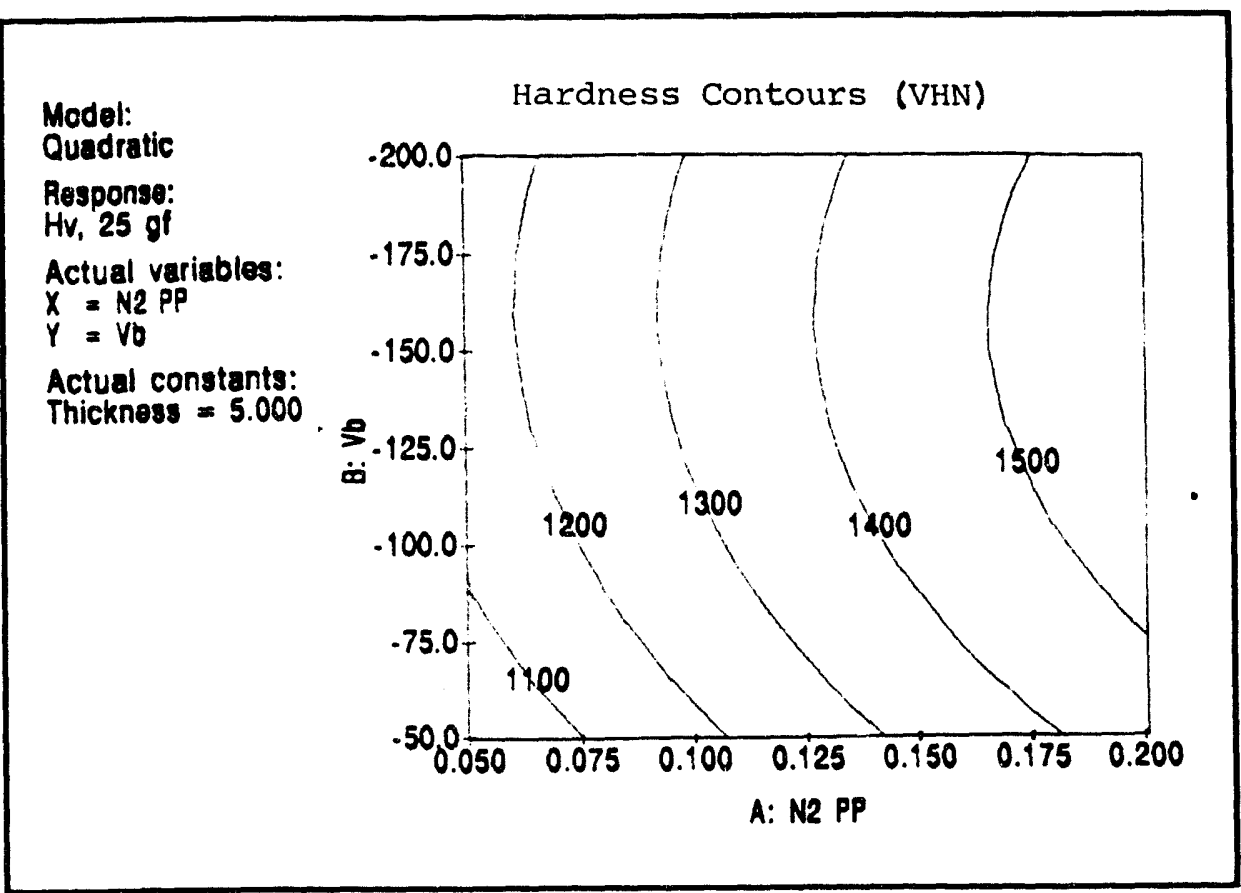

(a)

Figure 4. Contour plot for $\mathrm{Cr}-\mathrm{N}$ solld solution coatings:

(a) hardness (MHN) vs blas and nitrogen partlal pressure. 


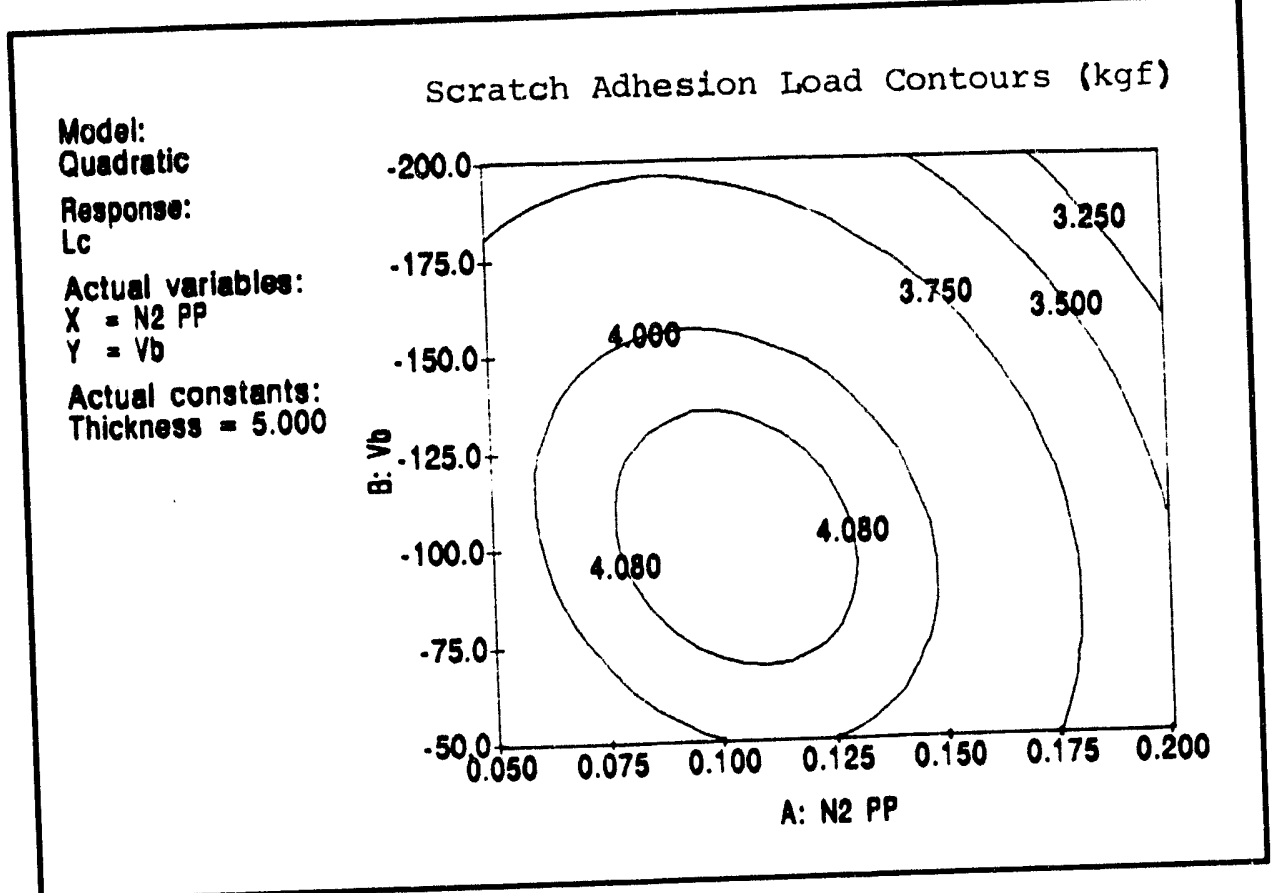

(b)

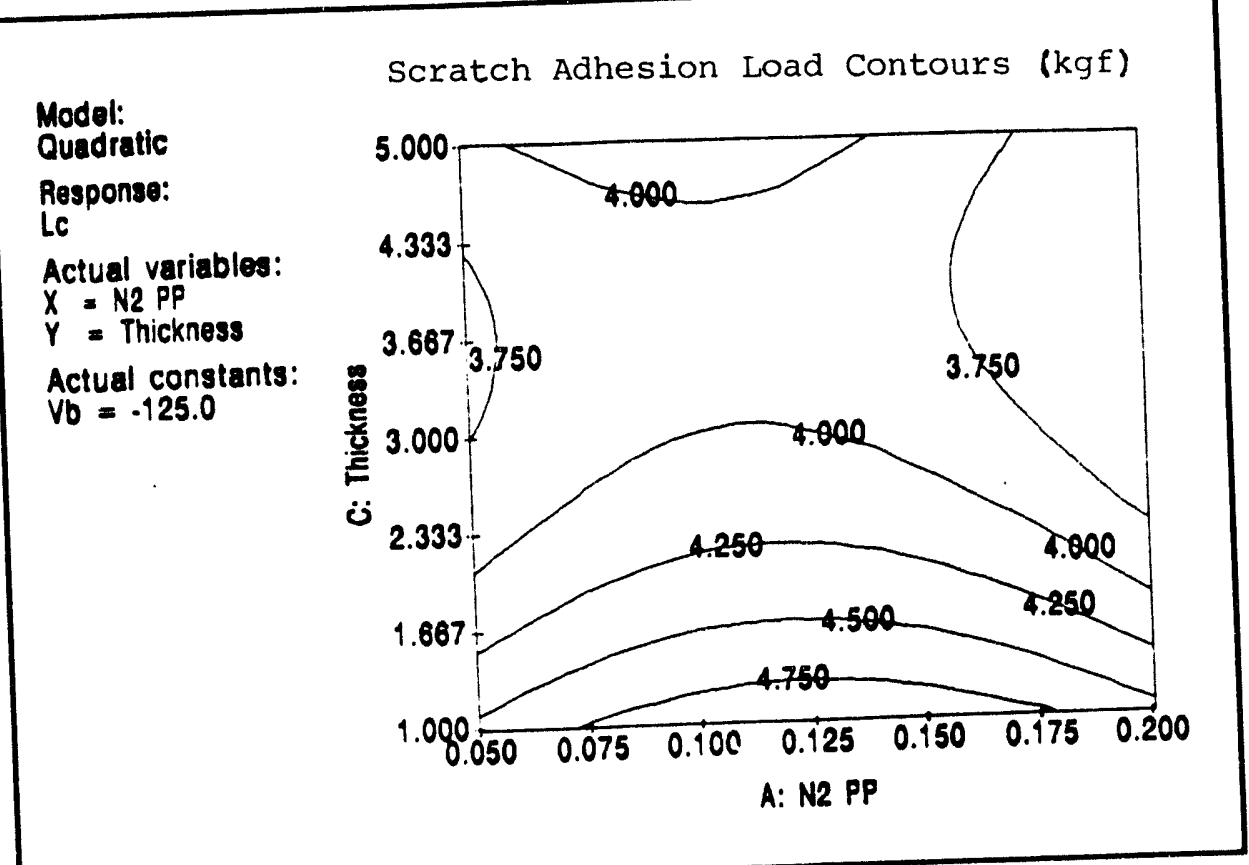

(c)

Figure 4. Contour plot for $\mathrm{Cr}-\mathrm{N}$ solid solution coatings:

(b) scratch adhesion load (kgf) vs bias and $\mathrm{N}_{2}$ partla pressure for 5 f
(c) scratch adhesion load vs coating thickness and $\mathrm{N}_{2}$ partial pressure for $-125 \mathrm{~V}$ blas. 


\section{Task 4 Imtearation of Coating Technoloar With the Piston Ring Manufacturina Process (CPRD)}

It is proposed to select two coatings based on the Phase 1 results and the additional development work in Tasks 1 - 3, with the objective of developing coating and finishing processes using actual piston ring arbors. CPRD will send arbors to the coating subcontractors for further processing development and coated rings will be returned for grinding and finishing tests. Finally, arbors containing up to 50 L10 piston rings will be sent out for coating and will subsequently be finished and processed for further evaluation in Task 5. AISI $440 \mathrm{C}$ sted wire has been ordered for the manufacture of prototype rings for coating development. Discussions have taken place between CPRD and the coating vendors to identify flxturing concerns for each coating process.

\section{Task 5 Evaluation of Coated Piston Rings (Cummins. CPRD)}

Tribological properties of all coatings developed in Tasks 1 - 3 will be evaluated, using test procedures developed during Phase 1. In addition, coated L10 plston rings produced in Task 4 will be evaluated for dimensional control, coating adhesion, microstructure, fatigue (selected coatings), thermal shock resistance and oxidation resistance.

\section{Status of Milestones}

Develop plans for coating deposition . . . . . . . . . May-31-1993 . . . . Completed

Develop thermally sprayed $\mathrm{Cr}_{3} \mathrm{C}_{2}$-based cermets $\ldots \ldots$ Nov-30-1994 . . . . . On schedule

Develop thick PVD CrN coatings . . . . . . . . . . . Nov-30-1994 . . . . O On schedule

Develop plasma sprayed ceramic coatings . . . . . . Nov-30-1994 . . . . O On schedule

Integration with ring manufacturing process . . . . . F Feb-28-1995 . . . . On schedule

Evaluation of coated piston rings . . . . . . . . . Feb-28-1995 . . . . On schedule

\section{Publications}

A paper enttted "Development of Wear-Resistant Ceramic Coatings for Dlesel Engine Components" was presented at the Department of Energy Annual Automottve Technology Contractor's Coordination Meeting, Dearborn, MI, 10/18/93 - 10/21/93. 
Thick Thermal Barrier Coating (TTBC) Systems for Low Heat Rejection Diesel Engines

M. B. Beardsley (Caterpillar Inc.)

Objective/Scope

The objective of this program is to advance the fundamental understanding of thick thermal barrier coating systems for application to low heat rejection diesel engine combustion chambers. Areas of TTBC technology that will be examined include powder characteristics and chemistry; bond coat composition; coating design, microstructure, and thickness as they affect properties: durability. and reliability: and TTBC " aging" effects (microstructural and property changes) under diesel engine operating conditions.

\section{Iechnical Progress}

TTBC POWDERS

Determination of deposition efficiency ( $D E)$. thermal conductivity (TC) and density of the fifteen lots of ceramic powders for the initial 36 parameters is completed. A comparison of the DE's and TC's of the zirconia materials is given in Tables 1 and 2 . The differential DE and TC were determined for each pair of parameters sets and the resulting average of the differences is shown. From this comparison it may be seen that the manufacturing method does impact the resulting DE and TC with a ranking of the processes as follows:

$$
\begin{aligned}
& \text { Deposition Efficiency } \\
& \mathrm{F} / \mathrm{C}<\mathrm{S} / \mathrm{C} / \mathrm{S}<\mathrm{HOSP}=\mathrm{S} / \mathrm{D}-\mathrm{S}=\mathrm{SOL} \mathrm{GEL}<\mathrm{SD} \text { * } \\
& \text { Thermal Conductivity } \\
& \mathrm{S} / \mathrm{D}-\mathrm{S}<\mathrm{HOSP}=\mathrm{S} / \mathrm{D}=\mathrm{SOL} \mathrm{GEL}=\mathrm{S} / \mathrm{C} / \mathrm{S}<\mathrm{F} / \mathrm{C} \text { * } \\
& \star \text { definitions are listed in Table } 1
\end{aligned}
$$

DESIGN. DEPOSITION, AND CHARACTERIZATION

Optimization runs for the baseline $8 \%$ yttria-zirconia material have been sprayed and a parameter set selected for the HOSP type of powders. Tensile and compressive strength specimens have been sprayed for the HOSP materials and testing is underway. The deposition efficiencies and thermal conductivities for HOSP lots 34547,34143 , and 34302 are given in Figures 1 and 2 for sets of parameters as well as the "book" parameters from the 
Table 1. Comparison of the deposition efficiencies of the 15 ceramic powders for the 36 sets of spray parameters.

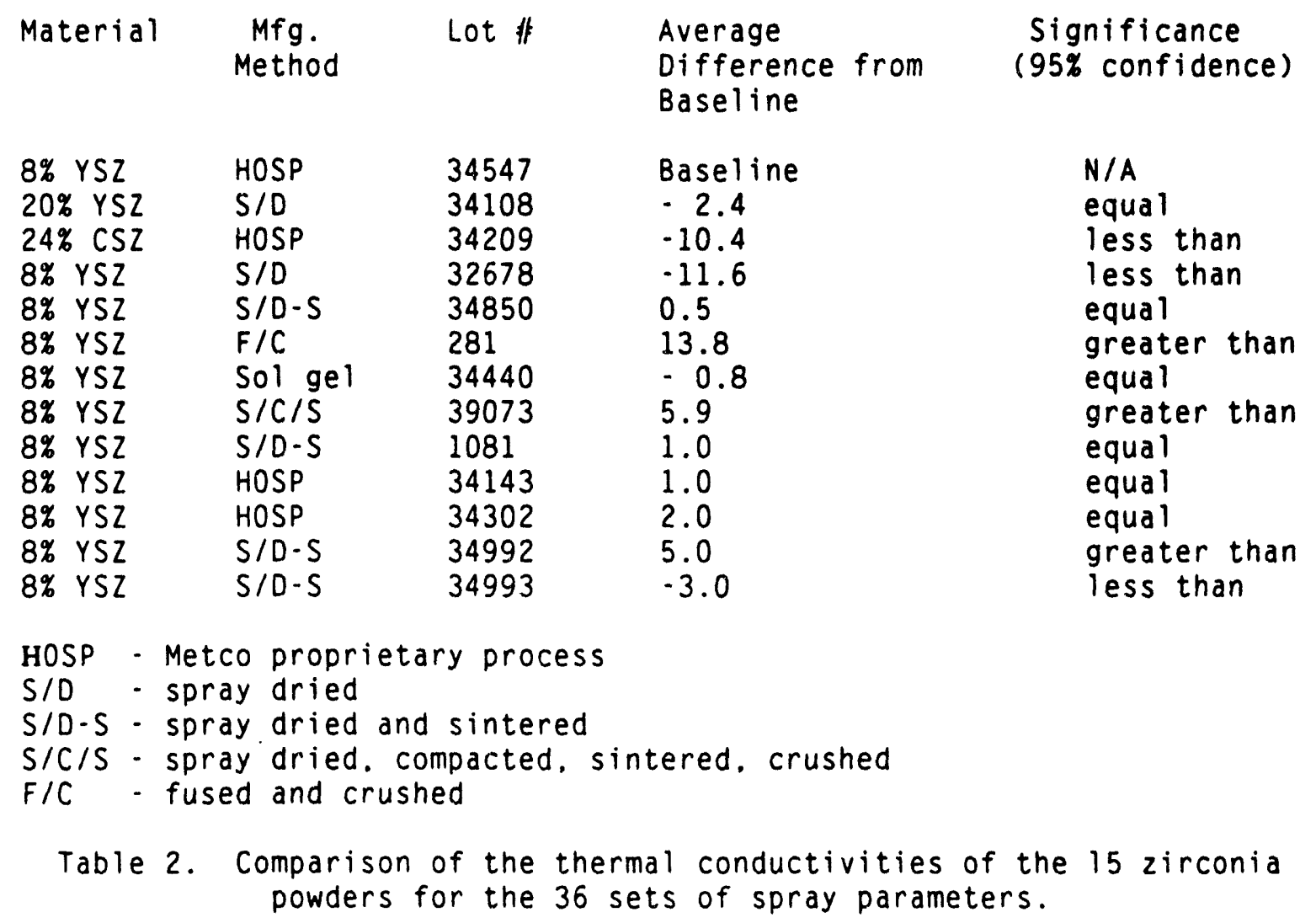

$\begin{array}{llllc}\text { Material } & \begin{array}{l}\text { Mfg. } \\ \text { Method }\end{array} & \text { Lot \# } & \begin{array}{l}\text { Average } \\ \text { Difference from } \\ \text { Baseline }\end{array} & \begin{array}{c}\text { Significance } \\ \text { (95\% confidence) }\end{array} \\ 8 \% \text { YSZ } & \text { HOSP } & 34547 & \text { Baseline } & \text { N/A } \\ 20 \% \text { YSZ } & \text { S/D } & 34108 & 0.16 & \text { lesS } \\ 24 \% \text { CSZ } & \text { HOSP } & 34209 & 0.04 & \text { lesS } \\ 8 \% \text { YSZ } & \text { S/D } & 32678 & 0.04 & \text { equal } \\ 8 \% \text { YSZ } & \text { S/D-S } & 34850 & 0.11 & \text { lesS } \\ 8 \% \text { YSZ } & \text { F/C } & 281 & -0.29 & \text { greater } \\ 8 \% \text { YSZ } & \text { SOI gel } & 34440 & 0.03 & \text { equal } \\ 8 \% \text { YSZ } & \text { S/CIS } & 39073 & 0.03 & \text { equal } \\ 8 \% \text { YSZ } & \text { S/D-S } & 1081 & -0.05 & \text { greater } \\ 8 \% \text { YSZ } & \text { HOSP } & 34143 & -0.18 & \text { greater } \\ 8 \% \text { YSZ } & \text { HOSP } & 34302 & -0.19 & \text { lester } \\ 8 \% \text { YSZ } & \text { S/D-S } & 34992 & 0.05 & \text { less } \\ 8 \% \text { YSZ } & \text { S/D-S } & 34993 & 0.07 & \end{array}$




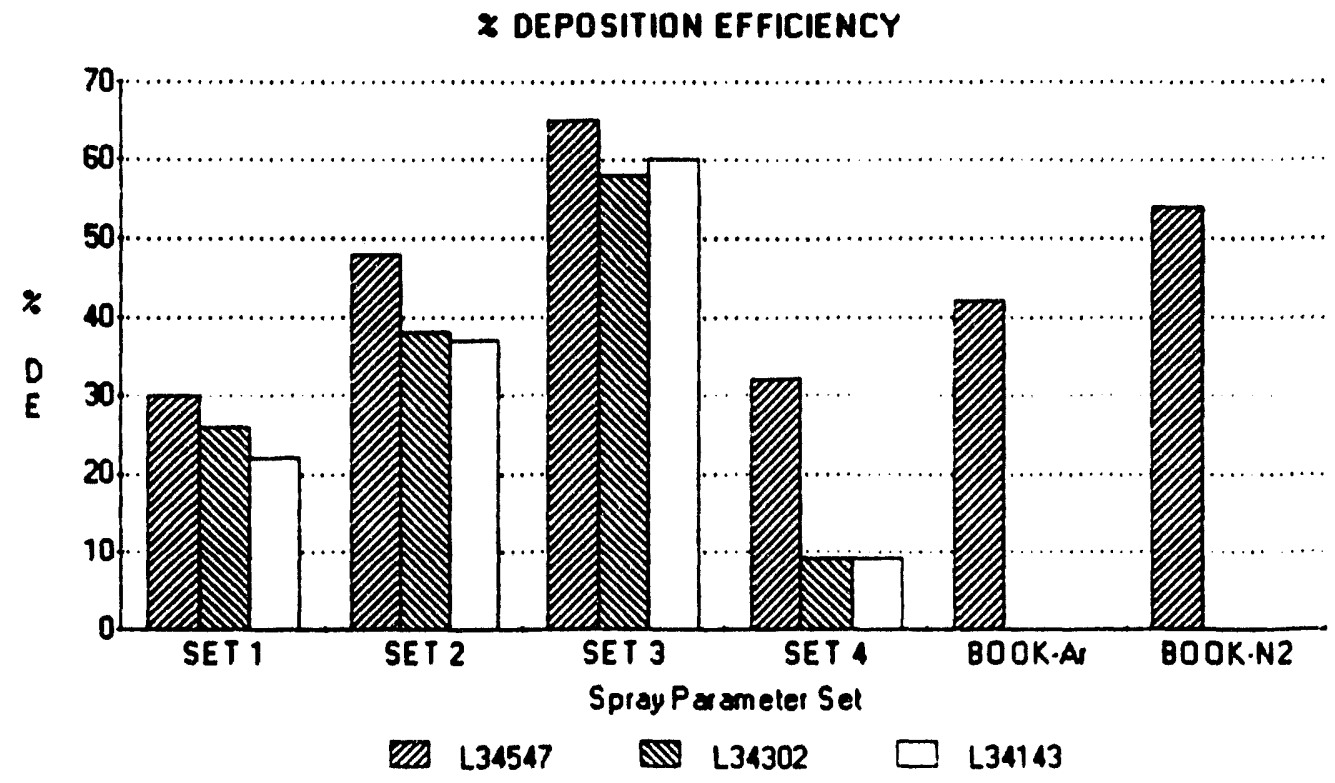

Figure 1

Deposition efficiencies for HOSP $8 \%$ yttria-zirconia lots for parameter sets and "book" parameters recommended by Metco.

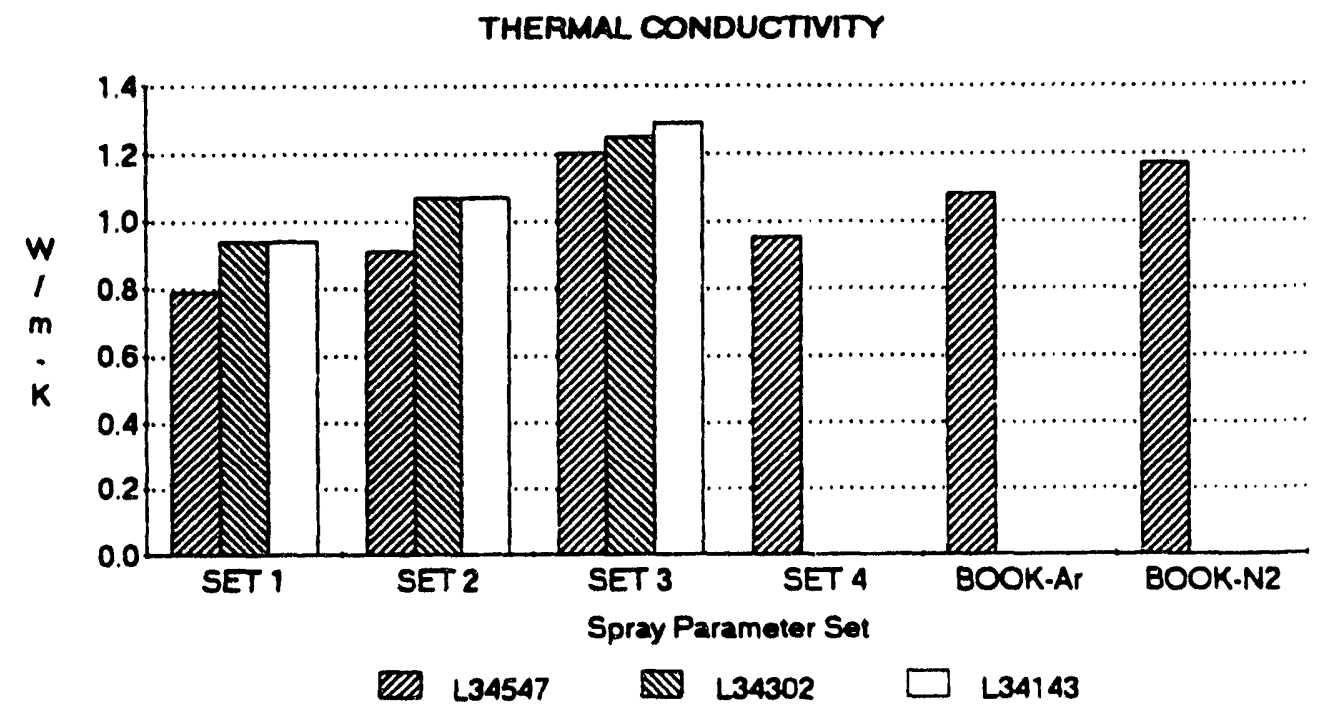

\section{Figure 2}

Thermal conductivities for HOSP $8 \%$ yttria-zirconia lots for same parameter sets as shown in figure 1.

For parameter Set 4 , the 34302 and 34143 had insufficient laydown to measure thermal conductivity. 
manufacture. The parameter Set 2 was selected for spraying of specimens for strength determination. This parameter set was selected for the good combination of high DE and low thermal conductivity. The tensile properties of the three HOSP $8 \%$ yttria-zirconia materials are given in Figure 3. Specimens for determination of the compressive strengths have been sprayed and testing is underway.

Parameter sets have been selected for the spray dried and sintered powder lots as well as the $24 \%$ ceria-zirconia and $20 \%$ yttria-zirconia powders. Spraying of specimens for these lots of materials is underway.

DURABILITY/RELIABILITY

The initial setup and testing of the tensile/compressive. coating fatigue test machine at the University of Illinois has been delayed due to flooding of their laboratory cause by the heavy rains in the Midwest this past summer. This has also delayed the testing of the additional materials for the fatigue response previously seen in the $8 \%$ yttria-zirconia material.

\section{AGING EFFECTS}

Tensile and compressive strength samples of the three HOSP $8 \%$ yttriazirconia materials have been aged for 500 hours at $800 \mathrm{C}$ in a simulated diesel exhaust environment. These samples are currently under evaluation. The testing of the $26 \%$ ceria-zirconia and calcium titanate for the stress/ temperature aging effect during fatigue testing has been delayed due to the flooding at the University of Illinois.

\section{Status of Milestones}

All milestones are on schedule.

\section{Publications}

A paper titled "Cyclic Compression of Thick Thermal Barrier Coatings"' by $K$. F. Wesling and D. F. Socie of University of Illinois and M. B. Beardsley of Caterpillar Inc. has been accepted for publication by the American Ceramic Society. 


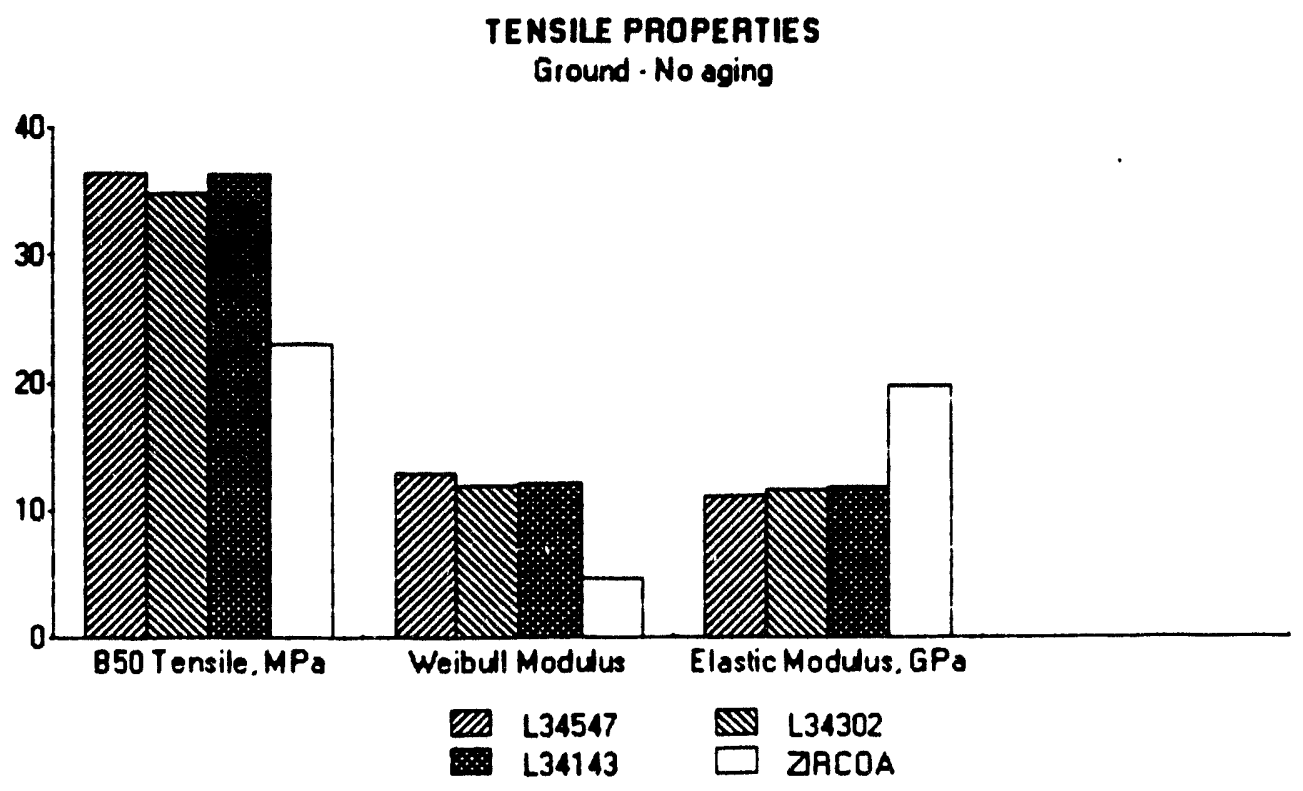

Figure 3

Tensile strengths determined by 4 -point bending for HOSP $8 \%$ yttria-zirconia lots sprayed using parameter Set 2 from Figures 1 and 2 . Fifteen specimens were 


\subsection{JOINING}

\subsubsection{Ceramic-Metal Joints}

Jolning of Ceramics for Heat Engine Applications

M. L. Santella (Oak Ridge National Laboratory)

\section{Objective/scope}

The objective of this task is to develop strong, reliable loints containing ceramic components for applications in advanced heat engines. The overall emphasis of this task is on studying the brazing characteristics of silicon nitride and silicon carbide. The techniques of direct brazing, as well as vapor coating, ceramics to circumvent wetting problems are being applied to these materials. The planned activities during FY 1993 will include continuing the study of both the high-temperature brazing of silicon nitride and the mechanical behavior of braze joints. The work will encompass creep testing of silicon nitride braze joints, further evaluation of a materials system and analysis package developed specifically for silicon nitride-to-metal braze joints, and evaluating nonmetallic bonding materials for joining sillicon nitride.

\section{Technical highlights}

$\mathrm{Si}_{3} \mathrm{~N}_{4}$ brazing: A study of bonding $\mathrm{Si}_{3} \mathrm{~N}_{4}$ with nonmetallic materials was continued by formulating a series of both $\mathrm{MgO}-\mathrm{Al}_{2} \mathrm{O}_{3}-\mathrm{SiO}_{2}$ (MAS) and $\mathrm{Y}_{2} \mathrm{O}_{3}-\mathrm{Al}_{2} \mathrm{O}_{3}-\mathrm{SiO}_{2}$ (YAS) mixtures and examining their general melting and wetting characteristics. Three compositions of each type of mixture (MAS1-3 and YAS1-3) were prepared by milling together individual oxide powders as described in earlier reports. Additional compositions were prepared by adding either 20 wt $\% \mathrm{Si}_{3} \mathrm{~N}_{4}$ powder or a combination of $20 w t \% \mathrm{Si}_{3} \mathrm{~N}_{4}+5 w t \% \mathrm{Si}$ powders to the base oxide mixtures. Two silicon nitride substrates were used: GS44 for the MAS compositions and PY6 for the YAS compositions. The substrates were approximately $12 \times 12 \times 5 \mathrm{~mm}$ in size, and, to ensure uniformity, the surfaces used for wetting were surface ground and then finished with 6- $\mu$ m-diamond paste on a metallographic wheel.

The various oxide-based mixtures were made into slurries with isopropyl alcohol and lightly pressed onto the $\mathrm{Si}_{3} \mathrm{~N}_{4}$ surfaces using a template with dimensions of $6.4 \mathrm{~mm}$ diam by $0.6 \mathrm{~mm}$ height. These specimens were then heated by RF induction using a Ta susceptor under a nitrogen pressure just below $1 \mathrm{~atm}$. Temperatures were monitored with an optical pyrometer. Once complete melting of the powders was visually confirmed, specimens were held at their melting temperatures for $10 \mathrm{~min}$ or until the melt began to foam.

The results from the inital set of experiments are summarized in Table 1, which shows that three general types of behavior were observed: (1) a stable droplet formed; (2) a stable droplet formed, then chemical reactions created a moderate level of porosity; or (3) relatively strong or rapid chemical reactions caused the droplet to foam. In all cases, adding $\mathrm{Si}_{3} \mathrm{~N}_{4}$ powder to the oxide mixtures reduced their chemical stability. For all mixtures except the one based on MAS3, a further addition of 5 wt \% Si suppressed the tendency for chemical instability. 
Table 1. Behavior of oxide mixtures melted on $\mathrm{Sl}_{3} \mathrm{~N}_{4}$

\begin{tabular}{|c|c|c|c|c|}
\hline Powder & Substrate & Temp., ${ }^{\circ} \mathrm{C}$ & Time, $\min$ & Result \\
\hline MAS1 & GS44 & 1350 & 10 & stable \\
\hline$+20 \% \mathrm{Sl}_{3} \mathrm{~N}_{4}$ & & 1360 & 10 & reaction \\
\hline$+5 \% S I$ & & 1420 & 10 & stable \\
\hline MAS2 & GS44 & 1650 & 2 & reaction \\
\hline$+20 \% \mathrm{Sl}_{3} \mathrm{~N}_{4}$ & & 1520 & 2 & foaming \\
\hline$+5 \% S I$ & & 1460 & 10 & reaction \\
\hline MAS3 & GS44 & 1580 & 2 & reaction \\
\hline$+20 \% \mathrm{SI}_{3} \mathrm{~N}_{4}$ & & 1510 & 3 & foaming \\
\hline$+5 \% \mathrm{SI}$ & & 1480 & 3 & foaming \\
\hline YAS1 & PY6 & 1350 & 10 & stable \\
\hline$+20 \% \mathrm{Si}_{3} \mathrm{~N}_{4}$ & & 1350 & 10 & reaction \\
\hline$+5 \% \mathrm{Si}$ & & 1360 & 11 & stable \\
\hline YAS2 & PY6 & 1380 & 10 & reaction \\
\hline$+20 \% \mathrm{SI}_{3} \mathrm{~N}_{4}$ & & 1370 & 10 & reaction \\
\hline$+5 \% \mathrm{Si}$ & & 1370 & 10 & stable \\
\hline YAS3 & PY6 & 1380 & 10 & reaction \\
\hline$+20 \% \mathrm{Sl}_{3} \mathrm{~N}_{4}$ & & 1350 & 10 & reaction \\
\hline$+5 \% \mathrm{Si}$ & & 1370 & 10 & stable \\
\hline
\end{tabular}

The photographs taken of the specimen surfaces and presented as Fig. 1 illustrate the effects of the $\mathrm{Si}_{3} \mathrm{~N}_{4}$ and $\mathrm{SI}$ metal additions on the melt stability. In the upper set of specimens, compositions based on MAS1 (20 MgO-18 Al $\mathrm{O}_{3}-62 \mathrm{SiO}_{2} \mathrm{Wt} \%$ ) were melted on GS44; in the lower set, compositions based on YAS1 $\left(33 \mathrm{Y}_{2} \mathrm{O}_{3}-21 \mathrm{Al}_{2} \mathrm{O}_{3}-46 \mathrm{SiO}_{2}\right)$ were melted on PY6. In both cases, the oxide mixtures resulted in stable droplets which appeared relatively translucent. The addition of $\mathrm{Sl}_{3} \mathrm{~N}_{4}$ powder to these mixtures produced a milky appearance with many small bubbles visible on the droplet surfaces. Further additions of Si powder appeared to suppress the bubble formation and produced an opaque appearance on both droplets.

The contact angles of the various mixtures, measured at room temperature, are given in Table 2 and are in a range that would make them suitable for brazing operations. 

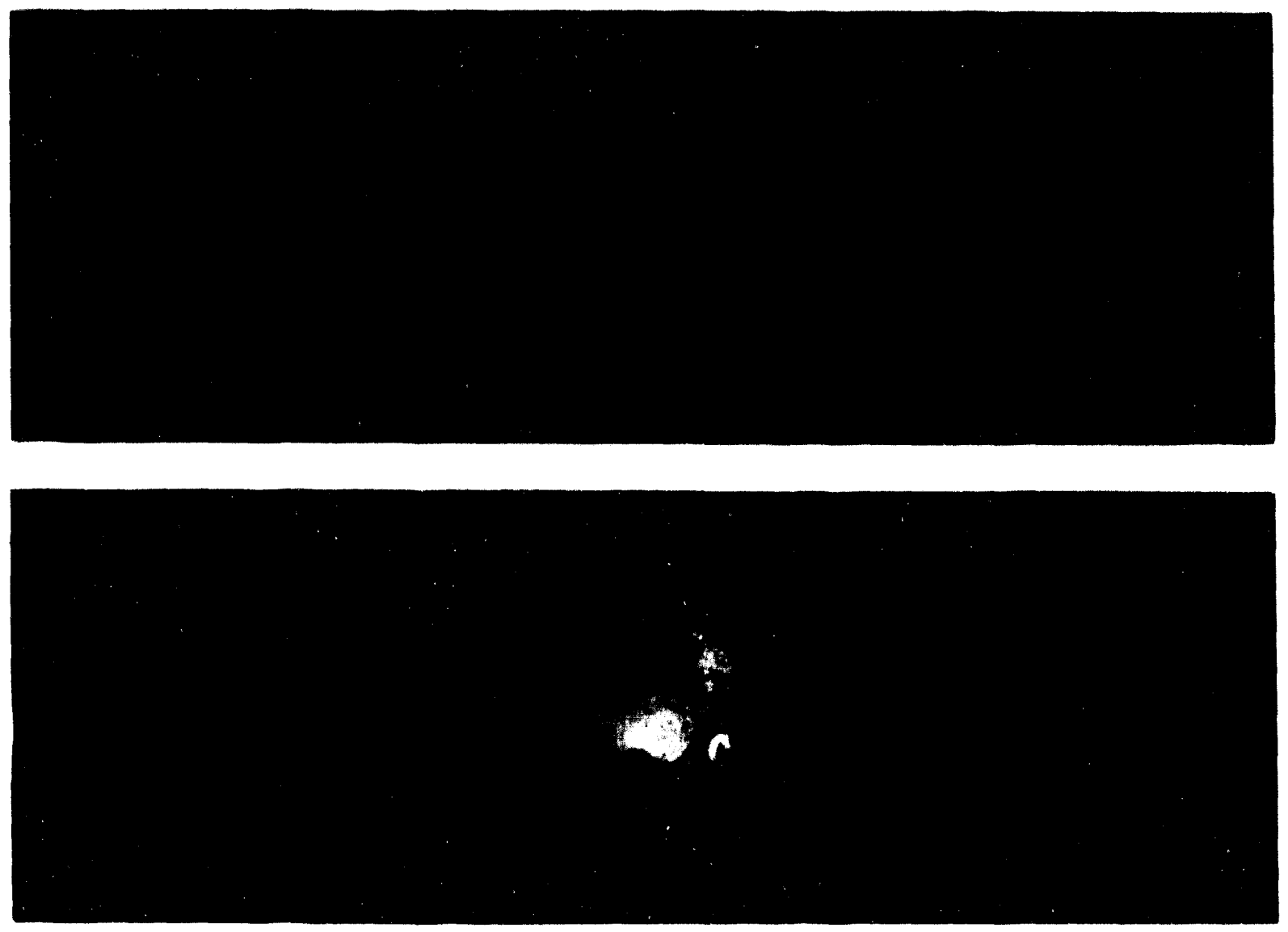

Fig. 1. Photographs of the surfaces of specimens of the MAS1 serles melted on QS44 (top), and the YAS1 serles melted on PY6 (bottom). From left to right, the melts contain only oxides, oxides $+\mathrm{Sl}_{3} \mathrm{~N}_{4}$, and oxides $+\mathrm{Sl}_{3} \mathrm{~N}_{4}+\mathrm{SI}$. Magnification: 2.2x.

Table 2. Contact angle measurements for selected oxlde mixtures melted on $\mathrm{Sl}_{3} \mathrm{~N}_{4}$

\begin{tabular}{|l|c|c|c|}
\hline Powder & Substrate & Temp., $^{\circ} \mathrm{C}$ & Contact angle, $^{\circ}$ \\
\hline MAS1 & GS44 & 1350 & 23 \\
\hline$+20 \% \mathrm{SI}_{3} \mathrm{~N}_{4}$ & & 1360 & 31 \\
\hline$+5 \% \mathrm{Si}$ & & 1420 & 38 \\
\hline YAS1 & PY6 & 1350 & 26 \\
\hline$+20 \% \mathrm{SI}_{3} \mathrm{~N}_{4}$ & & 1350 & 27 \\
\hline$+5 \% \mathrm{Si}$ & & 1360 & 33 \\
\hline
\end{tabular}


These data abo show that increading the 81 concentration in the molts increases thelr contact angles on $\mathrm{Si}_{\mathrm{g}} \mathrm{N}_{4}$.

The microetructure of the YAS1 mbxture containing edditions of both $\mathrm{Si}_{2} \mathrm{~N}_{4}$ and $\mathrm{B}$ molted on PYs bs shown in Fig. 2. As shown in Fig. 2(a), this droplet contains no poroalty, but a few fine cracks formed near the edge of the droplet. Abo, there wae no indication that any elgnilicant reaction ocourred between the $8 . \mathrm{N}_{4}$ and the mell. A doser view of the droplet surface is shown in Fig. 2(b). The small ctroular fectures are spheres of 81 , which are uniformly dietributed throughout the droplet except at the surtaco. The \&I

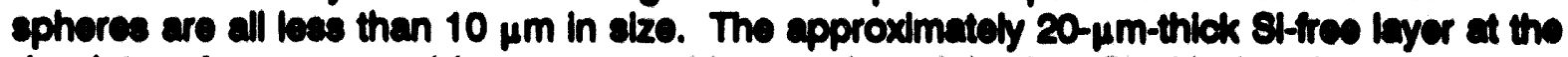
droplet surface presumably was caused by reaction of the free SI with the nitrogen gas atmoephere in the furnace.

The base oxide compositions were selected to give melting temperatures in the ranges of 1350 to $1400^{\circ} \mathrm{C}$ for the MAS mixturee and 1400 to $1800^{\circ} \mathrm{C}$ for the YAS mixtures. The composittions were not solected spectilcally for their glaes-forming ablitibes. As Table 1 shows, excopt for the MAS2 and MASs mixtures, the moasured melting temperatures were in their predicted ranges. The molting temperatures of MAS2 and MAS3 wore much higher than expected, but they wore reduced somewhat by an addition of 20 wt \% SI $\mathrm{N}_{4}$ powder. The Si additions caused further reduction in melting. temperature for these mixtures. The melting tomperature of MAS1 was ellightly increased by the $\mathrm{SI}_{3} \mathrm{~N}_{4}$ addition and increased even further by the $\mathrm{Si}$ addition. The motting temperatures for the YAS mixtures were not significantly iniluenced by elther addition.

The cause of the high melting temperatures for MAS2 and MASs is not known. The high temperatures required to melt these mixtures probably was a factor in their relattve instablity. The compositions of the mixtures were measured by semiquantttattve energy dleperelve $X$-ray analysis in a scanning electron microscope, and these results are compared to the nominal compositions in Table 3. The agreement between nominal and actual compositions is reasonably good considering the inherent errore in such an analysis. Using the actual compositions to estimate melting temperature still did not account for the behavior of MAS2 and MAS3.

\section{Status of milestones}

141112 Report on Inttlal evaluation of the wetting and melting characteriatics of mixed oxide and oxynitride glasses on $\mathrm{SI}_{3} \mathrm{~N}_{4}$.

On schedule: January 31, 1994.

\section{Publlcations}

None.

Unpublished work

None. 


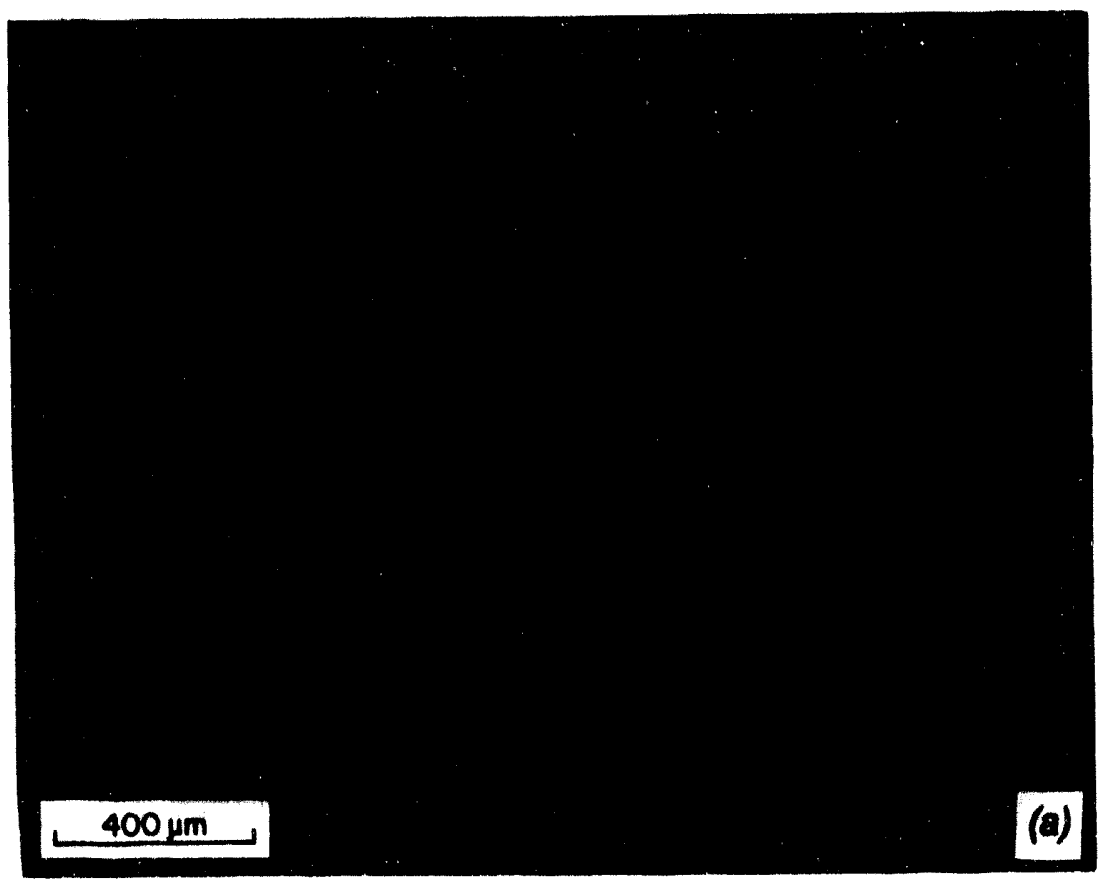

93-0551-3

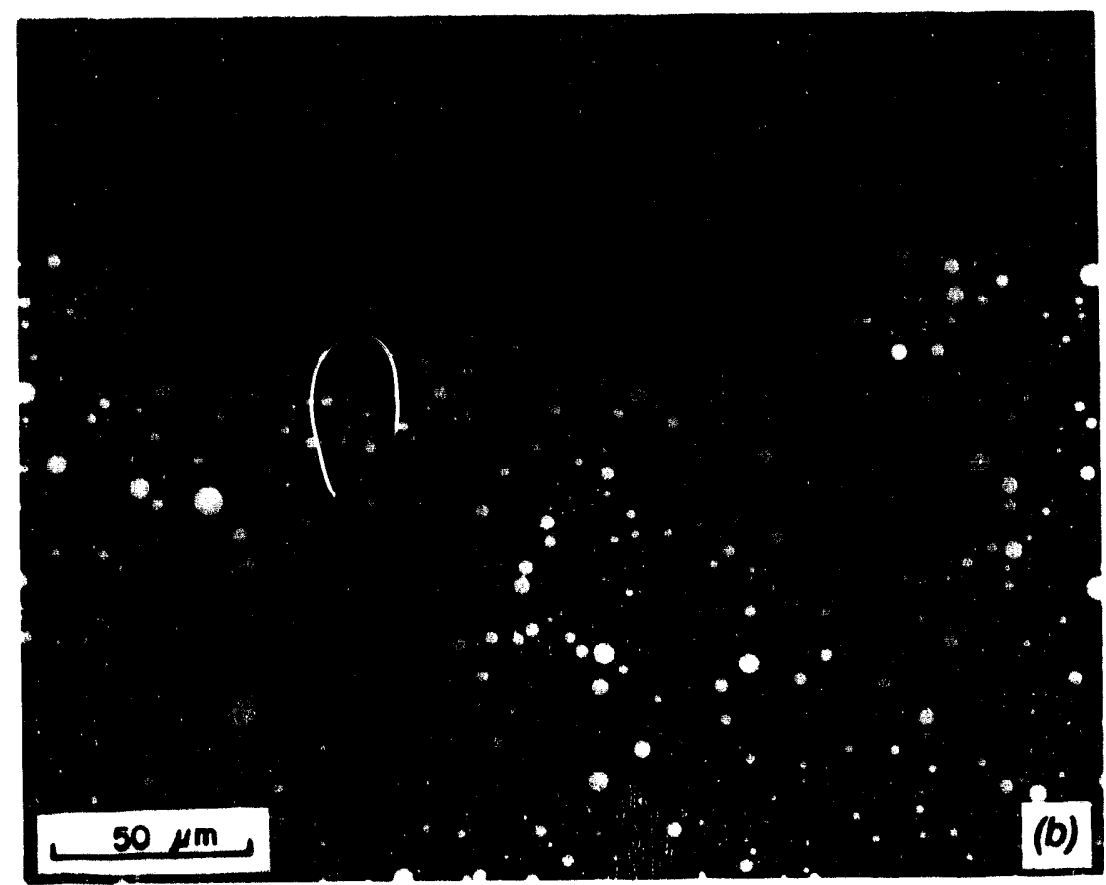

Fig. 2. Scanning electron microscope micrographs of cross-sectioned droplet of YAS1 + 20 wt $\% \mathrm{SI}_{3} \mathrm{~N}_{4}+5$ wt $\%$ SI melted on PY6. Droplet shape is shown in (a). Distribution of SI and reaction layer at the droplet surface are shown in (b). 
Table 3. Comparison of nominal and actual oxide mixture compositions

\begin{tabular}{|c|c|c|c|c|c|}
\hline & & \multicolumn{4}{|c|}{ Concontration, $w$ \% } \\
\cline { 3 - 6 } I.D. & Condition & S1 & N & Mg & $Y$ \\
\hline MAS1 & Nominal & 57.0 & 19.0 & 24.0 & 0.0 \\
\hline & Actual & 72.1 & 16.6 & 11.3 & 0.0 \\
\hline MAS2 & Nominal & 49.0 & 10.3 & 40.7 & 0.0 \\
\hline & Actual & 46.7 & 16.7 & 36.6 & 0.0 \\
\hline MAS3 & Nominal & 47.0 & 23.0 & 30.0 & 0.0 \\
\hline & Actual & 39.5 & 34.5 & 26.0 & 0.0 \\
\hline YAS1 & Nominal & 36.0 & 19.0 & 0.0 & 45.0 \\
\hline & Actual & 31.2 & 16.2 & 0.0 & 62.6 \\
\hline YAS2 & Nominal & 25.0 & 17.0 & 0.0 & 57.0 \\
\hline & Actual & 14.2 & 23.0 & 0.0 & 62.0 \\
\hline YAS3 & Nominal & 21.0 & 24.0 & 0.0 & 56.0 \\
\hline & Actual & 19.2 & 19.5 & 0.0 & 61.3 \\
\hline
\end{tabular}




\subsubsection{Ceramic-Ceramic Joints}

\section{Analytical and Experimental Evaluation of Joining Silicon Carbide to silicon Carbide and Silicon Nitride to Silicon Nitride for Advanced Heat Engine Applications}

G. J. Sundberg, J. A. Wade, and C. S. White (Norton Company)

\section{OBJECTIVE/SCOPE}

Joins of hot isostatically pressed (HIP'ed) $\mathrm{Si}_{3} \mathrm{~N}_{4}-4$ wt $8 \mathrm{Y}_{2} \mathrm{O}_{3}$ (NCX5100 family) and sintered Beta-SiC (NCX-4500) were developed during Phase I of the contract and were demonstrated to have mechanical properties attractive for advanced heat engine applications. ${ }^{1}$ An experimental database was developed for both materials based upon limited MOR and buttonhead tensile tests. Within the limitations of this database, analytical/numerical models were developed for prediction of join reliability. The purpose of this program is to develop joining technologies for $\mathrm{HIP}^{\prime}$ ed $\mathrm{Si}_{3} \mathrm{~N}_{4}$ with $4 \mathrm{wt} 8 \mathrm{Y}_{2} \mathrm{O}_{3}$ and for a siliconized SiC (NT-230) for various geometries including: butt joins, curved joins and shaft to disk joins. In addition, more extensive mechanical characterization of silicon nitride joins to enhance the predictive capabilities of the analytical/numerical models for structural components in advanced heat engines will be provided. Mechanical evaluation will be performed by: MOR at $22^{\circ} \mathrm{C}$ and $1370^{\circ} \mathrm{C}$, stress rupture at $1370^{\circ} \mathrm{C}$, high temperature creep, $22^{\circ} \mathrm{C}$ tensile testing and spin tests.

TECHNICAL/HIGHLIGHTS

Silicon Nitride Shaft To Disk - Spin Test (Task 1.4B)

The demonstration of curved join quality similar to planar butt joins developed during Phase I of this contract allows application of the joining technique to more complex shapes, such as a simulated rotor geometry. Five curved NCX-5101 joins of a shaft-to-disk configuration were fabricated (Figure 1). Grinding of the densified joins yielded the four-bladed spin test specimens (Figure 2). Five additional joins of the shaft-to-disk configuration were used to manufacture tensile specimens to determine tensile strength of the actual spin test specimen join geometry.

The tensile specimens were pin-loaded with flat grip sections and cylindrical gage section with 0.1 in diameter and 1.0 in length (Figure 3). Two join interlayers were within the gauge of each tensile specimen oriented perpendicular to the gauge length. The tensile specimens are identified with two numbers: the first number was the shaft-to-disk join from which the specimen was ground and the second number differentiates between specimens from the same parent join (Table 1). Six c.. eight specimens tested failed from surface origins within the gage section away from the join interface (Figure 4). The remaining two tensile specimens failed at the clevis-pin hole and were not considered valid. The mean tensile strength was $598 \mathrm{MPa}$. Weibull analysis of this limited data set suggests $\sigma_{0}=636 \mathrm{MPa}, \mathrm{m}=$ 8.2 (Figure 5).

Fractography suggests that all of the spin specimens failed from damage induced by machining in the regions of high curvature near the shaft, but away from the join. An example of surface damage is provided in the SEM micrograph in Figure 6. The failure speeds of the spin tests are given in Table 2 . 

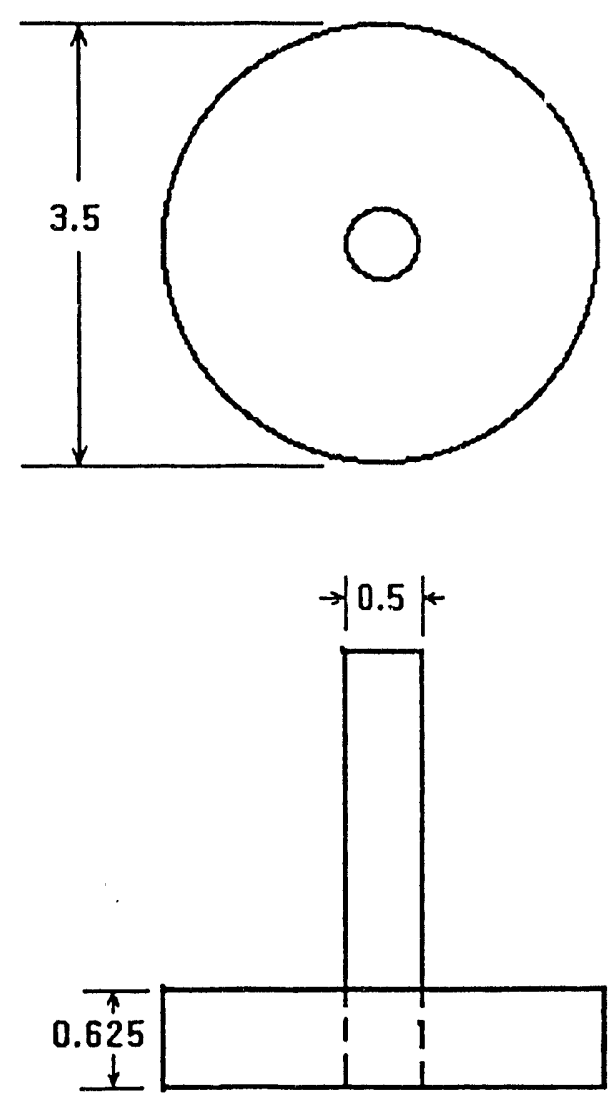

Figure 1: spin Test Specimen Blanks (Dimensions In Inches) 

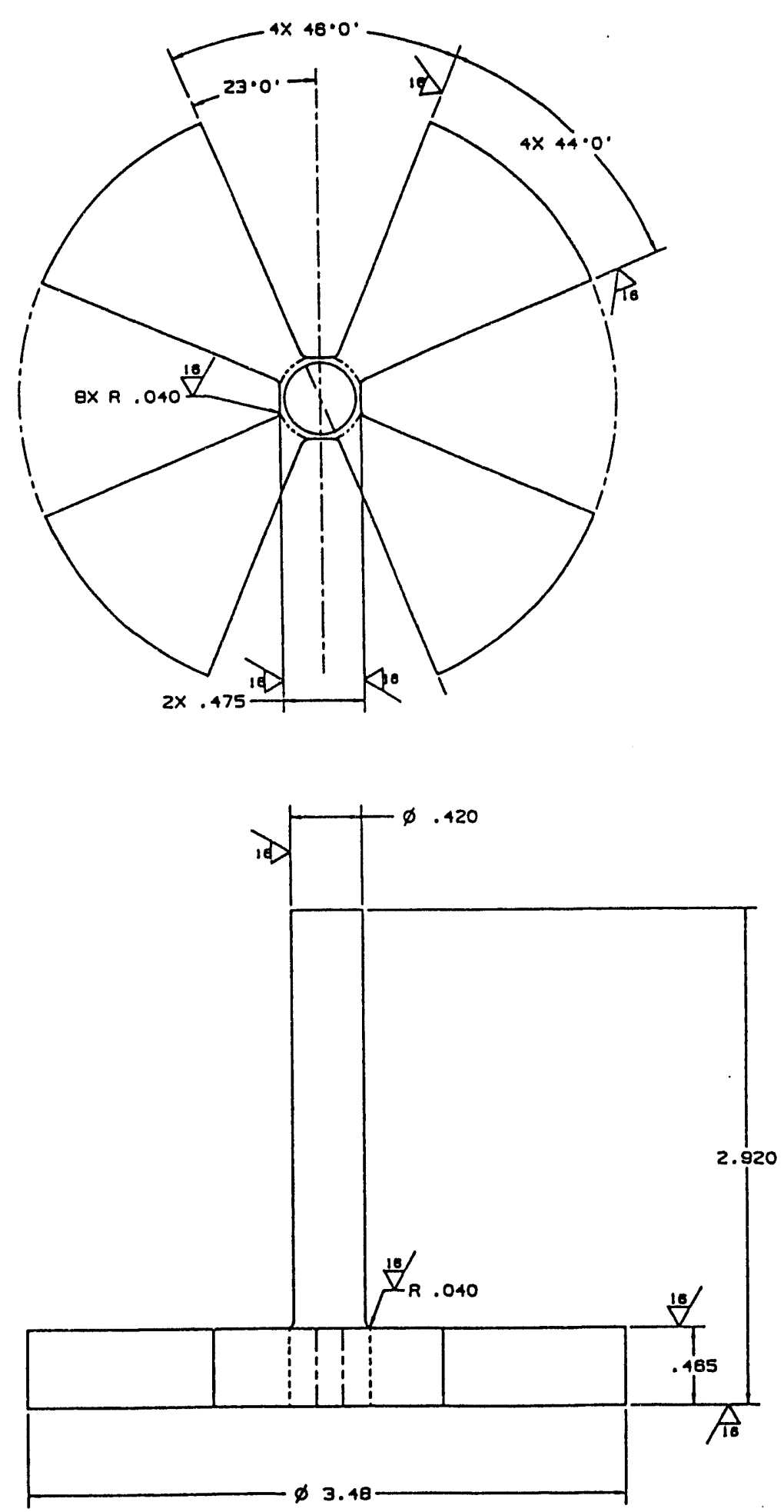

Figure 2: Spin Test Specimen Design (Dimensions In Inches) 


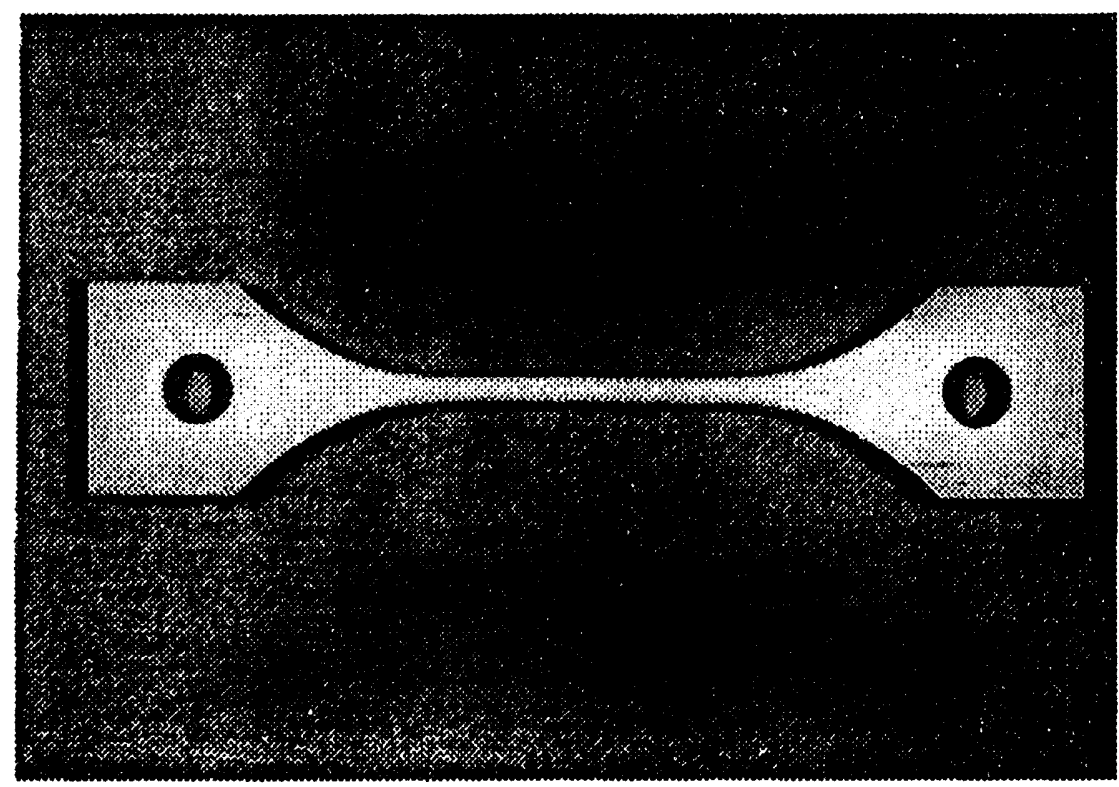

Figure 3: Pin Loaded Round Gauge Dogbone Tensile Specimen

Table 1: Round Gauge Dogbone Tensile Test Specimens

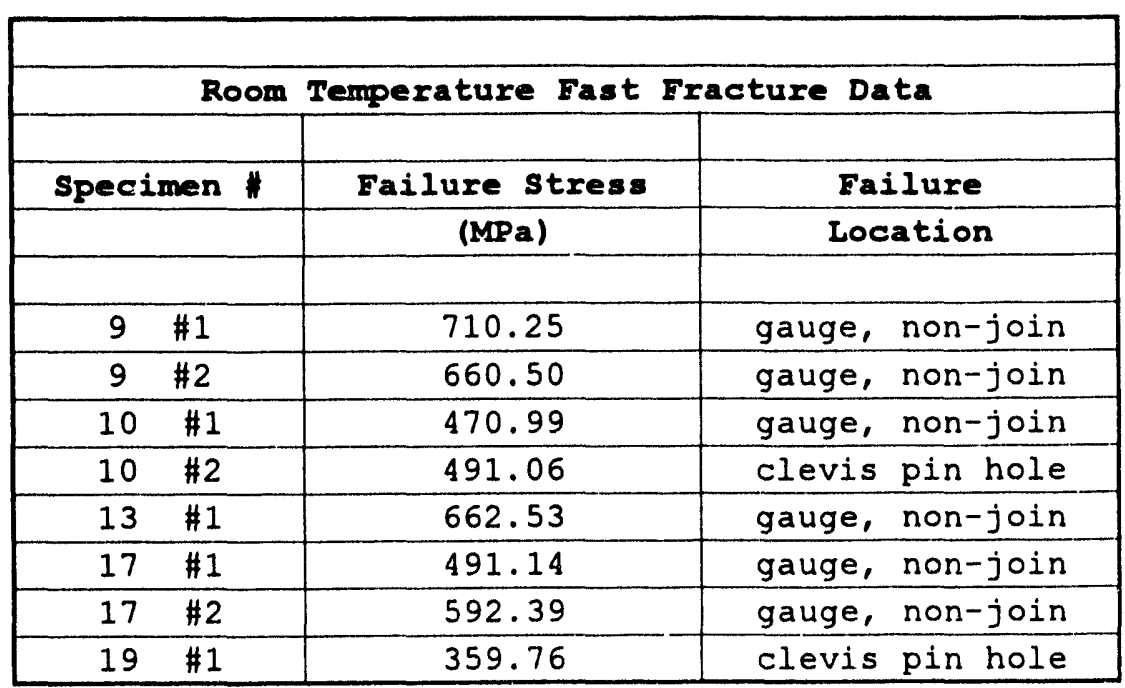




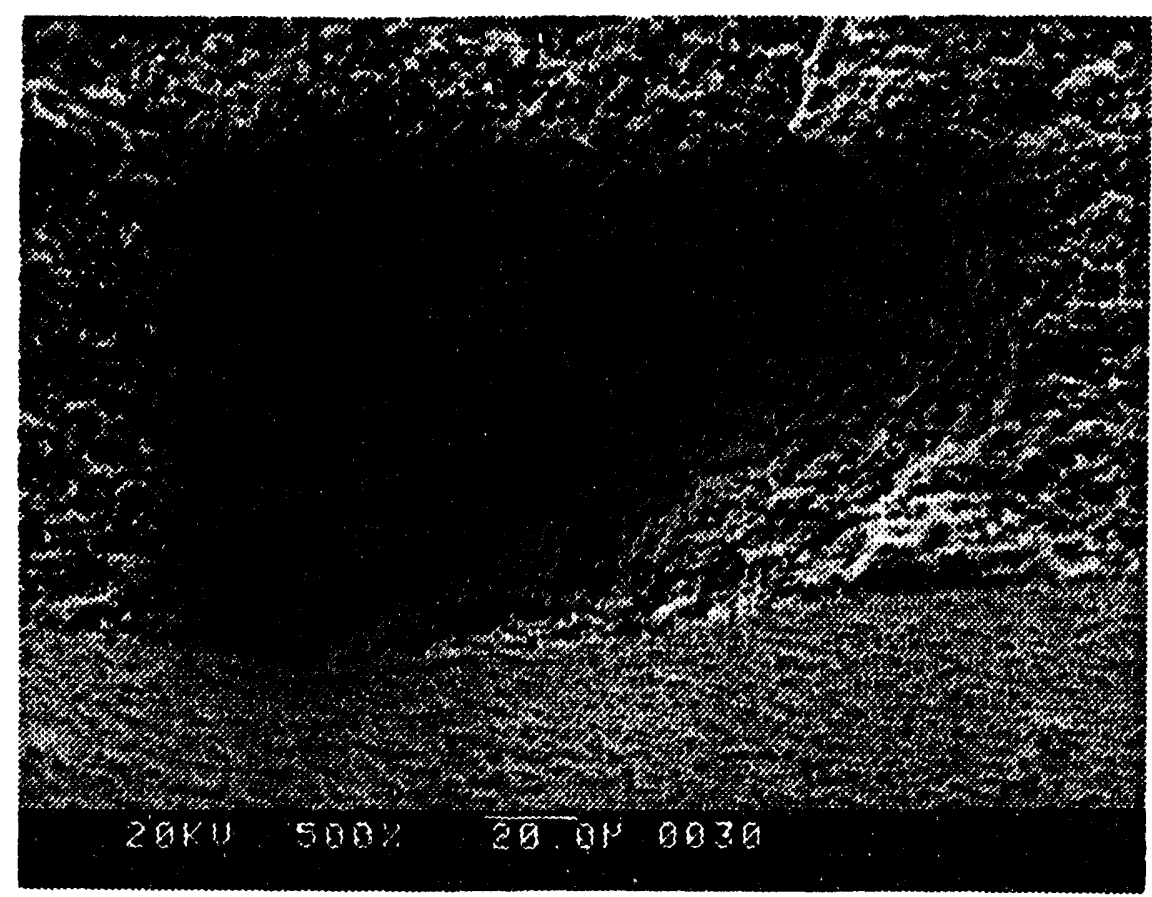

Elgure 4: Failure Origin of $\mathrm{A}$ silicon Nitride Round Gauge Dogbone Tenille specimen \#17-1 At 500X Magnification

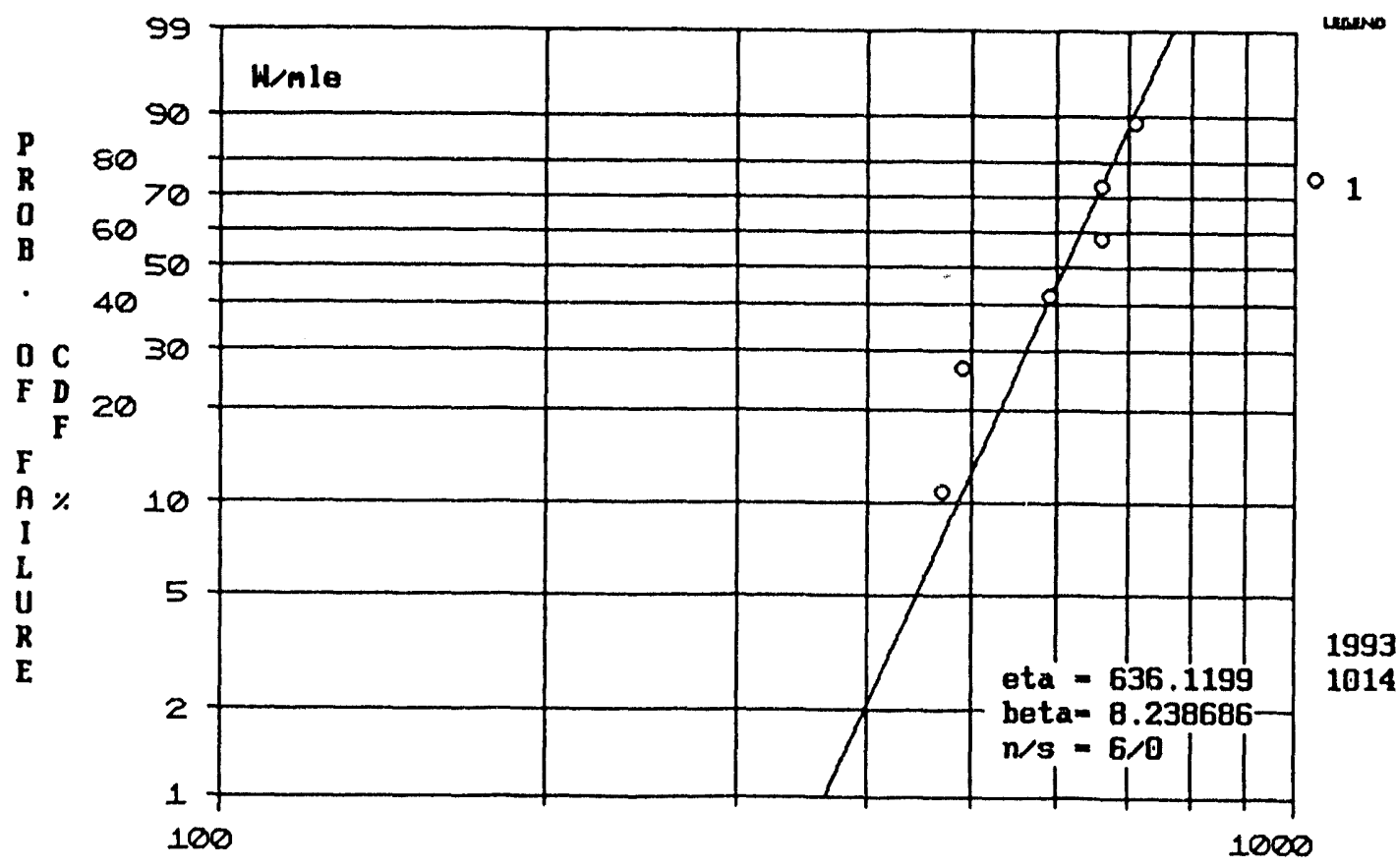

STRENGTH (MPa)

Flgure 5: Welbull Probabllity Plot of The Round Gauge Dogbone Tensile spocimens 


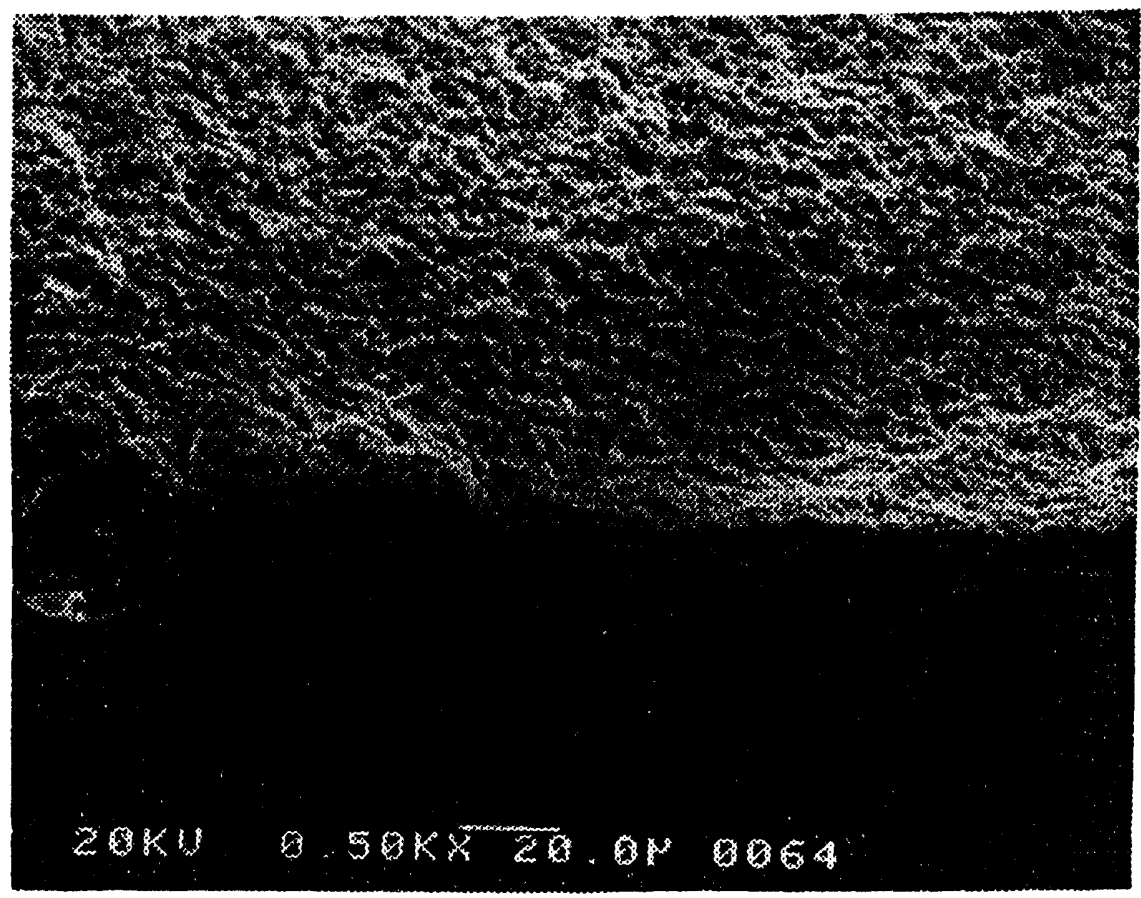

a) $500 x$ Magnification

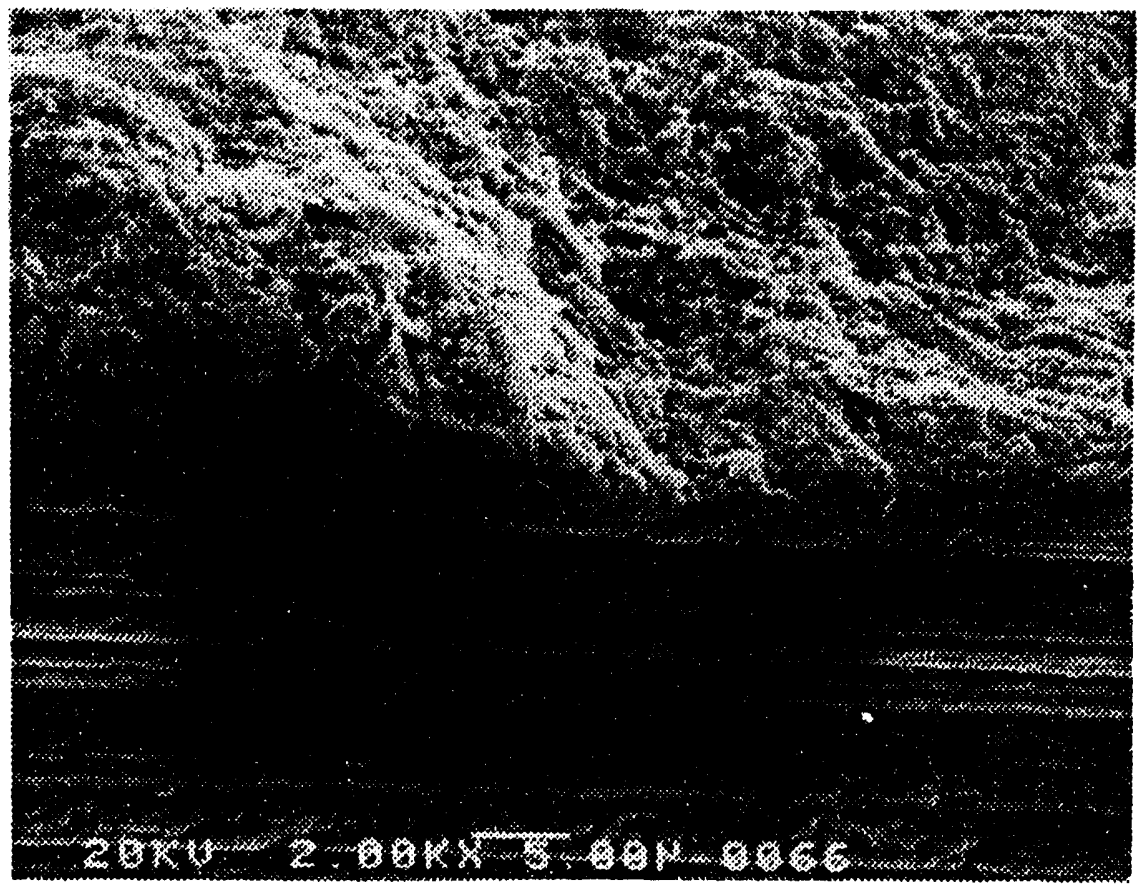

b) 2000X Magnification

Figure 6: Fallure origin of A Silicon Nitride spin Test specimen \#11 
151

Table 2 : Spin Test Pallure Data

\begin{tabular}{|c|c|}
\hline SRECIMEN & EAILURE SPEED (rPM) \\
\hline 1 & 17,000 \\
\hline 2 & 32,030 \\
\hline 3 & 36,820 \\
\hline 4 & 37,980 \\
\hline 5 & 42,530 \\
\hline
\end{tabular}

Finite element analysis has been conducted to assess the stress levels associated with the spin test and is near completion. The stress distribution determined from this analysis will be used in conjunction with the available strength data to establish failure predictions using CARES for comparison with the experimental data. 


\section{STATUS OF MILESTONES}

The following modifications to the S.O.W., requested by Norton Company during this reporting period, have been accepted by MMES/ORNL.

Milestone $2.1 \mathrm{~A}$ will be considered complete;

Milestones $2.1 \mathrm{~B}, 2.2,2.4 \mathrm{~A}$ and $2.4 \mathrm{~B}$ will be dropped; and

the subcontract will be extended through December 31,

1993 .

Milestones are on schedule according to the revised statement of work.

COMMUNICATIONS/VISITS/TRAVEL

None.

PROBLEMS ENCOUNTERED

See STATUS OF MILESTONES section.

PUBLICATIONS

None.

ACKNOWLEDGEMENTS

The authors would like to acknowledge the continued

contributions of J.G. Gillam, M.J. Mangaudis, L.D. Ton, T.M. Trostel and A.M. Vartabedian.

\section{REFERENCES}

1. M.R. Foley, G.A. Rossi, G.J. Sundberg, J.A. Wade, F.J. Wu, Analytical and Experimental Evaluation of Joining Silicon Carbide to Silicon Carbide and Silicon Nitride For Advanced Heat Engine Applications, Final Report, Subcontract $86 \mathrm{X}-58045 \mathrm{C}$, Norton Company. September 30, 1991, 56-86. 


\subsection{CERAMIC MACHINING}

Cost-Effective Ceramic Machining

P. J. Blau (Oak Ridge National Laboratory)

\section{Objective/scope}

The objective of this effort is to develop, in conjunction with U. S. industry, advanced technologies and the associated scientific and economic concepts necessary to reduce the costs associated with the machining of structural ceramics, especially as related to the use of these materials in energy-efficient, low-emissions transportation systems. This effort consists of subcontracts to industry and in-house research at Oak Ridge National Laboratory (ORNL), Argonne National Laboratory, and the National Institute of Standards and Technology. Progress reports for other than the ORNL inhouse research portion of this work may be found elsewhere in this publication.

The ORNL in-house research is aimed at two subtasks: (1) investigating the effects of machining practices on the durability of ceramics for valve and valve seat applications and (2) understanding and characterizing the detailed nature of machining-induced surface and subsurface damage and its evolution in advanced ceramic materials using a range of analytical tools. The scope of the first subtask includes both development of a repetitive impact testing machine to simulate operation of a valve and valve seat in combustion engines and studying the effect of machining methods on the repetitive impact behavior of machined ceramics.

\section{Technical highlights}

Repetitive impact tests designed to simulate the interaction between valves and valve seats were continued on a range of $\mathrm{Si}_{3} \mathrm{~N}_{4}$ specimens obtained from different suppliers. The impact test configuration has been discussed in previous reports. The three silicon nitride materials being tested are: Kyocera SN220M, Eaton sintered reactionbonded silicon nitride (SRBSN) (six different conditions of machining), and Norton/Saint Gobain NCX-5102.

The significant effects of relative humidity $(\mathrm{RH})$ on the impact wear were reported in a technical paper accepted for publication in the Journal of the American Ceramic Society. Tests conducted in flowing dry nitrogen atmosphere ["dry" tests (<3\% RH)] showed significant amounts of wear compared to tests done under "humid" conditions. This difference is attributed to a change in the fracture mode of the ceramic surface microstructures. The formation of brittle $\mathrm{SiO}_{2}$ glass at the crack tips may be mitigated by the presence of water, leading to a reduced crack propagation rate due to crack blunting in the region of the reaction products.

In related work, NCX-5102 silicon nitride was machined by Chand Kare Technical Ceramics, Inc., under seven conditions to systennaticially investigate the effect of machining parameters on repetitive impact wear Le/,1avior. Tests have begun on these materials.

In a cooperative effort, J. Bjerke of Caterpillar Technical Center, Peorla, Ilinols, has been measuring the residual stresses of variously machined specimens that have been subjected to repetitive impact tests. Correlations between the residual stress state and the rate of impact wear are being studied. This work may lead to an article or short communication. 
Work began on using the new Leltz scanning acoustlc mlcroscope, purchased under the Ceramic Technology Project, to study machining damage. Initial imaging results with both ground and polished silicon nitride suggest that to obtain high resolution of subsurface defects, the technique is best sulted to well-finished surfaces. Additional experiments to optimize this new subsurface flaw imaging instrument for ground coramics will be conducted during the next year.

A project coordinating meeting was held on September 8, 1993, in Oak Rilge, Tennessee, to improve coordination between principal investigators (Pls) in the CostEffective Ceramic Machining (CECM) project and to allow industry to critiqise the various projects. This meeting was attended by 43 people. Nine presentations were given on both subcontractual and government laboratory efforts. The program is shown in Fig. 1. Attendees were asked to grade presentations and projects on the basis of relevance to CECM, technical approach, progress to date, and usefulness of the project results to their own organizations. Consolidated responses and sets of comments were provided to each $\mathrm{Pl}$ as feedback on his work.

\section{Future plans}

Work will continue on repetitive impact testing using specimens of production metal alloy valves for comparison with the ceramic valve specimens.

Work will continue on correlating residual stress data with impact wear results.

Further studies of optimizing acoustic microscopy for ceramic machining studies will be conducted.

\section{Status of milestones}

On schedule.

\section{Communications/Nisitors/travels}

Dr. Bishu Bandyopadhyay, University of North Dakota, spent ten weeks at ORNL summer visiting faculty fellowship (May-July 1993). Working with Dr. Srinivasan, he made surface pullout measurements and helped to develop a new parameter to assess machinability based on specific energy and surface roughness.

Dr. Joe Kovach and K. Ziegler, Eaton Corporation, visited ORNL on July 23, 1993, to discuss results from the joint project on surface damage characterization of ground ceramic specimens.

P. J. Blau and S. Srinivasan attended the International Conference on Machining of Advanced Materials at the National Institute of Standards and Technology, Gaithersburg, Maryland, on July 19-22, 1993.

A CECM Coordinating Meeting was held at the Comfort Inn, Oak Ridge, Tennessee, on September 8, 1993, to review progress on the various subcontracts and in-house projects. Descriptions of all CECM projects were presented as was as a description of the related Defense Programs and User Center activities. 


\title{
COST-EFFECTIVE CERAMIC MACHINING Project Review and Coordination Meeting
}

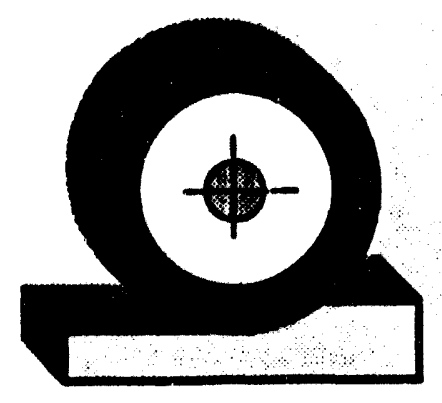

\author{
Comfort inn \\ IIIInols and Rutgers Avenue \\ Oak Ridgo, Tonnesseo
}

September 8, 1993

8:15 am - 4:00 pm

Purpose of this Meeting: The purpose of this meeting is to review progrese in the Deparument of Energy, Orice of Tranportution Matarials, project on Cost-Efroctive Ceramic Machining (CECM). Moat invited epenkess ane principal investigators from CEGM projects. Attendees will be encouraged to critique and discuss the current projects. A collection of extended absuracts for all CECM projects will be provided at the meeting.

\section{Schedule of Presentations}

8:16 Overview of the Cost-Effective Ceramic Machining Project - P. J. Blau, ORNL

8:45 Relationship of the CECM Project to the Low Cost Ceramics Effort - D. R. Johnson, ORNL

9:00 Environmental Safety and Health Aspects of Ceramic Machining - R. Ogle, ORNL

9:15 Japanese Ceramic Machining Technology - B. P. Bandhyopadhyay, U. of N. Dakota

9:45 Break

10:00 High-Speed, Low-Damage Grinding - J. A. Kovach, Eaton Corporation; S. Malkin, U. of Massachusetts

10:30 NIST Ceramic Machining Consortium - Said Jahanmir, NIST

11:00 Development of the Next-Generation Grinding Wheel for Ceramics - speaker to be announced

11:30 Lunch

1:00 Development of a Compact Grindability Test System for Ceramics - speaker to be announced

1:30 Repeated Impact Testing of Ground Ceramics for Valve Applicationa - S. Srinivasan, ORNL

2:00 Chemically-Assisted Grinding of Ceramics - S. M. Hsu, NIST

2:30 Break

2:45 Development of Novel Laser-Scattering Methods for In Situ Flaw and Damage Detection -

W. Ellingson, ANL; M. Hazelkorn, Caterpillar, Inc.

3:15 Status of the Ceramic Manufacturability Center and Machining CRADA's - speaker to be announced

3:30 Future Plans and General Discussion

3:45 Concluding Remarks - P. J. Blau, ORNL

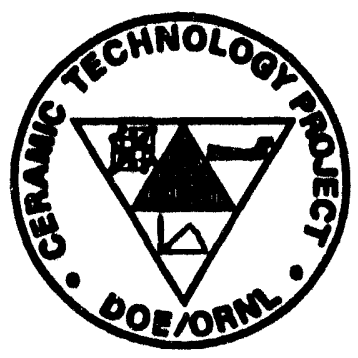

Fig. 1. Program for the CECM Coordinating Meeting in September 1993. 


\section{Problems encountered}

None.

\section{Publications/presentations}

1. B. P. Bandyopadhyay and P. J. Blau, Survey of Ceramic Machining in Japan, ORNL M/-2881, Martin Marietta Energy Systems, Inc., Oak Rldge Natl. Lab., July 1993.

2. S. R. Srinivasan and P. J. Blau, "Effect of Relative Humidity on the Repetitive Impact Behavior of Machined Sillicon Nitride Surfaces," accepted for publication by J. Am. Ceram. Soc. (1993).

3. J. A. Kovach, P. J. Blau, S. Malkin, S. Srinivasan, B. Bandyopadhyay, and K. Zeigler, "A Feasibility Investigation of High Speed, Low Damage Grinding for Advanced Ceramics," in Proc. of the Filth International Grinding Conference, Vol. I, October 26-29, 1993. 
Grindine Optimiartion for Advanced Ceramics

Said Jahanmir (National Institute of Standards and Technology)

\section{Objective/Scope}

The overall objective of this project is to develop guidelines and recommendations for grinding optimization of advanced structural ceramics to achieve minimum cost and maximum rellability. The following steps are being taken to achieve the objective: conduct grinding experiments jointly with industrial participants, determine effect of grinding parameters on machining damage and strength, elucidate mechanisms of material removal and damage formation, evaluate several damage detection techniques, and transfer data and information to industry in computerized database format.

\section{Technical Progress}

\section{a) Backsround}

Advanced structural ceramics, such as silicon nitride, are attractive for many advanced engine applications due to their high strength at elevated temperatures, resistance to chemical degradation, abrasive wear resistance, and low density. Despite these advantages, there are considerable impediments to the introduction of ceramics. Recent comprehensive studies have indicated that with current technology, fabrication costs are high and component reliability is uncertain. Machining was identified as a major contributor to both high cost and low reliability. The cost of machining can be as high as 90 percent of the total cost of some high precision components. Damage produced during machining can be detrimental to the performance, and can produce premature failure. Many industrial laboratories and companies have indicated that machining data and guidelines are badly needed for optimization of grinding, in order to produce cost-effective ceramic components.

The NIST Ceramic Machining Consortium has been established to provide measurement methods, data, and mechanistic information needed by industry to develop innovative cost-effective methods for machining advanced structural ceramics. Currently, the consortium has 17 members - Ceradyne, Cincinnati Milacron, Corning, Dow Chemical Company, Eaton Corporation, Ford Motor Company, GE Superabrasives, General Motors, Norton, SAC International, Sonoscan, Stevens Institute of Technology, Texas A\&M University, Therm Advanced Ceramics, Tower $0 i 1$ and Technology, University of Maryland, and W. R. Grace \& Company. In addition to the projects on Grinding Optimization for Advanced Ceramics, Ceramic Machinability Database, and Characterization of Machining Damage, which are described herein, research is performed on Nano-precision Grinding of Silicon Nitride Bearing Materials, Chemomechanical Effects in Drilling and Grinding of Ceramics, and Characterization of Ceramic Grinding Process. Consortium members participate in these projects by providing materials, testing, advice, and other in-kind contributions. Funding for the projects are provided by DOE - Ceramics Technology Project, DARPA Ceramic Bearing Technology Program, U.S. Navy - Manufacturing Technology Program, NIST - Ceramics Division, NIST - Office of Intelligent Processing of Materials, and NIST - Standard Reference Data Program. 


\section{b) Introduction}

Grinting with diamond wheels is the most prevalent method of machining advanced ceramics. This machining method is highly complex and its of imizacion requires detalled knowledge of many interdependent factors. The ma」or elements of a grinding system are the grinding wheel, the grinding fluid, the machine tool, and the workpiece. Each of these is assoclated with several parameters that can influence the grinding process. For example, the type of diamond grit, its size and concentration, as well as the bonding material control the behavior of the grinding wheel. The chemical and physical properties of the grinding fluid, and method of delivery to the grinding zone contribute to the grinding rate and the quality of finished surface. The variables used in grinding such as feed rate and wheel surface speed, and the machine tool characteristics such as stiffness and vibration are major factors in grinding. The workpiece material and its properties are important factors in the selection of the grinding parameters, since each material responds differently to the grinding action.

Optimization of the grinding process consists of finding the most appropriate set (or sets) of parameters to be used for each material such that a maximum machining rate is obtained and at the same time relevant performance parameters such as strength and/or surface roughness are maintained at the required level. This objective requires data and information on the effect of grinding parameters on material removal rate, strength, surface roughness, surface integrity, residual stress and others. In addition to these data, detailed information on the mechanisms of material removal processes, and reliable methods for damage detection are required.

\section{c) Grinding optimization Study}

This project has been planned in three phases. In Phase I, the participating consortium members were asked to use their experience in selecting grinding conditions to be used in the study. Each participant machined one set of flexure test bars (28 to 30 ), which were then tested and characterized at NIST for surface integrity and fracture strength. Grinding was performed along the length of the samples, i.e., parallel to the major tensile axis in four-point bending. The surface roughness was determined by a 3-D stylus surface profilometer; and the surfaces were examined by scanning electron microscopy to evaluate the surface condition. The test bars were subjected to four-point bend tests according to the ASTM Standard C 1161. The fracture strength data were analyzed using Weibili statistics. Two types of silicon nitride materials were selected fo: this study: reaction-bonded (RBSN) and sintered-reactionbonded (SRBSN). Six different grinding conditions were used to prepare the flexure bars using volumetric material removal rates which varied from 30 to $1737 \mathrm{~mm}^{3} / \mathrm{min}$. The different removal rates were achieved by using various combinations of down feed, cross feed, and table speed. In addition to these experiments, three of the grinding conditions were used to grind flexure bars in the transverse direction, 1.e., grinding perpendicular to the major tensile axis in four-point bending. These samples were used to evaluate the effect of grinding direction on strength. 
Figure 1 shows that although the volumetric material removal rate (i.e., grinding condition) had no influence on the characteristic strength of the samples ground in the longitudinal direction, the strength of the samples ground in the transverse direction is reduced as the removal rate is increased. The strength reduction by grinding in the transverse direction appears to be material dependent, and is larger for the sintered reaction-bonded silicon nitride (SRBSN) than for the reaction bonded silicon nitride (RBSN). This finding can be justified due to the lower microstructural defects in the latter material.

In phase two of this project, a statistical design of experiments will be employed to systematically analyze the effect of various grinding parameters. The aim of this study is to achieve high removal rates while maintaining an acceptable level of surface roughness and strength. It is also planned to identify the material removal mechanisms as a function of grinding parameters, and to use fractography to identify fracture initiation sites. A factorial design of experiments has been developed for this study, which will be performed on three types of silicon nitride materials: reaction-bonded (RBSN), sintered reaction bonded (SRBSN), and sintered silicon nitride (SSN). The material billets have been obtained from the consortium members, and have been sent out for slicing and sample preparation.

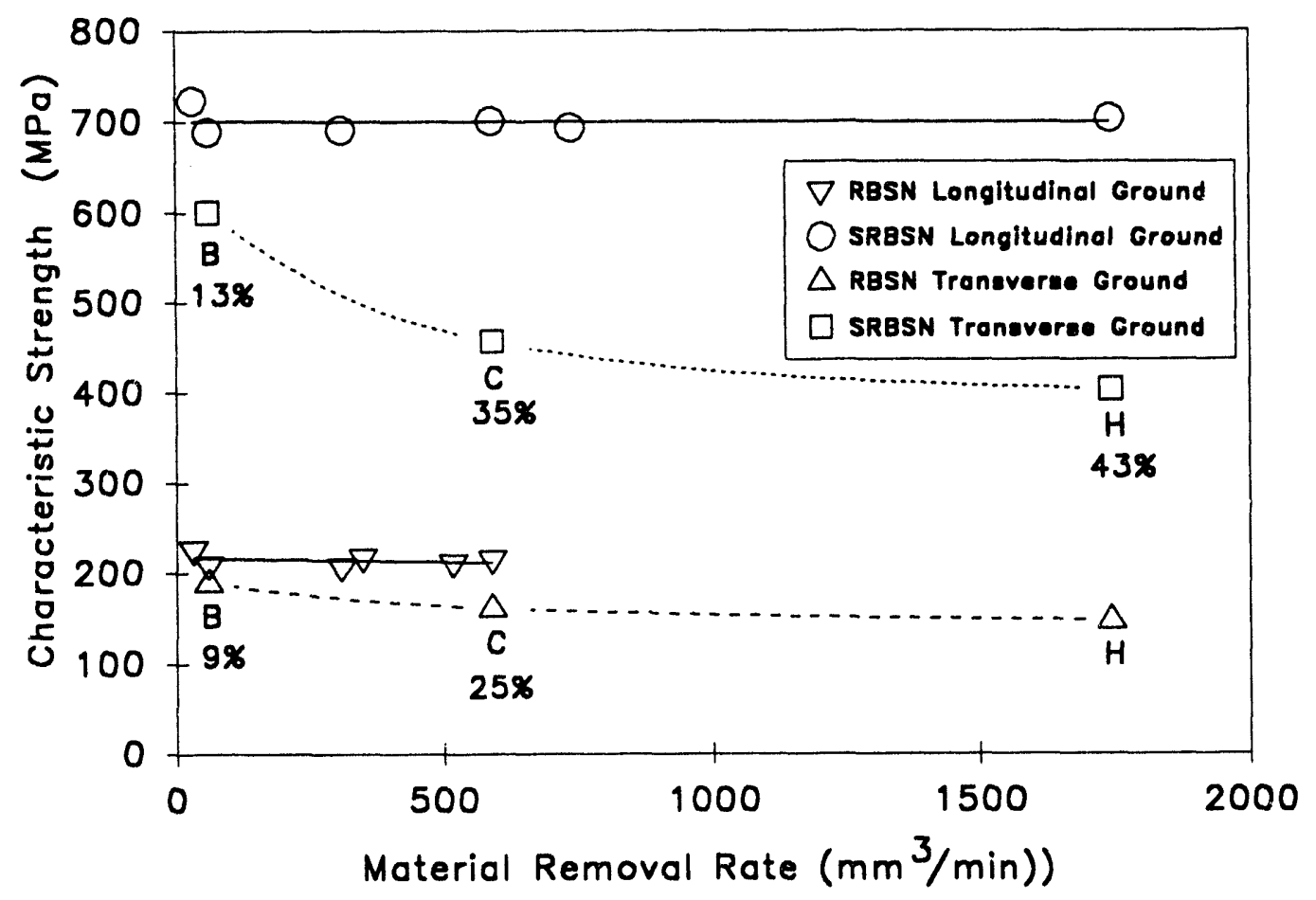

Figure 1. Effect of grinding direction and volumetric material removal rate on characteristic strength of two types of silicon nitride.

The factorial design developed for the next phase consists of a $2^{4}$ partially confounded, incomplete block design, with two replications for each material. In addition to the eight consortium members, who will 
participate in these tests, two members and NIST will perform optional tests. The parameters planned for the grinding tests are outlined in Table 1. According to this plan, table speed, down feed, wheel grit size, and grinding direction will be used as the variables; all other factors are defined, and will be kept constant. The grinding wheels have been prepared in one batch by Cincinnati Milacron with diamond particles supplied by GE Superabrasives. All slicing and pre-grinding will be done by one vendor, selected by the consortium members, to ensure uniformity of surface condition. The flexure bars will be prepared $0.125 \mathrm{~mm}$ oversized in thickness, to allow a sufficient amount of material for removal during final grinding. The flexure bars will be returned to NIST by the vendor for randomization and distribution to the participants.

Table 1. Grinding Parameters Used in the Factorial Design

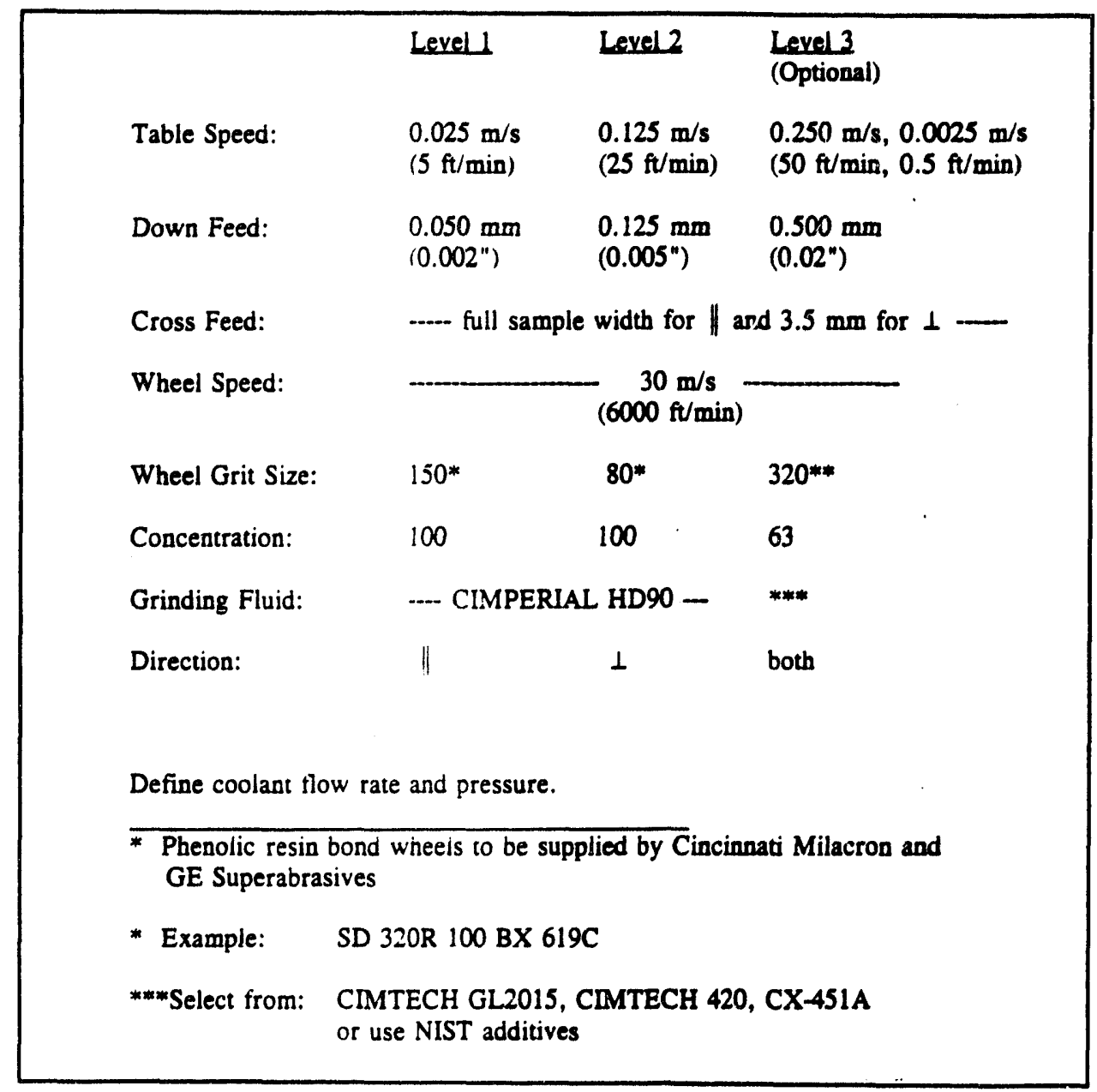

Each participant will receive complete instructions for performing the final grinding. The test order will be randomized to eliminate systematic errors. Instructions will include: a method for truing and dressing the wheel, dressing frequency, and values of fixed parameters. A sample test order for one participant is shown in Table 2. The participants will be 
asked to submit information such as machine tool characteristics, grinding forces, and other pertinent data. Throughout the slicing, pre-grinding, and final grinding, each flexure bar will be tracked as to the material type and billets and \or batch number. The finished flexure bars will be returned to the vendor for chamfering, before final submission to NIST.

Table 2. Sample Test Order for One Participant

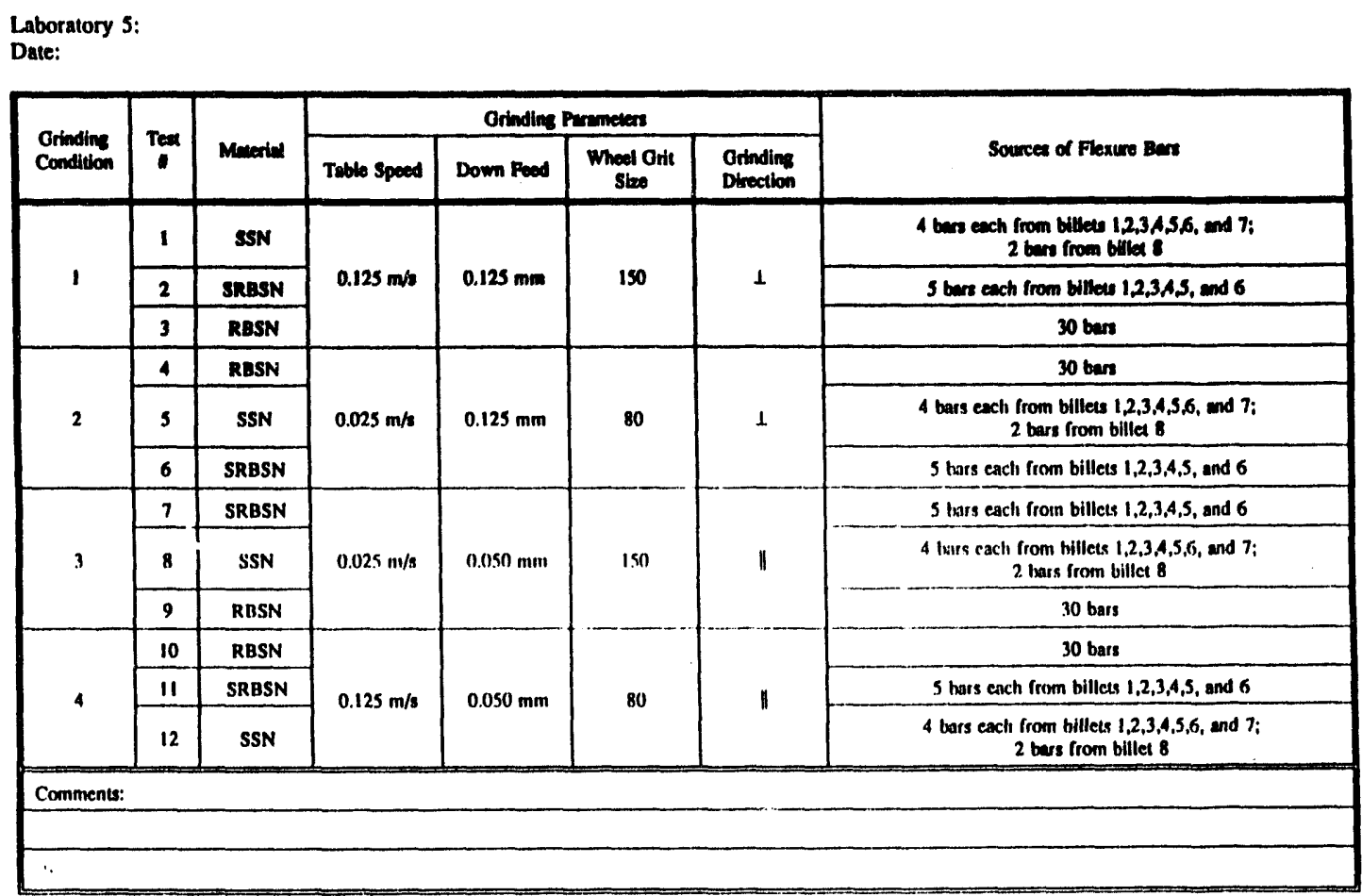

The flexure bars will be characterized at NIST for surface integrity and dimensional tolerance. All samples will be tested for strength using the ASTM four-point flexure testing procedure, and the data will be analyzed using the Weibull statistics. Statistical comparison will be made to evaluate the effects of main parameters and interactions between the main parameters. Although it would be desirable to perform complete fractography, this may not be possible due to the large number of flexure bars, i.e., over 3000 . Therefore, only selected fracture surfaces will be analyzed to detect failures due to machining damage. These data and those currently being gathered from literature, will be used in the Ceramic Machinability Database.

\section{b) Ceramic Machining Database}

The Ceramic Machinability Database will provide easy access to machinability data for different types of ceramics and will help users such as manufacturing engineers, tooling managers, and machinists develop machining plans for cost-effective production of ceramic parts. For example, the manufacturing engineer may have already selected the material 
to be used for the part and the necessary machining operations, but does not know what machining parameters to use. The database will provide this information for the selected material.

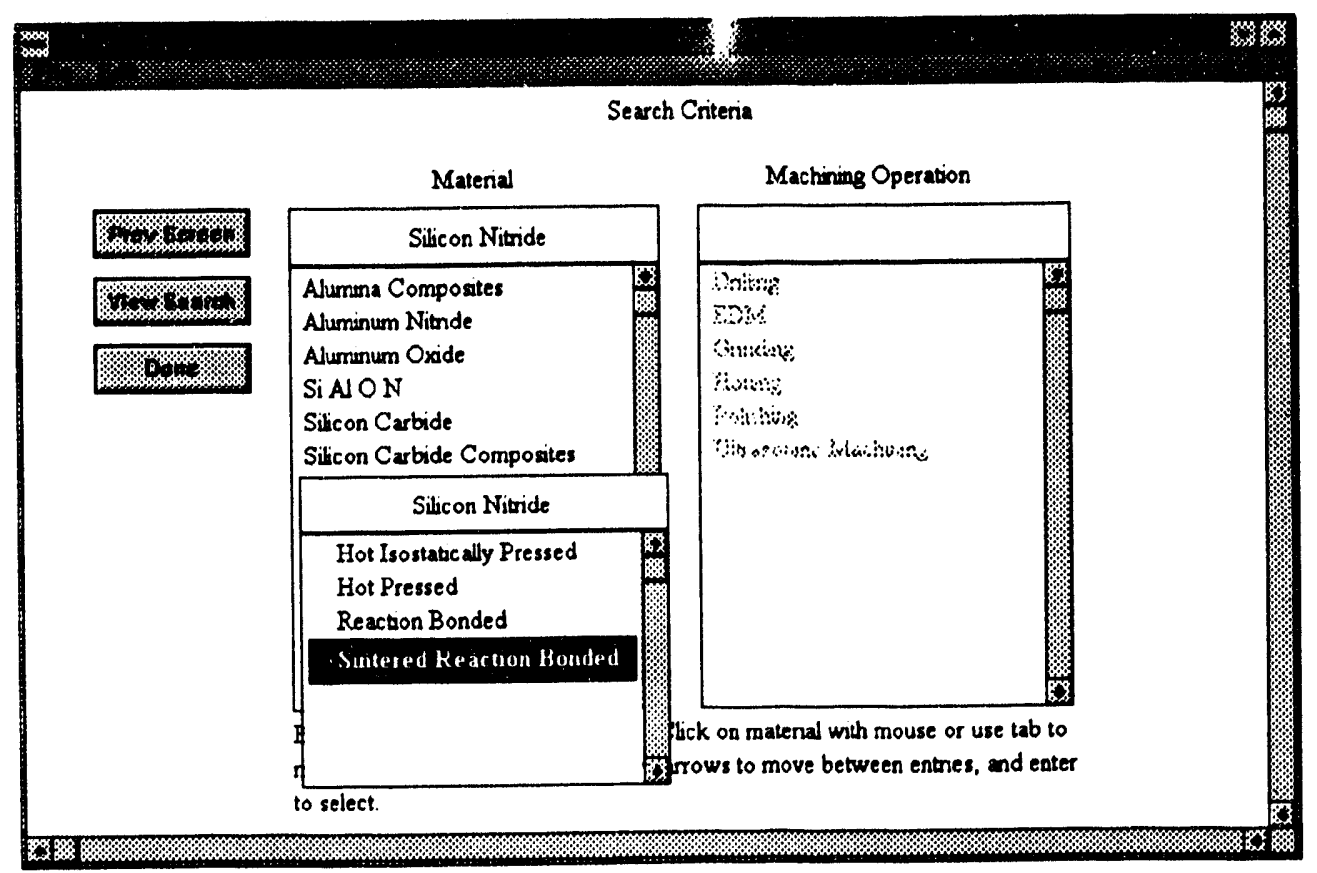

Figure 2. Material Selection Screen in the Database

The functionalicy of the database has been developed. The user will, in general, input criteria to obtain the data that is desired from all of the data within the database. A typical search of the database begins with the user choosing the material of interest. One of the screens used for conducting such a search is shown in Figure 2. The user then chooses the machining operation of interest. Next, the user may view all of the records corresponding to that material and machining operation, or may further narrow the search by some criteria. For example, the user may wish to look only at records where the rms roughness produced by machining the material is within a certain range. This is shown in Figure 3. After all of the search criteria has been entered, the user hits the "DONE" button and the records contained in the database that satisfy the search criteria are displayed. The user can order these records, view them one at a time or see them all at one time. The records contain complete machining parameters and measured results of machining such as strength, surface roughness, and machining forces. The user can further manipulate these results by comparing them graphically.

The database package FoxPro for Windows (Microsoft) has been purchased and the actual database tables for this application have been created. Foxpro was chosen because it has all the features needed to create this application, it is easy to use, it is a popular and well established database package, and the programs can be compiled to run on DOS, Windows, Macintosh, and Unix based computers. 


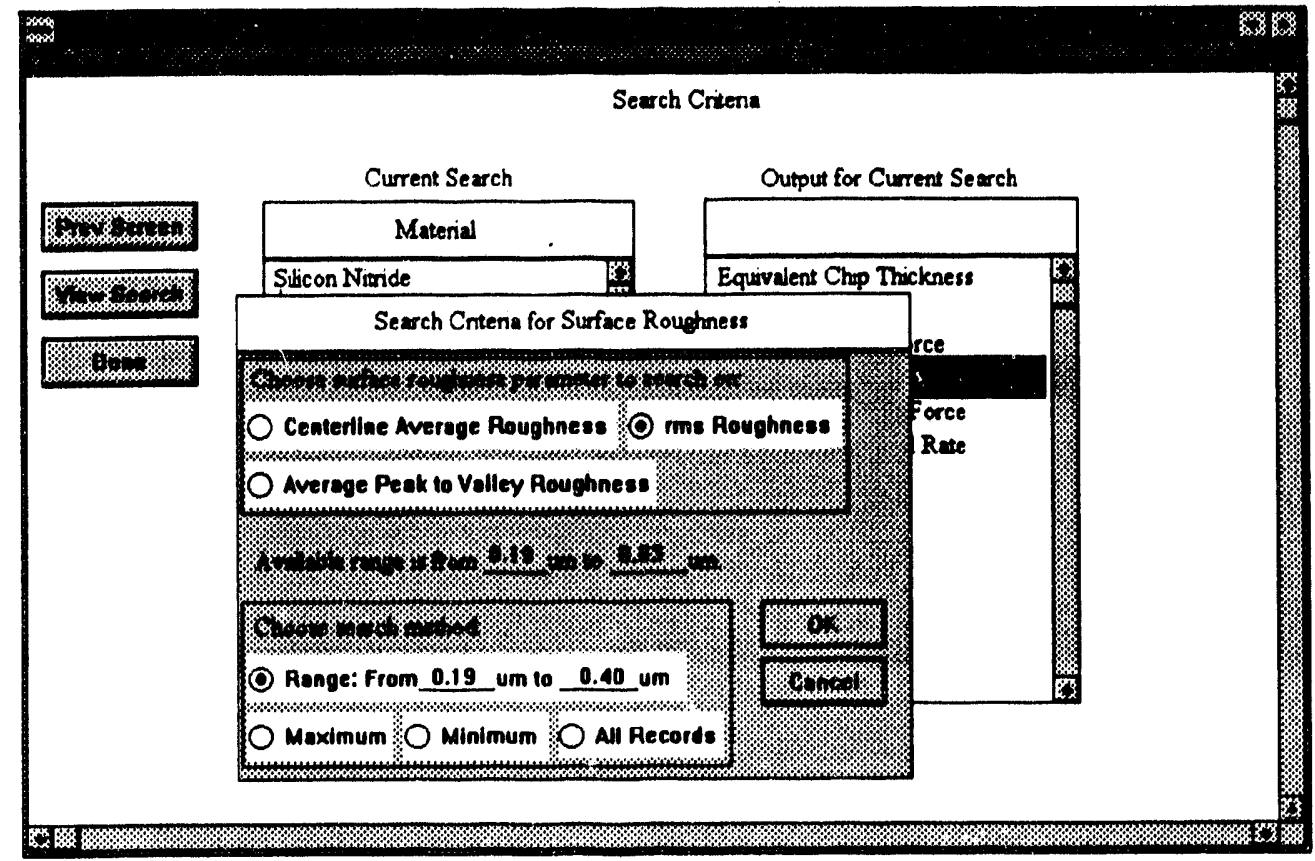

Figure 3. Search Criteria Screen in the Database

\section{c) Characterization of Machining Damage}

The objective of this study is to compare various techniques for detection and evaluation of machining damage. Taper-sectioning has been used for this purpose, and a few samples have been analyzed for machining damage by ultrasonic techniques and thermal wave measurement. It is also planned to use $x$-ray diffraction for residual stress measurement. The results of taper-sectioning and fractography on the longitudinal ground samples have been complementary in showing no machining damage under the various grinding conditions used in the first phase of this project. The preliminary results obtained by ultrasonic techniques and thermal wave measurement are encouraging; some of these results are described in this report.

The thermal-wave measurement technique is a powerful tool for evaluating the thermal properties of materials. This technique is based on the measurement of temperature distribution (both in time and in space) generated by localized heating of the material being tested. It has the advantages of being non-destructive and non-contact, and it can provide information on the thermal properties of the material as a function of depth. In our study of ground silicon nitride specimens, the samples were locally heated by a modulated laser beam. This modulated heating generates a changing temperature distribution, i.e. thermal wave, in the sample and in the air above the sample. The thermal wave in the air causes a modulated change of the index of refraction. The temperature distribution is then detected by measuring the deflection of a probe laser beam passing through the air near to the sample surface. This method is sometimes referred to as the mirage-effect thermal wave technique; and it is, in principle, sufficiently sensitive for the detection of surface and 
near surface microcracks, because the microcracks can change the local thermal flux.

The preliminary results obtained for ground SRBSN specimens are summarized in Figure 4. The grinding conditions, the volumetric removal rate and the surface roughness of the samples are listed in Table 3 . In Figure 4 , the phase of the mirage deflection signal (in radian) is plotted against the relative position between the two laser beams. The different slopes observed in Figure 4 for the samples prepared under different conditions indicate different time delays for the heat diffusion process in the specimens. Figure 5 indicates a difference between a baseline polished sample and the ground samples, and also a possible correlation between the thermal wave signal and volumetric removal rate for the ground samples. Although the surface roughness of the ground samples does not correlate with the thermal wave results, Figure 6 shows that the baseline polished sample produces a signal which is distinct from the ground surfaces. A more detailed study is planned to explore further the feasibility of the thermal wave technique for detection of machining damage of ceramics.

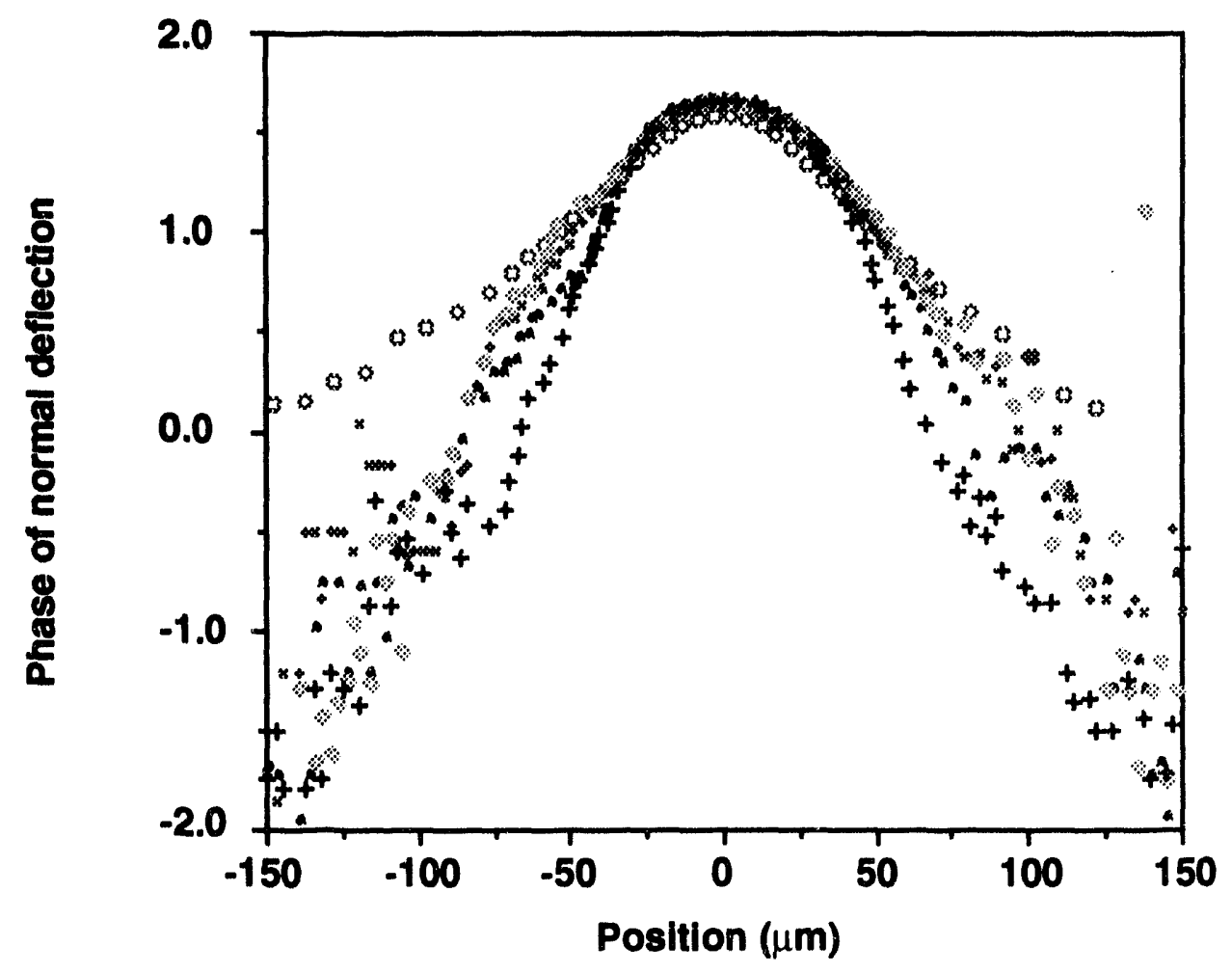

Figure 4. Thermal wave results obtained on SRBSN samples prepared by polishing and by different grinding conditions. (The data points are identified in Table 3) 
Table 3. Ground Surfaces Evaluated by Thermal Wave Measurement

\begin{tabular}{|c|c|c|}
\hline $\begin{array}{c}\text { Grinding } \\
\text { Specimen }\end{array}$ & $\begin{array}{c}\text { Volumetric Removal Rate } \\
(\mathrm{mm} 3 / \mathrm{min})\end{array}$ & $\begin{array}{c}\text { Surface roughness } \\
(\mu \mathrm{m})\end{array}$ \\
\hline$+\quad$ (Condition A) & 30 & 0.32 \\
$-\quad$ (Condition B) & 59 & 0.2 \\
(Condition D) & 310 & 0.18 \\
(Condition H) & 1737 & 0.37 \\
(Pollshed) & & 0.01 \\
\hline
\end{tabular}

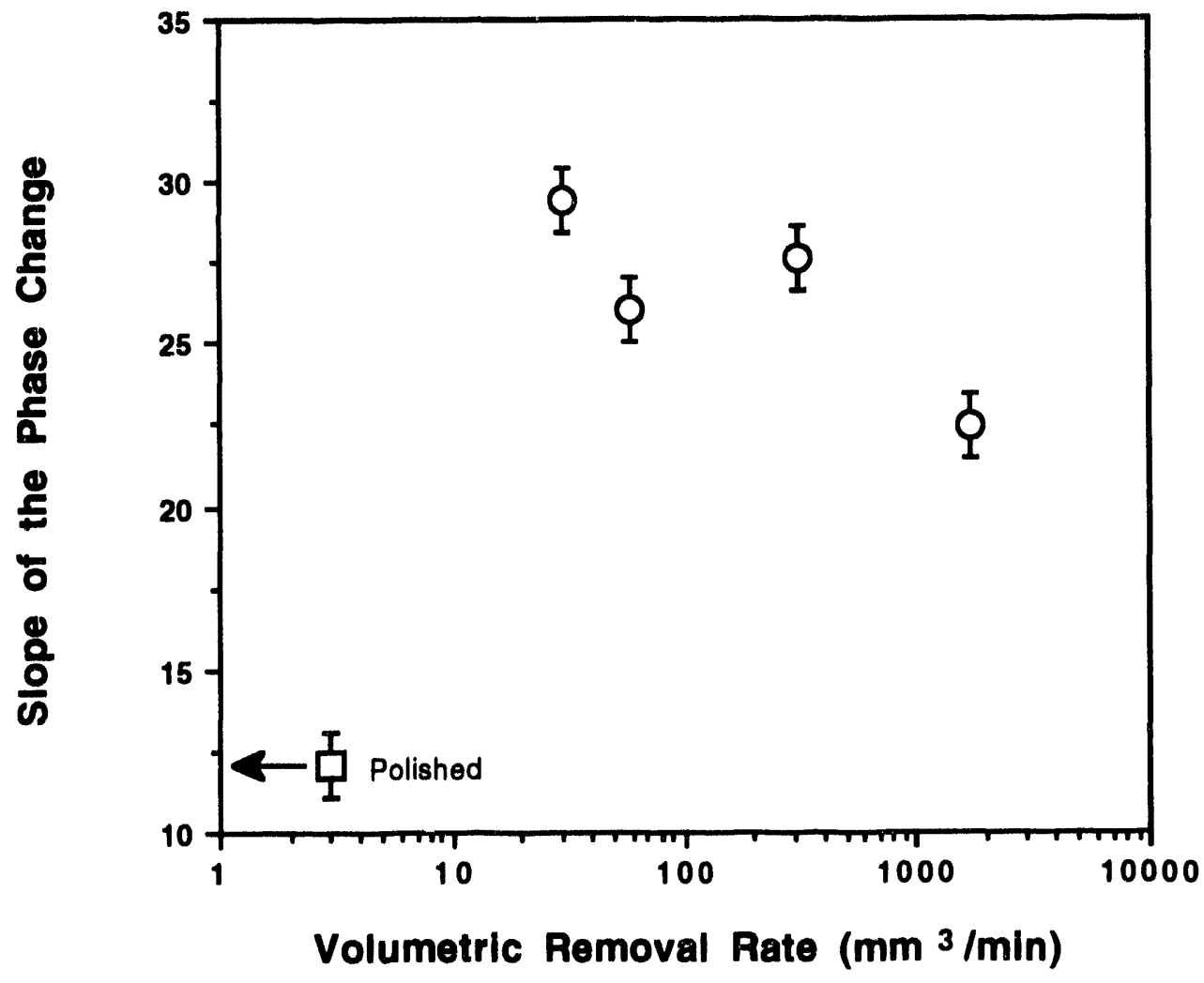

Figure 5. Effect of volumetric material removal rate on the slope of the phase change detected by thermal wave measurement on SRBSN. 


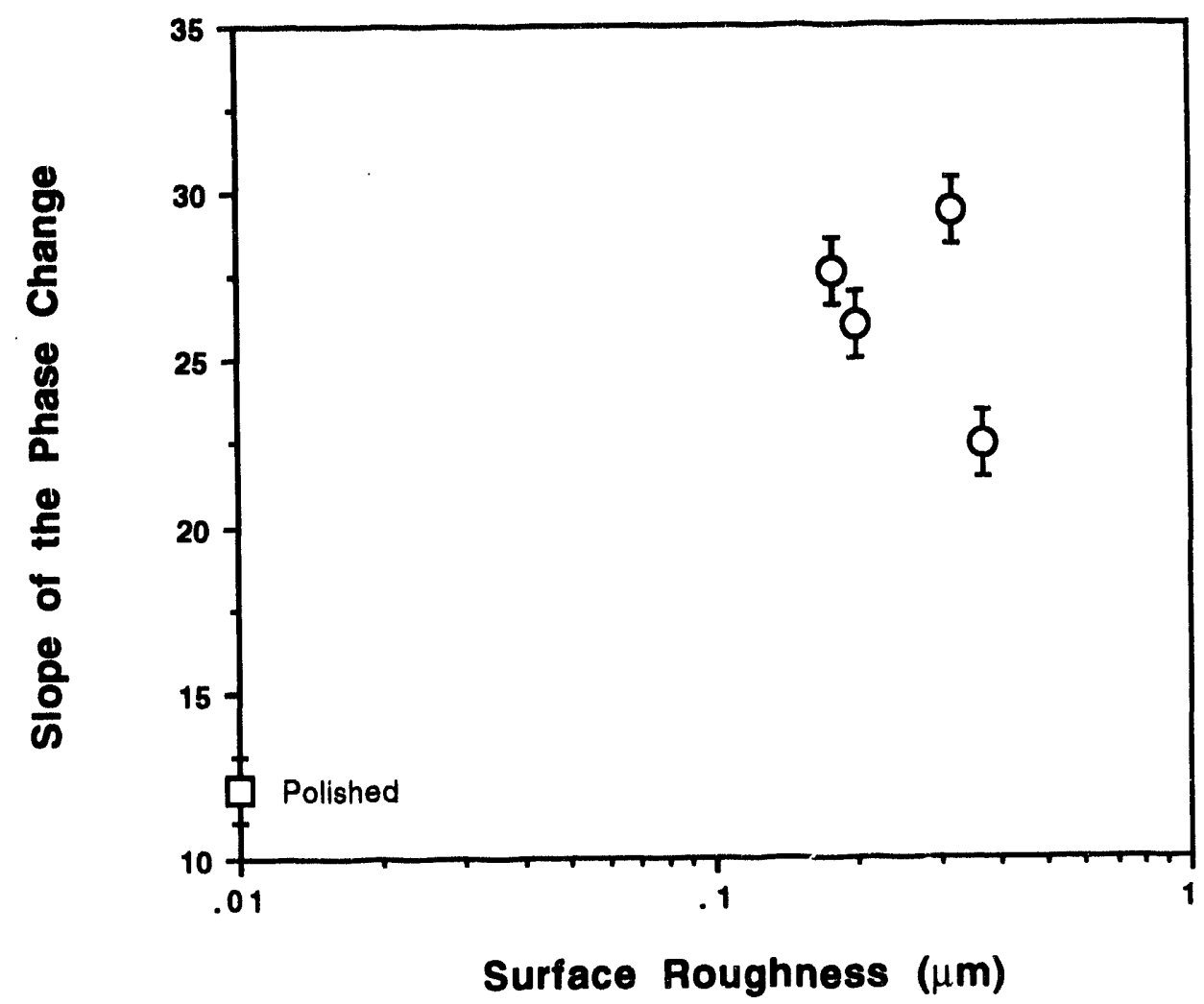

Figure 6. A comparison between the thermal wave results on a polished baseline sample and ground samples of SRBSN.

\section{Status of Milestones}

1. Prepare 300 specimens ground under "best in-house" conditions to establish bounds for a more extensive data program (Sept. 1, 1992, Completed).

2. Complete fracture testing, characterization, and preliminary statistical analysis of data (Dec. 1, 1992, Completed).

3. Evaluate feasibility of thermal wave measurement on selected flexure specimens ground under different conditions (Apr. 1, 1993, Completed).

4. Select grinding conditions based on statistical design of experiments, and distribute additional 2000 flexure bars for grinding (Jun. 1, 1993, On Schedule).

5. Develop a preliminary database structure to be used for data collected in this study and those collected from literature (Sept. 1, 1993, Completed). 


\section{Publications}

1. S. Jahanmir, T. Strakna, G. Quinn, H. Liang, R. Allor, and R. West, "Effect of Grinding on Strength and Surface Integrity of Silicon Nitride, Part 1," International Conference on Machining of Advanced Materials, NIST, Gaithersburg, MD, July 20-22, 1993.

2. S. Jahanmir, T. Strakna, G. Quinn, R. Kopp, S. C. Yoon, and K. Kumar, "Effect of Grinding on Strength and Surface Integrity of Silicon Nitride, Part 2," International Conference on Machining of Advanced Materials, NIST, Gaithersburg, MD, July 20-22, 1993. 


\section{Chemically Assisted Machinine of Ceramics \\ S. M. Hsu, T. N. Ying, J. Gu, Y. S. Wang \\ (National Institute of Standards and Technology)}

\section{Objective/Scope}

The ceramic industry has identified the lack of a rapid low-cost ceramic machining technology as one of the major barriers for widespread use of ceramics. Current machining technology for ceramics is slow and labor intensive. Residual surface damage on machined surface and the characterization of such surface defects are the key industrial concerns. This project aims to increase the machining rate of ceramics using chemical reactions at the interface. The chemical reactions could change the hard ceramic surface into something softer hence reduce the contact stresses and damage. The reaction product layer produced could also change the conditions at the interface between the diamond abrasive and the ceramic surface reducing the wear of the diamond thus increasing the machining rate. $\mathrm{Si}_{3} \mathrm{~N}_{4}$ is the main material of focus, but other materials such as $\mathrm{SiAlON}$ or $\mathrm{SiC}$ will also be examined.

The project involves several subtasks including:

1. Development of a bench test simulation to allow screening of chemistries under well-controlled conditions. Identify new chemistries that can significantly improve the machining rate of ceramics, especially for silicon nitrides.

2. Set up a surface grinder and develop test procedures to test and validate various chemistries identified in the bench test.

3. Characterize the quality of the machined surface. Develop a simple test method that can link surface damage from machining to strength. Establish surface quality using such technique for various chemistries.

4. Establish limits of performance and applicability of the chemistry on different material compositions and processes. Establish optimum machining conditions for each chemistry, material combinations.

5. Validate the concepts and methodology in industrial applications.

\section{Technical Progress}

\section{SCREENING OF CHEMISTRIES}

A simple cutting device (VC-50 diamond saw made by Leco Corp.) was used as the screening tool for various chemistries. The cutter has a maximum linear speed of $3.3 \mathrm{~m} / \mathrm{sec}$. 
with a diamond cutting wheel of $12.7 \mathrm{~cm}$ diameter, $0.35 \mathrm{~mm}$ thick. The average diamond grain size is $50 \mu \mathrm{m}$ and the diamond is bonded by copper. Before each test, the diamond wheel is dressed by a dressing stone for consistent initial cutting condition. The loading mechanism was modified to accommodate a dead weight loading system. A displacement transducer was attached on the loading arm to measured the cutting rate. The transducer was linked with a data acquisition system and a computer. The cooling fluid container was replaced by a plastic zipper bag. For each test, a new bag is used to avoid cross contamination of chemicals from test to test. The apparatus is shown in Fig. 1.

Baseline data on a silicon nitride supplied by Kennametal Corp. were obtained using current commercial cutting fluids used in NIST machine shop. For a rectangular bar of $4.6 \mathrm{x}$ $16.5 \mathrm{~mm}$, the time it takes to cut through the bar under a constant load of $7 \mathrm{~N}$ is from $248 \mathrm{sec}$. to $700 \mathrm{sec}$. depending on the fluid. For deionized water, the cut-through time is $1800 \mathrm{sec}$.

Previously we have demonstrated the functional dependence of cutting rate of silicon nitride as a function of the cutting fluid chemistry. Different fluids have different time decay characteristics, i.e. the cutting rate decreases with time. The cutting rate can be divided into two stages: the initial rate and the steady state rate. The initial cutting rate $K_{i}$ can be measured by the steepest slope method based on the cutting data at the beginning of the test. After some time, the cutting rate gradually decreases towards a steady state rate which can be measured by the average slope of the data using a least square method and can be defined as $\mathbf{K}_{\mathbf{a}}$. The interception of the two slopes defines the transition time $T_{i}$ which measures the time it takes for the initial rate to change to the steady state rate. The loss of cutting efficiency $L_{c}$ then can be defined as:

$$
L_{e}=\frac{K_{l}-K_{s}}{K_{l}} \%
$$

Using these terms, we now have a quantitative description of the process. This is important to characterize different fluids.

Tables and 2 present the data collected to date in organic and aqueous solvents. The tests were conducted with different chemical compound classes. In general, the loss of cutting efficiency in aqueous fluids is much higher than that of the organic-based fluids. This suggests that the current technology in water-based fluids can be improved significantly. The data also suggest that one of the ways to achieve high cutting rate is to use a fluid chemistry that can keep the initial cutting rate as long as possible.

So far, almost all of the data were obtained from a diamond blade cutting a rectangular silicon nitride piece. Although the data are useful to screen the chemistries, some issues important in the grinding operation cannot be simulated, such as the constant feed rate, down feeding, cross feeding etc. To validate the effect of the cutting fluids on grinding operations, the fluid has to be tested on a surface grinder. 


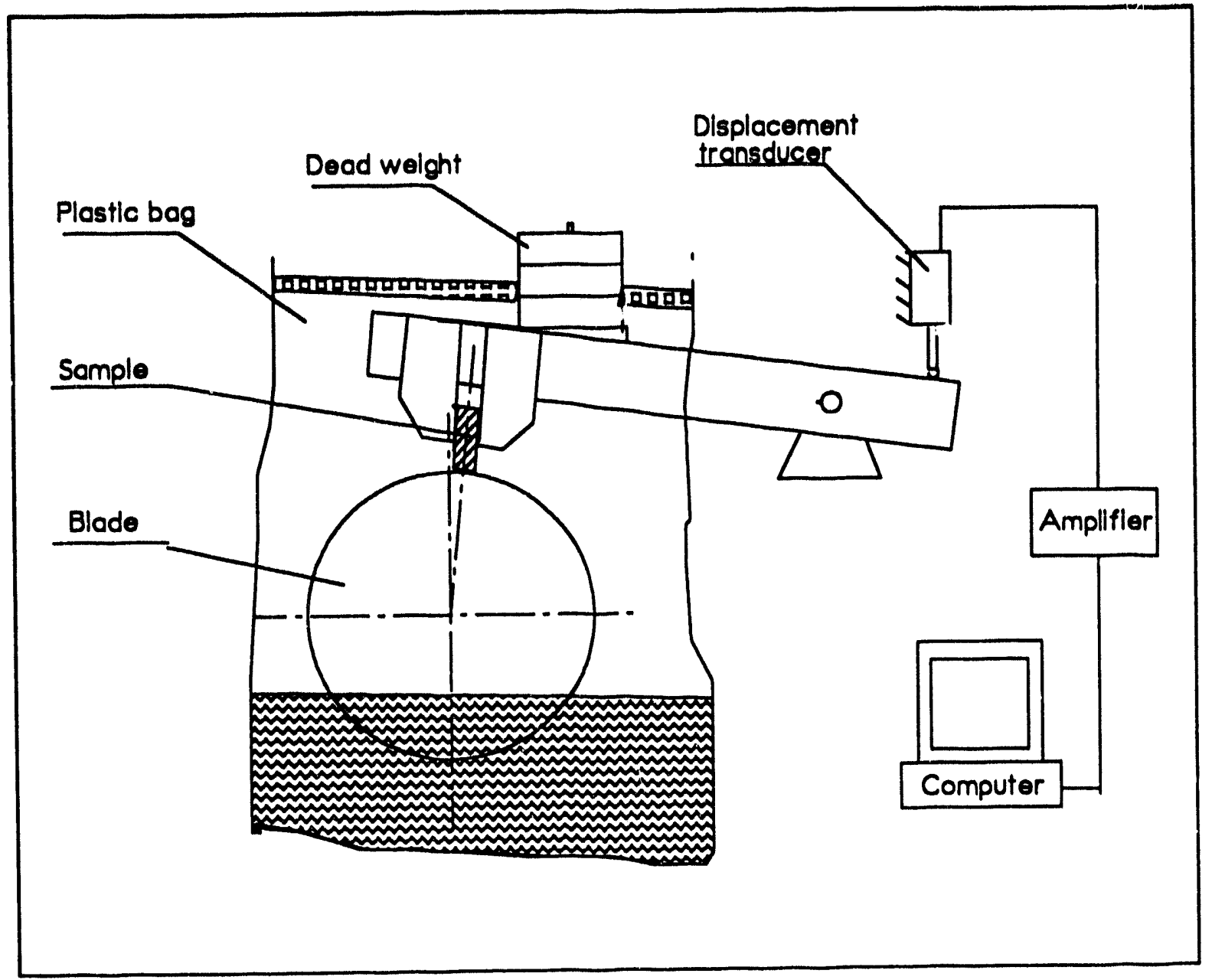

Figure 1 Schematic diagram of modified cutting tester. 


\begin{tabular}{|c|c|c|c|c|c|c|c|c|c|}
\hline \multirow[b]{2}{*}{ No } & \multirow[b]{2}{*}{ CACM: } & \multicolumn{2}{|r|}{ Cutting tim } & \multicolumn{4}{|c|}{ Cuttling rate, mm3/sec'100 } & \multicolumn{2}{|c|}{ Surface rougneas } \\
\hline & & Code & $M$ & initial & steady & $\Delta$ & $t^{\circ}$ & $\mathbf{R a}$ & $R_{\max }$ \\
\hline 1 & 151 & 10 & 240 & 14 & 3.7 & 50 & 168 & 0.14 & 2.28 \\
\hline 2 & 149 & 5,11 & 162 & 19 & 12.1 & 38 & 93 & 0.143 & 1.58 \\
\hline 3 & 150 & & 166 & 19 & 17 & 11 & 110 & 0.163 & 1.46 \\
\hline 4 & 146 & 5,12 & 180 & 16 & 10 & 38 & 95 & 0.14 & 1.5 \\
\hline 5 & 140 & & 180 & 10 & 12 & 33 & $\infty$ & 0.13 & 1.74 \\
\hline 6 & 147 & 11 & 100 & 10 & 0.6 & 47 & 110 & 0.152 & 2.01 \\
\hline 7 & 148 & 11 & 194 & 17 & 10 & 41 & 110 & 0.14 & 1.63 \\
\hline 8 & 78 & 13 & 220 & 8 & 1 & 88 & 130 & & \\
\hline 9 & $\infty$ & 14 & 210 & 16 & 12 & 25 & 159 & 0.1 & 2.03 \\
\hline 10 & 97 & 14 & 218 & 13.5 & 12 & 11 & 100 & 0.1 & 2.1 \\
\hline 11 & 96 & 14 & 242 & 12 & 9.0 & 17.5 & 100 & 0.09 & 1.71 \\
\hline 12 & 96 & 15 & 232 & 16 & 7.5 & 53 & 123 & 0.13 & 1.02 \\
\hline 13 & 144 & 5,12 & 240. & 16 & 8 & so & 80 & 0.15 & 1.43 \\
\hline 14 & 132 & 1,12 & 268 & 17.5 & 5.5 & 69 & $\infty$ & & \\
\hline 15 & 113 & 16 & 272 & 13.5 & 3 & 78 & 80 & & \\
\hline 16 & 103 & 12 & 200 & 17 & 8 & 53 & 120 & & \\
\hline 17 & 110 & 7,12 & 282 & 13 & 8 & 38 & 130 & & \\
\hline 18 & 133 & 7,12 & 303 & 17.5 & 5 & 74 & 90 & & \\
\hline 19 & 140 & 4,12 & 318 & 17 & 7 & 59 & 90 & & \\
\hline 20 & 141 & & 336 & 17.5 & 2.5 & 86 & 90 & & \\
\hline 21 & 130 & 18 & 364 & 13.7 & 3.3 & 78 & 135 & & \\
\hline 22 & 112 & 7.12 & 378 & 12 & 5 & 58 & 100 & & \\
\hline 23 & 83 & 17 & 417 & 11.5 & 3.3 & 71 & 180 & 0.13 & 1.8 \\
\hline 24 & 84 & & 324 & 21 & 5 & 78 & 100 & 0.13 & 1.64 \\
\hline 25 & 129 & 18 & 422 & 10.5 & 5 & 52 & 150 & 0.11 & 1.85 \\
\hline 26 & 123 & 19 & 42 & 12.2 & 3.5 & 71 & 110 & 0.13 & 1.86 \\
\hline 27 & 124 & & 430 & 13.5 & 3 & 78 & 90 & 0.09 & 1.78 \\
\hline 28 & 117 & 12,30 & 500 & 11 & 3.2 & 71 & 100 & & \\
\hline 29 & 88 & 20 & 540 & 8.7 & 3.3 & 62 & 140 & & \\
\hline 30 & 121 & 12.22 & 510 & 10.7 & 2.1 & 80 & 14 & & \\
\hline 31 & 122 & & 584 & 9 & 2.5 & 72 & 90 & & \\
\hline 32 & 142 & 4,22 & 622 & 14 & 2.5 & 82 & 75 & & \\
\hline 33 & 118 & 23 & $>700$ & 7 & 2 & 70 & 180 & & \\
\hline 34 & 115 & 24,12 & $>700$ & 10 & 2.5 & 75 & 80 & & \\
\hline 35 & 87 & 25 & $>700$ & 11 & 2.5 & $\pi$ & 90 & & \\
\hline 36 & 86 & 26,31 & $>700$ & 5.2 & 3.3 & 36 & 180 & & \\
\hline 37 & 64 & 9 & 2700 & 6.4 & 1.8 & 72 & 108 & & \\
\hline 38 & 79 & 7 & & 8 & 2.5 & 69 & 90 & 0.15 & 2.04 \\
\hline 39 & 77 & 7.8 & 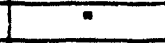 & 10.2 & 0.9 & 91 & 160 & & \\
\hline 40 & 75 & 27,28 , & 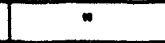 & 10 & 1.1 & 88 & 130 & 0.13 & 1.68 \\
\hline 41 & 87 & 25 & $\pi$ & 9.8 & 1.7 & 83 & 100 & & \\
\hline 42 & 89 & 15 & & & & & & & \\
\hline 43 & 90 & 15 & & & & & & 0.15 & 1.56 \\
\hline 44 & 91 & 15 & & & & & & 0.12 & 1.62 \\
\hline 45 & 92 & 15 & & & & & & 0.16 & 1.38 \\
\hline 48 & 93 & 15 & & & & & & 0.15 & 1.73 \\
\hline 47 & 94 & 15 & & & & & & 0.15 & 1.72 \\
\hline 48 & 103 & 12 & & 13.8 & 7.5 & 48 & 120 & & \\
\hline 49 & 104 & 17 & & & & & & 0.11 & 1.83 \\
\hline 50 & 105 & 25 & & & & & & 0.13 & 1.55 \\
\hline 51 & 106 & 32 & & & & & & 0.11 & 1.77 \\
\hline 52 & 107 & 20 & & & & & & 0.12 & 7.74 \\
\hline 53 & 81 & 8.9 & & 7.5 & 2 & 73 & 120 & 0.11 & 1.63 \\
\hline 54 & 130 & 35 & & & & & & 0.00 & 1.89 \\
\hline 55 & 76 & 7.9 & & & & & & & \\
\hline
\end{tabular}




\begin{tabular}{|c|c|c|c|c|c|c|c|c|c|}
\hline \multirow[b]{2}{*}{ No } & \multirow[b]{2}{*}{ CACM: } & \multirow[b]{2}{*}{ Code } & \multirow{2}{*}{\begin{tabular}{|c|} 
Cutting time \\
sec \\
\end{tabular}} & \multicolumn{4}{|c|}{ Cutting rate, $\mathrm{mm} 3 / \mathrm{sec}^{*} 100$} & \multicolumn{2}{|c|}{ Surface rougness } \\
\hline & & & & initial & steady & $\Delta \#$ & $t^{\circ}$ & $\mathbf{R a}$ & $R \max$ \\
\hline 1 & 118 & 1 & $>700$ & 8.2 & 2 & 75 & 180 & & \\
\hline 2 & 120 & 1 & 2700 & 9.1 & 1.7 & 81 & 168 & & \\
\hline 3 & 161 & 2 & $>700$ & 5.4 & 1.34 & 76 & 150 & & \\
\hline 4 & 62 & 2 & $>700$ & 8.3 & 1.5 & 82 & 87 & & \\
\hline 5 & 99 & 2 & 2700 & & & & & 0.1 & 1.7 \\
\hline 6 & 87 & 3 & 2700 & 7.7 & 1.3 & 82 & 90 & & \\
\hline 7 & 58 & 3 & $>700$ & 6.8 & 1.4 & 71 & 110 & & \\
\hline 8 & 78 & 3 & 2700 & 9 & 2 & 78 & 90 & & \\
\hline$\theta$ & 136 & 4 & 309 & 13.1 & 4.9 & 63 & 95 & 0.17 & 2.29 \\
\hline 10 & 136 & 4 & 334 & 12 & 6 & 50 & 110 & 0.09 & 1.87 \\
\hline 11 & 143 & $4,6,29$ & 368 & & & & & 0.1 & 1.1 \\
\hline 12 & 138 & 4,6 & 382 & & & & & 0.12 & 2.04 \\
\hline 13 & 134 & 4 & 394 & 11.5 & 5 & 57 & 100 & & \\
\hline 14 & 128 & 6 & $>700$ & 9.5 & 1.9 & 80 & 136 & 0.14 & 1.66 \\
\hline 15 & 127 & 6 & $>700$ & 7.5 & 2.5 & 67 & 180 & 0.11 & 1.87 \\
\hline 16 & 59 & 7 & 2700 & 6.8 & 1.5 & 78 & 107 & & \\
\hline 17 & 60 & 7 & 2700 & 6 & 1.4 & 77 & 160 & & \\
\hline 18 & 80 & 8 & $>700$ & 9.5 & 1 & 89 & 139 & 0.12 & 1.81 \\
\hline 19 & 82 & 7,33 & & 5 & 1.5 & 70 & 220 & 0.1 & 1.7 \\
\hline 20 & 85 & 9 & $>700$ & 3.8 & 1.4 & 63 & 120 & & \\
\hline 21 & 125 & 34 & & 7 & 2 & 71 & 160 & 0.14 & 1.95 \\
\hline 22 & 126 & 34 & & 9.5 & 2 & 79 & 120 & 0.09 & 1.7 \\
\hline 23 & 137 & 4 & & 12 & 6 & 50 & 130 & 0.12 & 1.68 \\
\hline 24 & 139 & 4,6 & & 12 & 6 & 50 & 150 & 0.13 & 1.67 \\
\hline 25 & 70 & 2 & & & & & & 0.09 & 1.52 \\
\hline 26 & 71 & 2 & & & & & & 0.12 & 1.7 \\
\hline 27 & 72 & 2 & & 6.3 & 1.34 & 79 & 72 & 0.14 & 1.69 \\
\hline 28 & 73 & 2 & & & & & & 0.11 & 2.1 \\
\hline 29 & 74 & 2 & & 8.2 & 2 & 78 & 140 & 0.09 & 1.79 \\
\hline
\end{tabular}




\section{GRINDING TEST}

The model of the surface grinder used is MD-1428AD from Mitek Machine Tools. The grinding machine is schematically shown in the Figure 2. A three dimensional force transducer is mounted underneath the sample. The normal force and the tangential force can be measured as the sample is machined. A software named Labview is used to record and analyze the data. During the machining, the sample was just submerged in the fluid contained in a small reservoir. This modification is necessary to avoid cross contamination of the fluids and also to avoid the sometime inconsistent cooling which is a function of the nozzle position.

The transducer is calibrated by dead weights. Figures 3 and 4 show the calibration data on the three dimensional force transducer. $X$ represents the grinding direction, $Y$ cross table movement direction, and $Z$ the normal direction perpendicular to the specimen surface. The sensitivity of the transducer in the $\mathrm{Z}$ direction is $0.17 \mu \mathrm{m} / \mathrm{v}-\mathrm{N}$. The sensitivity in the $\mathrm{Y}$ direction is 0.67 with the extension voltage of 10 volt. The gain of the amplifier is 4,000 . The relationship between the input load and output voltage readout for the $\mathrm{Z}$ direction is:

$1 \mathrm{~N}=0.17 \times 10^{-6}(\mathrm{v} / \mathrm{v}) \times 10(\mathrm{v}) \times 4000=0.0068(\mathrm{v})$.

In the $\mathrm{X}$ and $\mathrm{Y}$ direction,

$$
1 \mathrm{~N}=0.67 \times 10^{-6}(\mathrm{v} / \mathrm{v}) \times 10(\mathrm{v}) \times 4000=0.0268(\mathrm{v}) \text {. }
$$

After calibration, fluids were tested on the surface grinder.

Based on the results of the cutting tests, selected chemicals were tested on the grinding machine. The chemicals used in the initial tests are CM01, CM03, CM04, CM10, CM11 and CM47 (where CM01, CM03, CM04 and CM47 are water based, CM10 and CM11 are organic based). The conditions of the grinding tests are: diamond abrasive size $=180$ grit, wheel linear speed $=23.4 \mathrm{~m} / \mathrm{s}$, wheel diameter $=260 \mathrm{~mm}$, wheel width $=6.5 \mathrm{~mm}$, down-feed speed $=0.0127$ $\mathrm{mm}$ deep, average table speed $=0.12 \mathrm{~m} / \mathrm{s}$, cross speed $=2.5 \mathrm{~mm} / \mathrm{stroke}$. The silicon nitride specimen was immersed in the grinding fluids during the grinding tests. The specimen holder, the diamond abrasive wheel and the cover are thoroughly cleaned with water and alcohol and wiped to dry with paper towels before each test to prevent cross contamination. The specimen was mounted on the 3-D force transducer. The horizontal forces, the normal forces, the friction coefficient and the surface roughness are the primary parameters which were taken to evaluate the grinding process.

\section{TEST RESULTS}

The results of the grinding test are shown in Table 3 and Figures 5-10. Table 3 shows the summary of the maximum horizontal and vertical forces under different chemical fluids, the corresponding ratio of the horizontal and vertical forces (or friction coefficients), average surface roughness and the maximum surface roughness after grinding test with each chemicals. 


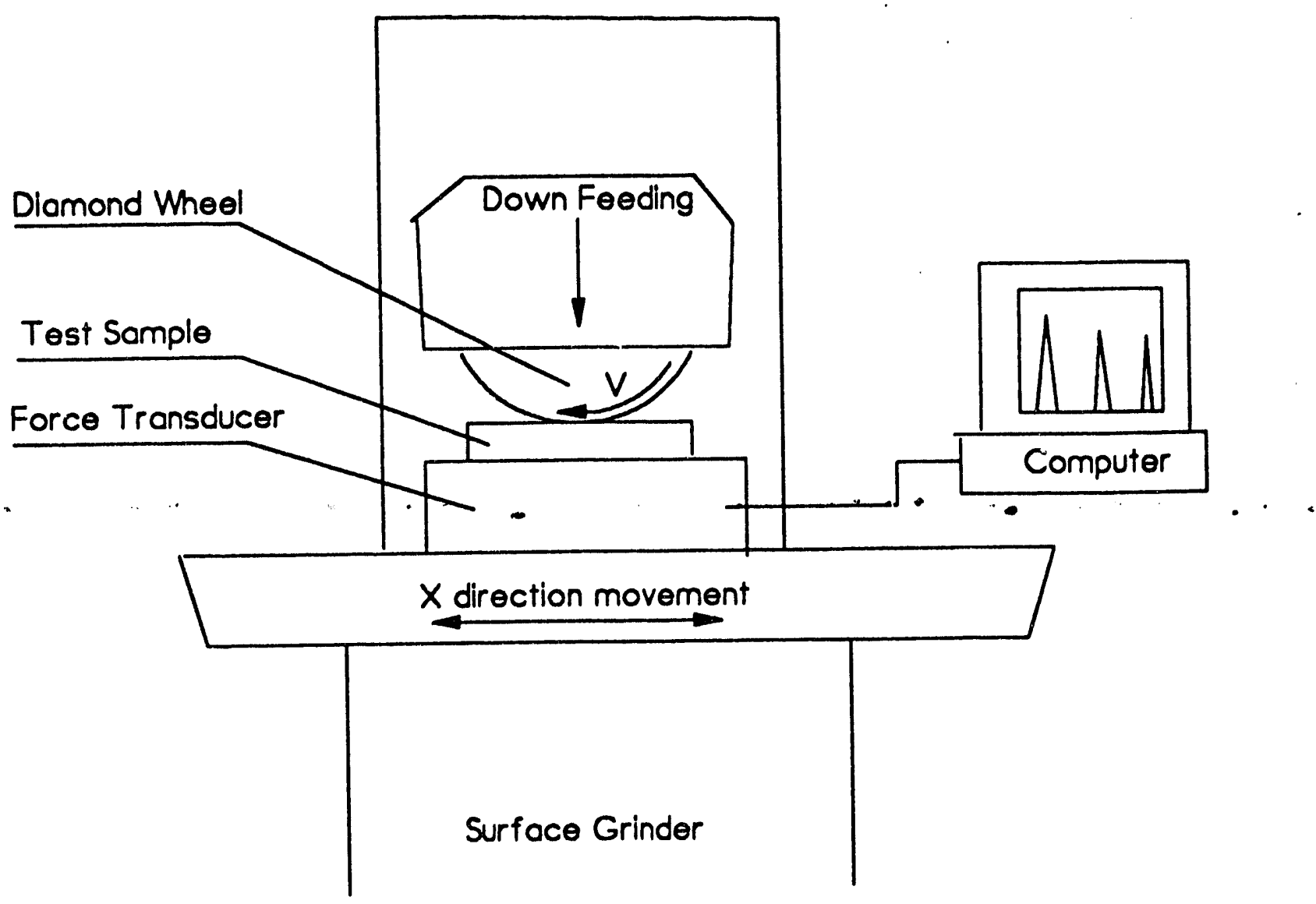

Figure 2 Schematic set-up of grinding machine. The wheel linear speed: $23.4 \mathrm{~m} / \mathrm{s}$; down feed speed: $0.0127 \mathrm{~m} / \mathrm{s}$; table speed: $0.12 \mathrm{~m} / \mathrm{s}$; cross speed: $2.5 \mathrm{~m} / \mathrm{s}$. 


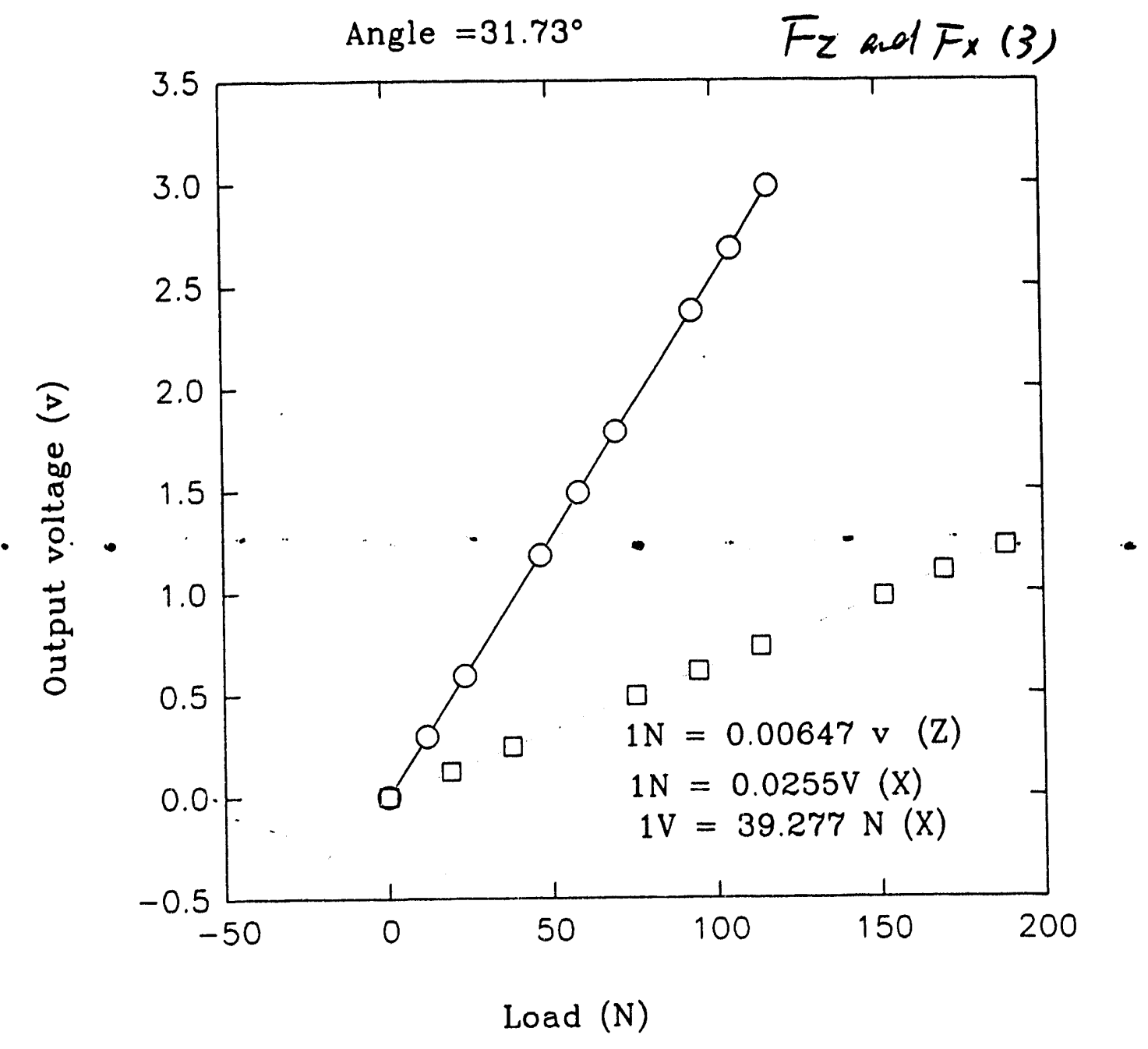

Figure 3 Calibration curves on the forces in the $\mathrm{X}$ and $\mathrm{Z}$ directions. 


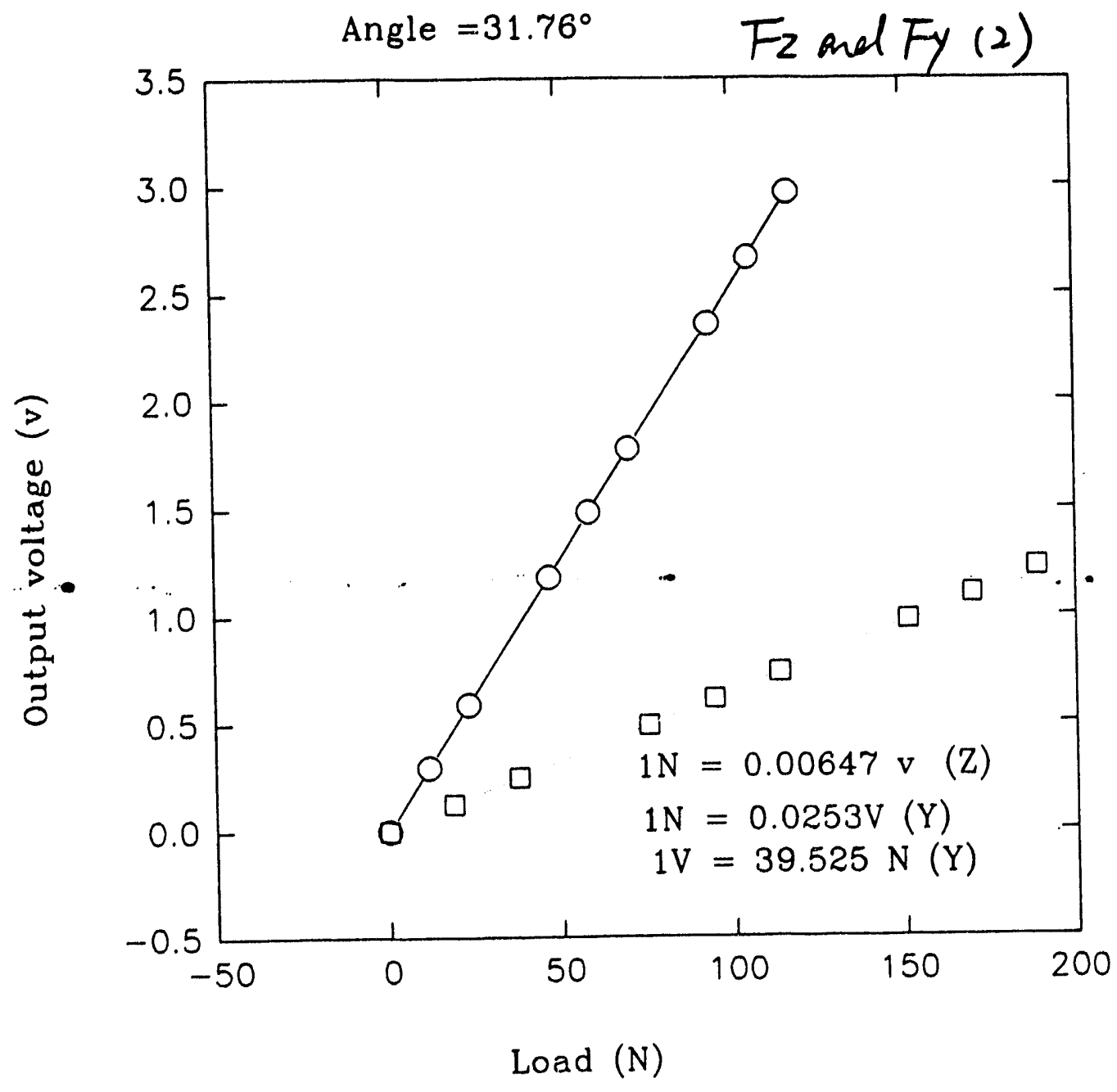

Figure 4 Calibration curves on the forces in the $\mathrm{Y}$ and $\mathrm{Z}$ directions. 
Table 3 Summary of horizontal force, vertical force, friction coefficient and roughness of ground surfaces

\begin{tabular}{|c|c|c|c|c|c|c|}
\hline \multirow{2}{*}{$\begin{array}{c}\text { GRD } \\
\#\end{array}$} & \multirow[t]{2}{*}{ FORMULATION } & \multirow{2}{*}{$\begin{array}{c}\text { HORIZONTAL } \\
\text { FORCE } \\
\text { (N) } \\
F_{X}\end{array}$} & \multirow{2}{*}{$\begin{array}{c}\text { VERTICAL } \\
\text { FORCE } \\
\text { (N) } \\
F_{2}\end{array}$} & \multirow{2}{*}{$\begin{array}{c}\text { FRICTION } \\
\text { COEFFICENT } \\
\mu\end{array}$} & \multicolumn{2}{|c|}{$\begin{array}{c}\text { SURFACE } \\
\text { ROUQHNESS } \\
(\mu \mathrm{m})\end{array}$} \\
\hline & & & & & R. & $\mathbf{R}_{\operatorname{mex}}$ \\
\hline \multicolumn{7}{|c|}{ AQUEOUS BASED } \\
\hline 42 & $\begin{array}{c}\text { Deionized } \\
\qquad \mathrm{H}_{2} \mathrm{O}\end{array}$ & 30.0 & 127 & 0.236 & 0.65 & 5.50 \\
\hline 44 & $\begin{array}{c}\text { CMO1 }(4 \%) \\
\text { (commercial) in } \\
\text { DI } \mathrm{H}_{2} \mathrm{O}\end{array}$ & 21.4 & 123 & 0.174 & 0.56 & 4.70 \\
\hline $\begin{array}{c}-43 \\
.\end{array}$ & $\begin{array}{c}\text { CMO4. }(1 \%) \text { in } \\
\text { DI } \mathrm{H}_{2} \mathrm{O}\end{array}$ & 34.5 & 171 & 0.202 & 0.53 & 4.48 \\
\hline 45 & $\begin{array}{l}\mathrm{CM} 47(5 \%) \text { in } \\
\text { DI } \mathrm{H}_{2} \mathrm{O}\end{array}$ & 27.5 & 150 & 0.184 & 0.59 & 4.92 \\
\hline \multicolumn{7}{|c|}{ ORGANIC BASED } \\
\hline 46 & $\begin{array}{c}\text { CM10 } \\
\text { (commercial) }\end{array}$ & 31.0 & 200 & 0.155 & 0.65 & 4.51 \\
\hline 47 & CM11 & 31.0 & 250 & 0.124 & 0.46 & 4.20 \\
\hline
\end{tabular}




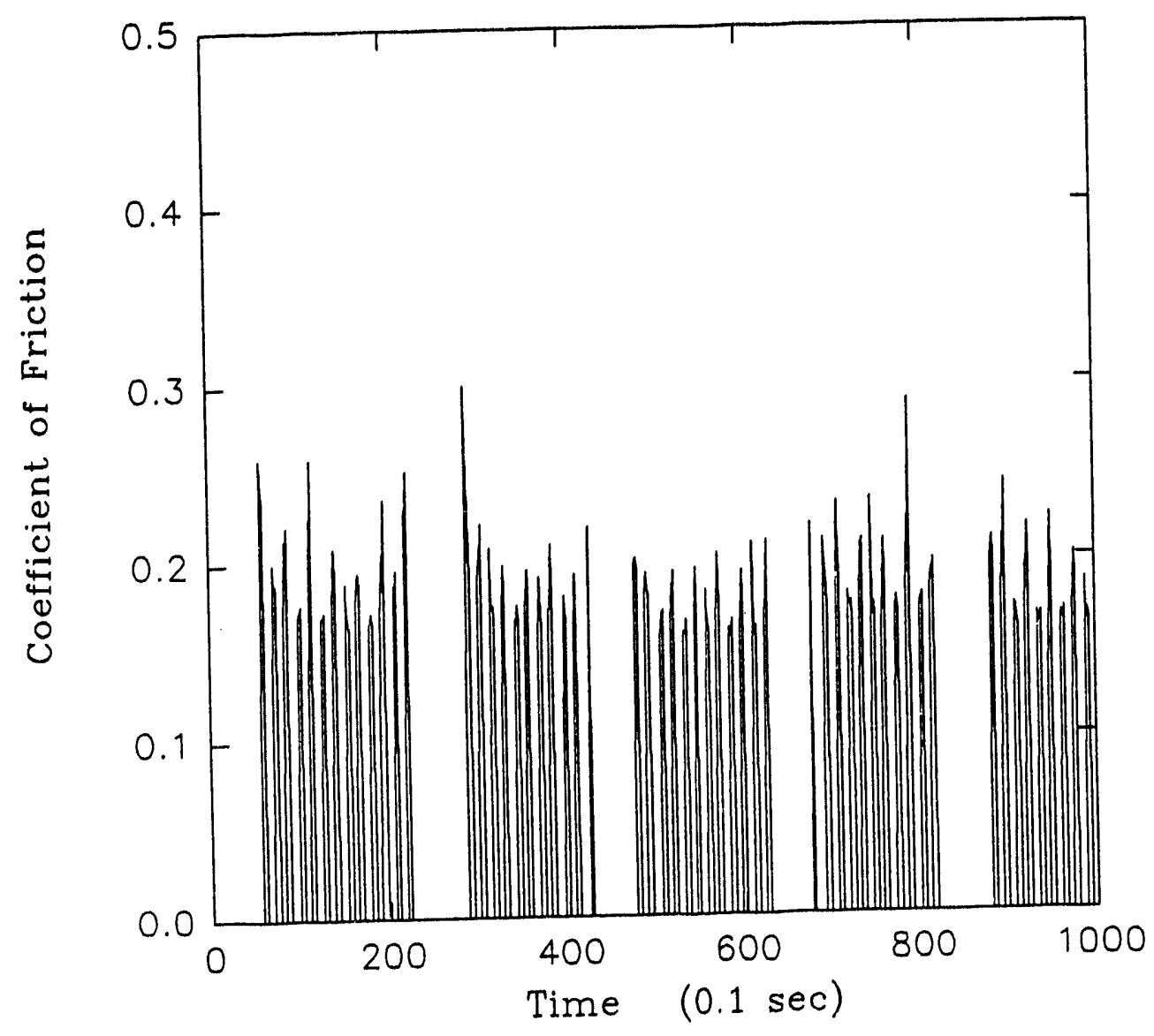

Figure 5 Friction coefficient of grinding test in $\mathrm{CM} 03$ with down feeding speed of $0.0127 \mathrm{~mm} / \mathrm{s}$, cross feeding speed of $2.5 \mathrm{~mm} / \mathrm{stroke}$. 


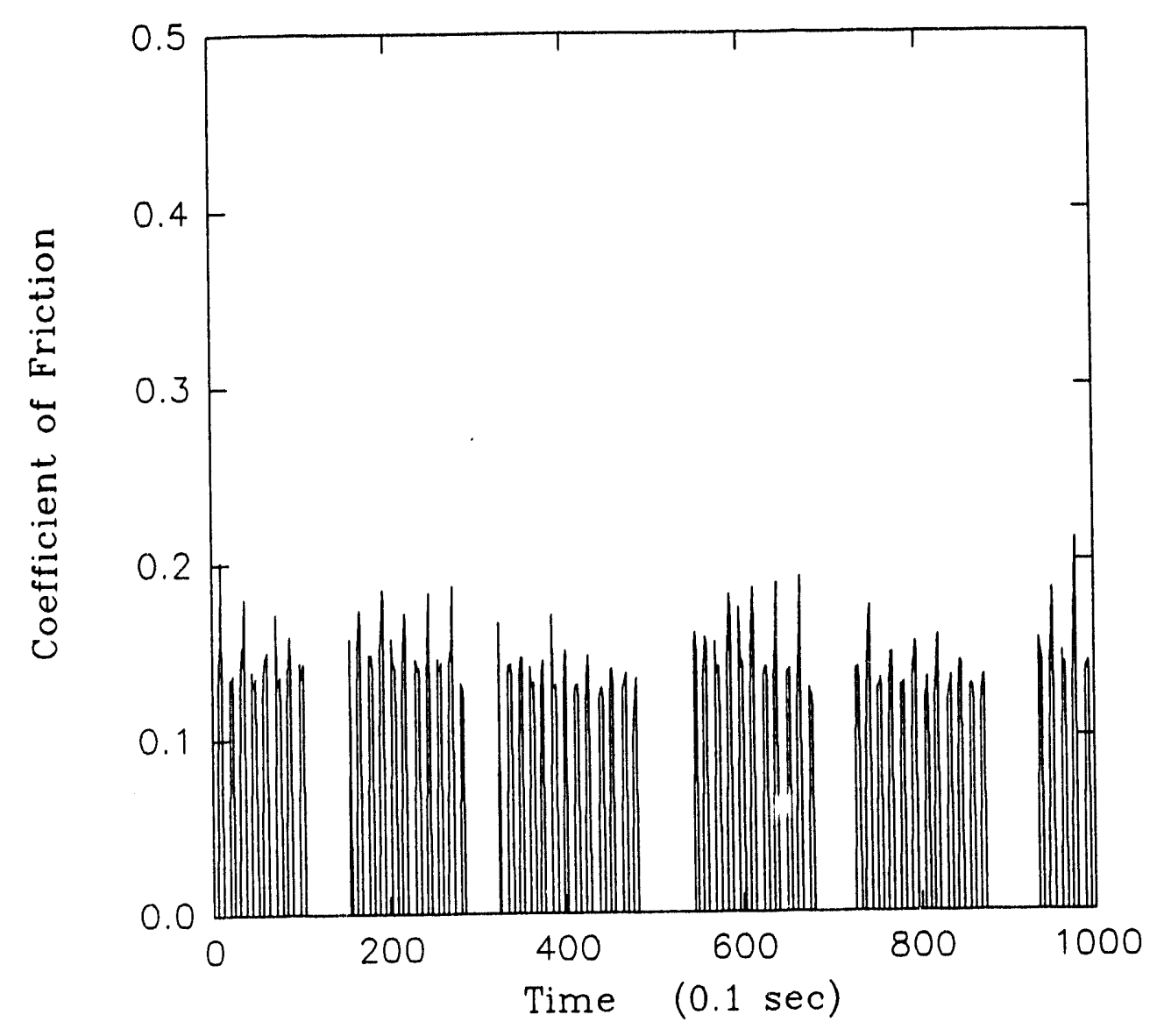

Figure 6 Friction coefficient of grinding test in CM01 with down feeding speed of $0.0127 \mathrm{~mm} / \mathrm{s}$, cross feeding speed of $2.5 \mathrm{~mm} /$ stroke. 


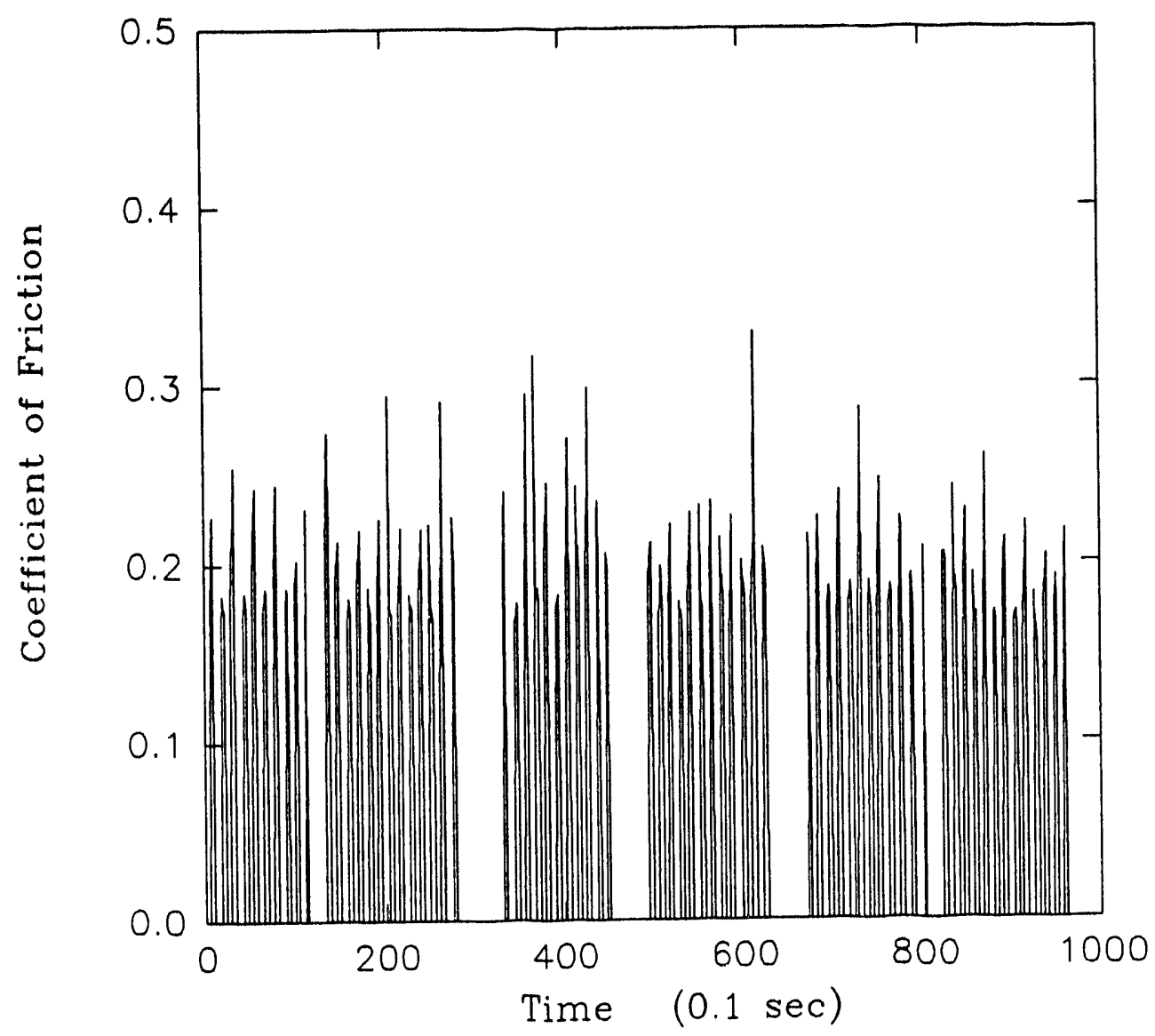

Figure 7 Friction coefficient of grinding test in CM04 with down feeding speed of $0.0127 \mathrm{~mm} / \mathrm{s}$, cross feeding speed of $2.5 \mathrm{~mm} / \mathrm{stroke}$. 


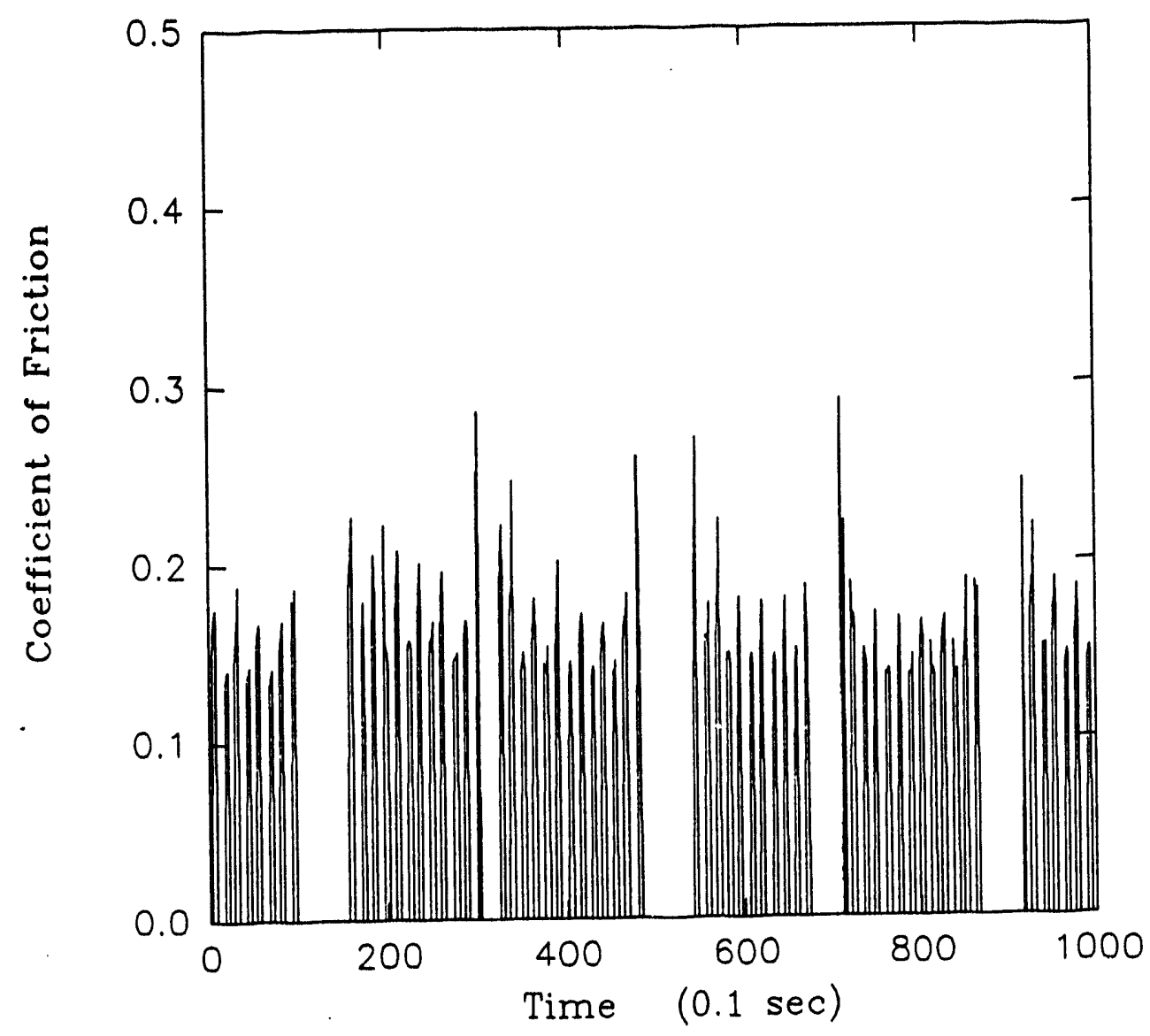

F'gure 8 Friction coefficient of grinding test in CM47 with down feeding speed of $0.0127 \mathrm{~mm} / \mathrm{s}$, cross feeding speed of $2.5 \mathrm{~mm} / \mathrm{stroke}$. 


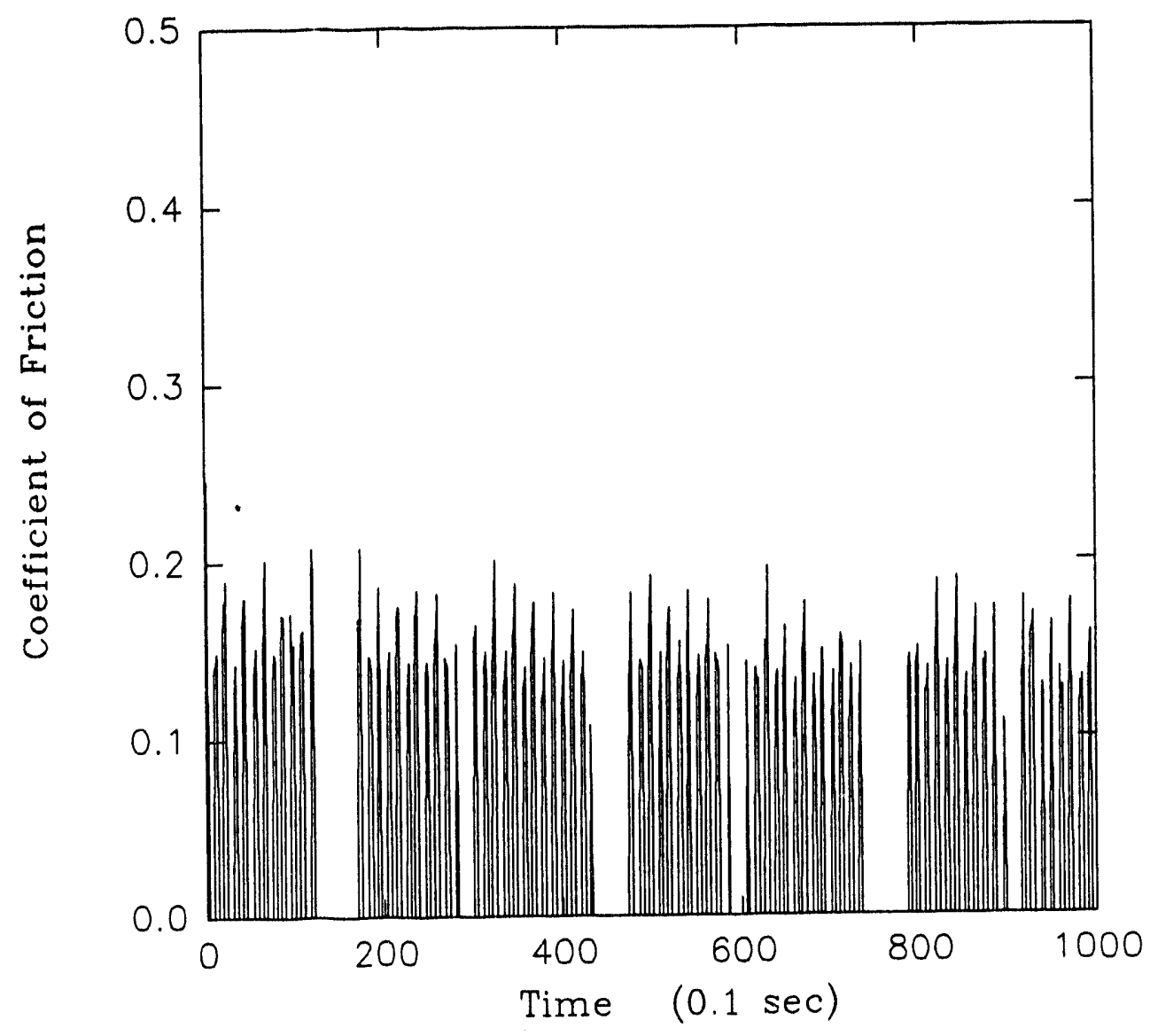

Figure 9 Friction coefficient of grinding test in CM10 with down feeding speed of $0.0127 \mathrm{~mm} / \mathrm{s}$, cross feeding speed of $2.5 \mathrm{~mm} /$ stroke. 


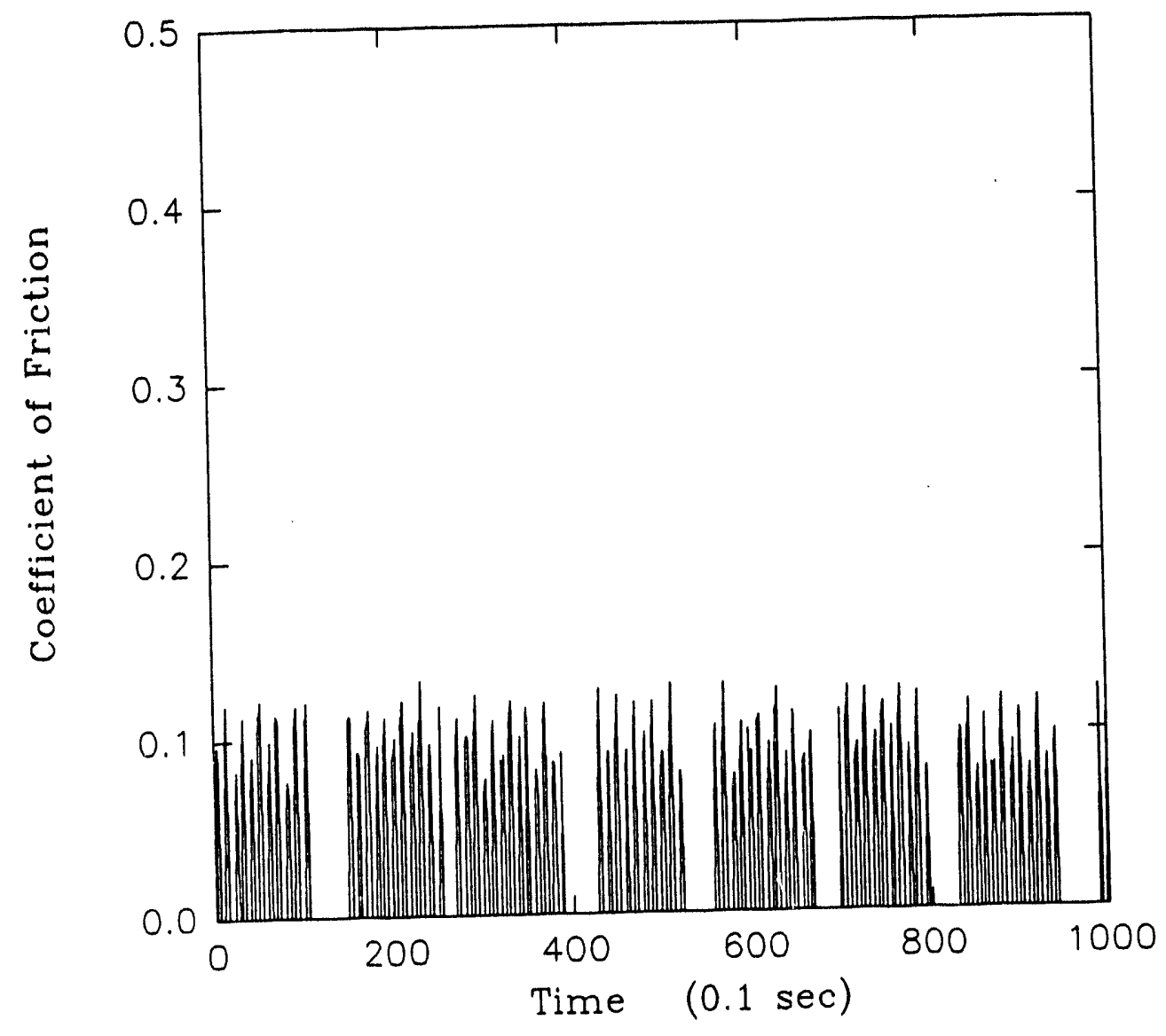

Figure jo Friction coefficient of grinding test in CM11 with down feeding speed of $0.0127 \mathrm{~mm} / \mathrm{s}$, cross feeding speed of $2.5 \mathrm{~mm} / \mathrm{stroke}$. 
Figures 5-10 show the coefficient of friction measured from the grinding tests. Figure 5 shows the friction coefficient in water (CM03). Figure 6 shows friction coefficient results in a commercial water-based fluid (CM01). Figure 7 shows the coefficient of friction results in a candidate fluid, CM04. Notice the increase of the vertical force from $123 \mathrm{~N}$ and $127 \mathrm{~N}$ to $171 \mathrm{~N}$ as shown in Table 3 . Figure 8 shows the coefficient of friction results in another candidate water-based fluid, CM47. In this case, there are spikes in the friction trace, but the normal force is still substantially higher. For water-based fluids, we need to explore the concentration effects. The surface roughness measurement suggests that there are some improvements, but the effect is minor.

For organic-based fluids, Figure 9 shows the coefficient of friction results in a commercial baseline fluid, CM10. Figure 10 shows the coefficient of friction results in a candidate fluid, CM11. Notice the low friction value and the extraordinary high normal force. The surface roughness of the machined surface is significantly lower.

\section{DISCUSSION}

The cutting test results in the last report have shown that the cutting rate is in the order of: $\mathrm{CM} 11>\mathrm{CM} 10>\mathrm{CM} 04>\mathrm{CM} 01>\mathrm{CM} 03$. The horizontal forces are in the ball park of 32 $\mathbf{N}$ for all the chemical fluids tested under the specific machining condition, however, the normal grinding forces differ substantially when the different chemicals are used. One speculation for the different normal forces under different grinding fluids with other grinding condition fixed is that the material removal during grinding is controlled by the diamond abrasive penetration depth. Since the horizontal forces for all tested chemicals are essentially the same and the vertical forces are substantially different. The greater vertical (or normal) forces causes deeper penetration of diamond abrasive into silicon nitride specimen surface which results in faster material removal. The low friction coefficient will reduce the wear of the diamond abrasive, leading to the longer high grinding rate.

\section{SURFACE QUALITY}

The quality of the as machined surface is an important issue with respect to the strength and durability of ceramics. The issue is complex and commonly used bend-bar tests and tensile tests are expensive and require relatively large number of samples for statistical significant correlation.

Eventhough the chemically assisted machining appears to be able to increase the machining rate and also able to improve the surface roughness, precise measurement of the quality of the surface as related to the strength is difficult. Towards this end, effort to develop such a measurement has been made, especially for the relatively smooth surfaces generated under the chemically assisted conditions. A single diamond indentor scratching on an inclined plane technique is being developed to assess the quality of the surface. 
The experimental set-up of this apparatus is schematically shown in Figure 11. The specimen surface is inclined with an angle $\theta$ (which is adjustable) with respect to the horizontal plane. A spherical diamond indentor (with $0.2 \mathrm{~mm}$ radius) is used. The horizontal force $\left(F_{x}\right)$ and vertical force $\left(F_{2}\right)$ are measured by force transducers.

The whole concept is to introduce well-controlled defects such as micro-indentation marks on the surface systematically hefore the sliding. When the indentor begins to slide on the surface, due to the increasing angle, the force increases with sliding distance. When the force reaches a certain level, the cracks at the tips of the preexisting indentor marks will propagate. The location can be identified and the stresses can be calculated.

For a sphere sliding on a plane, the maximum tensile stress $\left(\sigma_{\max }\right)$ during the sliding which has been derived by Hamilton is given by:

$$
\sigma_{\max }=p_{0}\left[\frac{(1-2 v)}{3}+\frac{(4+v)}{8} \pi \mu\right]
$$

where: $p_{0}$ is the maximum Hertzian contact pressure, $\mu$ is friction coefficient, and $\nu$ is the Poisson ratio of the specimen. The calculation of the external critical tensile stress at which crack propagates is based on the linear elastic fracture mechanic. We also consider the effecis of internal residual stress on the propagation of preexisted cracks and arrived at the following expression for the net stress iniensity factor for an equilibrium crack:

$$
\sum_{i} K_{l l}+K_{D}=T_{0}
$$

where $K_{b}$ is the stress intensity factor due to the applied loading. The term $K_{\mathrm{li}}$ represents contributions of "internal" forces on the crack, such as those associated with microstructure and machining. $T_{0}$ is taken to be the intrinsic material toughness (i.e., the effective $K_{I C}$ for bulk cleavage or grain boundary fracture) and is strictly independent of crack size. Neglecting gradients in the stress distributions over the flaw dimensions, the equilibrium requirement may be expanded in the form:

$$
\psi \sigma c^{1 / 2}+\psi \sigma_{D} c^{1 / 2}=T_{0}
$$

where $\psi$ is a crack-geometry coefficient, $\Sigma \sigma_{1}$ are the summary of internal stresses retained from the thermal process, with compressive stresses are represented a negative sign, $c$ is the preexisted crack size and $\sigma_{\mathrm{D}}$ is the critical tensile stress induced by external sliding required for microfracture. Equation (3) can be rewritten as follow: 


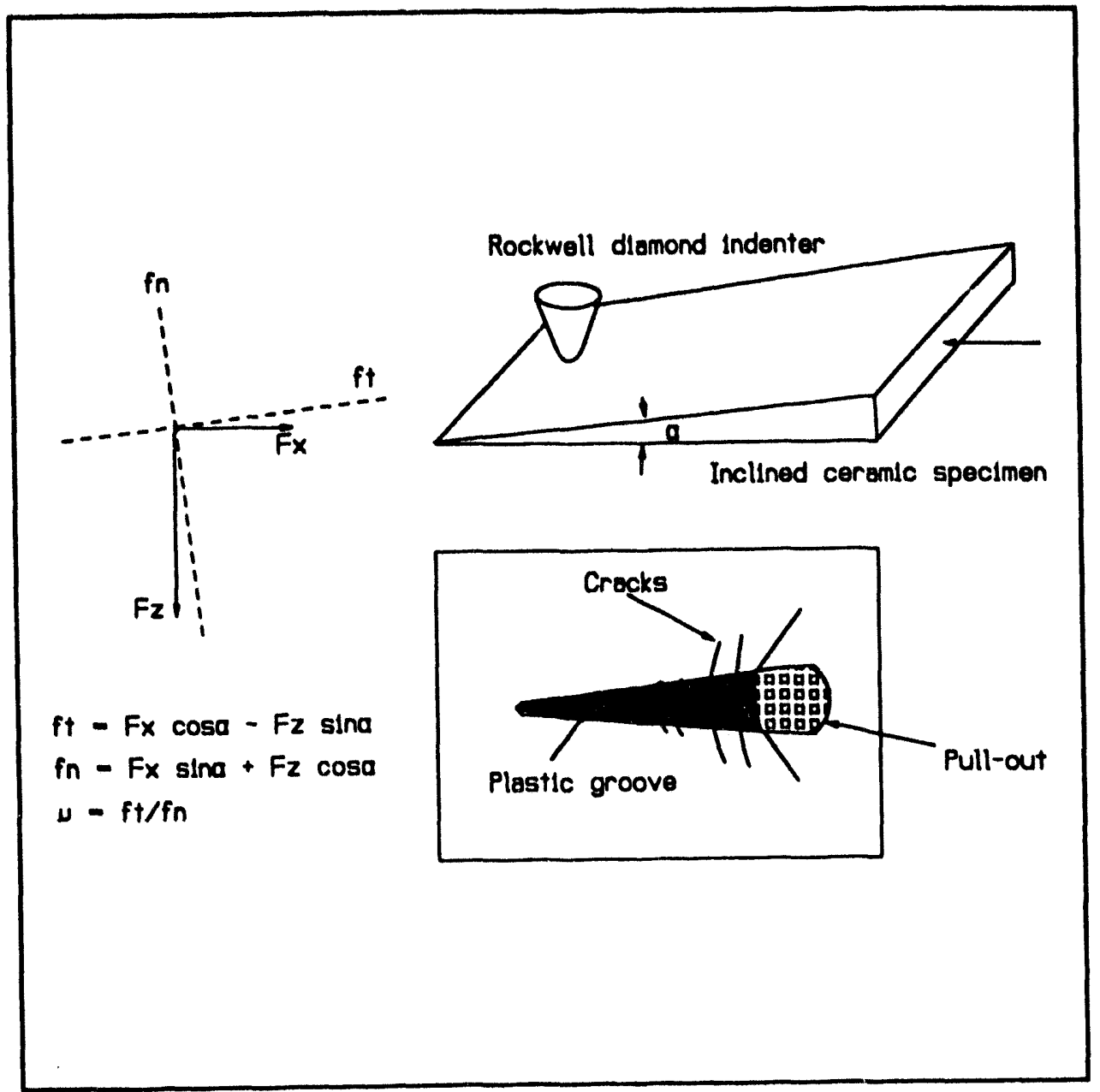

Figure 11. Schematic of sphere-scratch on inclined plane, contact configuration and damage patterns of scraich. 

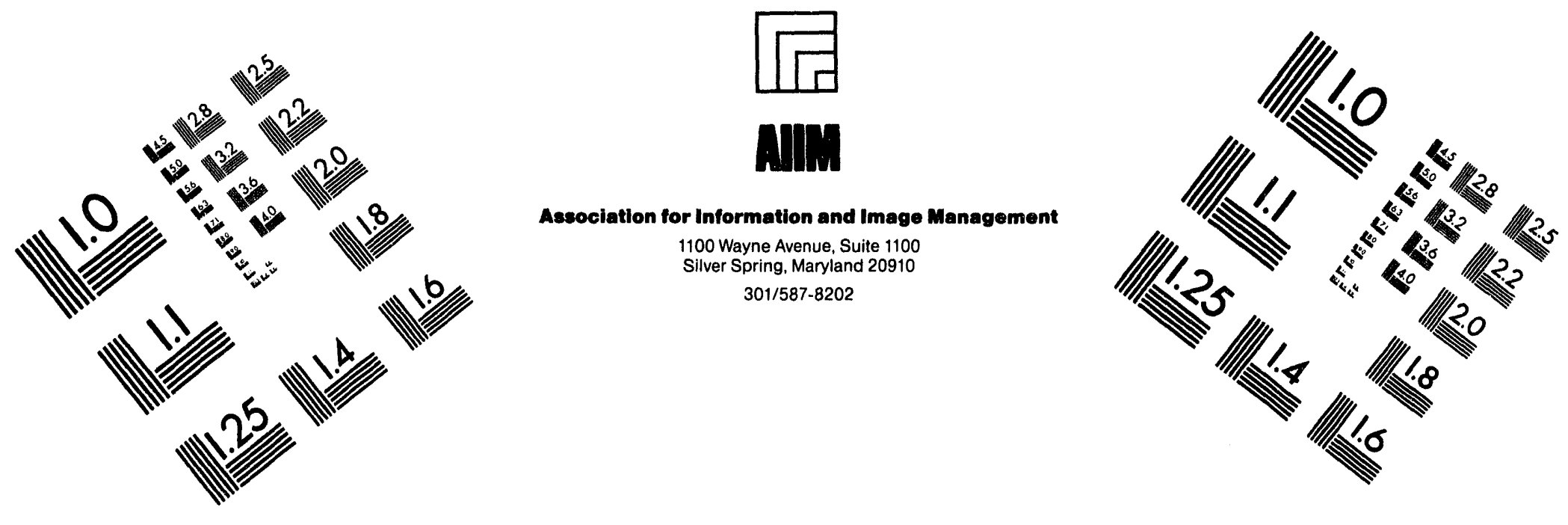

\section{Centimeter}

$\begin{array}{llllllllllllllll}1 & 2 & 3 & 4 & 5 & 6 & 7 & 8 & 9 & 10 & 11 & 12 & 13 & 14 & 15 & \mathrm{~mm}\end{array}$ Lun Tाग Inches
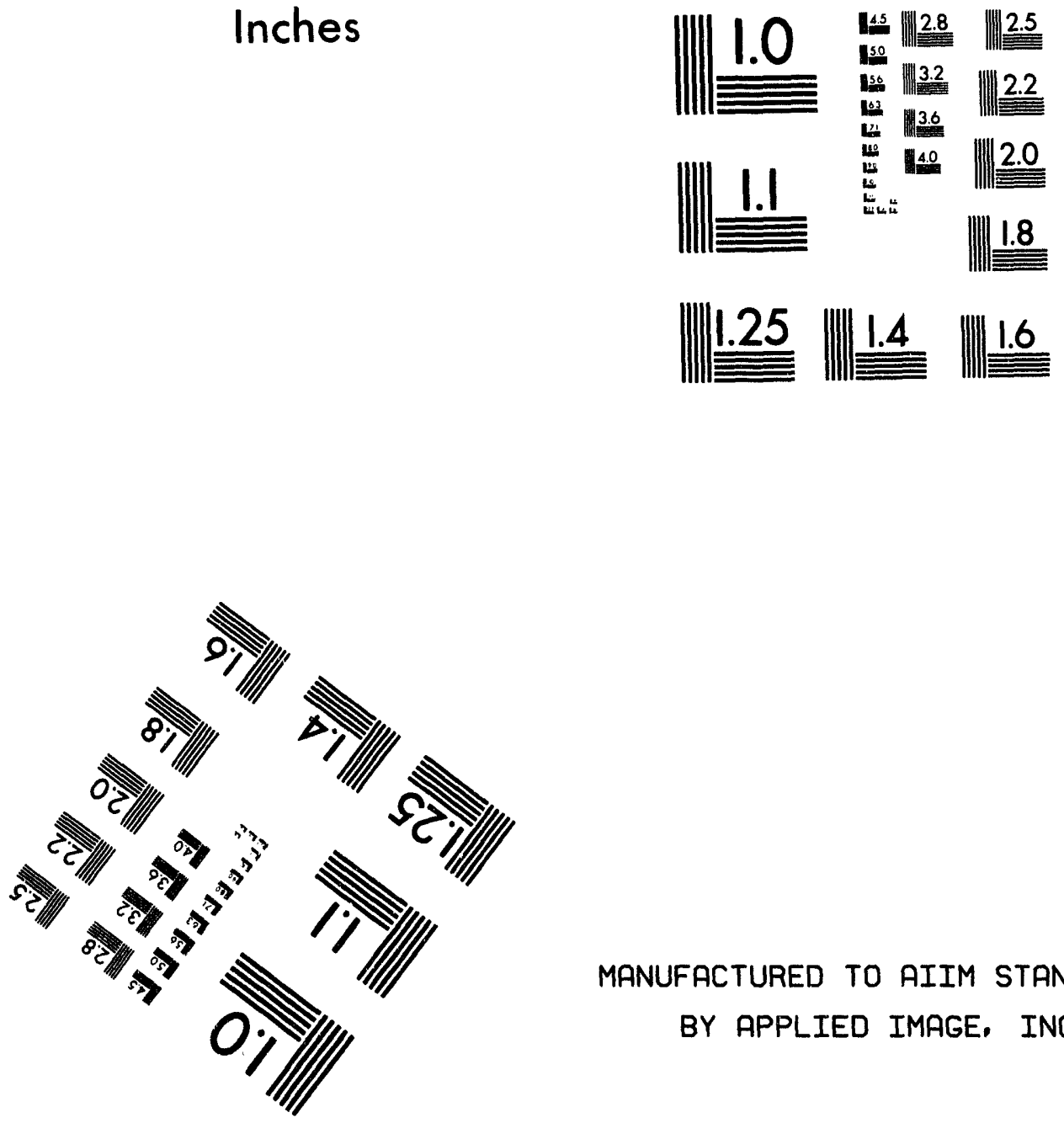

MANUFACTURED TO AIIM STANDARDS BY APPLIED IMAGE, INC.

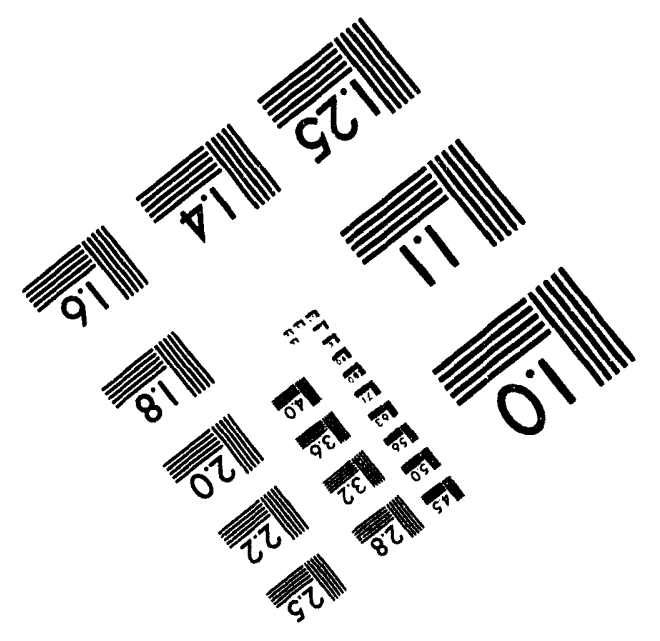



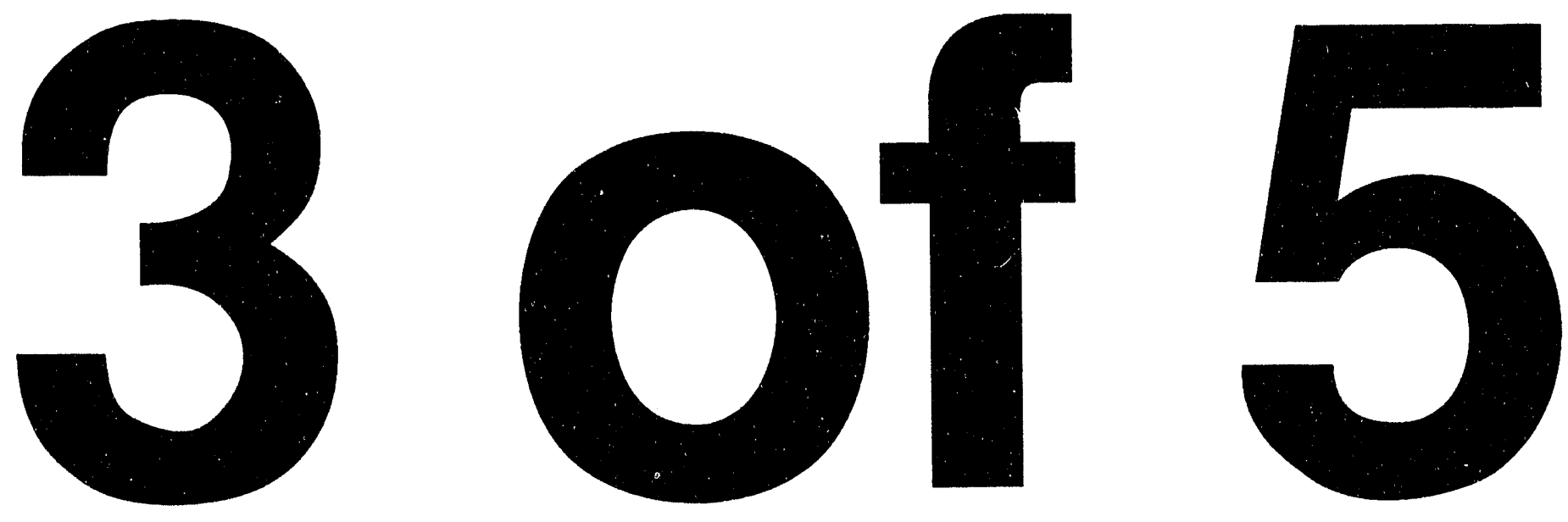


$$
\sigma_{D}=\frac{T_{0}}{\psi} c^{-\frac{1}{2}}-\sigma_{p} \quad c \neq 0
$$

Equation (4) shows that the critical external stress to propagate the cracks on the ceramic surface inversely proportional to the square root of the crack length and is proportional to the residual tensile stress on the surface. When micro cracks and/or residual tensile cracks exist on the surface due to machining, the external stress necessary to propagate these cracks will be lower. By using the diamond scratching on an inclined plane, the critical stress at which cracks will propagate can be determined. This critical stress can be used as the criterion to evaluate the effect of the machining process on the property of ceramic materials.

Figure 12 shows the results of an experiment where Vickers and Knoop indentations are introduced on a silicon nitride surface. There are no cracks on the surface except radial cracks at the corners of the Vicker's indentation mark. After scratching with the a spherical silicon nitride ball (3.2 $\mathrm{mm}$ diameter) close to the indentation marks on an inclined plane, some cracks are generated near the edges of indent. No such crack was observed at other places. This observation suggests that the residual stress near the indentation marks are high, when the external stress induced by scratching superimposes on the residual stress and exceed the strength of the material, cracks propagate and are then observed.

Figure 13 shows optical micrographs of the sphere ( $3.175 \mathrm{~mm}$ radius silicon nitride ball) scratched on the as-machined silicon nitride surfaces. Figure 13a shows the results of grinding test with CM01 fluid and Figure 12b shows the surface grounded with CM11 fluid. Figures 14 and 15 shows the forces, stresses and friction coefficient curves corresponding to the scratches shown in Figure 13.

The scratch test results on the as-machined surface show that the critical stresses for the microcrack initiation $\left(\sigma_{\mathrm{DC}}\right)$ are observably different on the surface with CM11 $\left(\sigma_{\mathrm{DC}}=4.5 \pm\right.$ $0.5 \mathrm{GPa})$ as the grinding fluid than with $\mathrm{CM} 01\left(\sigma_{D C}=3.0 \pm 0.5 \mathrm{GPa}\right)$ as the grinding fluid. With the lab developed grinding fluid CM11, both cutting rate and the surface quality are substantially increased. One explanation for the increased critical stress is as the following: with CM11 as the grinding fluid, higher normal forces generate higher residual compressive stress, Table 2, on the surface which will increase the critical stress for the microcrack to propagate.

\section{FUTURE PLAN}

* Continue screening chemicals with the cutting tests to improve further the cutting rate and surface quality.

* Mechanistic study of abrasive wear: 

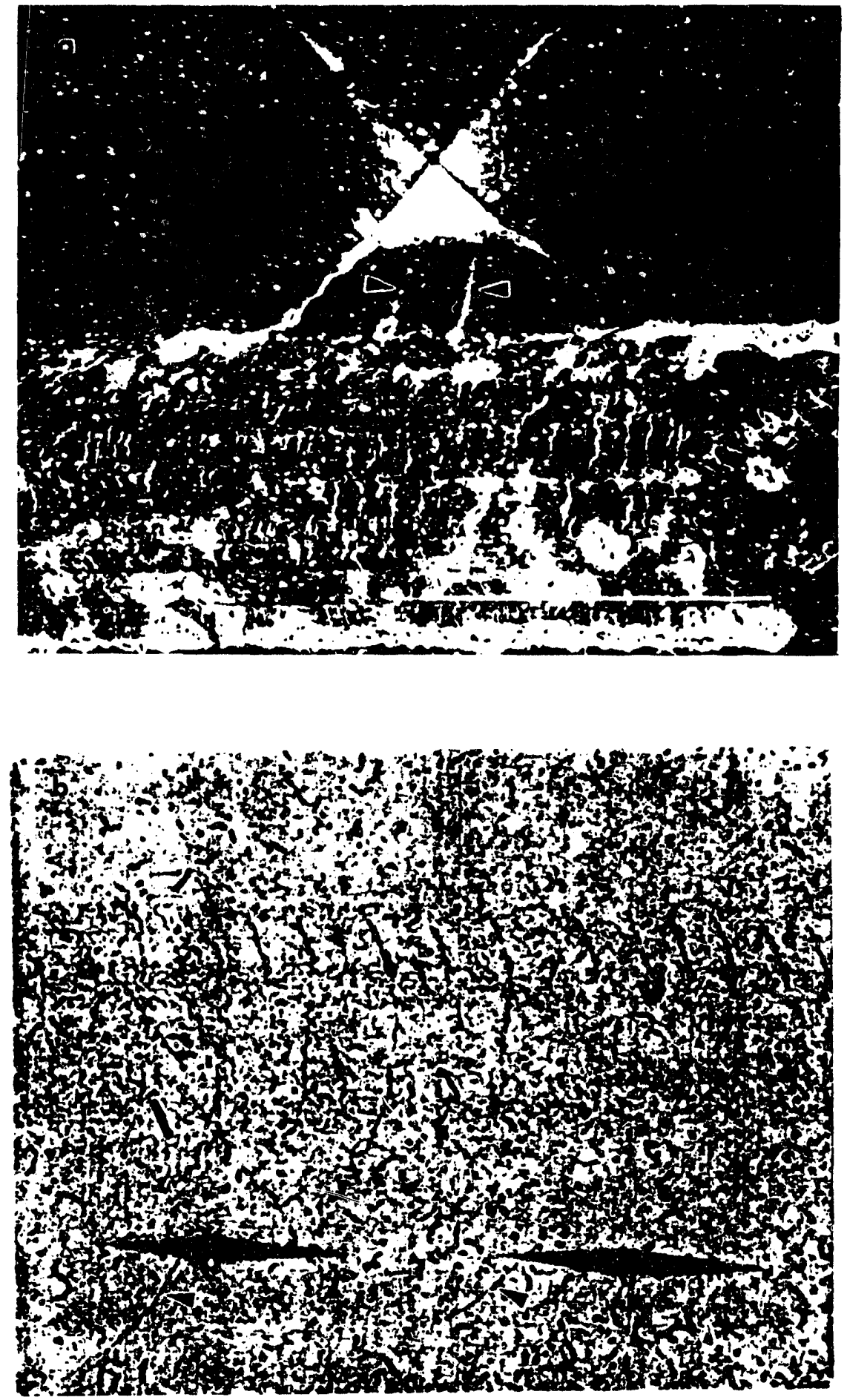

Figure 12 Micorgraphs of scratching test on inclined surface with (a) Vickers indents and (b) Knoop indents on. Cracks are generated during the scratching tests, 400x. 


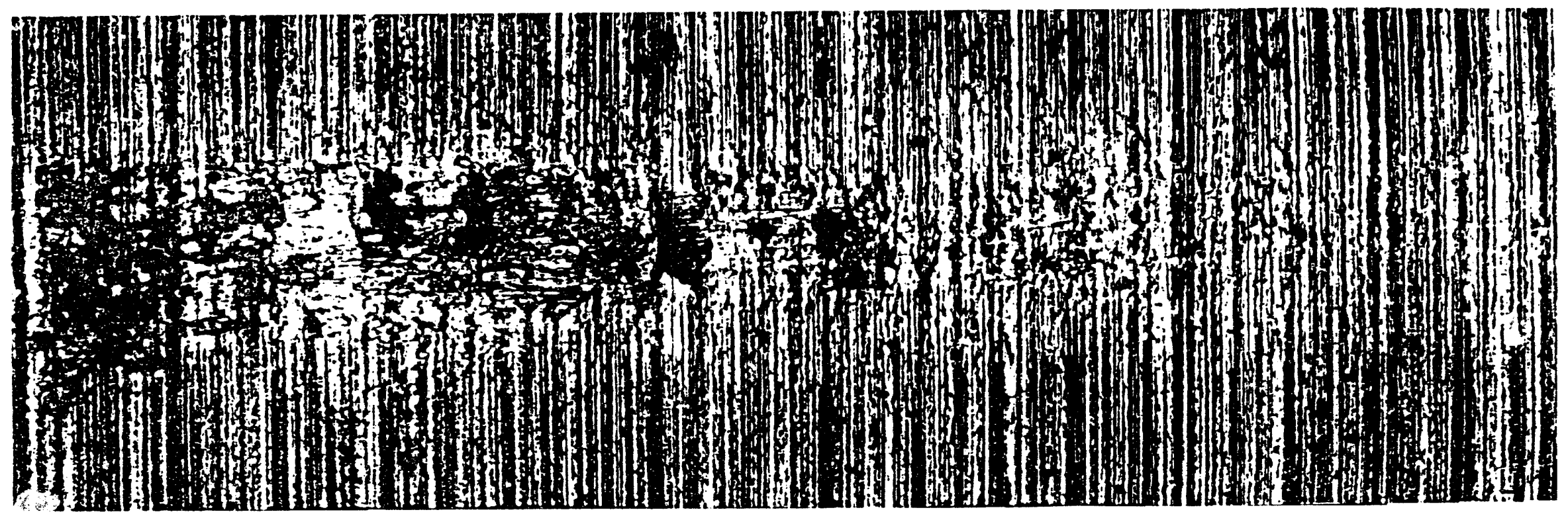

Figure 13.a Optical micrograph of sphere scratched on the inclined plane of as-machined surface. Specimen was grounded with CM1 grinding fluid before scratching, $100 \mathrm{x} . \sigma_{\mathrm{DC}}=3.0 \pm 0.5 \mathrm{GPa}$.

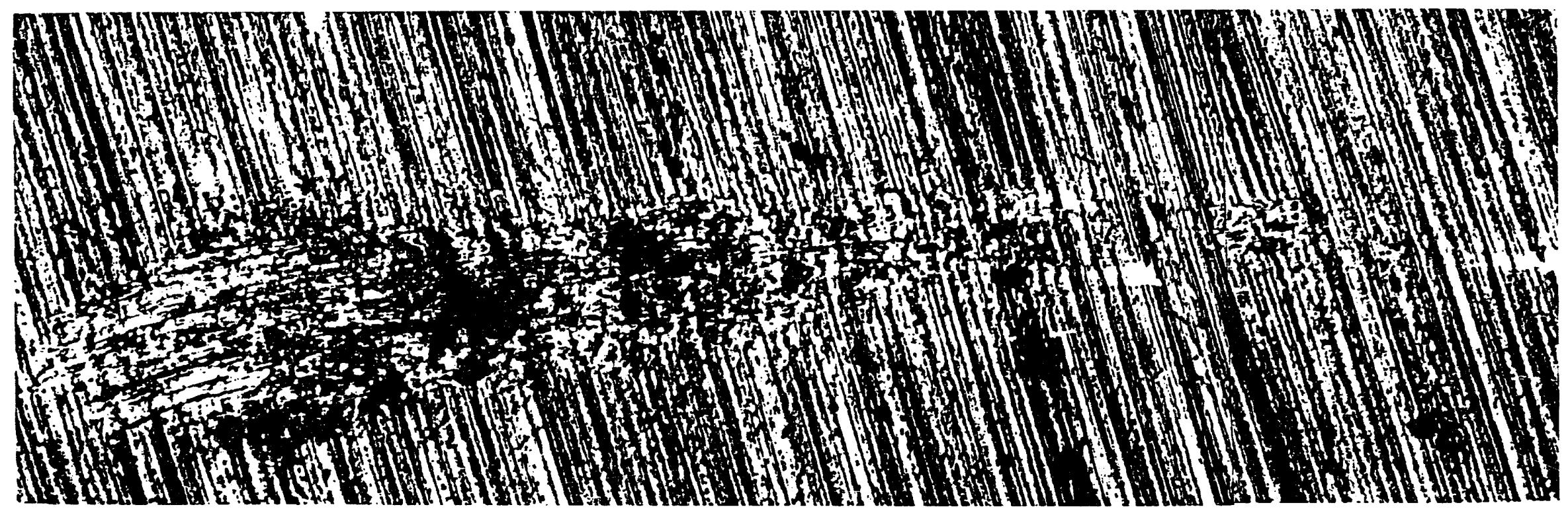

Figure 13 b Optical micrograph of sphere scratched on the inclined plane of as-machined surface. Specimen was grounded with CM11A grinding fluid before scratching, $100 \mathrm{x} . \sigma_{\mathrm{DC}}=4.5 \pm 0.5 \mathrm{GPa}$. 


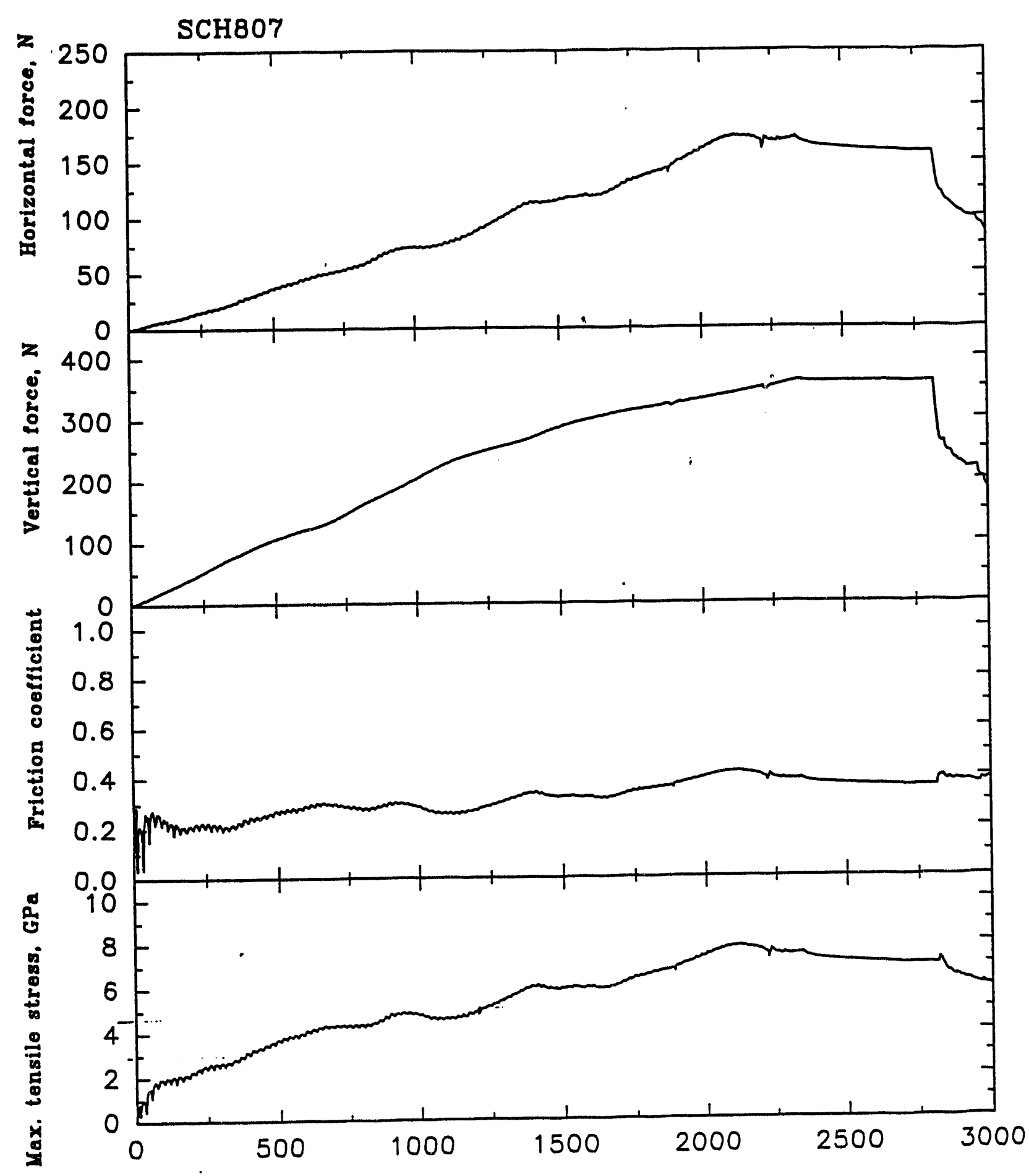

Distance, $\mu \mathrm{m}$

Figure 14 Horizontal and vertical forces, friction coefficient and maximum tensile stress vs. distance on the inclined surface, corresponding to the scratch shown in Figure 


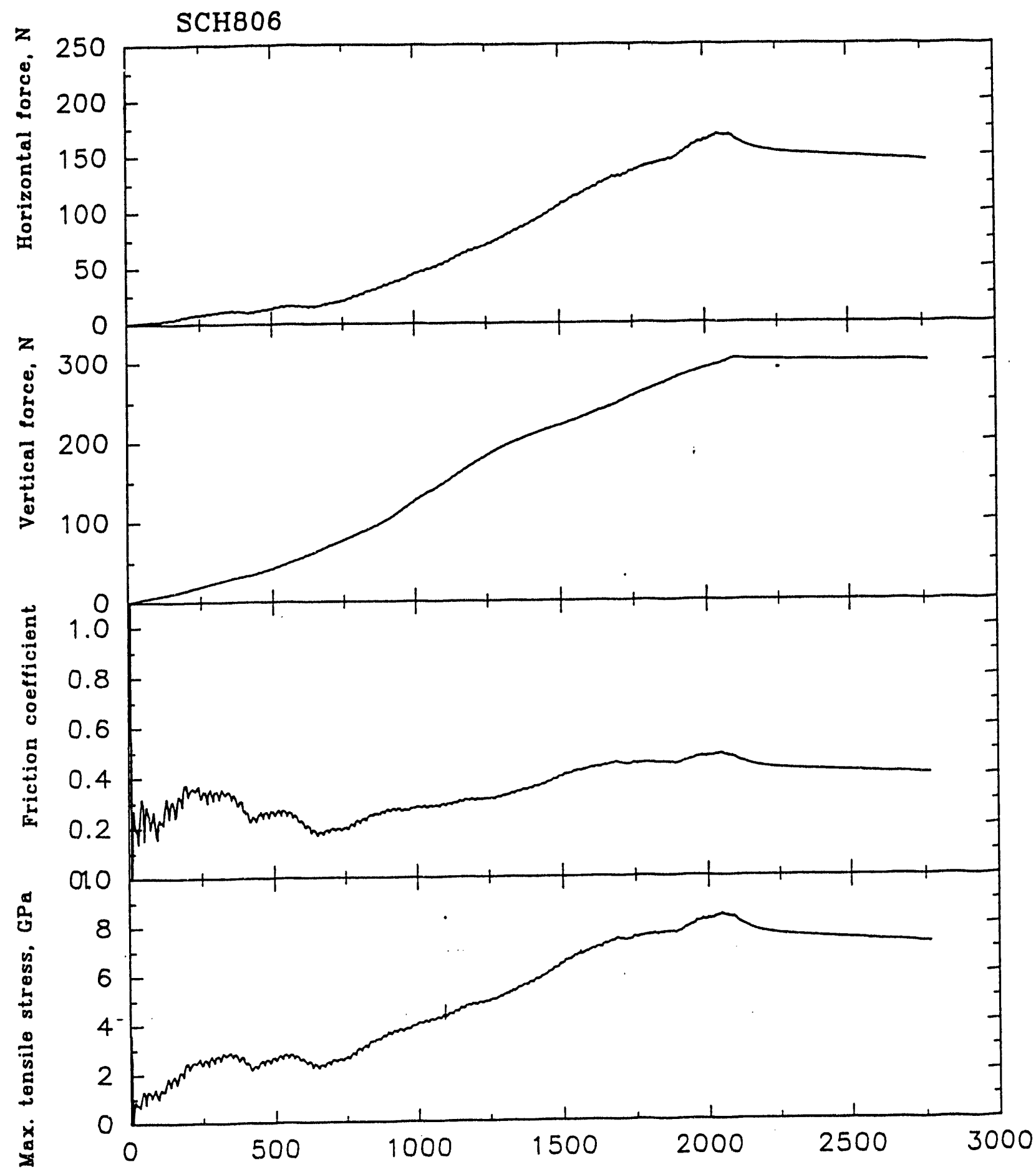

Distance, $\mu \mathrm{m}$

Figure 15 Horizontal and vertical forces, friction coefficient and maximum tensile stress vs. distance on the inclined surface, corresponding to the scratch shown in Figure 
(1) Design and set up a mini-grinding test capable of grinding small sample under constant loading and constant feeding conditions.

(2) Conduct single grain scratch tests in different fluids to investigate the mechanochemical mechanisms of ceramics during the machining.

(3) Develop analysis to understand why the normal forces are different with different grinding fluids under the same grinding condition.

\section{STATUS OF MILESTONE}

On schedule

\section{COMMUNICATIONS AND VISITS}

S. M. Hsu participated at the first annual Cost-effective ceramics program review at ONRL and presented a talk on the project.

Kennametal Inc. has furnished test procedures for corrosion evaluation and additional sample for machining evaluation.

\section{PAPERS/PATENTS}

A patent disclosure has been submitted to the NIST patent office for processing. 
High-Speed, Low-Damage Grinding of Advanced Ceramics

Dr. Joseph A. Kovach (Eaton Manufacturing Technologies Center)

Dr. Stephen Malkin (University of Massachusetts)

\section{Objective/Scope}

The fundamental objective of this project is to conduct a feasibility investigation of High Speed Low Damage (HSLD) grinding relative to the development of a single step, roughing/finishing process suitable for producing high quality silicon nitride ceramic parts. Current industrial grinding approaches sacrifice productivity and costs in order to achieve good surface finishes. However, by using high wheel speeds and fine grits to achieve the small grain depths of cut necessary for low damage grinding, it is anticipated that a process can be identified to finish grind silicon nitride at high material removal rates while producing acceptable surface integrity at substantially lower costs than traditional, multi-stage grinding processes.

\section{Technical Highlights}

This semiannual progress report describes some of the program technical highlights developed over the period from April 1, 1993 through September 30, 1993. The primary focus is on milestones 153203 (laboratory grinding studies), 153204 (specimen characterization), and 153205 (HSLD model development). The majority of the high speed laboratory grinding studies were performed in the Eaton MRC (Machining Research Center), while detailed specimen surface topographical characterization was conducted at the ORNL HTML, and HSLD model development taking place at the University of Massachusetts Grinding Laboratory.

To date, over 300 Eaton S/RBSN MOR bars were fabricated and prepared for use in the laboratory grinding studies. In addition, over 200 Eaton S/RBSN cylindrical rollers have been received and prepared for test purposes. Additional Silicon Nitride (SN-220) test specimens were also obtained from Kyocera. The majority of the grinding wheels and dressing tools were purchased from Norton, Universal/Beck Supercut, Abrasive Technology, and Coors Technical Ceramics in Oak Ridge. However, in an effort to avoid wheel rupture, only plated or brazed diamond wheels (from Abrasive Technology) were evaluated at the highest speeds (up to 35,000 SFM, $178 \mathrm{~m} / \mathrm{s}$ ). 
Using a relatively coarse (120 grit) brazed diamond wheel, some of the most extreme tests were designed to identify how high wheel speeds and removal rates might impact resulting grinding forces, finishes, and surface quality. For the purposes of this set of experiments, surface quality was given by the percent pull out or surface fragmentation. As reported by T. Bifano and J. Mayer, a percent damaged area on the order of $10 \%$ to $15 \%$ was used to roughly identify the ductile mode grinding threshold. The method employed for quantifying surface fragmentation at the HTML is based on the point-counting technique described in Quantitative Metallography by Vander Voort and in Quantitative Stereology by Underwood.

As a function of the process under examination, the following conditions were collectively varied to establish low damage grinding behavior at high material removal rates. Wheel speed was increased from $5000 \mathrm{SFM}(25 \mathrm{~m} / \mathrm{s})$ to 35,000 SFM $(178 \mathrm{~m} / \mathrm{s})$ in increments of $10,000 \mathrm{SFM}(51 \mathrm{~m} / \mathrm{s})$ while the material removal rate was varied from $0.125 \mathrm{in} 2 / \mathrm{min}(1.34 \mathrm{~mm} 2 / \mathrm{s})$ to $1 \mathrm{in} 2 / \mathrm{min}(10.75$ $\mathrm{mm}^{2} / \mathrm{s}$ ) by incrementing the depth of cut and workpiece velocity as follows:

\begin{tabular}{c}
$\begin{array}{c}\text { Depth of Cut } \\
\text { inches }(\mathrm{mm})\end{array}$ \\
\hline $0.0025(.0635)$ \\
$0.0050(.1270)$ \\
$0.0025(.0635)$ \\
$0.0050(.1270)$ \\
$0.0150(.3810)$ \\
$0.0100(.2540)$
\end{tabular}

\begin{tabular}{l} 
Part Velocity \\
in/min (mm/s) \\
\hline $50(21)$ \\
$50(21)$ \\
$100(42)$ \\
$100(42)$ \\
$50(21)$ \\
$100(42)$
\end{tabular}

\begin{tabular}{c}
$\begin{array}{c}\text { Removal Rate } \\
\text { in2/min (mm2/s) }\end{array}$ \\
\hline $0.125(1.34)$ \\
$0.250(2.69)$ \\
$0.250(2.69)$ \\
$0.500(5.38)$ \\
$0.750(8.06)$ \\
$1.000(10.8)$
\end{tabular}

Under the conditions outlined above, it can be seen that the grinding forces decrease considerably with increased wheel speed and/or reduced material removal rate (see Figures 1A \& 1B). In general, the grinding forces are reduced by approximately a factor of two when increasing the whe日l speed from conventional speeds (e.g. 5000 SFM, $25 \mathrm{~m} / \mathrm{s}$ ) to over 25,000 SFM $(127 \mathrm{~m} / \mathrm{s})$. From a production grinding standpoint this can be significant when rough grinding a relatively weak or difficult to fixture component. Also, as expected, the grinding forces decrease nearly linearly with decreased removal rate.

Figure 2 illustrates the wheel speed effects on surface finish for the Eaton S/RBSN material. This graph shows a tendency toward improved surface finish as wheel speed is increased. Hypothetically, this is a direct result of increased workzone temperatures which tend to promote increased ductile/glassy flow. Additional tests will be conducted to confirm this hypothesis. Note however, in several cases, the surface roughness increased somewhat at the highest wheel speed $(35,000$ SFM, $178 \mathrm{~m} / \mathrm{s})$. This is most likely the result of a slight wheel imbalance which was observed at the highest speed.

More interesting is the improved surface finish ashieved by going to high material removal rates - - even while operating at conventional wheel speeds. Realize that typical industrial ceramic roughing rates do not go much beyond 
$0.125 \mathrm{in} 2 / \mathrm{min}(1.34 \mathrm{~mm} 2 / \mathrm{s})$. However, by dramatically increasing the removal rate, an improved surface is developed. Again, it is speculated that this may be a result of increased workzone temperatures which promote plastic flow.

Possibly the most significant findings to date are graphically illustrated in

Figure 3. It can be seen that increasing wheel speed, while operating at a relatively low material removal rate of $0.125 \mathrm{in} 2 / \mathrm{min}(1.34 \mathrm{~mm} 2 / \mathrm{s})$ or less, can dramatically reduce surface fragmentation. A five fold wheel speed increase from 5000 SFM $(25 \mathrm{~m} / \mathrm{s})$ to 25,000 SFM $(127 \mathrm{~m} / \mathrm{s})$ reduced "pull out" by almost a factor of four. To a lesser extent, the same trend is true at higher material removal rates. Surface fragmentation was reduced 2.5 fold by increasing wheel speeds when operating at $1 \mathrm{in} 2 / \mathrm{min}(10.75 \mathrm{~mm} 2 / \mathrm{s})$. Alternatively, increasing the material removal rate was also shown to reduce surface fragmentation. Approximately a three fold reduction in "pullout" was achieved by increasing removal rates from $0.125 \mathrm{in} 2 / \mathrm{min}(1.34 \mathrm{~mm} 2 / \mathrm{s})$ to $1.0 \mathrm{in} 2 / \mathrm{min}(10.75 \mathrm{~mm} 2 / \mathrm{s})$ while operating at conventional wheel speeds. At $35,000 \mathrm{SFM}(178 \mathrm{~m} / \mathrm{s})$ a two fold reduction in surface fragmentation was achieved by increasing the material removal rate. It is important to note that the lowest level of surface fragmentation $(6 \%)$ was achieved at the highest removal rate and highest wheel spe日d.

Although extensive MOR tests are currently underway, these results tend to suggest that a transition from a "brittle fracture" mode of grinding to a low damage "ductile" grinding mode can be achieved by increasing wheөl spe日ds and/or material removal rates. As alluded to earlier, one possible explanation for this behavior stems from the fact that the grinding force per grit (unit grit load) is reduced significantly by increasing wheel speeds which, in turn, will reduce the surface fracture tendency. However, unit grit load considerations alone will not account for the low surface fragmentation witnessed when operating at the highest material removal rates. Additional consideration must be given to the potential effect of increased workzone temperature developed at high material removal rates and/or wheel speeds which could help to promote plastic flow within the workzone.

In an initial attempt to gain some preliminary understanding of how the grinding parameters might affect the workzone temperatures, approximate thermal calculations were performed using the Carslaw-Jaeger moving band heat source solution. It must be emphasized that, as with most thermal analyses, a linear heat transfer model has been used with the assumption of constant thermal properties independent of temperature. In addition, this initial model does not include convective cooling effects. Moreover, the actual fraction $(\varepsilon)$ of the total grifiding energy (utotal) which enters the workpiece as heat is yet to be identified; but, was assumed to be $50 \%$ for these preliminary calculations. Nevertheless, based on the following relationship it can be seen that increased specific grinding energy or increased material removal rates can lead to increased temperature rise $\left(\Theta_{m}\right)$ within the workzone. 
Where;

$$
\Theta_{m}=\frac{1.13 \alpha^{1 / 2} a^{3 / 4} V_{w}^{1 / 2}\left(\varepsilon u_{\text {total }}\right)}{k d e^{1 / 4}}
$$

$$
\begin{aligned}
\Theta_{m}= & \text { maximum grinding zone temperature rise } \\
\alpha= & \text { thermal diffusivity }=0.016 \mathrm{in}^{2} / \mathrm{sec}=0.10 \mathrm{~cm}^{2} / \mathrm{s} \theta \mathrm{c} \\
u= & \text { depth of cut } \\
V_{w}= & \text { workpiece velocity } \\
\varepsilon \quad= & \text { fraction of total grinding energy conducted as heat into the } \\
& \text { workpiece } \\
u_{\text {total }}= & \text { total specific grinding } \\
k= & \text { thermal conductivity }=17.34 \mathrm{BTU} / \mathrm{hr} . \mathrm{ft} .{ }^{\circ} \mathrm{R}=30 \mathrm{Watt} / \mathrm{m}^{\circ} \mathrm{K} \\
d_{e}= & \text { equivalent grinding whe日l diameter }
\end{aligned}
$$

General temperature trends were plotted in Figure 4 by using the above relationship with mean thermal property data and the actual grinding test data. Recognize that the primary purpose of this graph is not to predict absolute workzone temperatures, but rather to illustrate maximum grinding zone temperature trends as a function of wheel speed and material removal rate. From this perspective, the graph clearly shows the tendency toward increased workzone temperatures at elevated wheel speeds and material removal rates. Interestingly, the lowest level of surface fragmentation $(6 \%)$ occurred under the highest temperature conditions (i.e. highest MRR, highest wheel speed) while the lowest temperatures resulted in the highest surface fragmentation (43\%).

In an effort to gain additional insight into this behavior, rudimentary temperature measurements using embedded thermocouples were also conducted. The experimental setup for measuring the temperature response and grinding power is illustrated in Figure 5 . For these tests a hole is drilled in each specimen, and then a thermocouple (type $K, 36$ gauge wire) is installed and held with high temperature cement. The thermocouple junction is initially about 1.2 $\mathrm{mm}$ from the top suriace of the workpiece before the grinding begins.

The grinding test is continued by taking successive passes under constant conditions until the thermocouple is ground and destroyed. The last grinding pass is taken for reference as zero depth, and the locations of the previous grinding passes are then calculated. The machine is left idle for a few minutes between successive passes in order to ensure that the temperature of the workpiece returns to the ambient temperature before the next grinding pass.

All grinding passes were performed in the upgrinding mode using a $5 \%$ soluble oil in water and a Norton SD150-R100BX619C wheel. A plot of the maximum temperature rise for each grinding pass versus depth with this configuration is shown in Figure 6 . Although there is some scatter, the maximum grinding zone temperature obtained with each subsequent pass closer to the surface tended to increase as expected. An example of the temperature 
response for a depth of $0.0375 \mathrm{~mm}$ below the workpiece surface is shown in Figure 7. The horizontal scale is the dimensionless length $x / l$, where $x$ is the distance from the center of the heat source at the grinding zone (positive ahead) and $2 \mathrm{l}$ corresponds to the theoretical geometrical wheel-workpiece contact length $I_{C}$.

Using moving heat source theory, the measured temperature response can be compared with the theoretical temperature response for the input heat flux to the workpiece $\varepsilon q$, where $\varepsilon$ is the fraction of the total energy transported as heat to the workpiece and $q$ is the total heat flux at the grinding zone. The total heat flux at the grinding zone was obtained as $q=P / l_{C} b$, where $P$ is the measured net grinding power, $I_{C}$ is the geometrical wheel-workpiece contact length, and $b$ is the workpiece width. The net grinding power was about $1.8 \mathrm{kw}$, which corresponds to a specific energy of about $36 \mathrm{~J} / \mathrm{mm}^{3}$. The theoretical temperature response was numerically calculated using a finite difference method and the assumption of a triangular heat source at the grinding zone.

Unfortunately, poor correlation was found between the theoretical and measured temperature responses, as the measured temperature response tended to lag significantly behind the theoretical response (see Figure 7). Therefore, a time constant $T$ was also introduced into the theoretical model, which essentially models the temperature measuring system as a first order system. By selecting appropriate values for $\varepsilon$ and $T$, the modified theoretical results can be matched to the experimental results. In Figure 7, a time constant of $25 \mathrm{~ms}$ and an energy partition of $16 \%$ provide a reasonable match. From the above analysis, it would appear that the measuring system has a time constant of about $28 \mathrm{~ms}$ and the energy partition to the workpiece is about $18 \%$ rather than the $50 \%$ assumption used previously.

It is important to realize however, that due to the time delay of the thermocouple measuring system for the ceramic workpiece, the peak temperature can not be accurately measured during the grinding process. One possible reason is poor contact between the thermocouple tip and the ceramic workpiece. With a metal workpiece, the thermocouple is welded to the workpiece, thereby providing better contact and a shorter time constant of about $5 \mathrm{~ms}$ based on results obtained in the U. Mass. laboratory. The accuracy may also be worse due to the lower thermal conductivity of the ceramic workpiece, which increases the thermal inertia of the thermocouple junction and heat conduction from the junction down the thermocouple wires. A system with a faster time response and smaller heat transfer from the measuring area is required to improve the accuracy.

Consequently, an infrared system, which uses an optical fiber to conduct the signal from the workpiece to a sensor, is being developed at the University of Massachusetts. The experimental setup of the proposed infrared system is shown in Figure 8. Based on detailed thermal analyses, an optical fiber made of chalcogenide, which can transmit radiation from $3 \mu \mathrm{m}$ to $11 \mu \mathrm{m}$, has been chosen. The thermal signal is transferred from the workpiece to the fiber holder and through a chopper. (The chopper transforms the DC signal to an AC signal so that background radiation does not influence the measurements.) The signal 
then goes to the two-color detectors. Note that the InSb cell will absorb and detect radiation at wavelengths from 1.0 to $5.5 \mu \mathrm{m}$ while the $\mathrm{HgCdTe}$ cell will detect radiation with wavelengths longer than $6.0 \mu \mathrm{m}$, thus giving a total system range from room temperature to about $500^{\circ} \mathrm{C}$. Subsequently, the signal is then amplified and rectified to produce a DC signal for the data logger.

\section{Status of Milestones}

Based on the milestone/gantt chart given in the February, 1993 bi-monthly report, the majority of project is on schedule. However, a 120 day no-cost extension has been granted to complete all the technical contract requirements. Thus far, the specimen preparation (milestone 153201) has been completed. All experimental development (153202) is well nearly finished, with the exception of the infrared pyrometry system. Moreover, most of the laboratory grinding studies have been completed (153203). Additional tests are currently underway to identify the effects of wheels speed and MRR on G-Ratio and MOR. Some additional specimen characterization (153204) will be required once these tests are completed. Portions of the HSLD energy partition and thermal model (153205) have been completed, but will be refined by use of the infrared pyrometer system.

\section{Publications}

A paper entitled "A Feasibility Investigation of High Speed, Low Damage Grinding for Advanced Ceramics" was assembled for the Fifth International Grinding Conference held October 26-28 in Cincinnati and also for the SAE CCM meeting held in Detroit (October 18 - 21).

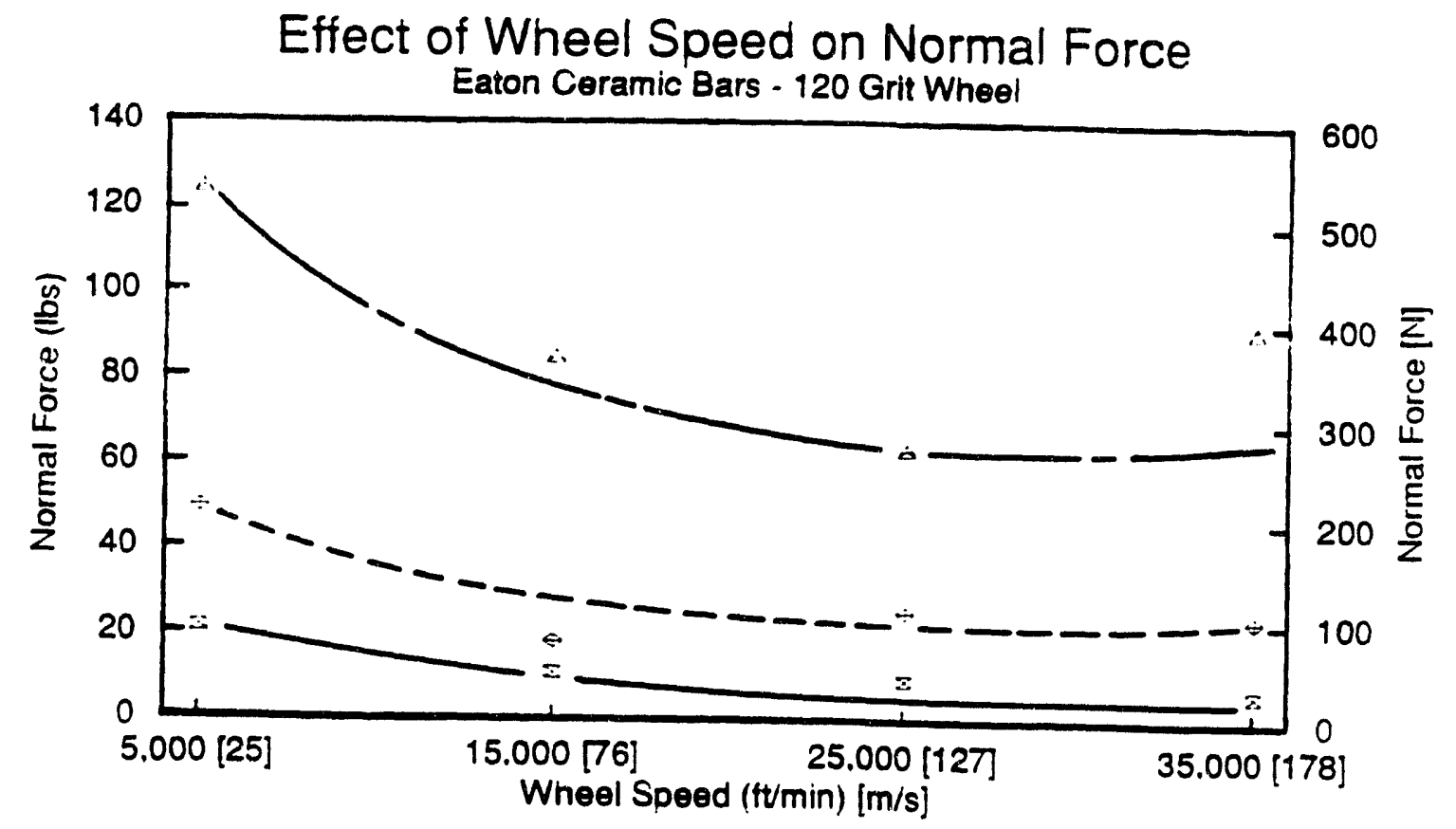

$-O^{\prime} w=0.125 \mathrm{sq}$ in $/ \mathrm{min}[1.34 \mathrm{sq} \mathrm{mm} / \mathrm{sec}]--Q^{\prime} w=0.5 \mathrm{sa} \mathrm{in} / \mathrm{min}[5.38 \mathrm{sq} \mathrm{mm} / \mathrm{sec}$ ]

$-O w=1.0 \mathrm{sq} \mathrm{in} / \mathrm{min}$ [10.75 sq $\mathrm{mm} / \mathrm{sec}$ ]

Figure 1-A. 


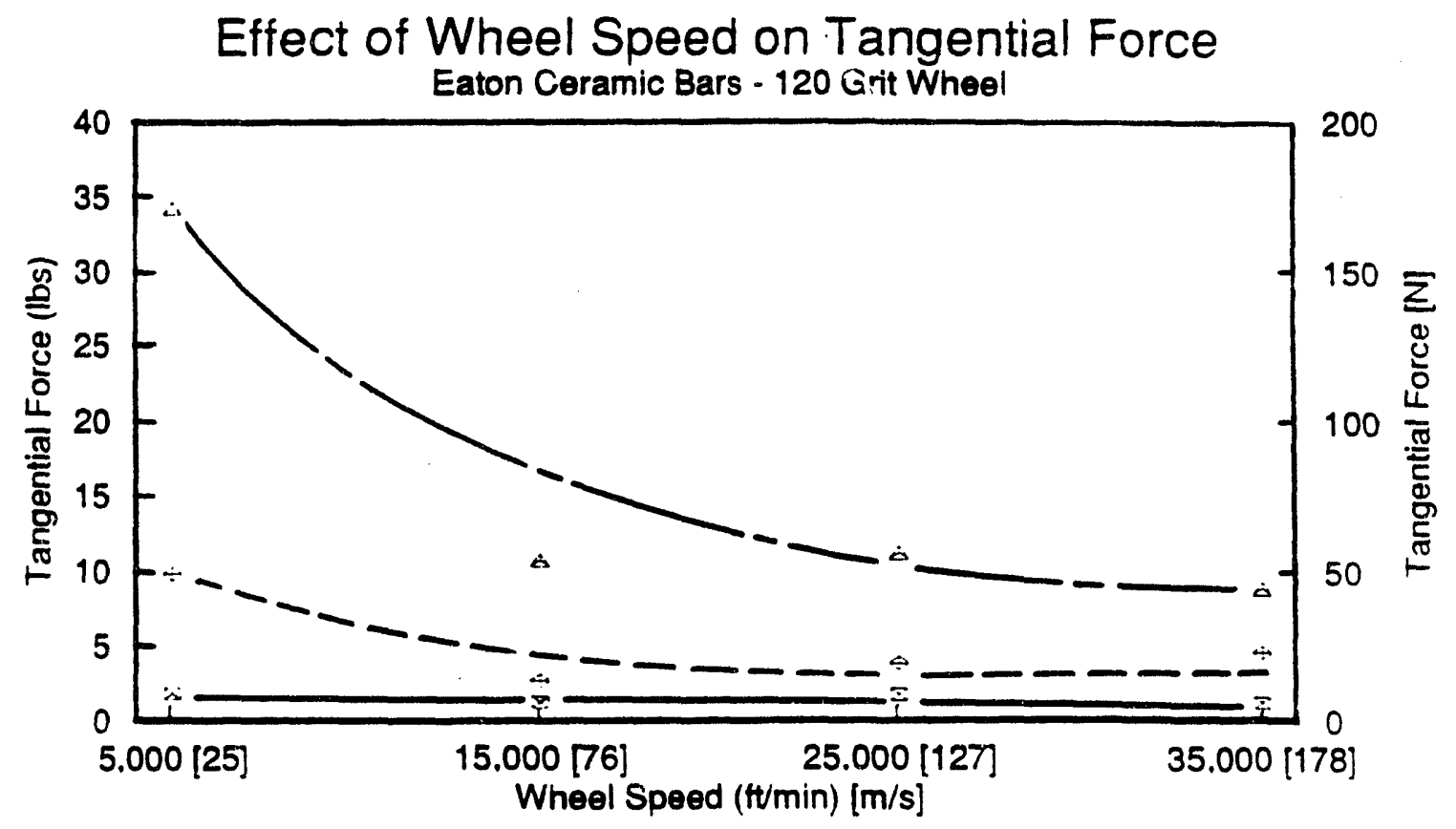

- $Q^{\prime} w=0.125 \mathrm{sq} \mathrm{in} / \mathrm{min}\left[1.34 \mathrm{sq} \mathrm{mm} / \mathrm{sec}^{\prime}\right.$ - $-Q^{\prime} w=0.5 \mathrm{sq} \mathrm{in} / \mathrm{min}[5.38 \mathrm{sq} \mathrm{mm} / \mathrm{sec}$ ] $-Q^{\prime} w=1.0 \mathrm{sq}$ in/min [10.75 sq mm/sec]

Figure 1-B.

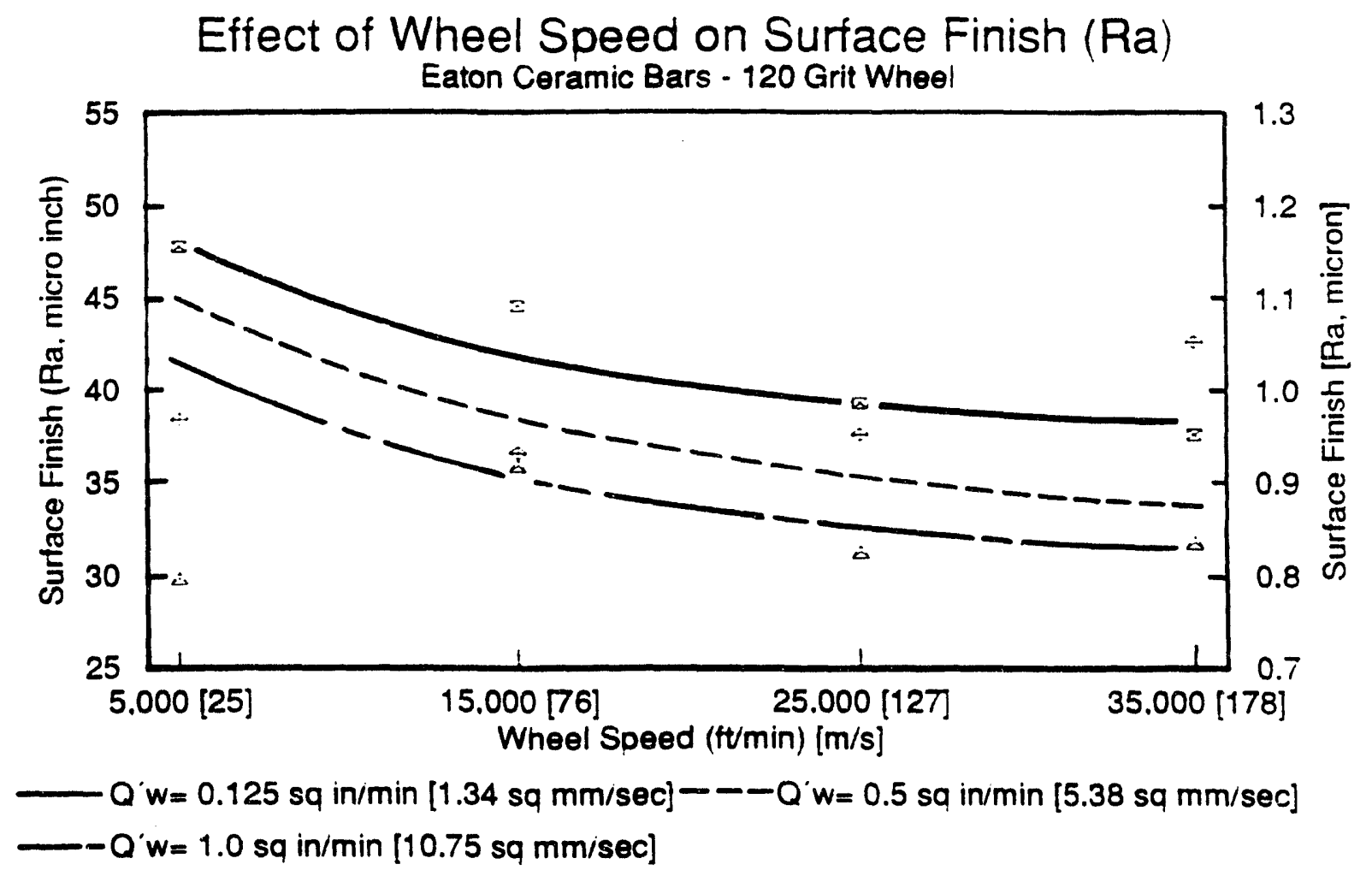

Figure 2. 


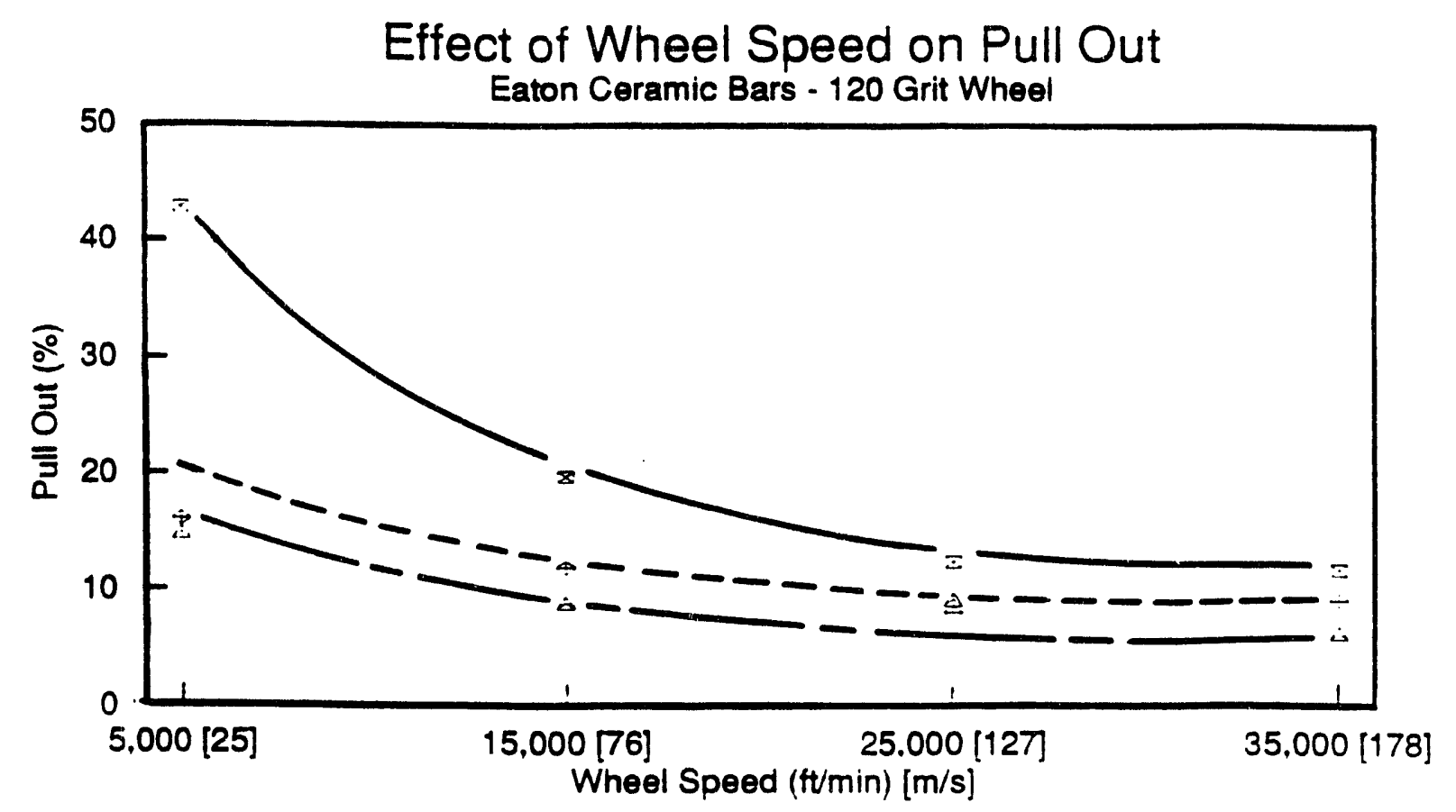

- $Q^{\prime} w=0.125 \mathrm{sq} \mathrm{in} / \mathrm{min}\left[1.34 \mathrm{sq} \mathrm{mm} / \mathrm{sec}^{\prime}\right.$ - $-Q^{\prime} w=0.5 \mathrm{sq} \mathrm{in} / \mathrm{min}$ [5.38 sq mm/sec] - $0^{\prime} W=1.0 \mathrm{sq} \mathrm{in} / \mathrm{min}[10.75 \mathrm{sq} \mathrm{mm} / \mathrm{sec}]$

Figure 3.

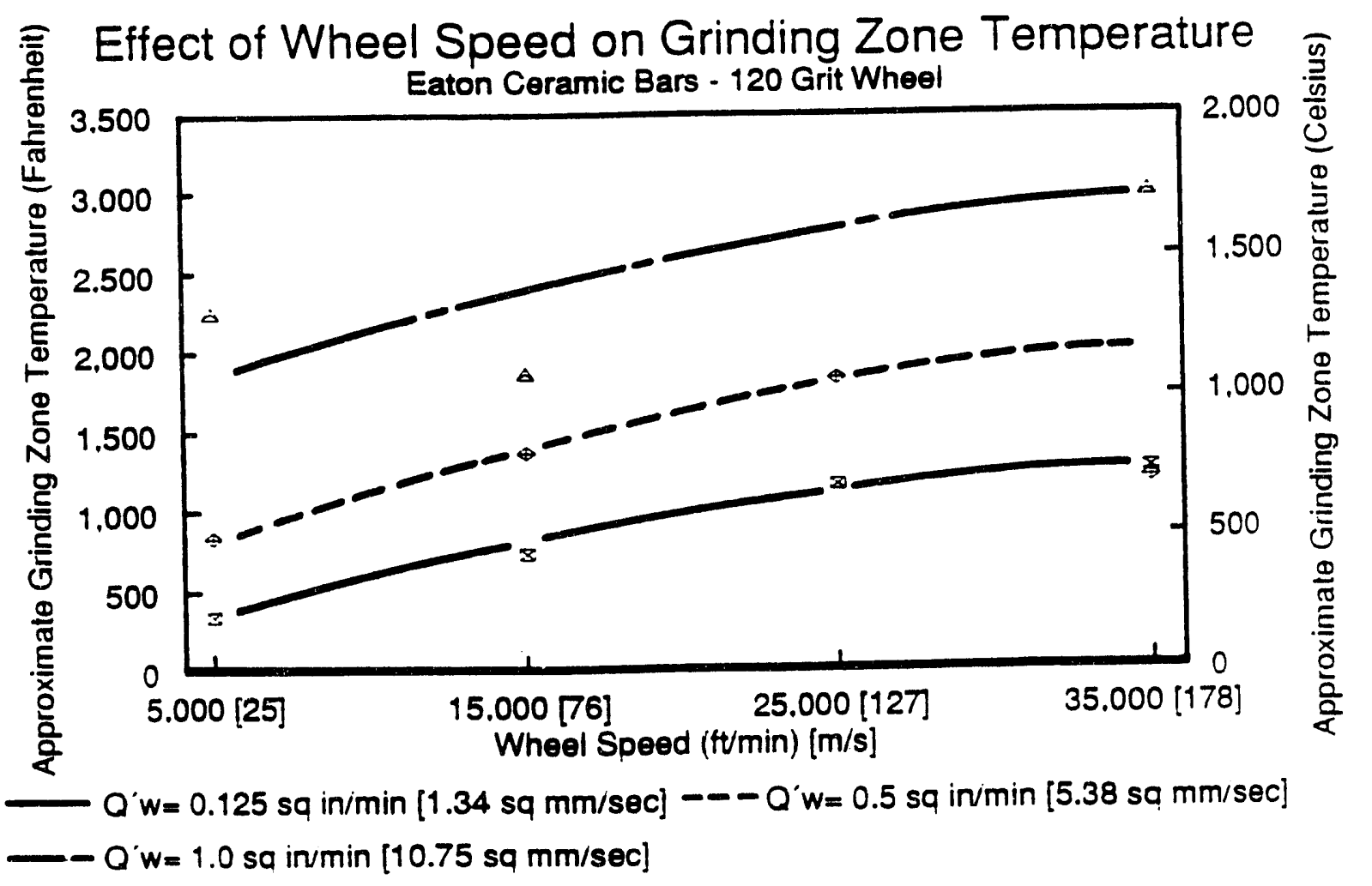

Figure 4 


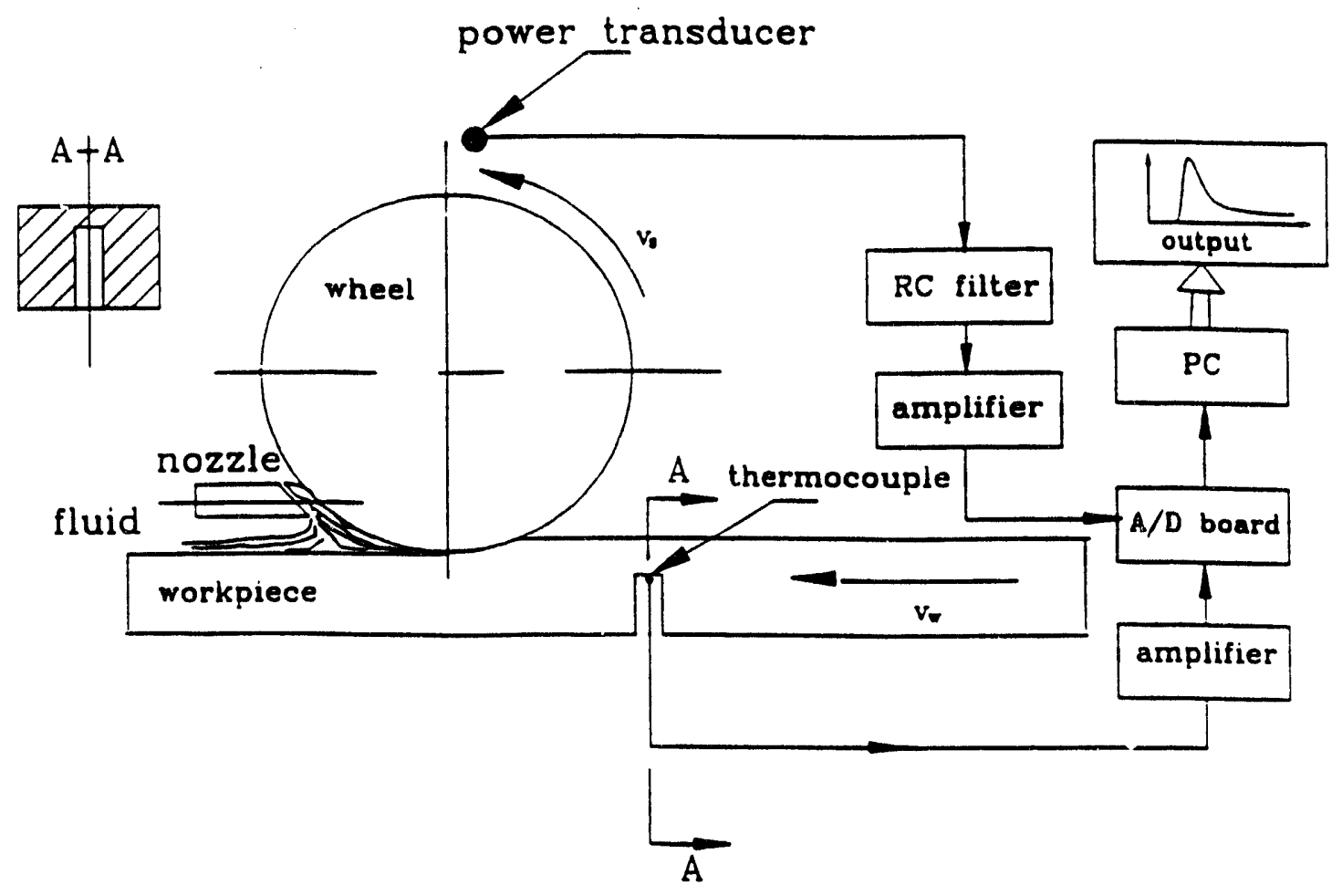

Figure 5. Experimental arrangement for grinding temperature measurement.

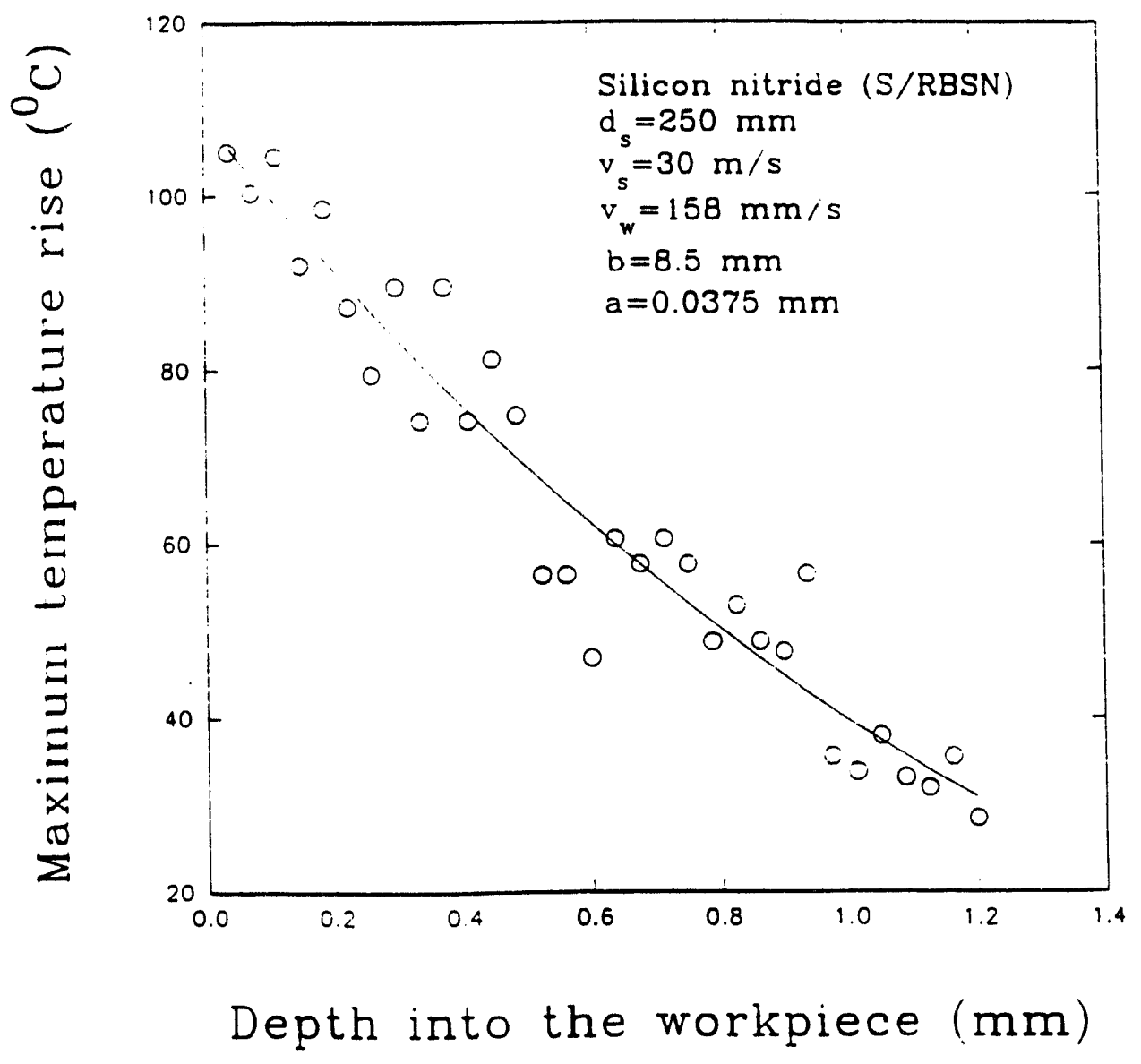

Figure 6 . Maximum temperature rise versus depth into the workpiece. The hole diameter for the embedded thermocouple was $1.0 \mathrm{~mm}$. 


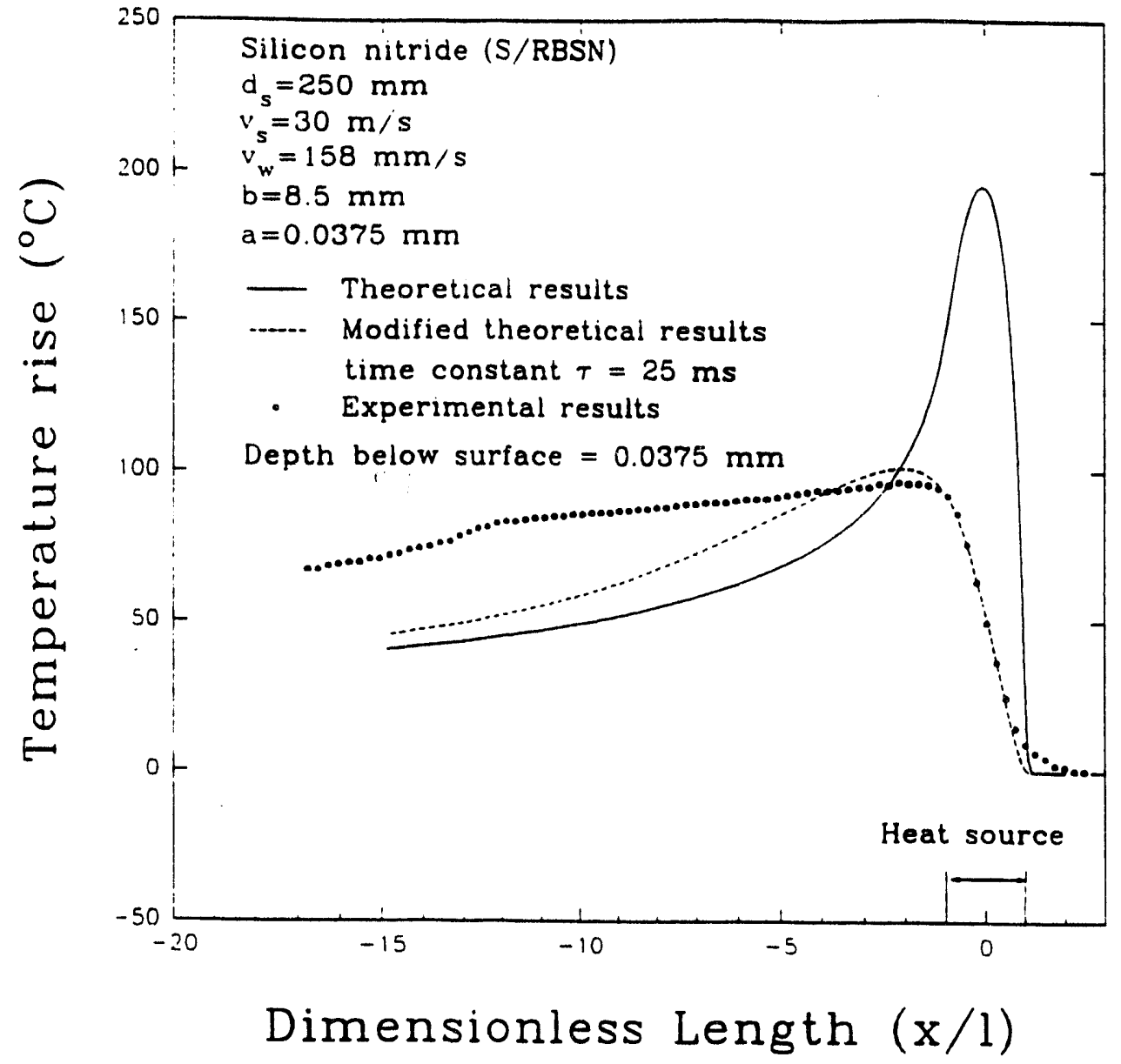

Figure 7 . Temperature results with triangular heat source: energy partition $\epsilon=16 \%$.

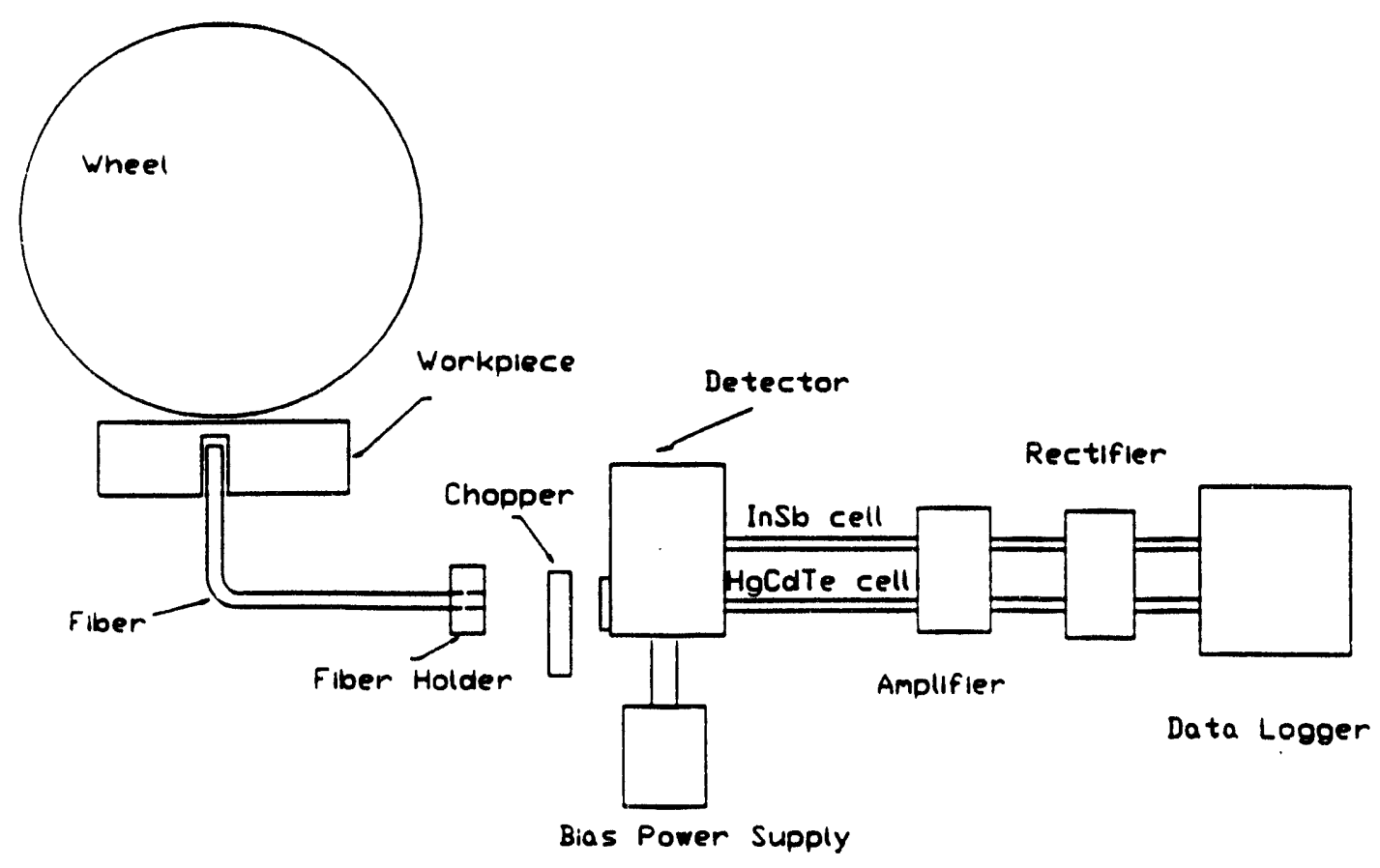

Figure 8 . The experimental setup of the infrared two-color detector system. 
Laser Scatter Methods for Detection of Subsurface Machining Damage in Ceramics

J. S. Steckenrider, W. A. Ellingson, G. A. Forster, M. H. Haselkorn, and

C. J. Anderson (Argonne National Laboratory)

\section{Objective/scope}

The primary objective of this program is to develop a laser scattering procedure which would provide a direct (near real-time) indication of changes in the subsurface (and surface) during machining - both machining induced damage such as median crack fromation and surface roughness. A second minor objective is to evaluate dye penetrant technology for crack detection as an otf-line indicator. The laser program will be executed in three steps. The first step will be to optimize the laser scattering procedure by examining specimens machined using innovative machining techniques. The second step will involve correlation of these laser scattering results with mechanical properties in "real" machined ceramic specimens The final step will be to develop a prototype instrument to be evaluated for on-line implementation in a production environment. The investigation into dyepenetrants for surface defect detection will be conducted in two steps: literature and on-site reviews and laboratory experiments.

\section{Technical progress}

The work accomplished during this period involved two areas: (1) acquisition and initial optical properties determination of $\mathrm{Si}_{3} \mathrm{~N}_{4}$ samples, and (2) initiation of exploratory work on dye penetrants. In addition, we prepared and submitted an abstract and 30 minute review of our project for the Project Review and Coordination Meeting of the CostEffective Ceramic Machining Program held September 8, 1993 at Oak Ridge.

\section{Part 1: Optical properties determination}

Initial procedures and protocols have been established for the determination of optical transmission properties of the $\mathrm{Si}_{3} \mathrm{~N}_{4}$ specimens. This information should ve useful not only for determining the relavtive sensitivity to subsurface damage in various type of $\mathrm{Si}_{3} \mathrm{~N}_{4}$, but also for quantitative measurement of defect depth. This "calibration" procedure requires a specimen $3 \mathrm{~mm} \times 4 \mathrm{~mm} \times 50 \mathrm{~mm}$ or larger for specimen preparation, and such a specimen was initially unavailable for one of the materials of interest in this program (Sialon). The other material of interest, Garrett's GN-10, has been replaced by Caterpillar Inc. with Garrett's GS-44, owing to the high cost of GN-10. A Sialon specimen will be obtained presently, samples of other $\mathrm{Si}_{3} \mathrm{~N}_{4}$ materials which were avaliable, including GS44, have been prepared and analyzed, and these results are illustrated in Fig. 1. As is shown, there is a wide distribution of optical transmission properties among the various $\mathrm{Si}_{3} \mathrm{~N}_{4}$ types. Sensitivity to subsurface defects will therefore be highly dependent on the material used. This is indicated in Fig. 2, which plots the detected signal for laser scatter from the front surface of a specimen whose back surface has been ground to steps of various thicknesses. Here, Kyocera's SN 253, which has a lower optical transmittance, shows a lesser depth of sensitivity (as evidenced by the flat response at thicknesses above $\approx 200 \mu \mathrm{m}$ ) than does Garrett's GS 44, which has a higher optical transmittance (whose response does not flatten until beyond $800 \mu \mathrm{m}$ ). However, because a specimen of zero thickness does not scatter at all, the scattered intensity must return to zero at a thickness of zero. This is shown for the GS 44 specimen, whose scattering is sufficiently weak as to peak in intensity around a thickness of $\approx 100 \mu \mathrm{m}$. Such behavior may introduce an ambiguity in determining defect depth for shallow defects. 


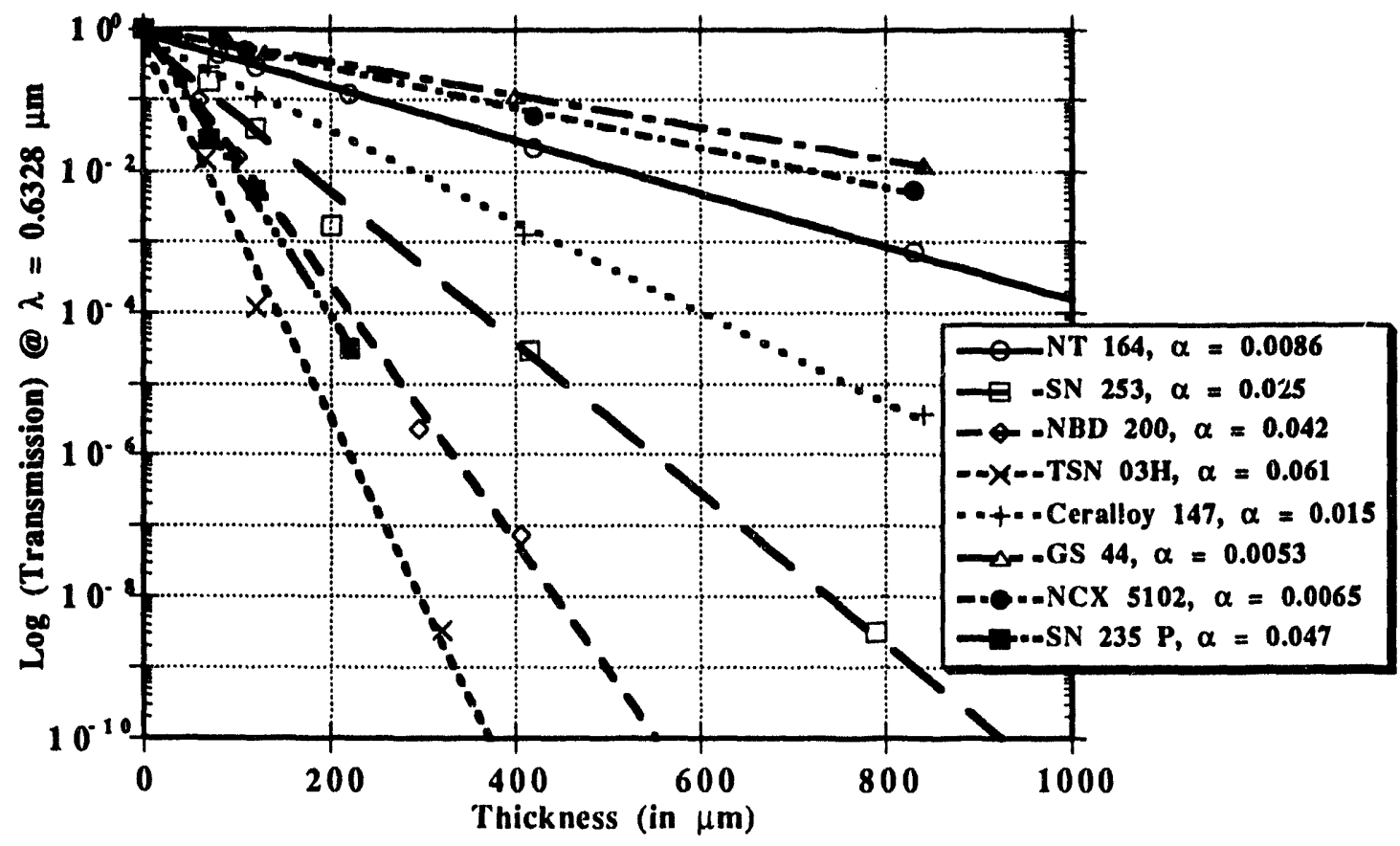

Figure 1. Graph of measured optical transmission properties for several $\mathrm{Si}_{3} \mathrm{~N}_{4}$ materials. Lines are best fits to optical transmission $T=I_{t} / I_{i}=e^{-\alpha t}$, where $t$ is thickness.

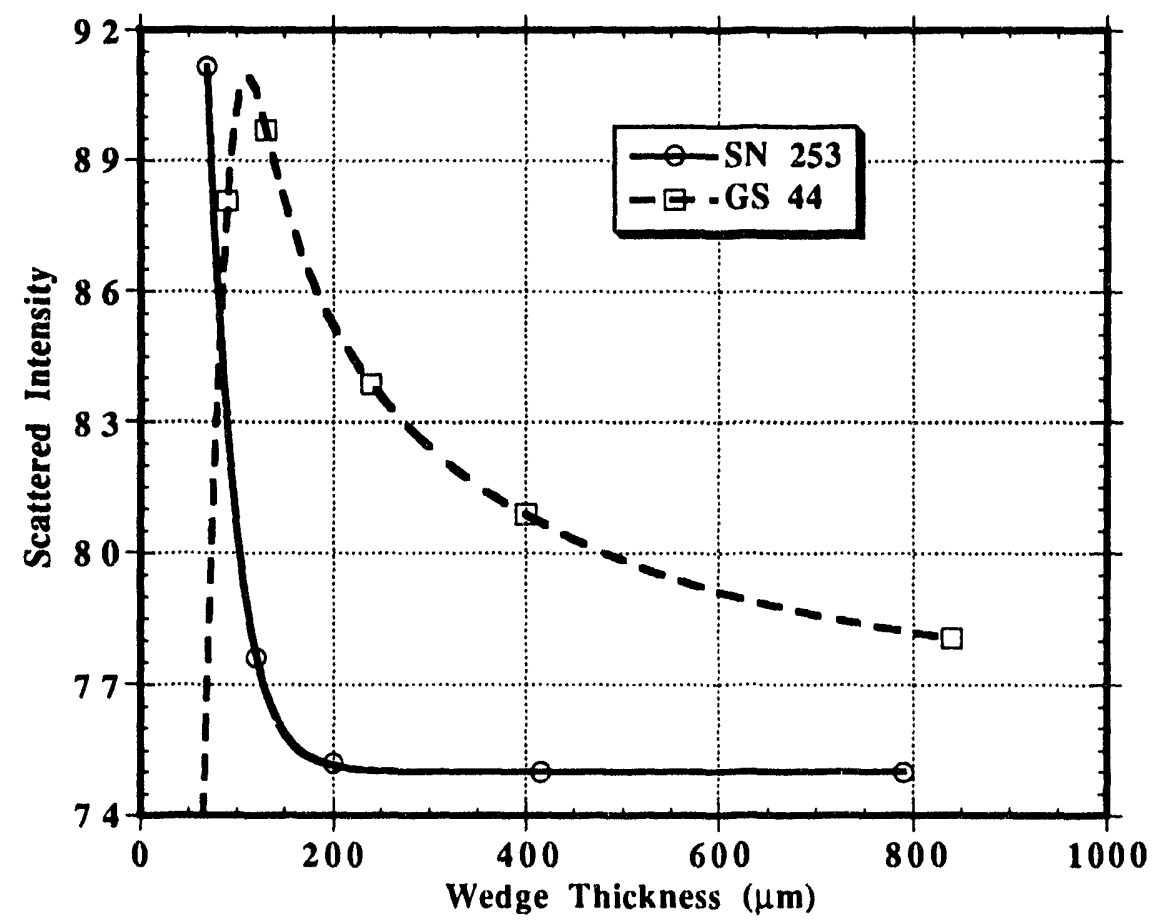

Figure 2. A comparison of laser scatter response to subsurf tce "defects" of varying depths for two materials. The curves are best fits to an exponential decay. 
Part 2: Dye Penetrant

Detection of surface cracking via dye penetrants is a well-developed technology and ASTM/ASME standards are available covering the technique (ASTM E165-91 - Standard Test Method for Liquid Penetrant Examination).

This standard covers the basic methods for penetrant examination of non-porous materials such as metals, glass and other ceramics, and some plastics. This standard is supplemented by a group of standards that cover different penetrant and developer types. ASTM E165-91 specifically does not address any safety problems related to the use of any materials and leaves this responsibility to the user. ANL's inspection department uses dye penetrant material in small amounts from spray cans. They follow the safe handling procedures listed on the Material Safety Data Sheet from the manufacturer. This mainly involves ventilation and protective masks if needed.

A new method of crack detection is under development in Moscow, Russial. The technique may improve detection of finer cracks than possible with large molecule liquid penetrants. The method uses gaseous diffusion. Contact has been made with the developers in Moscow and arrangements for cooperative exchange of information is being worked out.

A 486-33 computer with a Data Translation frame grabber board has been set-up to capture images of dye penetrant inspection with a $512 \times 512$ eight bit digital camc ca. Digital enhancement of images may improve crack detection in some instances.

In future work, we will investigate the applicability of dye penetrant techniques used by ceramic bearing manufacturers such as SKF and CERBEC. An electronically charged powder technique usable on insulators such as glass and other ceramics will also be investigated.

\section{Status of Milestones}

All are on schedule.

\section{Communications/Visits/Travel}

\section{Attended}

W.A. Ellingson attended and participated in the Project Review and Coordination Meeting of the Cost-Effective Ceramic Machining Project, September 8, 1993 at Oak Ridge, TN.

Planned

None.

\section{Problems Encountered}

None.

\section{Publications}

None.

\section{References}

1. Beriozkina, N.G., Larichev, M.N., Leipuvsky, I.O., Eremin, G.L. and Dergunov, N.N., Indicator Capillary - Diffusion Method for Non-Destructive Defectoscopy of Composite Materials, Institute of Energy Problems of Chemical Physics, USSR Academy of Sciences. 


\subsection{MATERIALS DESIGN METHODOLOGY}

\section{INTRODUCTION}

This portion of the project is identified as project element 2 within the work breakdown structure (WBS). It contains two subelements:

(1) Modeling, (2) Contact Interfaces, and (3) New Concepts. The subelements include macromodeling and micromodeling of ceramic microstructures, properties of static and dynamic interfaces between ceramics and between ceramics and alloys, and advanced statistical and design approaches for describing mechanical behavior and for employing ceramics in structural design.

The major objectives of research in Materials Design Methodology elements include determining analytical techniques for predicting structural ceramic mechanical behavior from mechanical properties and microstructure, tribological behavior at high temperatures, and improved methods for describing the fracture statistics of structural ceramics. Success in meeting these objectives will provide U.S. companies with methods for optimizing mechanical properties through microstructural control, for predicting and controlling interfacial bonding and minimizing interfacial friction, and for developing a properly descriptive statistical data base for their structural ceramics. 


\subsection{CONTACT INTERFACES}

\subsubsection{Dynamic Interfaces}

Development of Standard Test Methods for Evaluating

the Wear Performance of Ceramics

P. J. Blau (Oak Ridge National Laboratory)

\section{Objective/scope}

The goal of this effort is to improve consistency in reporting ceramic wear data by helping to develop one or more standard test methods for quantitatively determining the wear resistance of structural ceramics, in reciprocating sliding, a type of motion which is experienced by several types of automotive and truck engine wear parts. ORNL is working with the American Society for Testing and Materials (ASTM) in meeting this objective. Wear-test development normally falls within the scope of ASTM's G-2 Committee on "Wear and Erosion," and in 1990, P. J. Blau was appointed chairman of a newly established Task Group G02.40.07, "Reciprocating Sliding Wear Testing," within the G-2 Committee. This report describes activities with.ir, the Tank Group.

Technical highlights

An ASTM G-2 meeting was held on May 19-21, 1993, in Naperville, Illinois, in conjunction with a tour of the Falex Corporation's wear testing and machine assembly plant. Revisions to the draft standard were discussed. It was decided that a second interlaboratory test should be conducted.

After ORNL's determination of the proper conditions to produce a measurable amount of wear, silicon nitride wear test specimens were circulated to eight laboratories in conjunction with the second interlaboratory ("round-robin") testing series. The participants are: ORNL, General Motors (GM) R\&D Center (2 different departments), Cummins Engine Company, Caterpillar Tech Center, National Research Council Canada, Cameron-Plint Ltd. - United Kingdom (a wear machine manufacturer), and National Physical Laboratory (NPL) - United Kingdom. Each test kit contained two individually numbered, polished flat specimens of sintered reaction-bonded silicon nitride; one numbered test ball of bearing-grade silicon nitride; and a small bottle of mineral oil. Test conditions are given in Appendix 1, which contains a copy of the instruction set sent to all participants and the recording form.

To date, all sets of silicon nitride specimens have been tested and returned to ORNL except those sent to Cummins, GM (one of two), and NPL (United Kingdom). Cameron-Plint Ltd. was unable to perform profilometry at their facility, and those results were obtained on returned specimens at ORNL. After all data sets are received, a statistical analysis will be performed. The analysis is expected to be completed before the upcoming G-2 Meeting at the Dallas/Fort-Worth Airport in December 1993. That data will be incorporated into the precision and accuracy statement in the standard. 


\section{References}

None.

Status of milestones

222206 Make revisions to the first ballot and submit to ASTM G-2. Completed June 30, 1993.

222207 Complete reduction of data from the second set of round-robin wear tests, December 1993 (on schedule).

Communications/visits/travel

P. J. Ble, attended the ASTM G-2 Committee meeting in Naperville, Illinois, on May 19-21, 1993.

\section{Problems encountered}

Several of the interlaboratory test series participants have been late in completing their work. If necessary, their results will be excluded from the series. Six organizations represent the minimum recommended number of participants. This requirement will be met.

\section{Publications/presentations}

None. 
Appendix 1. Instructions to Interlaboratory Test Participants

\section{ASTM RECUPROCATING SLDING TEST PROCEDURE FOR LUBRICATED TLSTS OF CERAMICS}

\section{Le Backeround:}

This is the second round-robin testing program for ASTM task group G.02.40.07 on

"Reciprocating Wear Testing." The first round-robin results for unlubricated tool steel-on-tool steel and silicon nitride-on-silicon nitride did nor produce reproducible (between lab) results although the within-lab scatter was acceptable. Possible causes were: (1) proximity of the test machine to lubricated testing systems (vapor transport of oil to the surface of the specimens), (2) inability of participants to conteml ambient relative humidity levels, (3) possible specimen cleaning problems, (4) use of different types of resting machines, and (4) inaccurate or non-existent calibration of the normal force system and the friction force sensors beyond the initial set-up of the machine years ago. This round is limited to lubricated silicon nitride tested in $1500 \mathrm{C}$ oil (total of four tests).

Please read the revised proced ure (Section 3.0) below. If you are unable to comply with any of the requirements of the followine proced dure plesee returon the test specimens with out opening

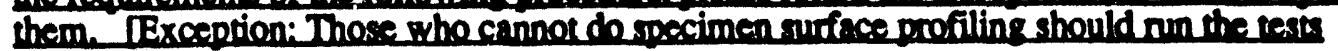
nevertheless.

\subsection{Contents of this Kit:}

2.1 Two flat ceramic specimens.

2.2 One ball

2.3 One ball holder adapter.

2.4 One $250 \mathrm{ml}$ container of test oil.

2.5 One materials safety data sheet for the oil.

2.6 This procedure.

2.7 Data sheet for reconding results.

\subsection{Procedure}

Step Procedure

1. Carefully unwrap the test specimens. They have been precleaned. [Nore: If you accidentally touch the wear surfaces of the specimens with your fingers, wipe them off with firsi scetone, then methanol.]

2. Warm up the testing machine for at least 1 hour.

3. Weigh the nat specimen to the nearest $0.1 \mathrm{mg}$. just before mounting.

4. Mount the ball specimen in the holder and wipe the tip with methanol being especially careful not to get any residual oil on the swab or wiper.

5. With the ball holder tilted up and away, fill the reservoir with fresh test oil such that the flat specimen is just below the surface. Do not re-use the oil!

6. Lower the ball holder until the ball is in contact (no load applied yet), and heat the bath to $150 \circ \mathrm{C}$. Take a humidity reading and write it down. 
7. Allow the system to remain at temperature for 5 minutes, then apply the load and start the test. Test conditions are as follows:

Load: 25. $N$

Stroke length: $10 \mathrm{~mm}$. (as close as possible)

Frequency: $\quad 5.0 \mathrm{~Hz}$ (as close as possible)

Test length: $16 \mathrm{~min} 10 \mathrm{sec}$ (for $100 \mathrm{~m}$. total sliding distance)

8. Record the friction force during the test.

9. Remove the specimens and ultrasonically clean each in acetone and methanol (3 min. each step).

10. Dry and weigh the flat specimen.

11. Measure the wear scar diameter on the ball. Note: In lubricated tests, sometimes a faint "halo" (ring) appears on the ball tip. If there is such a lightcolored halo, then report both inner and outer diameters of the halo.

12. Turn the ball to a new location and remount the flat specimen for the next test. Fresh oil is used for each test. Conduct two tests on each flat specimen for a total of four tests.

13. Record all relevant test data on the sheet provided.

When all four runs are finished. Proof read the data sheet to assure that all entries are clearly written and all spaces are filled in. Then make a copy for your own records. It will help us compile results faster if you FAX your data sheets to me (615) 574-6918.

Do not return the unused oil. Please dispose of all used oil in an environmentally safe manner.

Repack all test specimens, the data sheet; and the ball adapter fixture, and mail to

Dr. Peter J. Blau

Oak Ridge National Laboratory

P. O. Box 2008 (1 Bethel Valley Road)

Oak Ridge, TN 37831-6063 USA

Please try 10 complete all tests within 30 days. (Note: Non-U.S. Participants should clearly mark : Attention Customs Inspectors "ceramic test specimen materials - no intrinsic value." 


\section{INTER-LABORATORT RECIPROCATING WEAR-TEST PROGRAM ROUND 12 - Lubricated 8ilicon Nitride Tests \\ (ASTM Task Group G.02.40.07)}

Name of Participating Organization:

Participating Individual:

Phone:

FAX:

Test Kit Number:

Date recoived:

Date returned:

Type of Machine Used (include age of machine, if known):

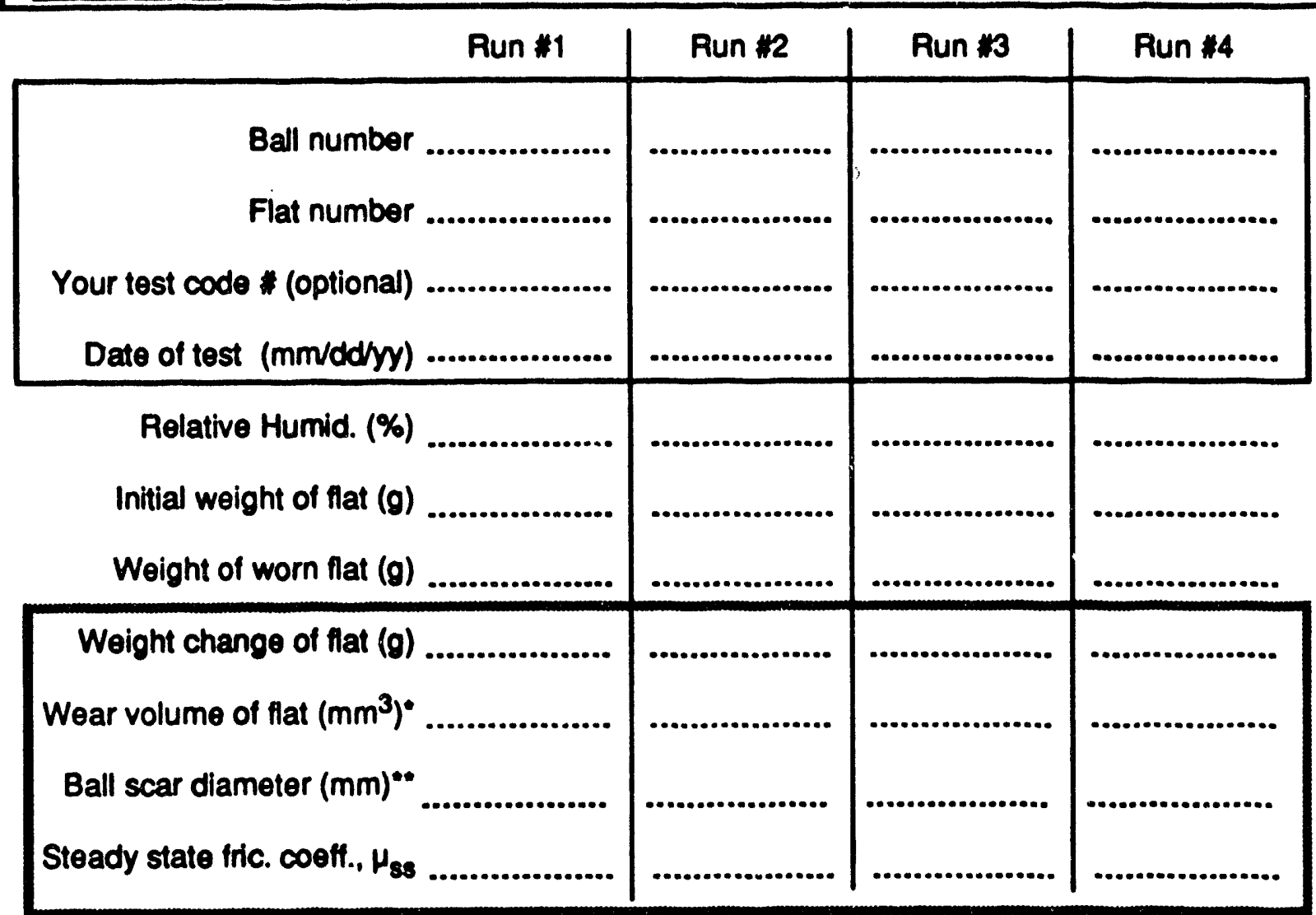

- by profilometry. - It the ball scar is elongated, take the average of the length and whth of the scar.

Check here if you have written additional comments on the reverse side of this sheet.

Besum all spectmene and date sheetele: Dr. Pcter J. Bieu, Osk Rldge Natlonal Laboratory P. O. Box 2008 (1 Bethel Valloy Road), Oak Ridge, TN $37831-6033$ USA. 


\subsection{NEW CONCEPTS}

\section{Advanced Statistical Concepts of Fracture in Brittle Materials C. A. Johnson and W. T. Tucker (General Electric Corporate Research and Development)}

\section{Objective/Scope}

The design and application of reliable load-bearing structural components from ceramic materials requires a detailed understanding of the statistical nature of fracture in brittle materials. The overall objective of this program is to advance the current understanding of fracture statistics, especially in the following four areas:

- Optimum testing plans and data analysis techniques.

- Consequences of time-dependent crack growth on the evolution of initial flaw distributions.

- Confidence and tolerance bounds on predictions that use the Weibull distribution function.

- Strength distributions in multiaxial stress fields.

The studies are being carried out largely by analytical and computer simulation techniques. Actual fracture data are then used as appropriate to confirm and demonstrate the resulting data analysis techniques.

Technical Highlights

Work during this reporting period concentrated in two areas: generalization of the Batdorf-Heinisch and Lamon-Evans multiaxial methods to cover time dependent effects; and a preliminary study of the Norton room temperature tensile data that takes into account the competing nature of the underlying failure modes.

\section{Time Effects for the Batdorf-Heinisch and Lamon-Evans Models}

During this reporting period study of $I(m)$ has continued with an aim toward generalizations. In these studies $I(m)$ is defined by

$$
P_{f}=1-\exp \left[-I V \sigma_{M}^{\prime \prime} / \sigma_{0}^{m}\right] \text {, }
$$

where

$$
I=I(m)=\frac{1}{2 \pi V} \int_{0}^{\pi / 2} \int_{0}^{2 \pi}\left(\int_{V}\left(\sigma_{c} / \sigma_{M}\right)^{m} d \nu\right) \cos \phi d \phi d \psi
$$

$\sigma_{e}$ is the local effective stress as defined by the failure criterion, the flaw orientation, and the local principal stresses; $\sigma_{M}$ denotes the maximum value of $\sigma_{c} ; m$ is the Weibull modulus; and $\sigma_{0}$ is the inherent strength or second Weibull parameter. The integration in Eq. 2 is carried out over all elements of volume, $\mathrm{dV}$, as indicated by $V$. In $\mathrm{E}_{\mathrm{l}} .2$ the angle $\psi$ is measured from the $x$-axis in a reference $(x, y)$-plane and the angle $\phi$ is muisured from the $(x, y)$-plane toward the $z$-axis. The angles define the plane of a potential failure producing crack and also the local direction cosines. (See Figure 3 in Ref. 1. and the developments in Ref. 2.) Eq.'s 1 
and 2 follow from the equivalence of the Batdorf-Heinisch (B-H) and Lamon-Evans (L-E) approaches as shown in Ref. 2. As pointed out in Ref. 2, use of $\sigma_{M}$ is natural from a mathematical viewpoint. However, use of any other value that is in a one-to-one and onto relationship to $\sigma_{M}$ can be made. The key is to employ a consistent usage of a failure stress, e.g., one that is measured at the same place and conditions for a test specimen.

In deriving the equivalence of the B-H and L-E approaches it was shown in Ref. 2 that the $\mathrm{B}-\mathrm{H}$ hazard function is given by

$$
\int_{V} d v \int_{0}^{\infty} d \sigma_{c}\left(\frac{d N\left(\sigma_{c}\right)}{d \sigma_{c}}\right) \frac{\Omega\left(\Sigma, \sigma_{c}\right)}{4 \pi}=\frac{1}{2 \pi} \int_{0}^{\pi / 2} \int_{0}^{2 \pi}\left[\int_{V}\left(\int_{0}^{\sigma_{e}} f\left(\sigma_{c}\right) d \sigma_{c}\right) d \nu\right] \cos \phi d \phi d \psi,
$$

where

$$
\Omega\left(\Sigma, \sigma_{c}\right)=2 \int_{0}^{\pi / 2} \int_{0}^{2 \pi} I\left(\Sigma, \sigma_{c}\right) \cos \phi d \phi d \psi
$$

with

$$
\begin{aligned}
& 1, \sigma_{c} \geq \sigma_{c} \text { at the given }(\phi, \psi) \text { and particular location } \\
& I\left(\Sigma, \sigma_{c}\right)= \\
& 0 \text {, otherwise, }
\end{aligned}
$$

$f\left(\sigma_{c}\right)$ denotes $d N\left(\sigma_{c}\right) / d \sigma_{c}$, and $\sigma_{c}$ denotes a possible value of the critical stress.

There are two important, related issues associated with Eq.'s 2-5. First in order to employ Eq. 2, a failure criterion must be defined. In recent reports we have discussed the use of

$$
\sigma_{e}=\frac{1}{2}\left[\sigma+\sqrt{\sigma^{2}+Q^{2} \tau^{2}}\right],
$$

(where $\sigma$ is the stress component normal to the crack surface, $\tau$ is the shear component parallel to the crack surface, and $Q$ is a "material" constant), as a candidate mixed mode failure criterion. However, work during this reporting period has concentrated on a second important issue in the use of Eq. 2 that is associated with Eq. 3. Eq. 2 indicates that it may be possible to obtain generalizations that cover time, temperature effects. The key is to generalize the approach leading to Eq. 2 by adding another dimension, say time, and then integrate over this dimension in a setup analogous to Eq. 3. Clearly, this implies that a suitable failure criterion, $\sigma_{e}$, can be formulated that covers the time effect.

Possibly the most straightforward situation in which a failure criterion can be easily developed is for those cases in which subcritical crack growth occurs. If the Paris growth law is assumed, an "effective" stress or delta stress that produces growth is known, and coplanar crack growth is assumed, then it is possible to generalize the innermost integrand of Eq. 2 so as to account for those cracks that are initially "safe" but eventually grow to a size that produces catastrophic growth. The details are related to work carried out during Phase I of this contract (Ref.'s 3 and 4) studying the consequences of a deterministic time-dependent crack growth on the evolution of an initial flaw distribution. Many relationships have been proposed to describe stress corrosion crack growth, high temperature diffusional crack growth, and/or cyclic fatigue crack growth. The following discussion will demonstrate the approach using a crack growth law for cyclic fatigue. Let the growth law be expressed as 


$$
d a / d N=A(\Delta K)^{n},
$$

where $A$ and $n$ are constants and

$$
\Delta K=Y \Delta S_{e} \sqrt{a},
$$

and where $Y$ denotes a geometry factor, $\Delta S_{e}$ is the effective stress range for crack propagation (generally a function of crack location and orientation), and $a$ is the crack length. For simplicity assume that $\sigma_{e}$ and $S_{e}$ are time invariant. Then as shown in Ref. 5, Eq. 8 can be substituted into Eq 7 and Eq. 7 can be integrated and rearranged to yield

$$
\left(\sqrt{a_{f}}\right)^{2-n}=\left(\sqrt{a_{0}}\right)^{2-n}+\left(\frac{2-n}{2}\right) A\left(Y \Delta S_{e}\right)^{n} N_{f}, \quad(\text { for } n \neq 2),
$$

where $a_{f}$ denotes the final crack length $\left(\geq a_{0}\right), a_{0}$ denotes the initial crack length, and $N_{f}$ is the number of loading cycles.

In order to use Eq. 9 in Eq. 3, a substitution in Eq. 9 for the crack lengths is made in terms of the critical stress via the relationship to $K_{I C}$ given by

$$
K_{I C}=Y o \sqrt{a},
$$

where $\sigma$ is the stress that will just produce failure for the length $a$. When this is carried out we obtain

$$
\left(\sigma_{f}\right)^{n-2}=\left(\sigma_{0}\right)^{n-2}-\left(\frac{n-2}{2}\right)\left(\frac{K_{I C}}{Y}\right)^{n-2} A\left(Y \Delta S_{e}\right)^{n} t
$$

where $n>2, N_{f}$ has been replaced by $t$, and the $f$ and 0 subscripts denote the final and initial critical stresses, respectively. Now failure occurs when $\sigma_{c}$ is less than or equal to the "load" to which the crack is exposed. In Eq 10 the load is given by $\sigma_{f}$ plus the contribution associated with subcritical crack growth (the right most term in Eq. 10), and the critical stress, $\sigma_{c}$, is given $\mathrm{b}_{y} \sigma_{0}$. Rearranging Eq. 10 and making the indicated substitutions yields

$$
\sigma_{c} \leq\left[\sigma_{e}^{n-2}+\left(\frac{n-2}{2}\right)\left(\frac{K_{I C}}{Y}\right)^{n-2} A\left(Y \Delta S_{c}\right)^{n} t\right]^{\frac{1}{n-2}}
$$

as the failure region of $\sigma_{c}$ values. In this setup the failure boundary now becomes the observed time of the failure in addition to the strength at failure. Thus the right hand side of Eq 11 becomes the upper limit of integration in the inner most integrand in Eq. 3. Therefore the effect of the additional term is to increase the value of the complete integrand in Eq. 3 over what it would be if there were no "time" effect and this in turn increases the probability of failure. This is also seen in that the inner integration reduces to that given by Eq. 3 when $t=0$.

\section{Preliminary Analysis of Norton Data}

Also during this reporting period study of the Phase III clata on the Norton Aclvanced Ceramics subcontract within the Ceramic Technology Project published in the final report ORNL/Sub/89-SB182/1 (Ref. 6) has begun. The purpose is to investigate the individual failure modes (Machining-M, Inclusion-I, Amorphous-Am, Microporosity-Mp, and Unknown-U) identified by fractography in the study of 320 specimens carried out by Norton. Censored data methods are being employed to study the four competing failure modes: $\mathrm{M}, \mathrm{I}$, 
$\mathrm{Am}$, and $\mathrm{Mp}$. Of special interest is the apparent need to use a distribution other than the 2parameter Weibull in order to explain the strength distributions arising from the individual failure modes. Preliminary studies indicate that a 2-parameter Weibull adequately fits the M, I, and Mp failure modes. However, there is a distinct lack-of-fit to a 2-parameter Weibull for the Am failure mode. Further study is continuing.

\section{References}

1. J. Lamon and A.G. Evans, "Statistical Analysis of Bending Strengths for Brittle Solids: A Multiaxial Fracture Problem," J. Am. Ceram. Soc., 66, 3, 177-182, 1983.

2. W.T. Tucker and C.A. Johnson, "The Multiaxial Equivalent of Stressed Volume," Life Prediction Methodologies and Data for Ceramic Materials, ASTM STP 1201, C.R. Brinkman and S.F. Duffy, Eds., American Society for Testing Materials, Philadelphia, 1993, to be published.

3. C.A. Johnson and W.T. Tucker, "Modifications in Strength Distributions Due to Slow Crack Growth," Proceedings of the Twenty-Fourth Automotive Technolog' Development Contractors' Coordination Meeting, SAE Publication P-197, pp 233-237, 198 ?

4. C.A. Johnson and W.T. Tucker, "Advanced Statistical Concepts of Fracture i.. Brittle Materials," Ceramic Technology for Advanced Heat Engines Project Semiannual Progress Report for April Through September 1986, ORNL/TM-10308, pp 190-198, March 1987.

5. G.G. Trantina and C.A. Johnson, "Probabilistic Defect Size Analysis Using Fatigue and Cyclic Crack Growth Rate Data," Probabilistic Fracture Mechanics and Fatigue Methods: Applications for Structural Design and Maintenance, ASTM STP 798, J.M. Bloom and J.C. Ekvall Eds., American Society for Testing Materials, Philadelphia, 1993, pp. 67-78.

6. V.K. Pujari, D.M. Tracey, M.R. Foley, N.I. Paille, P.J. Pelletier, L.C. Sales, C.A. Wilkens, and R.L. Yeckley, "Development of Improved Processing and Evaluation Methods for High Reliability Structural Ceramics for Advanced Heat Engine Applications, Phase I," ORNL/sub/89-SB182/1, Ceramic Technology for Advanced Heat Engines Project Final Report, U.S. Department of Energy Contract DE-AC0584OR21400, Subcontract 86X-SB182C, August 1993.

$\underline{\text { Status of Milestones }}$

All milestones are on schedule. Milestone number 231312 on goodness-of-fit testing was completed during this reporting period. Also milestone number 231313 on analytical approaches for use of the equivalent multiaxial size factor in Class IV strength problems was completed during the reporting period.

$\underline{\text { Publications }}$

1. W.T. Tucker and C.A. Johnson, "The Multiaxial Equivalent of Stressed Volume," Accepted for publication in Life Prediction Methodologies and Data for Ceranic Materials, ASTM STP 1201, 1993.

2. C.A. Johnson and W.T. Tucker, "Weibull Estimators for Pooled Fracture Data," Accepted for publication in Life Prediction Methodologies and Data for Ceramic Materials, ASTM STP 1201, 1993. 


\subsection{DATA BASE AND LIFE PREDICTION}

\section{INTRODUCTION}

This portion of the project is identified as project element 3 within the work breakdown structure (WBS). It contains five subelements, including (1) Structural Qualification, (2) Time-Dependent Behavior, (3) Environmental Effects, (4) Fracture Mechanics, and (5) Nondestructive Evaluation (NDE) Development. Work in the Structural Qualification subelement includes proof testing, correlations with NDE results and microstructure, and application to components. Work in the Time-Dependent Behavior subelement includes studies of fatigue and creep in structural ceramics at high temperatures. Research in the Environmental Effects subelement includes study of the long-term effects of oxidation, corrosion, and erosion on the mechanical properties and microstructures of structural ceramics. Work in the Fracture Mechanics subelement includes development of techniques for measuring the tensile strength and creep resistance of ceramic materials at high temperatures, and testing ceramic materials at high temperatures under uniaxial tension. Work in the NDE Development subelement is directed at identifying approaches for quant itative determination of conditions in ceramics that affect their structural performance.

Major objectives of research in the Data Base and Life Prediction project element are understanding and application of predictive models for structural ceramic mechanical reliability, measurement techniques for longterm mechanical property behavior in structural ceramics, and physical understanding of time-dependent mechanical failure. Success in meeting these objectives will provide U.S. companies with the tools needed for accurately predicting the mechanical reliability of ceramic heat engine components, including the effects of applied stress, time, temperature, and atmosphere on the critical ceramic properties. 


\subsection{STRUCTURAL QUALIFICATION}

Microstructural Analys is of Structural Ceramics

B. J. Hockey and S. M. Wiederhorn

(National Institute of Standards and Technology)

Objective/Scope

The objective of this part of the program is to identify mechanisms of failure in structural ceramics subjected to mechanical loads at elevated test temperatures. Of particular interest is the damage that accumulates in structural ceramics as a consequence of high temperature exposure to stresses normally present in heat engines.

Design criteria for the use of ceramics at low temperature differ from those at high temperature. At low temperature ceramics are elastic and brittle; failure is controlled by a distribution of flaws arising from processing or machining operations, and the largest flaw determines the strength or lifetime of a component. By contrast, at high temperature where ceramics are viscoelastic, failure occurs as a consequence of accumulated, or distributed damage in the form of small cavities or cracks that are generated by the creep process. This damage effectively reduces the cross-section of the component and increases the stress that must be supported. Such increases in stress are autocatalytic, since they increase the rate of damage and eventually lead to failure as a consequence of loss in cross section. When this happens, the individual flaw loses its importance as a determinant of component lifetime. Lifetime now depends on the total amount of damage that has occurred as a consequence of the creep process. The total damage is now the important factor controlling lifetime.

Recent studies of high temperature failure of the non-oxide ceramics intended for use for heat engines indicates that for long term usage, damage accumulation will be the primary cause of specimen failure. Mechanical defects, if present in these materials, are healed or removed by high temperature exposure so that they have little influence on long term 1 ifetime at elevated temperature. In this situation, lifetime can be determined by characterizing the damage and the rate of damage accumulation in the material at elevated temperatures. In ceramic materials such as silicon nitride and SiAlON, such characterization required high resolution analyses because of the fine grain size of these materials: hence the need for transmission electron microscopy as an adjunct to the mechanical testing of ceramics for high temperature applications is apparent. In this project, the creep and creep-rupture behavior of several ceramic materials will be correlated with microstructural damage that occurs as a function of creep strain and rupture time. Materials to be studied include: SiAlON; hot-pressed silicon nitride; sintered silicon carbide. This project will be coordinated with WBS 3.4.1.3, Tensile Creep Testing, with the ultimate goal of developing a test methodology for assuring the reliability of structural ceramics for high temperature applications. 


\section{Technical Highlights}

ATEM was used to study cavity damage produced in GTE PY- 6 silicon nitride during tensile creep. Results have now been obtained on samples crept over the full range of test temperatures, 1200 to 1400 C. Creep at $1200 \mathrm{C}$ was not found to result in appreciable cavitation, indicating delayed failure at this temperature occurs by the slow growth of pre-existing flaws. By contrast, creep at $1250 \mathrm{C}$ results in extensive cavitation, and it is concluded that creep rupture results from accumulated cavity damage. For the most part the cavities produced in PY-6 are similar in detail to those produced in NT-154, which contains a similar residual glass composition. Specifically, creep of PY 6 results in the formation of discrete, ellipsoidal shaped cavities at narrow ( $1 \mathrm{~nm}$ ) silicon nitride interfaces. While the average size of these cavities increases with temperature, their density decreases, regardless of strain. Unlike NT-154 (as will be discussed), interfacial cavities continue to form at $1400 \mathrm{C}$ in PY- 6 . Creep of PY- 6 also results in cavitation of the second phase situated primarily within multigrain junctions, resulting in interstitial cavities which can range in size from about 0.2 to 1.0 microns. Both the density and average size of these cavities appear to increase with temperature as well as strain. At $1400 \mathrm{C}$, interstitial cavitation appears to be the predominant form of cavitation in this material.

In a related effort, additional studies of cavity damage in Norton NT-154 were also made. Results from samples crept in tension under controlled conditions at 1400 and $1430 \mathrm{C}$ confirmed that creep at 1400 $C$ and above results exclusively in interstitial cavitation, i.e. cavitation of the second phase contained within multigrain junctions. Interfacial cavitation, although prevalent at lower temperatures, was not observed. Comparative results from samples crept to different strains and to similar strains at different temperatures have shown not only that the density of interstitial cavities increases with strain, but that the average cavity size increases with both strain and temperature.

\section{Experimental Technique}

The results of this study were obtained by analytical transmission microscopy (ATEM). ATEM was used to examine samples of GTE PY- 6 and Norton NT-154 silicon nitride which had been subjected to tensile creep under the tensile test task of this project (WBS 3.4.1.3). Standard ceramographic techniques were used to prepare specimens for ATEM analysis.

Results and Discussion

During the past six months, studies of the effect of microstructure on the creep/creep rupture of silicon nitride were continued. While this effort was primarily directed at characterizing cavity damage produced in GTE PY -6 and Norton NT-154 under conditions not previously established, additional results were also obtained on GTE AY-6 and Garrett GN-10. For the latter two grades, examination of 
samples from earlier studies revealed evidence for multigrain function cavities, identical to those found in NT-154 and PY-6. These results clearly establish interstitial cavities, which result from the cavitation of the second phase contained within triple or multigrain junctions, as a primary form of cavity damage in these grades of silicon nitride.

For PY-6, previous results on cavitation at 1350 and $1400 \mathrm{C}$ were extended by examination of samples crept at 1200 and $1250 \mathrm{C}$. Creep at $-1200 \mathrm{C}$ was not found to result in appreciable cavitation, which suggests that delayed fallure (up to $8 \mathrm{~h}$.) at this temperature occurs by the slow growth of pre-existing flaws. In contrast creep at higher temperatures results in extensive cavitation, and creep rupture appears to result from accumulated cavity damage. At $1250 \mathrm{C}$ long-term creep $(>2000 \mathrm{~h})$ to over $1 \%$ strain was found to result in the formation of high densities of discrete, ellipsoidal-shaped interfacial cavities. Creep at $1250 \mathrm{C}$ also results in cavitation of the second phase present within multi-grain junctions. However, even after $1 \%$ creep stain, the maximum size of these interstitial cavities was 1 imited to about $500 \mathrm{~nm}$. In contrast, creep at 1350 and $1400 \mathrm{C}$ to lower strains results in the formation of interstitial cavities of up to one micron, which is roughly the upper limit of multigrain junction dimensions.

In summary, creep of PY- 6 at temperatures of 1250 to $1400 \mathrm{C}$ results discrete interfacial cavities at narrow ( $1 \mathrm{~nm}$ or less) two grain boundaries and interstitial cavities at multigrain junctions. The nucleation and growth of interfacial cavities is identical to that in NT-154. Apparently, limited transport through the nearly "pure" yttrium silicate glass phase, unique to these two grades, restricts cavity growth into and along the silicon nitride grains and results in the formation of discrete cavities of nearly uniform size. While the average size of these interfacial cavities increases with increasing temperature, the density of cavities, both within individual

interfaces and overall, decreases with increasing temperature. In contrast the relative extent (as evidenced by cavity size and density) of interstitial cavitation appears to increase with increasing temperature. Most notably, there is a significant increase in the population large cavity sizes ( 0.5 to 1.0 microns) with increasing temperature, regardless of strain. As such, this increase in "average" cavity size reflects the strong temperature dependence of cavity growth rate within the second phase at multigrain junctions. At 1400 $\mathrm{C}$ and sufficiently high applied stresses, rapid cavity growth within the second phase also occurs within relatively wide (10 nm or more) two grain boundaries in PY- 6 to form crack-like cavities. While these cavities do not appear to grow with increased strain, their presence should contribute to the creep rupture process.

In a related effort, additional studies of cavitation in NT-154 were also made. Two sets of samples were examined. The first set were crept in tension to various strains up to failure (0.95\%) under the same conditions, $125 \mathrm{mPa}$ at $1400 \mathrm{C}$. The second set were crept in tension at $1430 \mathrm{C}$ at stresses ranging from 40 to $150 \mathrm{mPa}$. Lifetimes and total strains, respectively, ranged from $2 \mathrm{~h}$ and $<0.5 \%$ at $150 \mathrm{mPa}$ to nearly $700 \mathrm{~h}$ and $2 \%$ at $75 \mathrm{mPa}$; lower stress tests (at 40 and 50 
$\mathrm{mPa}$ ) were terminated at roughly $700 \mathrm{~h}$ and strains of 0.5 to $0.7 \%$. At both temperatures, creep resulted in extensive cavitation, which was predominately of the interstitial type. Extremely limited evidence for interfacial cavitation was found, regardless of the applied stress or total strain. The results, thus, confirm the previously reported suspicion that at $1400 \mathrm{C}$ and above, creep cavitation in NT-154 is nearly exclusively confined to the second phase situated at triple and multigrain functions. The dimensions of these regions range from about 0.1 to 1.0 microns, which sets the size limits for interstitial cavities. Results from the first set of samples (crept to various strains at $1400 \mathrm{C}$ ) indicate that increased strain results in an increase in both the density of cavities and the population of large cavity sizes (1.e. ranging from 0.5 to 1.0 microns). Results from the second set of samples (crept at $1430 \mathrm{C}$ ) were similar. Moreover, by comparison at similar strains, creep at $1430 \mathrm{C}$ was found to result in a larger population of larger cavity sizes. Currently, results from both sets of samples by ATEM, precision density measurement, and small angle $X$-ray scattering (SAXS) are being correlated to quantify the separate effects of temperature and strain on interstitial cavity density and size. In addition, reasons for absence of interfacial cavitation in NT-154 during creep at $1400 \mathrm{C}$ and above are being investigated by ATEM.

\section{Status of Milestones}

On schedule

\section{Publications/Communications}

"Creep Damage Mechanisms in Silicon Nitride", S. Wiederhorn, W. Luecke, B. Hockey, and G. Long. Presented at Workshop on "Tailoring of High Temperature Properties of Silicon Nitride Ceramics". Oct 6-9, 1993. Schloss Ringberg, Germany.

\section{References}

None 
Mechanical Properties and Microstructural Charactertzation of S1, Nh Ceremice

K. L. More, T. A. Nolan, and L. F. Allard (Oak Ridge National Laboratory)

\section{Objective/scope}

The objective of the research is to use analytical and high-resolution electron microscopy to characterize the microstructure of several $\mathrm{Si}_{3} \mathrm{~N}_{4}$ ceramic materials following mechanical strength (tensile) testing at elevated temperatures in alr. This work represents collaborations with K. Lu of Oak Ridge National Laboratory, J. Pollinger of AlliedSignal, and Norton-St. Gobain.

\section{Technical hlahlights}

Work during this reporting period has focussed on several aspects of sllicon nitride characterization. These investigations have included (1) evaluation of a plasma-etching technique for $\mathrm{Sl}_{3} \mathrm{~N}_{4}$ and the setup of a plasma etcher, (2) grain boundary analysis of NT-154/NT-164 silicon nitride using the new Hitachi HF2000 field emlssion guntransmission electron microscope (FEG-TEM), (3) microstructural characterization of GS-44 self-reinforced silicon nitride, and (4) microstructural evaluation of a Russian sillcon nitride.

\section{Plasma Etching of Sillcon Nitride}

The plasma-etching technique investigated here was first used by researchers at National Aeronautics and Space Administration (NASA)-Lowis to etch SiC whiskerreinforced silicon nitride ceramic composites.' Plasma etching has the advantage of selectlvely attacking the $\mathrm{SI}_{3} \mathrm{~N}_{4}$ grains rather than attacking the secondary phases, which occurs during etching using a molten salt. The other advantage is that the porosity appears to be undisturbed following etching, which may bo useful for analysis of cavitation and void formation following creep testing.

In order to evaluate the advantages of plasma etching $\mathrm{Si}_{3} \mathrm{~N}_{4}$, samples of SNW-1000, GN-10, NT-154, and NT-164 silicon nitride ceramics (a total of approximately 20 samples in all) were cut from tensile rods following creep testing as well as from uncrept material. The cut samples were mechanically ground flat and polishod sequentially using 6-, 3-, 1-, and $0.25-\mu \mathrm{m}$ diamond paste. All the specimens were then brought to NASA-Lewis in Cleveland and plasma etched using CF $4+4 \%{ }^{\circ} 2$ at 0.3 torr and a plasma RF power of $100 \mathrm{~W}$ for about $3 \mathrm{~min}$. Initial results for plasma-etched, hot-pressed SNW-1000 are compared to an as-polished SNW-1000 surface in Figs. 1 and 2, respectively. Clearly, the microstructure of the Si3N4 is revealed in much greater detall in the plasma-etched surface shown in Fig. 1. The other plasma-etched samples will be used to compare the microstructures of various silicon nitride materials and to evaluate the microstructural changes occurring as a function of elevated-temperature creep testing. It is anticipated that a system will be sat up at ORNL which is similar to that used for plasma etching at NASA-Lowis. 
YP18862

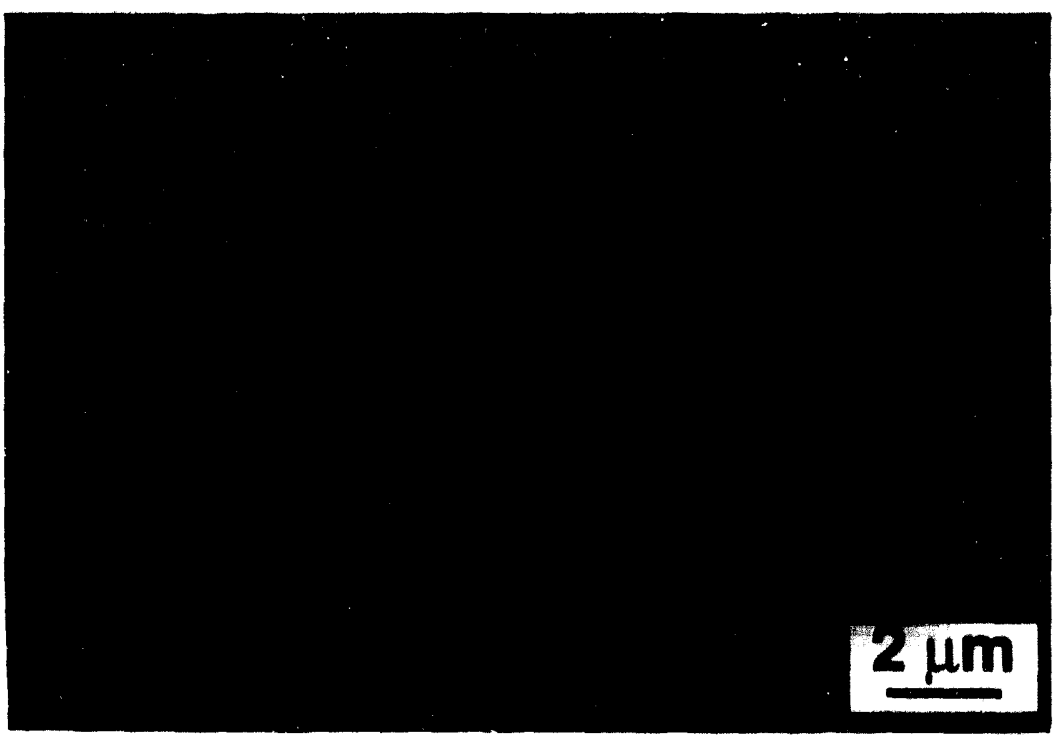

Fig. 1(a). Low-magnification SEM image showing the overall microstructure of hot-pressed SNW-1000 sillicon nitride revealed by plasma etching.

YP18869

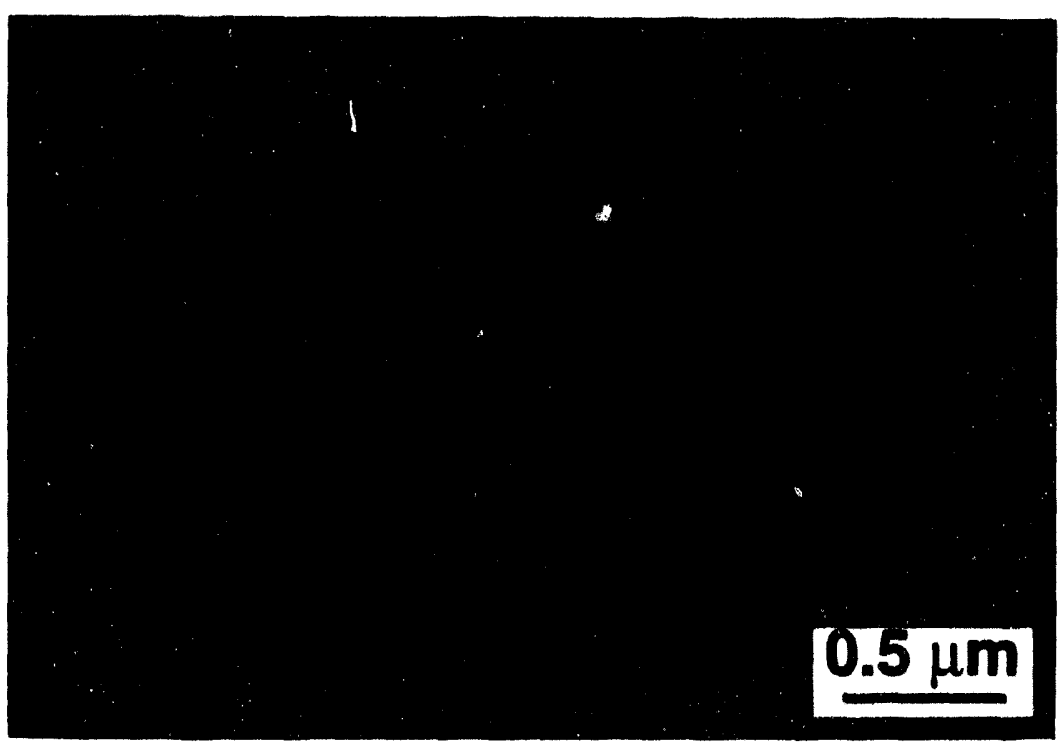

Fig. 1(b). SEM image showing the distribution of the secondary phases (light phase in micrograph) and general morphology of silicon nitride grains in hot-pressed SNW-1000 revealed by plasma etching. 
YP18863

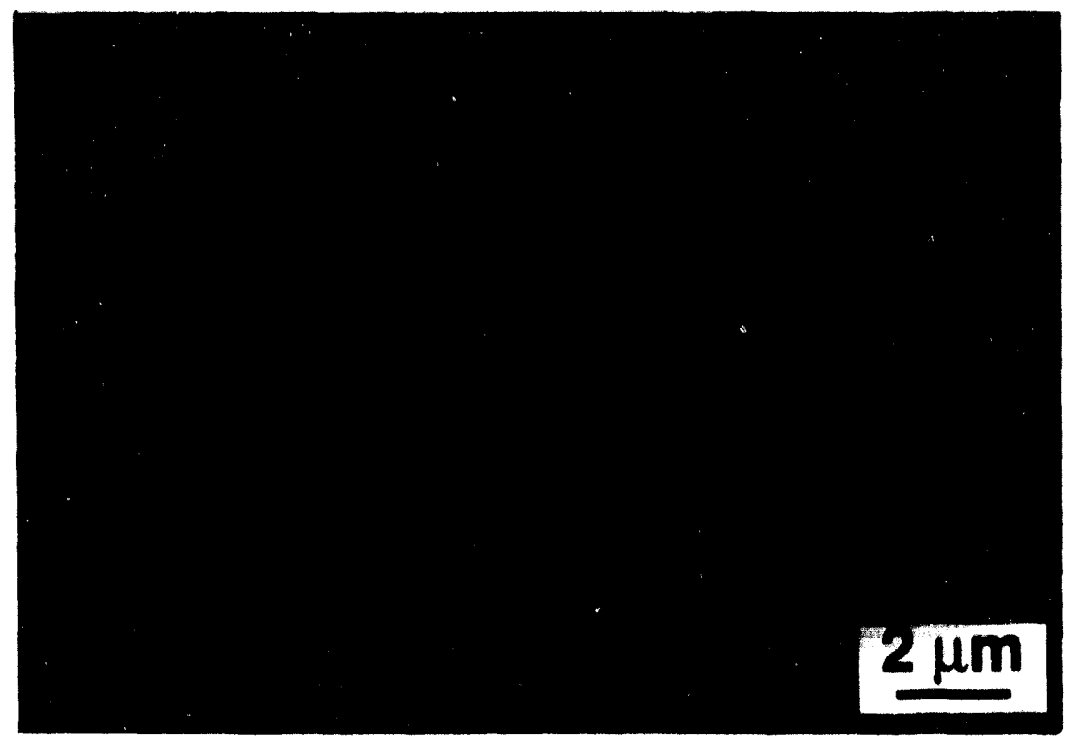

Fig. 2. As-polished surface of hot-pressed SNW-1000. The general microstructure of the SNW-1000 is not clearly resolved in this specimen as compared to the plasma-etched specimen.

Analysis of Grain Boundaries in Norton Silicon Nitride

The microstructures Norton-Saint Gobain $\mathrm{NT}$ - serles $\mathrm{SI}_{3} \mathrm{~N}_{4}$ ceramics have been studied extensively. NT-164 exhiblts several characteristics that differ from NT-154. It has superior high-temperature creep performance as compared to NT-154 and most other $\mathrm{Si}_{3} \mathrm{~N}_{4}$ ceramics. After creep testing, NT-154 typically contains two types of volds generated during the test. These are "triple-point" voids, micrometer-sized angular voids caused by shifting of grains and possibly other diffusional processes. The other class of voids that is observed includes $0.01-$ to $0.4-\mathrm{mm}$ lenticular voids that form at two grain junctions and are apparently caused by solution and reprecipitation of $\mathrm{Si}_{3} \mathrm{~N}_{4}$. Surprisingly, in NT-164, lenticular voids were extremely rare. It has been determined using highresolution transmission electron microscopy (TEM) that both characteristics can be explained by differences in the grain boundary structures. $\mathrm{NT}-154$ and other $\mathrm{Sl}_{3} \mathrm{~N}_{4}$ ceramics manufactured with powder precursors have a ubiqultous, typically less than 1.5-nm-thick amorphous film that separates the $\mathrm{Si}_{3} \mathrm{~N}_{4}$ grains. This film is composed of elements associated with sintering aids and impurities, such as yttrium and oxygen. One major microstructural difference between NT-164 and NT-154 prior to testing was observed; this film was not typically visible in NT-164. It is hypothesized that this film acts as the diffusion path for solution-reprecipitation processes that account for the lenticular void formation and may contribute to other phenomena associated with creep such as grain sllding, otc.

Present research has as a goal the determination of differences in the chemistry of the NT-154 and NT-164 grain boundaries using energy dispersive X-ray analysis (EDS) 
villizing the now Hitachl HF-2000 FEG-TEM. The high-brightness nanoprobe capablity of the HF-2000 makes it ideal for such studies. Analyals of numerous grain boundaries revealed that NT-164 has approximately one-third the amount of yttrium (a component of the amorphous phase that is present due to additions of $\mathrm{Y}_{2} \mathrm{O}_{3}$ to assist sintering) as compared to NT-154. This can be seen in Fig. 3, which shows typical EDS spectra with the vertical axls of one spectral region expanded 20 times and offeet to show the ytrilum K-lines. Thus, this result confirms the results of the high-resolution TEM studies. The fact that there is stll some yttrium present in NT-164 grain boundaries suggests that further adjustment in chemistry and processing could result in an even more creep-resistant coramic.

\section{Microstructural Charactorization of GS-44 Silicon Nitride}

Two different samples of GS-44 were obtained from John Pollinger of AlliedSignal, Carrett Coramic Components. These two specimens were a gas-pressure sintered control specimen, processed using yttria, alumina, and magnesla as the densification aids (Sample ID* 121-25), and a similarly processed specimen that was subsequently microwave annealed at $1600^{\circ} \mathrm{C}$ for $10 \mathrm{~h}$ (Sample ID* 324-16). The microwave-annealed material showed a substantial improvement in stress-rupture resistance at $900^{\circ} \mathrm{C}$; however, no obvious differences were observed in the fast-fracture properties or the toughnese between the control and the microwave-annealed materials. Thus, a complete microstructural characterization of the material was undertaken in order to determine the reason(s) for the enhanced stress-rupture.

ORNL-DWG 94-5611

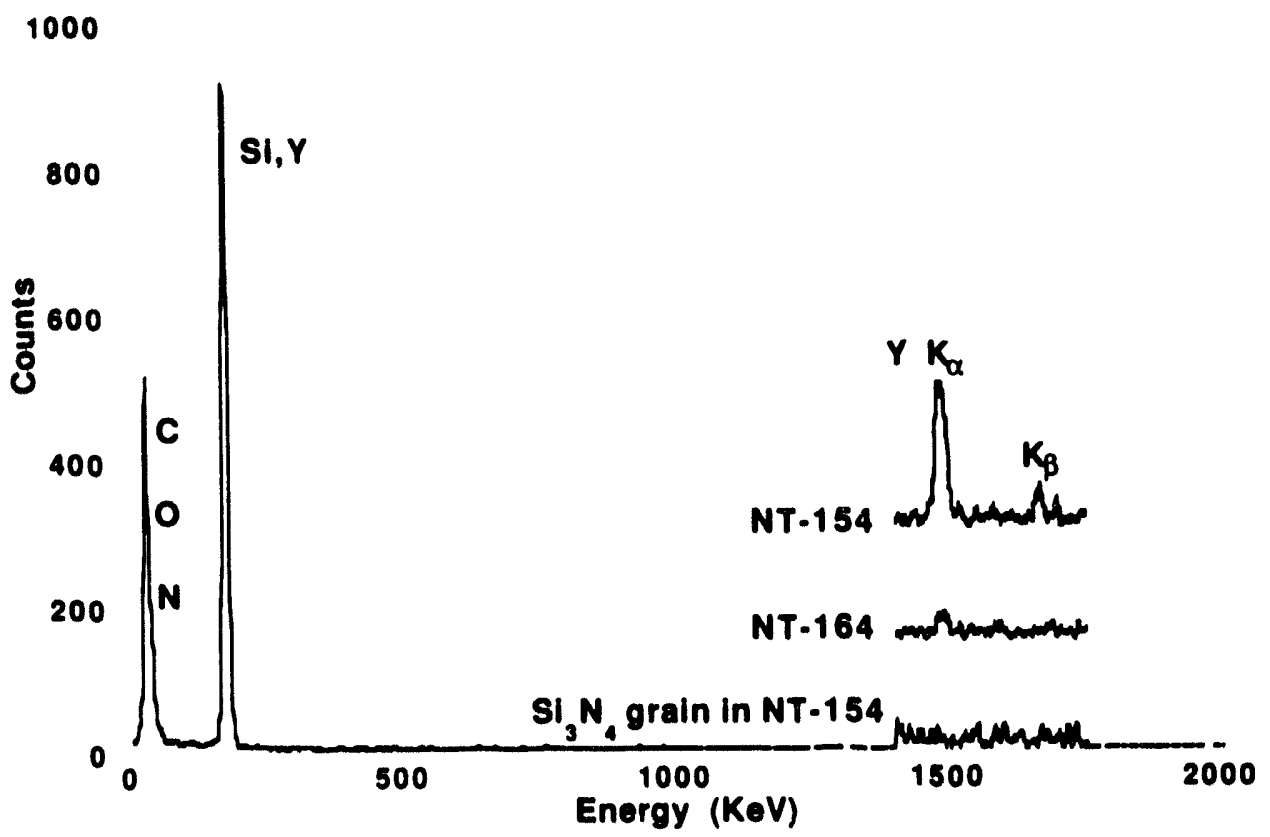

Fig. 3. Typical EDS spectra of grain boundaries in NT-154 and NT-164. The vertical scale of the spectral region from 1,400 to 1750 oV was expanded 20 times and offset to show th yttrium K-lines. Spectra were normalized using the silicon peak heighi. 
Initial scanning electron microscopy (SEM) examination of fractured surfaces from both specimens has shown small differences in the microstructures between the control and the microwave-annealed GS-44, as shown in Figs. 4(a) and 4(b), respecthely. The general microstructure of the $\mathrm{SI}_{3} \mathrm{~N}_{4}$ in the GS-44 material consists of relatively large acicular $\mathrm{Sl}_{3} \mathrm{~N}_{4}$ grains, approximately 5 to $10 \mu \mathrm{m}$ in length by 0.5 to $3 \mu \mathrm{m}$ in diameter (the seli-reinforcement), surrounded by much smaller $\mathrm{Sl}_{3} \mathrm{~N}_{4}$ grains. A general microstructural observation was that although both materials contained a similar size and distribution of the acicular grains, the grain size of the surrounding ${ }^{\circ} \mathrm{Si}_{3} \mathrm{~N}_{4}$ grains was smaller for the control material as compared to the microwave-annealed material. This is not only evident in Fig. 1 (low-magnification comparison), but also in the higher-magnification comparison shown in Figs. 5(a) and 5(b) for the control and microwave-annealed GS-44, respectlvely. The actual sizes and distributions for the $\mathrm{SI}_{3} \mathrm{~N}_{4}$ grains in these samples are currently being quantitatively determined using both thermally and plasma-etched samples.

In addition to SEM examination, X-ray diffraction was also done to determine difierences in the crystalline phases between the two samples. The primary phases determined for each sample were identical and are as follows: only $\beta-\mathrm{Sl}_{3} \mathrm{~N}_{4}$ (no $\alpha-\mathrm{Si}_{3} \mathrm{~N}_{4}$ ) with possible trace phases of $\mathrm{YSI}_{2}, \mathrm{Mg}_{2} \mathrm{Al}_{4} \mathrm{Si}_{5} \mathrm{O}_{18}$, and $\mathrm{Al}_{2} \mathrm{Y}_{4} \mathrm{O}_{9}$. The $\mathrm{\beta}-\mathrm{Si}_{3} \mathrm{~N}_{4}$ constitutes a volume fraction of approximately $98 \%$, and no evidence of a significant volume fraction of amorphous intergranular phase was detected. The phase identification and presence of amorphous material will be verified by TEM, the samples of which have already been prepared.

\section{Microstructural Evaluation of a Russian Silicon Nitride}

A single $\mathrm{Si}_{3} \mathrm{~N}_{4}$ cutting tool designated by a label on a plastic bag as 212-01 was characterized using primarily SEM and TEM. This document constitutes a summary of the observations to date. The tool was a rectangular parallelepiped with approximate dimensions of $12 \times 12 \times 4 \mathrm{~mm}$, and the four short corners were rounded.

The surface morphologies of one of the two large flats (termed "bases" herein) and two of the four sides were determined by SEM. The base appeared to be an as-pressed surface that had been subsequently polished (ground). One portion of the surface of the base had little or no grinding damage, as shown in Fig. 6. This morphology graded across the surface of the base to a region that showed a great deal of grinding, resulting in complete removal of the original as-pressed surface (Fig. 7). The as-pressed surface contained many pits or voids ranging in size from 5 to $50 \mu \mathrm{m}$. The larger voids were lined with crystals which are likely to be acicular $\beta$-grains [Fig. 6(d)], similar to those commonly seen in silicon nitride ceramics. In Fig. 7, striations resulting from the grinding appear to have random orientations such as might occur from a hand-held polishing operation. Voids were not as obvious on the ground surface, presumably because they were filled with grinding swart. Figure 8 shows several views of a side and the intersection of the side with the base. The side surface is clearly ground, and corners between sides are rounded [as seen by eye and in Fig. 8(a)]. The numerous voids that permeate thls material are quite obvious in Fig. 8(c) and 8(d).

A thin slice was cut from one side of the tool, and a TEM thin-foll specimen was prepared by dimple grinding and ion milling. A view of the typical structure of this material is shown in Fig. 9. $\mathrm{Sl}_{3} \mathrm{~N}_{4}$ grains are surrounded by amorphous material, presumably a residue of sintering additives. EDS results are shown in Fig. 10. EDS of $a_{1}$ 


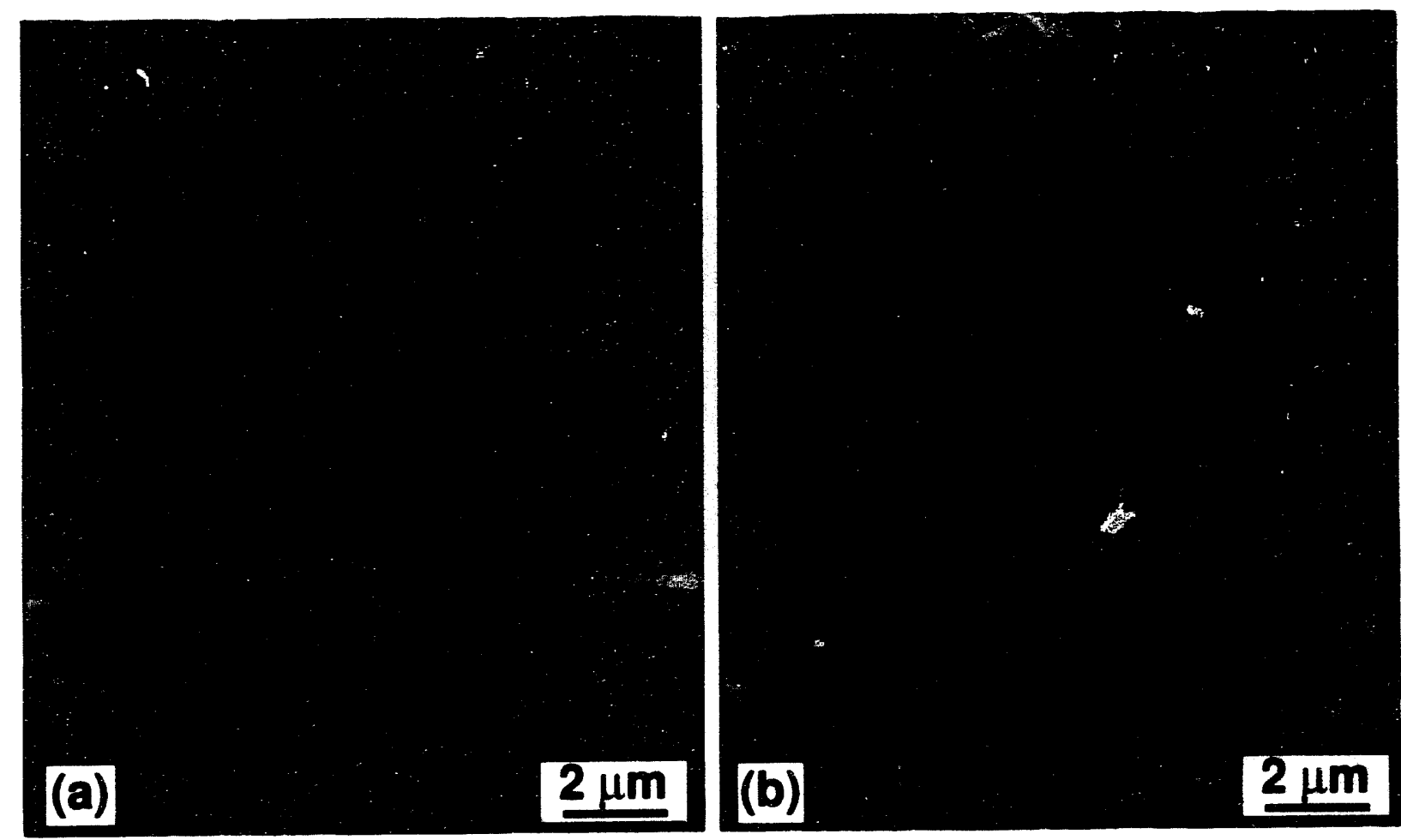

Fig. 4. Low-magnification SEM images of the fracture surfaces from (a) as-processed control GS-44 and (b) microwave-annealed GS-44. 
YP18861

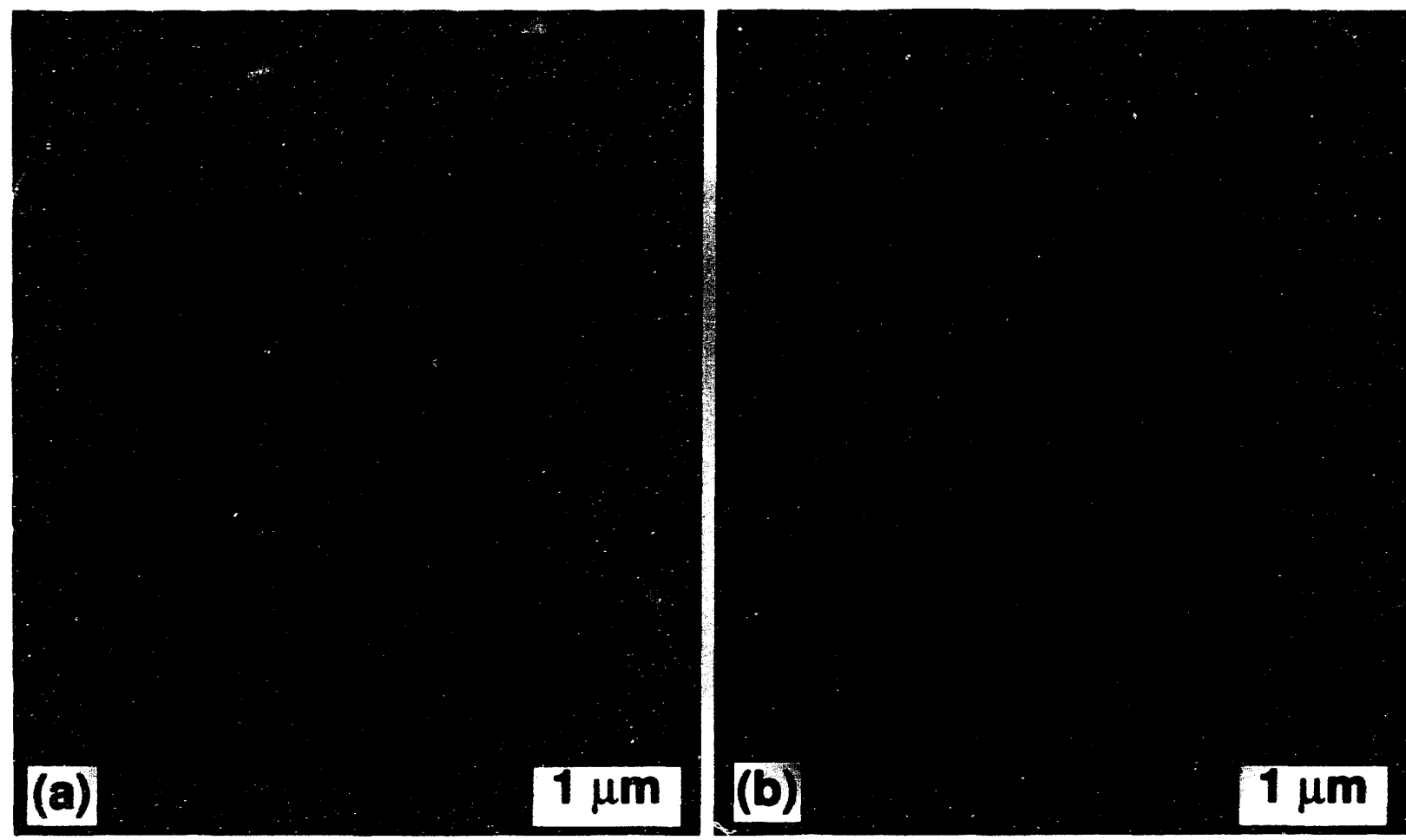

Fig. 5. High-magnification SEM images of the fracture surfaces from (a) as-processed control GS-44 and (b) microwave-annealed GS-44. 

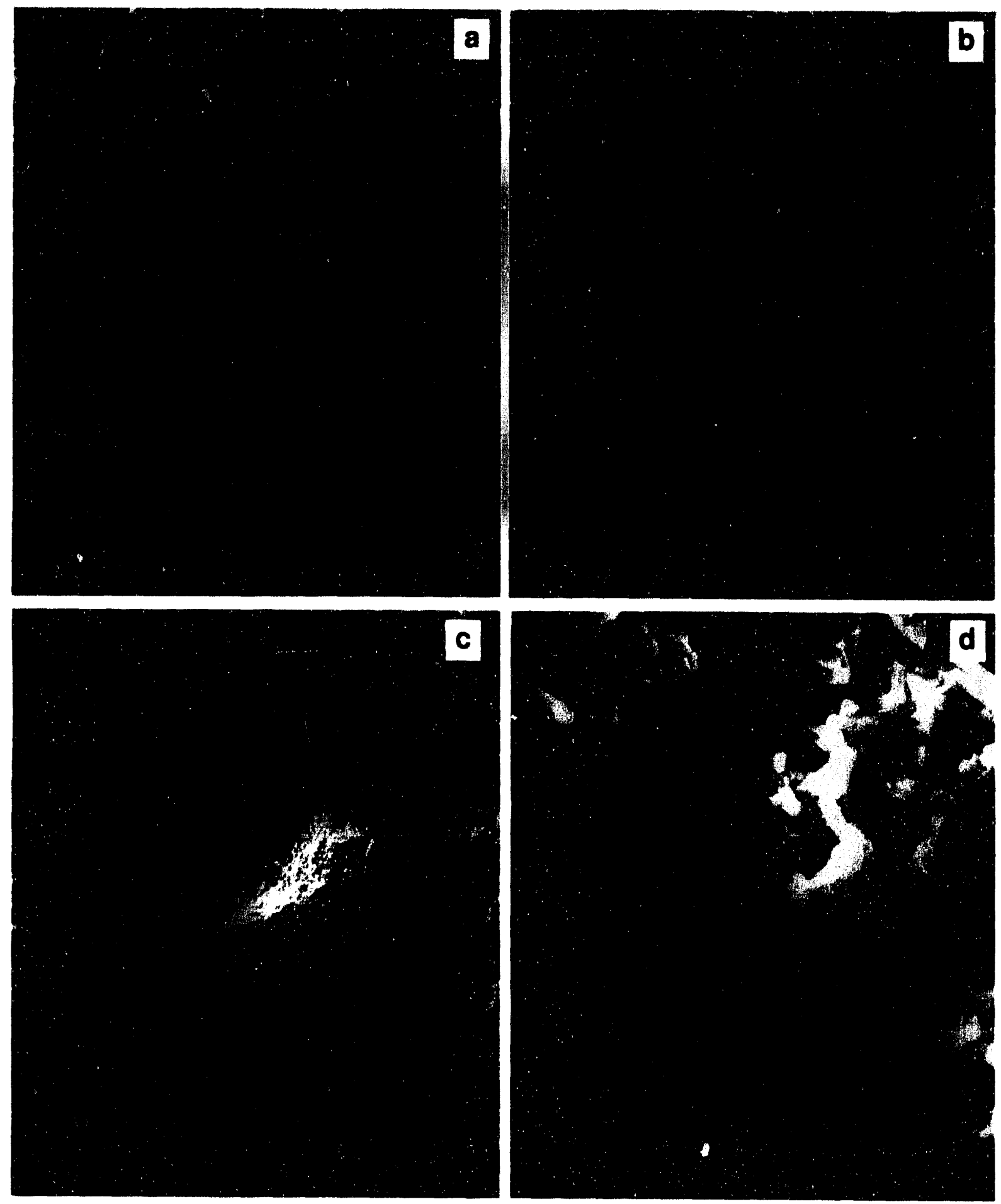

Fig. 6. SEM views of the base surface in a region that appeared to have little or no grinding. Many voids are present on this surface; larger voids (d) are lined with crystallites (presumably $\mathrm{B}-\mathrm{Si}_{3} \mathrm{~N}_{4}$ grains). 

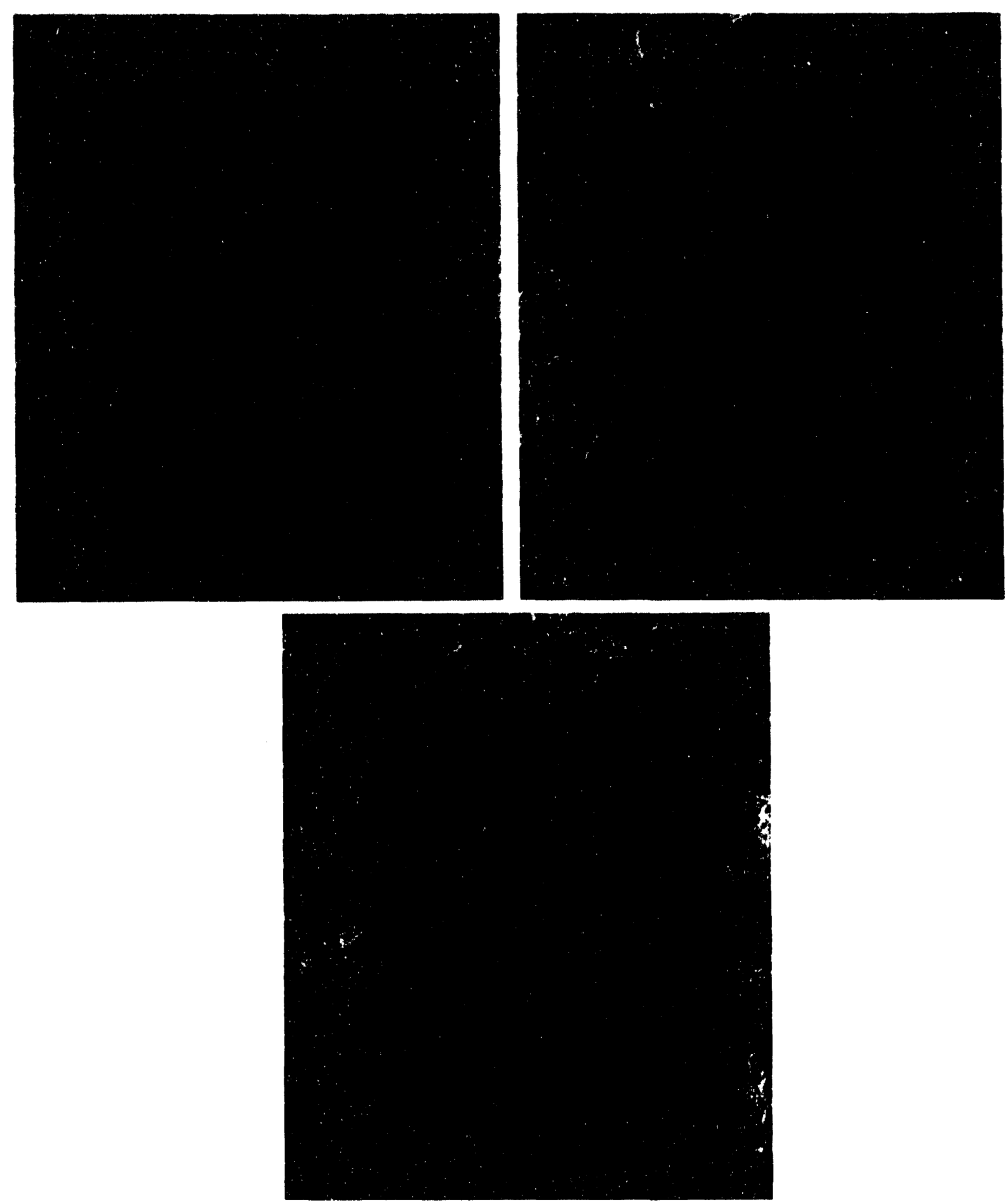

Fig. 7. SEM views of the base surface showing a region that has been ground. Striations resulting from grinding appear to have random orientations. 

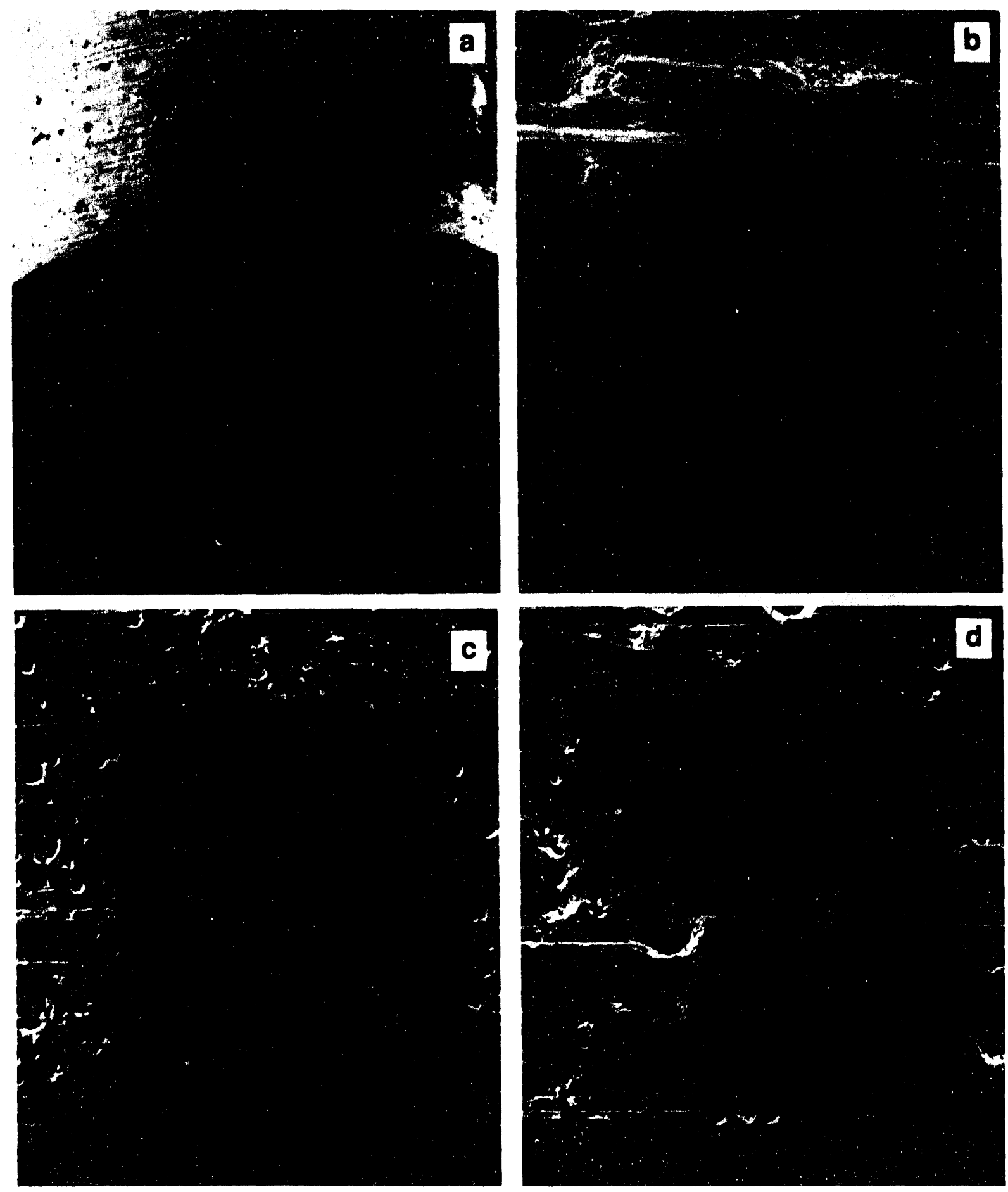

Fig. 8. SEM images of the intersection of a side with a base $[(a)$ and $(b)]$, and the surface of the side showing voids $[(c)$ and $(d)]$. 
YP18853

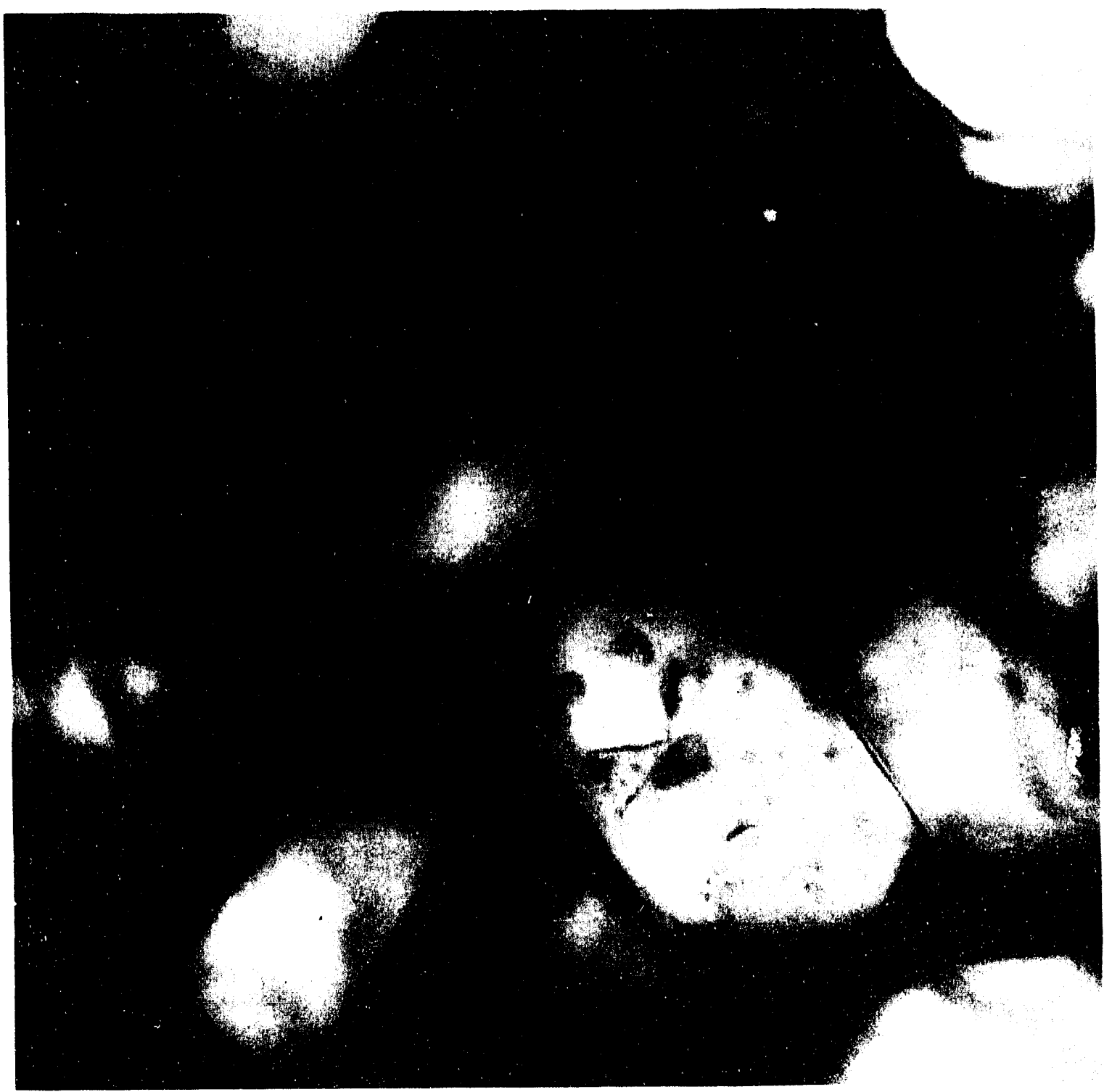

Fig. 9. Transmission electron micrograph of a typical region showing silicon nitride grains surrounded by amorphous material, presumably a residue of sintering additives. 
ORNL-DWG $94-5612$
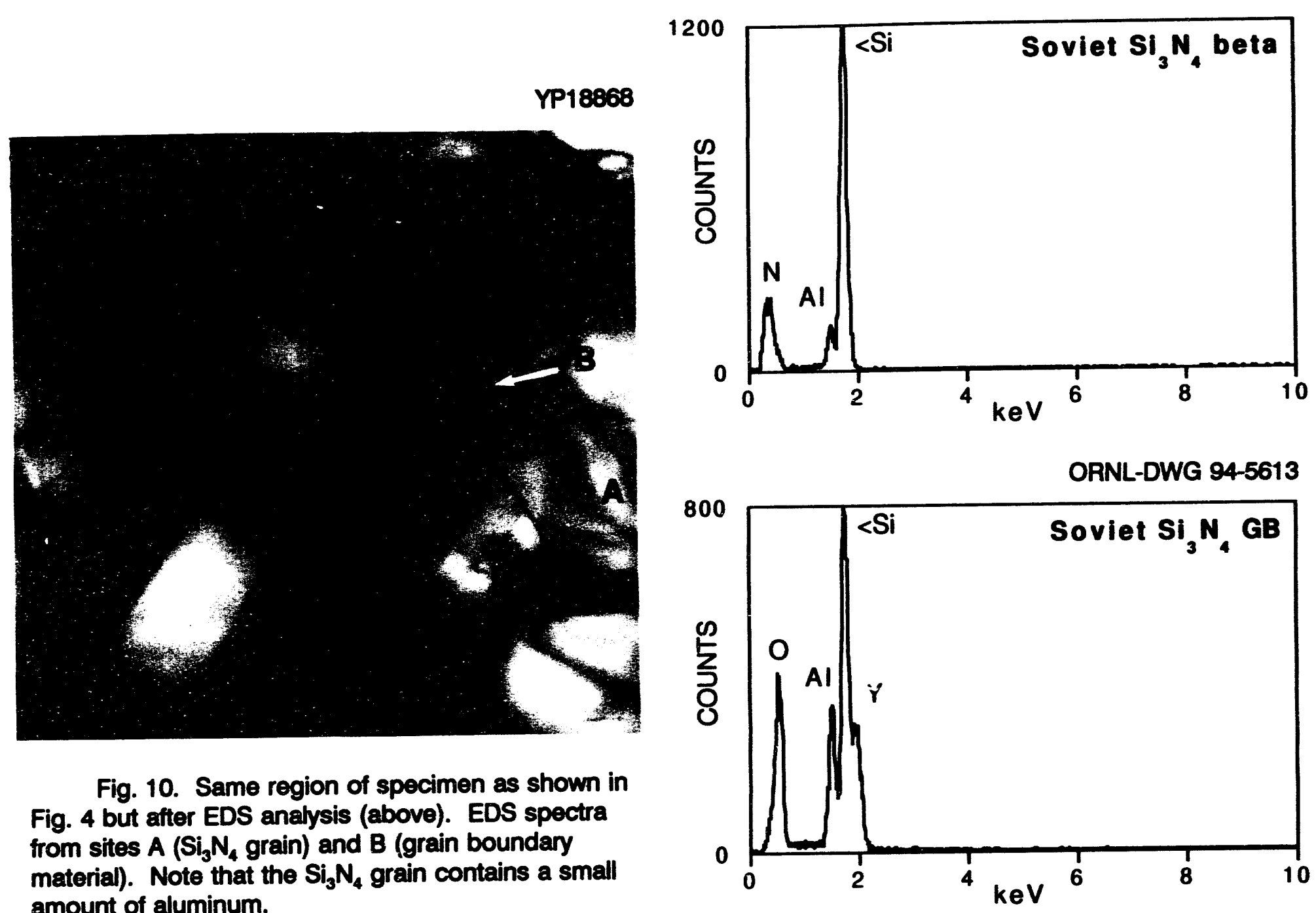

Fig. 10. Same region of specimen as shown in Fig. 4 but after EDS analysis (above). EDS spectra from sites $\mathrm{A}\left(\mathrm{Si}_{3} \mathrm{~N}_{4}\right.$ grain) and B (grain boundary material). Note that the $\mathrm{Si}_{3} \mathrm{~N}_{4}$ grain contains a small amount of aluminum. 
B-Sig $\mathrm{N}_{4}$ grain (see site $\mathrm{A}$ ) identified $\mathrm{Si}, \mathrm{N}$, and a small amount of $\mathrm{Al}$, which apparently substitutes for SI in the structure. EDS of the amorphous material (see site B) identified $O, A l$, and $Y$, as well as SI. This ceramic is similar in structure and composition to the GTE AY-6 Si $\mathrm{N}_{4}$, with the exception that AY-6 had very few internal volds. The results presented herein are based on observations of a limited number of areas from one TEM specimen. Further work remains to be done to determine the extent of compositional and structural variations in the material.

\section{References}

1. D. R. Hull, T. A. Leonhardt, and W. A. Sanders, "Plasma Etching a Ceramic Composite," prepared for the 24th Annual Convention of IMS, Monterey, Calif., July 29 August 1, 1991.

\section{Status of milestones}

Program on schedule.

Communications/visits/travel

1. K. L. More, "Defect Characterization in a CVD $\alpha-\mathrm{SI}_{3} \mathrm{~N}_{4}$ " invited presentation at (ASM/TMS) Materials Week '92, Chicago III., November 2-5, 1992.

\section{Problems encountered}

None.

\section{Publications}

1. J. L. Ding, K. C. Liu, K. L. More, and C. R. Brinkman, "Creep and Creep Rupture of an Advanced Silicon Nitride Ceramic," accepted for publication in J. Am. Ceram. Soc.

2. K. L. More, "Defect Characterization in CVD $\alpha-S_{3} \mathrm{~N}_{4}$ " invited talk at ASM/TMS Materials Week '92, Chicago, III., November 2-5, 1992.

3. K. L. More, "Defect Characterization in CIID Alpha Silicon Nitride," currently in review. 
Project Data Base

B. L. Keyes (Oak Ridge National Laboratory)

\section{Oblecthe/scope}

The objective of this task is to develop a comprehensive computer data base containing the experimental data on properties of ceramic materials generated in the total effort. This computer system should provide a convenient and efficient mechanism for the compllation and distribution of the large amounts of data involved. The data base will be avaliable in electronic form to all project participants. In addition, periodic hard-copy summaries of the data, including graphical representation and tabulation of raw data, will be lesued to provide convenient information sources for project participants.

Technical highlights

The Ceramic Technology Project (CTP) data base now contains 8417 records on results from 27 different types of tests, 700 material characterizations, 13 lubricant characterizations, 102 coating characterizations, and 2367 other associated material/test background information text records. The image data base contains 115 micrographs. A more detailed description may be found in Table 1.

Capital equipment funds for a micrograph storage system were approved, and the equipment has been received and installed. The basic system is on a Macintosh licx using dual 150-MB Bernoulli disks, compact disc-read-only memory (CD-ROM) technology, and a Hewlett-Packard Scanjet llc. Kodak's Shoebox Image Manager'M and Aldus' Fetch ${ }^{\mathrm{TM}}$ are being evaluated as image-only management systems, with a possibility of Fox Base $+{ }^{\mathrm{TM}}$ (for the Mac) and Fox Pro ${ }^{\mathrm{TM}}$ [for personal computer (PC) compatibles] to be used for total data base (image and test results data) management. Micrographs are resized and, If necessary, enhanced (lightened or darkened) using Adobe Photoshop. Initially, the image data base will be linked to the test results data base by relational keys. If this arrangement works satisfactorily, other graphic image subjects, such as scanned-in graphs, test specimen drawings, test equipment dlagrams, etc., will be added in the future. Data base personnel are also searching for the best method to transport image files to a PC-compatible system for PC users. Since plans to integrate the photo-micrograph images into the existing structure have not been completed, an index file was created within dBASE to acquaint the user with some of the avallable micrographs. Future plans call for all images to be stored on a CD-ROM for distribution purposes after enough pictures have been stored to justify the effort.

CTP bimonthly and semiannual progress reports have been the sources for the presently stored micrographs. The quality of the stored images has been high to average, depending on the clarity of the source Images. Original micrographs are needed and requested. All submitted micrographs will be returned to the senders after being scanned into the system. These images are valuable to industry as well as to the researcher.

Several new files were added during this bimonthly period. A method to store creep curves and stepped-stress curves in the data base was developed during this semiannual period, and an effort to collect a good representation of creep curves for as many materials as possible has begun. The main problem has been how to handle the variable number of point sets possible with these types of tests. Little data have been stored in these files due to other commitments and time constraints. If anyone has creep curves 
Table 1. Ceramic Technology Project data base summary as of September 30, 1993

\begin{tabular}{|c|c|c|c|c|c|c|c|c|c|c|}
\hline \multirow{2}{*}{$\begin{array}{l}\text { Material } \\
\text { class }\end{array}$} & \multicolumn{5}{|c|}{ Brazed specimens } & \multirow{2}{*}{ Creep } & \multirow{2}{*}{$\begin{array}{l}\text { Cyclic } \\
\text { fatigue }\end{array}$} & \multirow{2}{*}{ Density } & \multirow{2}{*}{$\begin{array}{l}\text { Dynawic } \\
\text { fatigue }\end{array}$} & \multirow{2}{*}{ Elasticity } \\
\hline & MOR 4a & Shear str. & Toughness & Torsion & Tor fat igue & & & & & \\
\hline $\begin{array}{l}\text { Alumina } \\
\text { Alumina + reinforcing fibers } \\
\text { Alumina + zirconia } \\
\text { Mullite } \\
\text { Mullite + reinforcing fibers } \\
\text { SiAlow } \\
\text { Silicon carbide } \\
\text { Silicon nitride } \\
\text { Silicon nitride + reinforcing fibers } \\
\text { Zirconia } \\
\text { Zirconia + reinforcing fibers } \\
\text { Other }\end{array}$ & $\begin{array}{r}87 \\
241\end{array}$ & $\begin{array}{l}12 \\
48 \\
58\end{array}$ & 43 & $\begin{array}{r}15 \\
6 \\
\end{array}$ & 7 & $\begin{array}{r}260 \\
9\end{array}$ & $\begin{array}{l}17 \\
36 \\
15 \\
51\end{array}$ & $\begin{array}{r}10 \\
64 \\
65 \\
158 \\
4 \\
\end{array}$ & $\begin{array}{l}23 \\
76 \\
14\end{array}$ & $\begin{array}{r}28 \\
\\
2 \\
11 \\
15 \\
135 \\
74 \\
119\end{array}$ \\
\hline Totals & 328 & 118 & 43 & 21 & 7 & 269 & 144 & 313 & 122 & 384 \\
\hline $\begin{array}{l}\text { Material } \\
\text { class }\end{array}$ & $\begin{array}{l}\text { Fracture } \\
\text { toughness }\end{array}$ & Hardness & $\begin{array}{l}\text { Interrupted } \\
\text { fatigue }\end{array}$ & $\begin{array}{c}\text { MORd } \\
\text { 3-Pt bend }\end{array}$ & $\begin{array}{c}\text { MORe }^{2} \\
\text { 4-Pt bend }\end{array}$ & $\begin{array}{l}\text { Oxidation } \\
\text { rate }\end{array}$ & $\begin{array}{l}\text { Poisson's } \\
\text { ratio }\end{array}$ & $\begin{array}{l}\text { Shear } \\
\text { modulus }\end{array}$ & Tensile & $\begin{array}{l}\text { Stress } \\
\text { rupture }\end{array}$ \\
\hline $\begin{array}{l}\text { Aluaina } \\
\text { Aluaina + reinforcing fibers }\end{array}$ & $\begin{array}{l}39 \\
39\end{array}$ & 4 & & & $\begin{array}{l}418 \\
145\end{array}$ & & & & $\begin{array}{l}15 \\
11\end{array}$ & 13 \\
\hline $\begin{array}{l}\text { Aluaina + zirconia } \\
\text { Mullite }\end{array}$ & 1 & & & 1 & 7 & & & & & \\
\hline $\begin{array}{l}\text { Mullite + reinforcing fibers } \\
\text { SiAlow }\end{array}$ & 12 & & & 9 & 20 & & & & & \\
\hline $\begin{array}{l}\text { SiAlon } \\
\text { Silicon carbide }\end{array}$ & 38 & 27 & & & $\begin{array}{r}52 \\
275\end{array}$ & & & 1 & 86 & 13 \\
\hline Silicon nitride & 153 & 124 & & 10 & 1305 & 1 & 31 & 30 & 214 & 101 \\
\hline Silicon nitride + reinforcing fibers & 56 & & & & 164 & 3 & 62 & 61 & 50 & \\
\hline $\begin{array}{l}\text { Zirconia } \\
\text { Zirconia + reinforcina fibers }\end{array}$ & 377 & 24 & 239 & & 1613 & & & & 16 & 17 \\
\hline $\begin{array}{l}\text { Zirconia + reinforcina fibers } \\
\text { Other }\end{array}$ & 2 & 39 & & & $\begin{array}{r}2 \\
61 \\
\end{array}$ & & & & & 3 \\
\hline Totals & 717 & 218 & 239 & 20 & 4066 & 4 & 93 & 92 & 392 & 147 \\
\hline
\end{tabular}


Table 1. (Continued)

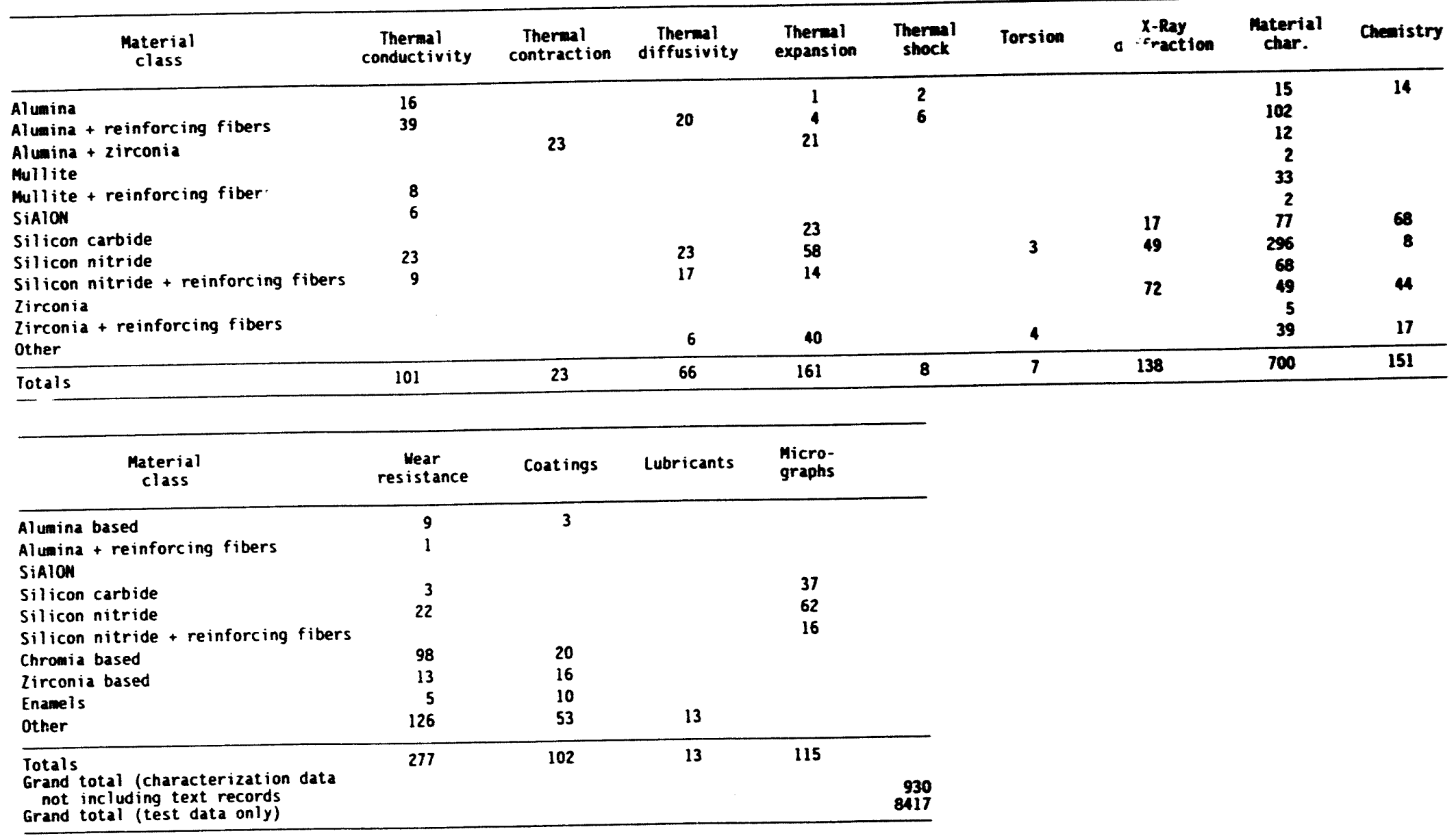


avallable (preferably in tabular form), data base persorinel would like to add them to the data base with approprlate acknowledgments and assoclated documentation (test, material, and testing facility information).

The annual data base summary report has been written, reviewed, and revised, and la now in the process of publication. Included in the report is information on a B-SIC (Dow-Corning), Hexoloy SX-G1, NT-451, SN-253, NT-154, NT-164, GN-10, GTE PY6, experimental sillcon nitride-based compositions, and a fow SIC whisker-reinforced ceramics, presented as test results (tabular and graphical), background information, and mlcrographs.

Progress on the computerized user interface continued during this semiannual reporting period. Enhancements to the searching menus and data access procedures were developed and partially tested. Routines will be added to handle the newly developed curve data. Work on the computerized interface for the data base was suspended to allow time to complete the data base summary report and to install and set up the newly acquired image storage system.

Data base personnel are involved in developing an American Society for Testing and Materials (ASTM) guideline document (for the E-49 Committee on Computerized Materials Data Bases) on ceramic material designations for computer data base storage. Problems encountered with ceramic material classification tables derlved from a draft VAMAS document have been alleviated due to a major revision of that draft document and its adoption by ASTM Committee C-28 on Advanced Ceramics. The E-49 document has been revised as much as can be done outside of the task group meetings. Several negative votes need committee votes before the remaining changes can be made.

Communications/visits/travel

B. L. Keyes travelled to Gaithersburg, Maryland, on October 1993 to attend the semiannual ASTM E49 committee meetings. Work is continuing on developing standards for computerizing ceramic materials property data.

\section{Problems encountered}

None.

Status of milestones

The September 1993 data base summary report is now in publication.

\section{Publications}

The Ceramic Technology for Advanced Heat Engines Project Database: September 1993 Summary Report, in publication. 


\subsection{TIME-DEPENDENT BEHAVIOR}

Eracture Behavior of Toughened Ceramics

H. T. Lin, P. F. Becher, and W. H. Wanwick (Oak Ridge National Laboratory)

\section{Objective/scope}

Ceramics with reinforcing microstructures and ceramic composites offer important advantages for heat engine applications. Chief among these is the improved fracture toughness that can be achieved by appropriate design of microstructural and material parameters. Previous studies show that these materials often exhibit substantial improvements in damage, thermal shock, and slow crack growth resistances. However, design of such systems must also consider those factors influencing their performance at elevated temperatures

In response to these needs, studies are conducted to determine the mechanical properties, (e.g., creep, delayed failure, strength, and toughness) at elevated temperatures for these toughened ceramics. Particular emphasis is placed on understanding how microstructure and composition influence the mechanical performance at elevated temperatures and the stability of these properties for extended periods at these temperatures. The knowledge gained from these studies provides input on how to modify materials to optimize their mechanical properties for the temperature ranges of interest.

\section{Iechnical hahlights}

During this 6-month reporting period, research efforts were directed to evaluate (1) the creep behavior in tension and flexure of silicon nitride ceramics with elongated grain structure and (2) the flexural creep behavior of alumina composites reinforced with $\mathrm{SiC}$ whiskers. The materials investigated in the first effort include gas-presst: $r$-sintered (GPS) and microwave-sintered reactionbonded $\mathrm{Si}_{3} \mathrm{~N}_{4}$ ceramic's. These are part of a large effort to provide an understanding of the effect of microstructure and composition on the creep response of in situreinforced silicon nitride ceramics and to develop more cost-effective approaches to manufacture $\mathrm{Si}_{3} \mathrm{~N}_{4}$ materials.

\section{Creep Behavior of Silicon Nitride Ceramics}

A. Tensile Creep Behavior. Tensile creep tests were conducted on in situreinforced silicon nitride ceramics containing sintering additives of $5 \mathrm{vol} \% \mathrm{Yb}_{2} \mathrm{O}_{3}$ (SN5Yb) and $10 \mathrm{vol} \% \mathrm{Yb}_{2} \mathrm{O}_{3}-0.5 \mathrm{vol} \% \mathrm{Al}_{2} \mathrm{O}_{3}$ (SN10YbAl). These silicon nitride materials were sintered to $>99 \%$ of theoretical density by a GPS process. A subsequent heat treatment at $1250^{\circ} \mathrm{C}$ for $12 \mathrm{~h}$ was carried out to crystallize the secondary phase(s). The $X$-ray analysis following the crystallization process indicates that the triple-point secondary phase in the SN5Yb material is $\mathrm{Y}_{2} \mathrm{Si}_{2} \mathrm{O}_{7}$ and in the $\mathrm{SN}_{10 \mathrm{YbAl}}$ material is $\mathrm{Y}_{2} \mathrm{Si}_{2} \mathrm{O}_{5}+\mathrm{Y}_{2} \mathrm{Si}_{2} \mathrm{O}_{7}$ as a minor phase. The $\mathrm{X}$-ray result is consistent with the phase diagram of the quasiquaternary system $\mathrm{Si}_{3} \mathrm{~N}_{4}-\mathrm{Yb}_{2} \mathrm{O}_{3}-\mathrm{SiO}_{2}-\mathrm{YbN}$ (ref. 1). Note that the secondary phase at two grain 
junctions remains amorphous after the heat ireatment, and the thickness of thin amorphous film is approximately 1 to $2 \mathrm{~nm}$ (ref. 2).

Figure 1 shows the creep results for the SN5Yb and SN10YbAl materials at 1200 and $1300^{\circ} \mathrm{C}$ at stress levels from 50 to $150 \mathrm{MPa}$ in an ambient air. Both materials exhibit similarly low creep rates $\left(\sim 2 \times 10^{-10} \mathrm{~s}^{-1}\right)$ at $1200^{\circ} \mathrm{C} / 50 \mathrm{MPa}$. However, at stresses $>50 \mathrm{MPa}\left(\right.$ at $1200^{\circ} \mathrm{C}$ ) or temperatures $>1200^{\circ} \mathrm{C}$, the SN10YbAl material exhibits higher creep rates (about four to ten times) as compared to the SN5Yb material. The creep data at $1200^{\circ} \mathrm{C}$ exhibit large scatter for the SN10YbAl material. Similar observations in scatter of creep rates have also been reported for other advanced silicon nitride materials (i.e., NT154). 3 The scatter of sreep rates observed in the present case may arise from the inhomogeneous distribution of residual glassy phase enriched with Al. In addition, the presence of Al (as a glass former) will further decrease the viscosity (as well as the softening temperature) of the glassy phase resulting in higher creep rates as observed in the SN10YbAl material. The creep stress exponents $(n)$ at 1200 and $1300^{\circ} \mathrm{C}$ for these two materials range from 4.6 to 5.8 suggesting that creep damage (creep cavitation) controls the creep life as in other $\mathrm{Si}_{3} \mathrm{~N}_{4}$ materials. 4,5

B. Flexural Creep Behavior. Flexural creep studies of microwave-sintered reaction-bonded silicon nitride (MW-SRBSN) were conducted to determine the creep behavior as a function of microstructure, composition, and processing condition. The MW-SRBSN materials were fabricated under W.B.S. Element 1.1.2.4 (Microwave Sintering of Silicon Nitride). This is part of a large effort to develop more cost-effective approaches to fabricate silicon nitride ceramics and to assess their limits for structural applications.

The starting powders for the MW-SRBSN material tested to date (designated as TM145) consisted of metallurgical-grade Si (<0.5 wt \% impurities), a-Siz $\mathrm{N}_{4}$, and oxide additives. 6 The nominal composition of TM145 after nitridation and sintering in a microwave furnace is $\mathrm{Si}_{3} \mathrm{~N}_{4}-3 \mathrm{wt} \% \mathrm{Al}_{2} \mathrm{O}_{3}-9 \mathrm{wt} \% \mathrm{Y}_{2} \mathrm{O}_{3}$. The $\mathrm{X}$-ray analysis indicates that the TM145 contains $100 \% \mathrm{~B}_{-} \mathrm{Si}_{3} \mathrm{~N}_{4}$ phase with a minor amount of the glassy phase. Mechanical testing results also show that the flexural strength at 20 and $1200^{\circ} \mathrm{C}$ of $\mathrm{TM} 145$ is 744 and $400 \mathrm{MPa}$, respectively. The density of MW-SRBSN is $97.7 \%$ of theoretical density.

Figure 2 shows the flexure creep results of MW-SRBSN (TM145) at $1200^{\circ} \mathrm{C}$ under applied stresses of 100 to $250 \mathrm{MPa}$ in air. The creep results for hot-pressed silicon nitride (HPSN) with a composition of $1.5 \mathrm{wt} \% \mathrm{Al}_{2} \mathrm{O}_{3}-6 \mathrm{wt} \% \mathrm{Y}_{2} \mathrm{O}_{3}$ (AY6) are also included for comparison. 7 Note that the hot-pressed AY6 material was fabricated by using high-purity grade a-Si $\mathrm{N}_{4}$ powder (Ube Grade $\mathrm{E}-10$ ) under W.B.S. Element 1.2.3.1. (Dispersion-Toughened Ceramic Composite). The AYG material has a room-temperature flexural strength of $1140 \mathrm{MPa}$ with density $>99 \%$ of theoretical density. The creep data show that the MW-SRBSN material (TM145) exhibits similar flexural creep resistance to the HPSN material (AY6) at $1200^{\circ} \mathrm{C}$ under the same stress level. Note that the MW-SRBSN material under 50 to $65 \%$ of its fracture strength at $1200^{\circ} \mathrm{C}$ still exhibits a low creep rate, approximately $3.0 \times 10^{-9} \mathrm{~s}^{-1}$. The creep stress exponent $(n)$ at $1200^{\circ} \mathrm{C}$ is approximately one that can be attributed to diffusional or viscous creep processes. 
ORNL-DWG 94-5614

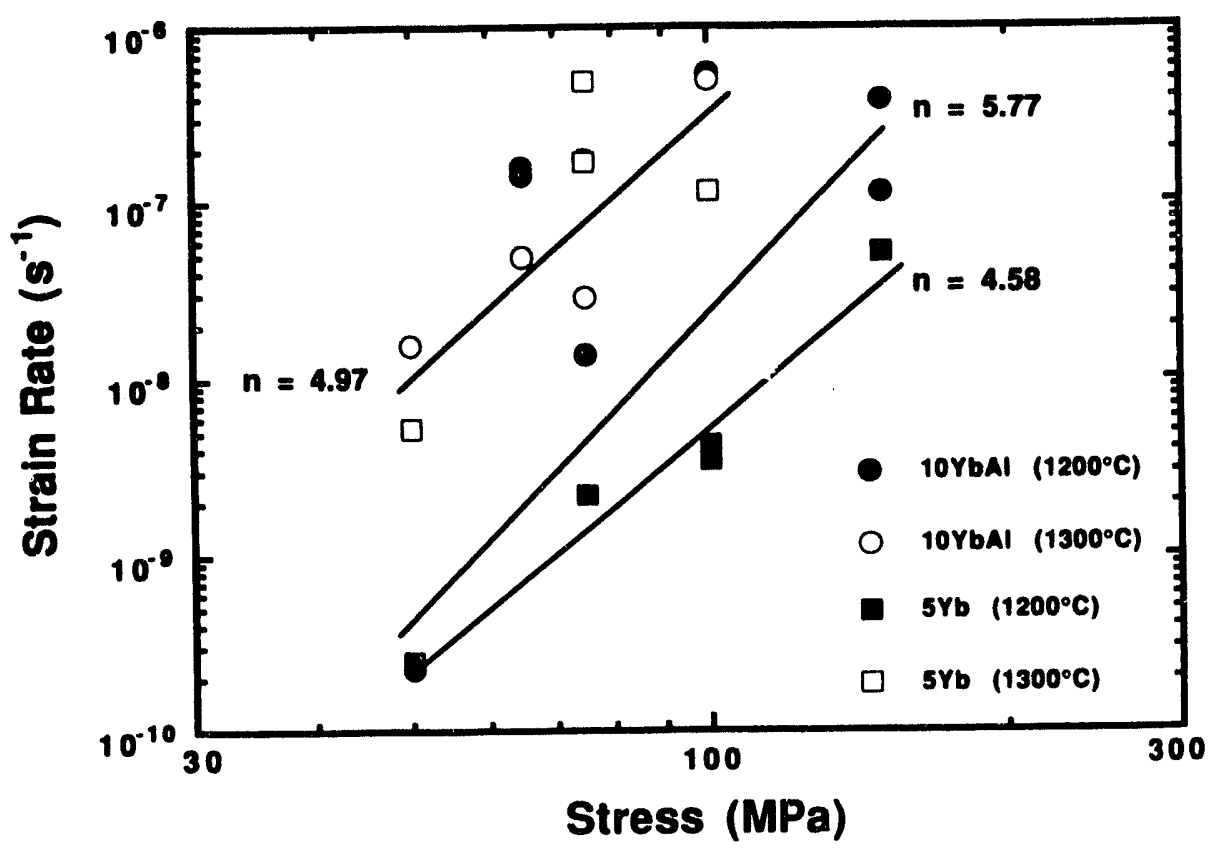

Fig. 1. Strain rate versus stress curves for $\mathrm{Yb}_{2} \mathrm{O}_{3}$ containing silicon nitride materials.

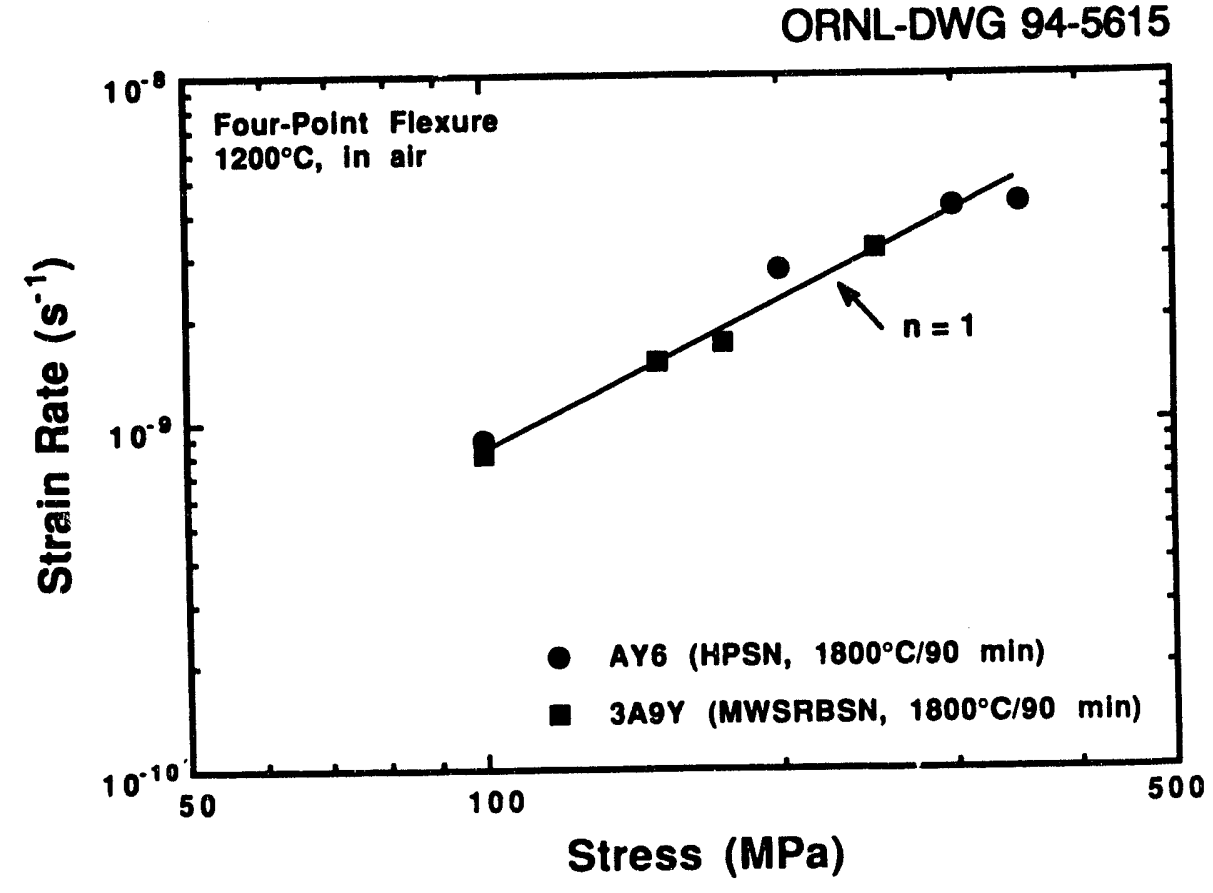

Fig. 2. Strain rate versus stress curves at $1200 / 36^{\circ} \mathrm{C}$ for microwave-sintered reaction-bonded silicon nitride material. 


\section{Creep Behavior of Alumina-SiC Composites}

The flexural creep behavior of alumina composites reinforced with $10 \mathrm{vol} \%$ $\mathrm{SiC}$ whiskers as a function of alumina matrix grain size was evaluated during this reporting period. The alumina-SiC material is used as a model system to understand the influence of reinforcing phase and/or microstructure on the creep response of other advanced toughened ceramics, i.e., in situ-reinforced silicon nitride ceramics with elongated grain structures. The alumina composites were fabricated under controlled hot-pressing conditions to achieve various grain sizes from 1.2 to $8 \mu \mathrm{m}$. The flexural creep studies were conducted at $1200^{\circ} \mathrm{C}$ and at stress levels from 100 to $230 \mathrm{MPa}$ in air.

Figure 3 shows the creep results of alumina-10 vol \% SiC materials at $1200^{\circ} \mathrm{C}$ as a function of alumina matrix grain size. The data indicate that the creep rate decreases with increasing alumina grain size. For instance, the material with grain size of $\mathbf{8 \mu \mathrm { m }}$ exhibits creep rates that are approximately one order of magnitude lower than the one having $1.2-\mu \mathrm{m}$ grain size under the same applied stress range. In this case the grain size exponent, $m$, can be obtained from the slope of a plot of log strain rate versus log grain size at a constant stress level (Fig. 4). The results show that a grain size exponent of approximately one is observed for stresses up to $230 \mathrm{MPa}$. In addition, regression analysis of the creep rate versus stress reveals that the stress exponent, $n$, is about two and is insensitive to the alumina grain size and consistent with grain boundary sliding (GBS) accommodated by diffusional processes. 8,9 It is also reported that the creep strain due to the GBS creep process should be proportional to $1 / \mathrm{d} m$ where $m$ is one and $d$ is the matrix grain size as observed here. 10

Status of milestones

Milestone No. 321314: "Determine tensile creep rupture life of promising toughened $\mathrm{Si}_{3} \mathrm{~N}_{4}$ ceramics" was completed.

Milestone No. 321315: "Complete characterization of strength and toughness behavior of gas-pressure-sintering $\mathrm{Si}_{3} \mathrm{~N}_{4}$ ceramics containing elongated grain structures" was completed.

\section{Publications}

None.

\section{References}

1. E. Hampp, "Phase Relationships and Sintering Behavior of Yb-Doped Si3N4," Ph.D. Thesis, University of Stuttgart, Germany, 1993.

2. J. S. Vetrano et al., "Yb2 $\mathrm{O}_{3}$-Fluxed Sintered Silicon Nitride, Part I: Microstructure Characterization," submitted to J. Mater. Sci. 


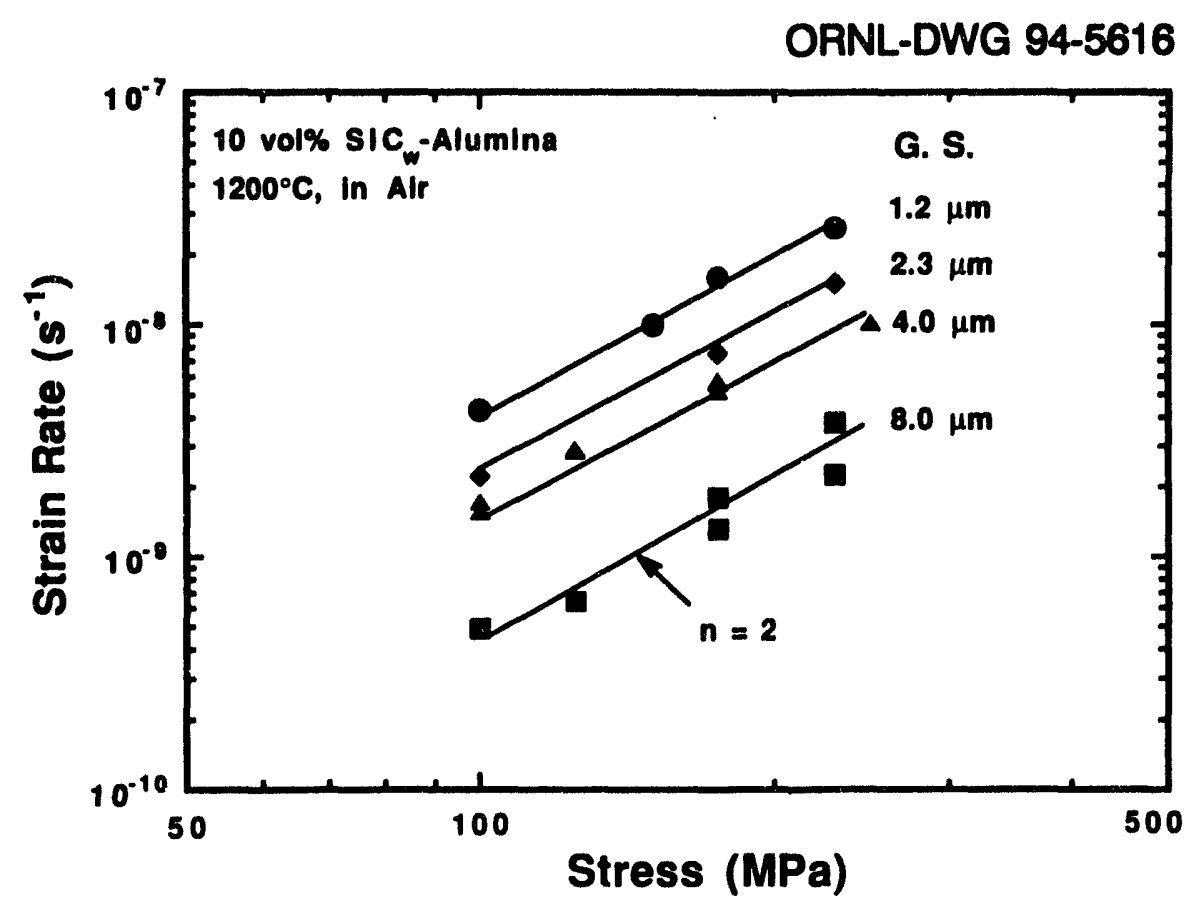

Fig. 3. Strain rate versus stress curves for alumina-10 vol\% $\mathrm{SiC}_{\mathrm{W}}$ materials as a function of alumina matrix grain size.

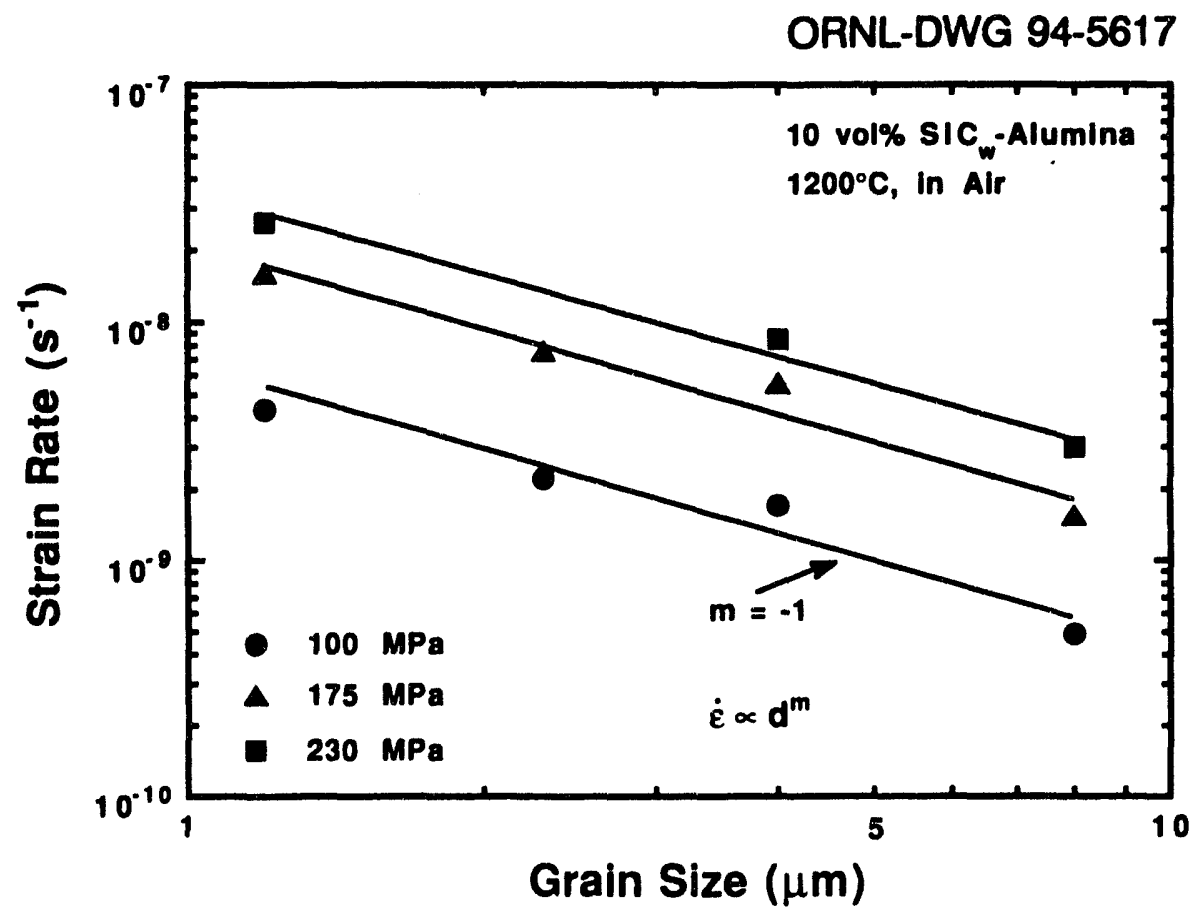

Fig. 4. Strain rate versus grain size curves of alumina-SiC materials as a function of stress. 
3. M. N. Menon et al., "Creep Rate and Stress Rupture Behavior of an Advanced Silicon Nitride," submitted to J. Am. Ceram. Soc.

4. M. K. Ferber and M. G. Jenkins, "Evaluation of the Strength and Creep-Fatigue Behavior of Hot-Isostatically Pressed Silicon Nitride," J. Am. Ceram. Soc. 75 [9], 2453-62 (1992).

5. S. M. Wiederhorn, B. J. Hockey, D. C. Cranmer, and R. Yeckley, "Transient Creep Behavior of Hot-Isostatically Pressed Silicon Nitride," J. Mater. Sci. 28, 445-53 (1993).

6. T. N. Tiegs, J. O. Kiggans, K. Ploetz, and P. A. Menchhofer, "Microwave Sintering of Silicon Nitride," pp. 2-6 in Ceramic Technology Project Bimonthly Technical Progress Report, ORNL/CF-92/285, Martin Marietta Energy Systems, Inc., Oak Ridge Natl. Lab., October-November 1992.

7. H. T. Lin, P. F. Becher, and W. H. Warwick, "Fracture Behavior of Toughened Ceramics," pp. 295-301 in Ceramic Technology Project Semiannual Progress Report, ORNLTM-12133, Martin Marietta Energy Systems, Inc., Oak Ridge Natl. Lab., September 1992.

8. H. T. Lin and P. F. Becher, "Creep Behavior of a SiC-Whisker-Reinforced Alumina," J. Am. Ceram. Soc., 73 [5], 1378-81 (1990).

9. H. T. Lin and P. F. Becher, "High-Temperature Creep Deformation of AluminaSiC-Whisker Composites," J. Am. Ceram. Soc., 74 [8], 1886-93 (1991).

10. T. G. Langdon, "Grain Boundary Deformation Processes," pp. 101-26, in Deformation of Ceramic Materials II, Vol. 18, ed. R. E. Tressler and R. C. Bradt, Plenum, New York, 1984. 
Cyclic Fatigue of Toughened Ceramics

K. C. Lu, C. O. Stevens, and C. R. Brinkman (Oak Ridge National Laboratory)

Objective/scope

The objective of this task is multifold:

1. To develop, design, fabricate, and demonstrate the capability of performing cyclic fatigue in tension-tension/compression and static fatigue testing in uniaxial tension/compression on candidate structural ceramics at elevated temperatures. While significant progress has been made in several areas of the experimental front (such as specimen/grip alignment, specimen heating, and high-temperature extensometry), testing capabilities in fully reversed tension-compression cyclic fatigue and compression creep in the uniaxial direction remain to be developed and demonstrated.

2. To develop baseline information on cyclic fatigue behavior of candidate ceramics and, in turn, to establish a design data base.

3. To develop creep and creep-rupture data bases for advanced heat-engines design applications in the 1150 to $1370^{\circ} \mathrm{C}$ range.

4. To evaluate and refine existing constitutive models based on the information generated above.

5. To develop new constitutive models to facilitate design analyses of high-temperature structural components and improve their reliability.

Technical highlights

Apparatus for tensile testing plate-type ceramic specimens

A U.S. patent (No. 5,237,876) was granted on August 24, 1993, for a new apparatus for tensile testing plate-type ceramic specimens having dogbone- or T-shaped ends, as shown in Fig. 1, without introducing bending stresses. To be effective, the apparatus must be used in association with the patented self-aligning grippers, which are currently commercially available.

The major components of the apparatus are a pair of two parallel pull rods suspended side by side to grip the shoulders on each T-shaped end of a specimen. The pull rods are pivotally attached to a disk-shaped part being supported by an array of miniature hydraulic piston assemblies. The specimen shoulders are supported by short bearing rollers [parts 80 and 82 shown in Fig. 2(a)]. Figure 2(a) illustrates the mechanical features of the apparatus, and Fig. 2(b) shows the view of "Section 3-3" as indicated in Fig. 2(a). Applying loads on the specimen shoulders eliminates the holes at the ends of the specimen for pin/clevis connections. Additionally, square shoulders can be machined at a lower cost compared to slanted shoulders used in other types of plate specimens. With the use of this apparatus, a specimen having a less perfect symmetry in shoulder heights can be successfully tested without bending due to the independent motions of the pull rods.

Because of this unique mechanical feature, a bar specimen (Fig. 3) having a square or round uniform cross section can be tested with steel lugs bonded to the ends of the bar. This specimen design permits the use of short specimen lengths and the flexibility of 
ORNL-DWG 94-5518

\section{U.S. Patent No. 5,237,876 August 24, 1993}
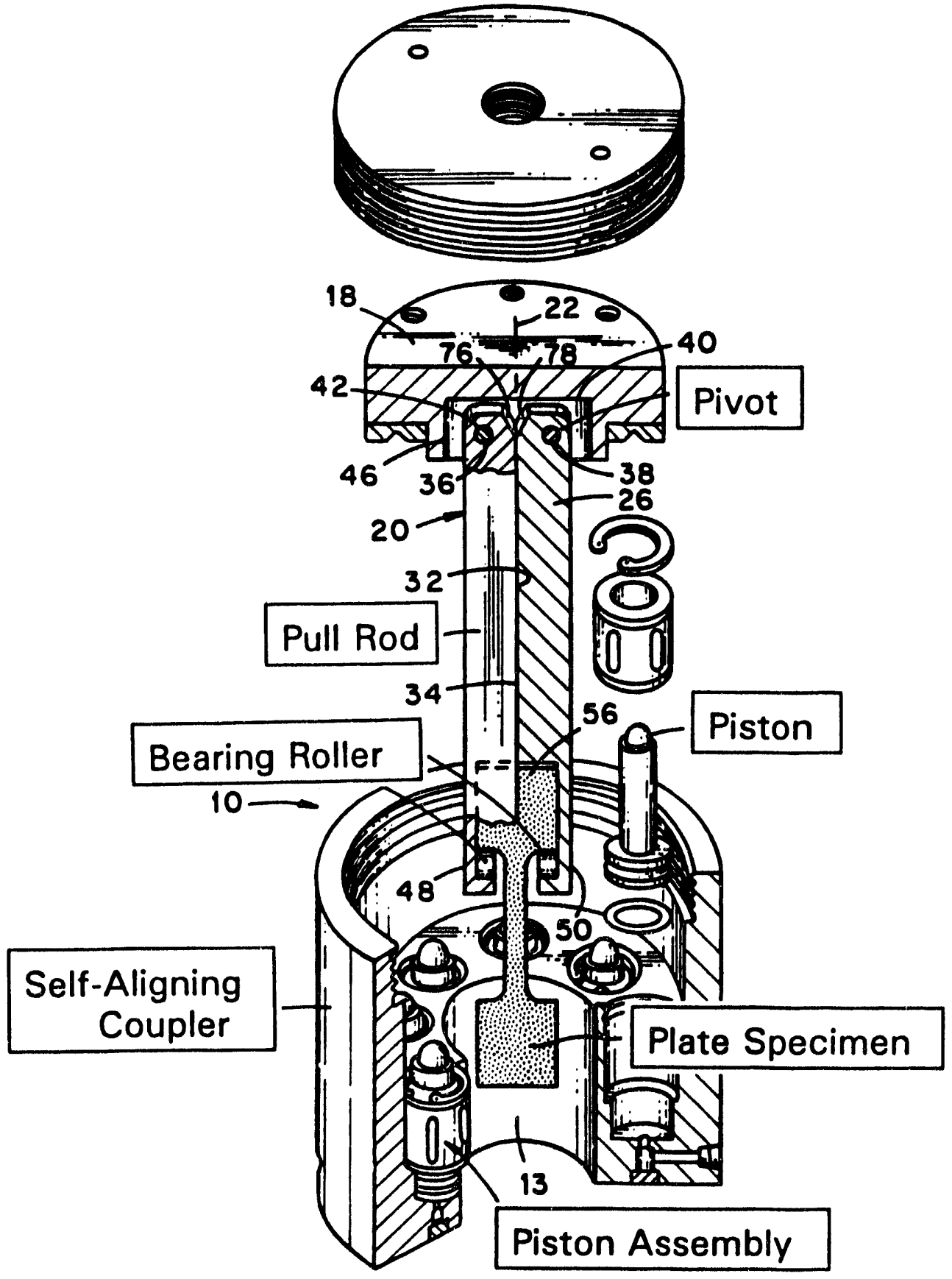

Fig. 1. A patented apparatus for tensile testing plate-type ceramic specimens. 

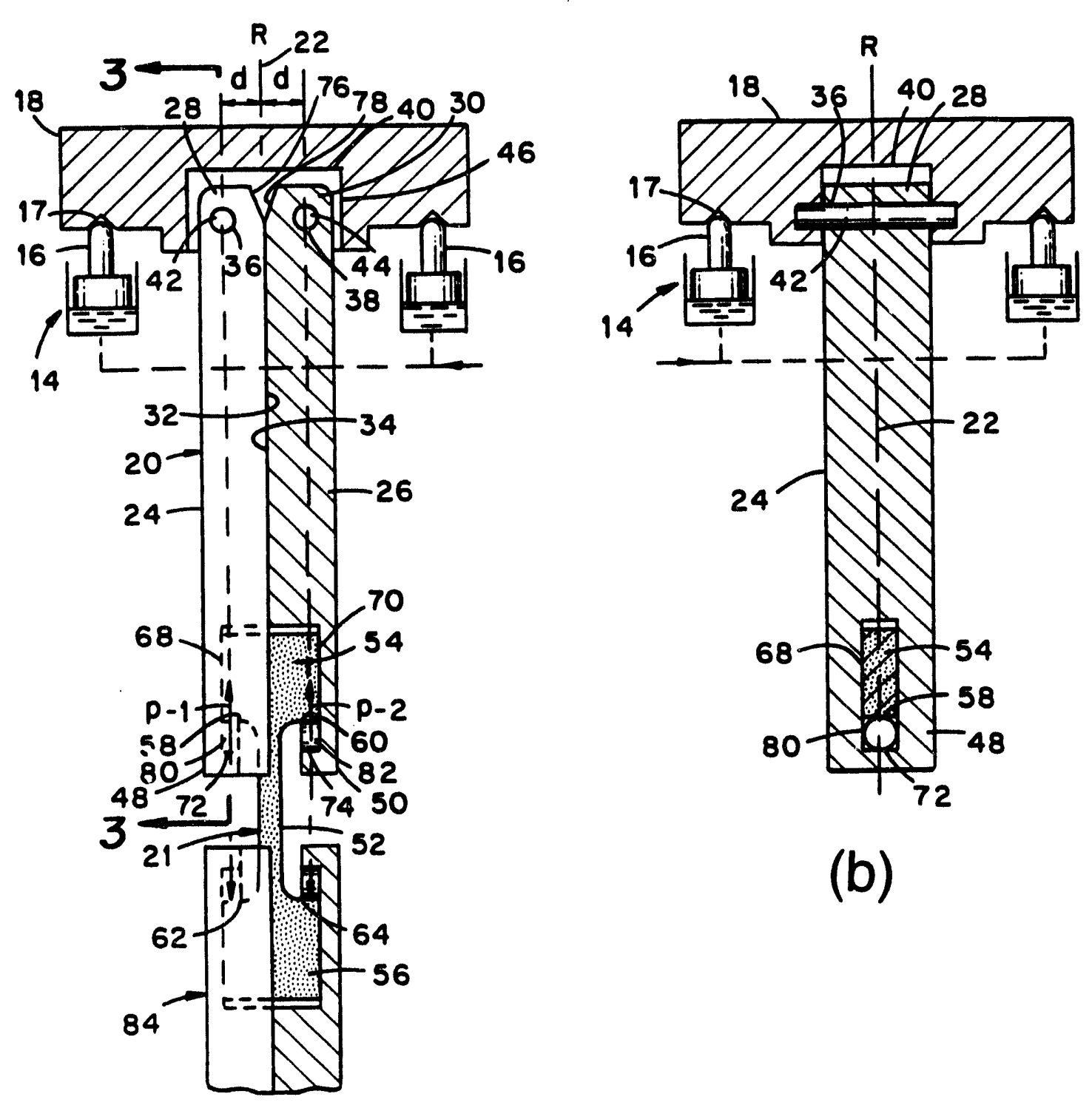

(a)

(b)

Fig. 2. A schematic showing the operational principle of the tensile testing apparatus: (a) front view and (b) view of cross-section 3-3 as indicated in (a). 


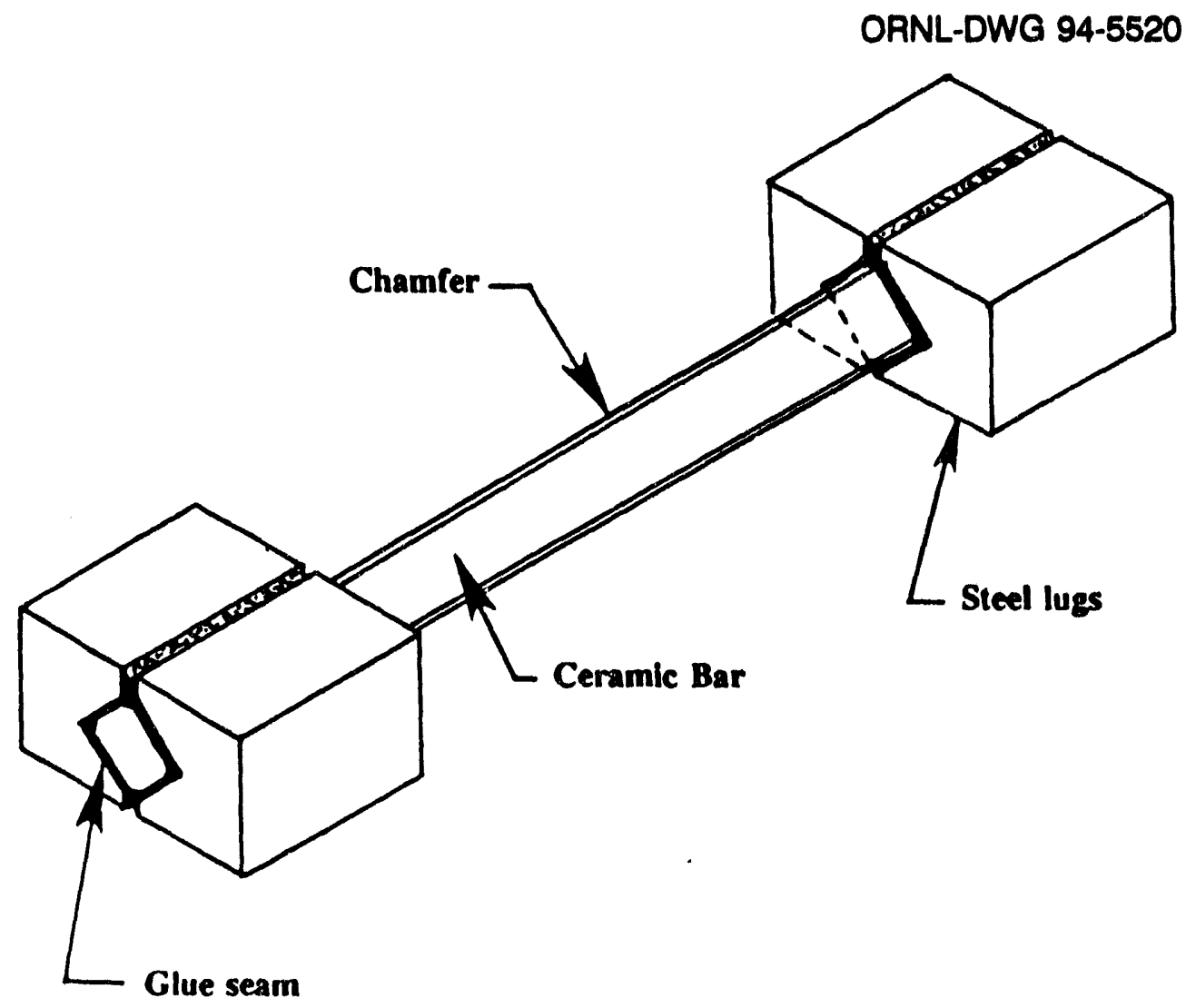

Fig. 3. A rod ceramic specimen for tensile testing.

size, which can significantly reduce the cost of conducting tensile testing of ceramic materials compared to that of using large buttonhead specimens.

\section{Cyclic fatique of $\mathrm{SIC}_{W} / \mathrm{Al}_{2} \mathrm{O}_{3}$ (CERCOM PAD-AS34W)}

Previously, we showed that the addition of $\mathrm{SiC}$ whiskers in $\mathrm{Al}_{2} \mathrm{O}_{3}$ can raise the room-temperature tensile strength of monolithic $\mathrm{Al}_{2} \mathrm{O}_{3}$ by $50 \%$ and fatigue strength in the high-cycle range by a factor of two. However, the strengthening effects diminish as temperature increases to $1200^{\circ} \mathrm{C}$ (see Fig. 4). The degenerative temperature at which the strengthening effects start to diminish is not known. This information is important to designers so that they can set the limiting temperature for applications and establish the design stress allowable.

To fill the information gap, cyclic fatigue testing at $1000^{\circ} \mathrm{C}$ was initiated as a starting point since little is known about the degenerate temperature of the composite material. All testing was performed in cyclic tension-tension using a constant-amplitude, triangular waveform with a stressing rate of $21,000 \mathrm{MPa} / \mathrm{min}$, as shown in Fig. $5(a)$. The cyclic load may be increased intermittently in small steps after completing a large block of cycles at each peak stress, as shown in Fig. $5(b)$. Since neither the tensile strength nor fatigue strength of the composite material at $1000^{\circ} \mathrm{C}$ is known, a specimen was first cycled to the 
ORNL-DWG 92-15418R2

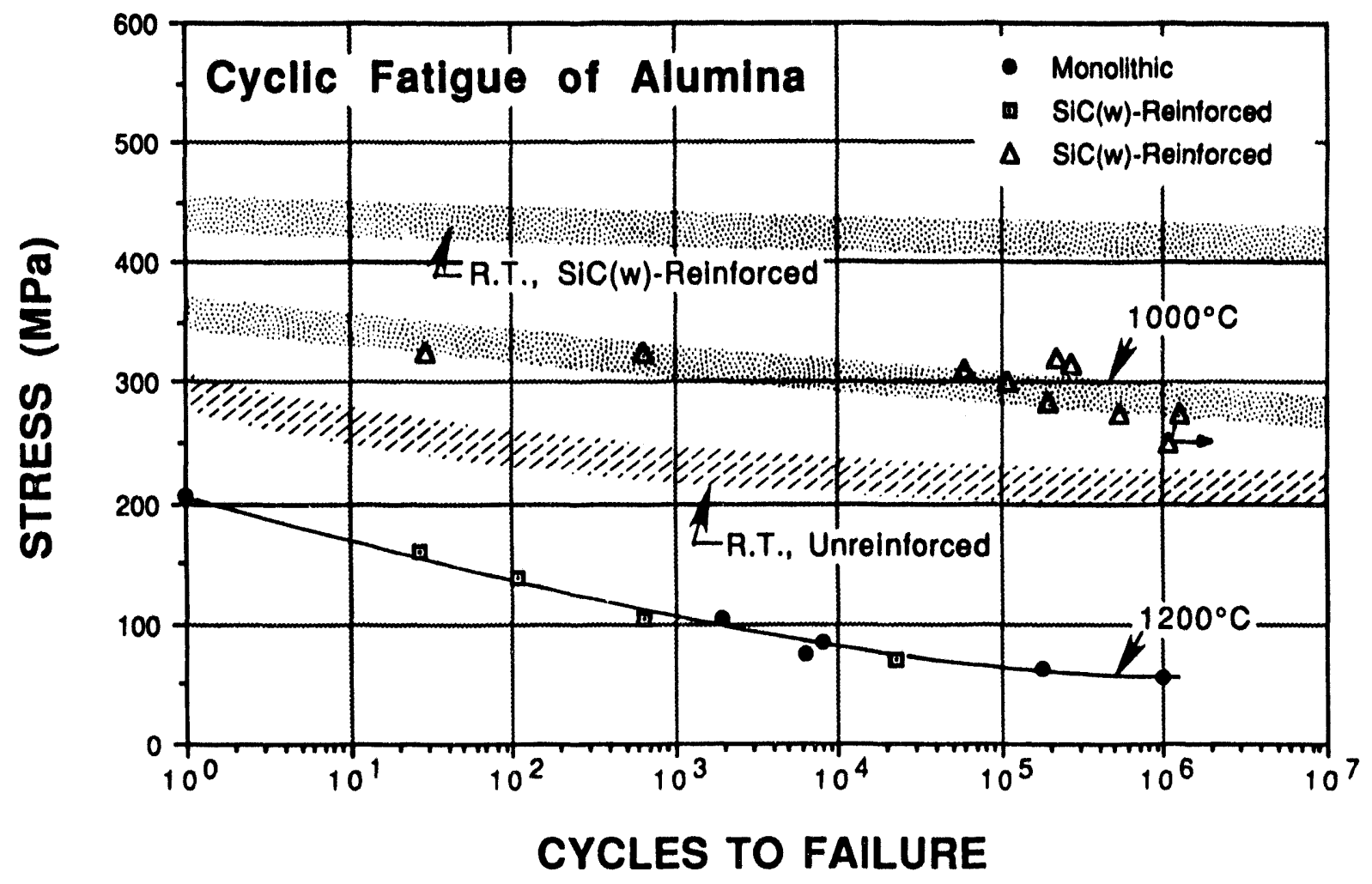

Fig. 4. Cyclic fatigue behavior of monolithic $\mathrm{Al}_{2} \mathrm{O}_{3}$ and $\mathrm{SiC}$ whisker-reinforced $\mathrm{Al}_{2} \mathrm{O}_{3}$ matrix composite materials tested at room and elevated temperatures.

peak stress of $250 \mathrm{MPa}$ as a starting point, which was about the midpoint between that of the room-temperature and $1200^{\circ} \mathrm{C}$ fatigue strengths. The peak stress was ralsed to $275 \mathrm{MPa}$ after completing a first block of $\sim 10^{6}$ cycles. The specimen failed after completing an additional block of 194,000 cycles, bringing the cyclic life to a total of $1.256 \times 10^{6}$ cycles to failure.

Subsequently, eight fatigue tests at $1000^{\circ} \mathrm{C}$ were conducted at various levels of peak cyclic stresses above $250 \mathrm{MPa}$. Results are summarized in Table 1, and data are plotted in Fig. 4. Because of the data scatter, the fatigue data are bracketed by a narrow scatter band. The limited information indicates that $\mathrm{SiC}_{\mathrm{w}} / \mathrm{Al}_{2} \mathrm{O}_{3}$ at $1000^{\circ} \mathrm{C}$ retained about 60 to $70 \%$ of its room-temperature fatigue strength. Uniortunately, no fatigue data for monolithic $\mathrm{Al}_{2} \mathrm{O}_{3}$ at $1000^{\circ} \mathrm{C}$ are avallable for comparison at this time. However, the beneficial effects of whisker reinforcement are clearly discernable when the $1000^{\circ} \mathrm{C}$ fatigue data for the $\mathrm{SiC}_{w} / \mathrm{Al}_{2} \mathrm{O}_{3}$ are compared with thes room-temperature fatigue curve of the monolithic $\mathrm{Al}_{2} \mathrm{O}_{3}$.

\section{Creep testing of NT-154 $\mathrm{Si}_{3} \mathrm{~N}_{4}$}

Three ongoing creep tests on NT-154 have been performing well with no indication of imminent failure. The status of the ongoing tests, as of this date, is as follows: 


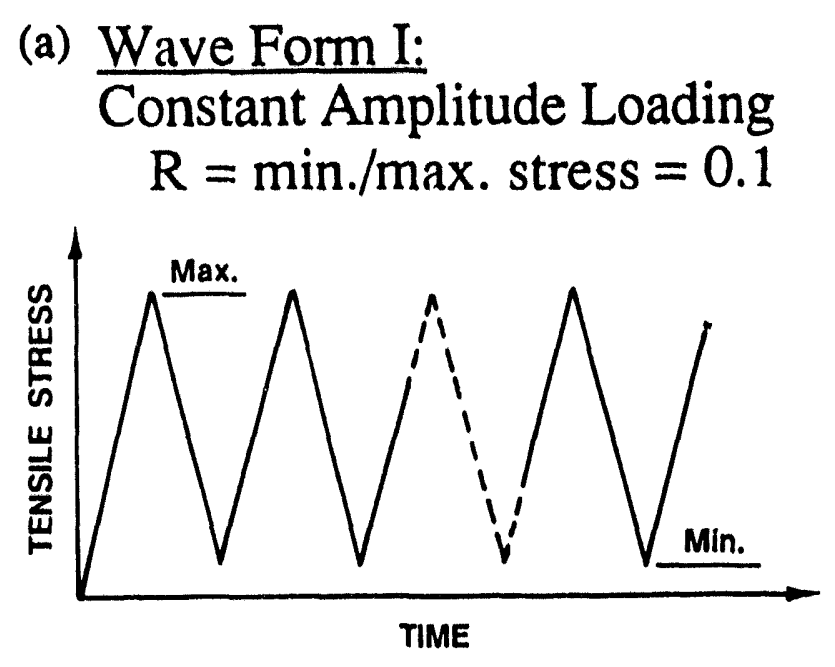

(b) Wave Form II:

Increasing Multiple-Step Loading

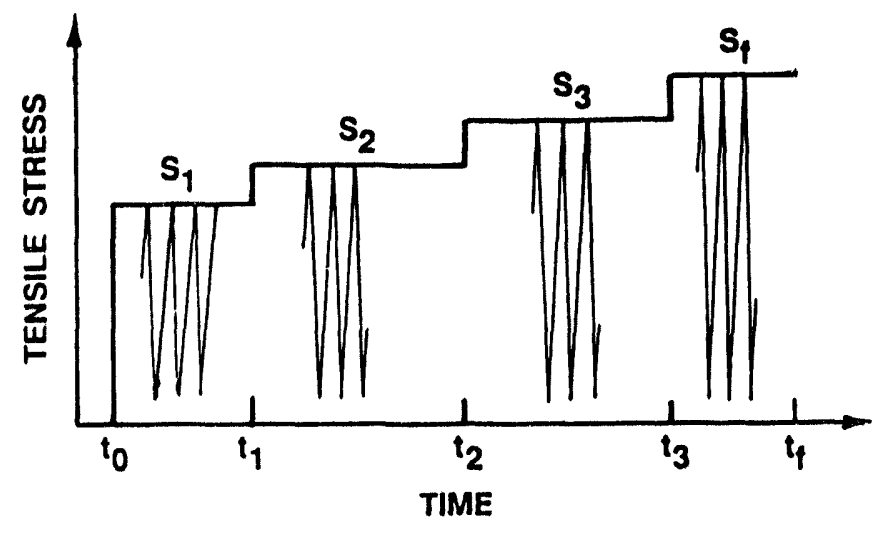

Fig. 5. Wave forms used in cyclic fatigue tests.

Specimen 20-56: The test is continuing at $1250^{\circ} \mathrm{C} / 175 \mathrm{MPa}$ and has accumulated a total of $0.85 \%$ strain after $21,000 \mathrm{~h}$ ( $\sim 2.5$ years) of testing, probably the longest creep test having been reported for $\mathrm{NT}^{-154} \mathrm{Si}_{3} \mathrm{~N}_{4}$ (Fig. 6). The creep rate is about $1.7 \times 10^{-11} \mathrm{~s}^{-1}$ and has been steady for the last $5,000 \mathrm{~h}$ of testing despite a brief interruption due to a power outage at $t=16,000 \mathrm{~h}$.

Specimen 20-00: The test is continuing at $1250^{\circ} \mathrm{C}$ under a constant stress of $150 \mathrm{MPa}$. The specimen has accumulated a total of about $0.5 \%$ strain after about $17,000 \mathrm{~h}$ ( $\sim 2$ years) of testing (Fig. 7). This test was also briefly interrupted by an unexpected power outage at $t \sim 12,200 \mathrm{~h}$. The specimen was creoping at a fast pace initially for $\sim 2500 \mathrm{~h}$, but the creep rate has decreased to $2.55 \times 10^{-11} \mathrm{~s}^{-1}$ during the last 
Table 1. Results of cyclle fatigue tests on SIC whisker-reinforced alumina tested at $1000^{\circ} \mathrm{C}$

\begin{tabular}{|c|c|c|c|c|c|}
\hline $\begin{array}{c}\text { Specimen } \\
\text { number }\end{array}$ & $\begin{array}{c}\text { Loading } \\
\text { sequence }\end{array}$ & $\begin{array}{c}\text { Cyclic } \\
\text { stress } \\
\text { (MPa) }\end{array}$ & $\begin{array}{c}\text { \% of } \\
\text { Fracture } \\
\text { strength }\end{array}$ & $\begin{array}{c}\text { Number of } \\
\text { cycles at } \\
\text { intermediate } \\
\text { loading }\end{array}$ & $\begin{array}{c}\text { Number of } \\
\text { cycles to } \\
\text { fallure }\end{array}$ \\
\hline B-5-1 & 1 & 250 & 68 & $1,062,857$ & \\
\hline B-5-2 & 1 & 275 & 75 & & $1,256,763$ \\
\hline B-5-3 & 1 & 285 & 78 & & 529,162 \\
\hline B-5-4 & 1 & 300 & 82 & & 191,265 \\
\hline B-5-5 & 1 & 310 & 85 & & 106,983 \\
\hline B-5-6 & 1 & 325 & 89 & & 58,159 \\
\hline B-5-7 & 1 & 315 & 86 & & 266,883 \\
\hline B-5-8 & 1 & 320 & 88 & & 220,993 \\
\hline B-4-1 & 1 & 325 & 89 & & 645 \\
\hline
\end{tabular}

ORNL-DWG 91-116014R5

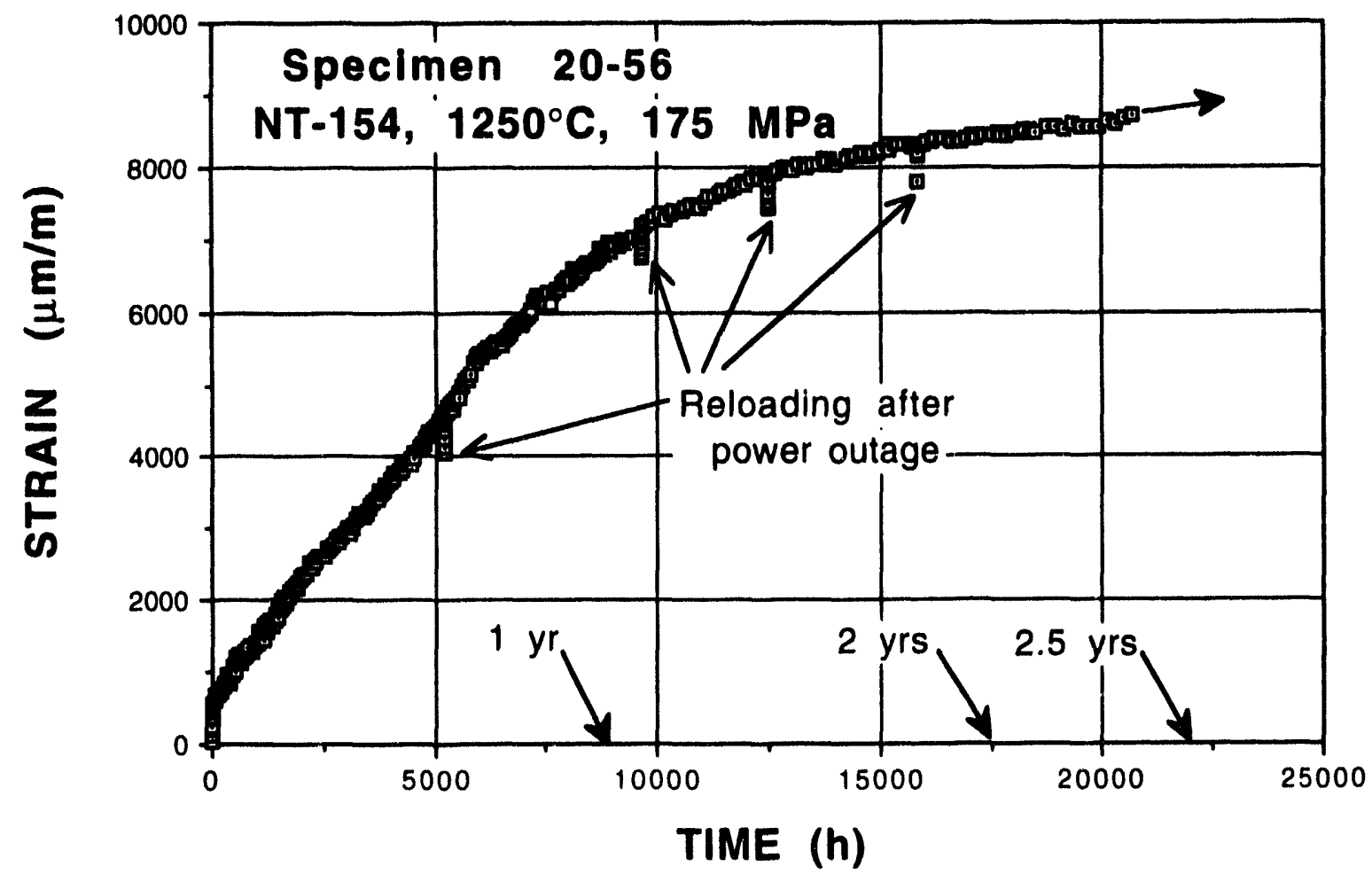

Fig. 6. Creep curve of NT-154 $\mathrm{Si}_{3} \mathrm{~N}_{4}$ (specimen 20-56) tested at $1250^{\circ} \mathrm{C}$ under an applied stress of $175 \mathrm{MPa}$. 
ORNL-DWG 91-16681R5

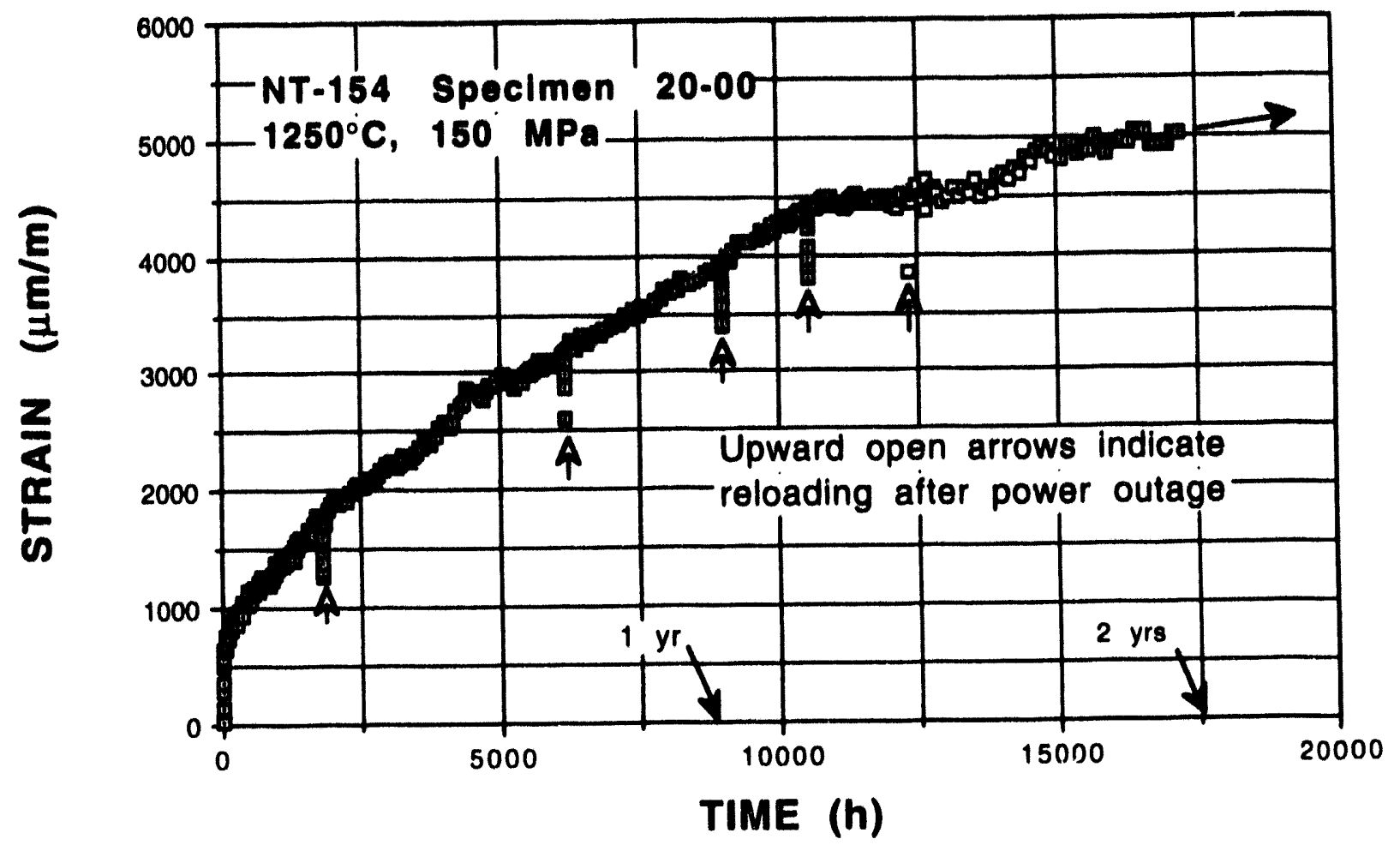

Fig. 7. Creep curve of $\mathrm{NT}_{-154} \mathrm{Sl}_{3} \mathrm{~N}_{4}$ (specimen 20-00) tested at $1250^{\circ} \mathrm{C}$ under an applied stress of $150 \mathrm{MPa}$.

$2500 \mathrm{~h}$ of testing. The creep curve appears to have fallen back on the track as if no Interruptions had occurred.

Specimen 20-32: The specimen has been tested at $1250^{\circ} \mathrm{C}$ under a constant stress of $150 \mathrm{MPa}$ for about $10,000 \mathrm{~h}$ since the stress was reduced from the earlier testing condition at $175 \mathrm{MPa}$ (Fig. 8). The total test time to date is $13,000 \mathrm{~h}$ ( $\sim 1.5$ years). Since the last power outage at $t=12,500 \mathrm{~h}$, the creep strain rate may have slowed down slightly, but the segment of the creep curve after the reloading was too short to confirm the observation.

\section{Creep testing of $\mathrm{GN}-10 \mathrm{Si}_{3} \mathrm{~N}_{4}$}

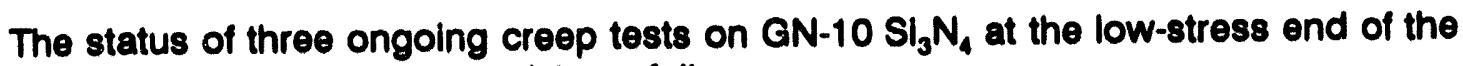
creep-rupture range (long-term tests) is as follows:

Specimen 89367-1-2: The specimen has been tested at $1200^{\circ} \mathrm{C}$ and $125 \mathrm{MPa}$ for $6400 \mathrm{~h}$ with a total creep strain of $0.345 \%$, and the test is continuing. The erratic creep behavior, which exhibited an intermittent strain riser and recovery reported previously, reoccurred with a big dip during the last $1000 \mathrm{~h}$ of testing (Fig. 9). The reason for the severe strain recovery over a long period of time is not known at this time. However, the total creep strain has recovered to the level that apparently will fall on the track of the purported creep curve. 
ORNL-DWG 92-14551R3

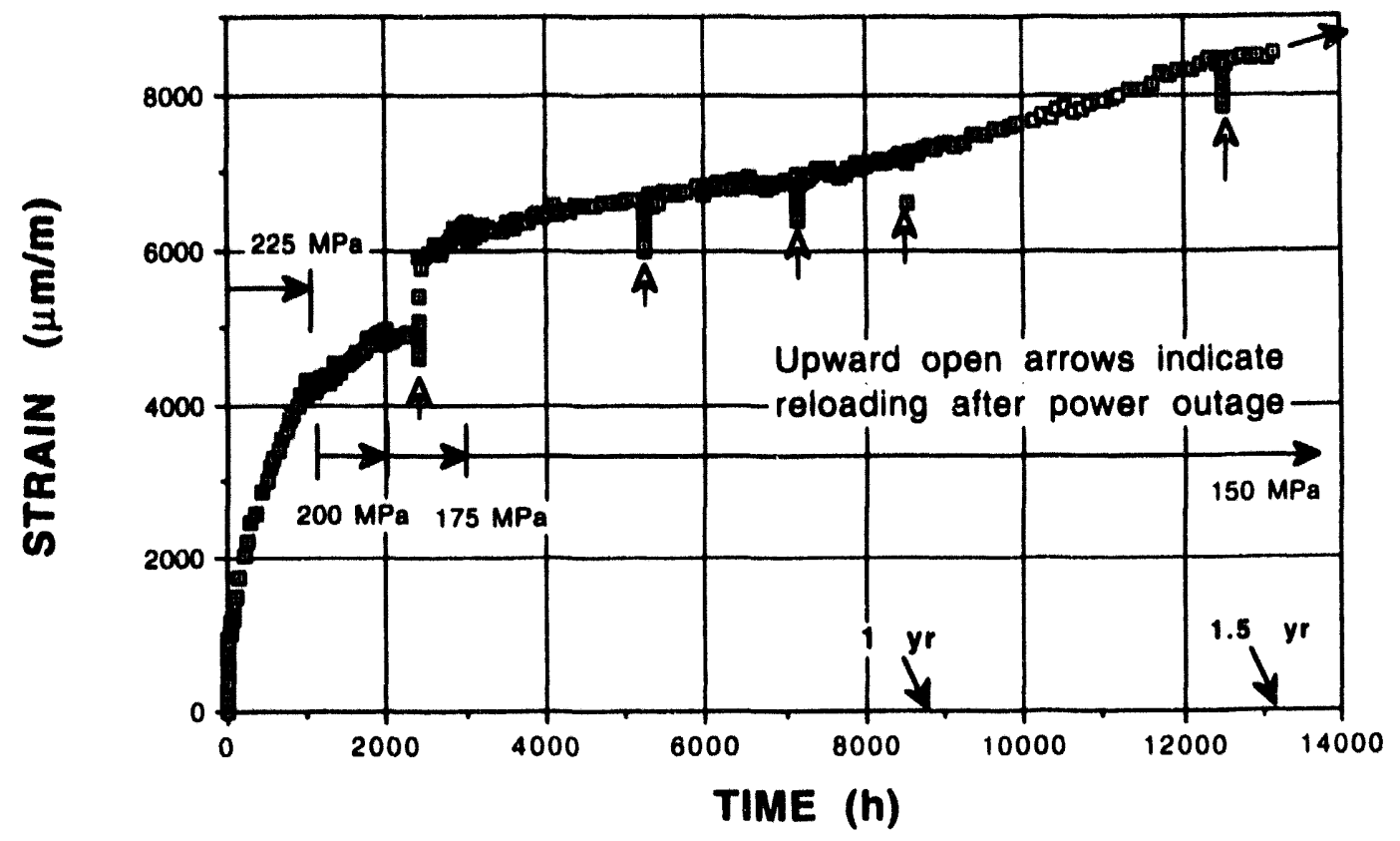

Fig. 8. Creep curve of $\mathrm{NT}-154 \mathrm{SI}_{3} \mathrm{~N}_{4}$ (specimen 20-32) tested at $1250^{\circ} \mathrm{C}$ under step-down loading conditions. The specimen was tested initially at $225 \mathrm{MPa}$ followed by partial unloading in steps of $25 \mathrm{MPa}$ at the end of each $1000 \mathrm{~h}$ of testing until the applied stress decreased to $150 \mathrm{MPa}$.

ORNL-DWG 93-8286R1

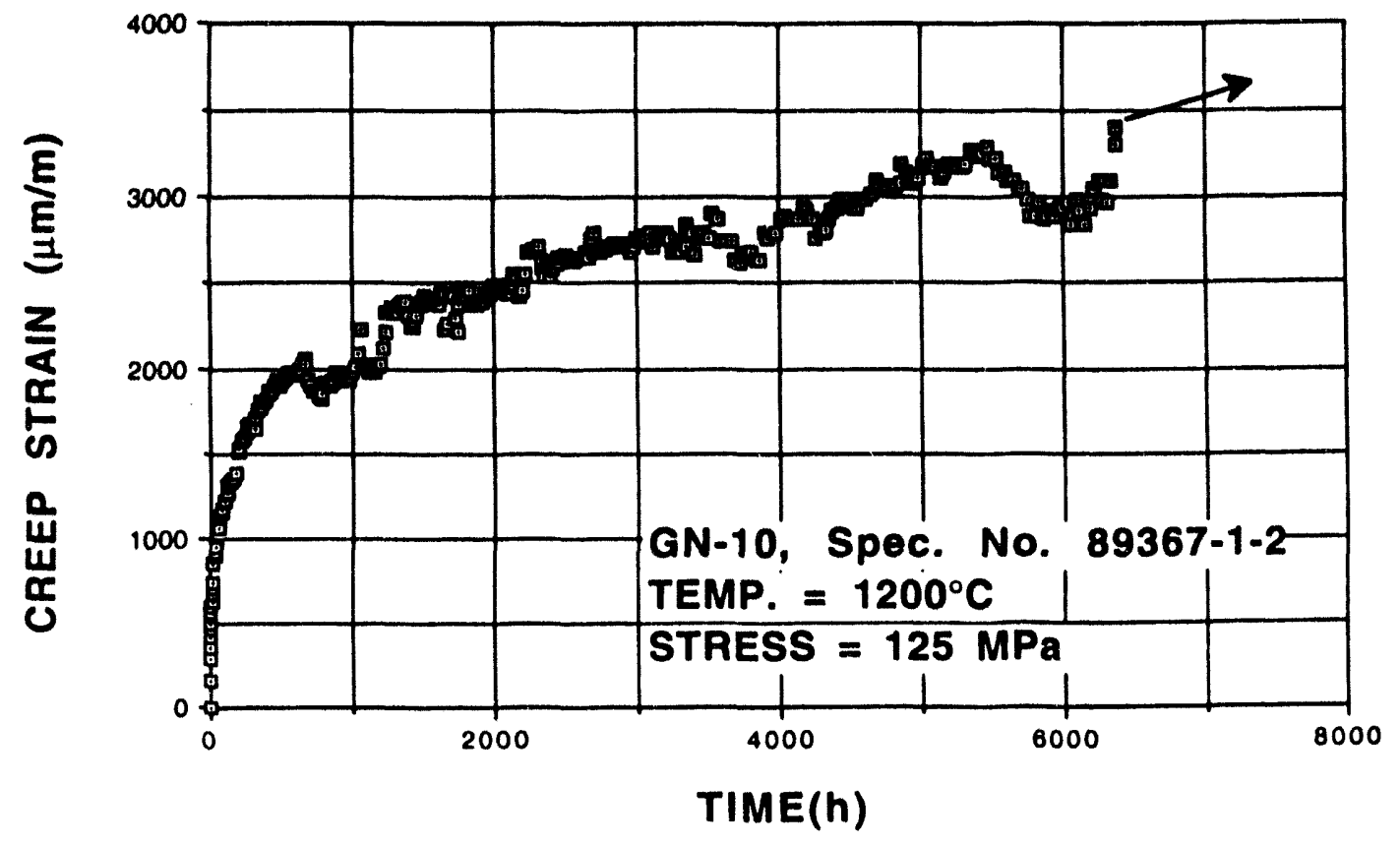

Fig. 9. Creep curve of $\mathrm{GN}-10 \mathrm{Si}_{3} \mathrm{~N}_{4}$ (specimen 89367-1-2) tested at $1200^{\circ} \mathrm{C}$ with an applied stress of $125 \mathrm{MPa}$. The severe strain recovery over a long period of time $(\sim 1000 \mathrm{~h})$ is believed to be a manifestation of internal changes in the material and was not caused by external factors such as fluctuations of amblent temperature. 
Specimen 89387-1-3: This specimen has been tested at $1150^{\circ} \mathrm{C}$ and $150 \mathrm{MPa}$ for nearly $6000 \mathrm{~h}$ of testing. The creep behavior was very erratic during the initial $3000 \mathrm{~h}$ (Fig. 10). Since then, there was a period of strain riser between $t=4000$ to $4500 \mathrm{~h}$. Otheiwise, the specimen appeared to have been deforming consistently with a creep rate of about $9 \times 10^{-11} 8^{-1}$.

Specimen GCC-14: This specimen is being tested at $1260^{\circ} \mathrm{C}$ with an applied stress of $80 \mathrm{MPa}$ (Fig. 11). The specimen has accumulated a total creep strain of 1.4\% after $1500 \mathrm{~h}$ of testing. The last haff of the creep curve shows the creep behavior was reasonably steady at a rate of $1.53 \times 10^{-6} \mathrm{~s}^{-1}$.

Three creep tests were completed on $\mathrm{GN}-10 \mathrm{Sl}_{3} \mathrm{~N}_{4}$, and test results are discussed in the following:

Specimen 89367-1-4: Testing of this specimen was successfully completed to rupture with a total creep strain of $0.41 \%$ and time to fallure of $2137 \mathrm{~h}$ (Fig. 12). This test was intended to examine whether the unstable creep behavior observed in the above test was characteristic of $\mathrm{GN}-10$ at $1150^{\circ} \mathrm{C}$ or due to the magnitude of applied stress. The tost was performed at the same temperature of $1150^{\circ} \mathrm{C}$ but at a higher applied stress of $200 \mathrm{MPa}$. Test results showed a smooth creep curve with primary creep ending at $\sim 800 \mathrm{~h}$ followed by steady-state creep with a creep rate of $1.67 \times 10^{-10} \mathrm{~s}^{-1}$. It appears that the erratic creep behavior may be triggered when the applied stress falls below a threshold stress level that has yet to be determined.

Specimen 89367-1-1: This specimen was successfully completed with a total creep strain of $4.27 \%$ after $8350 \mathrm{~h}\left(\sim 11.5\right.$ months) of testing at $1300^{\circ} \mathrm{C}$ under a constant stress of $50 \mathrm{MPa}$ (Fig. 13). The minimum creep rate was determined to be $6.31 \times 10^{-10} \mathrm{~s}^{-1}$. Results of this and other long-term creep tests discussed in earlier sections suggest that short-term creep test data (below approximately 3000 to $5000 \mathrm{~h}$ of testing, depending on the type of ceramic material) do not provide complete creep information in view of the change in creep rate throughout its lifetime.

Specimen GCG-J2: This specimen was tested at $1300^{\circ} \mathrm{C}$ with a stress of $75 \mathrm{MPa}$ (Fig. 14). The specimen failed after $178.3 \mathrm{~h}$ of testing with a strain of $1.22 \%$ when fracture occurred. A hint of increase in creep rate was observed shortly before specimen fracture. However, it was uncertain whether the acceleration of the creep rate was the inception of tertiary creop or not.

\section{Status of milestones}

1. Completed tensile and fatigue tests on $\mathrm{SiC}_{\mathrm{W}} / \mathrm{Al}_{2} \mathrm{O}_{3}$ ceramic composite at elevated temperatures (Milestone 321416, due on July 31, 1993).

2. Completed draft report covering results obtained from stress-rupture tests on $\mathrm{GN}-10$ and NT-154 $\mathrm{Sl}_{3} \mathrm{~N}_{4}$ ceramics (Milestone 321511, due on April 30, 1993).

3. Completed tensile creep tests for microwave-annealed $\mathrm{Si}_{3} \mathrm{~N}_{4}$ at elevated temperatures (Milestone 321512, due on September 30, 1993).

\section{Publications}

1. K. C. Lu and J. L. Ding, "A Mechanical Extensometer for High Temperature Tensile Testing of Ceramics," ASTM J. Test. Eval. 21(5), 406-13 (September 1993). 
ORNL-DWG 93-10151R2

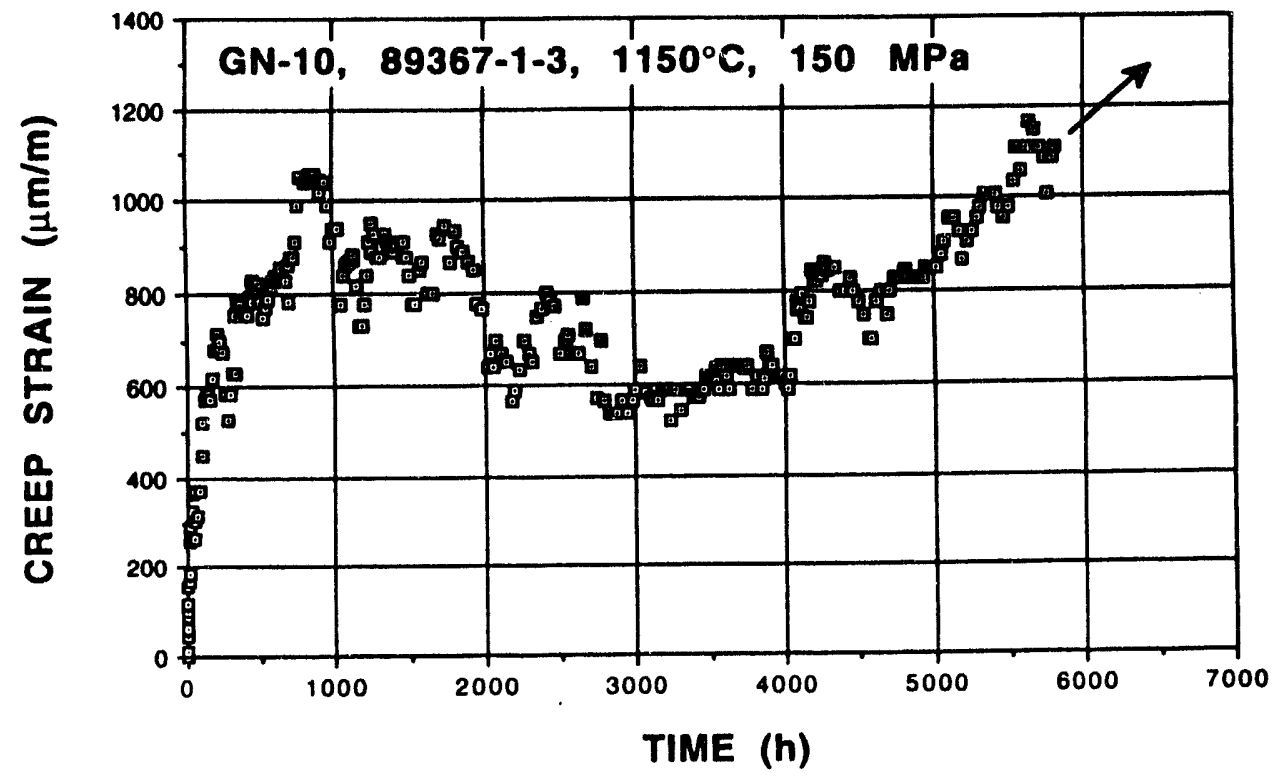

Fig. 10. Creep curve of $\mathrm{GN}-10 \mathrm{Si}_{3} \mathrm{~N}_{4}$ (specimen 89367-1-3) tested at $1150^{\circ} \mathrm{C}$ with an applied stress of $150 \mathrm{MPa}$. The creep behavior was erratic during the initial $3000 \mathrm{~h}$, but the specimen has been deforming consistently during the last $1500 \mathrm{~h}$ of testing.

ORNL-DWG 93-10154

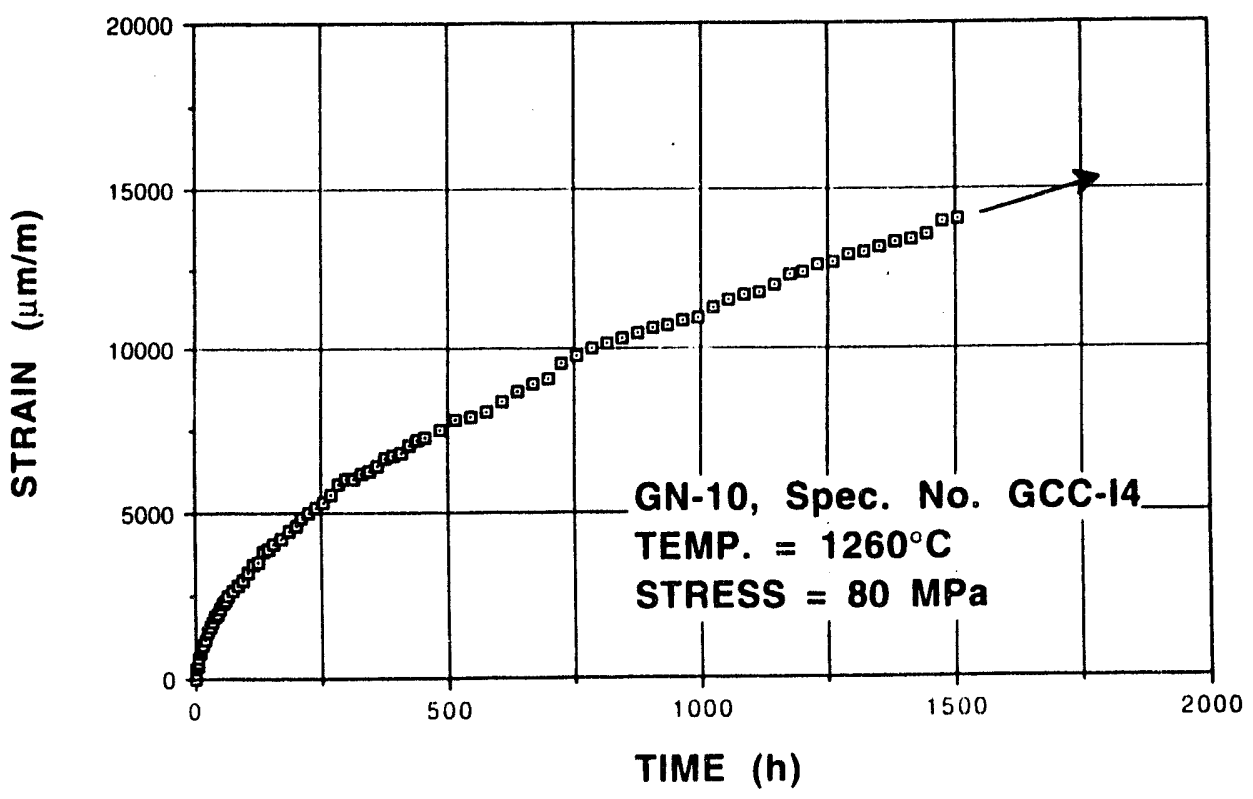

Fig. 11. Creep curve of $\mathrm{GN}-10 \mathrm{Si}_{3} \mathrm{~N}_{4}$ (specimen GCC-14) tested at $1260^{\circ} \mathrm{C}$ with an applied stress of $80 \mathrm{MPa}$. 
ORNL-DWG 93-10152R1

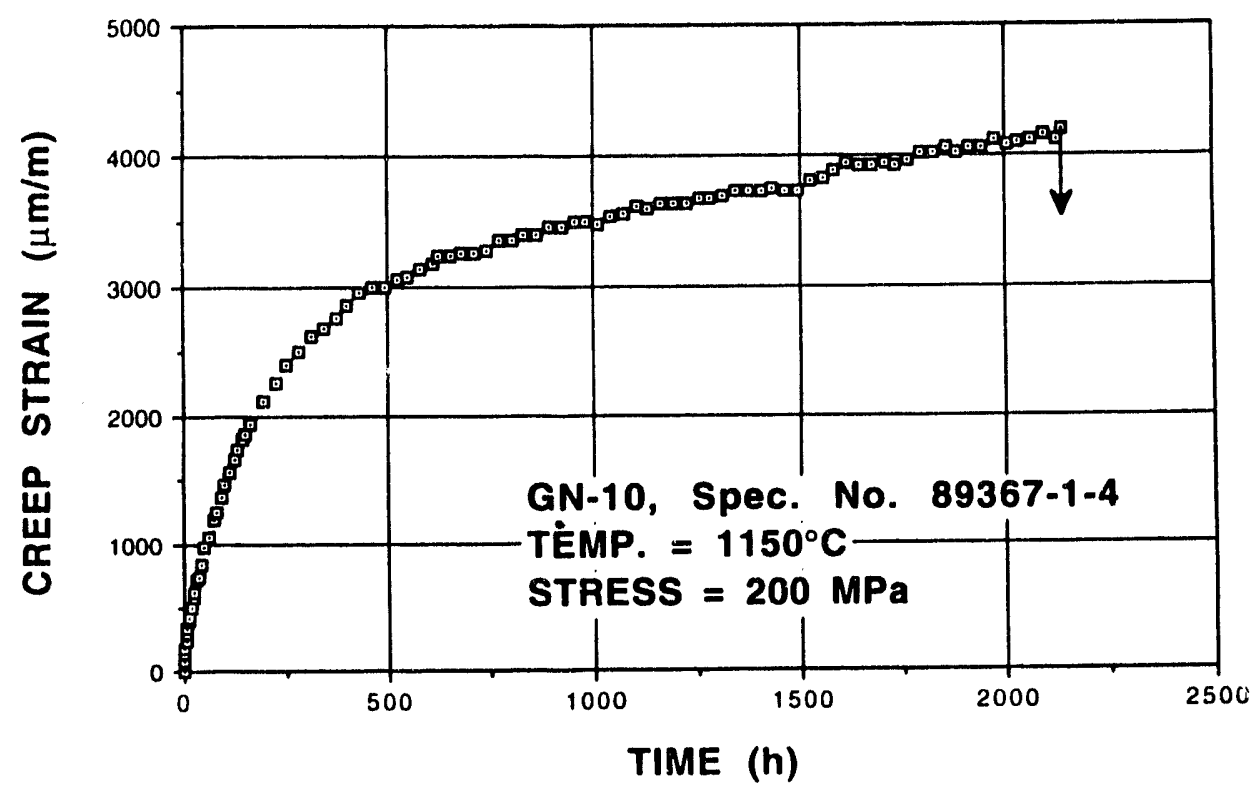

Fig. 12. Creep curve of $\mathrm{GN}-10 \mathrm{Si}_{3} \mathrm{~N}_{4}$ (specimen 89367-1-4) tested at $1150^{\circ} \mathrm{C}$ with an applied stress of $200 \mathrm{MPa}$. The erratic creep behavior exhibited in Fig. 10 was not observed for this specimen.

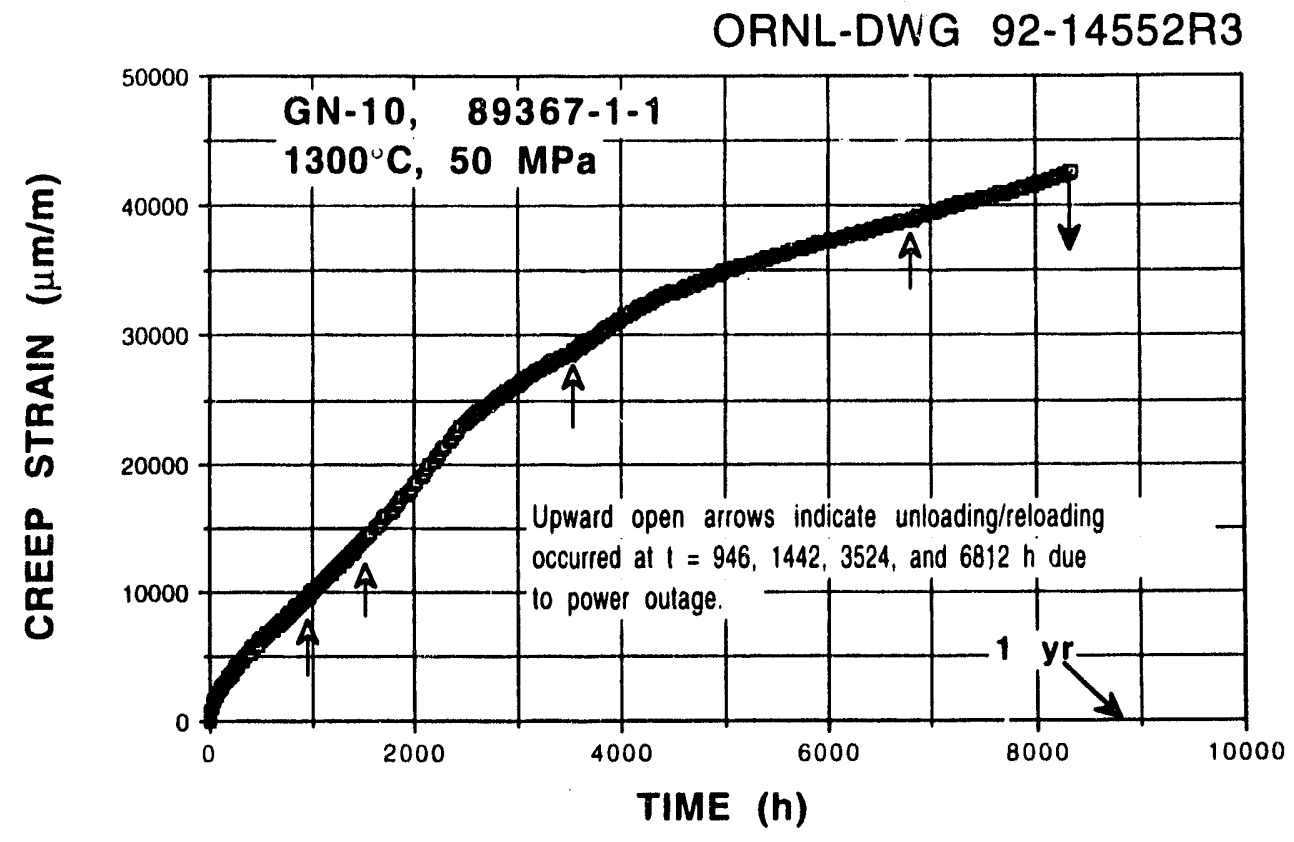

Fig. 13. Creep curve of $\mathrm{GN}-10 \mathrm{Si}_{3} \mathrm{~N}_{4}$ (specimen 89367-1-1) tested at $1300^{\circ} \mathrm{C}$ with an applied stress of $50 \mathrm{MPa}$. 
ORNL-DWG 93-10153

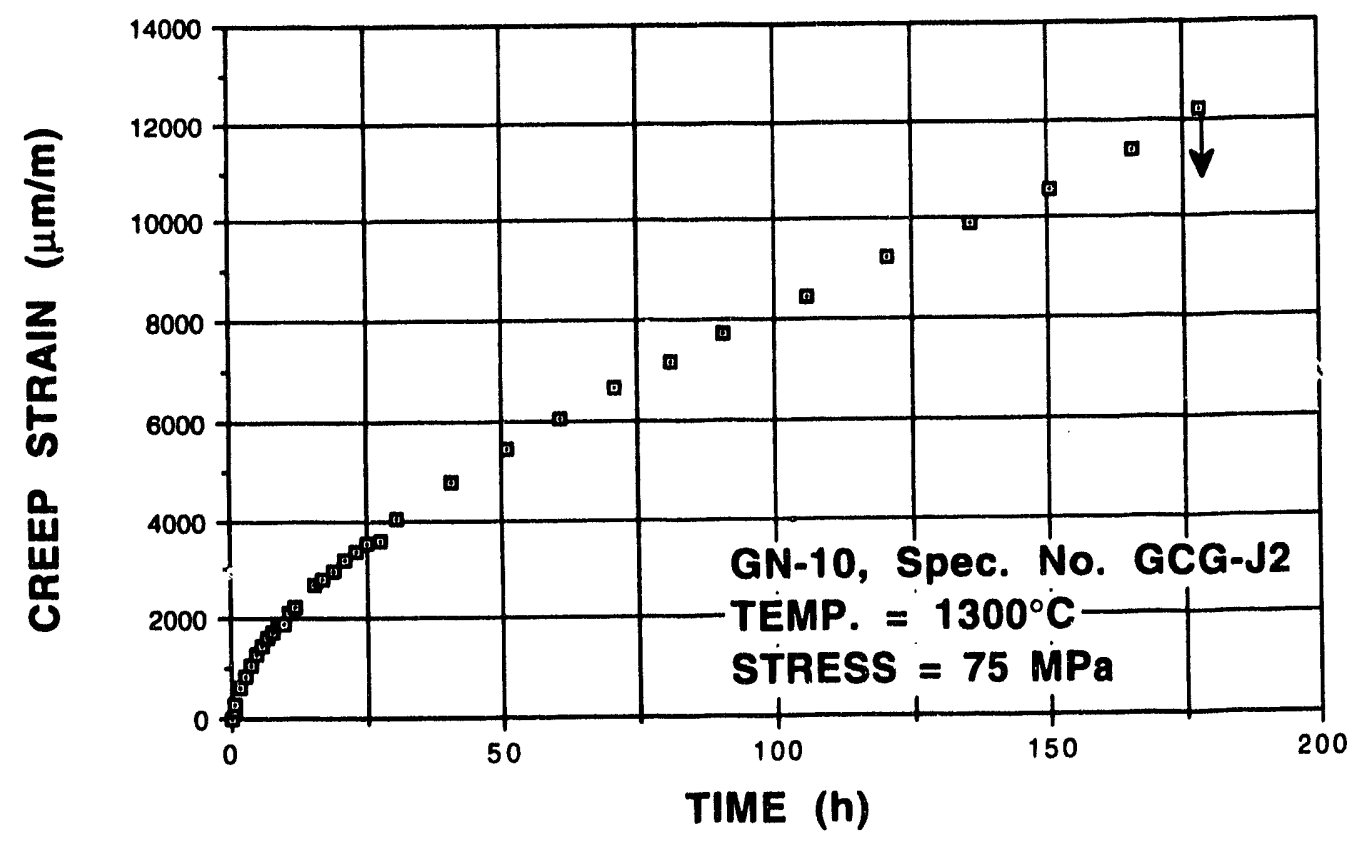

Fig. 14. Creep curve of $\mathrm{GN}-10 \mathrm{Si}_{3} \mathrm{~N}_{4}$ (specimen GCG-J2) tested at $1300^{\circ} \mathrm{C}$ with an applied stress of $75 \mathrm{MPa}$. 
Botor Data Base Generation

A. A. Wereszczak, M. K. Ferber, T. P. Kirkland, and C.-K. Lin (ORNL)

\section{Objective/scope}

The goal of the proposed research program is to systematically study the tensile strength of a silicon nitride ceramic as a function of temperature and time in an air environment. Initial tests will be aimed at measuring the statistical parameters characterizing the strength distribution of three sample types (two tensile specimens and one flexure specimen). The resulting data will be used to examine the applicability of current statistical models as well as sample geometries for determining the strength distribution.

In the second phase of testing, stress-rupture data will be generated by measuring fatigue life at a constant or cyclic stress. The time-dependent deformation will also be monitored during testing so that the extent of high-temperature creep may be ascertained. Tested samples will be thoroughly characterized using established ceramographic, scanning electron microscopy (SEM), and transmission electron microscopy (TEM) techniques. A major goal of this effort will be to better understand the microstructural aspects of high-temperature failure including:

1. extent of slow crack growth,

2. evolution of cavitation-induced damage and fracture,

3. transition between brittle crack extension and cavitation-induced growth,

4. crack blunting, and

5. the evolution and role of oxidation-assisted damage.

The resulting stress-rupture data will be used to examine the applicability of a generalized fatigue-life (slow crack growth) model. If necessary, model refinements will be implemented to account for both crack blunting and creep damage effects. Insights obtained from the characterization studies will be crucial for this modification process. Once a satisfactory model is developed, separate stressrupture (confirmatory) experiments will be performed to examine the model's predictive capability. Consequently, the data generated in this program will not only provide a critically needed base for component utilization in automotive gas turbines, but also facilitate the development of a design methodology for hightemperature structural ceramics.

\section{Iechnical progress}

In the previous reporting period, the evaluation of cyclic fatigue properties of the PY6 silicon nitride was conducted under cyclic tension-tension loading and described. The previously reported cyclic fatigue results indicated that cyclic tension-tension loading caused less damage than static tension loading as evidenced by the longer failure time under cyclic loading versus static loading with the 
same maximum applied stresses. There is sparse evidence of literature that has reported the tension-compression fatigue properties of advanced ceramics at elevated temperatures, which are of practical importance in the design of ceramic engine components.

During the present reporting period, the evaluation of an existing servohydraulic test frame for performance of cyclic tension-compression fatigue testing was conducted. The test frame contains a pair of grips specially designed for tension-compression loading. They have a built-in alignment capability that enables the user to minimize the axial and eccentric bending. Taking advantage of this capability requires that the buttonhead tensile specimen be prepared with eight strain gages bonded to its gage section. A cyclic tension-compression fatigue test using an alumina specimen at room temperature was successfully completed, with failure occurring in the gage section. This test was conducted with a $1-\mathrm{Hz} \sin e$ wave and a stress ratio $R=-1$. Load was applied in tension-compression from low to high stress level in inultiple steps. The specimen was initially cycled at $\pm 100 \mathrm{MPa}$ for 152,000 cycles $(42.2 \mathrm{~h})$. The cyclic stress was then increased to $\pm 125 \mathrm{MPa}$ and cycled for another 437,000 cycles $(121.4 \mathrm{~h})$ without failure. The stress level was raised again to $\pm 150 \mathrm{MPa}$, and the specimen finally failed at 78,481 cycles $(21.8 \mathrm{~h})$. This successful test verified the capability of the existing test frame for cyclic tension-compression testing.

Another tension-compression cyclic fatigue test was then initiated; however, it was conducted at $1200^{\circ} \mathrm{C}$. The specimen was cycled under conditions of $1 \mathrm{~Hz}$ with a stress ratio of $R=-1$. The test was initiated at $\pm 50 \mathrm{MPa}$. After 423,350 cycles $(\approx 117.6 \mathrm{~h})$, the stress was increased to $\pm 60 \mathrm{MPa}$ for 248,760 cycles $(\approx 69.1 \mathrm{~h})$, then increased to $\pm 75-\mathrm{MPa}$ for 87,380 cycles $(\approx 24.3 \mathrm{~h})$, increased to $90 \mathrm{MPa}$ for 9400 cycles $(\approx 2.6 \mathrm{~h})$, then increased to $\pm 100 \mathrm{MPa}$, where it failed during the tensile loading portion of the 6765th cycle $(\approx 1.9 \mathrm{~h})$. The specimen was loaded in an incremental fashion because it was desired to have the specimen last an appreciable amount of time while at the same time verifying that the break detection and test cessation capabilities of the instrument were satisfactorily working.

Now that the tension-compression cyclic testing capabilities have been successfully demonstrated at elevated temperatures, testing on a commercially available silicon nitride ${ }^{*}$ will be commenced. Fifty buttonhead tensile rods were delivered during the present reporting period. Ten of the specimens were strain gaged in preparation for tension-tension and tension-compression cyclic testing. Strain gaging is required of every specimen in order that tensile and compressive bending strains be minimized via suitable adjustments on the servohydraulic testing machine grips prior to testing. The motivation behind the testing of these specimens is to further characterize the behavior of slow crack growth, cavity evolution, the brittle-to-creep crack growth transition, and crack blunting in cyclic tension-tension and tension-compression stress fields. In addition to the examination of their high-temperature mechanical performance, specimens will be characterized using SEM, TEM, various chemical composition measurement techniques,

\footnotetext{
"NCX-5102, Saint-Gobain/Norton Industrial Ceramics Corporation, Northboro, MA.
} 
and $X$-ray diffraction (XRD) in order to understand these mechanisms more thoroughly.

The planned testing conditions for these specimens are shown in the test matrix in Table 1. Two temperatures combined with 5 different loading states comprise the test matrix; 5 specimens are to be tested at each of the 10 different conditions for a total of 50 specimens. Ten specimens tested under a static stress in ambient air will serve as the reference. Twenty of the remaining 40 specimens will be tested in ambient air under tension-tension $(R=0.1)$ or tension-compression $(R=-1)$ cyclic loading. The remaining 20 specimens will be tested in an inert atmosphere under static or tension-tension cyclic stressing conditions.

Three previously reported findings provided the motivation behind the planned test matrix shown in Table 1. Firstly, lifetimes have been shown to be longer in cold isostatically pressed/hot isostatically pressed (CIPed/HIPed) silicon nitride (PY6, GTE Labs., Waltham, MA) under tension-tension cyclic stressing at elevated temperatures, compared to static loading. ${ }^{1-4}$ Secondly, roomtemperature flexure strength retention was observed in this same material at $1370^{\circ} \mathrm{C}$ when tested in inert atmospheres at elevated temperatures, whereas it dramatically decreased when tested in ambient air. ${ }^{5}$ Lastly, a different dominant failure mechanism was shown to evolve for this same HIPed silicon nitride at 1260 and $1370^{\circ} \mathrm{C}$ (ref. 6). It is anticipated that the test matrix shown in Table 1 will ada further understanding of the behavior of all these phenomena and to the listed objectives above, while: (1) applying an additional tension-compression cyclic loading condition and (2) repeating the tests conducted on the PY6 material, but wholely using tension specimens for all testing.

Several of the as-received buttonhead tensile specimens contained visible spots along their machined surface and typically ranged in size between $\approx 0.4$ to $3 \mathrm{~mm}$. This HIPed silicon nitride was fabricated with $4 \mathrm{wt} \%$ yttria as a flux and is believed to lie along the $\mathrm{Si}_{3} \mathrm{~N}_{4}-\mathrm{Y}_{2} \mathrm{Si}_{2} \mathrm{O}_{7}$ tie line in the $\mathrm{Si}_{3} \mathrm{~N}_{4}-\mathrm{SiO}_{2}-\mathrm{Y}_{2} \mathrm{O}_{3}$ ternary phase diagram. Lewis has investigated analogous microstructures on a different silicon nitride and has defined these spots as $\beta-\mathrm{Y}_{2} \mathrm{Si}_{2} \mathrm{O}_{7}$ "islands" surrounded by an $\alpha-\mathrm{Y}_{2} \mathrm{Si}_{2} \mathrm{O}_{7}$ grain boundary matrix within the silicon nitride. ${ }^{7}$ These two polymorphs of $\mathrm{Y}_{2} \mathrm{Si}_{2} \mathrm{O}_{7}$ possess different densities, so their simultaneous presence likely creates local residual stresses. Lewis reported that the creation of the $\beta-\mathrm{Y}_{2} \mathrm{Si}_{2} \mathrm{O}_{7}$ "islands" was a consequence of the HIPed rods being subjected to a cooling rate that was too slow within the HIP furnace; specimens that cooled more rapidly did not contain them. The morphology of the spots in the silicon nitride being investigated in the present study has not yet been investigated; however, they are believed to be analogous to those examined by Lewis.

To examine the effect (if any) that the presence of the spots may have had on the creep performance, spotted and unspotted specimens were each tested at 125 and $140 \mathrm{MPa}$. Figure 1 illustrates the creep histories for these four specimens. For the two spotted specimens, fractography revealed that failure had originated where an "island" (spherically shaped in three dimensions) was situated at the specimen's surface. These preliminary static creep tests on the NCX-5102 silicon nitride suggests that the presence of these "islands" are somehow 
Table 1. Test matrix to be used in the testing of 50 NCX-5102 specimens

\begin{tabular}{l} 
Test type \\
\multicolumn{1}{c}{ Environment } \\
\begin{tabular}{|c|c|c|c|} 
\# of specimens & $\begin{array}{c}1260^{\circ} \mathrm{C} \\
\text { \# of specimens }\end{array}$ \\
\hline Static & Air & 5 & 5 \\
\hline Cyclic: Tens.-Tens. & Air & 5 & 5 \\
\hline Cyclic: Tens.-Comp. & Air & 5 & 5 \\
\hline Static & Inert & 5 & 5 \\
\hline Cyclic: Tens.-Tens. & Inert & 5 & 5 \\
\hline
\end{tabular}
\end{tabular}

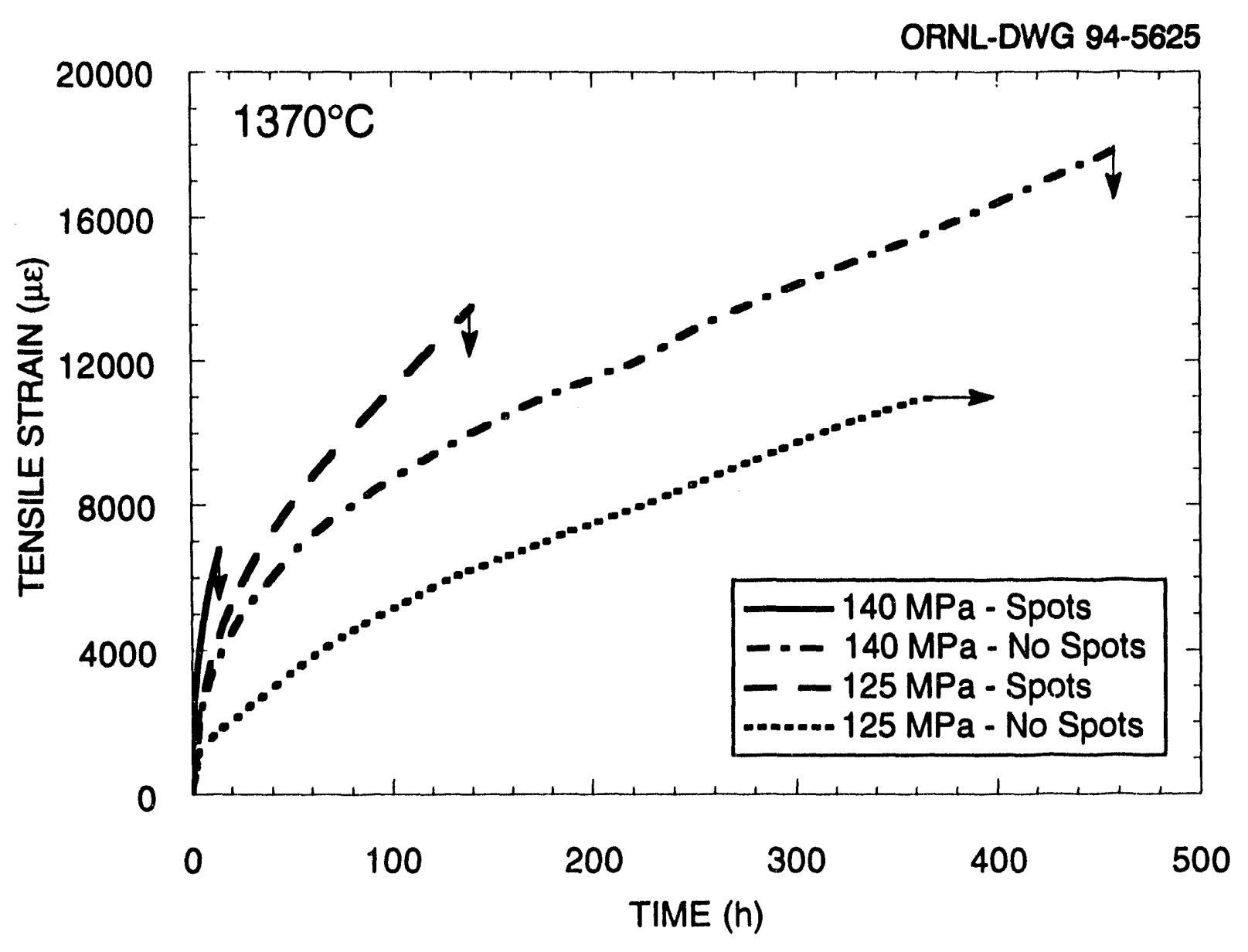

Fig. 1. Strain histories of spotted and unspotted specimens showed different creep performance (vertical arrows denote fracture; horizontal arrow denotes ongoing test). 
associated with shorter creep lifetimes and lower strains to failure. The poorer creep resistance of the spotted specimens may be due to the fact that $\rho_{\alpha} \neq \rho_{\beta}$ of the two $\mathrm{Y}_{2} \mathrm{Si}_{2} \mathrm{O}_{7}$ polymorphs. This evidence shows that the presence of these spots or "islands" introduces an additional, independent variable in the present study.

Static and cyclic testing is continuing. An environmental chamber is currently being fabricated, and it is hoped that the vendor will ship it by the end of the year. It was procured through the High Temperature Materials Laboratory (HTML) User Program and was designed to be mounted on one of the HTML's existing tensile testing machines. It will fulfill the inert atmosphere testing portion of the test matrix described in Table 1 once readied.

An additional project was initiated over the present reporting period that involved the examination of the creep performance of GN10\$ silicon nitride at $1275^{\circ} \mathrm{C}$ and a stress of $137.5 \mathrm{MPa}$ using the ORNL buttonhead specimen geometry. The results were to be compared with those previously generated at the National Institute of Standards and Technology (NIST), which has examined the creep behavior of the same batch of GN10 material with three different specimen geometries. 8 The motivation was to examine whether both laboratories would measure consistent creep histories for the same material.

Figure 2 illustrates the creep histories for the six GN10 buttonhead specimens tested for this project. Specimen A3 crept very rapidly and, consequently, had a short lifetime. Specimen B4 was the second specimen tested; however, the specimen was first subjected to a $24-\mathrm{h}$ pretest anneal at $1275^{\circ} \mathrm{C}$ prior to creep testing in an effort to anneal any present unstable grain boundary phases. It should be noted that the three specimen geometries tested at NIST are subjected to a 24-h pre-test anneal. The longer pre-test anneal time for specimen B4 decreased the overall creep rate of the GN10 while increasing the lifetime compared to that of specimen A3. However, the lifetime was still significantly shorter than those previously measured on this material at NIST for all three of their specimen geometries under these conditions. Being that the cross-sectional area of ORNL's buttonhead specimen is so much greater than that of the NIST specimens ( $31.67 \mathrm{~mm}^{2}$ compared to $5 \mathrm{~mm}^{2}$ ), a longer pre-test anneal was conducted in order to examine whether or not the "stabilization" of the grain boundary phases in this material, produced by the anneal at $1275^{\circ} \mathrm{C}$, was a consequence of some diffusional phenonemon. If this process was diffusional dependent, then the larger cross section of ORNL's buttonhead tensile specimen would require longer pre-test anneal times than the three NIST tensile specimen geometries in order to produce the same creep behavior in the GN10 material.

The longer pre-testing anneal time was found to be necessary for the ORNL buttonhead specimen to produce similar creep rates in the NIST tensile specimen geometries. The last four buttonhead tensile specimens (D4, D3, B3, and A4) were subjected to a $196-\mathrm{h}$ pre-tiest anneal at $1275^{\circ} \mathrm{C}$ prior to loading. Of these four, three showed remarkable consistency in creep performance (specimens D4, D3, and

\$ GN10, Garrett Ceramic Components Division, Allied-Signal Aerospace Company, Torrance, CA. 


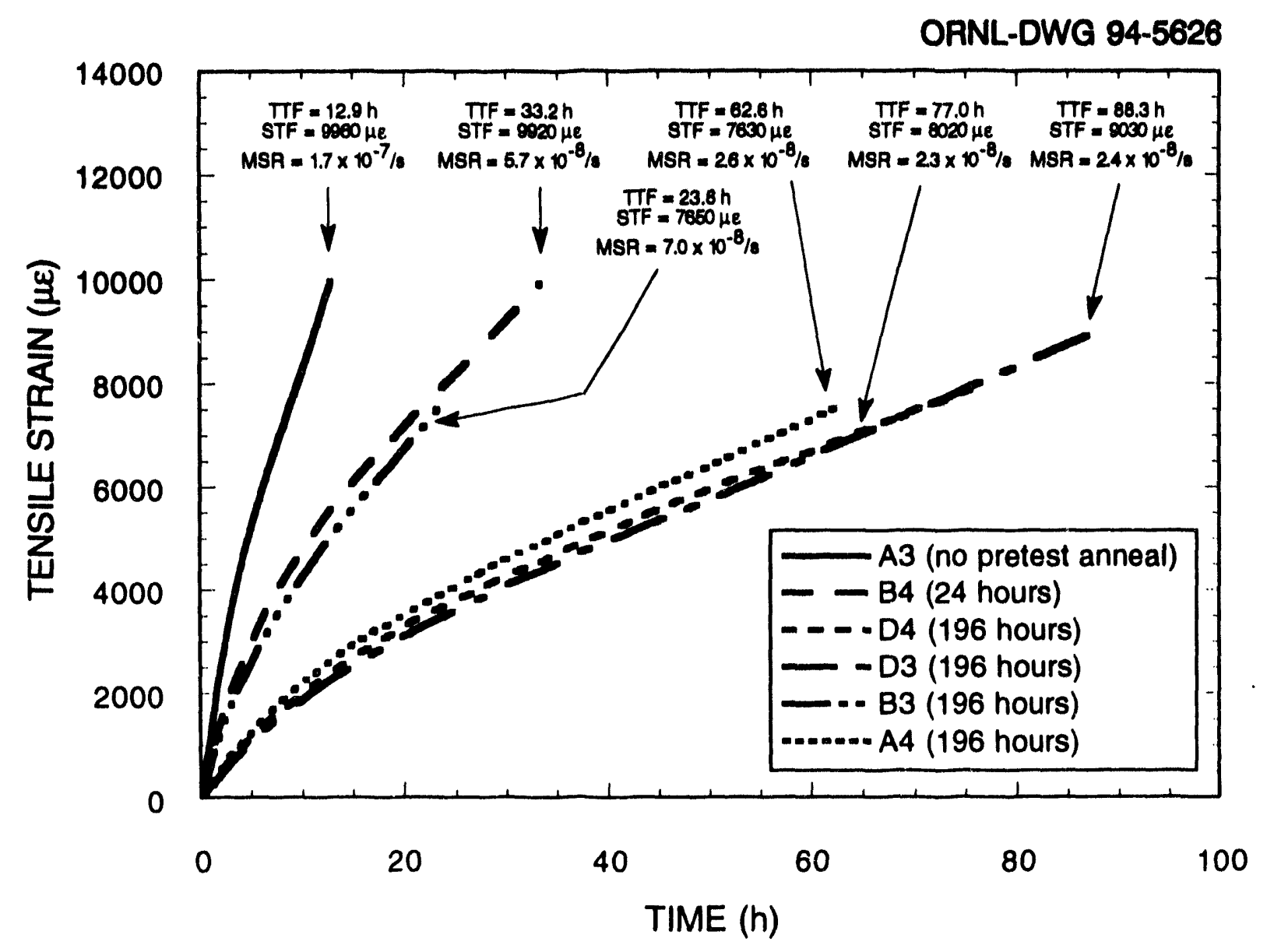

Fig. 2. Strain histories of the GN10 silicon nitride specimens tested at $1275^{\circ} \mathrm{C}$ and $137.5 \mathrm{MPa}$. The pretest anneal times are shown in the legend.

A4). Specimen B3 exhibited anomolous behavior by creeping somewhat rapidly; it did not appear to be sufficiently stabilized by the 196-h pre-test anneal. Figure 3 shows a Monkman-Grant plot of the NIST creep data ${ }^{1}$ and the creep-rupture data for the six ORNL buttonhead specimens tested. The data points for specimens D4, D3, and A4, which were all pre-test annealed for 196-h, are centrally positioned within the scatter of the NIST data. It is interesting to note that these three ORNL buttonhead specimens exhibited longer lifetimes at the same creep rates as the NIST double-reduction tensile specimens.

The morphologies of the tested ORNL. buttonhead tensile specimens were characterized. XRD was conducted in order to identify any presence or absence of unstable yttrium silicate phases which may be susceptible to diffusional processes, such as oxidation. 9

The morphology of three of the tested specimens (A3, B4, and D4) was examined by XRD. The first half of the XRD characterization involved identifying the material's morphology in its as-received state. Disks were cut off of the top of 


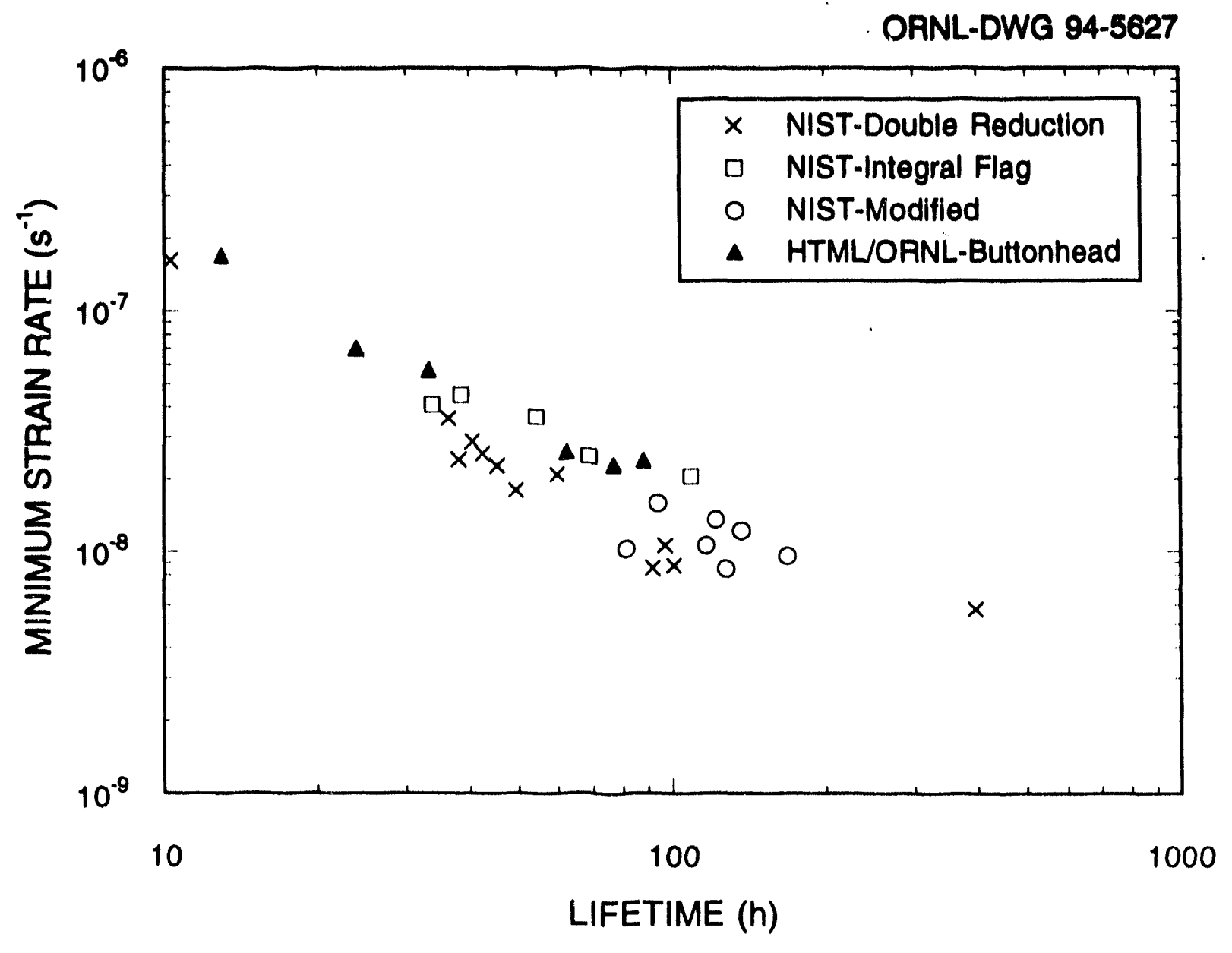

Fig. 3. Summary of HTML and NIST GN10 static creep-rupture results $\left(1275^{\circ} \mathrm{C}\right.$ and $\left.137.5 \mathrm{MPa}\right)$.

the buttonheads of tested specimens because their morphologies were considered to be representative of the as-received material (the buttonhead is cold-gripped and its temperature does not exceed $250^{\circ} \mathrm{C}$ thoughout the duration of the creep test) and were analyzed. The resulting intensity profiles as a function of two-theta are shown in Fig. 4 along with the identified peaks. The specimens appeared to have homogeneous phases and phase contents prior to testing. The second half of the XRD characterization involved the examination of the gage-section material after its creep exposure. Cylinders were cut out of the gage section of these tested specimens and were longitudinally sectioned. This provided a flat surface for XRD, and the interior morphology was examined to determine whether or not any phase changes had occurred. The profiles resulting from this analysis are shown in Fig. 5. The profiles in Figs. 4 and 5 are very similar; no new grain boundary phases appeared to have resulted from the creep exposure. Although these XRD results show the same phases being present before and after testing, it is not known what morphological changes (if any) these phases underwent at $1275^{\circ} \mathrm{C}$. 
ORNL-DWG 94-5628

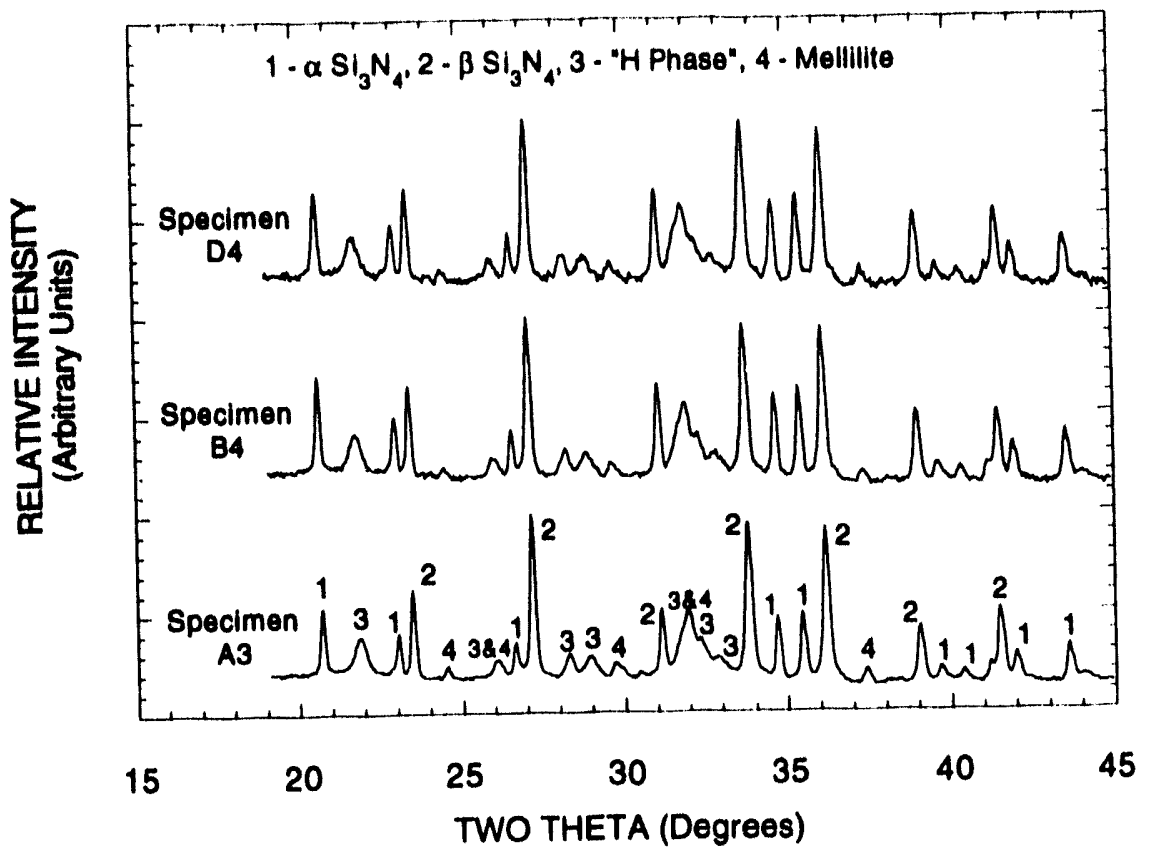

Fig. 4. XRD profiles of as-received GN10 specimens.

ORNL-DWG 94-5629

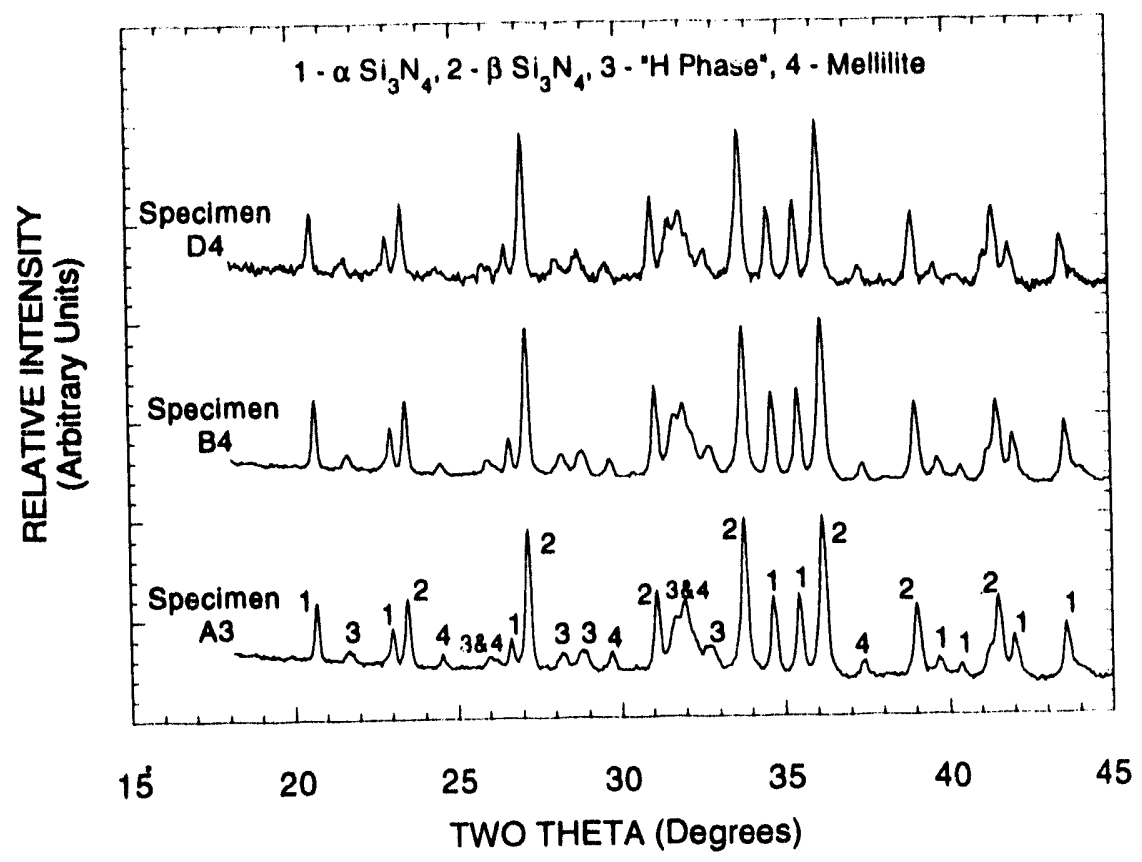

Fig. 5. XRD profiles of gage section interiors of creep-rupture-tested GN10 specimens. 


\section{Status of milestones}

In December 1993, creep relaxation (strain recovery) and stress recovery tests on PY6 are to be completed, and results are to be submitted for publication in open literature. To date, creep relaxation (strain relaxation) tests have been completed and stress relaxation (constant strain) tests are currently ongoing but will be completed in late November or early December 1993.

\section{Communications/visitors/travel}

(A) M. K. Ferber presented a talk entitled, "Creep and Fatigue Behavior of Silicon Nitride Ceramics," at the 95th Annual Meeting of the American Ceramic Society, Cincinnati, Ohio, April 18-22, 1993.

(B) C.-K. J. Lin presented a talk entitled, "Fatigue Behavior of a HIPed Silicon Nitride under Tensile Cyclic Loading at Elevated Temperatures," at the 95th Annual Meeting of the American Ceramic Society, Cincinnati, Ohio, April 18-22, 1993.

(C) A. A. Wereszczak presented a talk entitled, "Dynamic Fatigue Behavior of a HIPed Silicon Nitride in Air and Inert Environments at $1370^{\circ} \mathrm{C}$," at the 95th Annual Meeting of the American Ceramic Society, Cincinnati, Ohio, April 18-22, 1993.

(D) S. M. Wiederhorn visited ORNL on June 28-29, 1993. He presented a seminar entitled "Role of Cavity Formation in Creep Deformation of Silicon Nitride." Wiederhorn also brought a calibrated optical pyrometer to measure the temperature gradient on a buttonhead specimen that was within the heated furnace on the testing machine that performed the comparatory creep testing of the GN10 buttonhead specimens.

\section{Problems encountered}

Options are begin discussed with SGNIC regarding the observed large differences in the creep performance of the NCX-5102 material.

\section{Publications}

(1) C. -K. J. Lin, M. G. Jenkins, and M. K. Ferber, "Tensile Dynamic and Static Fatigue Relations for a HIPed Silicon Nitride at Elevated Temperatures," J. Eur. Ceram.Soc. 12, 3-13 (1993).

(2) C. -K. J. Lin, M. G. Jenkins, and M. K. Ferber, "Cyclic Fatigue of Hot Isostatically Pressed Silicon Nitride at Elevated Temperatures," accepted for publication in J. Mater. Sci.

(3) A. A. Wereszczak, K. Breder, and M. K. Ferber, "Role of Oxidation in TimeDependent Failure Behavior of HIPed Silicon Nitride at $1370^{\circ} \mathrm{C}$," accepted for publication in J. Am. Ceram. Soc. (November 1993). 


\section{Beferences}

1. M. G. Jenkins, M. K. Ferber, and C. -K. J. Lin, "Apparent Enhanced Fatigue Resistance under Cyclic Tensile Loading for a HIPed Silicon Nitride," J. Am. Ceram. Soc. 76 [3], 788-92 (1993).

2. C. -K. J. Lin, M. G. Jenkins, and M. K. Ferber, "Cyclic Fatigue of Hot Isostatically Pressed Silicon Nitride at Elevated Temperatures," accepted for publication in J. Mater. Sci.

3. C. -K. J. Lin, M. G. Jenkins, and M. K. Ferber, "Evaluation of Tensile Static, Dynamic, and Cyclic Fatigue Behavior for a HIPed Silicon Nitride at Elevated Temperatures," pp. 455-60 in Silicon Nitride Ceramics, ed. I. W. Chen, P. F. Becher, M. Mitomo, G. Petzow, and T. S. Yen., Vol. 287, Materials Research Society, Pittsburgh, 1993.

4. C. -K. J. Lin, A. A. Wereszczak, and M. K. Ferber, "Rotor Data Base Generation," pp. 63-65 in Ceramic Techology Project Bimonthly Progress Report to DOE Office of Transportation Technologies, Martin Marietta Energy Systems, Inc., Oak Ridge, Natl. Lab. February-March 1993.

5. A. A. Wereszczak, K. Breder, and M. K. Ferber, "Role of Oxidation in TimeDependent Failure Behavior of HIPed Silicon Nitride at $1370^{\circ} \mathrm{C}$," to be published in J. Am. Ceram. Soc. (November 1993).

6. M. K. Ferber and M. G. Jenkins, "Evaluation of the Strength and Creep-Fatigue Behavior of Hot Isostatically Pressed Silicon Nitride," J. Am. Ceram. Soc. 75 [9], 2453-62 (1992).

7. M. H. Lewis, "SiAlONs and Silicon Nitrides; Microstructural Design and Performance," pp 159-72 in Silicon Nitride Ceramics, ed. I. W. Chen, P. F. Becher, M. Mitomo, G. Petzow, and T. S. Yen., Vol. 287, Materials Research Society, Pittsburgh, 1993.

8. S. Malghan, S. Wiederhorn, B. Hockey, G. Quinn, and S. Hsu, "Ceramic Characterization and Standards for Heat Engines," pp. 96-104 in Ceramic Techology Project Bimonthly Progress Report to DOE Office of Transportation Technologies, Martin Marietta Energy Systems, Inc., Oak Ridge, Natl. Lab. April-May 1993.

9. F. F. Lange, S. C. Singhal, and R. C. Kuznicki, "Phase Relations and Stability Studies in the $\mathrm{Si}_{3} \mathrm{~N}_{4}-\mathrm{SiO}_{2}-\mathrm{Y}_{2} \mathrm{O}_{3}$ Pseudoternary System," J. Am. Ceram. Soc. 60 [5-6], 249-52 (1977). 
TOUGHENED CERAMICS LIEE PREDICTION

Jonathan A. Salem, Sung R. Chol and Noel N. Nemeth

(NASA Lewis Research Center)

\section{Objective/Scope}

The purpose of this research is to understand the room temperature and high temperature $\left[51370^{\circ} \mathrm{C}\left(2500^{\circ} \mathrm{F}\right)\right]$ behavior of toughened ceramics as the basis for developing a life prediction methodology. A major objective is to understand the relationship between microstructure and mechanical behavior within the bounds of a limited number of materials. A second major objective is to determine the behavior as a function of time and temperature. Specifically, the room temperature and elevated strength and reliability, the fracture toughness, slow crack growth and the creep behavior will be determined for the as-manufactured material. The same properties will also be evaluated after long-time exposure to various high temperature isothermal and cyclic environments. These results will provide input for parallel materials development and design methodology programs. Resultant design codes will be verified.

\section{Technical Highliahts}

The objective of this work was to determine the effects of a typical, uniaxial grinding process on the strength distribution of a ceramic material. The strength of ceramic materials is typically measured in accordance with ASTM C1161 [1] which specifies that machined specimens be ground in a single longitudinal direction and tested so that the maximum principal stress is parallel to this direction. Such a grinding process induces minimal damage in the longitudinal direction, but significant damage in the transverse direction, resuiting in an anisotropic flaw distribution on the surface of the beam. Since the beam is stressed longitudinally, such a preparation is sufficient to avoid failures from machining damage, and result in measurements that are representative of the materials strength limiting defects. However, components are subjected to multiaxial stresses and thus will be sensitive to planer flaws with the crack plane oriented in both the longitudinal and the transverse directions. Thus if uniaxial grinding is used or if axial wear occurs, such anisotropies can be of importance in design of components with a multiaxial stress state. Additionally, investigations of the strength anisotropy due to grinding may provide a means to measure a materials strength response under mixed mode (I \& II) conditions, thus providing information that can be applied to isotropic cases (e.g. polished or as-processed material).

The fast-fracture strength of a sintered alpha silicon carbide was measured in four-point bending with the principal stress oriented at angles between 0 and $90^{\circ}$ relative to the grinding direction. Also, specimens were tested in an annealed condition to determine if a simple procedure could be used to heal machining damage. 
Alpha silicon carbide was chosen because it exhibits a very low fracture toughness, no crack growth resistance, high elastic modulus and a very low susceptibility to slow crack growth (static fatigue). Such properties make this an ideal ceramic for the verification of fast fracture reliability models and codes.

\section{EXPERIMENTAL METHOD}

Material and Specimen Preparation

The material used in this study was a commercially available sintered alpha silicon carbide processed in the form of 25 by 25 by 42 $\mathrm{mm}$ billets. Plates were ground from the billets and finished by 320 grit diamond grinding one face of the plates at angles ranging from 0 to $90^{\circ}$ relative to the plate edge. Bend tests specimens were then cut from the plates. A random selection of plates was used for the beams of any grinding angle in order to block the effects of billet and location on the test results. The specimen edges along the tensile surface were beveled by hand to eliminate spurious edge failures. Bend specimens nominally measured 2 by 3 by $25 \mathrm{~mm}$.

In order to determine if the deleterious effects of grinding damage could be negated, a group of 0 and $90^{\circ}$ as-ground specimens were annealed at $1200^{\circ} \mathrm{C}$ for two hours in air prior to testing.

Bend Testing

Fast-fracture bend tests were conducted at room temperature with a stroke rate of $0.05 \mathrm{~mm} / \mathrm{min}$. The inner and outer spans of the four-point fixture were 8 and $20 \mathrm{~mm}$, respectively. The rollers of the test fixture were free to roll and the upper span to articulate relative to the lower span. A minimum of 30 specimens were tested per condition.

\section{RESULTS AND DISCUSSION}

\section{(a) Strength Distributions}

Specimen strength as a function of grinding angle relative to the longitudinal direction is shown in Figure 1 and the results are summarized in Table 1. The average strength and standard deviation decrease continually as the angle increases with exception of the 30 and $45^{\circ}$ data which are quite similar. Annealing did not significantly change the average strength of specimens ground at $0^{\circ}$. However, specimens ground at $90^{\circ}$ and annealed exhibit strengths not significantly different from those of the $0^{\circ}$ annealed and $0^{\circ}$ as-ground specimens. This indicates that annealing eliminates the grinding damage, but does not significant-

\footnotetext{
'Carborundum hexoloy SA alpha SiC.
} 
ly enhance the strength of longitudinally $\left(0^{\circ}\right)$ ground specimens.

Weibull plots (maximum likelihood estimator) of the annealed and as-ground specimens are shown in Figures 2a-2d. The Weibull modulus continuously increases with increasing grinding angle while the characteristic strength decreases. Annealing does not significantly. change the strength distribution of $0^{\circ}$ ground specimens, and annealing appears to totally heal machining damage associated with the $90^{\circ}$ ground specimens, as the distributions are not significantly different. Thus, the annealed specimen data and the $0^{\circ}$ as-ground data were pooled.

Table 1. Summary of Strength Data

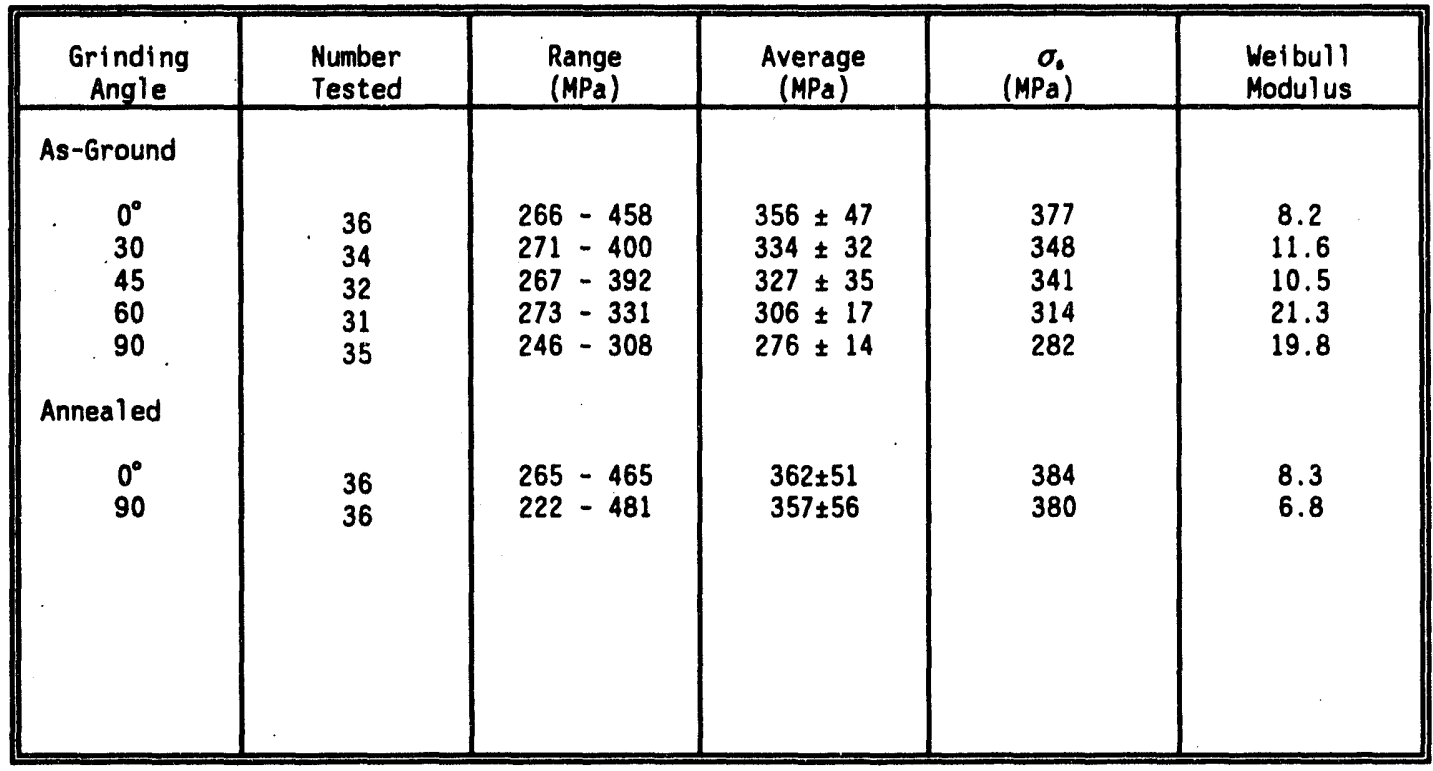

(b) Fractography

Fractographic analysis is a necessary aspect of reliability analysis in order to determine whether surface, volume, or combined (surface and volume) flaw reliability analysis should be performed, and if flaws of different processing sources are present.

Fractography to determine the sources and locations of failure has been done in accordance with military handbook procedures [2] and is nearly complete for all the specimens. The results to date are summarized in Table 2. Annealed specimens and $0^{\circ}$ as ground specimens appear to fail from surface and near surface processing agglomerates, while 30, 45,60 , and $90^{\circ}$ as-ground specimens fail from either surface agglomerates, machining cracks or hybrid flaws created when machining damage occurs at/to processing agglomerates. 
The various type of origins are shown in Figure 3. The processing flaws that induced failure were agglomerates located at the tensile surface (i.e. cut open during machining) or located slightly below (within $0.1 \mathrm{~mm}$ ). Machining damage consisted of poorly defined, semielliptical cracks that are typically, though not always, oriented parallel to the grinding direction. Although both the processing and machining flaws are complex shapes, the processing flaws are typically larger in overall size, indicating a bluntness relative to the machining flaws.

Note (Figure 3 ) how the fracture from a $60^{\circ}$ hybrid flaw is initially parallel to the grinding direction and gradually turns normal to the principal stress direction. Evidently mixed stress intensity modes exist during such failures. Also, the macroscopic fracture plane can occasionally be observed to jog parallel to the grinding direction. An elliptical crack can typically be observed at the jogs.

Table 2. Summary of Failure Origins

\begin{tabular}{|c|c|c|c|c||}
\hline $\begin{array}{c}\text { Grinding } \\
\text { Angle }\end{array}$ & $\begin{array}{c}\text { Surface \& Near } \\
\text { Surface Agglomerates }\end{array}$ & $\begin{array}{c}\text { Machining } \\
\text { Damage }\end{array}$ & $\begin{array}{c}\text { Hybrid } \\
\text { Flaws }\end{array}$ & $\begin{array}{c}\text { Not } \\
\text { Identifiable }\end{array}$ \\
\hline As-Ground & & & & \\
$0^{\circ}$ & -- & 0 & -- & -- \\
30 & 30 & 9 & 2 & 0 \\
45 & 21 & -- & -- & 0 \\
60 & 11 & & & -- \\
90 & -- & 0 & 0 & 1 \\
Annealed & & -- & -- & - \\
$0^{\circ}$ & -- & & & \\
90 & & & & \\
\hline
\end{tabular}

(c) Modeling of the Strength Distribution

As a result of the multiple origins, concurrent analysis must be used in parameter estimation and modeling. Weibull plots of the concurrent populations for 30,45 , and $60^{\circ}$ grinding angles are shown in Figure 4. Note that as the grinding angle increases, the frequency of machining flaws increases and that they populate the upper end of the overall distributions. 
Several strength distribution models were investigated, including two and three parameter Weibull distributions, shear sensitive and insensitive flaw (Batdorf) models, the effects of superimposing a residual stress field, and also incorporation a threshold or truncation stress. The overall strength distribution was modeled as a bimodal distribution of agglomerate flaws and machining flaws. The effect of hybrid flaws was not considered for this report. The agglomerate flaws were modeled as randomiy distributed microcracks, and therefore an isotropic strength response was assumed. In this case, assuming a particular flaw geometry was not necessary. The machining flaws were modeled using a version of the CARES program that incorporates a generalized anisotropic distribution function for flaw orientation into the Batdorf mode1. The machining flaws were assumed to be randomly oriented within 1 degree of the direction of the grind and perpendicular to the surface (in other words the orientation of the flaws was highly anisotropic). A semi-elliptical flaw geometry was also assumed. In this manner the effect of mixed-mode loading on the machining flaws could be investigated.

The mechanics of Batdorf methodology will not be described here; however the basic underlying Weibull distribution used for these models will be briefly discussed. The two and three parameter Weibull distributions (not considering the effect of stress state, component geometry, and flaw geometry and orientation) are described by

$$
P_{f}=1-\exp \left\{-\left(\left(\sigma-\sigma_{u}\right) /\left(\sigma_{0}-\sigma_{u}\right)\right)^{m}\right\}
$$

where $P_{f}$ is the failure probability, $\sigma$ is the applied uniaxial stress, and $\sigma_{0}$ and $\sigma_{u}$ are the scale parameter and threshold strengths, respectively. For the two parameter case $\sigma_{u}$ goes to zero. $\sigma_{4}$ can either represent a residual stress or the strength of the largest possible flaw in the population. The truncated (or attenuated) Weibuli distribution is described in its most basic form as

$$
P_{f}=1-\exp \left\{-\left(\left(\sigma^{m}-\sigma_{p}^{m}\right) / \sigma_{0}^{m}\right)\right\}
$$

where $\sigma_{p}$ is a threshold strength whereby no flaw exists with a strength less than this value.

The models are shown in Figure 5 and compared to the actual data in Figure 6 for the three-parameter and truncated distribution cases. These models are based on best fit distributions to the 0 and 90 degree data. The behavior at the 30, 45, and 60 degree orientations is then predicted within the framework of these models. A crude finite element model of the tensile ground surface was used to obtain the predicted strength distribution. As shown in the figures the two parameter model fits the data poorly at the lower probabilities of failure.

The similarity between the annealed and the as-ground $0^{\circ}$ data implies that no residual stress exists or that the residual stresses are nominally uniaxial and normal to the grinding direction, while the 
similarity between the as-ground $0^{\circ}$ data and the annealed $90^{\circ}$ data implies no residual stresses exist or that annealing relieves the stresses. Referring to figure 5; the addition of a uniaxial compressive residual stress applied perpendicular to the machining flaws al so provided a poor fit to the experimental data. It was assumed that the residual stress was highly localized at the surface and therefore the residual stress field was not imposed on the agglomerate flaws. Attempts at other combinations of superimposed residual stress fields yielded even worse correlation to the data.

Both the shear sensitive three parameter and truncation distribution models are better fits to the data, however, no specific justification for the lower strength boundary can be given. The shear insensitive models do not appear to correlate to the data. The shear sensitive models use a Shetty shear sensitivity coefficient of approximately 1.0 .

Continuing Efforts

Along with fractographic analysis of the specimens, the effects of grinding orientation on reliability predictions with the CARES code are being considered. Further, the shear sensitivity constant, $C$, will be determined for this material and used in future verification work.

\section{CONCLUSIONS}

(1). The strength distribution of silicon carbide is a function of grinding orientation for a typical grinding procedure (e.g. ASTM C1161). The Weibull modulus increases with the fraction of machining flaws in the distribution, as they are relatively consistent in effective size.

(2). Annealing did not make longitudinally ground bars significantly different from the as ground condition.

(3). Annealing of transversely $\left(90^{\circ}\right)$ ground bars resulted in a similar strength distribution to that of the longitudinally $\left(0^{\circ}\right)$ ground bars.

(4). Annealed and longitudinally ground specimens typically fail from surface and near surface agglomerates while transversely ground specimens predominantly fail from machining cracks.

(5). Truncated distribution and three-parameter models appear to best approximate the experimental data generated, to date, in this work.

(6). The effects of mixed-mode fracture of machining cracks was adequately predicted by the models for the larger angles of orientation $\left(>30^{\circ}\right)$.

(7). Strength data for low grinding angles showed some deviation from predicted results, possibly reflecting damage to the agglomerate flaws during the machining process. Evidently, fractography did not reveal the damage. 


\section{REFERENCES}

[1] ASTM C 1161-90 "Standard Test Method for Flexural Strength of Advanced Ceramics at Ambient Temperature, "Annual book of ASTM Standards, Vol. 15.01, 333-339, (1990).

[2] "Fractography and Characterization of Fracture Origins in Advanced Structural Ceramics," MIL-HDBK-790, (July, 1992).

\section{Communication/Visits/Travel}

ASME $10^{\text {th }}$ conference on Reliability, Stress Analysis and Fallure Prevention, Albuquerque, NM, September 19-22, 1993.

\section{Publications}

S.R. Choi, V. Tikare, and J. A. Salem, "Effect of Environments on Fracture Toughness of 96 wt \% Alumina," Scripta METALLURGICA et MATERIALIA, Vol 29, 189-192, 1993.

L. M. Powers, J. A. Salem and S. R. Choi, "Failure Prediction Using The Ring-On-Ring Test and The CARES/Life Integrated Design Program," in Reliability, Stress Analysis and Failure Prevention, ASME DE-Vol. 55, pp. 55-63, 1993.

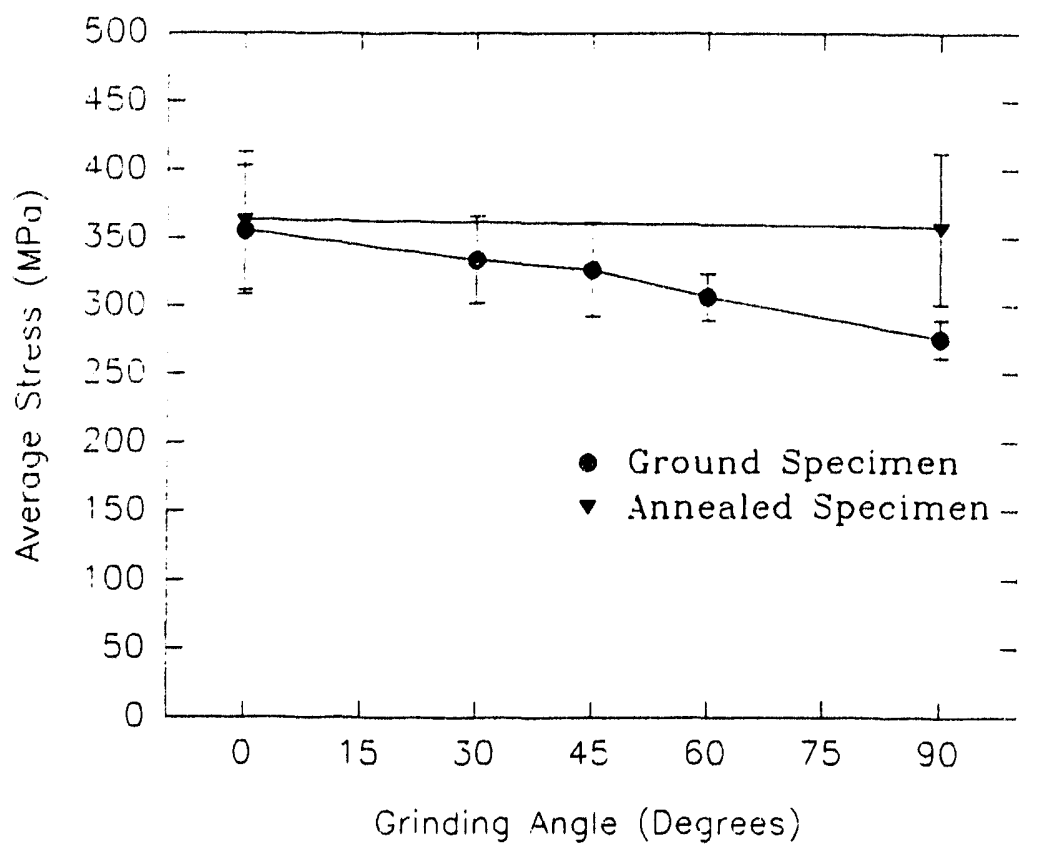

Figure 1. - Average four-point bend strength as a function of grinding angle. Error bars are \pm one standard deviation. 


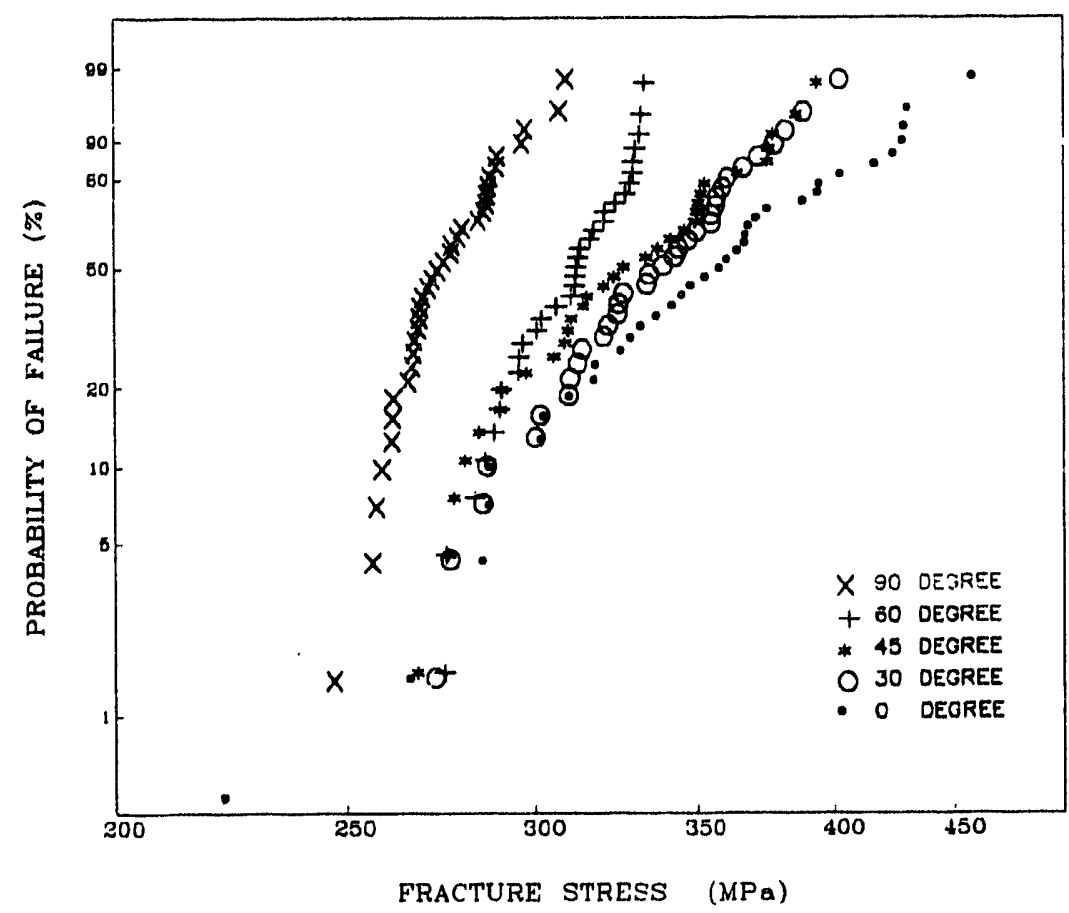

(a)

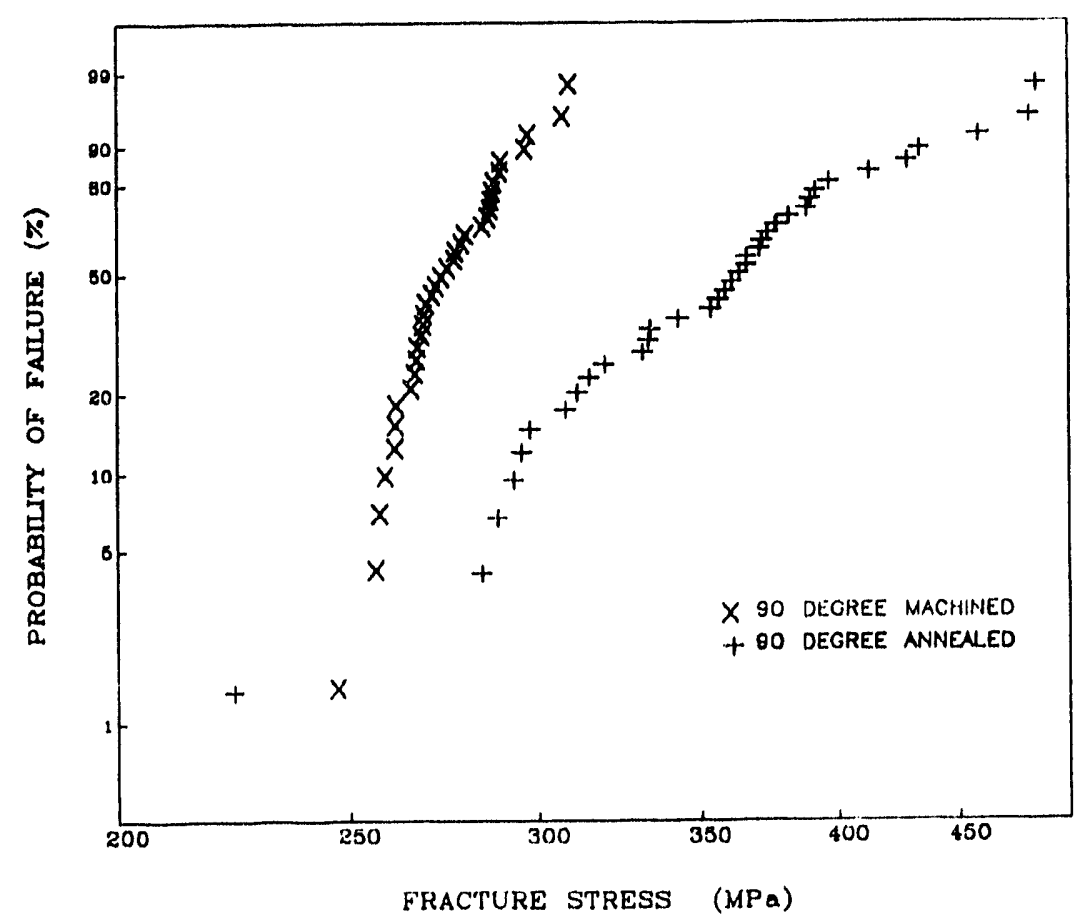

(b)

Figure 2. - Weibull plots of the fracture stresses for (a) as-ground specimens, (b) annealed and $90^{\circ}$ as-ground specimens, (c) annealed and $0^{\circ}$ as-ground specimens and (d) $90^{\circ}$ annealed and $0^{\circ}$ as-ground specimens. 


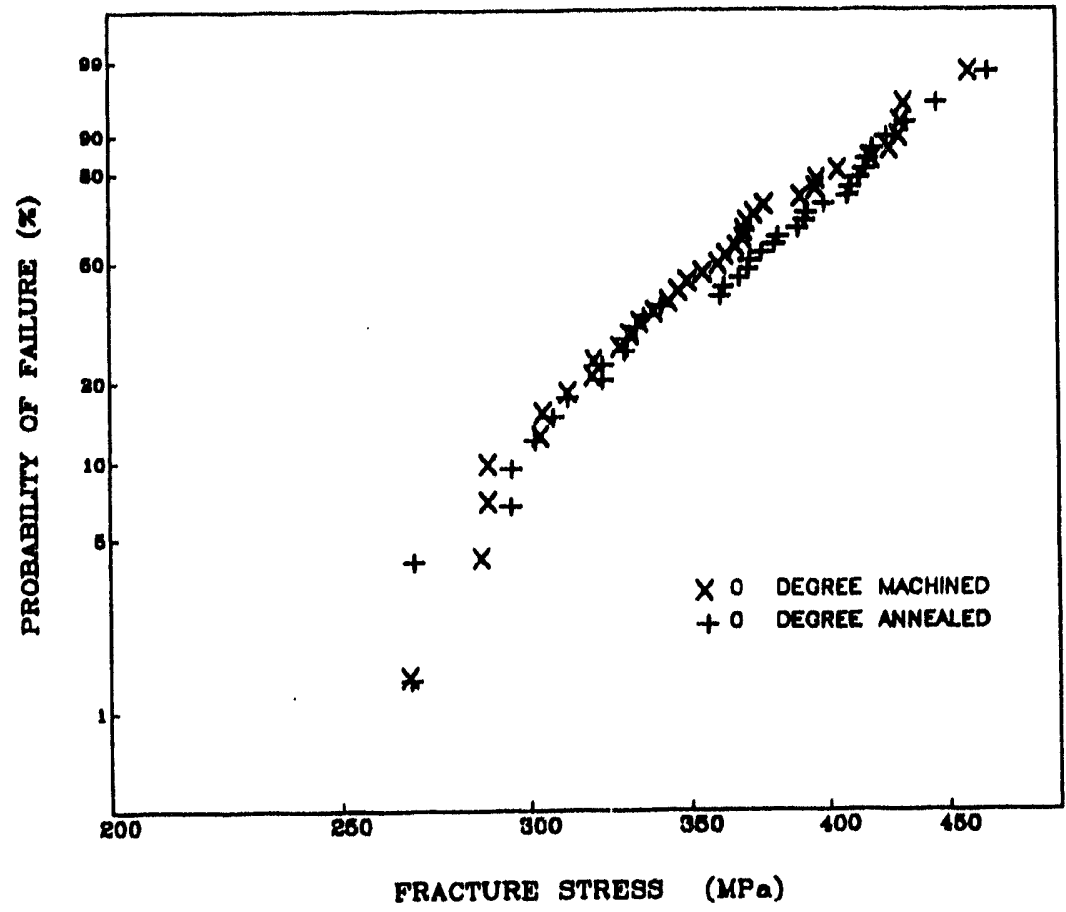

(c)

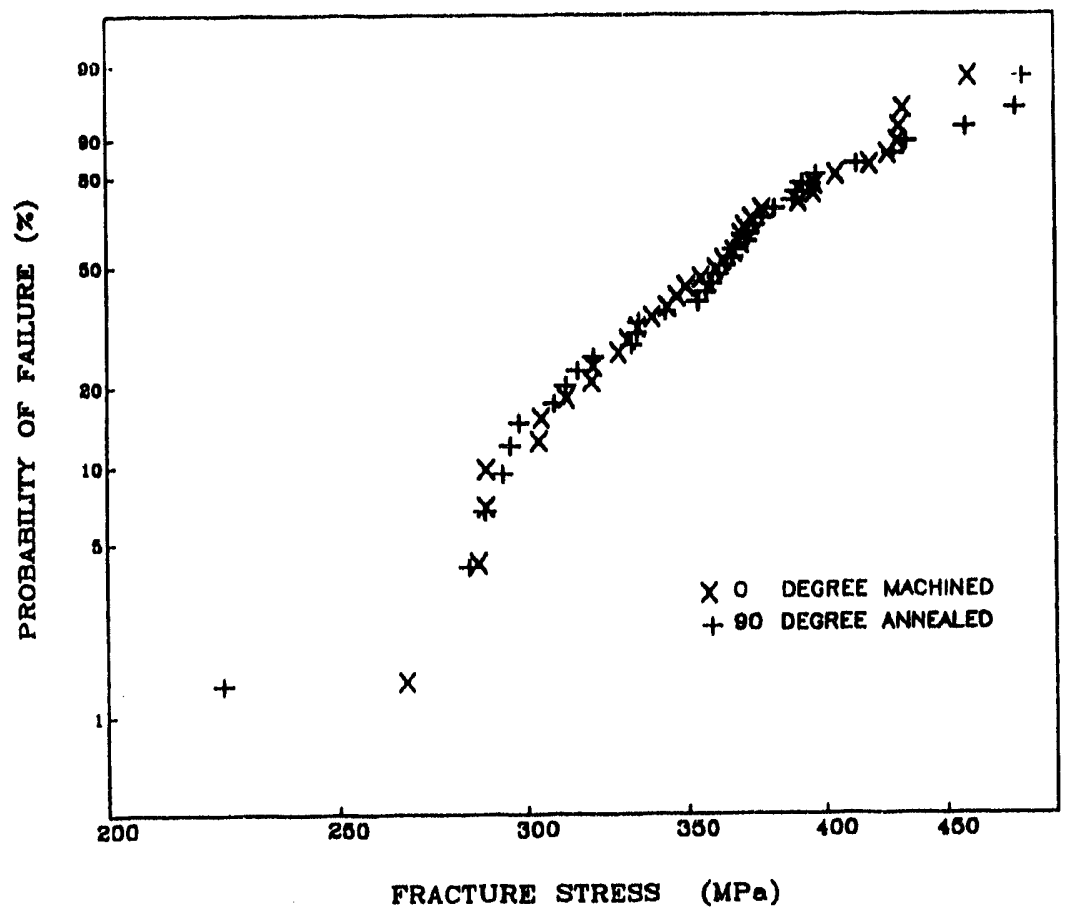

(d)

Figure 2 (Continued) 


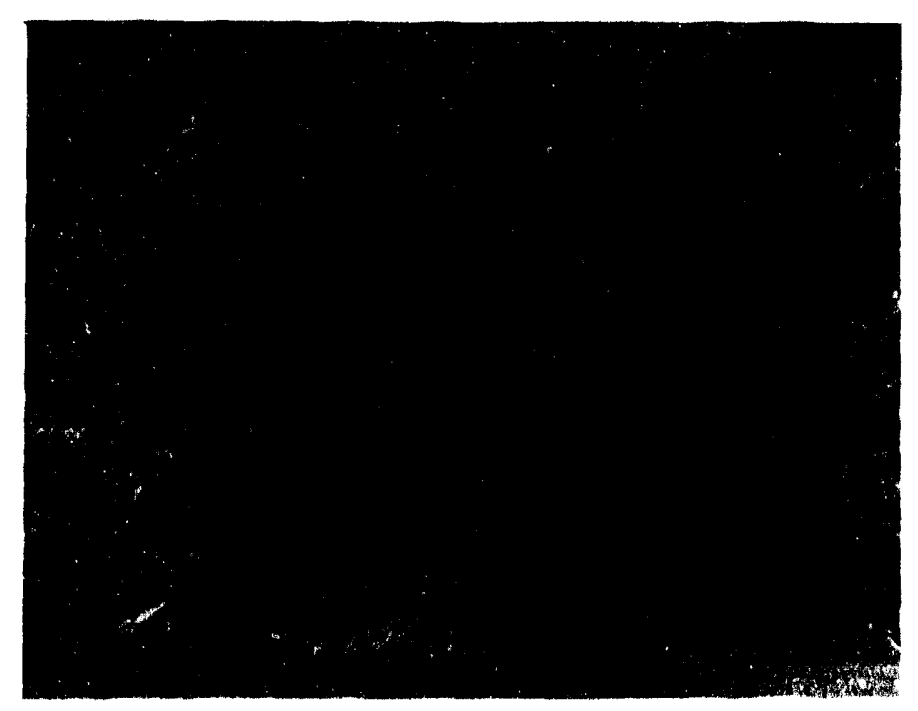

(a)

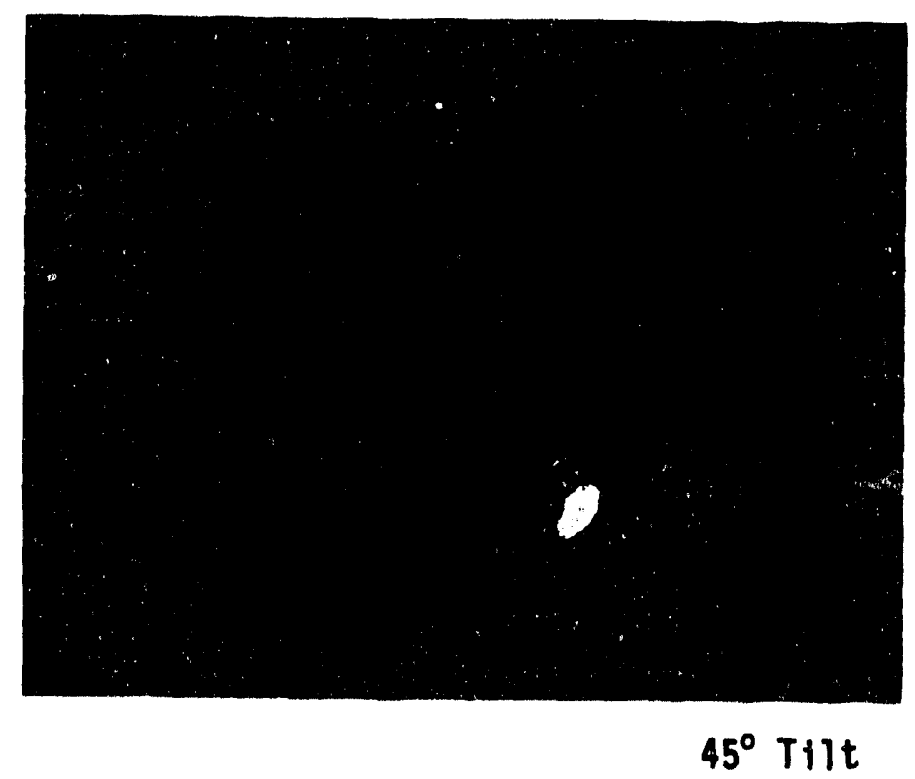

(b)

Figure 3. - Fallure origins showing (a) surface connected processing agglomerate, (b) machining crack and (c) hybrid flaw. 


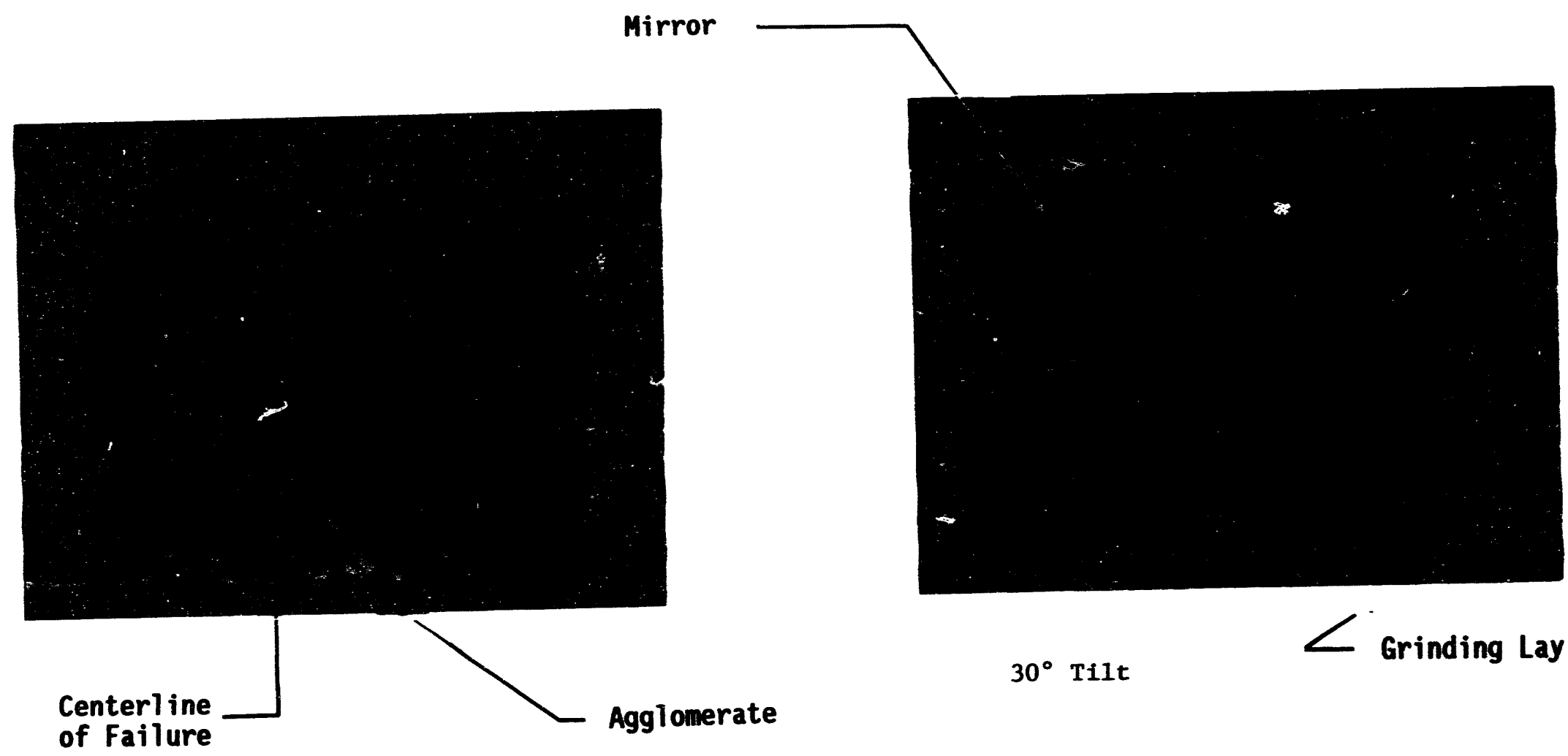

(c)

Figure 3 (Continued) 

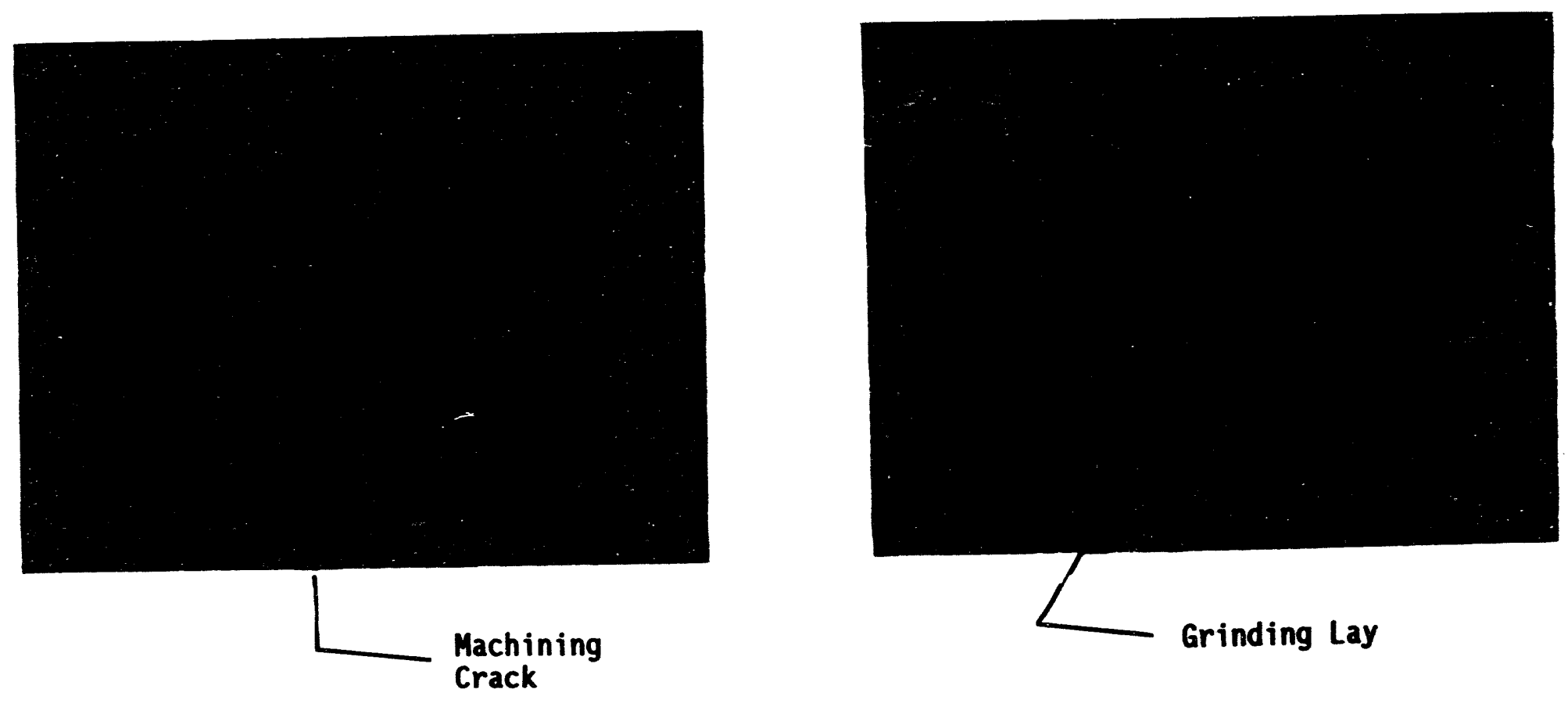

(c)

Figure 3 (Continued) 


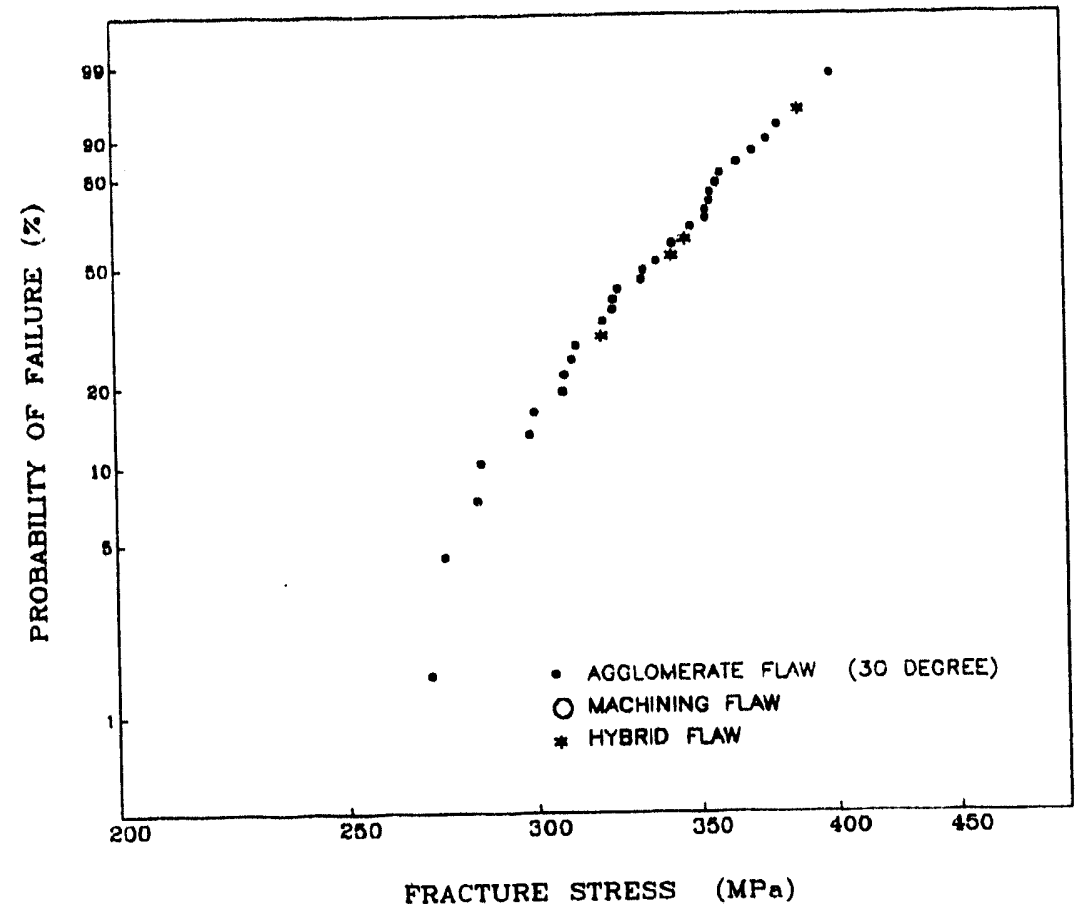

(a)

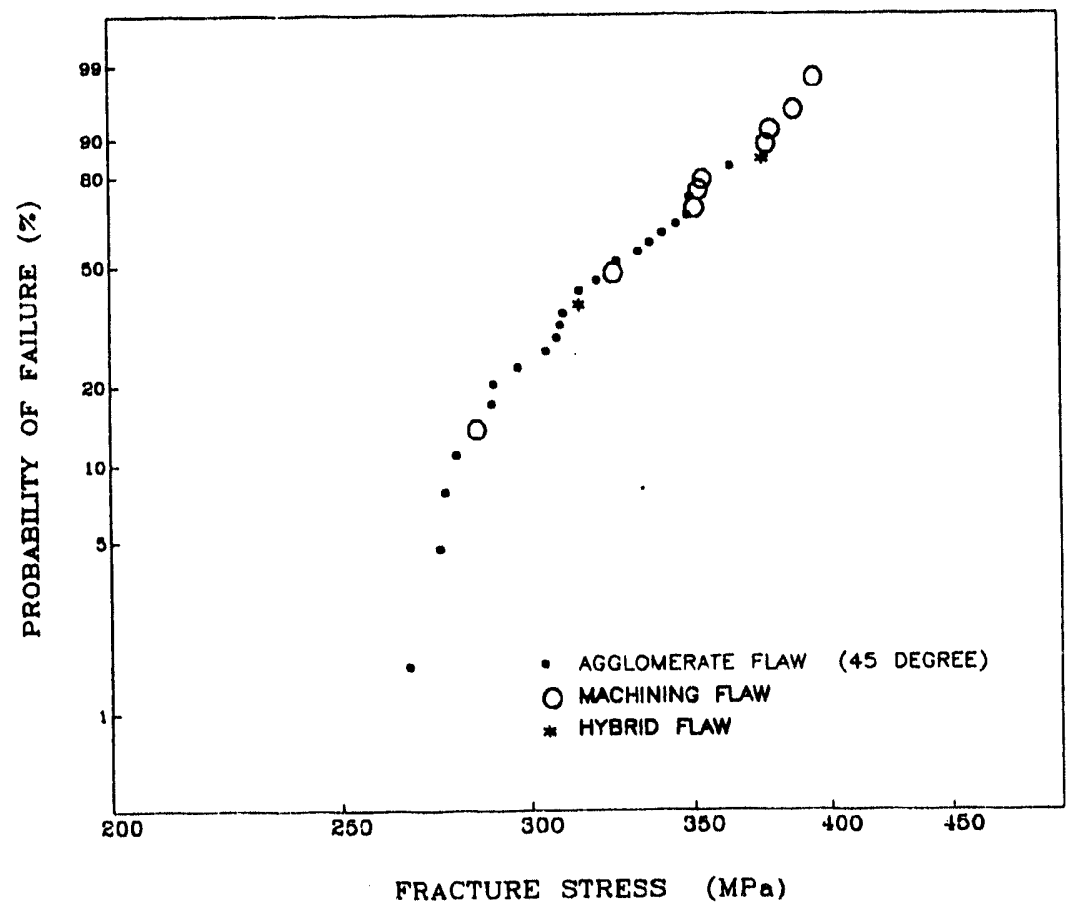

(b)

Figure 4. - Weibull plot of the fracture stresses for $30,45,60$ and $90^{\circ}$ as-ground specimens and the annealed specimens pooled with $0^{d}$ as-ground specimens. 


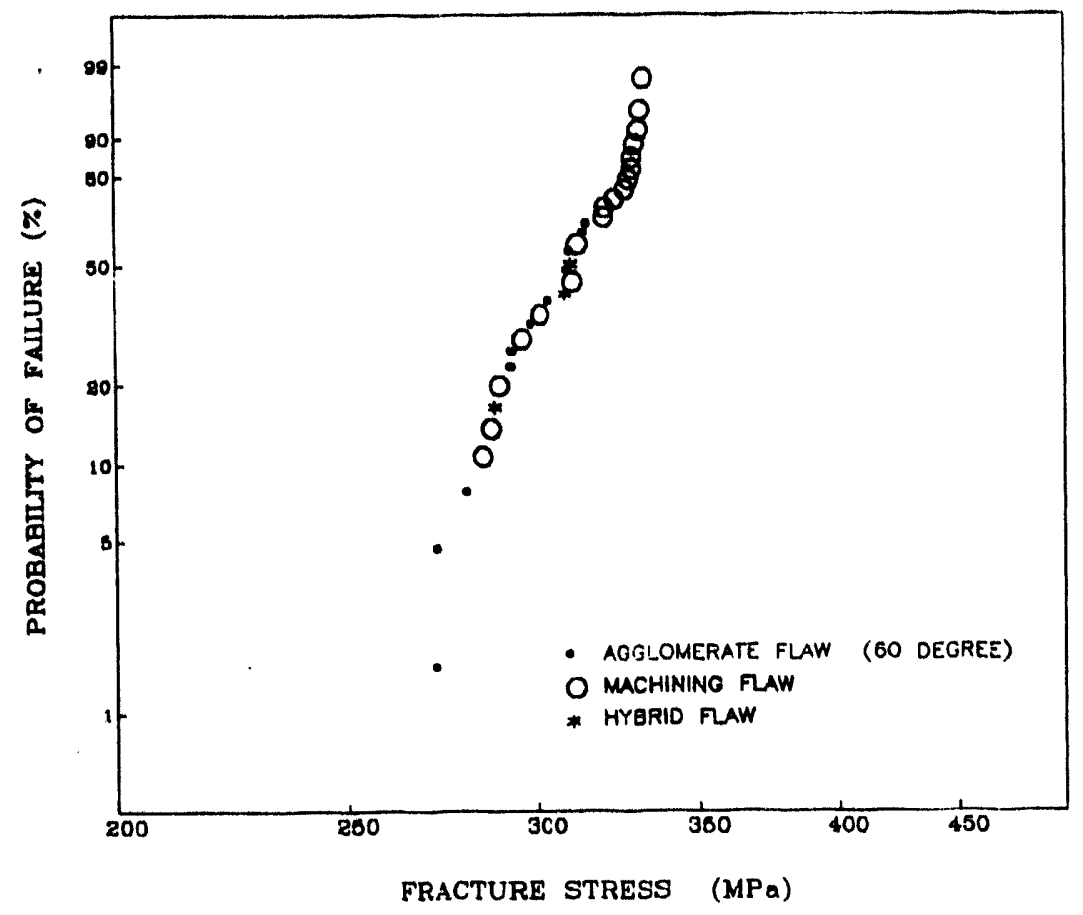

(c)

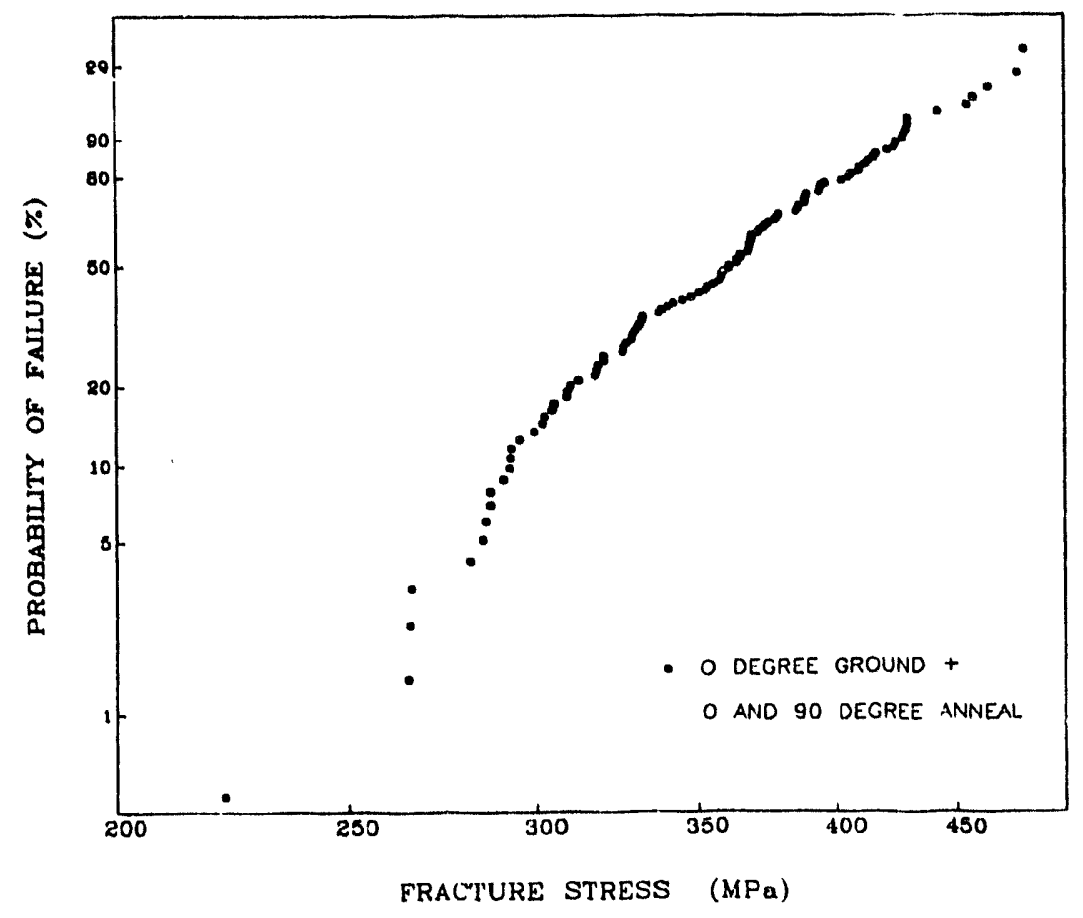

(d)

Figure 4 (Continued) 


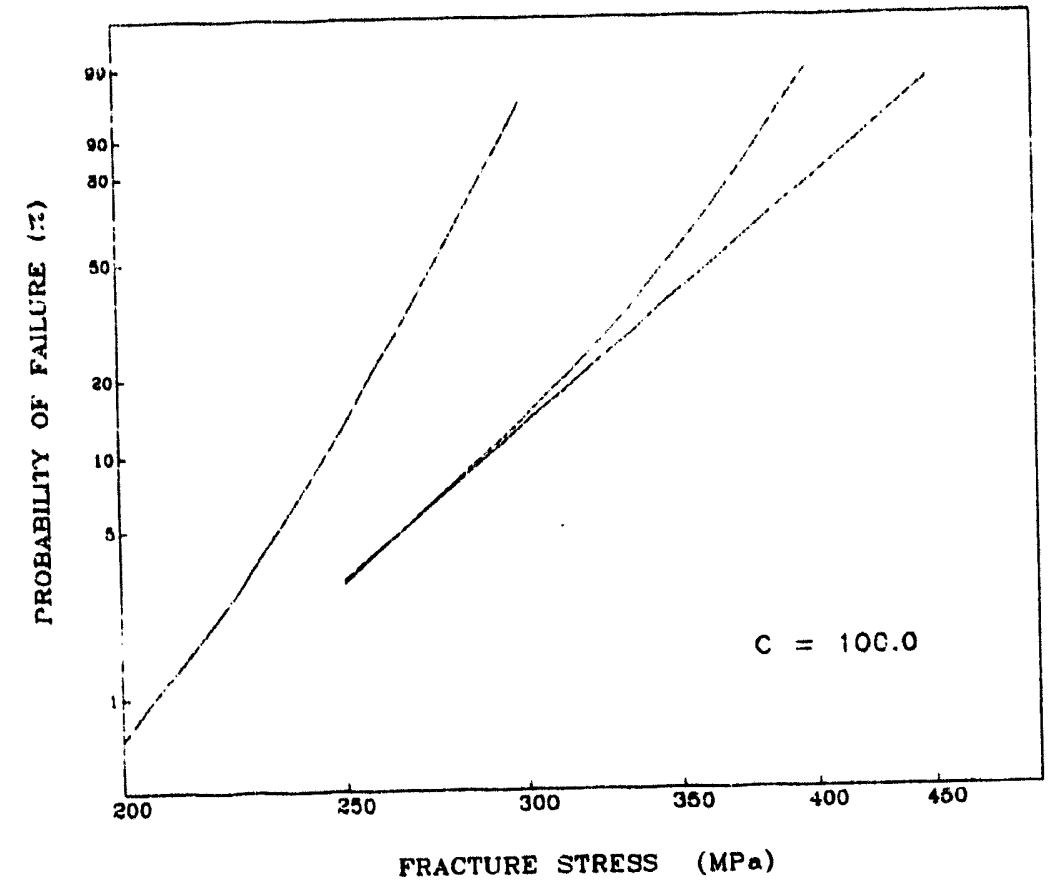

(a)

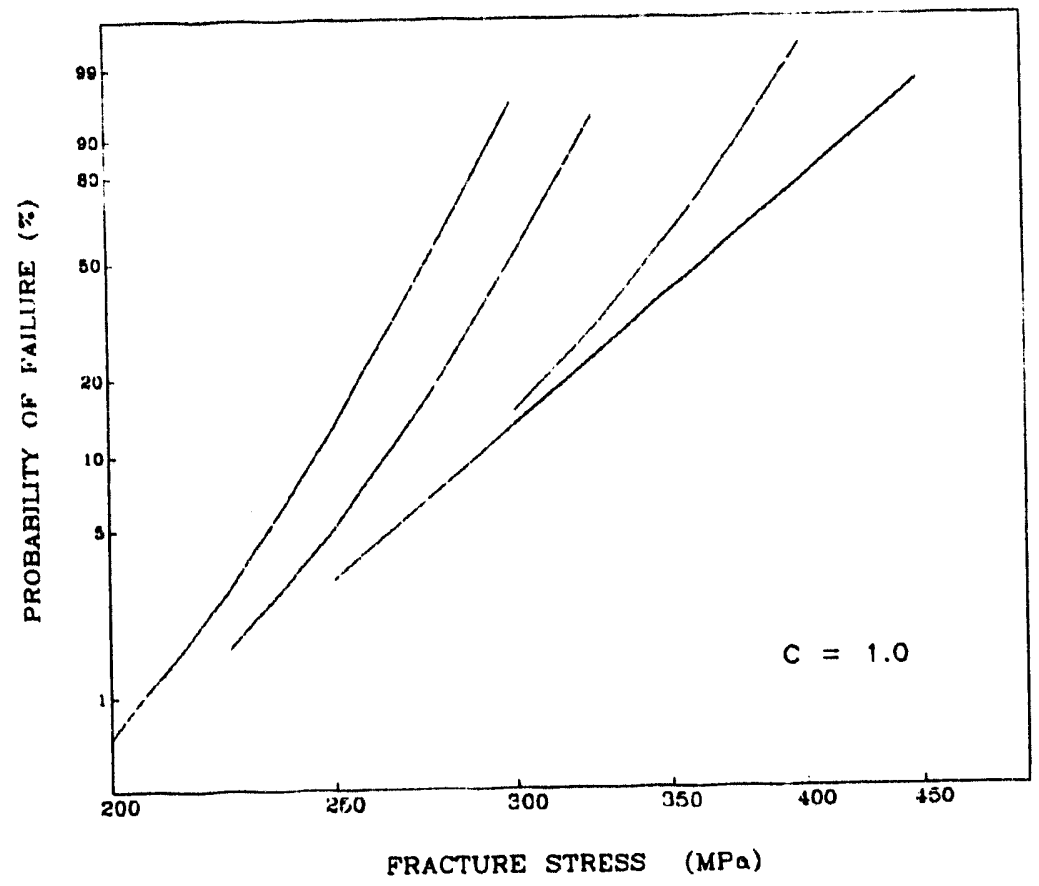

(b)

Figure 5. - Stress distrihutions for (a) 2-parameter shear insensitive model, (b) 2-parameter shear sensitive model, (c) 3-parameter shear insensitive model, (d) three parameter shear sensitive model, (e) two parameter shear sensitive model with residual compressive uniaxial stress applied perpendicular to machining flaws and ( $f$ ) two parameter shear sensitive model with a truncation load (truncated Weibull distribution). 

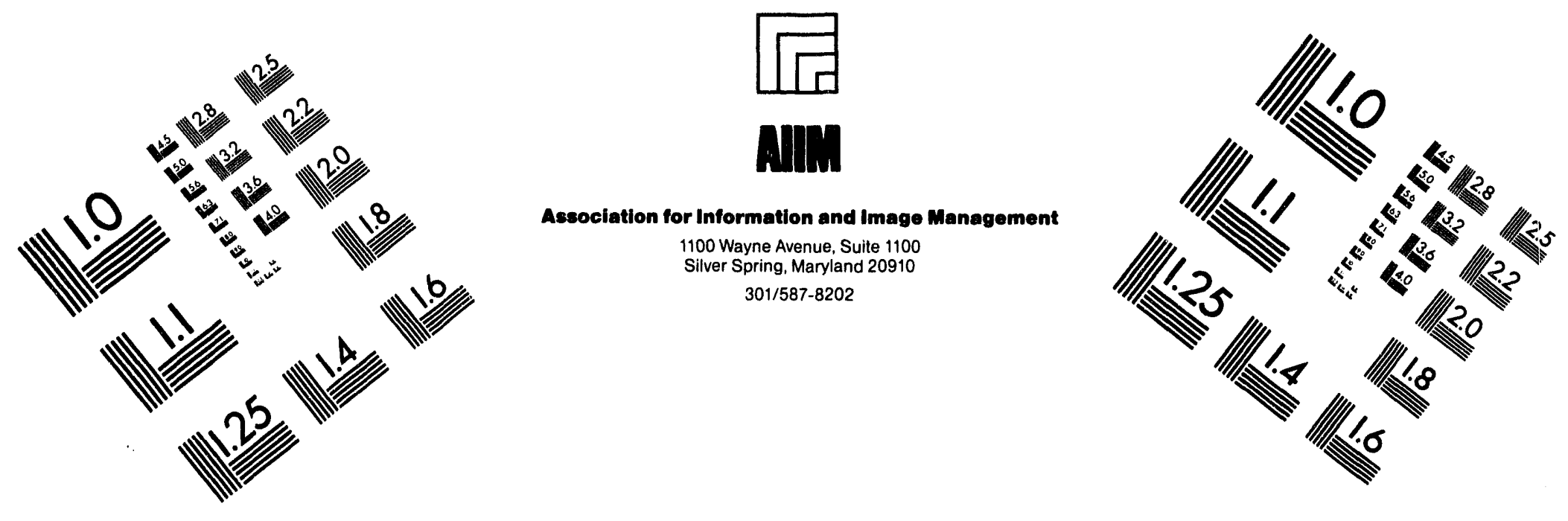

\section{Centimeter}

$\begin{array}{llllllllllllllll}1 & 2 & 3 & 4 & 5 & 6 & 7 & 8 & 9 & 10 & 11 & 12 & 13 & 14 & 15 & \mathrm{~mm}\end{array}$

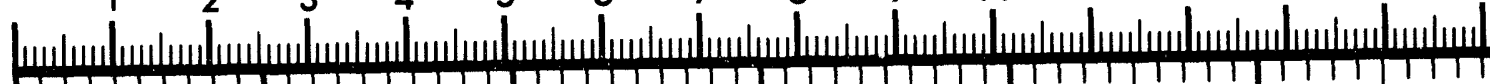

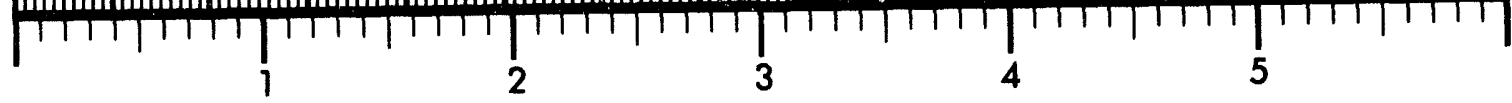
Inches
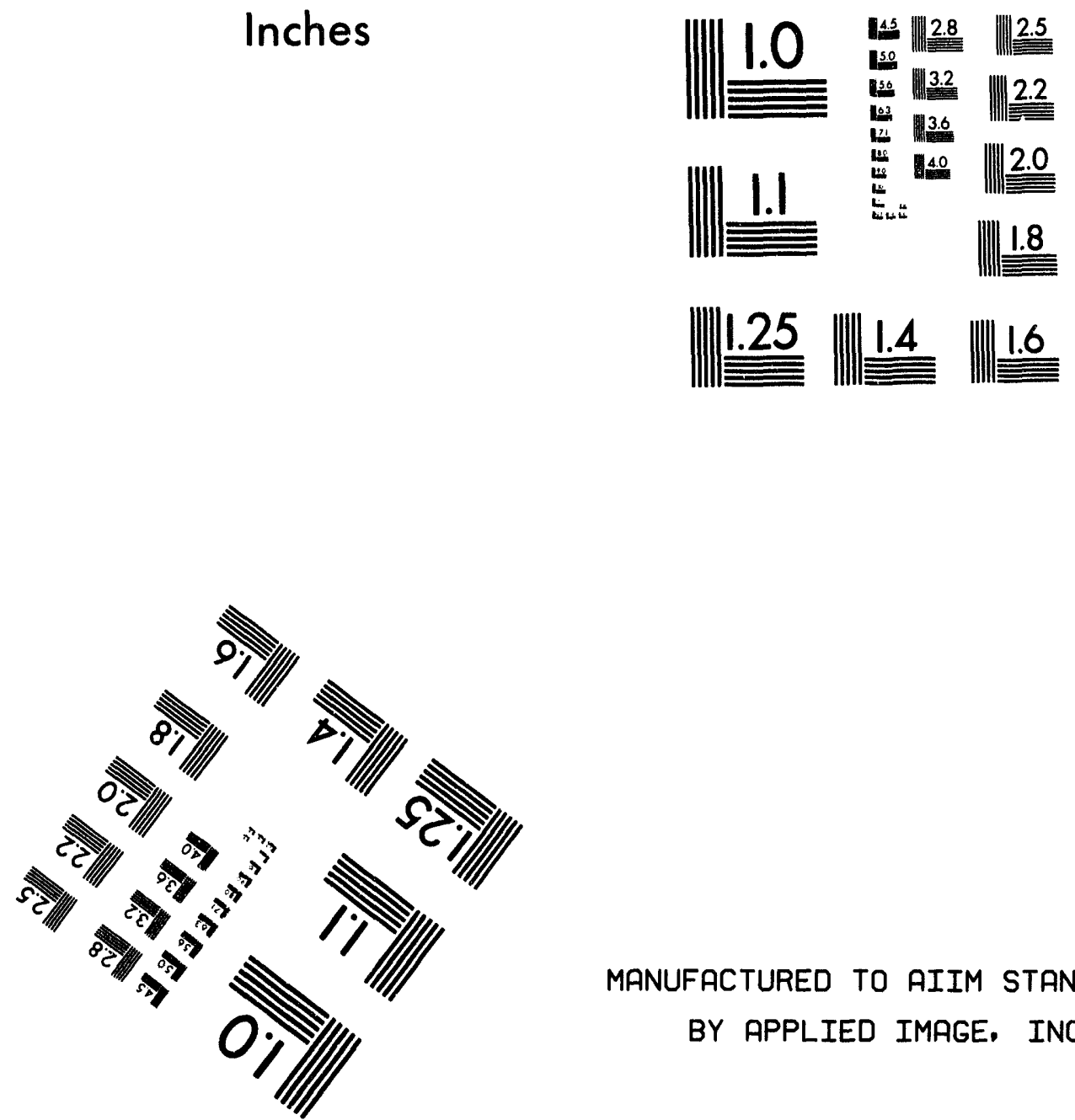

MANUFACTURED TO AIIM STANDARDS

BY APPLIED IMAGE, INC.

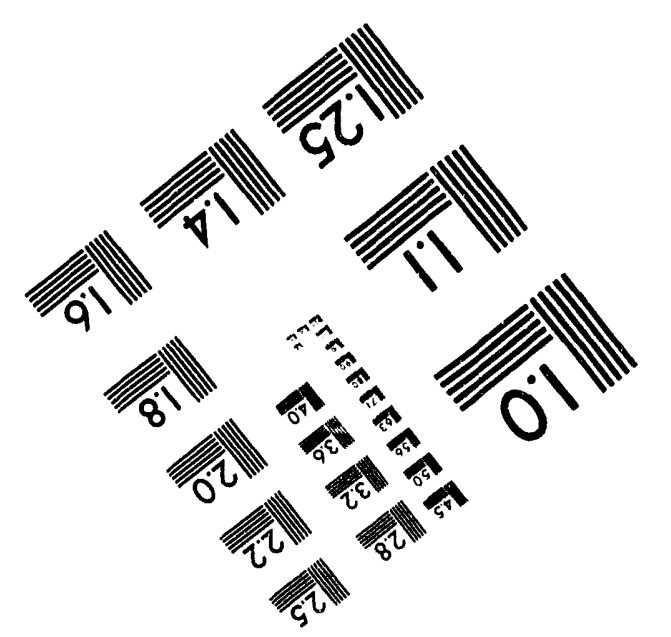



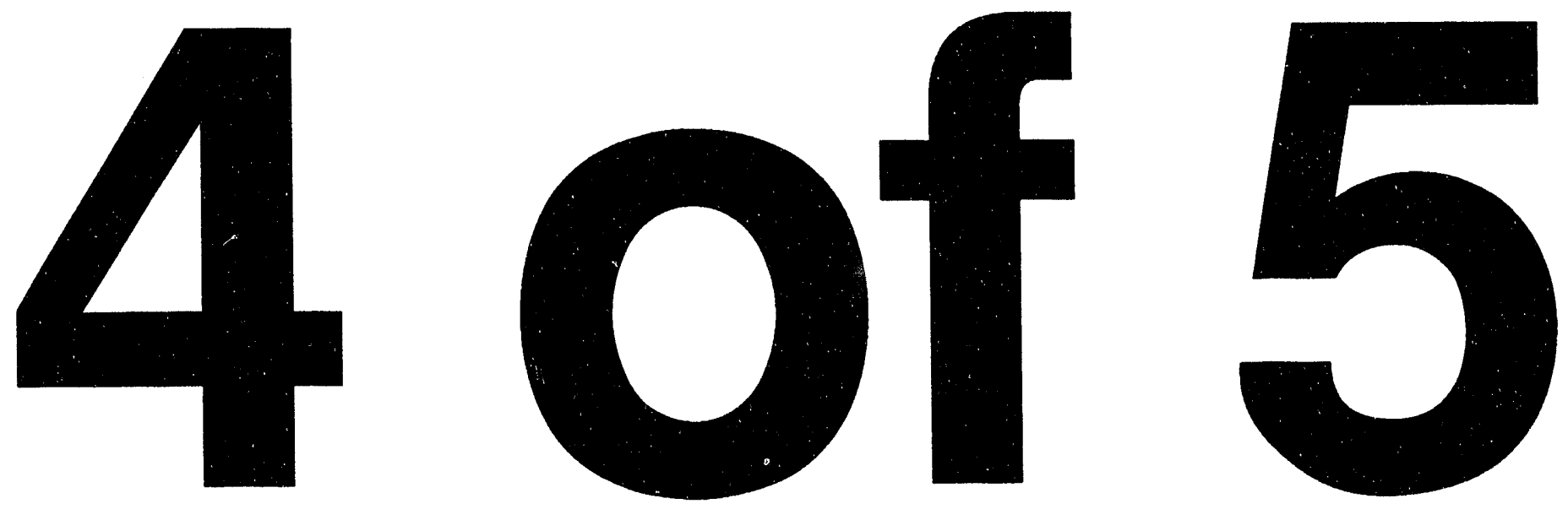


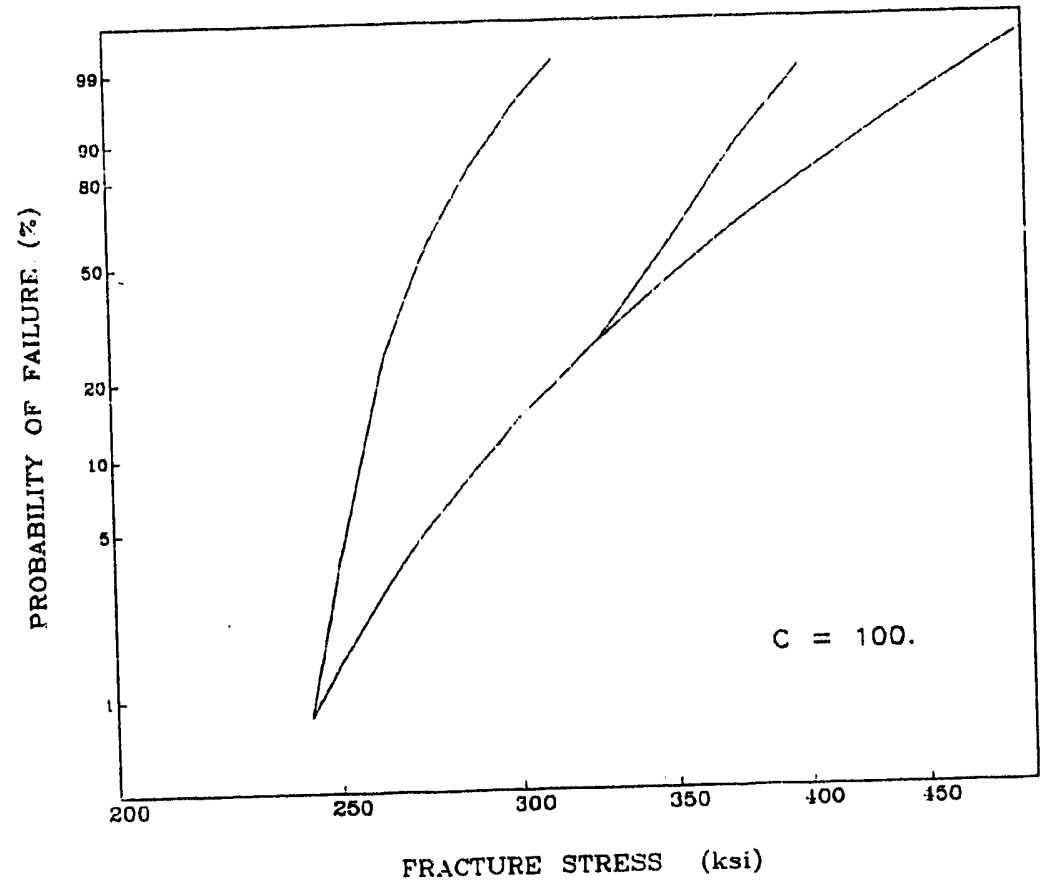

(c)

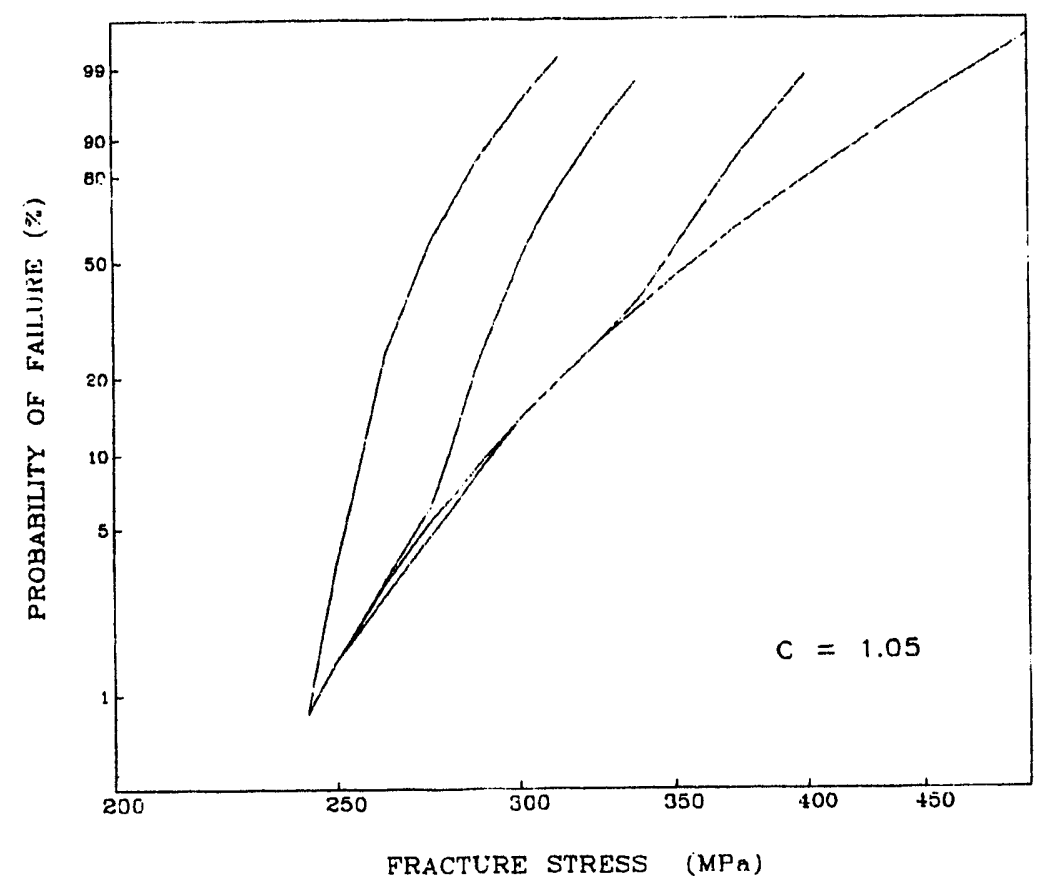

(d)

Figure 5 (Continued) 

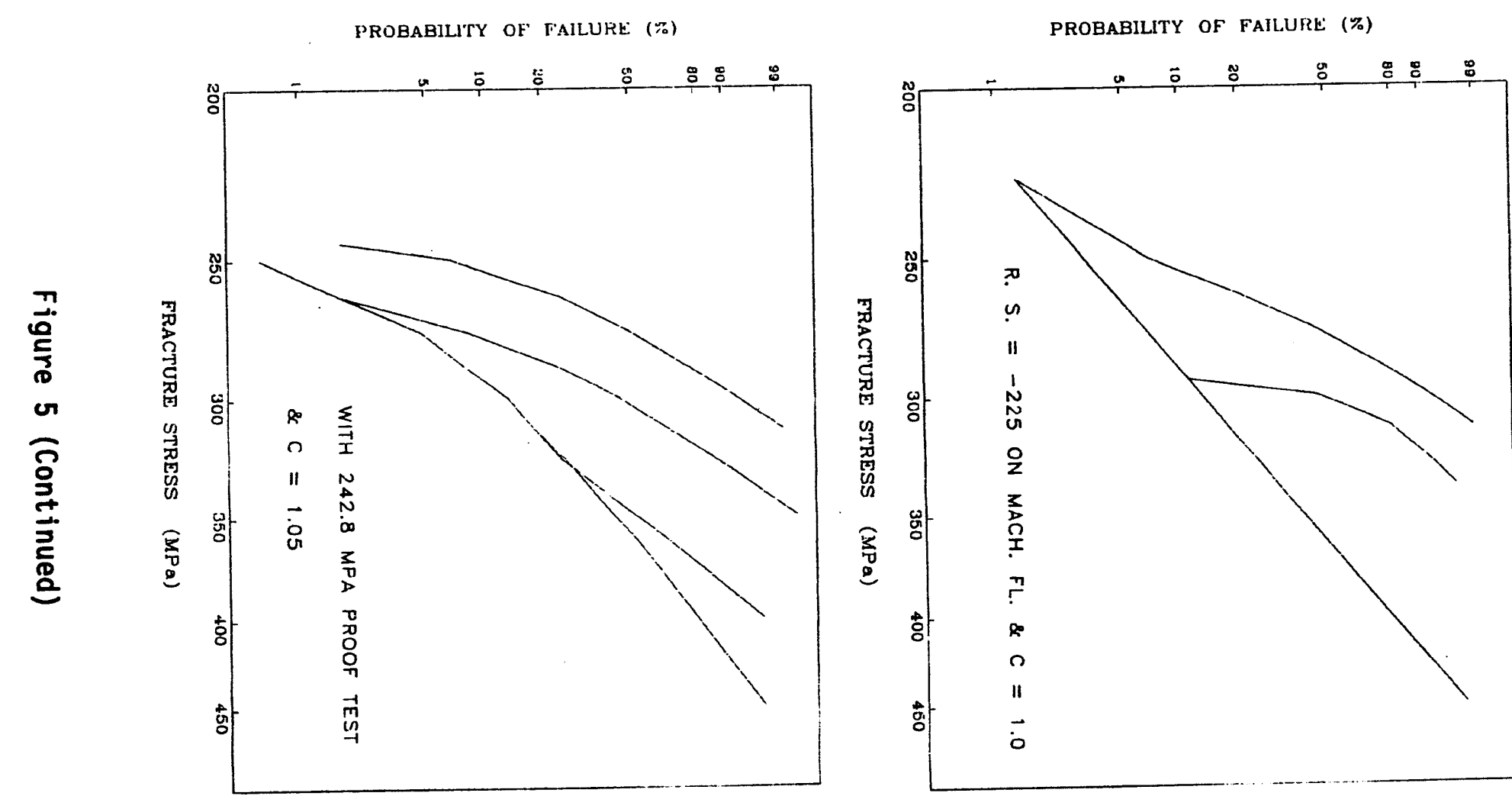

Ф 


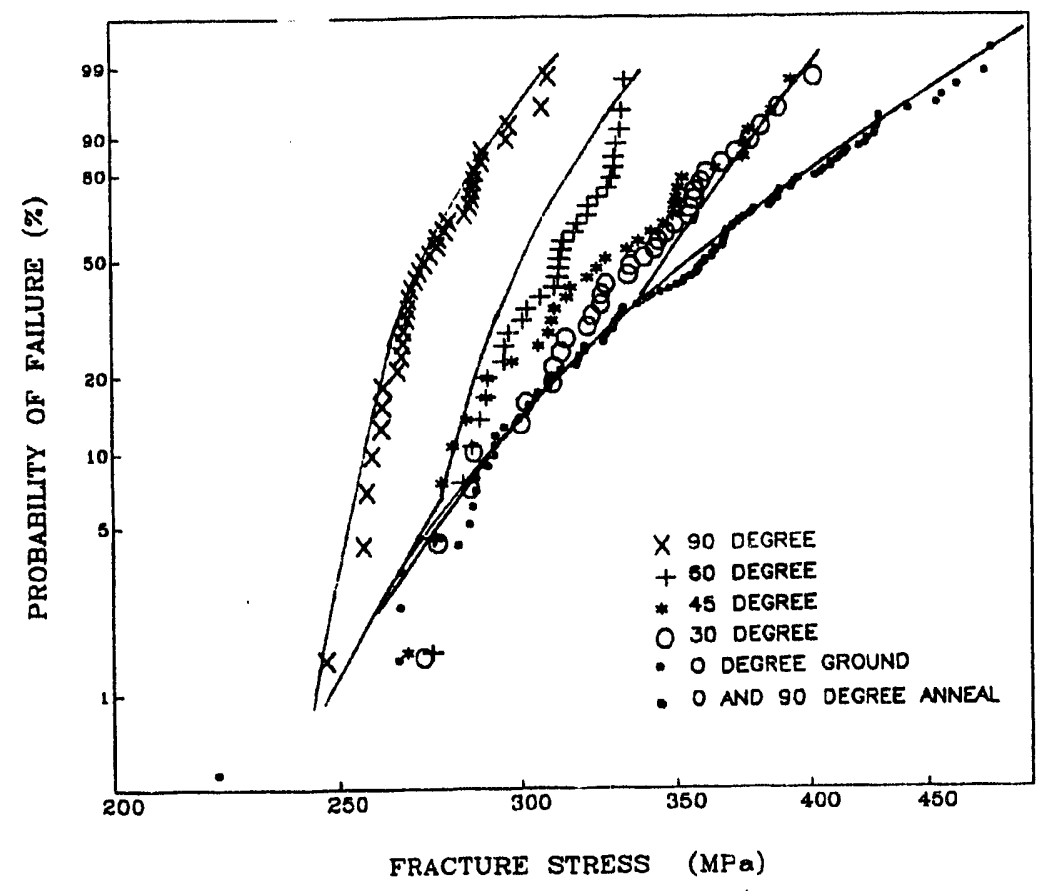

(a)

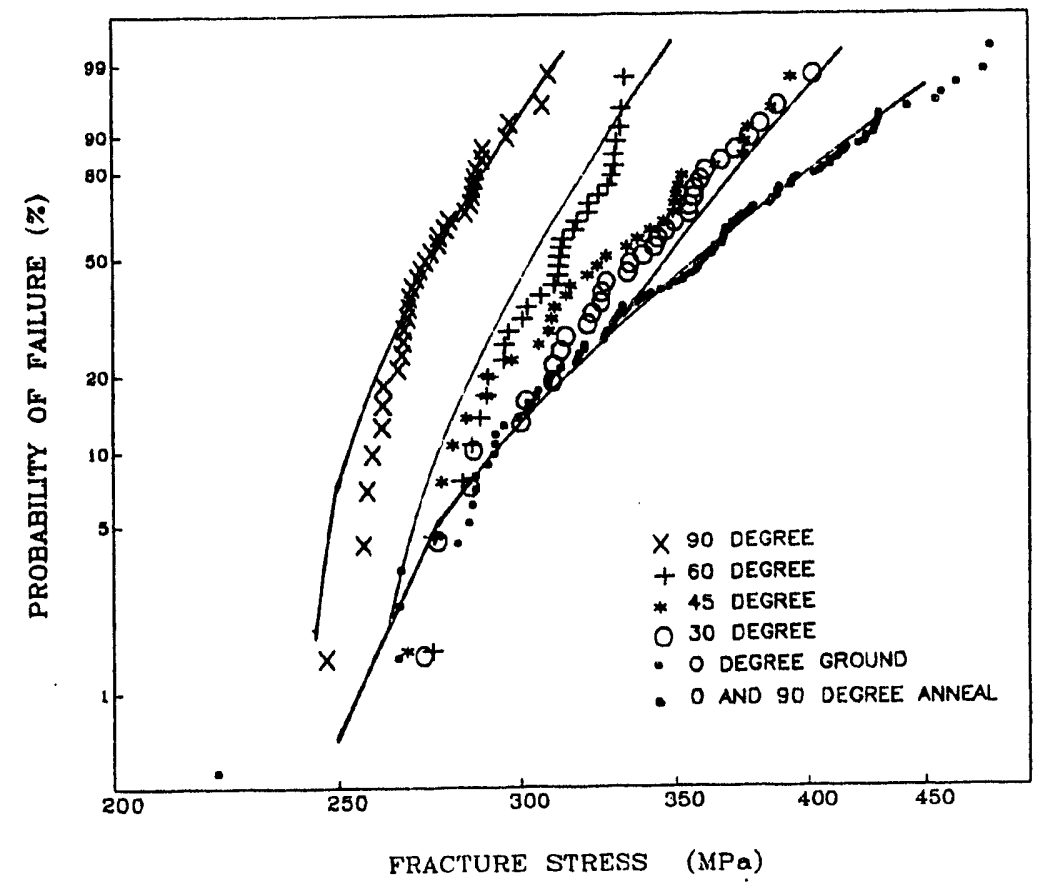

(b)

Figure 6. - Experimental data and (a) three parameter shear sensitive model and (b) two parameter shear sensitive model with a truncation load (truncated Weibull distribution). 
Life Prediction Methodology

P K. Khandelwal (Allison Engine Company)

Objective/Scope

The objective of this project is to develop and demonstrate the necessary nondestructive examination (NDE) technology, materials data base, and design methodology for predicting useful life of structural ceramic components of advanced heat engines. The analytical methodology will be demonstrated through confirmatory testing of ceramic components subject to thermal-mechanical loading conditions similar to those anticipated to occur in actual vehicular service. The project addresses fast fracture, slow crack growth, creep, and oxidation failure modes.

\section{Technical Highlights}

\section{Data Base Development}

\section{Uniaxial Tensile Testing (Button-Head)}

Monotonic tensile testing of 262 PY6 injection molded and hot isostatic pressing (HIP processed) silicon nitrides between $1000^{\circ} \mathrm{C}$ and $1400^{\circ} \mathrm{C}$ at $4137 \mathrm{MPa} / \mathrm{min}(600 \mathrm{KSI} / \mathrm{min})$ was completed during this reporting period at Southern Research Institute (SoRI). The entire data set was analyzed during this reporting period using the NASA CARES program to estimate the Weibull modulus $(\mathrm{m})$ and characteristic strength $\left(\sigma_{0}\right)$ of the material at each temperature. The two parameter Weibull analysis utilized the maximum likelihood estimator (MLE) with suspended items. Table 1 summarizes the results. The room temperature Weibull modulus $(\mathrm{m})$ and characteristic strength $\left(\sigma_{0}\right)$, respectively, were calculated to be 7.3 and $86.25 \mathrm{KSI}$ for surface defects and 6.9 and $64.0 \mathrm{KSI}$ for volume flaws. At elevated temperatures, between $1000^{\circ} \mathrm{C}$ and $1400^{\circ} \mathrm{C}$, the Weibull moduli varied between 3.3 and 7.1 for both the surface and volume defects except at $1300^{\circ} \mathrm{C}$ when calculated to be 11.75 for volume defects. The characteristic strength $\left(\sigma_{0}\right)$ varied between 51 and $72 \mathrm{KSI}$ within the same temperature range. Note that the Weibull modulus for volume defects at elevated temperatures is equal to or higher than that for surface defects. This may due to surface oxidation effects which probably modified the surface flaw characteristics and distribution during the heat-up and soaking of specimens for 10-15 minutes to obtain steady state temperatures prior to testing.

\section{Tensile Creep Rupture Testing}

SoRI completed the tensile creep rupture testing of 95 specimens from $1150^{\circ} \mathrm{C}$ to $1400^{\circ} \mathrm{C}$ to ascertain the slow crack growth and creep behavior of the PY 6 injection molded and HIP processed silicon nitride material. Modeling of the data has been completed at Allison and will be discussed elsewhere in this report. Failure analysis to date at Allison, ORNL, and SoRI has not shown any classical slow crack growth behavior in the PY6 material characterized under the present program. The ORNL cold isostatically pressed (CIP processed) and HIP processed material showed extensive cavitation even at $1200^{\circ} \mathrm{C}$ after a prolonged period of testing. Similar orders of magnitude of cavitation were observed in the Allison vintage injection molded and HIP processed PY 6 material at $1400^{\circ} \mathrm{C}$. In other words, the injection molded material is 
Table 1.

Summary of maximum likelihood (MLE) analysis of tensile fast fracture strength data using NASA CARES program.

\begin{tabular}{|c|c|c|c|c|c|c|c|c|c|c|}
\hline Temp & $\begin{array}{l}\text { Flaw } \\
\text { type }\end{array}$ & $\begin{array}{l}\text { Number of } \\
\text { specimens }\end{array}$ & $\underline{M}$ biased & Upper M & Lower M & $\begin{array}{l}\text { Char. } \\
\text { strength } \\
\text { KSI }\end{array}$ & $\begin{array}{l}\text { Upper } \\
\text { C.S. } \\
\text { KSI }\end{array}$ & $\begin{array}{l}\text { Lower } \\
\text { C.S. } \\
\text { KSI }\end{array}$ & $\begin{array}{c}\text { Mean } \\
\text { KSI }\end{array}$ & $\begin{array}{l}\text { Std. } \\
\text { dev. } \\
\text { KSI }\end{array}$ \\
\hline \multirow[t]{2}{*}{25} & Surface & 6 & 7.318 & 10.5 & 3.004 & 86.25 & 98.97 & 75.86 & 80.87 & 13.04 \\
\hline & Volume & 50 & 6.868 & 8.042 & 5.588 & 63.98 & 66.34 & 61.72 & 59.79 & 10.22 \\
\hline \multirow[t]{2}{*}{1000} & Surface & 10 & 3.351 & 4.54 & 1.854 & 74.05 & 90.31 & 61.11 & 66.48 & 21.88 \\
\hline & Volume & 10 & 4.368 & 5.919 & 2.417 & 72.73 & 84.69 & 62.76 & 66.25 & 17.16 \\
\hline \multirow[t]{2}{*}{1100} & Surface & 12 & 5.505 & 7.32 & 3.273 & 52.69 & 58.62 & 47.49 & 48.65 & 10.2 \\
\hline & Volume & 6 & 7.12 & 10.22 & 2.923 & 58.19 & 67.03 & 51 & 54.48 & 9.01 \\
\hline \multirow[t]{2}{*}{1200} & Surface & 53 & 5.412 & 6.323 & 4.411 & 50.95 & 53.33 & 48.69 & 46.99 & 10.01 \\
\hline & Volume & 21 & 6.647 & 8.361 & 4.635 & 58.95 & 62.76 & 55.42 & 54.99 & 9.694 \\
\hline \multirow[t]{2}{*}{1300} & Surface & 4 & 6.436 & 0 & 0 & 72.22 & 0 & 0 & 67.26 & 12.22 \\
\hline & Volume & 15 & 11.75 & 15.26 & 7.511 & 59.17 & 61.79 & 56.71 & 56.65 & 5.852 \\
\hline \multirow[t]{2}{*}{1400} & Surface & 27 & 3.946 & 4.872 & 2.881 & 57.1 & 62.66 & 52.09 & 51.72 & 4.69 \\
\hline & Volume & 30 & 6.501 & 7.909 & 4.899 & 53.41 & 56.21 & 50.78 & 49.77 & .955 \\
\hline
\end{tabular}

C.S. - Characteristic strength

substantially more creep resistant than the CIP processed material. This conclusion agrees extremely well with the findings of the Wiederhorn, et. al., at National Institute of Science and Technology (NIST) for the injection molded PY 6 material tested under the Allison Ceramic Life Prediction program.

\section{Nondestructive Evaluation Development (NDE)}

During this reporting period reference standards were fabricated and examined. Ultrasonic velocity of silicon nitride and single crystal sapphire in the C-axis direction are nearly identical. Sapphire single crystal imaging standards were fabricated at the University of California, Berkeley, using a USAF-1951 resolution master pattern to create subsurface voids by ionetching a photoresist layer on the surface of an optical quality sapphire billet. The pattern was etched on the surfaces of two $2 \mathrm{~mm}$ thick billets. One such billet was diffusion bonded by hot pressing to a $2 \mathrm{~mm}$ thick sapphire billet and the other to a $4 \mathrm{~mm}$ thick billet, respectively (Figure 1). This facilitated line-pair defects $2 \mathrm{~mm}$ and $4 \mathrm{~mm}$ below the surface. The $2 \mathrm{~mm} \times 2$ $\mathrm{mm}$ billet was examined using a $50.0 \mathrm{MHz}$ focused transducer with a focal length of 0.5 inch and 
NUMBER OF LINES PER MILLIMETER IN USAF

RESOLVING POER TEST TARGET 1951

\begin{tabular}{|c|c|c|c|c|c|c|c|}
\hline \multicolumn{7}{|c|}{ GROUP NUMBER } \\
\hline EUMT & 0 & 1 & 2 & 3 & 4 & 5 & 6 \\
\hline 1 & 1.00 & 2.00 & 4.00 & 8.0 & 32.0 & 32.0 & 64.0 \\
\hline 2 & 1.12 & 2.24 & 4.49 & 8.98 & 17.95 & 36.0 & 71.8 \\
\hline 3 & 1.26 & 2.52 & 5.04 & 10.1 & 20.16 & 40.3 & 80.6 \\
\hline 4 & 1.41 & 2.83 & 5.66 & 11.3 & 22.62 & 45.3 & 90.5 \\
\hline 5 & 1.59 & 3.17 & 6.35 & 12.7 & 25.39 & 50.8 & 102. \\
\hline 6 & 1.78 & 3.56 & 7.13 & 14.3 & 28.51 & 57.0 & 114. \\
\hline
\end{tabular}


a transducer lens diameter of 0.25 inch. A line-pair $210 \mu \mathrm{m}$ apart $2 \mathrm{~mm}$ below the surface was resolved (Figure 2). Many other voids were also detected because of the somewhat poor bonding of the sapphire billets in the unctched areas. The line-pair resolution in the $4 \mathrm{~mm} \times 2 \mathrm{~mm}$ specimen was $315 \mu \mathrm{m}$ at a depth of $4 \mathrm{~mm}$ below the surface using a $50 \mathrm{MHz}, 1.5$ inch nominal focal length transducer. Signal processing schemes are being explored to further improve the sub-surface resolution.

Reference specimens with pilot and laser drilled holes in a flat rectangular billet were examined using a pulse-echs ultrasonic imaging method to ascertain the detection of volume flaws. Four zones with seven holes/zone of pilot holes were fabricated at various depths ranging from $0.5 \mathrm{~mm}$ to $3 \mathrm{~mm}$ at Bullen Ultrasonics, Eaton, Ohio. Excimer laser drilled holes, each with a $1 \mathrm{~mm}$ depth and either a $50 \mu \mathrm{m}, 100 \mu \mathrm{m}$, or $250 \mu \mathrm{m}$ size diameter, were drilled into the pilot holes by Resonatics, Inc. This billet was examined using a $25 \mathrm{MHz}$ nominal frequency 3 in. fucal length transducer with a water path of about $2.75 \mathrm{~mm}$. The 50 micron laser drilled holes were readily detected to a subsurface depth of $14 \mathrm{~mm}(0.55 \mathrm{in}$.) (Figure 3$)$. A time-of-flight measurement of the hole depth showed that the holes were drilled within 10 percent of the desired depth. In other words, Excimer laser is capable of drilling 50 micron diameter holes with an aspect-ratio of $20 / 1$ within 10 percent accuracy. It should be noted, however, the quality of the bottom of the holes is unknown.

\section{Analytical Methodology}

During this reporting period, three failure mechanisms were addressed for PY6 material.

- fast fracture

- subcritical crack growth

- oxidation

A summary of work accomplished in each of these follows:

- Fast fracture analysis of PY6 MOR MIL-B data from room temperature to $1400^{\circ} \mathrm{C}$ was completed using the CARES program. Development and verification of a methodology of consolidating fast fracture data in the range of $1000^{\circ} \mathrm{C}$ to $1400^{\circ} \mathrm{C}$ using a single Weibull exponent was accomplished. Finally, a fast fracture methodology was developed to predict strength of confirmatory biaxial ball-on-ring specimens using uniaxial test bar Weibull properties.

- We demonstrated the consistency of slow crack growth material constants obtained from constant stress rate testing by four different labs using three specimen geometries in both axial and four point bend loading. Differences between SCG constants obtained from static and dynamic load testing resulted in the initial formulation of a methodology to consider both SCG and oxidation to better define the material constants. Finally it was shown that SCG data obtained from static tensile data could be used to predict results of static biaxial ball-on-ring tests at $1200^{\circ} \mathrm{C}$.

- A methodology to predict the effect of oxidation time and temperature upon the strength of PY6 MOR bar room temperature strength was developed. Material constants obtained from measuring the rate of oxide thickness development were shown to agree reasonably well with those obtained from strength measurements. 


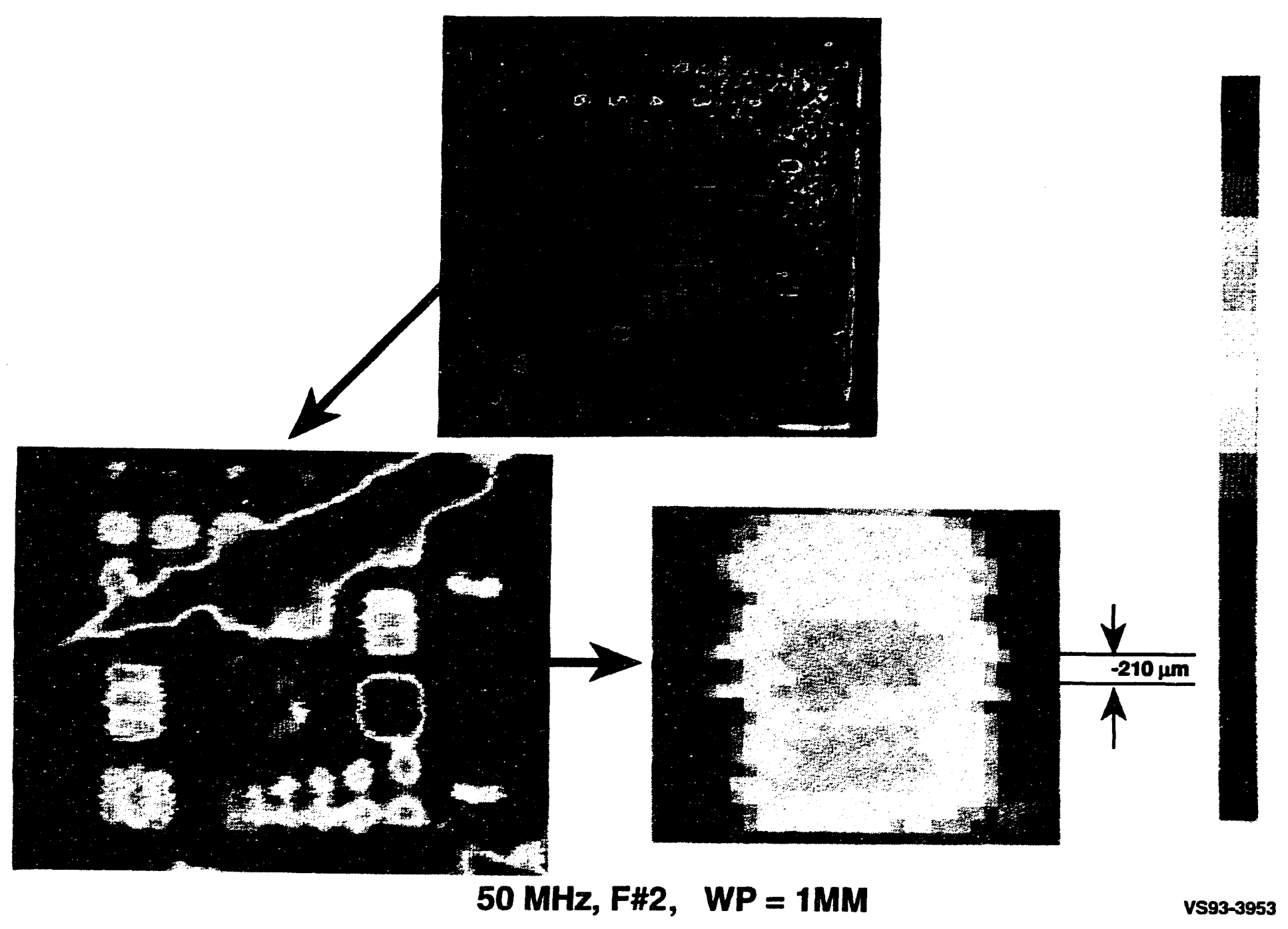

Figure 2. Acoustic microscopy of sapphire standard $2 \mathrm{~mm}$ below the surface showing line-pairs 210 miles apart were resolved. 

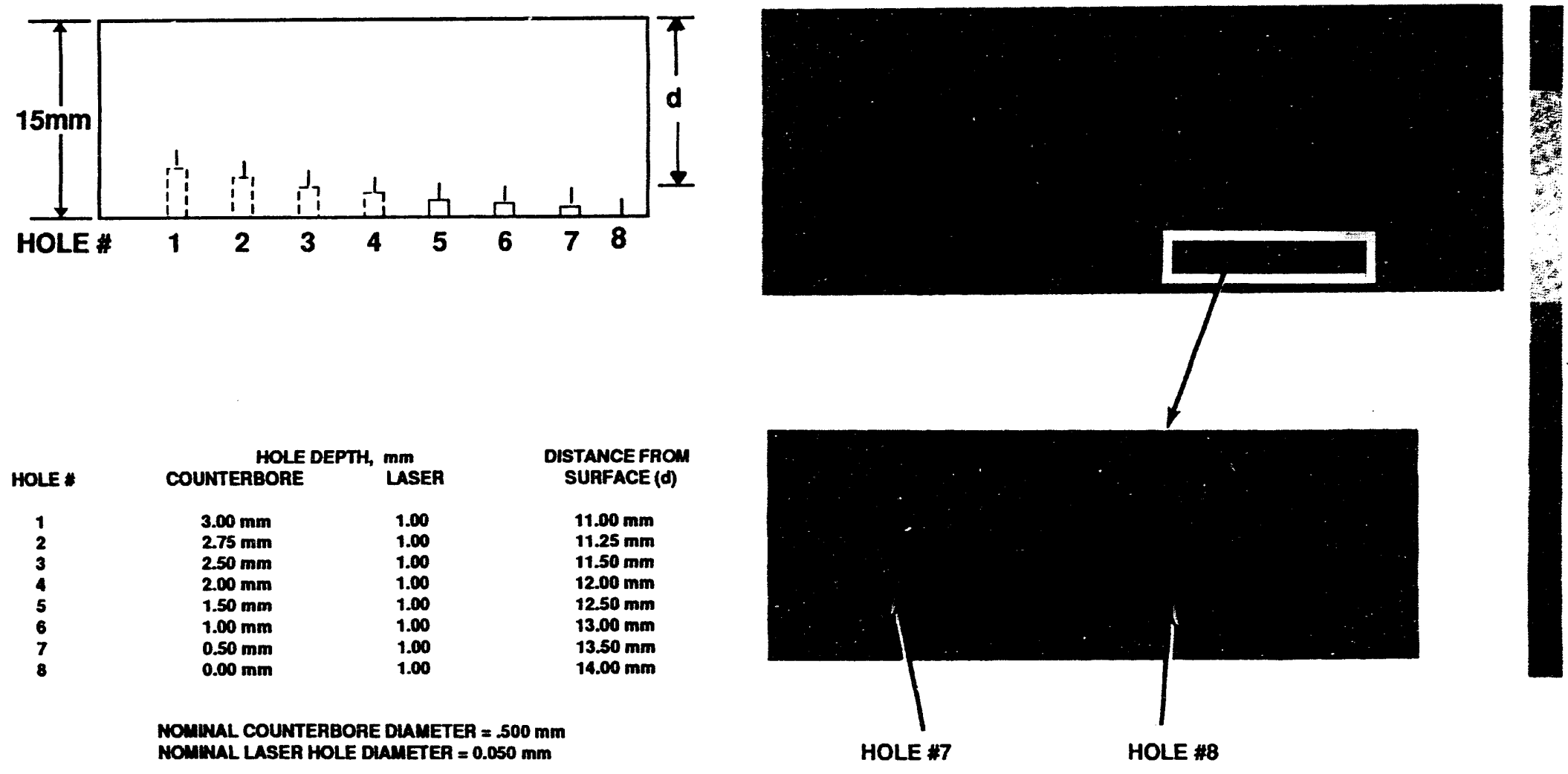

NOMIMAL COUNTERBORE DLAMETER $=.500 \mathrm{~mm}$ NOMNAL LASER HOLE DIAMETER $=0.050 \mathrm{~mm}$

DISTANCE FROM
SURFACE (d)
$11.00 \mathrm{~mm}$
$11.25 \mathrm{~mm}$
$11.50 \mathrm{~mm}$
$12.00 \mathrm{~mm}$
$12.50 \mathrm{~mm}$
$13.00 \mathrm{~mm}$
$13.50 \mathrm{~mm}$
$14.00 \mathrm{~mm}$

$14.00 \mathrm{~mm}$

HOLE \#7

DETECTED 50 um DIA. HOLES

Figure 3. Ultrasonic detected $50 \mu \mathrm{m}$ diameter holes $14 \mathrm{~mm}$ below the surface. 


\section{Fast Fracture Analysis}

\section{Mil-B MOR Uniaxial Specimens}

The PY6 injection molded and HIP processed Type MIL-B MOR bars have been characterized at Allison from room temperature to $1400^{\circ} \mathrm{C}$. A total of 320 specimens were evaluated at a cross-head speed of $0.5 \mathrm{~mm} / \mathrm{min}$ in a servo-hydraulic MTS system. The data regression for surface, volume, and corner failures was accomplished using the CARES program and the MLE methodology with suspended item analysis. Table 2 summarizes the data.

At room temperature, specimen failures are particularly influenced by surface or corner features. Eighty percent of the specimens failed from corner flaws while the remaining failed from the surface flaws. These failures are generally influenced by the process-induced, naturally occurring defects, machining marks on the surface, residual stresses, or stress risers at the cormers.

Table 2.

Summary of CARES analysis of PY6 MIL-B MOR bar testing using MLE analysis with suspended items.

\begin{tabular}{|c|c|c|c|c|}
\hline $\begin{array}{l}\text { Temperature } \\
{ }^{\circ} \mathrm{C}\end{array}$ & $\begin{array}{l}\text { Flaw } \\
\text { type }\end{array}$ & $\begin{array}{l}\text { Number of } \\
\text { specimens }\end{array}$ & $\begin{array}{l}\text { Weibull } \\
\text { exponent }\end{array}$ & $\begin{array}{l}\text { Characteristic } \\
\text { strength-ksi }\end{array}$ \\
\hline \multirow[t]{3}{*}{25} & Surface & 16 & 8.65 & 159 \\
\hline & Corner & 64 & 5.91 & 133.6 \\
\hline & Volume & 0 & -- & -. \\
\hline \multirow[t]{3}{*}{1000} & Surface & 7 & 14.5 & 124.3 \\
\hline & Corner & 9 & 8.76 & 124.5 \\
\hline & Volume & 4 & 20.9 & 126.7 \\
\hline \multirow[t]{3}{*}{1100} & Surface & 12 & 14.66 & 92.68 \\
\hline & Corner & 6 & 16.44 & 96.66 \\
\hline & Volume & 1 & -- & -- \\
\hline \multirow[t]{3}{*}{1200} & Surface & 52 & 11.28 & 99.32 \\
\hline & Corner & 21 & 6.64 & 115.4 \\
\hline & Volume & 15 & 11.21 & 111 \\
\hline \multirow[t]{3}{*}{1300} & Surface & 20 & 17.85 & 88.81 \\
\hline & Corner & 3 & 11.21 & 105.5 \\
\hline & Volume & 6 & 29.91 & 92.86 \\
\hline \multirow[t]{3}{*}{1400} & Surface & 54 & 12.95 & 72.66 \\
\hline & Corner & 21 & 11.6 & 78.76 \\
\hline & Volume & 4 & 11.98 & 90.24 \\
\hline
\end{tabular}


None of the specimens at room temperature failed from volume flaws primarily because of the small volume under high stress. Even at elevated temperatures, only a few volume failures were observed. Above $1000^{\circ} \mathrm{C}$ about 13 percent of the specimens failed from volume flaws, 62 percent failed on the surface, while corner failures were found in 25 percent of the specimens.

One of the problems incurred in the development of a ceramic design system is the large amount of testing necessary to obtain the fast fracture Weibull properties at operational temperatures. A possible approach in reducing the data requirements involves consolidating the elevated temperature data using a single Weibull modulus. While the surface Weibull exponent is calculated to be 8.6 at room temperature, except for the value of $m=18$ observed at $1300^{\circ} \mathrm{C}$, the Weibull exponent of $11-14$ remains in a tight range from $1000^{\circ} \mathrm{C}$ to $1400^{\circ} \mathrm{C}$. This suggests that it may be reasonable to consolidate the elevated temperature data using a single value of $(m)$.

It can be analytically demonstrated that for a group of specimens with a fast fracture strength dominated by Mode I failure, the Weibull exponent is independent of temperature. Further, individual specimen strengths may be normalized to a single base temperature by multiplying the ratio of average strength at the base temperature to that at the test temperature. Once fast fracture strengths are normalized to a single temperature, the CARES program, using the MLE methodology, may be used to find the Weibull exponent $(\mathrm{m})$. A Weibull characteristic strength is determined at each temperature by using the equation:

$$
\mathrm{S}=\mathrm{Sm} / \mathrm{Gamma}(1+1 / \mathrm{m})
$$

$$
\begin{aligned}
& S=\text { Characteristic strength } \\
& \text { Sm = Mean strength at each } \\
& \text { temperature } \\
& \text { Gamma = Gamma function }
\end{aligned}
$$

Finally, at each temperature, a Weibull plot must be made to verify that the consolidated $(\mathrm{m})$ results in a reasonable data fit.

In Table 3, only surface failures (no censored data) are used to determine the Weibull exponent and characteristic strength at each temperature from $1000^{\circ} \mathrm{C}$ to $1400^{\circ} \mathrm{C}$. All this elevated temperature data is then used to determine a consolidated value of $(\mathrm{m}), 11.97$ in this case. The characteristic strengths are then recomputed to be consistent with the new $(m)$. As can be seen, even at $1300^{\circ} \mathrm{C}$, the characteristic strengths do not change greatly. Figure 4 illustrates that the Weibull fit, using the consolidated $(\mathrm{m})$ value, works well even for the bulk of the $1300^{\circ} \mathrm{C}$ fast fracture data where a large discrepancy might have been expected. At other temperatures, the fit is even better.

The surface Weibull exponent $(\mathrm{m}=8.6)$ is smaller than observed at elevated temperatures. It is believed that at elevated temperatures the process and machining induced surface defects are modified and probably blunted, which decreases the number of corner failures and reduces the scatter in the surface strength as evidenced by an increased Weibull modulus at elevated temperatures.

Thus, while a theoretical argument suggests that $(\mathrm{m})$ is independent of temperature, it is essential that a Weibull plot be used to verify the fit after consolidated Weibull constants are obtained. (For PY6 the elevated temperature Weibull exponent results in a rather poor fit of room temperature data.) 
Table 3.

Comparison of surface Weibull constants using both a consolidated $(\mathrm{m})$ and isothermal data only. MLE analysis without suspended items.

$\begin{array}{llcccc}\begin{array}{l}\text { Temperature } \\ { }^{\circ} \text { C }\end{array} & \begin{array}{l}\text { Flaw type/ } \\ \text { number of } \\ \text { specimens }\end{array} & \begin{array}{l}\text { W-a--Baseline-----> } \\ \text { Weibull } \\ \text { exponent }\end{array} & \begin{array}{l}\text { Character } \\ \text { strength* }\end{array} & \begin{array}{l}\text { Weibull } \\ \text { exponent }\end{array} & \begin{array}{c}\text { Character } \\ \text { strength }\end{array} \\ 1000 & \text { Surface/7 } & 13.54 & 117.2 & 11.97 & 117.7 \\ 1100 & \text { Surface/12 } & 13.91 & 89.67 & 11.97 & 90.17 \\ 1200 & \text { Surface/52 } & 10.46 & 95.94 & 11.97 & 95.45 \\ 1300 & \text { Surface/20 } & 18.80 & 86.77 & 11.97 & 88.04 \\ 1400 & \text { Surface/54 } & 12.02 & 70.93 & 11.97 & 70.96\end{array}$

* Characteristic strength, ksi

\section{Ball-on-Ring Confirmatory Testing}

During this reporting period Battelle Research Laboratories, Columbus, Ohio, completed additional biaxial and MOR strength measurements at room temperature using flat circular disk specimens of $31.75 \mathrm{~mm}$ nominal diameter and $2.5 \mathrm{~mm}$ thickness. The disk surface was machined using a protocol developed at Battelle. The specimens were tested using a ball-onring arrangement and loaded at the center with a $6.35 \mathrm{~mm}$ diameter ball and supported at a 25.4 $\mathrm{mm}$ diameter. MOR specimens, cut from machined disks, ensured that both types of specimens had identical surface finishes.

The maximum stress on the disk occurs at the tensile surface at the center of the disk where both radial and tangential stresses are equal and given by:

$$
\operatorname{Smax}=3 P(1+M u) / 4 \mathrm{Pi}^{*} \mathrm{t}^{2}\left(1+2 \ln \mathrm{a} / \mathrm{b}+(1-\mathrm{MU}) /(1+\mathrm{Mu})^{*}\left(1-\mathrm{b}^{2} / 2 \mathrm{a}^{2}\right) \mathrm{a}^{2} / \mathrm{R}^{2}\right)
$$

where $P=$ load, $t=$ disk thickness, $a=$ support radius, $b=$ radius of center loading $(b=t / 3), R=$ disk radius, and $\mathrm{Mu}=$ Poisson's ratio taken as 0.28 at room temperature ( $\mathrm{Pi}=3.14159)$. Table 4 summarizes the measured disk stresses.

After several iterations, a promising approach was found that allowed the prediction of the biaxial results from uniaxial MOR testing. Initially, Weibull shape and scale parameters obtained from room temperature testing of longitudinally ground MIL-B MOR bars were used to 

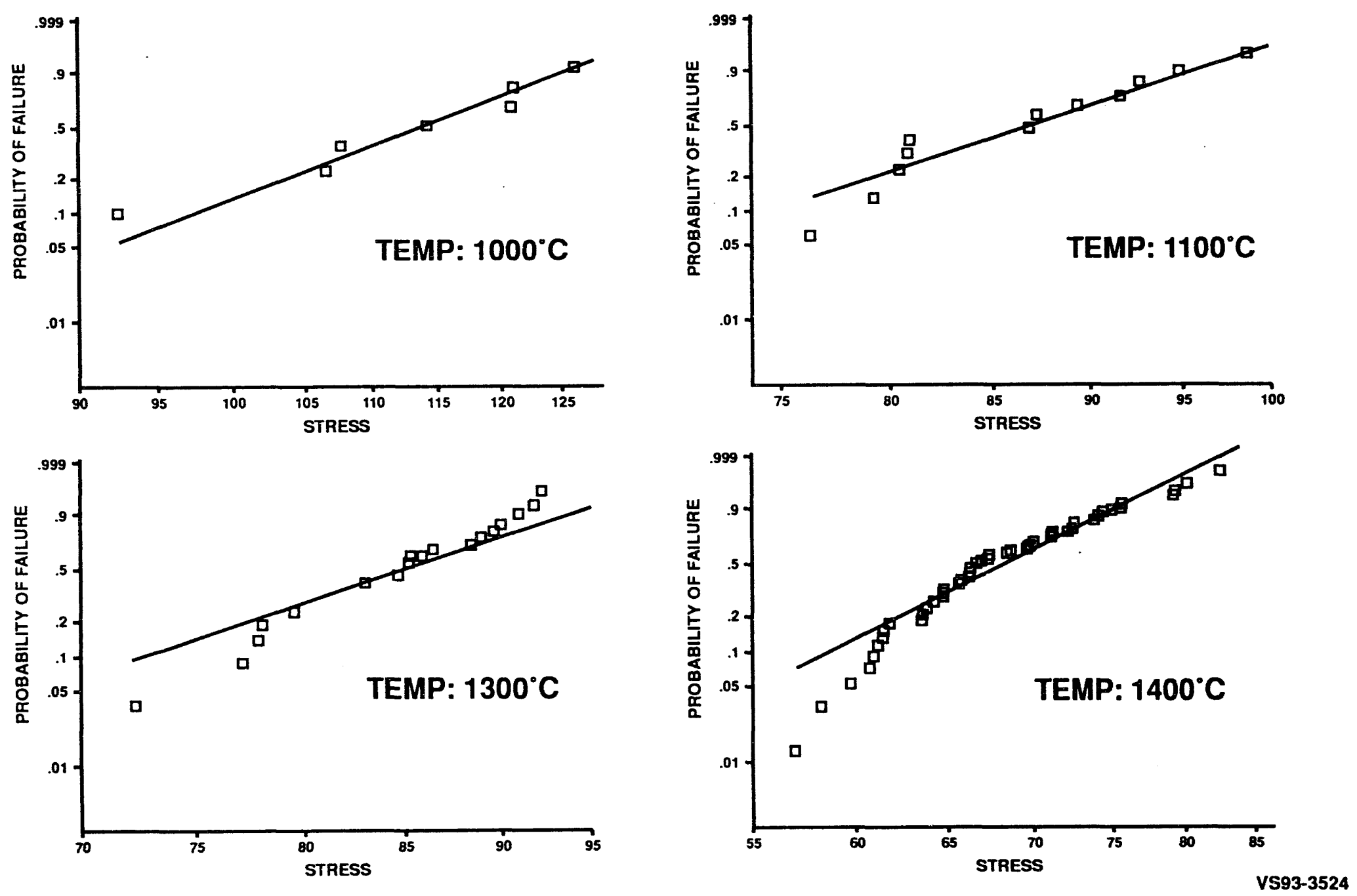

Figure 4. Comparison of predicted versus experimental results $\mathrm{PY}_{6} \mathrm{Si}_{3} \mathrm{~N}_{4} \mathrm{MOR}$ specimen overall Weibull modulus $=11.97$. 
Table 4.

Biaxial strength of PY 6 silicon nitride at $25^{\circ} \mathrm{C}$.

\begin{tabular}{lllll}
$\begin{array}{l}\text { Spec. } \\
\text { number }\end{array}$ & $\begin{array}{c}\text { Load } \\
\text { lb }\end{array}$ & $\begin{array}{c}\text { Dia., } \\
\text { in. }\end{array}$ & $\begin{array}{c}\text { Thick., } \\
\text { in. }\end{array}$ & $\begin{array}{c}\text { Strength } \\
\mathrm{MPa}\end{array}$ \\
\hline $4-81$ & 570 & 1.254 & 0.1000 & 813.44 \\
$4-82$ & 538 & 1.251 & 0.1000 & 767.97 \\
$4-83$ & 480 & 1.253 & 0.1000 & 685.06 \\
$4-84$ & 548 & 1.254 & 0.1000 & 782.04 \\
$4-86$ & 600 & 1.254 & 0.1005 & 846.48 \\
$4-88$ & 572 & 1.251 & 0.0995 & 825.90 \\
$4-90$ & 540 & 1.251 & 0.0995 & 779.70 \\
$4-92$ & 520 & 1.254 & 0.0995 & 750.63 \\
$4-93$ & 510 & 1.252 & 0.0995 & 736.32 \\
$4-98$ & 505 & 1.254 & 0.1000 & 720.68 \\
$3-1$ & 520 & 1.254 & 0.099 & 759.38 \\
$3-2$ & 490 & 1.253 & 0.099 & 715.63 \\
$3-9$ & 549 & 1.255 & 0.101 & 765.67 \\
$3-23$ & 483 & 1.252 & 0.099 & 705.47 \\
$3-34$ & 478 & 1.253 & 0.098 & 714.53 \\
$3-37$ & 460 & 1.253 & 0.099 & 671.82 \\
$3-38$ & 531 & 1.251 & 0.099 & 775.64 \\
$3-77$ & 517 & 1.254 & 0.099 & 755.00
\end{tabular}

predict the biaxial strengths. Results were not encouraging. In particular, the room temperature Weibull modulus of 8.6 differed greatly from the value of 17 found for the disk specimens. Fractographic examination of the ball-on-ring specimens showed that failure occurred on the tensile surface across machining marks. To better approximate the observed biaxial results, a set of MIL-B MOR bars were manufactured with 320 grit transverse machining and evaluated at room temperature. When this data was analyzed, the Weibull modulus was still found to be approximately 8 , again resulting in poor correlation.

Finally, $20 \mathrm{MOR}$ specimens were machined from ball-on-ring disk specimens. The specimen surface was first ground and polished identical to the biaxial disk specimens. MOR bars were then dissected from the disks such that machining marks were transverse to the specimen length. These MOR bars varied minimally in material and surface finish from the disk specimens and truly represented the surface condition of the biaxial disk specimen. The variables that tend to obscure the development of a multiaxial predictive methodology were minimized. The Weibull modulus of 20 observed on these MOR specimens agreed well with that of the disks.

Material properties from the MOR specimens cut from the disks were used to compute the disk characteristic strength using effective areas from two differing multiaxial models. In the 
first model, only the stress normal to machining marks was assumed to influence the fast fracture failure probability. In the second model, the effective area calculation was based upon the Weibull principal of independent action (PIA). Characteristic strength of the ball-on-ring specimens was predicted using the aforementioned two model approaches and Weibull properties of the transversely ground MOR specimens that were cut from the flat disks. Results were quite encouraging. The first model predicted a characteristic strength of $785 \mathrm{MPa}$ versus an experimental value of $776 \mathrm{MPa}$, a difference of only 1 percent. The PIA value of 759 was within 2 percent of the measured value. The predicted characteristic strength using the Weibull parameters of the transversely ground MIL-B bars was $979 \mathrm{MPa}, 26$ percent high (see table 5). This clearly indicates that the prediction of Weibull properties for biaxial loading conditions from uniaxial MOR specimen test data is extremely sensitive to the surface preparation of the specimens.

\section{Table 5.}

Comparison of the predicted characteristic strength of ball-on-ring specimens with the measured value.

\begin{tabular}{|c|c|c|c|c|c|c|}
\hline \multirow{2}{*}{$\begin{array}{l}\text { Baseline } \\
\text { trans. gr. } \\
\text { MOR spec. }\end{array}$} & \multirow[b]{2}{*}{$\begin{array}{l}\text { Applied } \\
\text { theory }\end{array}$} & \multicolumn{2}{|c|}{ <--- Baseline -.---> } & \multicolumn{3}{|c|}{ <-.- Ball-on-Ring -........- > } \\
\hline & & $\begin{array}{l}\text { Weibull } \\
\text { exponent }\end{array}$ & $\begin{array}{l}\text { Unit char. } \\
\text { strength }\end{array}$ & $\begin{array}{l}\text { Effect. } \\
\text { area }\end{array}$ & $\begin{array}{l}\text { Pred. ch. } \\
\text { strength }\end{array}$ & $\begin{array}{l}\text { Act. ch. } \\
\text { strength }\end{array}$ \\
\hline $\begin{array}{l}\text { Battelle } \\
\text { MOR }\end{array}$ & $\begin{array}{l}\text { Weibull } \\
\text { PIA }\end{array}$ & 20.19 & 412.6 & 4.58 & 759 & 776 \\
\hline $\begin{array}{l}\text { Battelle } \\
\text { MOR }\end{array}$ & $\begin{array}{l}\text { Stress nor. } \\
\text { mach. marks }\end{array}$ & 20.19 & 412.6 & 2.29 & 785 & 776 \\
\hline $\begin{array}{l}\text { Allison } \\
\text { MOR }\end{array}$ & $\begin{array}{l}\text { Weibull } \\
\text { PIA }\end{array}$ & 7.96 & 218.0 & 6.32 & 979 & 776 \\
\hline
\end{tabular}

The effective area in $\mathrm{mm}^{2}$, Characteristic strength in MPa,

Unit characteristic strength MPa-m 2/Weibull modulus. The effective area of the Battelle MOR bars was $87.84 \mathrm{~mm}^{2}$ based upon failure of the ground top surface only. Characteristic strength is related to unit characteristic by the equation:

$$
\begin{aligned}
\mathrm{Sc} & =\mathrm{So} /(\text { Aeff })^{1 / \mathrm{ms}} \quad \mathrm{Sc}=\text { characteristic strength } \\
& \text { So }=\text { unit ch. strength } \\
& \mathrm{ms}=\text { Weibull modulus }
\end{aligned}
$$


In Figure 5, assumptions from the first model are used along with MOR specimen properties to predict a 90 percent scatterband for the ball-on-ring disks. This was done by first using the following equation to convert the MOR measured strengths to that of the ball-on-ring specimens, which have a smaller effective area.

$$
\begin{array}{ll}
\mathrm{Sb}=\mathrm{Ss} *(\mathrm{As} / \mathrm{Ab})^{1 / \mathrm{ms}} & \mathrm{Ss}=\text { measured specimen strength } \\
\mathrm{Sb}=\text { ball-on-ring strength } \\
\mathrm{ms}=\text { specimen Weibull exponent, } 20.19 \\
\mathrm{As}=\text { specimen effective area (based on } \\
\text { top surface only) } \\
\mathrm{Ab}=\text { effective area of ball-on-ring }
\end{array}
$$

Table 6 summarizes the MOR test data. The CARES program was then used to find the predicted scatterband. When the measured disk results are plotted, the correlation appears to be quite good. All of the disk data lies within the 90 percent confidence band with a Weibull slope that visually is close to that predicted.

\section{Slow Crack Growth Methodology}

\section{Uniaxial Theory and Test Results}

Two experimental methods are commonly used to study the SCG behavior of ceramic materials:

- the constant load test (static fatigue)

- the constant load rate test (dynamic fatiguc)

In the constant load test, the rupture time of the specimens is determined at various applied stress levels. In the dynamic fatigue characterization of materials, the specimen failure strength is measured at various stressing rates. The governing equations for the two types of tests are as follows:

Constant load:

1) $\mathrm{Tf}=\mathrm{B}^{*} \mathrm{Si}^{\mathrm{N}-2} * \mathrm{~S}^{-\mathrm{N}} * \operatorname{EXP}(\mathrm{Q} / \mathrm{RT})$

Constant rate:

2) $\mathrm{Sf}=\left(\mathrm{B}^{*}(\mathrm{~N}+1)^{*} \mathrm{Si}-\mathrm{N}-2 \dot{\mathrm{S}}\right)^{1 /(N+1)} * \operatorname{EXP}\left(\mathrm{Q} / \mathrm{RT}^{*}(1+\mathrm{N})\right)$

$$
\begin{aligned}
& \text { Where: } \quad \mathrm{Tf}=\text { time to failure (constant load test) } \\
& \text { Sf }=\text { fracture strength (rate test) } \\
& \mathrm{Si}=\text { initial, fast fracture, strength } \\
& \dot{\mathbf{S}}=\text { applied stress } \\
& \mathrm{S}=\text { applied stress rate } \\
& \mathrm{T}=\text { temperature (absolute) } \\
& Q=\text { activation energy (material constant) } \\
& \mathrm{B}, \mathrm{N}=\text { material constants }
\end{aligned}
$$




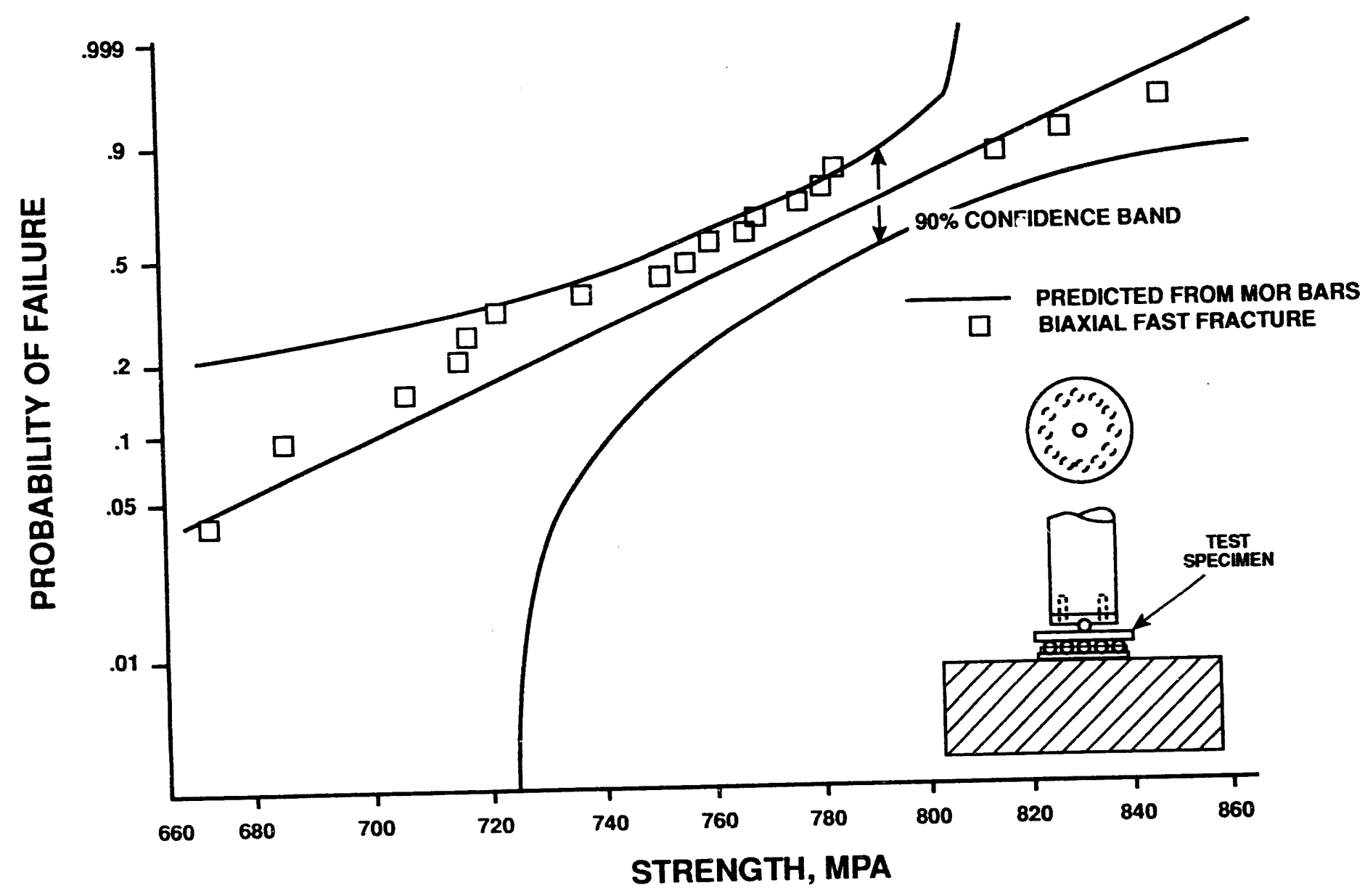

Figure 5. Biaxial ball-on-ring confirmatory test room temperature prediction versus experimental results. 
Table 6.

Strength of the Battelle MOR specimens used to predict strength of ball-on-ring specimens.

\section{MOR spec.}

1

2

3

4

5

6

7

8

9

10

11

12

13

14

15

16

17

18

19

20
Strength-MPa

of MOR bar

614.3

602.9

604.1

627.4

651.6

665.4

613.3

611.2

586.4

605.0

620.2

597.1

669.8

608.6

692.5

682.4

681.3

671.1

676.9

686.5
Predicted strength of

ball-on-ring specimen

735.9

722.2

723.7

751.6

780.7

797.1

734.7

732.2

702.5

724.7

743.0

715.3

802.4

729.1

829.6

817.5

816.2

804.0

810.9

822.4

The predicted strength is based upon:

As $=87.84 \mathrm{~mm}^{2}$

$\mathrm{Ab}=2.29 \mathrm{~mm}^{2}$

$\mathrm{ms}=20.19$

Constant rate or dynamic fatigue behavior of four groups of PY6 specimens was measured and analyzed using equation (2). The most comprehensive data set was developed at Allison on 120 Type-B MOR bars, which were identified to have failed on the surface. Testing occurred in the temperature range of $1200-1400^{\circ} \mathrm{C}$. A second set of 29 Type-B MOR bars were tested from $1000-1400^{\circ} \mathrm{C}$ under a user agreement at Oak Ridge National Laboratories with the direction of Dr. M. K. Ferber. A third set of 28 button head tensile specimens was tested at SoRI at various temperatures and test rates. A final group of 18 dogbone tensile specimens was tested at NIST under Dr. S. M. Wiederhorn.

Table 7 summarizes the results. As can be seen, all four of the data sets result in similar values of the activation energy $(Q)$ and the crack velocity exponent $(N)$. The consistency of the crack velocity exponent was quite encouraging. The value of $B$, which is, quite sensitive to the 
Table 7.

Comparison of PY6 SCG constants obtained from differing specimen testing.

\begin{tabular}{|c|c|c|c|c|c|c|}
\hline Source & $\begin{array}{l}\text { Temperature } \\
\text { degrees } C\end{array}$ & $\begin{array}{l}\text { No. of } \\
\text { spec }\end{array}$ & $\begin{array}{l}\text { Specimen } \\
\text { type }\end{array}$ & $\begin{array}{l}\text { Norton } \\
\text { exponent }\end{array}$ & $\begin{array}{l}\text { Coefficient } \\
\text { MPa2-sec }\end{array}$ & $\begin{array}{l}\text { Activation } \\
\text { energy } \\
\text { KJ/MOLE }\end{array}$ \\
\hline Allison & $1200-1400$ & 120 & MIL-B MOR & 17.2 & $3.44 \mathrm{E}-4$ & 277 \\
\hline Oak Ridge & $1000-1400$ & 29 & MIL-B MOR & 20.2 & $4.43 E-4$ & 206 \\
\hline SoRI & $1000-1400$ & 28 & $\begin{array}{l}\text { Buttonhead } \\
\text { Tensile }\end{array}$ & 17.8 & $2.74 \mathrm{E}-6$ & 283 \\
\hline NIST & $1000-1400$ & 18 & $\begin{array}{l}\text { Dog-bone } \\
\text { Tensile }\end{array}$ & 16.3 & $8.90 \mathrm{E}-4$ & 231 \\
\hline
\end{tabular}

fast fracture strength estimate, was within a factor of two for three of four data sets, which is quite reasonable. Overall, considering the small size of some of the data sets, the results appear quite consistent and yield SCG constants that can be used in a probabilistic SCG model, such as that which has been added to the CARES program.

The button head type of tensile specimen, dynamically tested at SoRI, was also statically tested at the same laboratory. An analysis of the static data, using equation (1), resulted in slow crack growth constants considerably different from those obtained dynamically. As can be seen in table 3 , the crack velocity exponent is 50.9 versus 17.8 from dynamic testing. The activation energy of $587 \mathrm{KJ} /$ Mole is more than twice that of the dynamic test. When static test data was predicted by using dynamic material constants, the correlation was found to be conservative. The strength of the specimens was predicted to drop more quickly with time than was observed. Thus, dynamic fatigue results might be inherently conservative when used in a design system.

The different results between the two types of testing used to determine PY6 slow craik growth constants indicate the possibility of other mechanisms, particularly oxidation, influencing the results. In dynamic fatigue, most of the exposure time is spent at a stress level less than that resulting in failure. In static loading, all of the time is spent at the fracture stress. Oxidation may be causing additional damage, related primarily to exposure time. If this is the case, at failure, the ratio of oxidation damage to SCG damage would be greater in the dynamic fatigue tests, resulting in apparently smaller crack velocity exponents. 
Table 8.

Comparison of static and dynamic slow crack growth testing of buttonhead tensile specimens.

$\begin{array}{lcccc}\begin{array}{l}\text { Type of } \\ \text { test }\end{array} & \begin{array}{l}\text { Number of } \\ \text { specimens }\end{array} & \begin{array}{l}\text { Crack velocity } \\ \text { exponent-N }\end{array} & \begin{array}{c}\text { Activation } \\ \text { energy KV/M }\end{array} & \begin{array}{c}\text { B 2 } \\ \text { MPA-SEC }\end{array} \\ \text { Dynamic fatigue } & 28 & 17.8 & 283 & 2.74 \mathrm{E}-6 \\ \text { Static fatigue } & 31 & 50.9 & 587 & 1.88 \mathrm{E}-25\end{array}$

A model that assumes the crack length caused by oxidation at temperature is proportional to the exposure time raised to a power has been shown capable of quanitizing the reduction of strength on PY6 MOR specimens. Combining this oxidation model with classical crack growth equations results in the following nonlinear differential equation, which describes the change of strength with time:

3) $\mathrm{DS} / \mathrm{DT}=-\mathrm{Sa}^{\mathrm{N}} * \mathrm{~S}^{3-N} /(\mathrm{N}-2)^{*} \mathrm{~B}-\mathrm{B} 1 * \mathrm{~S}^{3} \mathrm{tal}^{\mathrm{al}}$

$\mathrm{B}, \mathrm{N}=$ slow crack growth constants as used in equations 1 and 2

$B_{1}, a_{1}=$ oxidation constants

$\mathrm{S}=$ the specimen strength

$\mathrm{Sa}=$ the applied stress

In the case of static fatigue, the applied stress is constant. During dynamic fatigue, the applied stress is proportional to time. In both cases, the strength decreases with time and failure occurs when the applied stress exceeds the specimen strength. The initial strength is the measured fast fracture strength.

If this model results in a better physical description of the static and dynamic tests, a single set of four material constants B, N, B1, and a1 should allow the model to fit both the static and dynamic test results. This is currently being investigated for the buttonhead specimen tested by SoRI. If this model is valid, the values of $B$ and $N$ should be close to those found from static loading.

\section{Biaxial Verification-Ball-on-ring Testing}

At $1200^{\circ} \mathrm{C}$, Battelle Laboratories completed biaxial static fatigue measurements on 10 flat circular plates using the ball-on-ring arrangement. These specimens had a 31.75 nominal diameter and a $1.78 \mathrm{~mm}$ thickness. Support was at $15.9 \mathrm{~mm}$. At elevated temperatures, available fast fracture data tends to indicate a lower sensitivity to the initial surface preparation. Certainly after oxide begins to form, this would be expected to be true. As a result, SCG constants obtained from buttonhead tensile specimens in static loading were used to predict the biaxial results. The initial strength of the ball-on-ring specimen was estimated using the MIL-B MOR 
fast fracture results and the model which correlated the room temperature ball-on-ring data. As can be seen in Figure 6, the prediction appears to fit the data quite well.

\section{Oxidation Methodology}

During this period, work was done in developing a statistical methodology applicable to oxidation damage on a PY6 component.

The model is based on four assumptions:

- The oxide thickness increases with time following a log linear relationship.

- The temperature dependence can be consolidated using an Arrhenius relationship.

- The flaw resulting in failure is proportional to the oxide layer thickness.

- Linear elastic fracture mechanics relate fracture strength and flaw size.

The equations describing the average behavior of oxide thickness growth and the effect of oxidation on strength can be written as follows:

4) $T h=C^{*} t^{a} * \operatorname{EXP}(-Q / R / T)$

5) $S=A^{*} K I C^{*} t^{-} .5 a * \operatorname{EXP}(.5 * Q / R / T)$

Where $T h=$ oxide thickness; $S=$ room temperature strength after exposure at temperature; $C, a$, and $A=$ material constants from a least square fit of data; $Q=$ activation energy; $R=$ gas constant; $\mathrm{KIC}=$ the room temperature fracture toughness, $\mathrm{t}=$ exposure time; and $\mathrm{T}=$ the absolute temperature.

In developing the material model, $65 \mathrm{Mil}-\mathrm{B}$ specimens were exposed to temperatures of $1260,1300,1371$, or $1400^{\circ} \mathrm{C}$ for periods of time varying from 1 up to 500 hours. The thicknesses of the oxide layers were measured, and the room temperature flexural strengths of the specimens were measured using a four point bend test.

Since the oxide thickness and the strengths are both measured, a comparison of predicted activation energies $(Q)$ and the value (a) are obtained independently from the two tests. In applying the data to a statistical model, the values obtained from MOR testing are fundamental. The values obtained from oxide thickness measurements are provided for comparison.

Material constants from thickness testing

$$
\begin{aligned}
& C=167 \\
& a=0.11 \\
& Q=63 \mathrm{KJ} / \mathrm{MOLE}
\end{aligned}
$$

Material constants from MOR testing

$$
\begin{aligned}
& A^{*} \mathrm{KIC}=1050 \mathrm{MPA} \\
& \mathrm{a}=0.067 \\
& \mathrm{Q}=-8 \mathrm{KJ} / \mathrm{MOLE}
\end{aligned}
$$

The low value of activation energy reflects the relative temperature insensitivity of the strength over this temperature range. After 100 hours of exposure, the average strength at $1400^{\circ} \mathrm{C}$ differed only 3 percent from the $1260^{\circ} \mathrm{C}$ value. The negative value obtained from MOR 


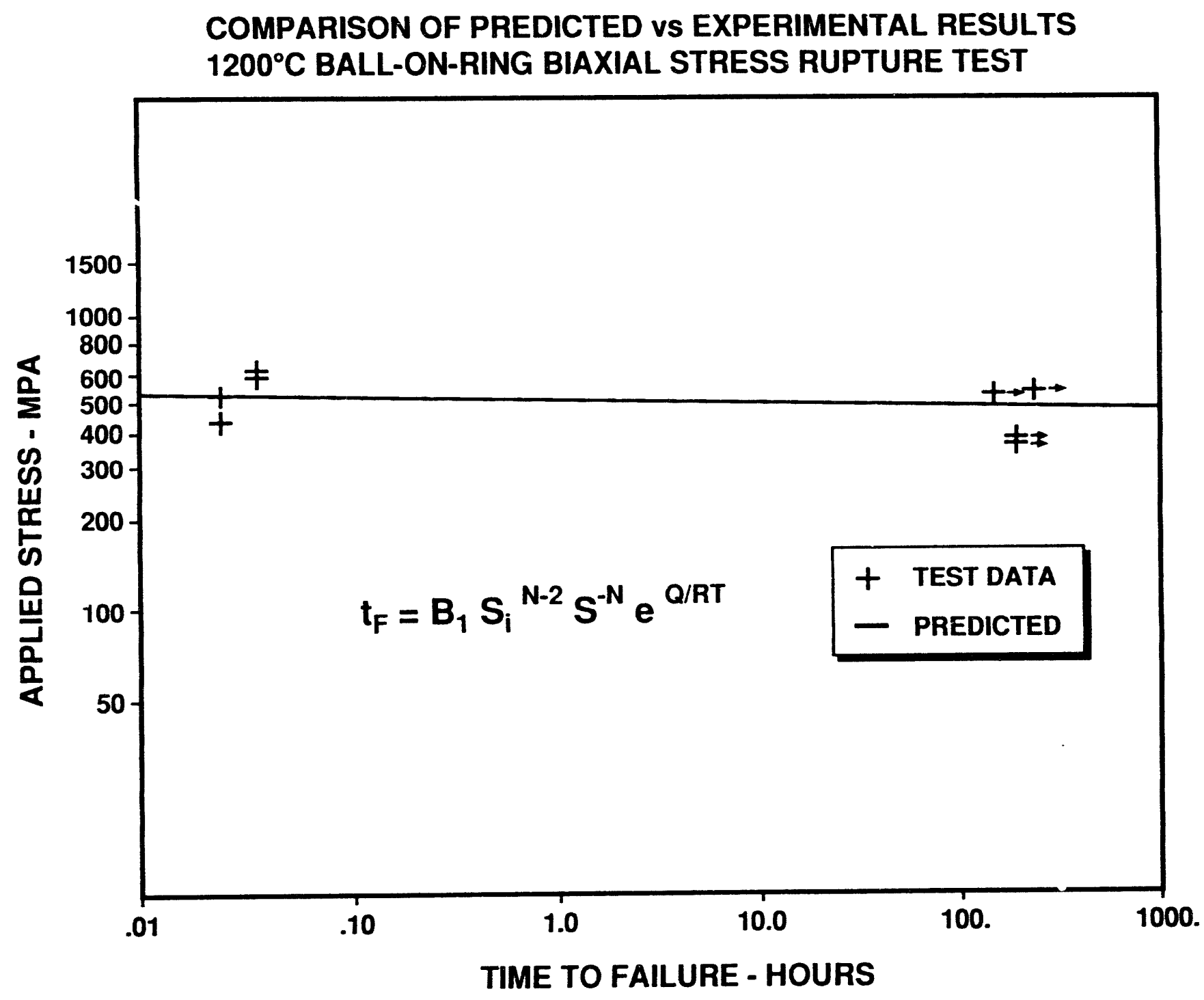

Figure 6. Comparison of predicted versus experimental results $1200^{\circ} \mathrm{C}$ ball-on-ring biaxial stress rupture test. 
testing shows that the measured strengths after exposure at $1400^{\circ} \mathrm{C}$ were actually slightly higher than those measured at $1260^{\circ} \mathrm{C}$.

Activation energy obtained from thickness measurements shows that the rate of oxide thickness does increase with temperature as would be expected.

Values of (a), obtained from both types of testing, while not exactly identical, agreed reasonably well. As can be seen in tablc 9 , use of the regression constants obtained from bend testing allow a very reasonable prediction of average strength behavior. (Each average is based on from 4 to 10 test specimens.) A standard deviation on strength is calculated to be 11.7 percent corresponding to a Weibull modulus of about 10.3. The fact that this exceeds the room temperature fast fracture sui face Weibull modulus of 8.65 indicates that the oxidation process results in a greater consistency of critical flaw sizes.

While the regression of strength data fit the equation quite well, the less important regression of oxidation thickness data (as shown in table 10) showed a much larger standard deviation. Based upon measured thickness data, one standard deviation was 26.4 percent compared to a value of only 11.7 percent for the strength data. In table 11 , the strengths of the individual specimen tests were compared to the \pm 1 standard deviation values. As expected, about 70 percent of the data lay within this scatter band. Examining the predictions made at each of the four temperatures shows that the percentage of specimen strengths in the predicted scatter band varied from 60 to 80 percent indicating that the data fit was not strongly biased at any temperature.

Table 9.

Comparison of the predicted average strength of oxidized specimens with the measured value.

$\begin{array}{ccccc}\text { Temp }{ }^{\circ} \mathrm{C} & \text { Time-hr } & \begin{array}{c}\text { Average } \\ \text { strength-MPa }\end{array} & \begin{array}{l}\text { Predicted } \\ \text { strength }\end{array} & \begin{array}{c}\text { Ratio } \\ \text { actual/pred }\end{array} \\ 1260 & 100.00 & 659.68 & 653.05 & 1.01 \\ 1300 & 100.00 & 710.61 & 658.42 & 1.08 \\ 1300 & 500.00 & 564.56 & 624.09 & 0.90 \\ 1371 & 100.00 & 669.60 & 667.40 & 1.00 \\ 1400 & 1.00 & 746.77 & 781.97 & 0.95 \\ 1400 & 3.00 & 780.96 & 753.90 & 1.04 \\ 1400 & 6.00 & 755.45 & 736.72 & 1.03 \\ 1400 & 10.00 & 723.41 & 724.30 & 1.00 \\ 1400 & 50.00 & 699.64 & 686.54 & 1.02 \\ 1400 & 100.00 & 683.55 & 670.89 & 1.02 \\ 1400 & 500.00 & 636.80 & 635.91 & 1.00\end{array}$


Table 10.

Comparison of the predicted oxide thickness with the measured value.

\begin{tabular}{rrrrr} 
Temp ${ }^{\circ} \mathrm{C}$ & Time-hr & $\begin{array}{c}\text { Average } \\
\text { strength-MPa }\end{array}$ & $\begin{array}{l}\text { Predicted } \\
\text { strength }\end{array}$ & $\begin{array}{c}\text { Ratio } \\
\text { actual/pred }\end{array}$ \\
1260 & 100.00 & 1.91 & 1.95 & 0.98 \\
1300 & 100.00 & 2.56 & 2.22 & 1.16 \\
1300 & 500.00 & 3.06 & 2.63 & 1.16 \\
1371 & 100.00 & 2.30 & 2.73 & 0.84 \\
1400 & 1.00 & 1.67 & 1.80 & 0.92 \\
1400 & 3.00 & 2.70 & 2.03 & 1.33 \\
1400 & 6.00 & 2.80 & 2.18 & 1.28 \\
1400 & 10.00 & 1.70 & 2.31 & 0.74 \\
1400 & 50.00 & 2.40 & 2.74 & 0.87 \\
1400 & 100.00 & 3.20 & 2.96 & 1.08 \\
1400 & 500.00 & 4.25 & 3.51 & 1.21 \\
& & & & \\
\hline
\end{tabular}

Table 11.

Comparison of the predicted \pm 1 standard deviation stresses with measured values for all oxidized specimens.

\begin{tabular}{cllccc} 
Time ${ }^{\circ} \mathrm{C}$ & Time-hr & $\begin{array}{c}\text { Specimen } \\
\text { strength } \\
\text { MPA }\end{array}$ & $\begin{array}{c}\text { Predicted } \\
1 \text { std. } \\
\text { deviation }\end{array}$ & $\begin{array}{c}\text { Predicted } \\
-1 \text { std. } \\
\text { deviation }\end{array}$ & $\begin{array}{c}\text { Is data in } \\
\text { scatter } \\
\text { band? }\end{array}$ \\
\cline { 2 - 4 } 1260 & 100 & 636.89 & 729.20 & 576.91 & Y \\
1260 & 100 & 545.20 & 729.20 & 576.91 & N \\
1260 & 100 & 577.14 & 729.20 & 576.91 & Y \\
1260 & 100 & 634.61 & 729.20 & 576.91 & Y \\
1260 & 100 & 576.17 & 729.20 & 576.91 & N \\
1260 & 100 & 701.69 & 729.20 & 576.91 & Y \\
1260 & 100 & 700.37 & 729.20 & 576.91 & Y \\
1260 & 100 & 809.92 & 729.20 & 576.91 & N \\
1260 & 100 & 662.81 & 729.20 & 576.91 & Y \\
1260 & 100 & 751.96 & 729.20 & 576.91 & N \\
1300 & 100 & 762.35 & 735.19 & 581.65 & N \\
1300 & 100 & 710.49 & 735.19 & 581.65 & Y \\
1300 & 100 & 642.21 & 735.19 & 581.65 & Y \\
1300 & 100 & 764.51 & 735.19 & 581.65 & N \\
1300 & 100 & 673.49 & 735.19 & 581.65 & Y \\
1300 & 500 & 520.55 & 696.86 & 551.33 & N \\
1300 & 500 & 586.31 & 696.86 & 551.33 & Y \\
1300 & 500 & 554.03 & 696.86 & 551.33 & Y
\end{tabular}




\begin{tabular}{|c|c|c|c|c|c|}
\hline 1371 & 100 & 657.91 & 745.22 & 589.59 & $Y$ \\
\hline 1371 & 100 & 548.61 & 745.22 & 589.59 & $\mathbf{N}$ \\
\hline 1371 & 100 & 702.61 & 745.22 & 589.59 & $Y$ \\
\hline 1371 & 100 & 677.76 & 745.22 & 589.59 & $Y$ \\
\hline 1371 & 100 & 611.89 & 745.22 & 589.59 & $Y$ \\
\hline 1371 & 100 & 598.42 & 745.22 & 589.59 & $Y$ \\
\hline 1371 & 100 & 720.77 & 745.22 & 589.59 & $Y$ \\
\hline 1371 & 100 & 674.42 & 745.22 & 589.59 & $Y$ \\
\hline 1371 & 100 & 687.51 & 745.22 & 589.59 & $Y$ \\
\hline 1371 & 100 & 816.11 & 745.22 & 589.59 & $\mathbf{N}$ \\
\hline 1400 & 1 & 784.94 & 873.14 & 690.80 & $Y$ \\
\hline 1400 & 1 & 822.87 & 873.14 & 690.80 & $Y$ \\
\hline 1400 & 1 & 731.89 & 873.14 & 690.80 & $Y$ \\
\hline 1400 & 1 & 834.24 & 873.14 & 690.80 & $Y$ \\
\hline 1400 & 1 & 559.93 & 873.14 & 690.80 & $N$ \\
\hline 1400 & 3 & 891.19 & 841.80 & 666.00 & $\mathrm{~N}$ \\
\hline 1400 & 3 & 841.32 & 841.80 & 666.00 & $Y$ \\
\hline 1400 & 3 & 585.74 & 841.80 & 666.00 & $N$ \\
\hline 1400 & 3 & 709.24 & 841.80 & 666.00 & $Y$ \\
\hline 1400 & 3 & 877.29 & 841.80 & 666.00 & $N$ \\
\hline 1400 & 6 & 692.55 & 822.61 & 650.82 & $Y$ \\
\hline 1400 & 6 & 765.61 & 822.61 & 650.82 & $Y$ \\
\hline 1400 & 6 & 890.49 & 822.61 & 650.82 & $N$ \\
\hline 1400 & 6 & 754.04 & 822.61 & 650.82 & $Y$ \\
\hline 1400 & 6 & 674.55 & 822.61 & 650.82 & $Y$ \\
\hline 1400 & 10 & 758.05 & 808.75 & 639.85 & $\mathrm{Y}$ \\
\hline 1400 & 10 & 706.13 & 808.75 & 639.85 & $Y$ \\
\hline 1400 & 10 & 694.90 & 808.75 & 639.85 & $Y$ \\
\hline 1400 & 10 & 875.19 & 808.75 & 639.85 & $\mathrm{~N}$ \\
\hline 1400 & 10 & 582.80 & 808.75 & 639.85 & $\mathrm{~N}$ \\
\hline 1400 & 50 & 688.65 & 766.58 & 606.49 & $Y$ \\
\hline 1400 & 50 & 751.41 & 766.58 & 606.49 & $Y$ \\
\hline 1400 & 50 & 723.70 & 766.58 & 606.49 & $\mathrm{Y}$ \\
\hline 1400 & 50 & 643.56 & 766.58 & 606.49 & $Y$ \\
\hline 1400 & 50 & 690.90 & 766.58 & 606.49 & $Y$ \\
\hline 1400 & 100 & 753.89 & 749.11 & 592.66 & $N$ \\
\hline 1400 & 100 & 650.56 & 749.11 & 592.66 & $Y$ \\
\hline 1400 & 100 & 754.06 & 749.11 & 592.66 & $\mathrm{~N}$ \\
\hline 1400 & 100 & 717.98 & 749.11 & 592.66 & $Y$ \\
\hline 1400 & 100 & 541.26 & 749.11 & 592.66 & $\mathbf{N}$ \\
\hline 1400 & 500 & 622.03 & 710.05 & 561.76 & $Y$ \\
\hline 1400 & 500 & 693.88 & 710.05 & 561.76 & $Y$ \\
\hline 1400 & 500 & 608.47 & 710.05 & 561.76 & $Y$ \\
\hline 1400 & 500 & 593.40 & 710.05 & 561.76 & $\mathrm{Y}$ \\
\hline 1400 & 500 & 666.21 & 710.05 & 561.76 & $Y$ \\
\hline
\end{tabular}


Once the regression constants (a) and $(Q / R)$ are obtained from room temperature $M O R$ testing, a probabilistic oxidation model may be generated. An "equivalent strength" is defined as the room temperature strength of a specimen exposed at a baseline temperature for a baseline time. Using equation (5), equation (6) is found to have the form:

6) $\operatorname{Seq}=\operatorname{Srt}^{*}(t / t B) \cdot 5 a * \operatorname{EXP}(.5 \mathrm{Q} / \mathrm{R}(1 / \mathrm{TB}-1 / \mathrm{T}))$

Srt $=$ room temperature MOR strength

$t=$ specimen exposure time

$\mathrm{tB}=$ reference time selected

$\mathrm{T}=$ specimen exposure temperature (absolute)

$\mathrm{TB}=$ reference exposure temperature (absolute)

A Weibull MLE analysis of the equivalent strengths from equation (6) allows the computation of a room temperature Weibull modulus, $(m)$, and a unit characteristic strength.

Similar to the practice for fast fracture, this Weibull modulus is assumed constant at all temperatures, while the characteristic strength is obtained at temperature by ratioing by KIC. This approach is valid as long as the material strength is determined by the mode I failure mechanism.

7) So $(T)=\operatorname{So}(R T) * K I C(T) / K I C(R T)$

So $(T)=$ unit characterist ${ }^{2} \mathrm{c}$ strength at temperature

So(RT) $=$ unit characteristic strength at room temperature

$\mathrm{KIC}(\mathrm{T})=$ mode I fracture toughness at temperature

$\mathrm{KIC}(\mathrm{RT})=$ mode I fracture toughness at room temperature

At temperatures other than room temperature, the effective stress is given by equation (8) where $S$ is the actual applicd stress.

8) $\operatorname{Seq}=S *(t / t B) \cdot 5 a * \operatorname{EXP}(.5 \mathrm{Q} / \mathrm{R}(1 / \mathrm{TB}-1 / \mathrm{T}))$

Finally, the Weibull equation may be used to determine the survival probability of a component at a temperature subjected to oxidation damage.

9) $\operatorname{POS}=\operatorname{EXP}\left(-\right.$ Aeff* $\left.^{*}(\text { Seqmax } / \text { So(T) })^{m}\right)$

Aeff $=$ the effective surface area based on Seq

Seqmax $=$ the maximum surface equivalent stress

It should be noted that this methodology does not apply in situations where the presence of stress accelerates the rate of oxidation of a flaw. Such situations can be considered using a subcritical crack growth methodology. 


\section{Status of Milestones}

322201: Computer Implementation of Initial Failure Models -- complete

322202:

322203:

322204:

322205:

322206:

322207:

322208:

Initiation of MOR Testing - complete

$$
\text { Initiation of Tensile Testing -- complete }
$$

Initiation of Biaxial Testing -- complete

Confirmatory Testing discontinued because of the poor quality spin disks received from GTE

Completion of All Specimen Testing - on schedule

Finalization/Verification of Computer Code -- on schedule

Draft Final Report -- on schedule

322209:

Final Report -- on schedule

\section{Publications}

A paper entitled "Environmental Effects on the Flexure Strength of HIP processed Silicon Nitride at Elevated Temperatures" by A. A. Wereszczak, K. Breder, M. K. Ferber, T. P.

Kirkland, and P. K. Khandelwal was accepted for presentation at the Electrochemical Society, New Orleans, October 10-15, 1993. 


\subsection{ENVIRONMENTAL EFFECTS}

\section{Environmental Effects in Toughened Ceramics}

G. A. Graves, Jr. (University of Dayton)

\section{Objective/scope}

Since December 1984, the University of Dayton has been involved in a fivephase project to investigate the effects of environment on the mechanical behavior of commercially available ceramics being considered for heat engine applications. In the first phase of this project, the effects of environment on the mechanical behavior of transformation-toughened $\mathrm{ZrO}_{2}$ ceramics were investigated. In the second phase, two $\mathrm{Si}_{3} \mathrm{~N}_{4}$ ceramics (GTE PY6 and Norton/TRW XL144) and one $\mathrm{SiC}$ ceramic (Hexoloy SA) were evaluated. In the third phase, the tensile, flexural, and fatigue strength of three $\mathrm{SiC}$ and $\mathrm{six} \mathrm{Si}_{3} \mathrm{~N}_{4}$ ceramics were evaluated at temperatures ranging from 20 to $1400^{\circ} \mathrm{C}$. Microstructure, chemistry, and physical properties were also investigated. In the fourth phase, the flexural strength and fatigue behavior of two additional $\mathrm{Si}_{3} \mathrm{~N}_{4}$ ceramics (Kyocera SN-260 and Garrett $\mathrm{GN}-10$ ) were investigated. In addition, the fatigue behavior of one $\mathrm{Si}_{3} \mathrm{~N}_{4}$ ceramic (Norton/TRW NT-154) was investigated. In phase five, five newly developed SiC and three newly developed $\mathrm{Si}_{3} \mathrm{~N}_{4}$ ceramics are being investigated. In addition, the effects of different machining processes on the mechanical behavior of selected $\mathrm{SiC} / \mathrm{Si}_{3} \mathrm{~N}_{4}$ ceramics will be studied.

During the past six months the tensile cyclic fatigue results for Kyocera SN-253 were completed and a ceramic machining effects on mechanical strength study was initiated.

\section{Technical projress}

The tensile cyclic fatigue study was carried out on four Kyocera SN-253 buttonhead tensile specimens in a tension-tension mode. The maximum tensile stress was $22 \mathrm{MPa}$ (3200 psi), and the minimum tensile stress was $16 \mathrm{MPa}(2300 \mathrm{psi})$. The loading waveform was sawtooth at a frequency of $0.8 \mathrm{~Hz}$. The test was run for 450,000 cycles (approximately 100 hours) in air at $1350^{\circ} \mathrm{C}$. After testing for 450,000 cycles the specimens were loaded to failure at an actuator rate of $4 \times 10^{-5} \mathrm{~m} / \mathrm{s}$ $(0.1 \mathrm{in} / \mathrm{min})$. The results of the test are given in Table 1 . A photomicrograph of a typical fracture surface is shown in Figure 1. All of the specimens failed at surface fracture initiation sites. Three of the specimens studied under low power (19-30X) magnification had fracture surface features similar to flexural test specimen tested previously that were found to have elongated grains at the fracture initiation site. 


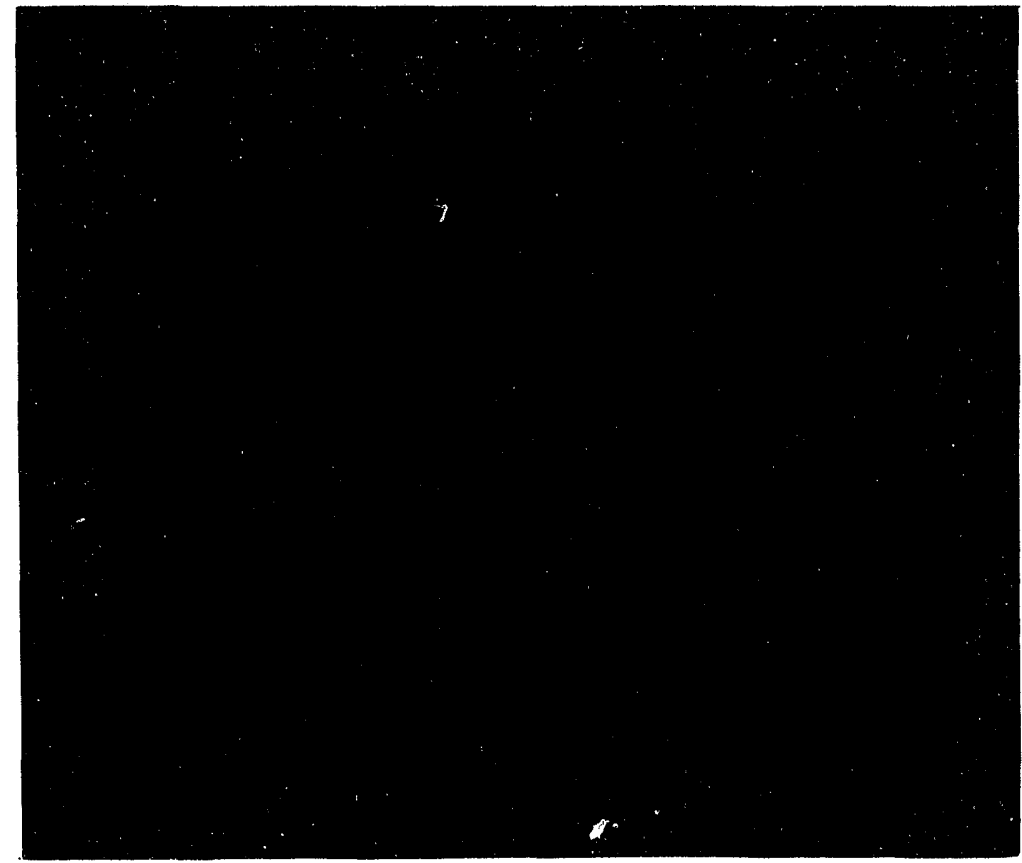

Figure 1. Typical Kyocera SN-253 Cyclic Fatigue Fracture Surface after 450,300 Cycles at $1350^{\circ} \mathrm{C}$ and then Fast Fractured at $4 \times 10^{-2} \mathrm{~mm} / \mathrm{s}$.

Table 1. Tensile Cyclic Fatigue Results for Kyocera SN-253

\begin{tabular}{|c|c|c|c|cc|c|}
\hline $\begin{array}{c}\text { Specimen } \\
\text { Number }\end{array}$ & $\begin{array}{c}\text { Cycles } \\
\text { Completed }\end{array}$ & $\begin{array}{c}\text { Diameter } \\
\text { (in) }\end{array}$ & $\begin{array}{c}\text { Failure } \\
\text { Load (lbs) }\end{array}$ & \multicolumn{2}{|c|}{ Residual Tensile Strength } & Fracture \\
(ksi) & (MPa) & Origin \\
\hline 49 & 450,000 & 0.2512 & 3,080 & 62.1 & 429 & Surface \\
\hline 50 & 450,000 & 0.2501 & 2,940 & 59.8 & 413 & Surface* $^{*}$ \\
\hline 51 & 450,000 & 0.2508 & 2,960 & 59.9 & 413 & Surface* $^{*}$ \\
\hline 52 & 450,000 & 0.2508 & 3,000 & 60.7 & 419 & Surface* $^{*}$ \\
\hline & & & Average & 60.7 & $418+$ & \\
\hline
\end{tabular}

"Fracture occurred at an elongated grain

+Note: The average fast fracture tensile strength measured for $\mathrm{SN}-253$ at $1350^{\circ} \mathrm{C}$ was $432 \mathrm{MPa} \pm 66 \mathrm{MPa}$.

The initial machining effects study was performed on Garrett GS-44 silicon nitride flexural bars prepared by Chand Kare Technical Ceramics and ORNL. The type of machine, machining conditions, and test matrix are given in Table 2. The average flexural strength results are given in Table 3 . The different machining conditions in the longitudinal direction did not appear to alter the strength significantly; however, the transverse machining direction did lower the strength significantly when compared to the longitudinal grinding spocimen strengths. The data for each group of specimens are contained in Tables 4 through 9. 
Table 2. GS-44 Flexural Specimen Preparation and Testing Matrix

\begin{tabular}{|c|c|c|c|c|c|c|c|c|c|c|}
\hline $\begin{array}{l}\text { Specimen Prep } \\
\text { Machining Source: } \\
\text { Machine: } \\
\text { Grind Type: } \\
\text { Grind Direction: }\end{array}$ & \multicolumn{3}{|c|}{$\begin{array}{l}\text { Chand Kare } \\
\text { CC Surface Grinder } \\
\text { Std. Grind (ASTM C1161) } \\
\text { Longitudinal }\end{array}$} & \multicolumn{3}{|c|}{$\begin{array}{l}\text { ORNL } \\
\text { Harig NC } \\
\text { Std. Grind (ASTM C1161) } \\
\text { Longitudinal }\end{array}$} & \multicolumn{2}{|c|}{$\begin{array}{l}\text { ORNL } \\
\text { Harig NC } \\
\text { Std. Grind } \\
\text { Transverse }\end{array}$} & \multicolumn{2}{|c|}{$\begin{array}{l}\text { ORNL } \\
\text { Nicco } \\
\text { Creep Feed Grind } \\
\text { Longitudinal }\end{array}$} \\
\hline \multirow{4}{*}{$\begin{array}{l}\text { Test Conditions } \\
\text { Test Temp. }\left({ }^{\circ} \mathrm{C}\right) \\
\text { Crosshead Speed }(\mathrm{m} / \mathrm{s}) \\
\text { Post-machining } \\
\text { Treatment }\end{array}$} & & & & & & & & & & \\
\hline & 20 & 20 & 20 & 20 & 20 & 20 & 20 & 20 & 20 & 20 \\
\hline & $4 \times 10^{-5}$ & $4 \times 10^{-7}$ & $4 \times 10^{-5}$ & $4 \times 10^{-5}$ & $4 \times 10^{-7}$ & $4 \times 10^{-5}$ & $4 \times 10^{-5}$ & $4 \times 10^{-7}$ & $4 \times 10^{-5}$ & $4 \times 10^{-7}$ \\
\hline & - & - & $\begin{array}{c}200 \text { hrs } @ \\
1100^{\circ} \mathrm{C}\end{array}$ & - & - & $\begin{array}{c}200 \mathrm{hrs} @ \\
1100^{\circ} \mathrm{C}\end{array}$ & - & - & - & - \\
\hline No. of Specimens & 10 & 10 & 10 & 10 & 10 & 4 & 7 & 7 & 9 & 9 \\
\hline
\end{tabular}

Table 3. Average Flexural Strength Measured for GS-44 Specimens

\begin{tabular}{|l|l|l|l|l|}
\hline $\begin{array}{l}\text { Specimen Prep. } \\
\text { Machining Source: } \\
\text { Grind Type }\end{array}$ & $\begin{array}{l}\text { Chand Kare } \\
\text { ASTM-C1161 }\end{array}$ & $\begin{array}{l}\text { ORNL } \\
\text { ASTM-C1161 }\end{array}$ & $\begin{array}{l}\text { ORNL } \\
\text { Std. Grind-Transverse }\end{array}$ & $\begin{array}{l}\text { ORNL } \\
\text { Creep Feed }\end{array}$ \\
\hline $\begin{array}{l}\text { Test Conditions } \\
20^{\circ} \mathrm{C} / 4 \times 10^{-5} \mathrm{~m} / \mathrm{s} \\
20^{\circ} \mathrm{C} / 4 \times 10^{-7} \mathrm{~m} / \mathrm{s}\end{array}$ & $\begin{array}{c}1160 \mathrm{MPa}( \pm 162) \\
1139 \mathrm{MPa}( \pm 42)\end{array}$ & $\begin{array}{l}1135 \mathrm{MPa}( \pm 55) \\
1054 \mathrm{MPa}( \pm 84)\end{array}$ & $\begin{array}{l}871 \mathrm{MPa}( \pm 71) \\
985 \mathrm{MPa}( \pm 53)\end{array}$ & $\begin{array}{l}1183 \mathrm{MPa}( \pm 71) \\
1073 \mathrm{MPa}( \pm 49)\end{array}$ \\
\hline $\begin{array}{l}\text { After Oxidation for } \\
200 \mathrm{hrs} @ 1100^{\circ} \mathrm{C} \\
\begin{array}{l}\text { Tested at } 20^{\circ} \mathrm{Cl} \\
4 \times 10^{-5} \mathrm{~m} / \mathrm{s}\end{array}\end{array}$ & $984 \mathrm{MPa}( \pm 24)$ & $867 \mathrm{MPa}( \pm 67)$ & & \\
\hline
\end{tabular}


Table 4. Four Point Flexure Test Results for Garrett GS-44. Machined by Chand Kare using ASTM-C1161 Specifications

\section{Fast Fracture}

\begin{tabular}{ccccc}
$\begin{array}{c}\text { Specimen } \\
\text { Number }\end{array}$ & $\begin{array}{c}\text { Load } \\
\text { (lbs) }\end{array}$ & $\begin{array}{c}\text { Flexural } \\
\text { (ksi) }\end{array}$ & $\begin{array}{c}\text { Strength } \\
\text { (MPa) }\end{array}$ & $\begin{array}{c}\text { Fracture } \\
\text { Origin }\end{array}$ \\
\hdashline$-\cdots$ & $-\cdots-22$ & 119.5 & 824 & $*$ \\
\hdashline 1 & 222 & 117.9 & 1227 & $*$ \\
2 & 332 & 179.4 & 1237 & $*$ \\
3 & 334 & 155.8 & 1074 & $*$ \\
4 & 290 & 183.8 & 1267 & $*$ \\
5 & 343 & 135.9 & 937 & $*$ \\
6 & 254 & 187.6 & 1293 & $*$ \\
7 & 350 & 181.6 & 1252 & $*$ \\
8 & 339 & 186.2 & 1284 & $*$ \\
9 & 348 & 175.3 & 1208 & $*$ \\
10 & 327 & & & \\
& & 168.3 & 1160 & \\
& Average & 162 &
\end{tabular}

Test Temperature: $21^{\circ} \mathrm{C}$

Crosshead Speed: $4 \times 10^{-2} \mathrm{~mm} / \mathrm{s}(0.1 \mathrm{in} / \mathrm{min})$

* Fracture origins were difficult to identify due to high fracture energy.

\section{Slow Fracture}

\begin{tabular}{ccccc}
$\begin{array}{c}\text { Specimen } \\
\text { Number }\end{array}$ & $\begin{array}{c}\text { Load } \\
\text { (lbs) }\end{array}$ & $\begin{array}{c}\text { Flexural } \\
\text { (ksi) }\end{array}$ & $\begin{array}{c}\text { Strength } \\
\text { (MPa) }\end{array}$ & $\begin{array}{c}\text { Fracture } \\
\text { Origin }\end{array}$ \\
\hdashline 21 & 306 & 163.7 & 1128 & $*$ \\
\hdashline 2 & 313 & 167.3 & 1154 & $*$ \\
23 & 310 & 165.8 & 1143 & Surface \\
24 & 292 & 156.2 & 1077 & Edge \\
25 & 324 & 173.0 & 1193 & $*$ \\
& & & & \\
& Average & 165.2 & 1139 & \\
& Stdev. & 6.1 & 42 &
\end{tabular}

Test Temperature: $21^{\circ} \mathrm{C}$

Crosshead Speed: $4 \times 10^{-4} \mathrm{~mm} / \mathrm{s}$ (0.001 in/min)

* Fracture origins were difficult to identify due to high fracture energy. 
Table 5. Four Point Flexure Test Results for Oxidized Garrett GS-44. Machined by Chand Kare using ASTM-C1161 Specifications

\begin{tabular}{ccccc}
$\begin{array}{c}\text { Specimen } \\
\text { Number }\end{array}$ & $\begin{array}{c}\text { Load } \\
\text { (Ibs) }\end{array}$ & $\begin{array}{c}\text { Flexural } \\
\text { (ksi) }\end{array}$ & $\begin{array}{c}\text { Strength } \\
\text { (MPa) }\end{array}$ & $\begin{array}{c}\text { Fracture } \\
\text { Origin }\end{array}$ \\
\hdashline 11 & 266 & 141.9 & 978 & $*$ \\
12 & 275 & 146.7 & 1012 & Surface \\
13 & 261 & 139.3 & 961 & Surface \\
14 & 273 & 145.9 & 1006 & $\begin{array}{c}\text { Surface } \\
\text { Vol. at Incl. }\end{array}$ \\
\hline 15 & 261 & 139.5 & 962 & \\
& & & & \\
& Average & 142.7 & 984 & \\
& Stdev. & 3.5 & 24 &
\end{tabular}

Test Temperature: $21^{\circ} \mathrm{C}$

Oxidation: 200 hours at $1100^{\circ} \mathrm{C}$

Crosshead Speed: $4 \times 10^{-2} \mathrm{~mm} / \mathrm{s}(0.1 \mathrm{in} / \mathrm{min})$

* Fracture origins were difficult to identify due to high fracture energy. 
Table 6. Four Point Flexure Results for Garrett GS-44.

Prepared by ORNL using ASTM-C1161 Specifications

\section{Fast Fracture}

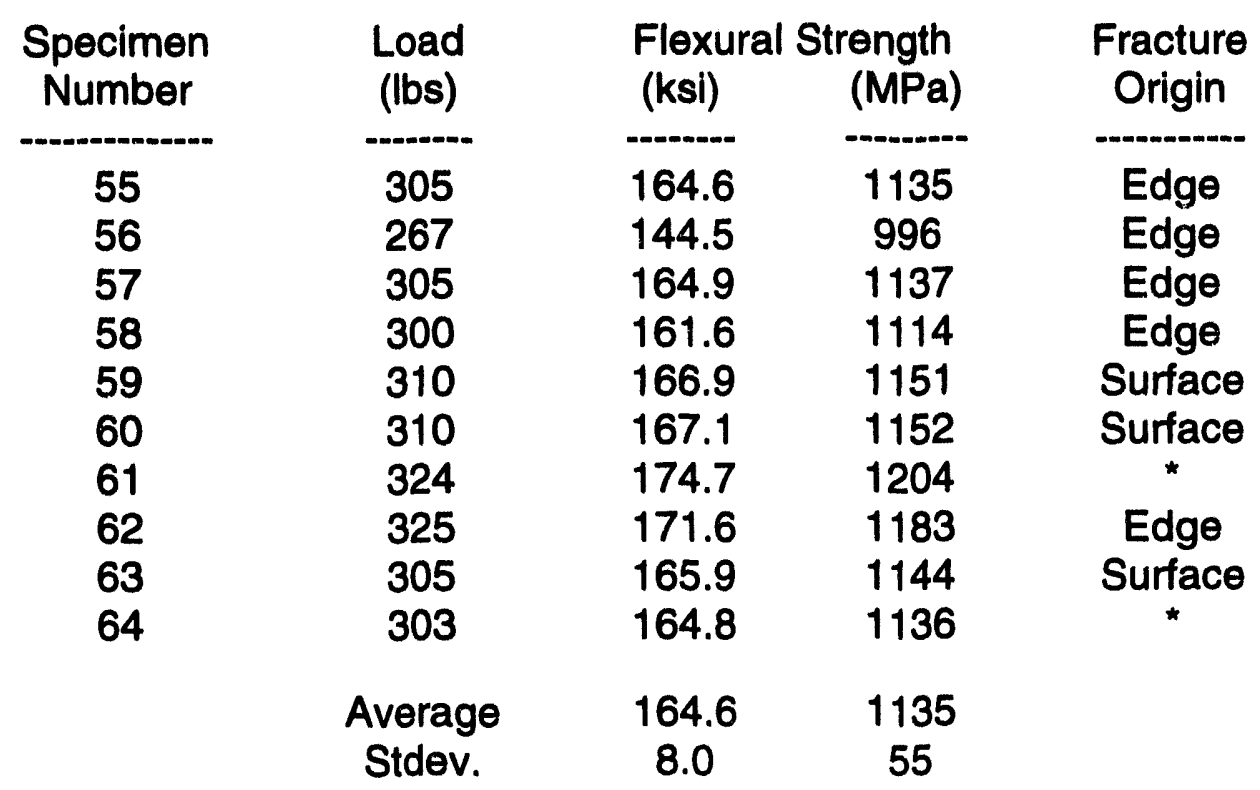

Test Temperature: $21^{\circ} \mathrm{C}$

Crosshead Speed: $4 \times 10^{-2} \mathrm{~mm} / \mathrm{s}(0.1 \mathrm{in} / \mathrm{min})$

* Fracture origins were difficult to identify due to high fracture energy

\section{Slow Fracture}

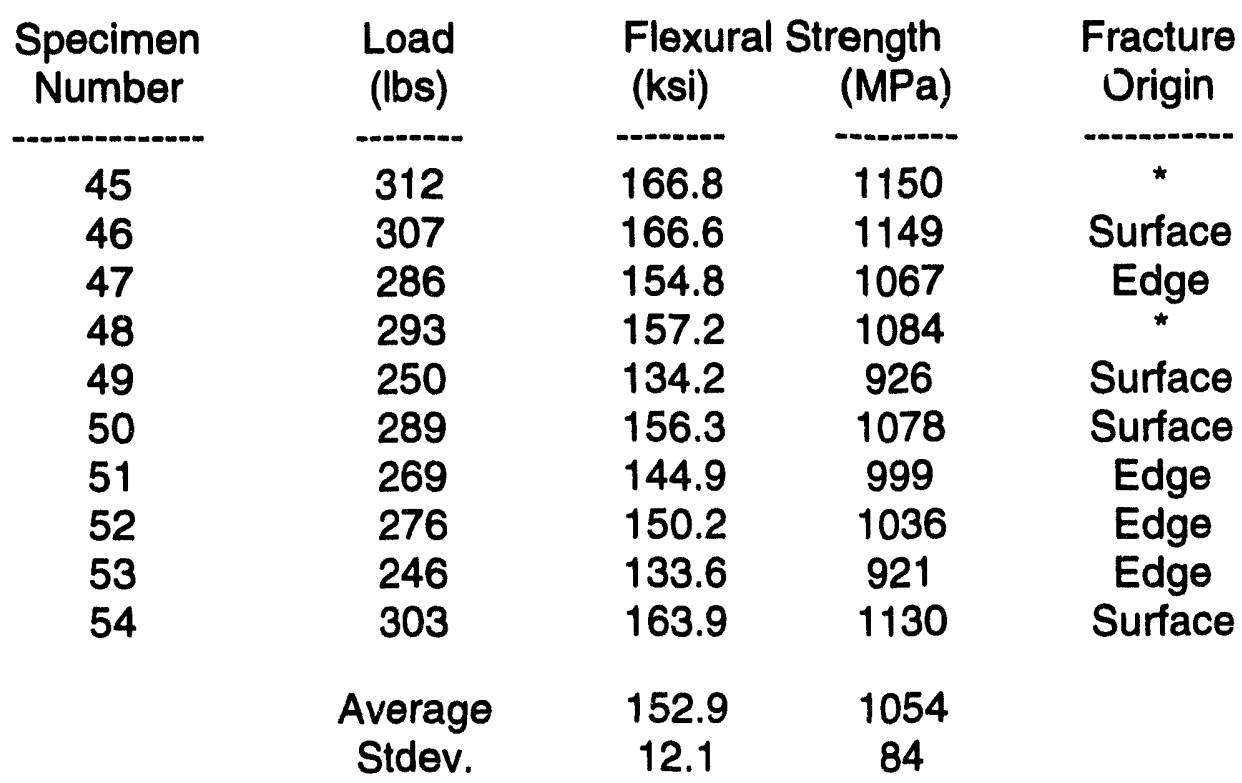

Test Temperature: $21^{\circ} \mathrm{C}$

Crosshead Speed: $4 \times 10^{-4} \mathrm{~mm} / \mathrm{s}(0.001 \mathrm{in} / \mathrm{min})$

* Fracture origins were difficult to identify due to high fracture energy 
Table 7. Four Point Flexure Results For Garrett GS-44

Machined by ORNL using Transverse $\times$ Transverse Grinding

\section{Fast Fracture}

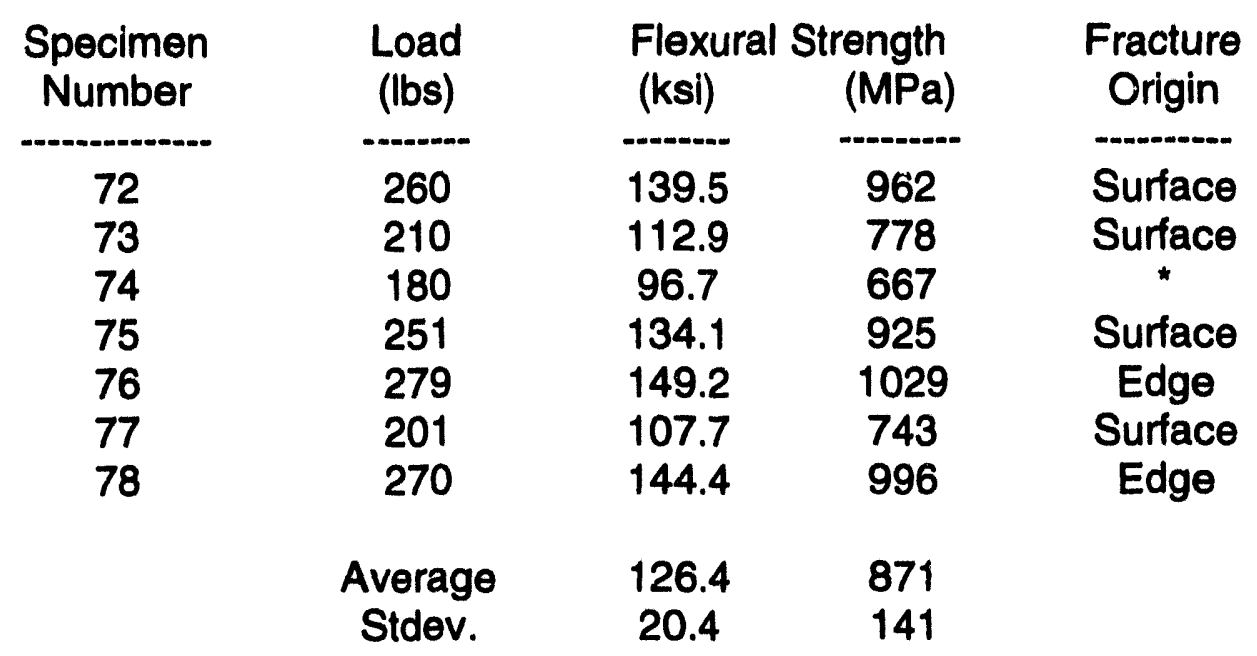

Test Temperature: $21^{\circ} \mathrm{C}$

Crosshead Speed: $4 \times 10^{-2} \mathrm{~mm} / \mathrm{s}(0.1 \mathrm{in} / \mathrm{min})$

* Fracture origins were difficult to identify due to high fracture energy.

\section{Slow Fracture}

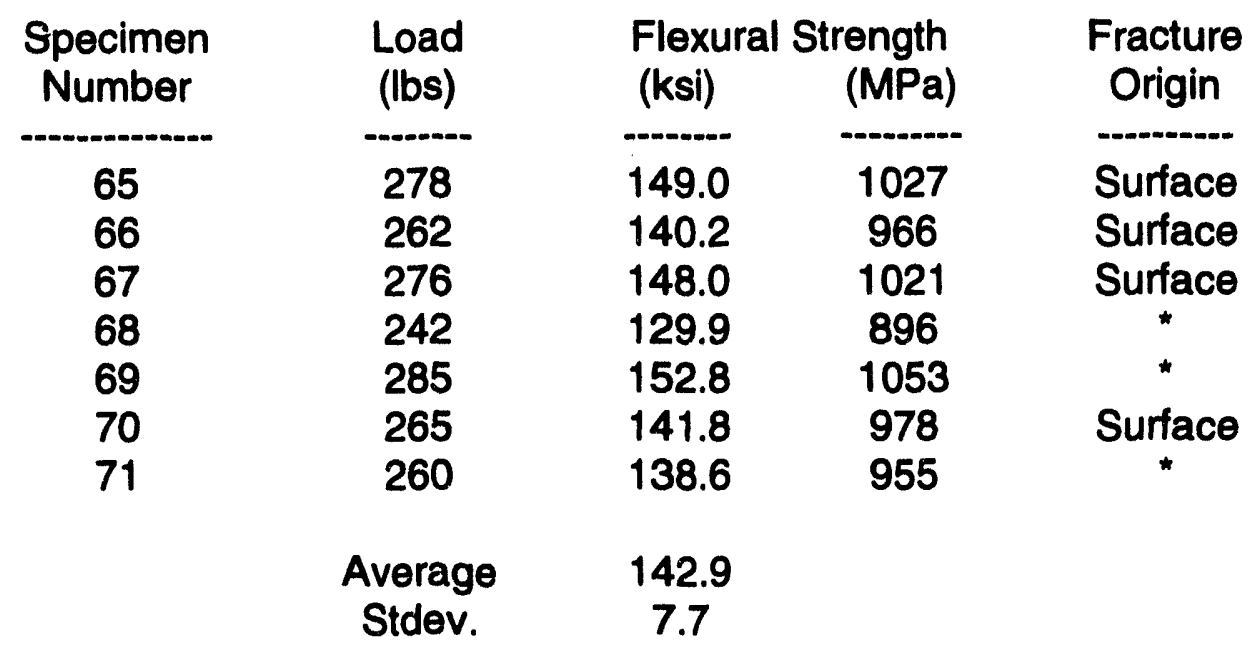

Test Temperature: $21^{\circ} \mathrm{C}$

Crosshead Speed: $4 \times 10^{-4} \mathrm{~mm} / \mathrm{s}$ (0.001 in/min)

* Fracture origins were difficult to identify due to high fracture energy 
Table 8. Four Point Flexure Results For Garrett GS-44. Machined by ORNL using Creep Feed Grinding

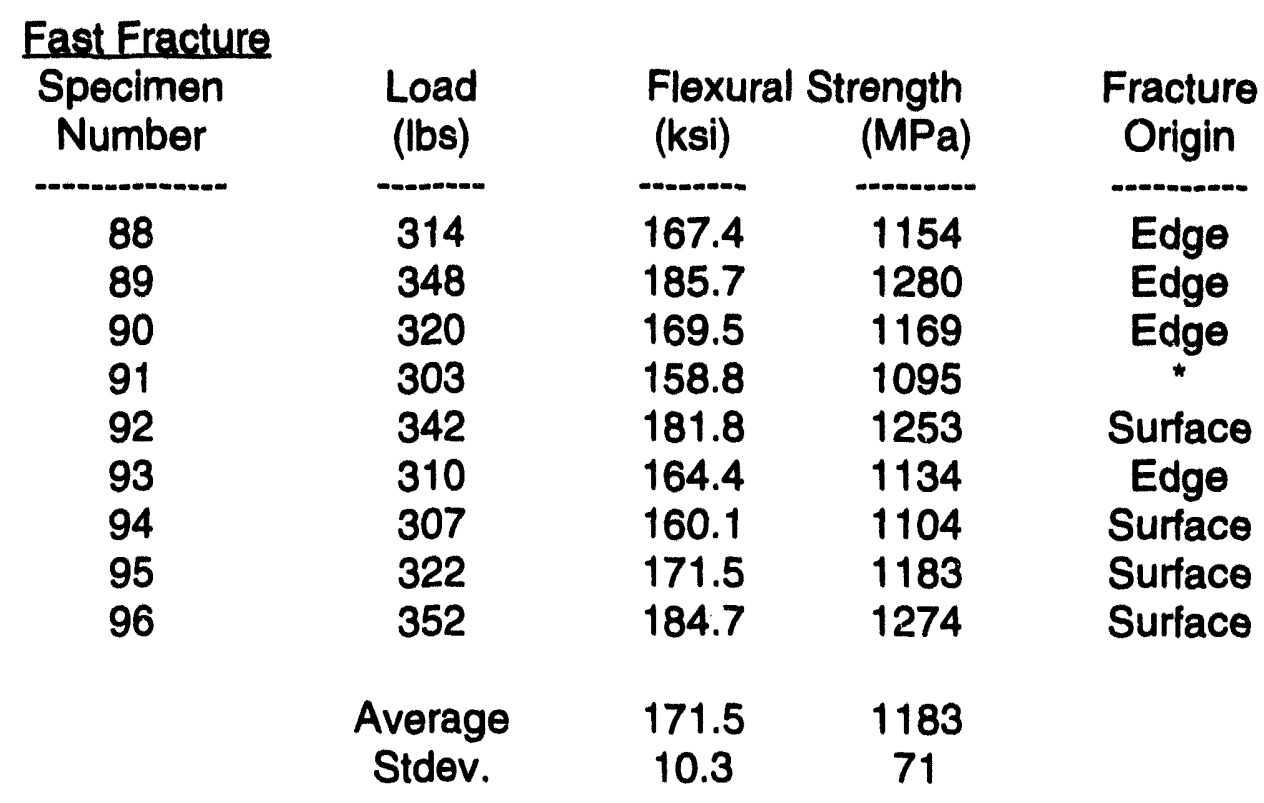

Test Temperature: $21^{\circ} \mathrm{C}$

Crosshead Speed: $4 \times 10^{-2} \mathrm{~mm} / \mathrm{s}$ (0.1 in/min)

* Fracture origins were difficult to identify due to high fracture energy

Slow Fracture

\begin{tabular}{|c|c|c|c|c|}
\hline $\begin{array}{l}\text { Specimen } \\
\text { Number }\end{array}$ & $\begin{array}{l}\text { Load } \\
\text { (Ibs) }\end{array}$ & $\begin{array}{l}\text { Flexur } \\
\text { (ksi) }\end{array}$ & $\begin{array}{l}\text { rength } \\
\text { (MPa) }\end{array}$ & $\begin{array}{c}\text { Fracture } \\
\text { Origin }\end{array}$ \\
\hline $\begin{array}{l}79 \\
80 \\
81 \\
82 \\
83 \\
84 \\
85 \\
86 \\
87\end{array}$ & $\begin{array}{l}315 \\
295 \\
292 \\
313 \\
300 \\
293 \\
287 \\
274 \\
290\end{array}$ & $\begin{array}{l}167.0 \\
156.5 \\
152.8 \\
163.8 \\
158.4 \\
155.4 \\
150.3 \\
143.1 \\
153.2\end{array}$ & $\begin{array}{c}1151 \\
1079 \\
1053 \\
1129 \\
1092 \\
1072 \\
1036 \\
987 \\
1057\end{array}$ & $\begin{array}{c}\text { Surface } \\
\text { Edge } \\
\text { Surface } \\
\text { Surface } \\
\text { Edge } \\
\text { Surface } \\
\text { Edge } \\
\text { Edge } \\
\text { Edge }\end{array}$ \\
\hline & $\begin{array}{l}\text { Average } \\
\text { Stdev. }\end{array}$ & $\begin{array}{c}155.6 \\
7.1\end{array}$ & $\begin{array}{c}1073 \\
49\end{array}$ & \\
\hline
\end{tabular}

Test Temperature: $21^{\circ} \mathrm{C}$

Crosshead Speed: $4 \times 10^{-4} \mathrm{~mm} / \mathrm{s}$ (0.001 in/min) 
Table 9. Four Point Flexure Results For Oxidized Garrett GS-44. Machined by ORNL using ASTM-C1161 Specifications

\section{East Fracture}

\begin{tabular}{ccccc}
$\begin{array}{c}\text { Specimen } \\
\text { Number }\end{array}$ & $\begin{array}{c}\text { Load } \\
\text { (Ibs) }\end{array}$ & $\begin{array}{c}\text { Flexural } \\
\text { (ksi) }\end{array}$ & $\begin{array}{c}\text { Strength } \\
\text { (MPa) }\end{array}$ & $\begin{array}{c}\text { Fracture } \\
\text { Origin }\end{array}$ \\
\hdashline$-1 .-$ & -122.4 & 844 & Surface \\
\hdashline 41 & 230 & 126.2 & 870 & Surface \\
42 & 235 & 138.7 & 956 & Surface \\
43 & 257 & 115.4 & 796 & Surface \\
44 & 214 & & & \\
& & & & \\
& Average & 125.7 & 867 & \\
& Stdev. & 9.7 & 67 &
\end{tabular}

Test Temperature: $21^{\circ} \mathrm{C}$

Oxidized: 200 hours at $1100^{\circ} \mathrm{CX}$

Crosshead Speed: $4 \times 10^{-2} \mathrm{~mm} / \mathrm{s}(0.1 \mathrm{in} / \mathrm{min})$ 
A second machining strength study was also initiated and completed during the reporting period. Chand Kare Technical Ceramics agreed to machine SiC using various types of commercial grinding wheels and remove rates as shown in Table 10. The SiC material selected for the study was Morton International's $\beta$-SiC prepared by chemical vapor deposition (CVD). The material was chosen because of Chand Kare's experience with machining it and for Morton International's ability to consistently prepare pore-free, high-purity, homogeneous, fine-grained material in large sizes (1.5 $\mathrm{m}$ dia $\times 1.0 \mathrm{~m}$ thick).

Table 10. Flexural Strength Machining Effects Study Baseline Material - CVD SiC

\begin{tabular}{|c|c|c|c|c|c|c|}
\hline \multirow{2}{*}{$\begin{array}{r}\text { Test Group } \\
\text { Grinding } \\
\text { Wheel Type }\end{array}$} & \multirow{2}{*}{$\begin{array}{c}\begin{array}{c}\text { Removal Rate } \\
\text { per Pass }\end{array} \\
\mathrm{mm} \text { (in) }\end{array}$} & \multirow{2}{*}{\begin{tabular}{|c}
$\begin{array}{c}\text { Total Amount } \\
\text { Removed/Side }\end{array}$ \\
$\mathrm{mm}$ (in)
\end{tabular}} & \multirow{2}{*}{$\begin{array}{c}\begin{array}{c}\text { Average Flexural } \\
\text { Strength }\end{array} \\
\mathrm{MPa}, \text { Std. Dev. } \\
\text { (Ksi, St. Dev.) }\end{array}$} & \multicolumn{2}{|c|}{ Test Conditions } & \multirow{2}{*}{$\begin{array}{l}\text { No. } \\
\text { Specimens } \\
\text { Tested }\end{array}$} \\
\hline & & & & $\begin{array}{c}\text { Crosshead Speed } \\
\mathrm{mm} / \mathrm{s} \text { (in/min) }\end{array}$ & $\begin{array}{l}\text { Temp. } \\
\left({ }^{\circ} \mathrm{C}\right)\end{array}$ & \\
\hline $\begin{array}{r}\text { Norton SD } 150 \\
\text { R75Bg9E-1/4 }\end{array}$ & $0.005(0.0002)$ & $0.025(0.001)$ & $\begin{array}{l}352,29(51,4.3) \\
340,23(49,3.3)\end{array}$ & $\begin{array}{c}0.04(0.1) \\
0.0004(0.001)\end{array}$ & $\begin{array}{l}20 \\
20\end{array}$ & $\begin{array}{c}10 \\
5\end{array}$ \\
\hline $\begin{array}{r}\text { Norton SD } 320 \\
\text { R75Bg9E-1/4 }\end{array}$ & $0.005(0.0002)$ & $0.20(0.008)$ & $\begin{array}{l}383,23(56,3.4) \\
369,15(54,2.1)\end{array}$ & $\begin{array}{c}0.04(0.1) \\
0.0004(0.001)\end{array}$ & $\begin{array}{l}20 \\
20\end{array}$ & $\begin{array}{c}10 \\
5\end{array}$ \\
\hline $\begin{array}{r}24 \text { General Dia. } \\
\text { CGD600 R75B-1/4 }\end{array}$ & $0.0025(0.0001)$ & $0.025(0.001)$ & $\begin{array}{l}454,17(66,2.5) \\
422,52(61,7.6)\end{array}$ & $\begin{array}{c}0.04(0.1) \\
0.0004(0.001)\end{array}$ & $\begin{array}{l}20 \\
20\end{array}$ & $\begin{array}{c}10 \\
5\end{array}$ \\
\hline $\begin{array}{r}25 \text { Norton SD } 800 \\
\text { R50-1/32 }\end{array}$ & $0.0025(0.0001)$ & $0.025(0.001)$ & $\begin{array}{l}389,32(56,4.6) \\
432,24(63,3.4)\end{array}$ & $\begin{array}{c}0.04(0.1) \\
0.0004(0.001)\end{array}$ & $\begin{array}{l}20 \\
20\end{array}$ & $\begin{array}{c}10 \\
5\end{array}$ \\
\hline 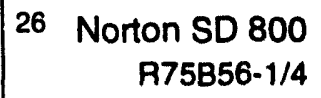 & $0.0025(0.0001)$ & $0.025(0.001)$ & $\begin{array}{c}478,52(69,7.6) \\
438,91(64,13.2)\end{array}$ & $\begin{array}{c}0.04(0.1) \\
0.0004(0.001)\end{array}$ & $\begin{array}{l}20 \\
20\end{array}$ & $\begin{array}{c}10 \\
5\end{array}$ \\
\hline $\begin{array}{r}27 \text { Norton D } 3 / 6 \mathrm{mic} \\
\mathrm{A} 75 \mathrm{~B}-1 / 4\end{array}$ & $0.0025(0.0001)$ & $0.025(0.001)$ & $\begin{array}{c}297,65(43,9.5) \\
337,48(48.9,6.9)\end{array}$ & $\begin{array}{c}0.04(0.1) \\
0.0004(0.001)\end{array}$ & $\begin{array}{l}20 \\
20\end{array}$ & $\begin{array}{c}10 \\
5\end{array}$ \\
\hline
\end{tabular}

'All specimens were ground in the longitudinal direction.

In addition, UDRI has a large database on this material obtained through Air Force programs that helped develop the material. It was felt that the material's consistency would make it a good baseline material for a machining study.

The flexural strength results are given in Table 10 and a graphic representation is shown in Figure 2. Figure 3 shows machining damage in the specimens in test group 27 which may account for the low flexural strength obtained for the specimens. 


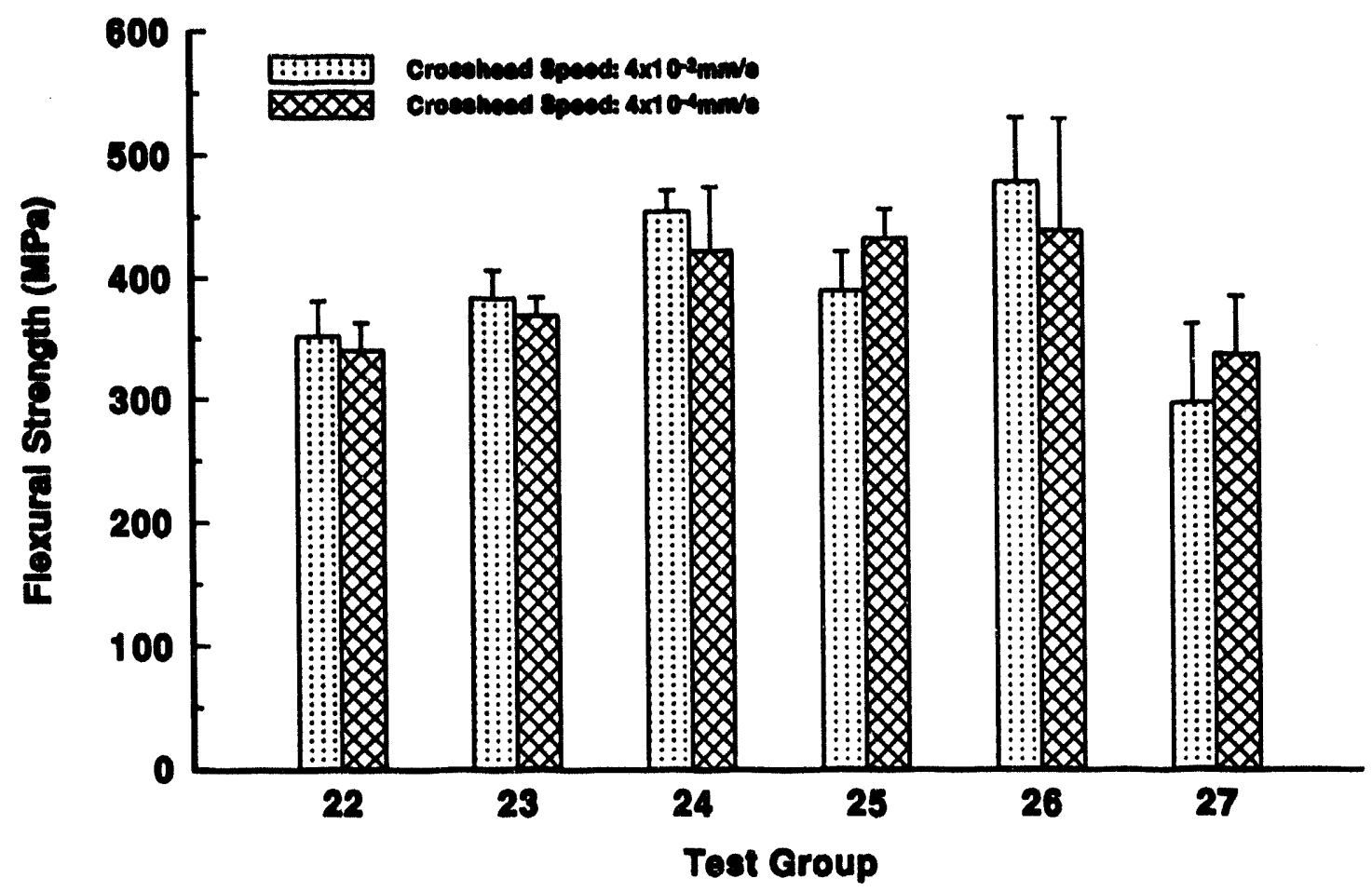

Figure 2. Flexural Strength Machining Effects Study.

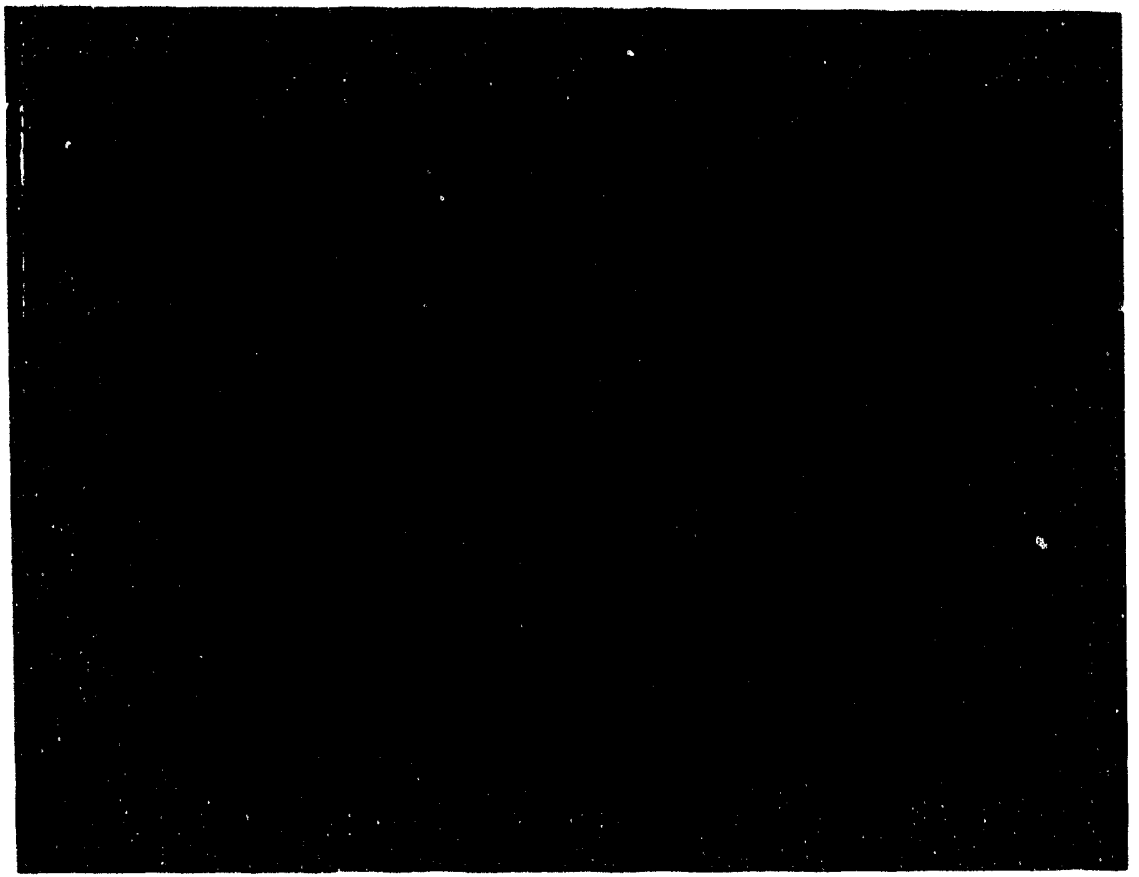

Figure 3. Machining Damage Found on Specimens in Machining Group 27. 
The test data for each machining group, 22-27, are given in Tables 11 through 16. Tables 17 and 18 give the fast- and slow-fracture flexural strength data from specimens supplied by Chand Kare that were cut from another billet of Morton International CVD SiC. These specimens were machined by Chand Kare using the standard grinding procedures (ASTM C1161) on their CC surface grinder.

\section{Status of milestones}

Milestones 331413 and 331414 have been completed. Milestone 331415 will be completed after microstructure studies. 
Table 11. Group 22 Four Point Flexure Results For CVD SiC.

Test Temperature: $20^{\circ} \mathrm{C}$

Crosshead Speed: $4 \times 10^{-2} \mathrm{~mm} / \mathrm{s}(0.1 \mathrm{in} / \mathrm{min})$

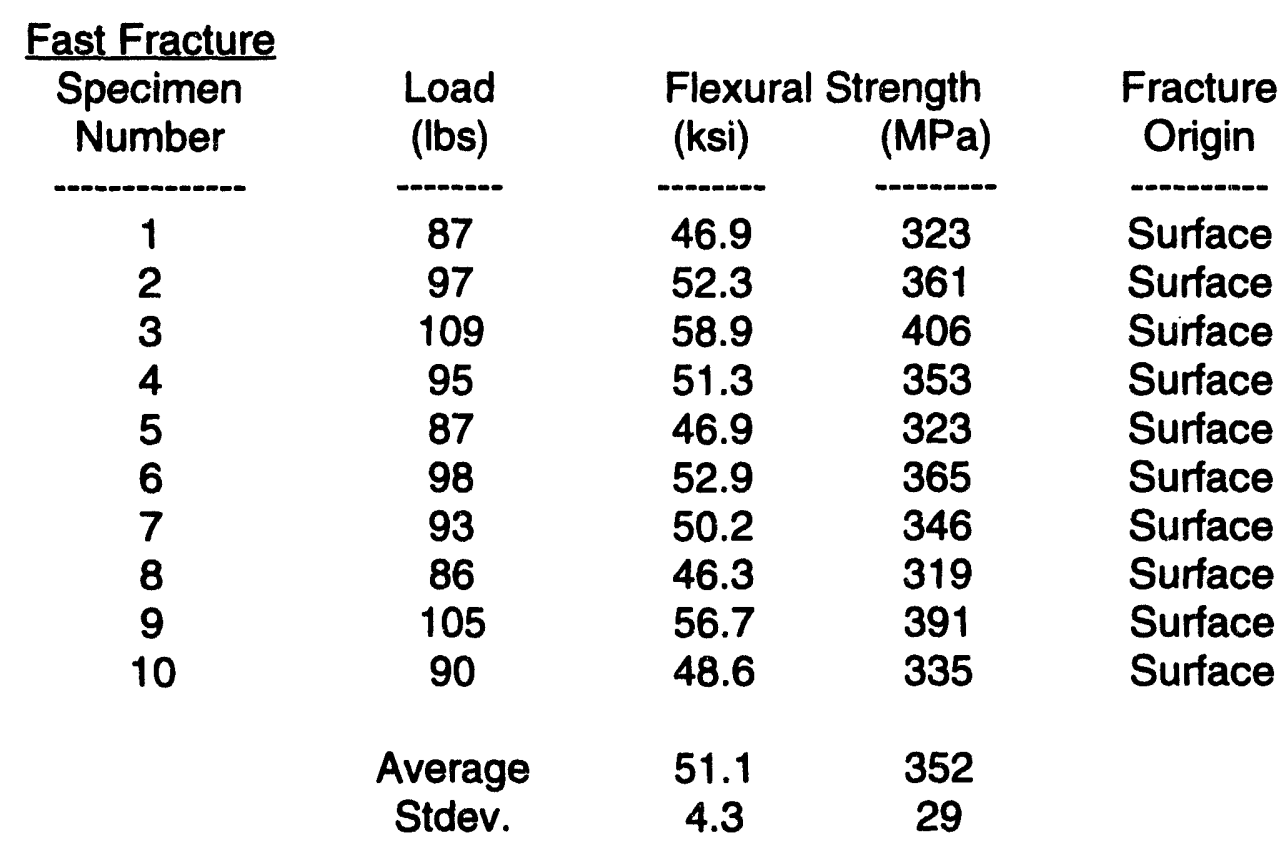

Test Temperature: $20^{\circ} \mathrm{C}$

Crosshead Speed: $4 \times 10^{-4} \mathrm{~mm} / \mathrm{s}(0.001 \mathrm{in} / \mathrm{min})$

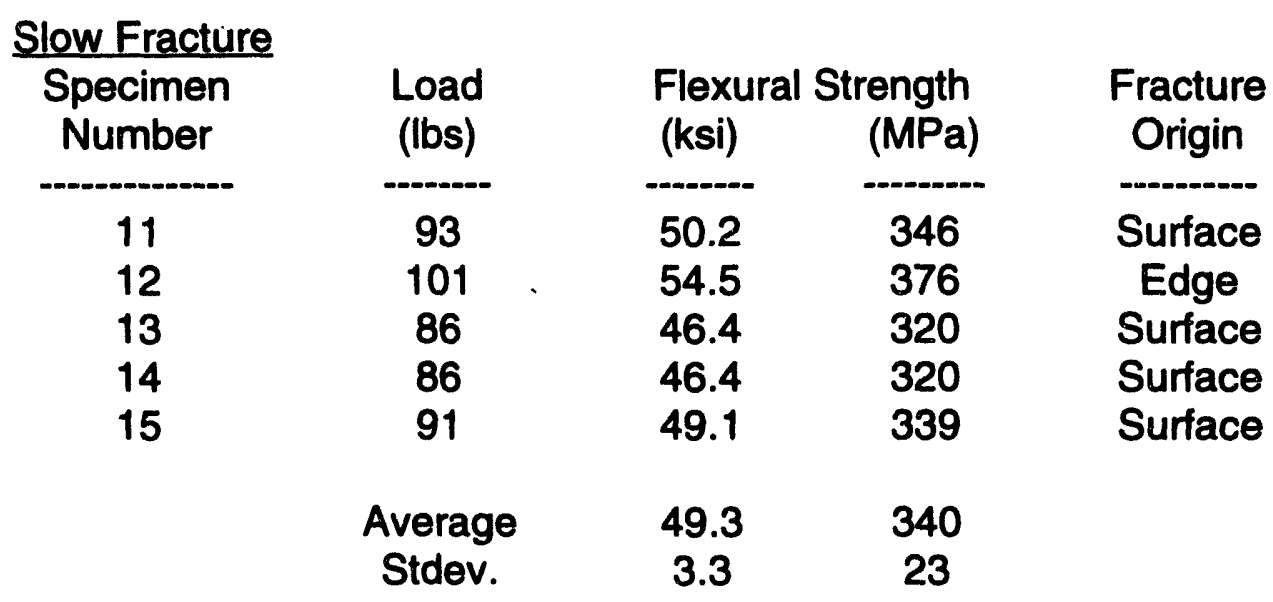




\section{6}

Table 12. Group 23 Four Point Flexure Results For CVD SiC.

Test Temperature: $20^{\circ} \mathrm{C}$

Crosshead Speed: $4 \times 10^{-2} \mathrm{~mm} / \mathrm{s}(0.1 \mathrm{in} / \mathrm{min})$

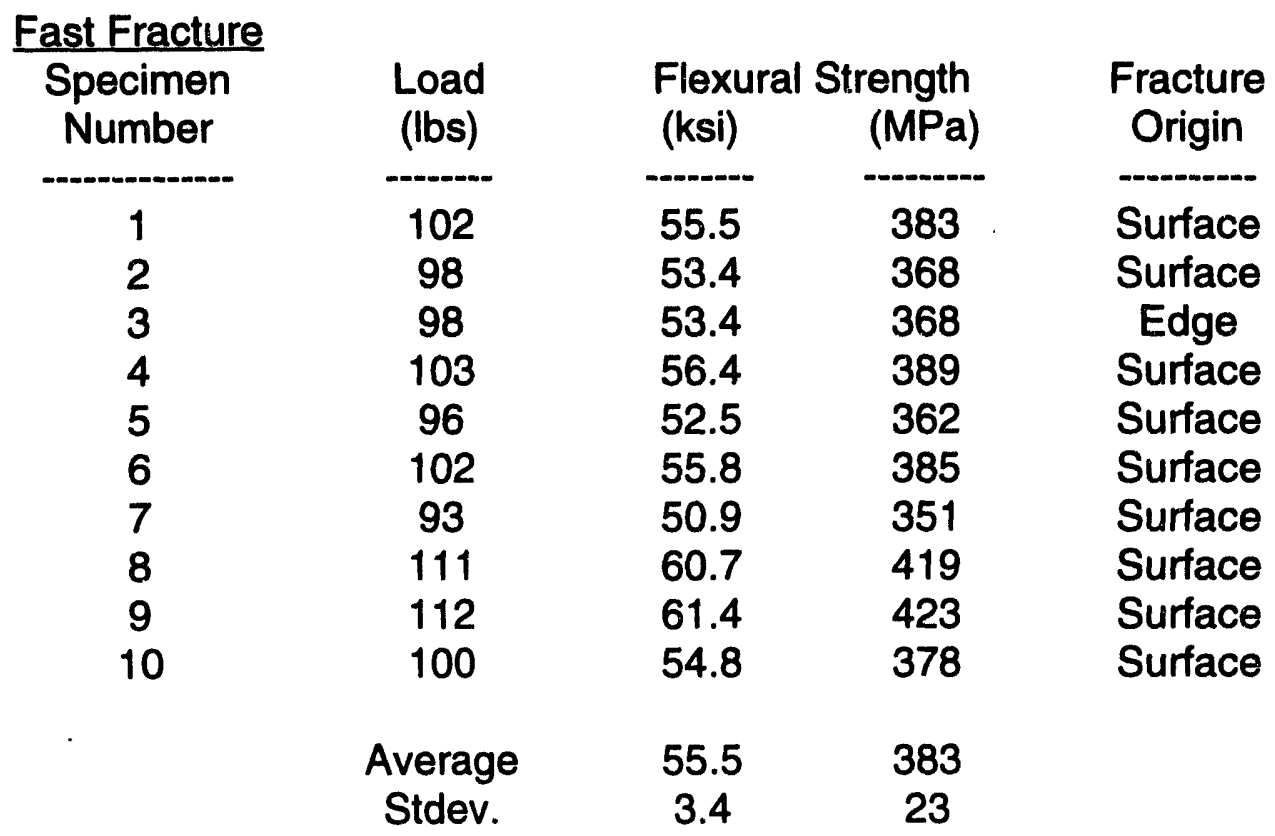

Test Temperature: $20^{\circ} \mathrm{C}$

Crosshead Speed: $4 \times 10^{-4} \mathrm{~mm} / \mathrm{s}$ (0.001 in/min)

Slow Fracture

\begin{tabular}{|c|c|c|c|c|}
\hline $\begin{array}{l}\text { Specimen } \\
\text { Number }\end{array}$ & $\begin{array}{l}\text { Load } \\
\text { (lbs) }\end{array}$ & $\begin{array}{l}\text { Flexur } \\
\text { (ksi) }\end{array}$ & $\begin{array}{l}\text { rength } \\
\text { (MPa) }\end{array}$ & $\begin{array}{c}\text { Fracture } \\
\text { Origin }\end{array}$ \\
\hline 11 & 99 & 54.2 & 374 & Surface \\
\hline 12 & 91 & 49.8 & 344 & Surface \\
\hline 13 & 99 & 54.2 & 374 & Edge \\
\hline 14 & 101 & 55.2 & 381 & Surface \\
\hline \multirow[t]{2}{*}{15} & 99 & 54.1 & 373 & Surface \\
\hline & Average & 53.5 & 369 & \\
\hline
\end{tabular}


Table 13. Group 24 Four Point Flexure Results For CVD SiC.

Test Temperature: $20^{\circ} \mathrm{C}$

Crosshead Speed: $4 \times 10^{-2} \mathrm{~mm} / \mathrm{s}(0.1 \mathrm{in} / \mathrm{min})$

\section{Fast Fracture}

Specimen

Number

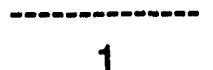

1

2

3

4

5

6

7

8

9

10

\begin{tabular}{c}
$\begin{array}{c}\text { Load } \\
\text { (Ibs) }\end{array}$ \\
\hline 120 \\
\hline 123 \\
130 \\
117 \\
124 \\
120 \\
119 \\
114 \\
117 \\
120
\end{tabular}

Flexural Strength

(ksi)

(MPa)

65.5

452

464

67.3

71.1

490

64.0

441

67.9

468

65.6

65.0

453

448

$62.1 \quad 428$

64.0

442

65.5

452

Fracture

Origin

Surface

Surface

Surface

Surface

Surface

Surface

Surface

Surface

Surface

Surface

$\begin{array}{ccc}\text { Average } & 65.8 & 454 \\ \text { Stdev. } & 2.5 & 17\end{array}$

Test Temperature: $20^{\circ} \mathrm{C}$

Crosshead Speed: $4 \times 10^{-4} \mathrm{~mm} / \mathrm{s}$ (0.001 in/min)

\section{Slow Fracture}

Specimen

Number

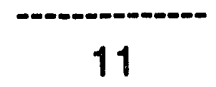

12

13

14

15
Load

(Ibs)

121

121

88

118

113
Flexural Strength

(ksi)

66.2

66.0

48.1

64.3

61.7

61.2

7.6

(MPa)

456

455

332

443

425

422
Stdev.

Average 
Table 14. Group 25 Four Point Flexure Results For CVD SiC.

Test Temperature: $20^{\circ} \mathrm{C}$

Crosshead Speed: $4 \times 10^{-2} \mathrm{~mm} / \mathrm{s}(0.1 \mathrm{in} / \mathrm{min})$

Fast Fracture

\begin{tabular}{|c|c|c|c|c|}
\hline $\begin{array}{l}\text { Specimen } \\
\text { Number }\end{array}$ & $\begin{array}{l}\text { Load } \\
\text { (Ibs) }\end{array}$ & $\begin{array}{l}\text { Flexura } \\
\text { (ksi) }\end{array}$ & $\begin{array}{l}\text { ength } \\
\text { (MPa) }\end{array}$ & $\begin{array}{c}\text { Fracture } \\
\text { Origin }\end{array}$ \\
\hline 1 & 102 & 55.3 & 381 & Surface \\
\hline 2 & 99 & 53.5 & 369 & Surface \\
\hline 3 & 92 & 50.0 & 345 & Surface \\
\hline 4 & 104 & 56.5 & 390 & Surface \\
\hline 5 & 108 & 58.8 & 405 & Surface \\
\hline 6 & 103 & 56.1 & 387 & Edge \\
\hline 7 & 98 & 53.0 & 366 & Surface \\
\hline 8 & 107 & 57.5 & 397 & Surface \\
\hline 9 & 123 & 67.3 & 464 & Surface \\
\hline \multirow[t]{2}{*}{10} & 103 & 55.6 & 384 & Surface \\
\hline & $\begin{array}{c}\text { Average } \\
\text { Stdev. }\end{array}$ & $\begin{array}{c}56.4 \\
4.6\end{array}$ & $\begin{array}{c}389 \\
32\end{array}$ & \\
\hline
\end{tabular}

Test Temperature: $20^{\circ} \mathrm{C}$

Crosshead Speed: $4 \times 10^{-4} \mathrm{~mm} / \mathrm{s}(0.001 \mathrm{in} / \mathrm{min})$

Slow Fracture

\begin{tabular}{ccccc}
$\begin{array}{c}\text { Specimen } \\
\text { Number }\end{array}$ & $\begin{array}{c}\text { Load } \\
\text { (Ibs) }\end{array}$ & $\begin{array}{c}\text { Flexural } \\
\text { (ksi) }\end{array}$ & $\begin{array}{c}\text { Strength } \\
\text { (MPa) }\end{array}$ & $\begin{array}{c}\text { Fracture } \\
\text { Origin }\end{array}$ \\
\hdashline 11 & -107 & 57.9 & 400 & Surface \\
\hdashline 12 & 111 & 60.1 & 415 & Surface \\
13 & 123 & 66.2 & 456 & Surface \\
14 & 119 & 64.1 & 442 & Surface \\
15 & 120 & 64.7 & 446 & Surface \\
& & & & \\
& $\begin{array}{c}\text { Average } \\
\text { Stdev. }\end{array}$ & 62.6 & 432 & \\
& & 3.4 & 24 &
\end{tabular}


Table 15. Group 26 Four Point Flexure Results For CVD SiC.

Test Temperature: $20^{\circ} \mathrm{C}$

Crosshead Speed: $4 \times 10^{-2} \mathrm{~mm} / \mathrm{s}(0.1 \mathrm{in} / \mathrm{min})$

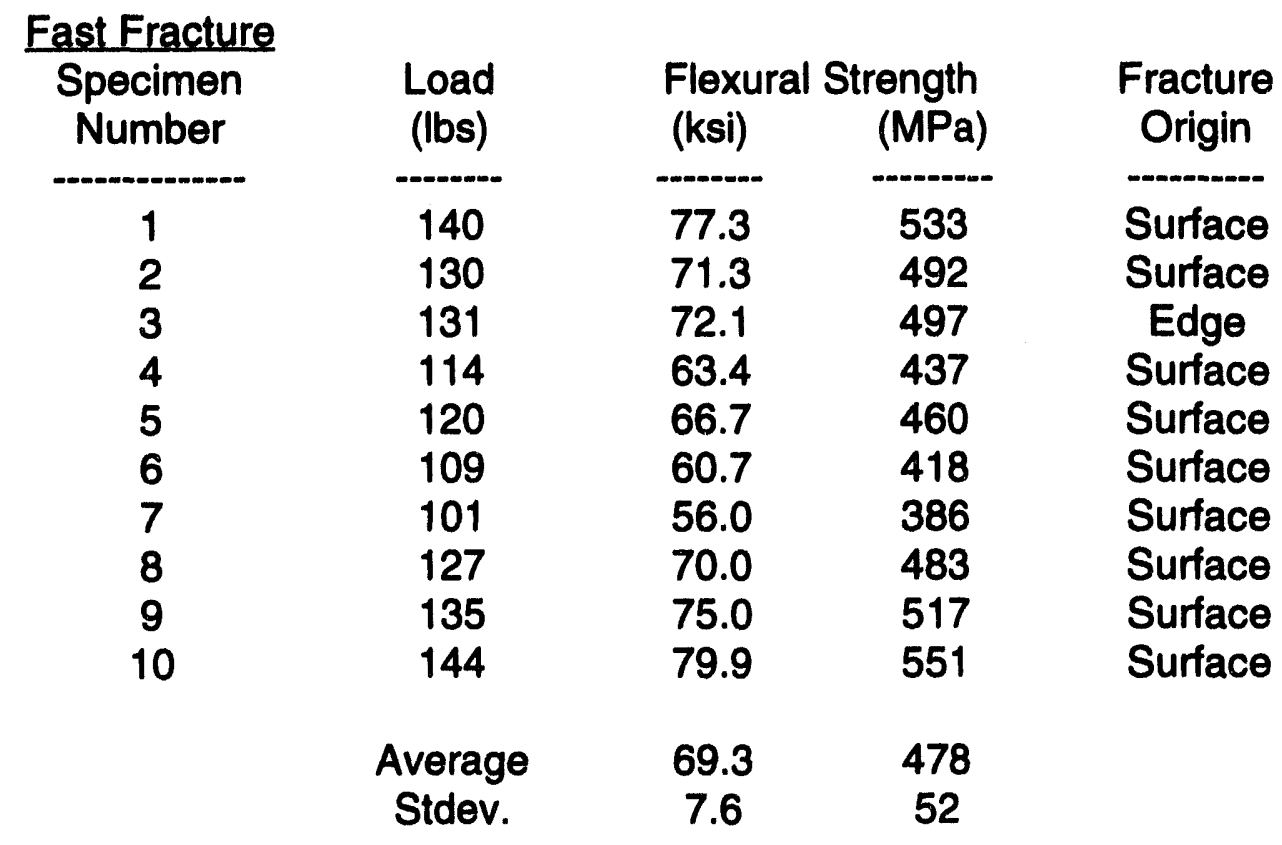

Test Temperature: $20^{\circ} \mathrm{C}$

Crosshead Speed: $4 \times 10^{-4} \mathrm{~mm} / \mathrm{s}(0.001 \mathrm{in} / \mathrm{min})$

\section{Slow Fracture}

Specimen

Number

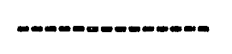

11

12

13

14

15
Load

(Ibs)

141

90

90

120

134

Average

Stdev.
Flexural Strength

(ksi) (MPa)

---.-.-

77.8

49.7

50.0

66.2

74.0

63.6

13.2
Fracture

Origin

Surface

Surface

Surface

Edge

Surface 
Table 16. Group 27 Four Point Flexure Results For CVD SiC.

Test Temperature: $20^{\circ} \mathrm{C}$

Crosshead Speed: $4 \times 10^{-2} \mathrm{~mm} / \mathrm{s}(0.1 \mathrm{in} / \mathrm{min})$

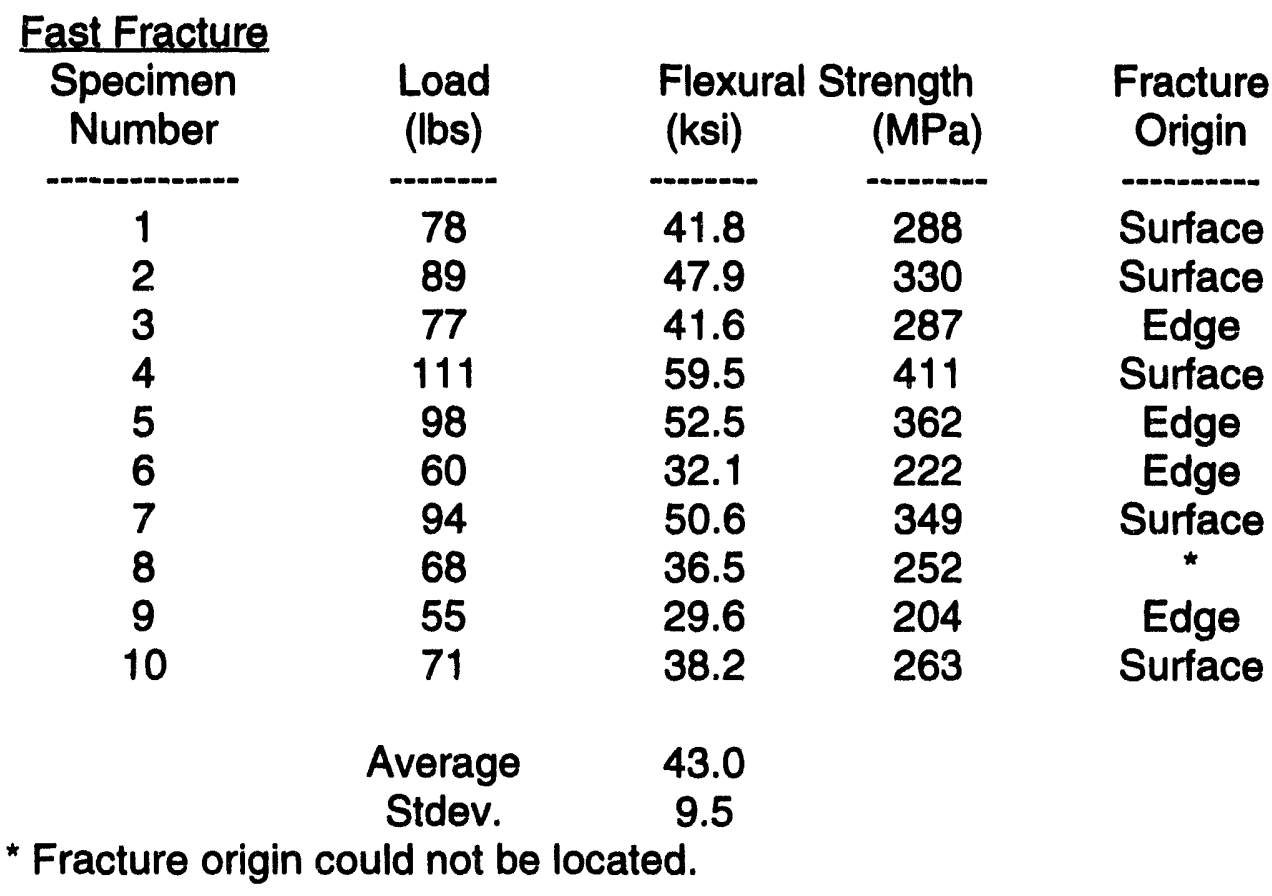

Test Temperature: $20^{\circ} \mathrm{C}$

Crosshead Speed: $4 \times 10^{-4} \mathrm{~mm} / \mathrm{s}(0.001 \mathrm{in} / \mathrm{min})$

Slow Fracture

\begin{tabular}{|c|c|c|c|c|}
\hline $\begin{array}{l}\text { Specimen } \\
\text { Number }\end{array}$ & $\begin{array}{l}\text { Load } \\
\text { (lbs) }\end{array}$ & $\begin{array}{l}\text { Flexura } \\
\text { (ksi) }\end{array}$ & $\begin{array}{l}\text { trength } \\
(\mathrm{MPa})\end{array}$ & $\begin{array}{c}\text { Fracture } \\
\text { Origin }\end{array}$ \\
\hline $\begin{array}{l}11 \\
12 \\
13 \\
14 \\
15\end{array}$ & $\begin{array}{c}92 \\
92 \\
101 \\
100 \\
69\end{array}$ & $\begin{array}{l}49.8 \\
49.5 \\
54.3 \\
53.9 \\
37.2\end{array}$ & $\begin{array}{l}343 \\
341 \\
374 \\
372 \\
257\end{array}$ & $\begin{array}{c}\text { Edge } \\
\text { Surface } \\
\text { Surface } \\
\text { Surface } \\
\text { Surface }\end{array}$ \\
\hline & $\begin{array}{l}\text { Average } \\
\text { Stdev. }\end{array}$ & $\begin{array}{c}48.9 \\
6.9\end{array}$ & $\begin{array}{c}337 \\
48\end{array}$ & \\
\hline
\end{tabular}


Table 17. Four Point Flexure Results For CVD SiC. Machined by Chand Kare using ASTM-C1161 Specifications

Test Temperature: $20^{\circ} \mathrm{C}$

Crosshead Speed: $4 \times 10^{-2} \mathrm{~mm} / \mathrm{s}(0.1 \mathrm{in} / \mathrm{min})$

\section{Fast Fracture}

Specimen

Number

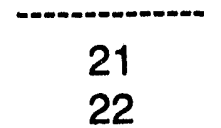

23

24

25

26

27

28

29

30

31

32

33

34

35

36

37

38

39

40
Load

(Ibs)

100

100

101

101

108

101

99

99

91

94

104

107

109

114

98

113

107

110

114

101
Flexural Strength

(ksi)

53.2

53.2

53.7

53.6

57.6

53.8

52.8

52.6

48.5

49.7

55.4

56.5

57.7

60.8

52.2

60.2

56.9

58.5

60.9

53.6
(MPa)

367

367

370

370

397

371

364

363

334

342

382

390

398

419

360

415

392

404

420

369
Fracture

Origin
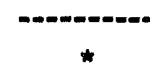

*

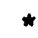

*

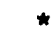

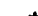

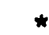

*

*

*

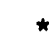

$\begin{array}{lll}\text { Average } & 55.1 & 380\end{array}$

Stdev.

3.5

24

* Fracture origin could not be located. 
Table 18. Four Point Flexure Results For CVD SiC.

Machined by Chand Kare using ASTM-C1161 Specifications

Test Temperature: $20^{\circ} \mathrm{C}$

Crosshead Speed: $4 \times 10^{-4} \mathrm{~mm} / \mathrm{s}(0.001 \mathrm{in} / \mathrm{min})$

\section{Fast Fracture}

\begin{tabular}{ccccc}
$\begin{array}{c}\text { Specimen } \\
\text { Number }\end{array}$ & $\begin{array}{c}\text { Load } \\
\text { (lbs) }\end{array}$ & $\begin{array}{c}\text { Flexural } \\
\text { (ksi) }\end{array}$ & $\begin{array}{c}\text { Strength } \\
\text { (MPa) }\end{array}$ & $\begin{array}{c}\text { Fracture } \\
\text { Origin }\end{array}$ \\
\hdashline 41 & -99 & 52.5 & 362 & $*$ \\
\hdashline 42 & 99 & 49.9 & 344 & $*$ \\
43 & 94 & 51.5 & 355 & $*$ \\
44 & 97 & 55.0 & 379 & $*$ \\
45 & 104 & 60.5 & 417 & $*$ \\
46 & 114 & 55.2 & 380 & $*$ \\
47 & 104 & 49.2 & 339 & $*$ \\
48 & 93 & 58.6 & 404 & $*$ \\
49 & 111 & 53.8 & 371 & $*$ \\
50 & 102 & 56.4 & 389 & $*$ \\
51 & 107 & 58.1 & 400 & $*$ \\
52 & 110 & 57.0 & 393 & $*$ \\
53 & 107 & 54.6 & 377 & $*$ \\
54 & 102 & 56.0 & 386 & $*$ \\
55 & 105 & 58.1 & 401 & $*$ \\
56 & 109 & 549 & $*$ \\
57 & 102 & 54.3 & 374 & $*$ \\
58 & 97 & 51.5 & 355 & $*$ \\
59 & 82 & 43.6 & 301 & $*$ \\
60 & 87 & 46.1 & 318 & \\
& 101 & 53.6 & 370 & $*$ \\
& & & & \\
& Average & 53.8 & 371 &
\end{tabular}

* Fracture origin could not be located. 


\subsection{FRACTURE MECHANICS}

Testing and Evaluetion of Advenced Ceramics of High Temperature J. Sankar, A. D. Kelkar, and J. Neogi (North Carolina A\&T State University)

\section{Objective/Scope}

The objective of this research is to test and evaluate the long-term mechanical reliability of a $\mathrm{Si}_{3} \mathrm{~N}_{4}$ at temperatures upto $1300^{\circ} \mathrm{C}$. The emphasis of this effort in the current year is to microstructurally characterize the specimens tested in fatigue/creep/tension, using scanning electron microscopy (SEM), transmission electron microscopy (TEM) and energy dispersive spectral analysis (EDS).

\section{Technical Highlights}

During this reporting period microstructural characterization of mechanically tested GTE SNW-1000 materials were conducted to investigate the effect of precycling on creep and residual tensile strength.

Table 1 summarizes the tests conducted and the results obtained. The time and precycling dependencies of the tensile creep strain rates as compared to pure creep strain are shown in Fig. 1. Samples were prepared from a GTE SNW-1000 specimen which had been coaxed $\left(50 / 60 / 70 \% \sigma_{f}\right)$ followed by residual tension test. TEM analysis were performed on these samples.

\section{Test results and discussion}

High temperature mechanical behavior of silicon nitride is also known to be influenced by the crystalline structure of the grain boundary material resulting due to various sintering aids. Fabrication/processing methods such as sintering, gas pressure sintering, and hot isostatic pressing are used to densify silicon nitride in order to improve its mechanical properties. Since the low self-diffusivity of silicon nitride does not allow densification by classical solid-state sintering techniques, processing to near-theoretical density requires the use of sintering aids like $\mathrm{Y}_{2} \mathrm{O}_{3}, \mathrm{MgO}, \mathrm{Al}_{2} \mathrm{O}_{3}$, or a combination of these to promote liquid phase densification of this material (Cinibulk et al., 1990; Cranmer et al., 1991). This results in an intergranular glassy phase which controls the high temperature behavior (Ahn and Thomas, 1983; Tsuge et al, 1975). It is these amorphous (intergranular) phases that soften at temperatures above $\sim 1000^{\circ} \mathrm{C}$, leading to the eventual failure of silicon nitride.

Additives such as $\mathrm{MgO}$ result in a continuous, amorphous magnesium silicate intergranular phase, whilst those containing $\mathrm{Y}_{2} \mathrm{O}_{3}-\mathrm{Al}_{2} \mathrm{O}_{3}$ additions may 
Table 1. Fatigue/ Creep/ Tension tests conducted on GTE SNW-1000

Summary of the test results

All tests were conducted at $1200^{\circ} \mathrm{C}$

$X$ - denotes test condition

\begin{tabular}{|c|c|c|c|c|c|}
\hline \multicolumn{4}{|c|}{$\begin{array}{c}\text { Cyclic Loading Stress (Max) and Pattern } \\
50,000 \text { cycles, } 0.5 \mathrm{~Hz} \text {, R-ratio }=0.1\end{array}$} & \multirow[t]{2}{*}{$\begin{array}{l}\text { Creep } \\
70 \% \sigma_{t s} \\
\text { constant } \\
\text { loading }\end{array}$} & \multirow{2}{*}{$\begin{array}{c}\text { Average } \\
\text { Residual } \\
\text { Tensile } \\
\text { Strength } \\
\text { (MPa) }\end{array}$} \\
\hline $25 \% \sigma_{\text {n }}$ & $50 \% \sigma_{n}$ & $70 \% \sigma_{n}$ & $50 / 60 / 70 \% \sigma_{n}$ & & \\
\hline & $x$ & & & $x$ & - \\
\hline & & $x$ & & $x$ & - \\
\hline & & & $x$ & $x$ & 580 \\
\hline \multirow[t]{4}{*}{$x$} & & & & & 371 \\
\hline & $x$ & & & & 505 \\
\hline & & $x$ & & & 451 \\
\hline & & & $x$ & & 501 \\
\hline
\end{tabular}




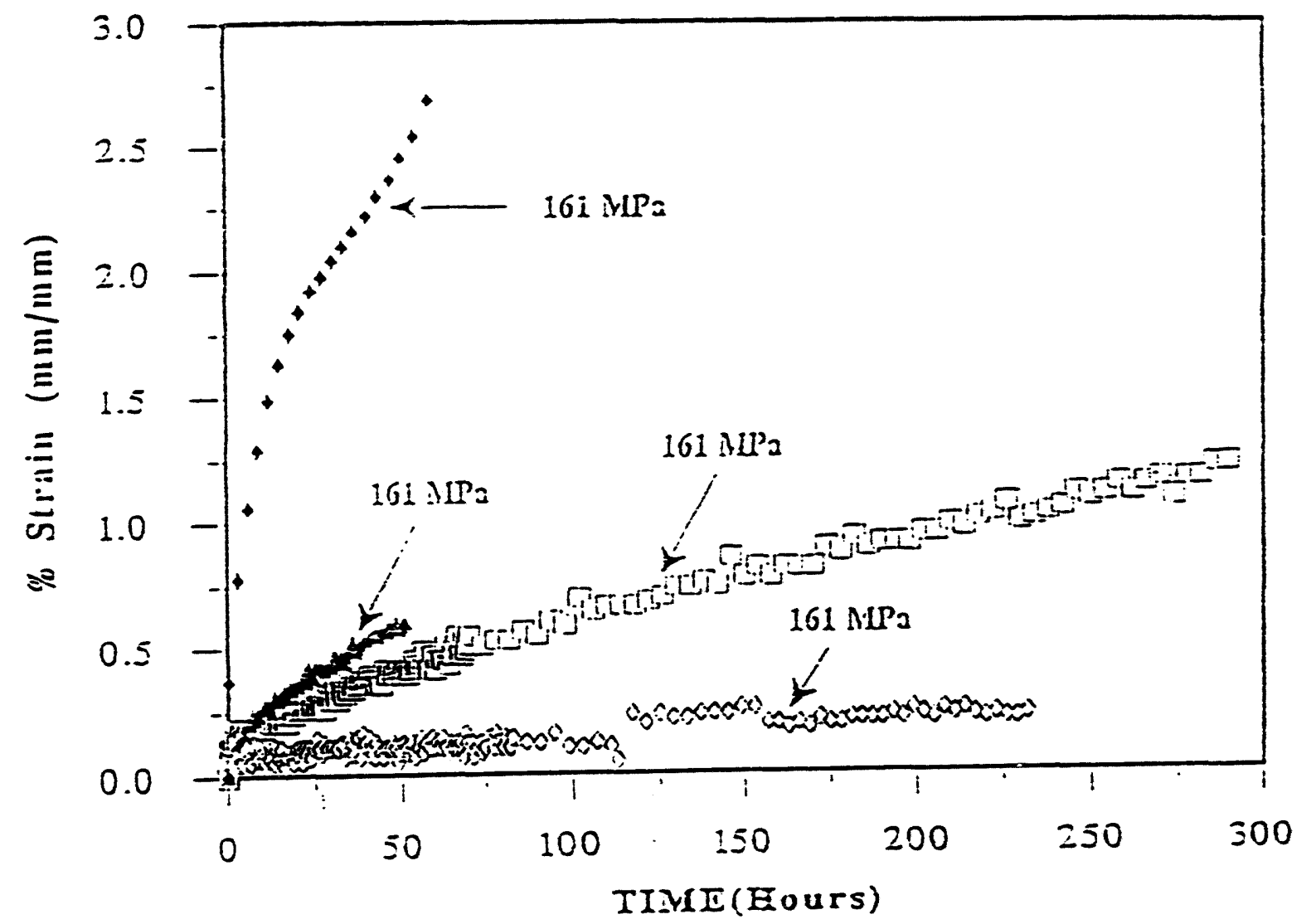

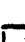

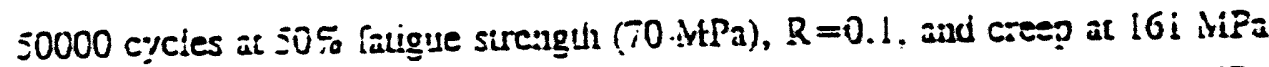

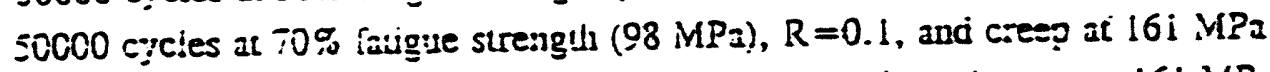
50000 cycies coaxed from 50\% 10 70\% fortigue strength, and crees at $16 \mathrm{i} \mathrm{MPa}$ Pure cieso at $1: 00$ dez. $C$ and $16 \mathrm{i}: \mathrm{MPa}$

Figure 1. Effect of fatigue on steady state strain rates of GTE SNW-1000. 
possess both crystalline and amorphous grain boundary phases (Todd et al., 1989). The primary factor for the improvement in creep resistance of GTE SNW1000 could be the presence of 12-13 wt $\% \mathrm{Y}_{2} \mathrm{O}_{3}$ and 2-3 wt $\% \mathrm{Al}_{2} \mathrm{O}_{3}$. But, a possible reasoning for the much lower primary creep strain in fatigued specimens could be due to the fact that creep process (equivalent to thermal annealing) besides the precycling process could have aided in devitrification. Devitrification is the process by which the glass contained within the multi-grain junctions crystallizes as a secondary phase. Research (Cinibulk et al., 1990; Lee et al., 1988) has showed that amorphous intergranular phase of silicon nitride can be devitrified by thermal annealing in the temperature range above $1350^{\circ} \mathrm{C}$ or by cyclic loading at an appropriate temperature. Liu et al., (1989) have also observed a behavior similar to this in a HIPed silicon nitride at $1300^{\circ} \mathrm{C}$. A comparison of their creep curves between unannealed, annealed, and precycled specimens, showed that the precycled specimen exhibited the least primary and secondary creep strains. They attribute'd this behavior to devitrification of intergranular glassy phase by precycling.

Samples were prepared from a GTE SNW-1000 specimen which had been coaxed $\left(50 / 60 / 70 \% \sigma_{f}\right)$ followed by residual tension test. Fig. 2 shows a representative view of the microstructure showing variable size and morphology of $\beta-\mathrm{Si}_{3} \mathrm{~N}_{4}$ grains. Despite the rapid crystallization of the multi-grain junctions, complete devitrification of the intergranular glass was never observed. The interfaces containing residual glasses were generally irregular, exhibiting gradual or abrupt changes in both orientation and apparent thickness.

Fig. 3 shows a representative view of the glassy interface separating adjacent $\mathrm{Si}_{3} \mathrm{~N}_{4}$ grains and amorphous pockets located at the triple point junction. It was observed that narrow and highly irregular glassy interfaces were redistributed by viscous flow which restricted interfacial sliding. Thus, it is possible that deformation may be inhomogeneous and relative displacement of adjacent grains are physically limited by grain-to-grain contact. Evidence for distributed grain-contact sites were obtained by observation of "STRAIN WHORLS" in the sample.

Fig. 4 shows isolated ellipsoidal-shaped cavities produced within narrow interfaces between $\mathrm{Si}_{3} \mathrm{~N}_{4}$ grains during coaxing. The cavity widths exceed the thickness of the interface, which is inclined to the plane of view and results in apparent cavity overlap. Observations from uniaxial tension tests with HIPed$\mathrm{Si}_{3} \mathrm{~N}_{4}$ suggest that it is possible to initiate cavities in glass-ceramics even in pure shear and that the cavities nucleate at triple junctions (Lange et al. 1980). A mechanism of cavity nucleation which is consistent with these observations is that grain boundary sliding produces a negative pressure in the glass segregated in triple junctions, which then causes the fluid to cavitate. It is recognized that fluids cavitate quite easily possibly because in comparison to solids they have a low bulk modulus (Appel, R. E., 1972). The presumption of negative pressure is consistent with the fact that porous, granular, materials dilate when stressed 


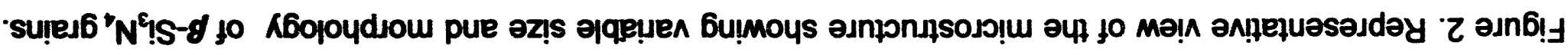
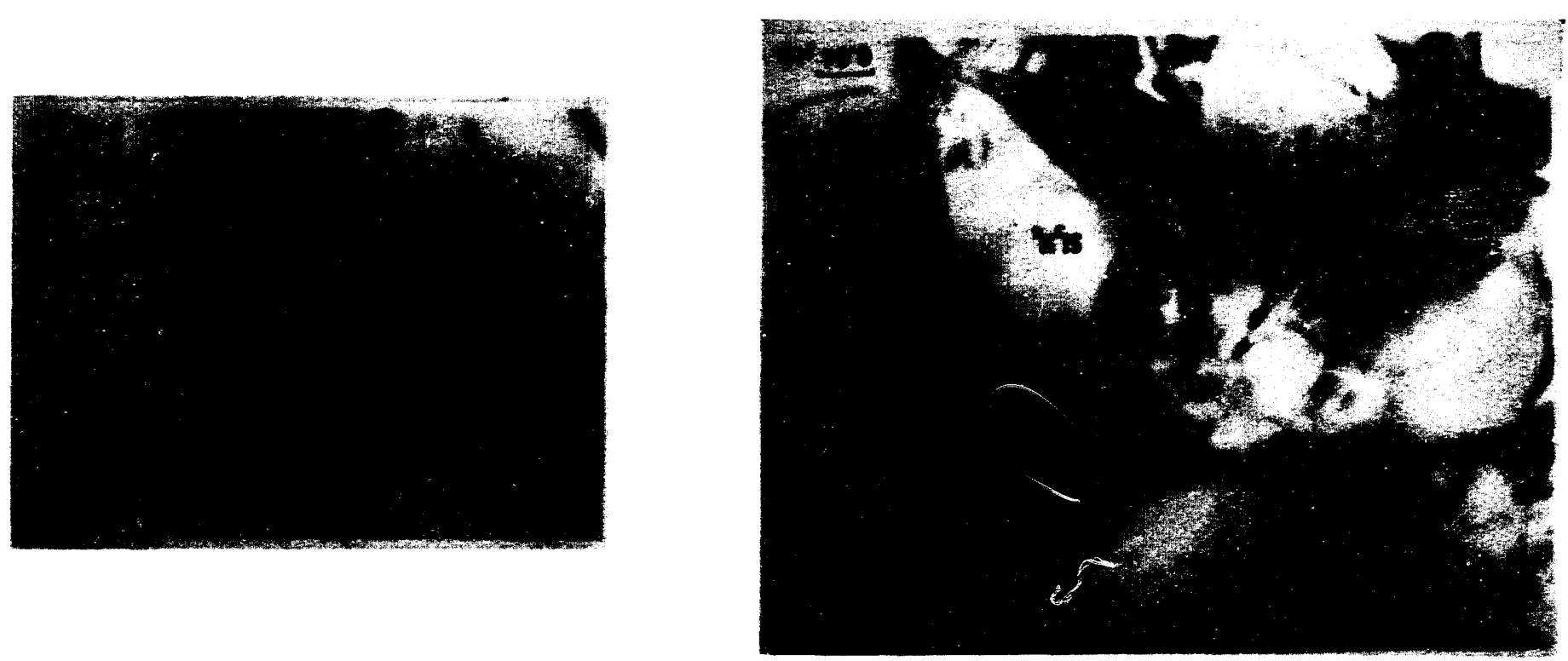


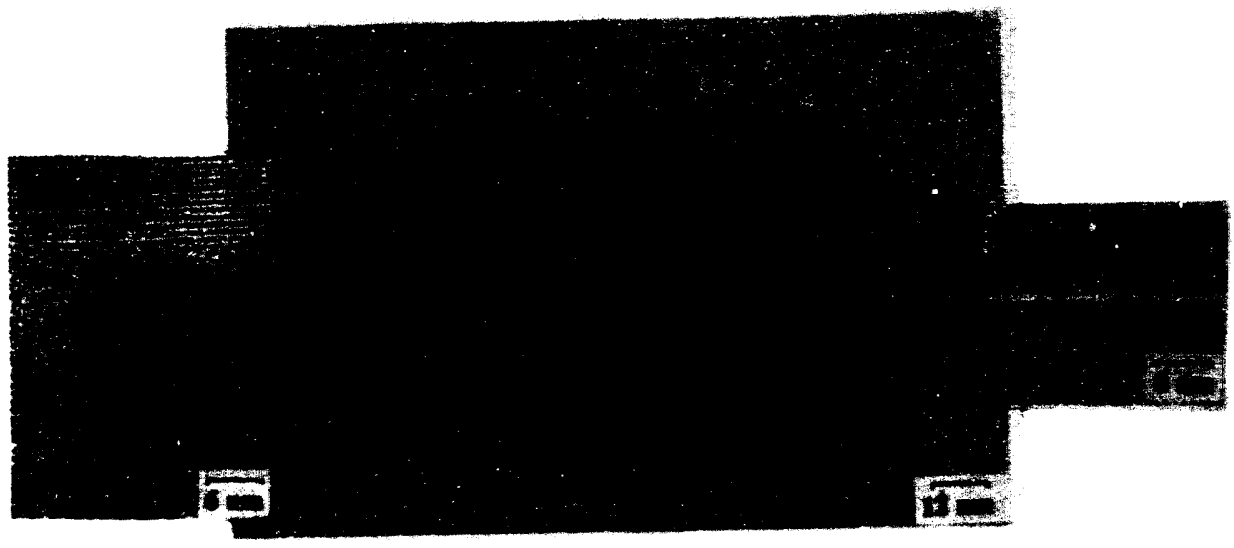

Figure 3. Representative view of the glassy interface separating adjacent $\mathrm{Si}_{3} \mathrm{~N}_{4}$ grains and amorphous pockets located at the triple point junction. 

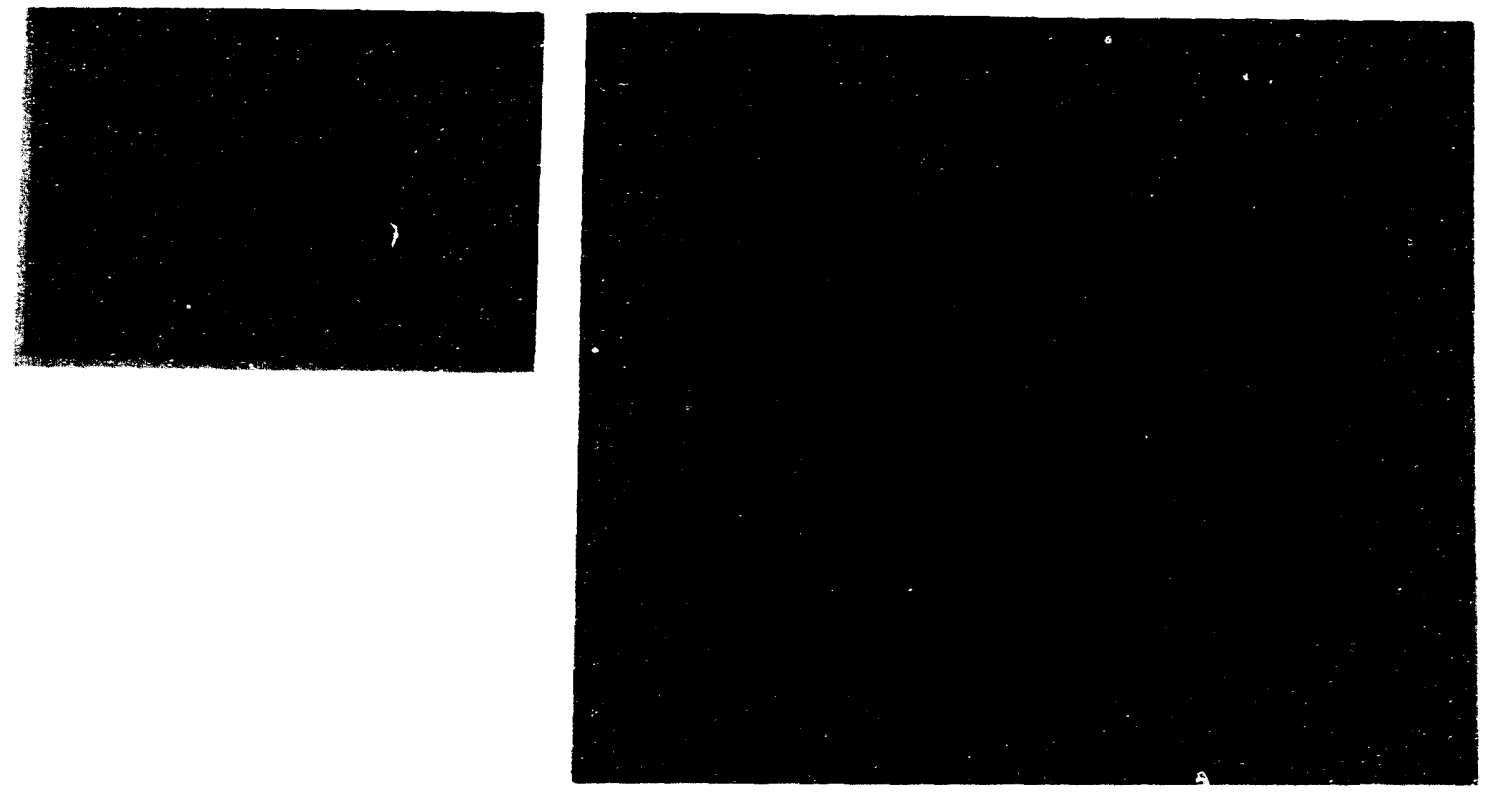

Figure 4. Isolated ellipsoidal-shaped cavities produced within narrow interfaces between $\mathrm{Si}_{3} \mathrm{~N}_{4}$ grains during coaxing. 
in pure shear. Therefore, if the pores are filled with a fluid, and if the fluid is constrained, it will develop a negative pressure (Tsai and Raj, 1982). An approximate expression for the magnitude of negative pressure, $P$ is given as

$$
P=4 \frac{\sigma_{s}}{G^{\prime}} B_{g}+\sigma_{m}
$$

where the factor 4 arises from the proportionality between the applied shear strain and the volume strain in the hole (Tsai and Raj, 1982). G' is the anelastic modulus, $B_{9}$ is the bulk modulus of the fluid, $\sigma_{8}$ is the applied shear stress and $\sigma_{m}$ is the mean stress. If the principle components of the applied stress are $\sigma_{1}$, $\sigma_{2}$ and $\sigma_{3}$, then $\sigma_{3}$ and $\sigma_{m}$ can be defined as

$$
\begin{gathered}
\sigma_{s}=\sqrt{1 / 2\left(\sigma_{1}-\sigma_{2}\right)^{2}+\left(\sigma_{2}-\sigma_{3}\right)^{2}+\left(\sigma_{3}-\sigma_{1}\right)^{2}} \\
\text { and } \\
\sigma_{m}=\frac{\sigma_{1}+\sigma_{2}+\sigma_{3}}{3}
\end{gathered}
$$

Dislocation loops were observed in the $\mathrm{Si}_{3} \mathrm{~N}_{4}$ grains. A reasonable explanation for this could be the presence of planar defects within the grain which led to the generation of dislocation loops.

\section{References}

Ahn, C. C., and Thomas, G., "Microstructure and Grain-Boundary Composition of Hot-Pressed Silicon Nitride With Yttria and Alumina," Journal of the American Ceramic Society, 66, [1], pp. 14-17, 1983.

Appel, R. E., "Tensile Strength of Liquids," Scientific American, 227, pp. 58-71, 1972.

Cinibulk, M. K., Thomas, G., and Johnson, S. M., "Grain-Boundary-Phase Crystallization and Strength of Silicon Nitride with a YSiAION Glass," Journal of the American Society, 73, [6], pp. 1606-1612, 1990. 
Cranmer, D. C., Hockey, B. J., Wiederhorn, S. M., and Yeckley, R., "Creep and Creep Rupture of HIPed Silicon Nitride," Ceramic Engineering and Science Proceedings,12, [9-10], pp. 1862-1872, The American Ceramic Society, Westerville, $\mathrm{OH}, 1991$.

Lange, F. F., Davis, B. I., and Clarke, D. R., "Compressive Creep of $\mathrm{Si}_{3} \mathrm{~N}_{4} / \mathrm{MgO}$ Alloys, Part 1, Effect of Composition," Journal of Materials Science, 15, pp. 601610, 1980.

Lee, W. E., Drummond III, C. H., Hilmas, G. E., Kiser, J. D., and Sanders, W. A., "Microstructural Evolution on Crystallizing the Glassy Phase in a 6 wt\% $\mathrm{Y}_{2} \mathrm{O}_{3}$ $\mathrm{Si}_{3} \mathrm{~N}_{4}$ Ceramics," Ceramic Engineering Science Proceedings, $\underline{9}$, [9-10], pp. 13551366, 1988.

Liu, K. C., and Brinkman, C. R., "High Temperature Tensile and Fatigue Strengths of Silicon Nitride," Proceedings of the Twenty-Seventh Automotive Technology Development Contractor's Co-ordination Meeting, P-230, pp. 235244, Society of Automotive Engineers, Warrendale, PA, 1989.

Todd, J. A., and $\mathrm{Xu}$, Zhi-Yue., "The High-Temperature Creep Deformation of $\mathrm{Si}_{3} \mathrm{~N}_{4}-6 \mathrm{Y}_{2} \mathrm{O}_{3}-2 \mathrm{Al}_{2} \mathrm{O}_{3}$," Journal of Materials Science, 27, pp. 4443-4452, 1989.

Tsai, R. L., and Raj, R., "Creep Fracture in Ceramics Containing Small Amounts of a Liquid Phase," Acta Metallurgica, 30, pp. 1043-1058, 1982.

Tsuge, A., Nishida, K., and Komatsu, M., "Effect of Crystallizing the GrainBoundary Glass Phase on the High-Temperature Strength of Hot-Pressed $\mathrm{Si}_{3} \mathrm{~N}_{4}$ Containing $\mathrm{Y}_{2} \mathrm{O}_{3}$," Journal of the American Ceramic Society, 58, [7-8], pp. 323326, 1975.

\section{Status of Milestones}

On schedule

\section{Communications/Visitors/Travel}

None

\section{Problems Encountered}

None 


\section{Publications and Presentations}

J. Neogi, S. Krishnaraj, J. Sankar and R. Vaidyanathan, "Mechanical Properties Investigation of Silicon Nitride Ceramics," paper presented at Materials Conference '93, Oct. 27 - 29, 1993.

S. Neogi, J. Neogi, R. Vaidyanathan and J. Sankar, " TEM Sample Preparation Technique for Ceramic Materials," Poster presented at the Materials Conference '93, Oct. 27 - 29, 1993. 
Standard Tensile Test Development

S. M. Wiederhorn, R. F. Krause, Jr. and W. E. Luecke

(National Institute of Standards and Technology)

\section{Objective/Scope}

This project is concerned with the development of test equipment and procedures to determine the tensile strength and creep resistance of ceramic materials at elevated temperatures. Inexpensive techniques for measuring the creep behavior and strength of structural ceramics have been developed and are being used to characterize the mechanical behavior of these materials. The ultimate goal of the project is to help develop a data base and a test methodology for the structural design of heat engines for vehicular applications.

\section{Technical Highlights}

During the past six months we have focussed efforts on quantifying and understanding the asymmetry in the tensile and compressive creep response of silicon nitride, focussing on studies of NT154 at elevated temperatures. When deformed at $1430^{\circ} \mathrm{C}$, NT154 exhibits markedly different creep behavior. In compression, the creep rate is extremely low, and is linearly proportional to the applied stress. In contrast, tensile creep rates are 10-100 times as large as those in compression. At low stresses the creep rate is proportional to the square of the applied stress, while at high stress it becomes proportional to the fourth power of stress.

\section{Background}

Despite the enormous number of creep experiments conducted on ceramics in the past 30 years, there are few instances in which both the tensile and compressive creep behavior of a material have been measured on compositionally identical materials. Most of these few instances show an interesting behavior that sets the creep of ceramics apart from that of metals; namely, that at equivalent stress, the creep rate in tension may often be hundreds or even thousands of times greater than that in compression. Morrell and Ashbee[1] made one of the first observations of this effect in a $\mathrm{Li}_{2} \mathrm{O}-\mathrm{ZnO}-\mathrm{SiO}_{2}$ glass-ceramic. The microstructure of their glass-ceramic was a complicated network of interlocking, star-shaped clusters of lithium disilicate surrounded by smaller grains of lithium disilicate and residual glass. In both tension and compression the glassceramic showed an increasing stress exponent, $n,\left(d \epsilon / d t \alpha \sigma^{n}\right)$ with increasing stress. In addition, at a given stress, the strain rate in tension was 10 to 100 times greater that in compression. For a given tensile strain rate, about four to ten times the stress was necessary in compression. Specimens deformed in tension showed a greater volume fraction of cavities than those deformed in compression.

In a study of the superplastic deformation of several lithium aluminosilicate $\beta$-spodumene glass ceramics, Wang and Raj [2] reported tensile creep rates twice as large as compressive creep rates. Roughly 1.5-2 times the stress in compression was required to effect the same 
creep rate in tension. The microstructure of their glass-ceramic was composed of equiaxed, $1 \mu \mathrm{m}$ grains whose triple junctions held the residual glass. The material sustained large strains to failure and showed a stress exponent of unity in both tension and compression. They attributed the tension/compression asymmetry to the friction between the sample ends and the alumina push-rods during compression, which effectively reduced the stress available to drive the solution-reprecipitation creep. Wiederhorn et al. [3] demonstrated extreme asymmetry between tension and compression creep of reaction-bonded SiC. About $2 / 3$ by volume of this reaction-bonded $S i C$ is $5 \mu \mathrm{m}$ SiC grains which form a complete threedimensional network, whose interstices are filled with silicon metal. Like the $\mathrm{Li}-\mathrm{Zn}$ glass-ceramic this material shows an increasing stress exponent with increasing stress, rising from $n-4$ at low stresses to $n-10$ at the highest stresses in both tension and compression. For a given creep rate, roughly twice the stress in compression is required over tension. At a given stress, the creep rate in tension exceeded that in compression by 10 to 100 times. At low stress in both tension and compression the material did not cavitate, but at higher stresses in tension, cavitation was common, often accounting for a substantial fraction of the strain.

Several silicon nitrides also show tension-compression asymmetry. Kossowsky et al. [4] seem to have been the first to observe this behavior, but reported only anecdotal evidence, noting that it required almost 10 times the stress in compression (almost $700 \mathrm{MPa}$ at $1370 \mathrm{C}$ ) to effect the same creep rate as that measured in tension. This material must have been either Norton HS-110 or HS-130, both early high-temperature silicon nitrides. Lou et al. [5] describe the microstructure of these Mg0-hotpressed materials as having a significant fraction of elongated $\mathrm{Si}_{3} \mathrm{~N}_{4}(2-4$ $\mu \mathrm{m}$ by $0.2-0.4 \mu \mathrm{m}$ ) grains. Hockey et al. [6] showed an enormous asymmetry between the tensile and compressive creep of silicon nitride reinforced by 30 volume-percent SiC fibers. The fibers were typically $10 \mu \mathrm{m}$ long by 0.2-1.0 $\mu \mathrm{m}$ in diameter and were randomly dispersed in a matrix of submicrometer $\mathrm{Si}_{3} \mathrm{~N}_{4}$. The fibers seem to have retarded the growth of the acicular $\mathrm{Si}_{3} \mathrm{~N}_{4}$ grains that normally grow during processing. In tension the material showed a stress exponent greater than five, but a stress exponent of unity in compression. Creep rates in tension exceeded those in compression by at least one hundred times. To achieve the same creep rate in tension at high stress required compressive stresses more than six times as large. Extensive cavitation accompanied tensile creep.

In contrast to the aforementioned results which show a distinct asymmetry of the tension and compression creep behavior, there is at least: one instance in which tension and compression produced identical creep rates. Robertson et al. [7] showed that a yttria-magnesia-doped, hotpressed alumina crept at the same rate in both tension and compression at $1250 \mathrm{C}$ under stresses between 40 and $150 \mathrm{MPa}$. This material was singlephase alumina with equiaxed, $1 \mu \mathrm{m}$, equiaxed grains. This short note describes our findings on the tension/compression creep asymmetry of a commercial, hot-isostatically-pressed $\mathrm{Si}_{3} \mathrm{~N}_{4}$. 


\section{EXPERIMENTAL PROCEDURE}

Reference [8] describes the tensile creep testing procedure in great detail. A pneumatic system applies the load to the $50 \mathrm{~mm}$ dogbone specimens via SiC pull rods. The entixe specimen sits in the hot-zone of the furnace. Typical gauge lengths are $10 \mathrm{~mm}$, and specimens are $2 \times 2.5$ $\mathrm{mm}$ in area. A laser-extensometry system measures the distance between two Sic flags hanging from the specimen, defining the gauge length. Although the laser system measures the separation of the flags very precisely, the true gauge length is somewhat uncertain, introducing a random error in the strain measurement of about ten percent. For compression experiments, a screw-driven testing machine applies the load via SiC push-rods. We

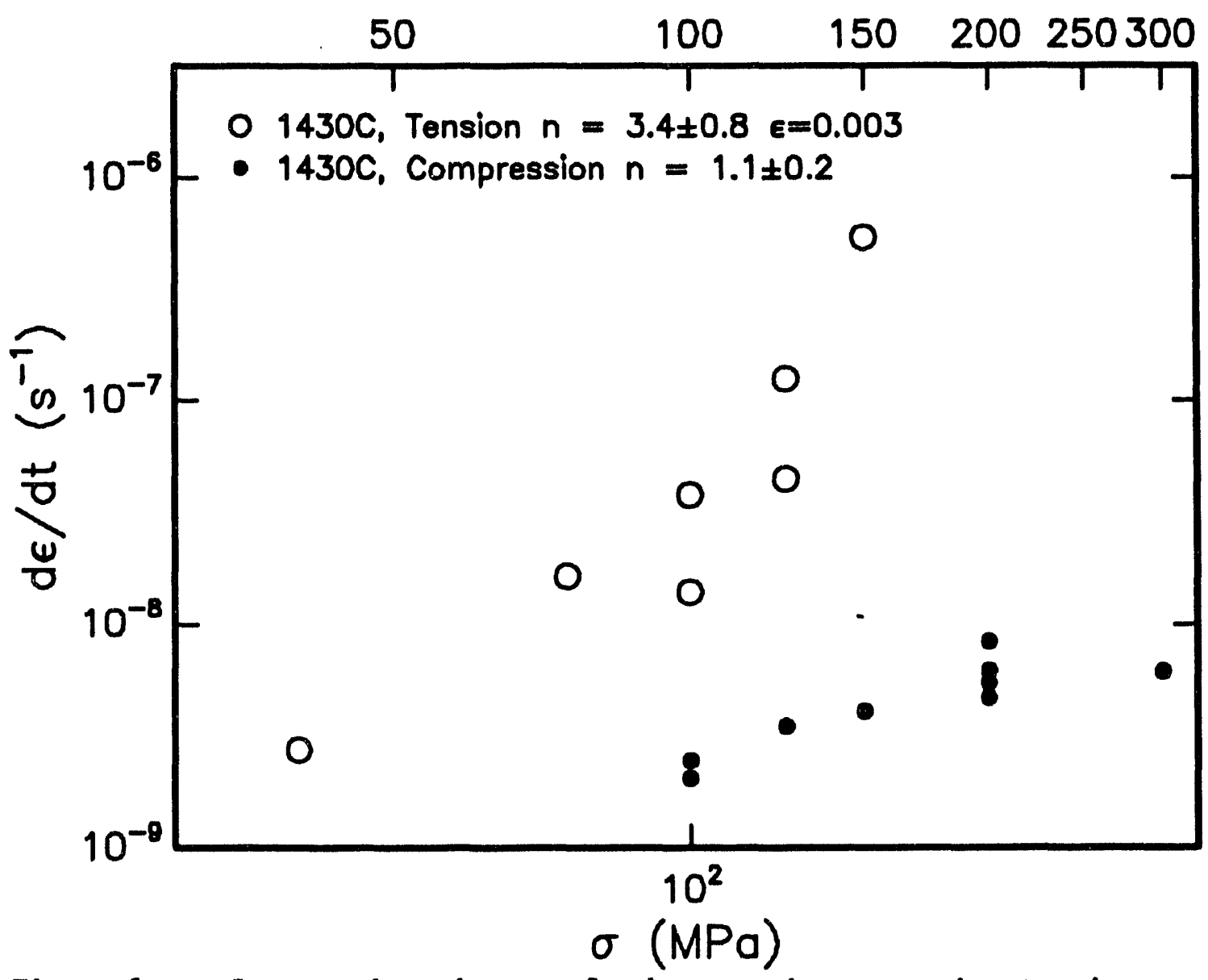

Figure 1. Stress dependence of the strain rate in tension and compression for Si3N4 deformed at $1430 \mathrm{C}$.

measure the strain by measuring the displacement of two SiC fibers attached to the platens on the ends of the specimen. Typical compression creep specimens were $1.8 \times 2.4 \mathrm{~mm}$ by $5.5 \mathrm{~mm}$ long, and came from the 
flange-end of already-tested tension specimens. ${ }^{1}$ Reference [9] describes the density measurement equipment used to assess the cavity volume fraction. All densities were calculated by a sink-float technique in a mixture of $\mathrm{CH}_{2} \mathrm{I}_{2}$ and $\mathrm{CH}_{2} \mathrm{Br}_{4}$ using calibrated density standards. Each specimen used for the volume-fraction assessment consumed the entire gauge length of the tension specimen, or the entire compression specimen, after removal of all surface oxide. Typically, the uncertainty in the density was less than $0.0005 \mathrm{~g} / \mathrm{cm}^{3}$, giving an uncertainty in the cavity volume fraction of less than five percent. For the tension specimens, the volume fraction of cavities was always calculated relative to a section of the undeformed flange of the specimen to compensate for a slight change in density with exposure to high temperature. For the compression specimens, we estimated the change in density of an undeformed reference piece from previous experiments using undeformed specimens.

${ }^{1}$ Norton NT-154, Norton/TRW. The use of commercial designations or company names does not indicate endorsement by the National Institute of Standards and Technology. 


\section{RESULTS}

In tension, all of the specimens crept at a unique stress until fallure. Only rarely did they exhibit steady-state creep. Generally, the strain rate decreased continuously until failure intervened. No specimen showed any evidence of tertiary creep. In contrast, the compression specimens crept under multiple stresses. Figure 1 summarizes the stress dependence of the creep rate for all the specimens tested.

Because of the non-steady-state creep in tension, the creep rates shown are evaluated at constant strain $(\epsilon=0.003)$. Although it is possible to fit a line to the tension data, it seems clear from Figure 1 that the

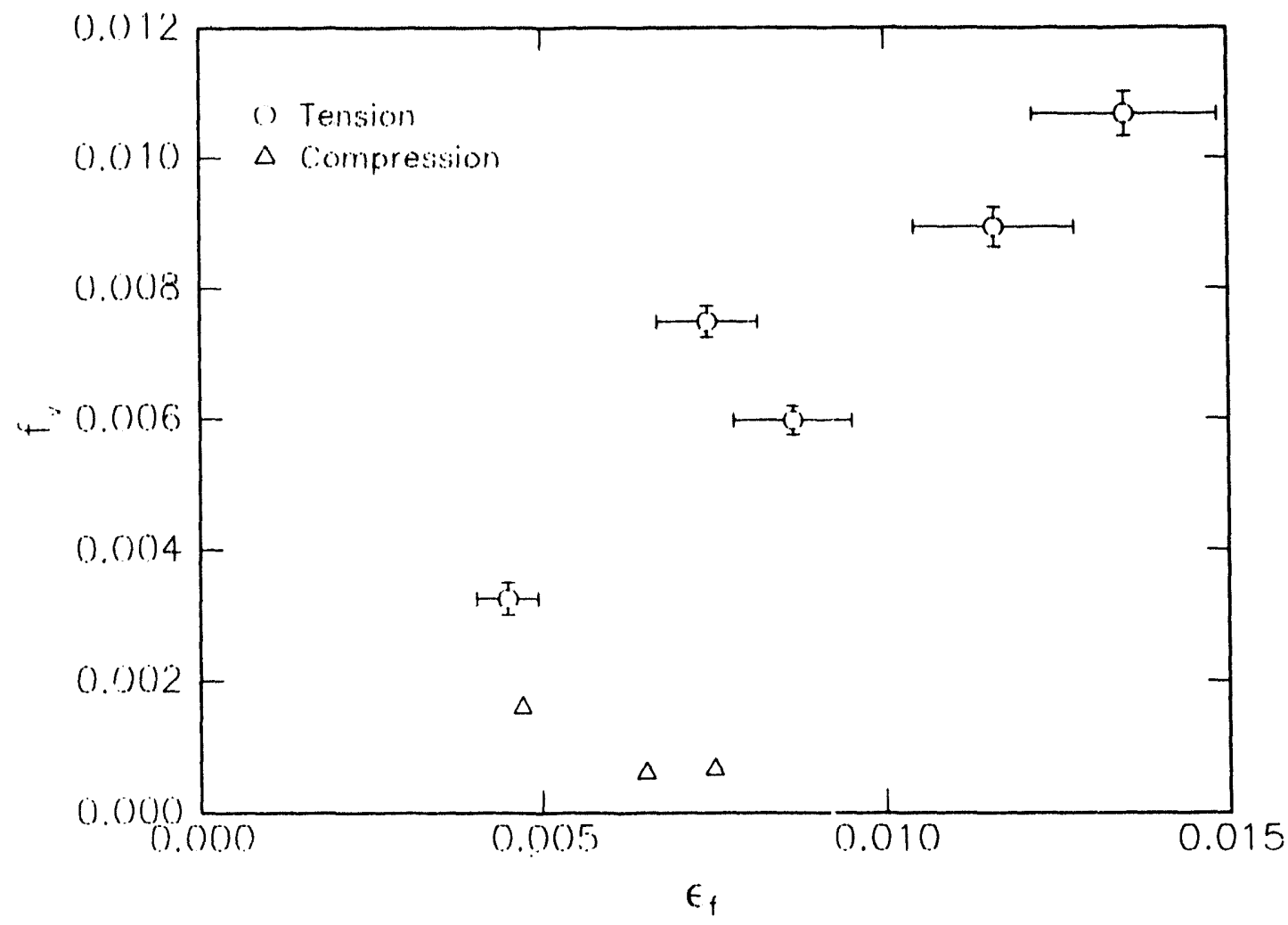

Figure 2. Volume fraction of cavities in specimens deformed in tensile and compressive creep at $1430 \mathrm{C}$, as a function of strain.

strain-rate increases more strongly than linear:ly on the $\log -\log$ plot. In contrast, in compression, the strain rate is linear with stress, with a stress-exponent of unity.

The major difference in the microstructure of the $\mathrm{Si}_{3} \mathrm{~N}_{4}$ in tension and compression is the appearance of a substantial number of cavities in specimens deformed in tension. From TEM investigations, the bulk of the cavitation occurred in the clusters of equiaxed $\mathrm{Si}_{3} \mathrm{~N}_{4}$ that 1 ie in the interstices of the acicular grain network. Figure 2 shows the volume 
fraction of cavities for specimens deformed in tension. If all the volume of the cavities were to contribute to the tensile strain, then the volume fraction of cavities is analogous to a cavitation strain. In this case, more than $2 / 3$ of the total strain is due to the cavitation process. In contrast to the tension specimens, the compression specimens showed no evidence of any significant cavitation.

\section{Discussion}

The major microstructural difference between the materials which show tension/compression creep asymmetry, (the Li-Zn glass ceramic [1], the reaction-bonded $S I C$ [3], and the SiC-fiber-reinforced $\mathrm{Si}_{3} \mathrm{~N}_{4}$, but not the $\beta$-spodumene glass-ceramic [2]), and the alumina [7] which does not, is that the former are all composed of an interlocking hard phase whose interstices are filled with a less creep resistant phase. A second difference is that the former often show cavitation in tension, but not in compression, the reaction-bonded SiC at low stress, for example. Microstructurally, the NT-154 $\mathrm{Si}_{3} \mathrm{~N}_{4}$ is very similar to those other materials that show the creep asymmetry. The acicular grains form a three-dimensional, interlocking network whose interstices are filled with a much less creep resistant, by virtue of its small grain size, submicrometer $\mathrm{Si}_{3} \mathrm{~N}_{4}$.

James and Ashbee [10] presented a dilatational model of creep that predicts an exponentlal dependence of strain-rate on stress. They argued that for the hard particle network to deform, in either tension or compression, the entire network must expand in volume as the hard particles slide over one another. Th1s expansion forces the hard particles together, effectively increasing the frictional resistance to their sliding. The creep rate is controlled by the rate at which contact points between hard grains can dissolve away. Increasing the stress increases the number of contact points between hard grains, reducing the diffusion distance that material that dissolves from the hard grains must travel before redeposition. While their model does address the exponential dependence of the creep rate on stress, it neglects the asymmetry between tension and compression.

Hockey and Wiederhorn [11] extended the dilatation model advanced by James and Ashbee. Their model, based on similar models used to explain the deformation of wet soils, does not address the exponential dependence of strain rate on stress, but offers an explanation for the suppression of cavitation in compressive creep. As the hard particle network (in their work, the $\mathrm{SIC}$ network, here, the interlocking large $\mathrm{Si}_{3} \mathrm{~N}_{4}$ grains) dilates during deformation, material must flow into the interstices. In response to the dilatation, material must flow into regions that are dilating. This flow creates a net hydrostatic tension that pulls the hard particle network together, effectively increasing the friction between the grains. If sufficient flow into the dilating regions is not possible, cavitation results. An applied tensile stress tends to lift the sliding hard grains off each other, reducing the frictional stress and increasing the strain rate. An applied compressive stress tends to force the sliding hard grains together, increasing the frictional resistance to sliding, and lowering the creep rate. With the decreased creep rate, the flow into the dilating regions can now keep up with the deformation of the large grains, thus suppressing the need for cavitation. 


\section{References}

(1) R. Morrell and K. H. G. Ashbee, J. Mater. Sc1. 8, 1253 (1973).

[2] J.-G. Wang and R. Raj, J. Am. Ceram. Soc. 67, 399 (1984).

[3] S. M. Wlederhorn, D. E. Roberts, T. -J. Chuang, and L. Chuck, J. Am. Ceram. Soc. 71, 602 (1988).

[4] R. Kossowsky, D. G. Millex, and E. S. Diaz, J. Mater. Sc1. 10, 983 (1975).

[5] L. K. V. Lou, T. E. Mitche11, and A. H. Heuer, J. Am. Ceram. Soc. 61,392 (1978).

16] B. J. Hockey, S. M. Wiederhorn, W. Liu, J. G. Baldoni, and S.-T. Buljan, J. Mater. Sc1. 26, 3931 (1991).

[7] A. G. Robertson, D. S. Wilkinson, and C. H. Cáceres, J. Am. Ceram. Soc. 74, 915 (1991).

[8] D. F. Carroll and S. M. Wiederhorn, Int. J. High Technology Ceramics 4, 227 (1988).

[9] W. Luecke, S. M. Wiederhorn, B. J. Hockey, and G. G. Long, Cavity evolution during tensile creep of $\mathrm{Si}_{3} \mathrm{~N}_{4}$, in Silicon Nitride CeramicsScientific and Technological Advances, edited by I.-W. Chen, P. F. Becher, M. Mitomo, G. Petzow, and T. S. Yen, The Materials Research Society, 1993.

[10] K. James and K. H. Ashbee, Progress in Materials Science 21, 3 (1975).

[11] B. J. Hockey and S. M. Wiederhorn, J. Am. Ceram. Soc. 75, 1822 (1992).

\section{Status of Milestones}

All milestones on schedule.

\section{Communications/Visits/Travel}

Dr. Wiederhorn was scheduled to make a presentation at Silicon Nitride ' 93 in Stuttgart, Germany, October 4-6. An illness in the family forced cancellation of his trip. Dr. Luecke delivered his paper entitled "HighTemperature Structural Reliability of Silicon Nitride"

Following this meeting, The Max-Planck-Institut für Metallforschung invited Dr. Wiederhorn to make a presentation entitled "Creep Damage Mechanisms in $\mathrm{Si}_{3} \mathrm{~N}_{4}$ " at a workshop on "Tailoring of High-Temperature Properties of $\mathrm{Si}_{3} \mathrm{~N}_{4}$-Ceramics". Dr. Luecke delivered this presentation as we11.

Dr. Luecke also presented two other papers at silicon Nitride '93, Stuttgart, Germany, October 4-6: one entitled "Tension/Compression creep asymmetry in silicon nitride;" the other entitled "Tensile Creep of a Silicon Nitride Ceramic," was presented for R. F. Krause, Jr. and S. M. Wiederhorn. 


\section{Publications}

W1Iliam Luecke and S.M. Wiederhorn, "Tension/Compression Creep Asymmetry in $\mathrm{Si}_{3} \mathrm{~N}_{4}$ ", Proceedings of the International Conference on Silicon NitrideBased Ceramics (Silicon Nitride 93), M.J. Hoffman, P.F. Becher and G. Petzow, eds.,pp 586-592, Trans Tech Publications, 1993.

S.M. Wlederhorn, G.D. Quinn and R. Krause, Jr. "HIgh Temperature Structural Reliability of silicon Nitride," Proceedings of the International Conference on silicon Nitride-Based Ceramics (Silicon Nitride 93), M.J. Hoffman, P.F. Becher and G. Petzow, eds., pp 475-580, Trans Tech Publications, 1993.

R.F. Krause, Jr, and S.M. Wiederhorn, "Tensile Creep of a Silicon Nitride Ceramic," Proceedings of the International Conference on Silicon NitrideBased Ceramics (Silicon Nitride 93), M.J. Hoffman, P.F. Becher and G. Petzow, eds., pp 619-624, Trans Tech Publications, 1993. 


\subsection{NONDESTRUCTIVE EVALUATION DEVELOPMENT}

Nondestructive Characterization

D. J. McGulre (Oak Ridge National Laboratory)

\section{Objective/scope}

The purpose of this program is to conduct nondestructive evaluation (NDE) development directed at identifying approaches for quantitative determination of conditions (including both properties and flaws) in ceramics that affect the structural performance. Those materials that have been serlously considered for application in advanced heat engines are all brittle materials whose fracture is affected by structural features whose dimensions are on the order of the dimensions of their microstructure. This work seeks to characterize those features using high-frequency ultrasonics and radiography to detect, size, and locate critical flaws and to measure nondestructively the elastic properties of the host material.

\section{Technical progress}

Ultrasonics - W. A. Simpson, Jr., and K. V. Cook

We continue to develop our capabilities in ultrasonic synthetic aperture imaging for both monolithic and composite ceramics. We previously described' a modification to our inspection hardware that permits both conventional and synthetic aperture techniques to be applied to ceramic components having a cylindrical geometry. The equations necessary to implement the latter technology in the new geometry were also presented. Additions and modifications to the in-house-developed software and to the cornputer system now permit data files up to $20 \mathrm{MB}$ to be processed in high-speed random access memory (RAM). This data file size is sufficient to inspect up to about $175,000 \mathrm{~mm}^{3}$ of such ceramics as alumina, silicon nitride, and silicon carbide. For comparison, this volume is more than 36 times that contained in the gauge length $(152.4 \mathrm{~mm})$ of a 6.35-mm-diam tensile specimen.

The most pressing problem in developing our synthetic aperture capabilities lies in displaying the processed data appropriately. We can currently display cross-sectional slices of the inspected part corresponding to the scan lines in the original synthetic aperture. However, a two-dimensional scan (with the digitized temporal data forming the third, or depth, dimension of the data set) properly requires a three-dimensional (3-D) display, preferably with the outline of the part superimposed. This will require considerable software development which we can ill afford to pursue while continuing our technique development. We are slowly writing software modules as time permits in an effort to address the shortcomings of our current synthetic aperture data display.

A test data set simulating three flaws in a cylindrical specimen of zirconia has been generated for evaluation of our synthetic aperture software. This data set has not yet been processed.

We continue to see increased use of composite ceramics in structural applications. In many cases, the characteristic of interest in these materials is the integrity of the fiber/matrix or whisker/matrix bond. However, because of the very small size of individual fibers or whiskers (and particularly of any interlayers applied to the fiber/whisker to 
enhance matrix bonding), the nondestructive assessment of bond integrity in a bulk sense is an exceedingly difficult problem. Athough it is possible to detect whisker/matrix separation in individual whiskers using sufficiently high ultrasonic frequencies, such an approachi would be impractical for process control or evaluation. What is needed is a technique that can detect changes in the bond integrity globally and which can be applied with approximately the same ease as can conventional ultrasonic evaluation. Unfortunately, subtle changes in the whisker/matrix bonding have only a very small effect on the usual ultrasonic variables (veloclty, attenuation). Attempts by others to quantify the degree of bonding through measurement of these variables have generally been unsuccesstul.

One aspect of materials that has been largely neglected in traditional NDE is the nonlinear behavior of solids, particularly composites. Such nonlinearities include changes (depending on the third-order and higher elastic constants) in the elastic wave velocity with stress and harmonic generation, in which the inherent anharmonicity of the material causes part of the fundamental energy to be converted to second and higher harmonics. Measurement of both of these nonlinzarities has been documented in the literature. Y'ost and Cantrell $\left.\right|^{2}$ established that fatigue damage in aluminum increased the nonlinearity parameter (a combination of second-and third-order elastic constants) by a factor of three, while $L$ et al. ${ }^{3}$ showed that only $3 \%$ second-phase content in aluminum produced a $70 \%$ increase in the nonlinearity parameter. Prosser, ${ }^{4}$ studying a fiber/matrix system, was able to show that microscopic bond imperfections significantly increased the nonlinearity of a graphite/epoxy composite. In fact, evidence continues to mount that the nonlinearity parameter is one of the most sensitive indicators of the presence of lattice imperfections, microstructural anomalles, and fiber/matrix integrity in composites. The first of these contributions, lattice imperfections, is particularly interesting in that it consists of two terms: lattice anharmonicity (which, strictly speaking, is inherent in all materials and is therefore not properly an imperfection) and lattice dislocations. Both of these effects contribute to the second-harmonic content and are extremely difficult to separate. Dislocation loop length, however, is virtually the lone contributor to third-harmonic content; thus, Hikata et al. ${ }^{5,6}$ were able, by measuring both the second-and thirdharmonic contributions, to separate the two contributions and determine nondestructively the dislocation loop length. Even the presence of natural imperfections in otherwise homogeneous materials can drastically affect the nonlinear behavior.'

The primary impediment to development of viable nonlinear measurement techniques has been the extreme difficulty in determining the very small harmonic displacement amplitudes. In order to quantify the nonlinear behavior, it is necessary to determine the absolute displacement of both the fundamental and harmonic waves. The former can be estimated from the piezoelectric properties of the transducer. In the absence of external forces, the strain induced in a piezoelectric transducer by an applied voltage is given by:

$$
\ddot{S}=\boldsymbol{D} \cdot \vec{E}
$$

where $\vec{S}$ is the strain dyadic, $\vec{E}$ is the electric fleld vector, and $D$ is the third-rank piezoelectric strain constant tensor. For a typical piezoelectric transducer material such as $\mathrm{LNbO}_{3}$, the $\mathrm{d}_{33}$ element of $\mathrm{D}$ is the quantity of interest and is equal to about $6 \times 10^{-12}$ coulomb/N. At a frequency of $10 \mathrm{MHz}$ and an applied voltage of $250 \mathrm{~V}$, the displacement amplitude of the crystal is about $15 \AA$. Assuming this to be the fundamental wave 
amplitude in the sample, the second-harmonic amplitude will typically be 2 to 3 orders of magnitude smaller, depending on the material, or 0.015 to $0.15 \AA$. Clearly, absolute measurement of displacement in this range is beyond the sensitivity even of optical techniques.

The most commonly used detector for harmonic amplitude measurement is the capacitive detector. The requisite sensitivity is available, but the technology is expensive and requires extremely precise sample surface preparation, a fact which precludes routine production sampling. However, the sensitivity of piezoelectric sensors is certainly adequate for this task. For example, the voltage produced by the $\mathrm{LiNbO}_{3}$ transducer described above can be estimated from the inverse piezoelectric constitutive relations. Assuming no external electrical fields, the relationship between applied stress and generated electric field is:

$$
\vec{E}=\boldsymbol{\sigma} \cdot \ddot{T}
$$

where $\mathbf{G}$ is the third-rank piezoelectric voltage tensor and $T$ is the stress dyadic. Again, the salient component of $G$ is $G_{33}$, whose value is about $0.023 \mathrm{~m}^{2} /$ coulomb for $\mathrm{LiNbO}_{3}$. Now, the relation between particle displacement and acoustic pressure (stress) is given by:

$$
p=\rho c \omega \xi \quad
$$

where $p$ is acoustic pressure, $p$ is the material density, $c$ is the material compressional wave velocity, $\omega$ is the angular frequency, and $\xi$ is the particle displacement. Assuming a value of $0.15 \AA$ for $\xi$ and alumina for the ceramic, the induced second-harmonic voltage in the $20-\mathrm{MHz}$ receiving transducer would be about $330 \mathrm{mV}$, which is easily detectable with conventional piezoelectrics. These calculations assume no conversion, matching, or material losses, which would further reduce the detected signal.

Since it would appear that conventional piezoelectric detection has adequate sensitivity for the detection of harmonics in materials, the question naturally arises regarding why they have not been widely used for this purpose. The reason is that absolute measurements of the fundamental and harmonic wave amplitudes are necessary, and this requires a rather involved calibration procedure as well as assurance that reciprocity holds for the transducer/couplant system. Recently, Dace et al. ${ }^{8}$ have shown that this is, indeed, the case and have given a procedure for obtaining the necessary calibration. Their work, which involved simple piezoelectric elements and water coupling, has placed the measurement of nonlinear properties on a footing comparable to that underpinning conventional ultrasonic testing.

Of the manifestations of elastic nonlinearity described above (stress-induced velocity changes and harmonic generation), the latter is preferred for material characterization because no static loading of the specimen is necessary. It can be shown $n^{9}$ that the displacement amplitude in a solid due to a propagating compressional wave is given by:

$$
\xi=A_{1} \sin (k x-\omega t)-\left(\frac{K_{3}}{K_{2}}+3\right) \frac{A_{1}^{2} k^{2} x}{8} \cos 2(k x-\omega t)+\ldots,
$$


where $A_{1}$ is the displacement amplitude of the fundamental, $k$ is the wave vector of the fundamental, $x$ is the specimen thickness, $\omega$ is the angular frequency, and $K_{2}$ and $K_{3}$ are combinations of the second- and third-order elastic constants, respectively. The term $-\left(K_{j} / K_{2}+3\right)$ is the nonlinearity parameter, $\beta$. If we designate the constants preceding the cosine term by $A_{2}$, the second harmonic displacement amplitude, then the nonlinearity parameter can be expressed in terms of the fundamental and second-harmonic displacement amplitudes by:

$$
\beta=\frac{8 A_{2}}{A_{1}^{2} k^{2} x} .
$$

The problem thus reduces to that of measuring $A_{1}$ and $A_{2}$, from which $\beta$ can be calculated.

Er,uation (1) indicates that the second-harmonic amplitude increases quadratically with both the driving (fundamental) amplitude and frequency. Thus, we would want to use as high a frequency and driving amplitude as possible. Fortunately, most ceramics are inherently wideband materials; hence, the choice of operating frequency depends primarily on the equipment available. In the present case, we are using a radio frequency (II) power amplifier capable of operation up to $105 \mathrm{MHz}$. The amplifier is driven by a gated oscillator controllable via a general-purpose interface bus (GPIB) interface.

Although this combination covers the frequency range of interest to ceramic evaluation, the maximum if power output is only $100 \mathrm{~W}$, which, into a 50-ohin load, means a peak output of $100 \mathrm{~V}$. Stability problems in the amplifier limit the useable output to 60 to $75 \mathrm{~V}$. With this low level of excitation, our results to date have not been satisfactory. This is very likely attributable to the lack of a high-power excitation source. We are currently seeking to obtain such a source. We have also obtained a lock-in ainplifier with the capability of locking on the second harmonic of the reference frequercy, which should be useful in extracting very low-amplitude signals.

We are presently working with materials whose nonlinearity parameters have been documented in the literature (fused silica, aluminum, etc.) for establishment of the technique. When this is accomplished, we will begin applying the technique to ceramics both before and after fatiguing. We have written software to implement the calibration procedure described by Dace, ${ }^{8}$ and we are examining several transducer materials in order to select elements that may be more suitable for nonlinearity measurements.

We continue to receive requests from both vendors and purchasers of structural ceramics for assistance in evaluating their materials. One recent request from a purchaser was concerned with the effect of surface preparation on a monolithic alumina. Since we had recently completed a study of machining damage in several structural ceramics ${ }^{10}$ (see also publication below), we were able to perform this evaluation in a timely manner. Figure 1 shows the result of a high-frequency surface-wave scan on ten modulus of rupture (MOR) bars. The data show linear grinding marks and a few very small indications attributable to near-surface voids of approximately 20 to $30-\mu \mathrm{m}$ diam. In general, this material was as dense and homogeneous as any we have seen.

Figure 2 shows the surface-wave result obtained on one end of a 13-mm-diam cylinder of the alumina. The sea shell pattern and radial lines evident in the figure are grinding marks and were of considerable interest to the purchaser. Figure 3 shows the result obtained on the other end of the cylinder. Grinding marks are also visible here as well, and the dark circular indication at about the 10 o'clock position on the figure was 


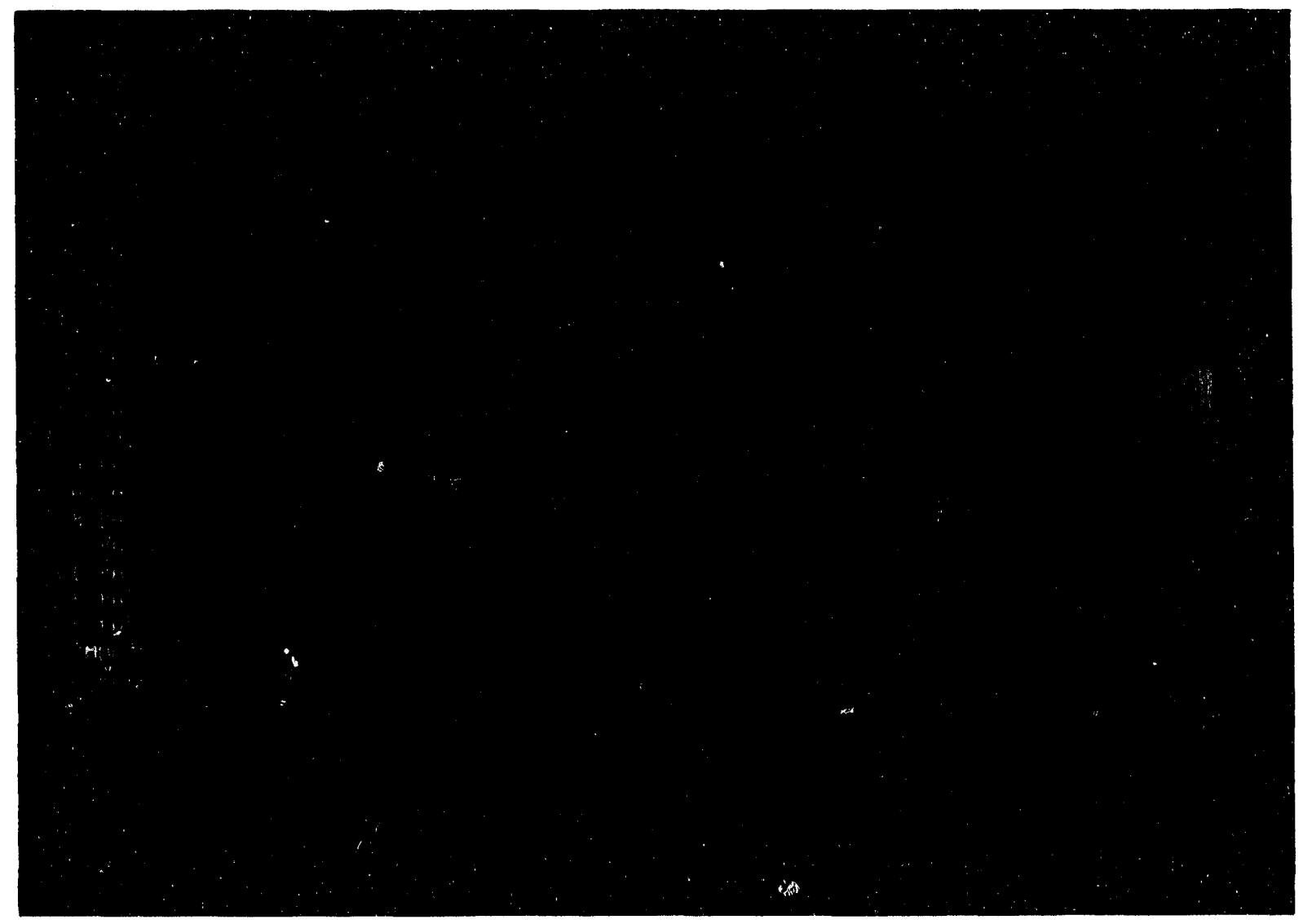

Fig. 1. Ultrasonic surface-wave image of grinding marks and voids in alumina MOR bars.

produced by pullout of material during grinding. None of these features was detectable by casual visual analysis. The purchaser is requesting additional samples with several different types of surface preparation to determine which technique is most suitable for the intended use.

Figure 4 shows the ultrasonic results obtained on a second cylindrical specimen that had been prepared using linear grinding rather than the rotary/radial technique used to grind the first specimen. The grinding marks are quite evident, and the intensity of the indications suggests that subsurface cracking may be more severe than for the rotary/radial technique. Another possibility, which we have not been able to verify, is that the root mean square (rms) amplitude of the linear grinding marks is greater. The specimens will be tested to fallure using cyclic compression testing.

We have received, installed, and begun using our very high-frequency acoustic microscope. This system is capable of operation in the frequency range 0.1 to $2.0 \mathrm{GHz}$, the lowest frequency corresponding to the maximum useable frequency of our previous hardware. At the highest frequency, the surface resolution of the new equipment is approximately $0.75 \mu \mathrm{m}$, and features much smaller can be detected. Because of the very 


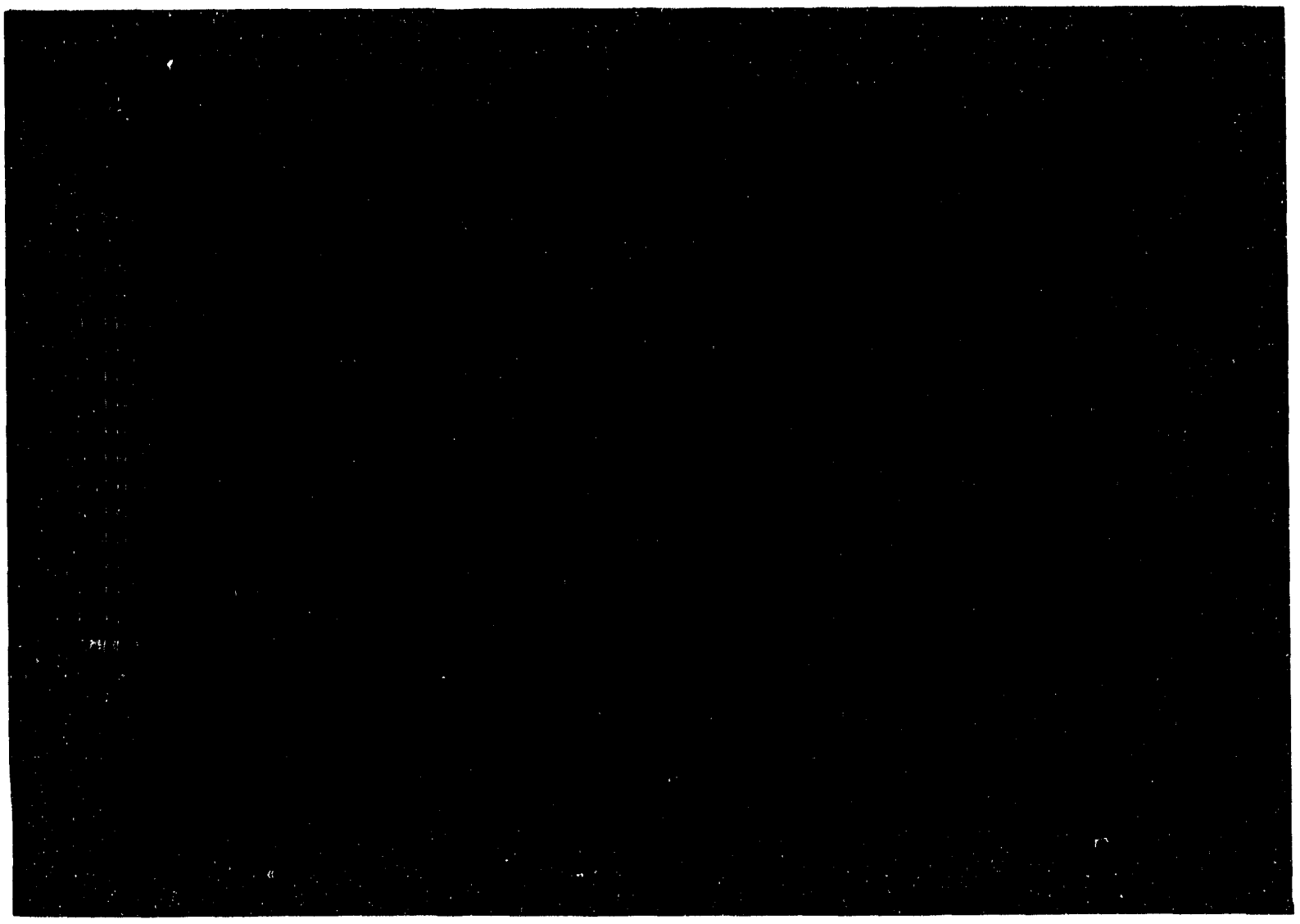
cylinder.

Fig. 2. Ultrasonic surface-wave image of grinding marks on the end of an alumina

high frequencies involved, the instrument is primarily designed for surface studies, and it should be of unparalleled benefit in characterizing surface machining damage in structural ceramics. The system also contains an optical microscope which is parfocal with respect to the acoustic lenses and whose image is centered on the latter. This greatly facilitates location of the object to be examined. The acoustic image at any selected frequency provides user selectable magnifications of $125,250,400,625,1250$, and $2000 x$.

In addition to the acoustic microscope itself, we also purchased the optional image analysis system which is available for digitization, storage, measurement, and enhancement of acoustic images. This option permits acquisition of 512 by 512 or 1024 by 1024 images to a depth of 8 bits. These images are acquired in one of three trame buffers and may then be transferred to an internal hard disk for permanent storage. Image analysis features include addition and subtraction of images; image summation and averaging; pseudo color; high-pass, low-pass, and Laplacian filtering, as well as numerous other pixel- and neighborhood-oriented operations. We have found the Image storage feature to be indispensable since, without the frame buffers and hard disk, the only other method for storing images is by photography, capabilities for which are 


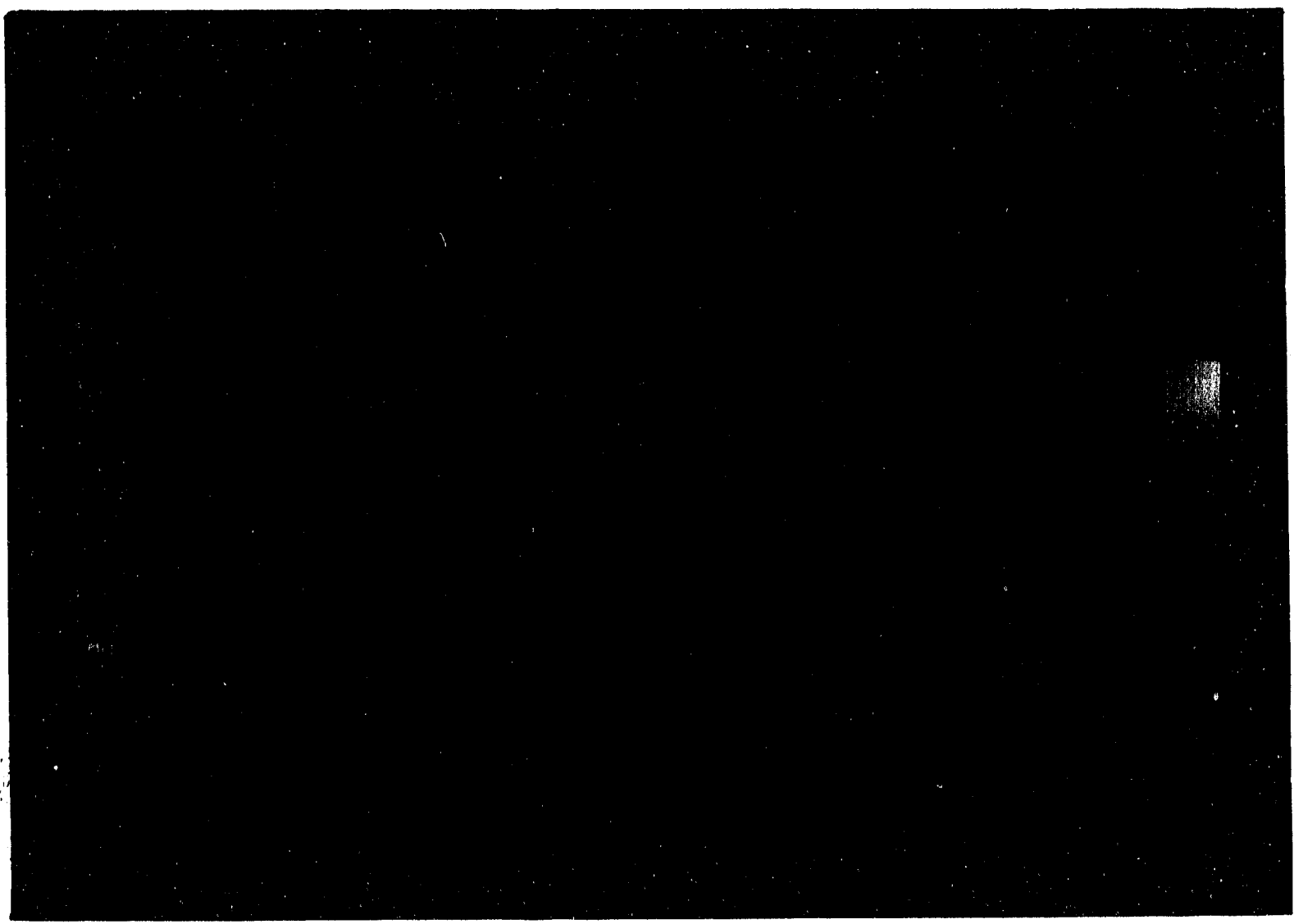

Fig. 3. Ultrasonic surface-wave image of grinding marks on the end of an alumina cylinder. Dark circular indication is grinding-induced pullout.

Included in the basic system but which are difficult to use. In addition, the acquired Images can be recalled at leisure and the measurement features applied to the image. In this mode, a mouse-driven cursor is used to select any two points on the image, such as the diameter of a pore, and the software then computes the distance between the points. The system is callbrated to $0.1 \mu \mathrm{m}$.

One of the samples which we had avallable for study was an alumina pellet containing seeded voids of various sizes from 25 to $100 \mu \mathrm{m}$. The voids were produced by inserting, in a periodic array, polydivinyl benzene styrene microspheres in the alumina powder, pressing, and firing the resulting sample. The spheres volatilize, leaving a spherical pore of approximately the same diameter. The sample was produced several years ago and subsequently examined by our $100-\mathrm{MHz}$ system. We were able to detect the artificial pores down to about 25- $\mu \mathrm{m}$ diam at depths of about $3 \mathrm{~mm}$. The sample was then ground and polished down to the depth of the $100-\mu \mathrm{m}$ voids for optical comparison with the acoustic results. Unfortunately, most of the smaller artificial volds were lost in the process because of their lesser depth. However, numerous natural pores of 5 to $10-\mu \mathrm{m}$ diam could be discerned optically in the polished surface. This sample was then 


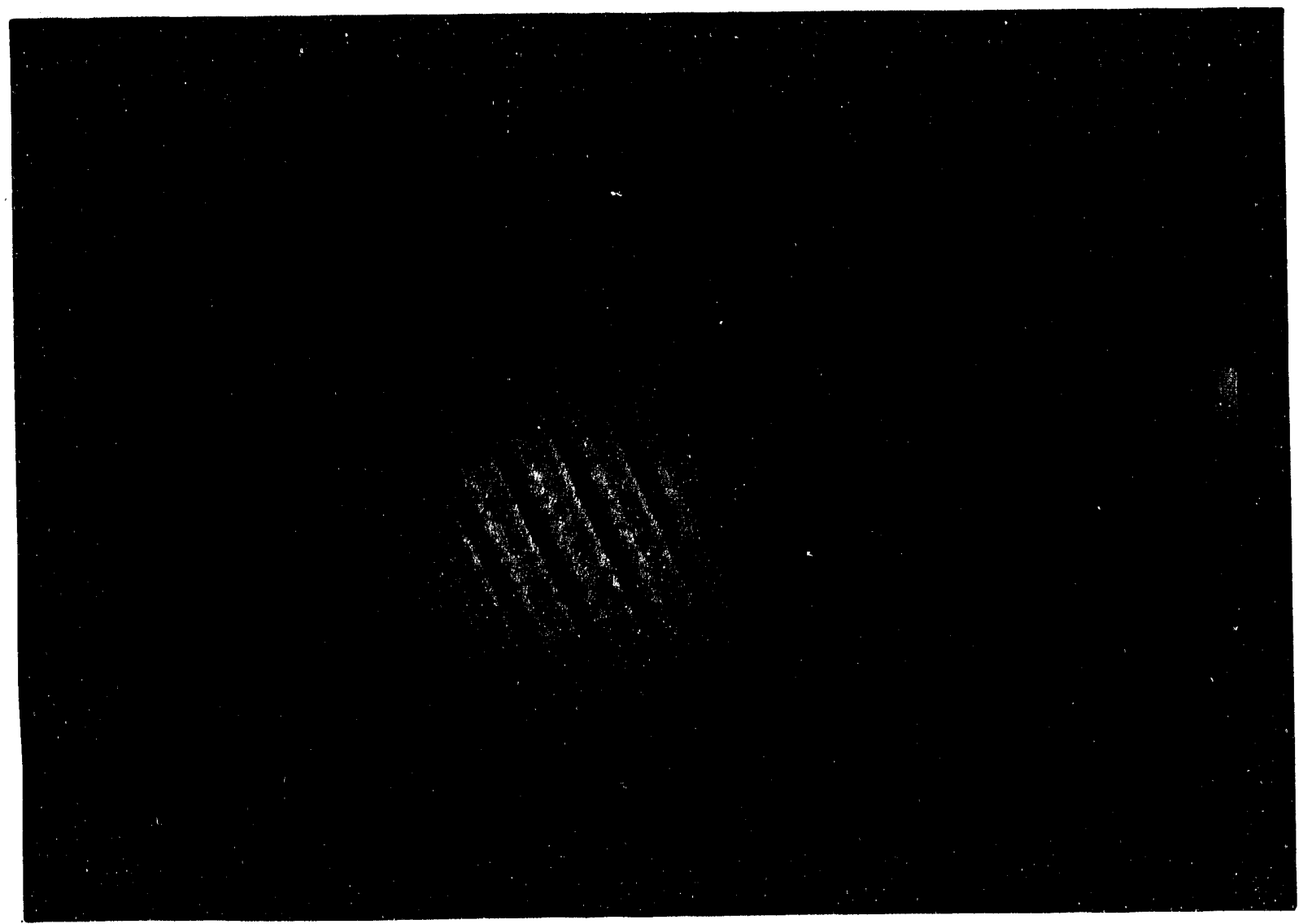

Fig. 4. Ultrasonic surface-wave image of grinding marks in alumina produced by a linear grinding technique.

examined with the new high-frequency microscope. Figure 5 shows the image obtained at $1 \mathrm{GHz}$ and a magnification of $625 \mathrm{x}$ of one of the $100-\mu \mathrm{m}$ pores. The interference fringes in the center of the pore image are caused by acoustic reflection from the curved surface of an air bubble trapped in the pore. The actual diameter of the pore, as measured by the image analysis software, averaged about $95 \mu \mathrm{m}$. The smallest measurable features are about $1 \mu \mathrm{m}$, and still smaller features can be seen in the image. At this frequency, the resolution appears to exceed that of the optical image.

Figure 5 also illustrates another characteristic noted in the acoustic images. The pore image is surrounded by a ring of darkening that may possibly be attributable to residual stress. The surface in the vicinity of the pore, as measured optically, shows neither depression nor elevation, thus changes in focal position are not the source of the darkening. Another possibility is the presence of the original polydivinyl benzene styrene In the matrix adjacent to the pore. This contaminant could change the acoustic impedance, and hence the image contrast, of the region in which it resides.

Figure 6 shows an image of a second pore obtained at $1.5 \mathrm{GHz}$ and at a magnification of 625x. The increased resolution compared to that of Fig. 5 is evident. The smallest features discernable here are definitely in the submicron range. 
YP18187

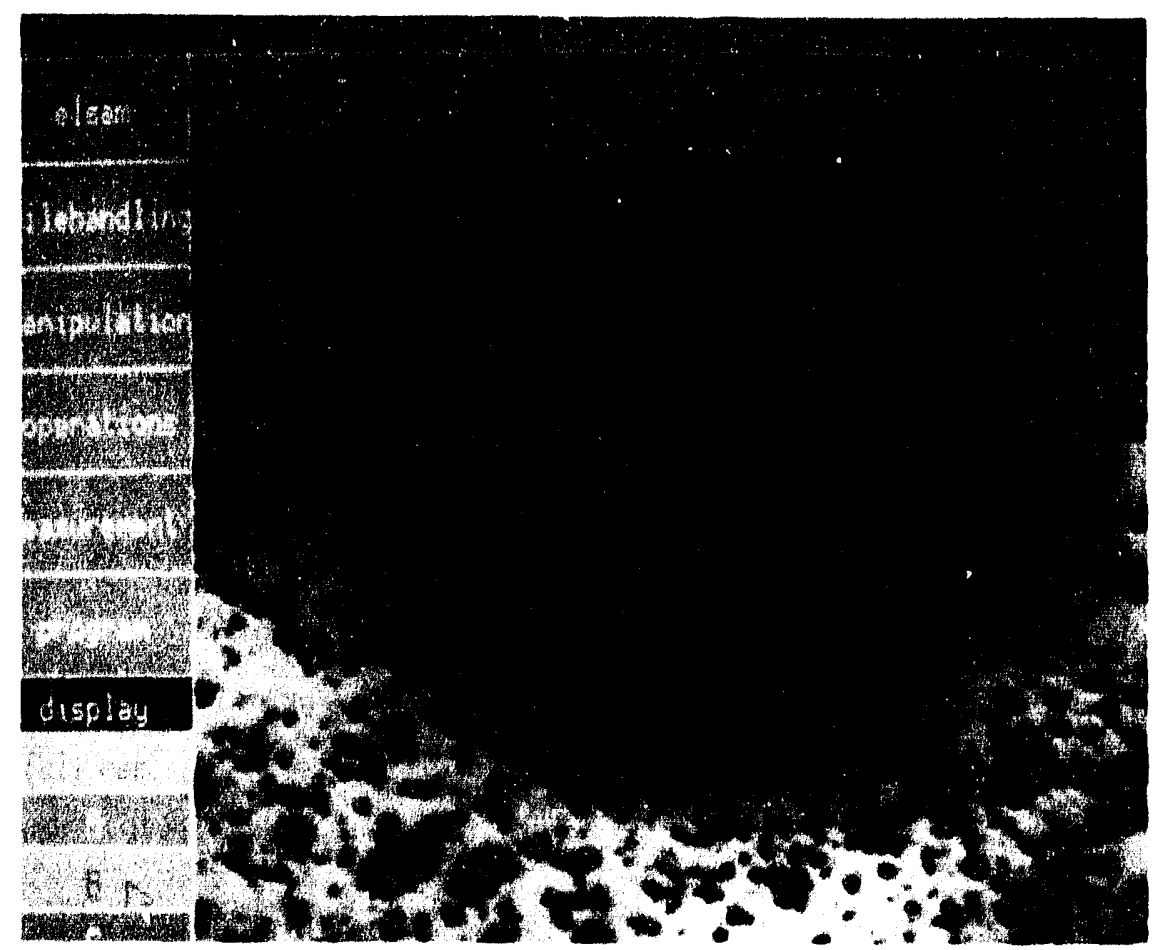

Fig. 5. Ultrasonic image at $1 \mathrm{GHz}$ of a $95-\mu \mathrm{m}$ pore in alumina.

YP18185

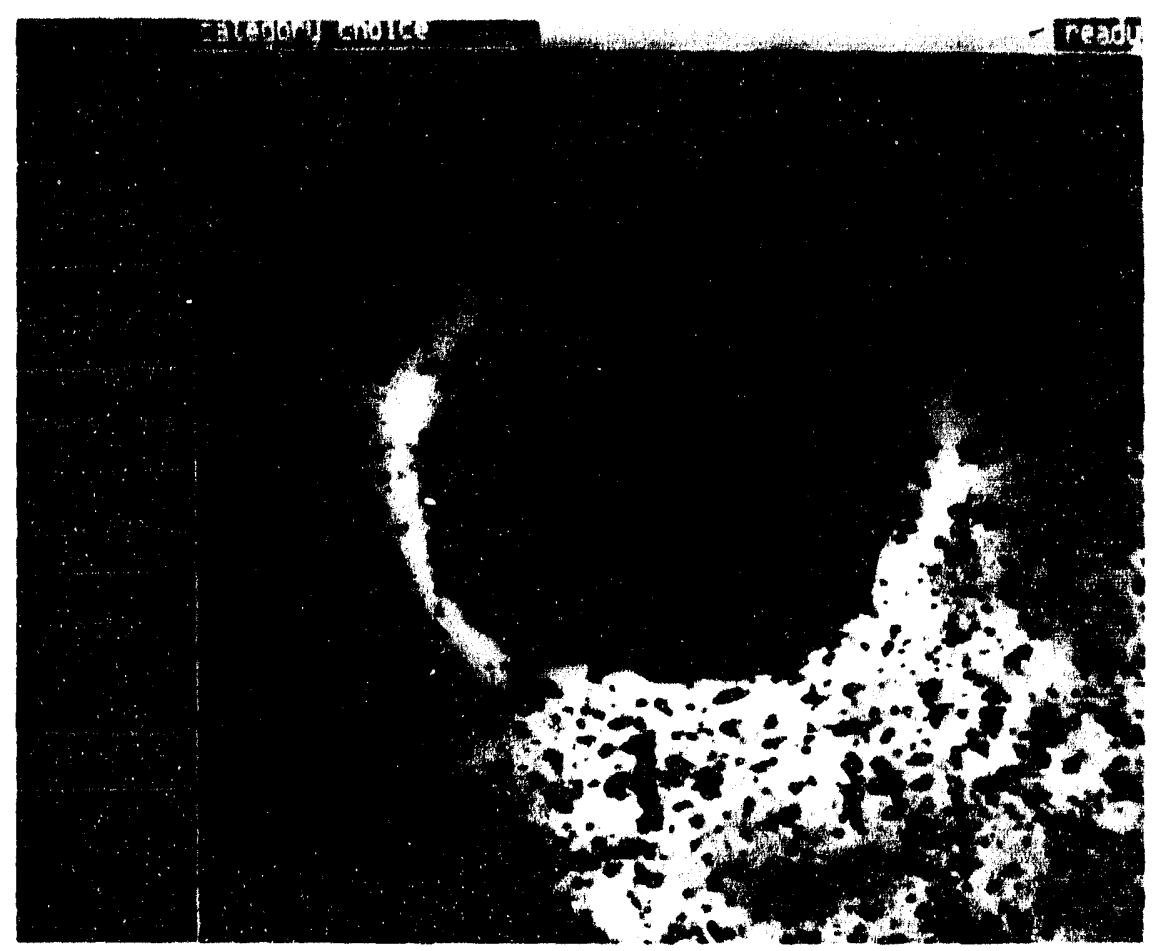

Fig. 6. Ultrasonic image at $1.5 \mathrm{GHz}$ of a $100-\mu \mathrm{m}$ pore in alumina. Smallest discernable detalls are $<1 \mu \mathrm{m}$. 
Figure 7 shows a 1-GHz image of a 70- $\mu \mathrm{m}$ pore, also taken at a magnification of 626x. The darkening around the pore is particularly evident here, and the irregular nature of the inner surface of the pore is also easlly seen.

We have also examined diamond indentations of sillcon nitride with the new system. It is known that such indentation produces very small cracks radiating out of the apexes of the indentation in brittle materials, but we have not been able to demonstrate thle previously because of the frequency limitation of $100 \mathrm{MHz}$. At this frequency, the cracks are sutiliciently ilght that most of the wave energy propagates through the crack, rendering It transparent to the elastic wave. This was also found to be the case with the new system for frequencles of 100 and $200 \mathrm{MHz}$. At $400 \mathrm{MHz}$, however, the first evidence of material cracking was seen. At frequencies of $1 \mathrm{CHz}$ and higher, the cracks were readily discernable. Figure 8 shows an Image obtained at $1 \mathrm{GHz}$ of the indentation cracks.

We also had available a polished sample of sillcon nitride containing several scratches produced by a diamond stylus. The stylus loading was increased untll cracking was observed visually in the area adjacent to the scratch. Figure 9, taken at a magnification of 125x, shows a portion of three such scratches. Stylus lozding increases from left to right, as the width of the scratches suggests. Several cracks can be clearly discerned radiating from each crack, one of which, at the lower right of the image, is bifurcated. The most interesting aspect of the image, however, is the presence of lighter and darker bands parallel to the scratches. These features are almost certainly stress or defor nation patterns produced by the loading. Note that the cracks interrupt or deform

\section{YP18186}

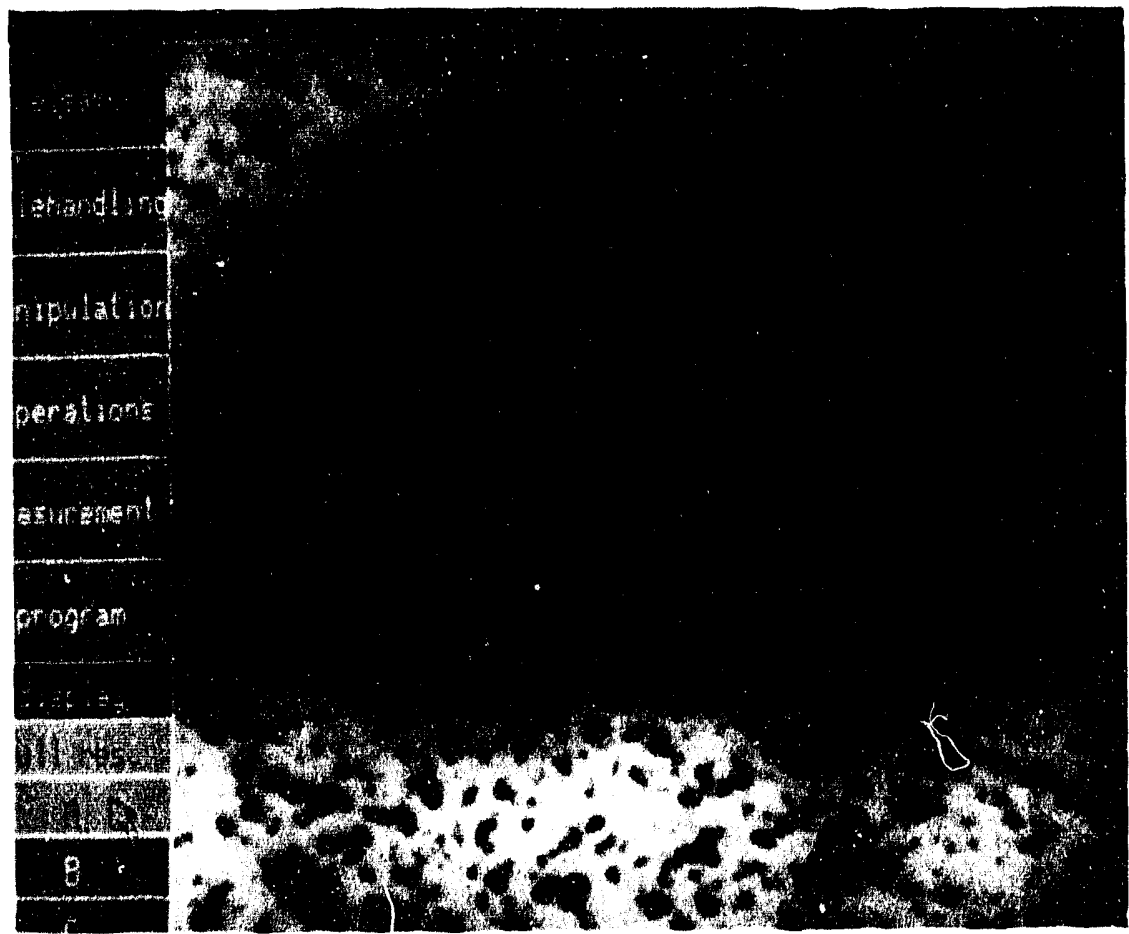

Fig. 7. Ultrasonic image at $1 \mathrm{GHz}$ of a $70-\mu \mathrm{m}$ pore in alumina. 

YP18413

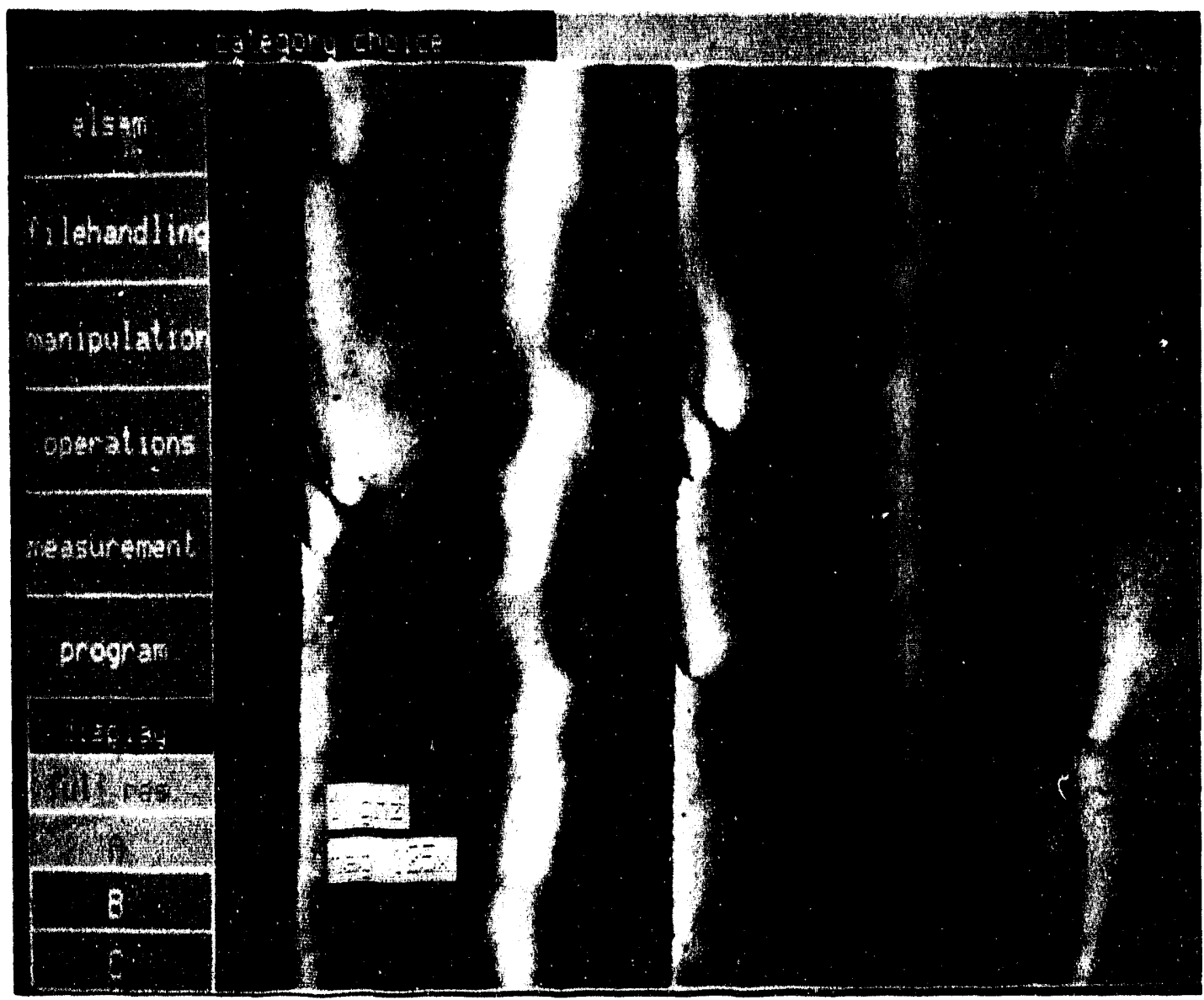

Fig. 9. Ultrasonic image at $1 \mathrm{GHz}$ of cracking and residual stress (light and dark bands) in sillcon nitride surface induced by scratching with a dlamond stylus.

gelcasting of several materials. These materials include silicon nitride and alumina, with the goal of improving the mechanical properties of components. Several types of defects present in these components may limit their strength. These defects include metallic inclusions, picked up from tramp impurities or the metallic processing equipment; carbon inclusions from incomplete gelcast binder burnout; small gel-rich volumes which arise from premature gelation at catalyst-enriched locations; and bubbles due to trapped air or other gases. The defects cover a complete spectrum of sizes, from several hundred to less than one micron, with corresponding effects on strength and product quality. These defects need to be found prior to testing (fracturing) the specimen. CT is a viable tool that will be used in this effort to locate these flaws in both the green and dense state in sillcon nitride components.

Members of the NDT Group and Ceramic Processing Group are laying out a program plan to accomplish the CT of gelcast sillcon nitride ceramics. In addition, film radiography will be used when needed. The plan will include detectability limits of each of the above defects (or at least those determined to be the most important) in both the 
YP18411

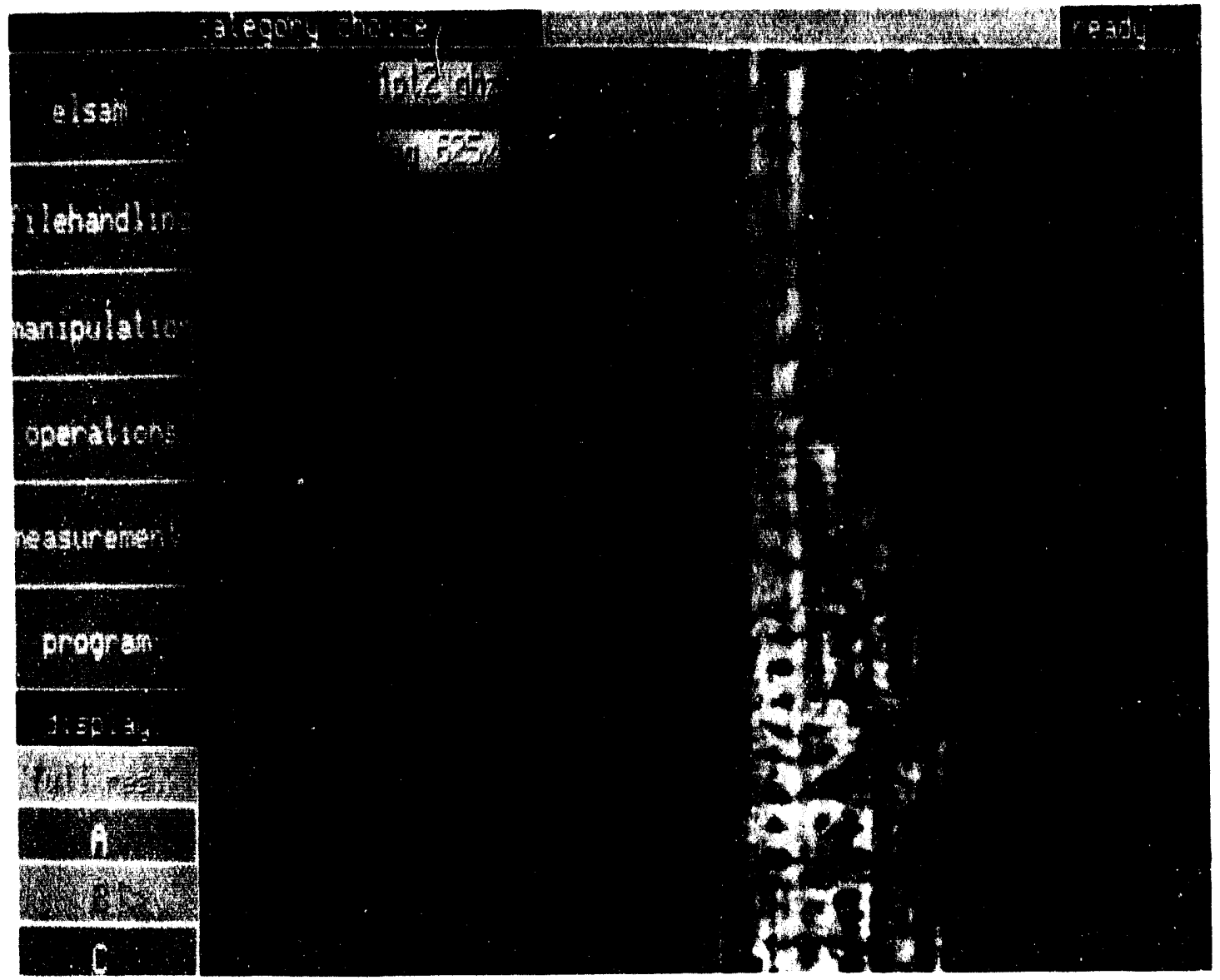

Fig. 10. Ultrasonic image at $1.2 \mathrm{GHz}$ of transverse cracking in the bottom of a scratch produced in sillicon nitride by a diamond stylus.

green and dense state. This effort will entall the preparation of simple shapes in the green state, drilling of holes, addition of metallic and ceramic inclusions into the shapes, and CT analysis of them prior to and after densification. Additional work will include examination of specimens prepared via improved processing techniques, with the potential for developing some predictive capability for strength.

During this reporting period, the rotary table on the CT unit began to show several undesirable resonances, as well as occasional stalls at several different speeds. The problem was lsolated to needed readjustment of the worm gear in the rotary table and a defective C-drive (power supply) for the motor driving the rotary table. The necessary troubleshooting and repairs were accomplished at no additional costs because of the maintenance and service agreement. The CT equipment is back in operation, and callbration is in progress.

The acceptance testing of the Sun workstation Model 670-MP was completed at the manufacturing site (Scientific Measurement Systems) in Austin, Texas, on July 30, 1993. During the acceptance tests, a few software errors were noted that were related to file 
tranafer between the Mlorovax II and Sun system. These were corrected. The system Installation and accoptance testing was then completed at ORNL In August 1893.

Several exparimental unfired $\mathrm{SI}_{3} \mathrm{~N}_{4}$ gelcast eamples have been recelved from the OANL Coramic Proceseing Group for CT ovaluation. Three samples approximatoly $17 \mathrm{~mm}$ dlam by $55 \mathrm{~mm}$ long were ldentified as Nos. 4, 6, and R86; one sample was approxlmately $30 \mathrm{~mm}$ diam by $56 \mathrm{~mm}$ long; one sample was approximately $30 \mathrm{~mm}$ diam by $80 \mathrm{~mm}$ long and was noted as having the binder removed; one rectangular sample identified as Denka 85 was approximately $10 \times 22 \times 88 \mathrm{~mm}$. In addition, there were two fired $\mathrm{Sl}_{3} \mathrm{~N}_{4}$ samples, $12 \mathrm{~mm}$ long, Identified as Nos. 001 and 002 with respective diameters of 6.25 and $12.5 \mathrm{~mm}$; and three fired SIC samples, $12 \mathrm{~mm}$ long, identified as Nos. 0.06, 007 , and 008 with respective dlameters of 6.25, 12.5, and $25 \mathrm{~mm}$. In total, there were six unifired and two fired SI3N4 samples and three fired SiC samples.

Initial CT scanning has been accomplished on some of the samples. Figures 11 through 19 illustrate some of the indications found using a $0.25-\mathrm{mm}$ CT sllce. Figure 11 is from the unfired 30-mm-dlam sample and shows a linear indication running from about the 10 o'clock position to 3:30. Figure 12 is from the same sample displaced $23 \mathrm{~mm}$ and shows a vold-like indication at about the 5 o'clock position. Figure 13 is from the unfired sample No. 4 and shows a $1 \mathrm{~mm}$ dlam vold and surface indentation. Figure $14 \mathrm{ls}$ from the unfired sample No. 6 and shows a linear 'ndication at about the 70 olock position. Figure 15 is from the unfired 30 -mm-diam sample that had the binder removed and shows several linear indications near the center of the Image as well as at about the 7 o'clock position. Figures 16, 17, and 18 are from the fired SIC sample No. 7. Each of these images is displaced about $2 \mathrm{~mm}$ from the prevlous CT image. In Fig. 16, several linear Indications from about the 8 o'clock position can be seen, while in Fig. 17 those indications are not apparent, but other indications are seen near the center of the image, and in Fig. 18 those indications are not apparent, but another indication is seen at about the 6 o'clock position. The linear indications noted in the previous figures could be associated with reconstruction artifacts; verification of their existence must be done with subsequent scans at different rotational positions to 800 if the indications move to the new position. This will be accomplished with the Sun workstation and new software. Figure 19 is from the fired $\mathrm{Si}_{3} \mathrm{~N}_{4}$ sample No. 2 and shows several linear indications including one shaped like the "smiley face" near the bottom of the image. These are real and were verified by images made at Scientific Measurement Systems (SMS) on their CT scanner during acceptance testing.

As mentioned earller, the installation and acceptance testing of the Sun workstation Model 670-MP has been completed at ORNL. The workstation is linked to the existing microVAX by Ethernet, using Transmission Control Protocol/Internet Protocol (TCP/IP) and Network File Server (NFS) protocols which support transfer rates of $1 \mathrm{MB} / \mathrm{s}$. Four array processors reside in the workstation for backprojection. The 670-MP is a single SuperSPARC processor with supercache. The base configuration includes three SBus expansion slots, one SBus/MBus expansion slot, and a 22-MHz VersaModule European (VME) bus for interfacing to array processors. The 670-MP is configured with $64 \mathrm{MB}$ of ECC memory (expandable to a maximum of $1 \mathrm{~GB}$ ) and a 19-in., 1152 by 900 plxel, 258-color monitor with keyboard and mouse, Ethernet controller, and a small-computer aystem interface (SCSI) controller. Attached to the SCSI controller are two 1.2-GB disk drives; a 644 MB compact disc (CD) drive (for SUN sottware distribution); and a 5-GB, 8-mm tape drive for archival backup. Extra bus slots are avallable for the option of serial ports for the addition of terminals. The Ethernet connection to the existing microvax is a 


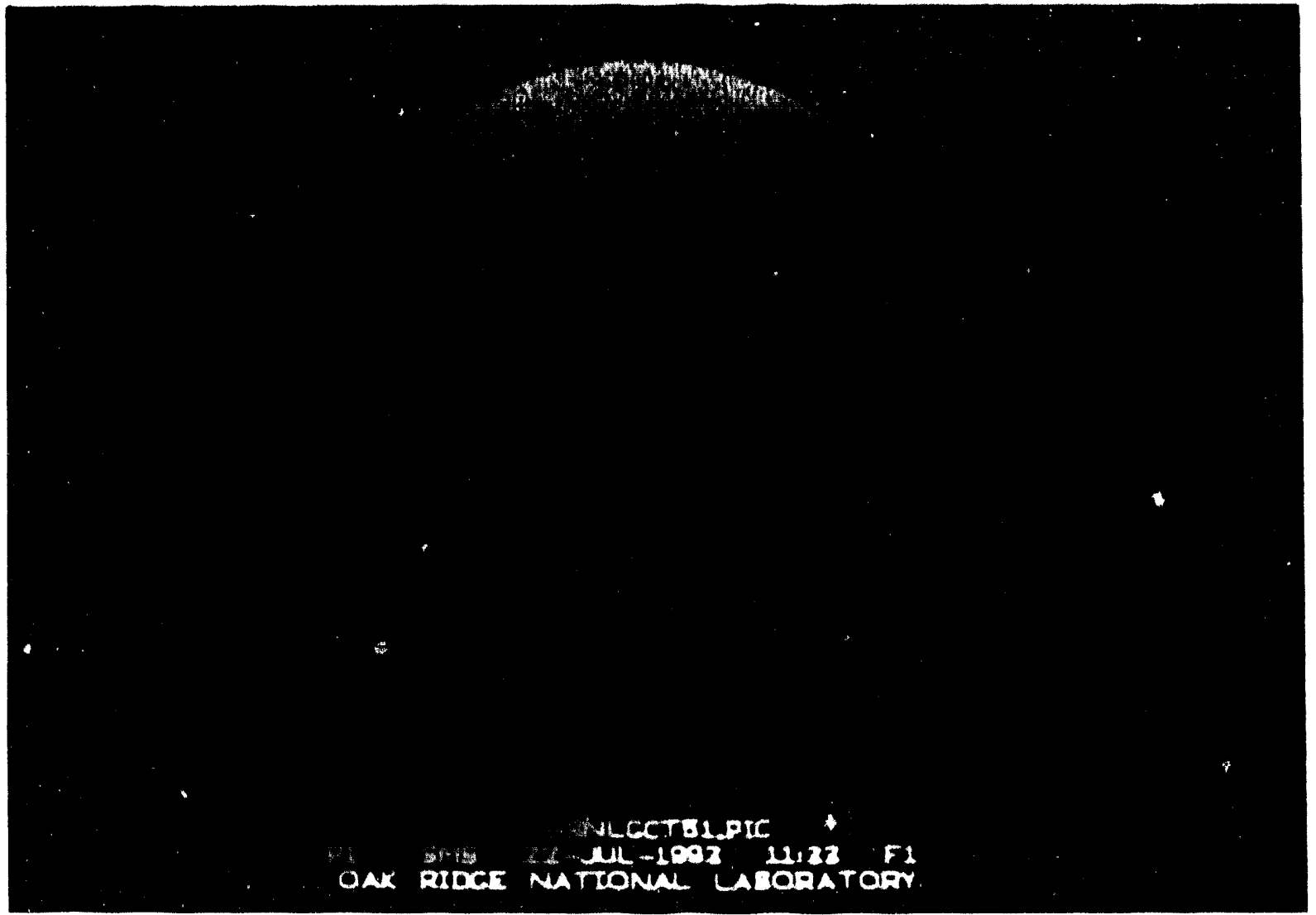

Fig. 11. CT slice (0.25 $\mathrm{mm}$ thick) of the unfired $30-\mathrm{mm}$-diam sample.

coax cable with the addition of a DEC DELQA Ethernet controller to the microVAX QBus. Each of the four array processors is an Analogic MSP6C30, 6U VME board, capable of 68 millions of floating-point operations per second (MFLOPS) per board with a backprojection rate of approximately 5 megapixels per second per board.

The SUN workstation runs on SunOS, SUN's UNIX-based operating system, with Open Windows, an X-Windows-based graphical usur interface. The SMS software was adapted to this environment to provide image file reconstruction (XRP), Image display and analysis (DIS), quick viow of images (FLASH), image file reduction (SNAPNNSNAP), and 3-D imaging (SOLID). Additional software provides SMS file conversion between the SUN and the microVAX for complete compatibility of all SMS files, to and from the microVAX. All network functions are provided via a TCP/IP network, which is standard with SunOS. The microVAX was upgraded with Multinet ${ }^{\text {Tw }}$, which is a TCP/IP Implementation for VAXWMS. In addition, the following programs were provided:

1. VSX: VAX-to-SUN translation of SMS binary files (data and Images);

2. SVX: SUN-to-VAX translation of SMS blnary files (data and images);

3. SRP: Remote image reconstruction in SUN from VAX;

4. RLOGIN: Remote log-in from VAX to SUN, and conversely; and

5. VRP: SUN program to reconstruct CT Images without array processors. 
YP17514

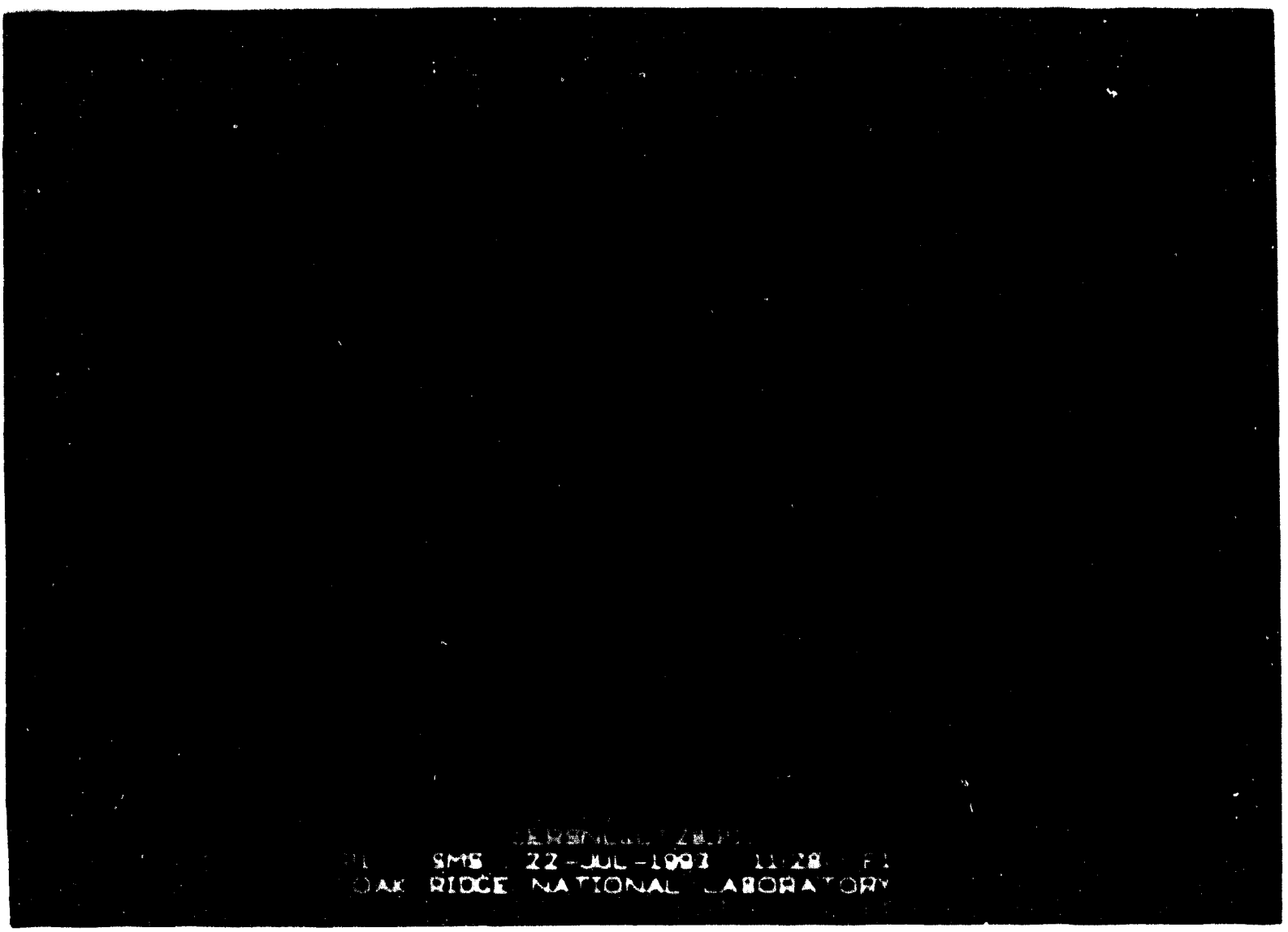

Fig. 12. CT slice (0.25 $\mathrm{mm}$ thick) of the large unfired $30-\mathrm{mm}$-dlam gelcast sample displaced $23 \mathrm{~mm}$.

The acceptance tests included the use of four transmission files created from the existing microVAX system and four additional files provided by SMS. Each of the specified system characteristics was demonstrated by a separate automated command procedure. The previously created microVAX image files of tomograms, radiograms, and snapshots were converted to workstation format and displayed on the Sun monitor. Several microVAX transmission data files for parallel-beam tomograms, fan-beam tomograms, and fan-beam radiograms were converted to workstation format, reconstructed with the workstation, and subsequently displayed.

Sample command files were edited and run on both computers to show that no degradation was suffered during the conversion from one computer to the other. These tests included: a file created on the workstation was edited on the microVAX and run on the workstation; a file created on the workstation was edited and run on the microVAX; a file created on the microVAX was edited on the workstation and run on the microVAX; a file created on the microVAX was edited and run on the workstation. The workstation full-screen images were saved as snapshot files, then displayed on the microVAX screen and used to make hard coples on the microVAX. Thermal hardcopy printing from the 


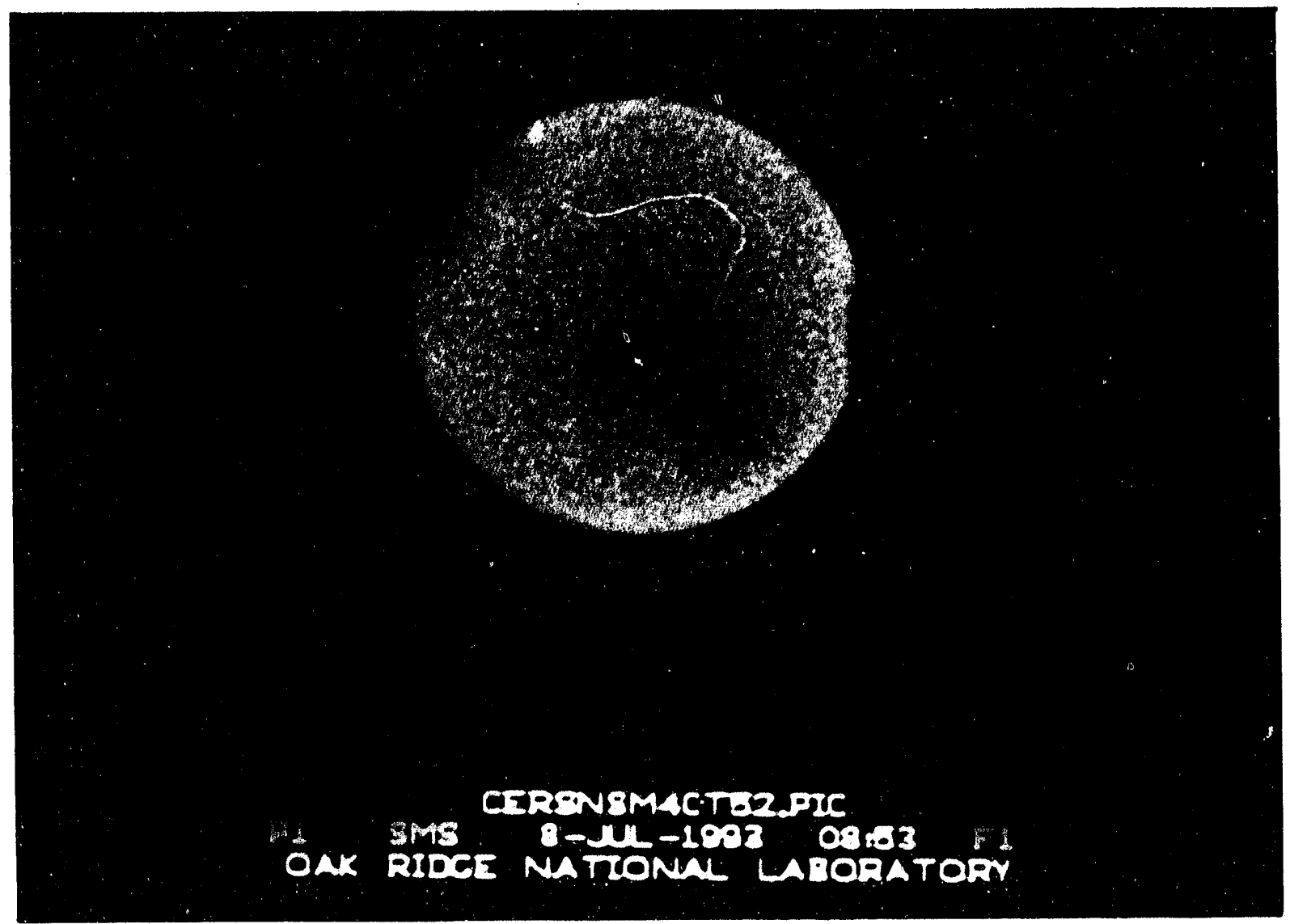

Fig. 13. CT slice $(0.25 \mathrm{~mm}$ thick) of the unfired gelcast sample no. 4 .

workstation is not presently available. Full compatibility with existing microVAX CT data and command files was demonstrated by running existing microVAX image-analysis command files on converted microVAX image files to produce duplicate results. The images displayed on the workstation were much sharper than on the microVAX.

The SOLID program can be run on the microVAX, but the reconstruction and subsequent tying together of usually at least $40 \mathrm{CT}$ slices for eventual display is prohibitively slow, e.g., several days. The same SOLID run on the workstation takes only about $2 \mathrm{~h}$. We obtained a small experimental ceramic rotor from the Ceramic Processing Group for evaluation of the SOLID program and to assess the rotor per se. However, we determined that a sottware glitch was pioducing several straight line surfaces (nonexistent on the sample) in the 3-D image of this rotor. The glitch is present when either computer is used. The vendor is in the process of resolving this complex problem. Most of the remainder of this reporting period was spent in learning the numerous new commands and tools for the workstation, testing those commands not covered in acceptance testing, and gaining experience in file transfer and data handling with the new format. In addition, some time was lost because of the failure of the central processing unit (CPU) board in the microVAX. However, this repair (which could have been very expensive) was also accomplished at no additional cost using our maintenance agreement with SMS. 


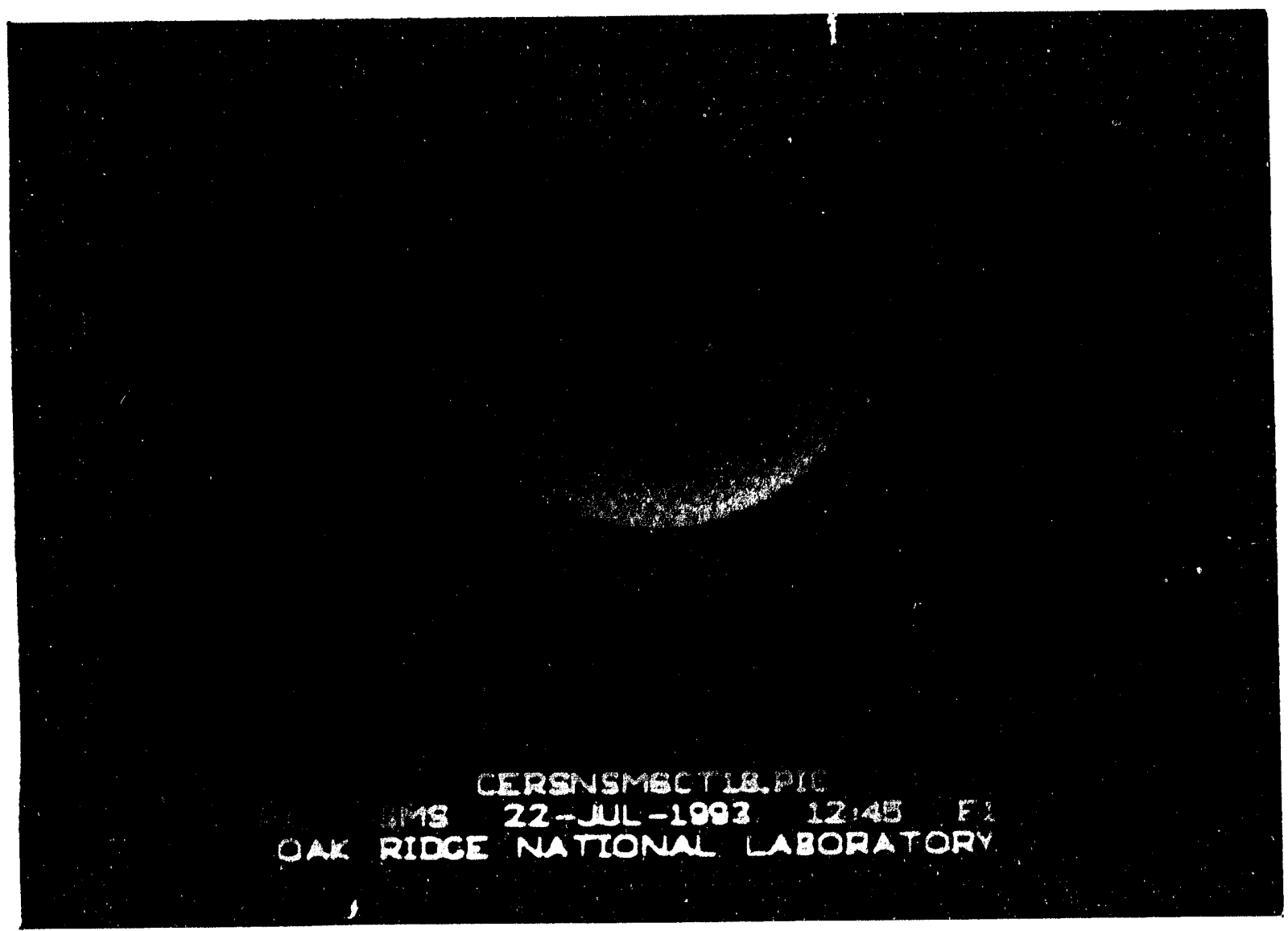

Fig. 14. CT slice (0.25 $\mathrm{mm}$ thick) of the unfired gelcast sample no. 6.

The experimental unfired $\mathrm{Si}_{3} \mathrm{~N}_{4}$ gelcast samples, fired $\mathrm{Si}_{3} \mathrm{~N}_{4}$ samples, and fired $\mathrm{SiC}$ samples previously scanned and evaluated using the microvAX are being re-scanned for reconstruction and evaluation with the workstation. The purpose of this operation is to attempt to verify the existence of several linear indications reported earlier that could have been associated with reconstruction artffacts.

\section{Mllestones}

On schedule.

\section{Publications}

A. J. Moorhead and W. A. Simpson, Jr., "Effect of Surface Preparation on Strength of Ceramic Joints Brazed With Active Filler Metal," Ceramic Transactions Vol. 35, Structural Ceramics Joining II, ed. A. J. Moorhead, Ronald E. Loehman, and Sylvia M. Johnson, American Ceramics Society, Westerville, Ohio, September 1993. 


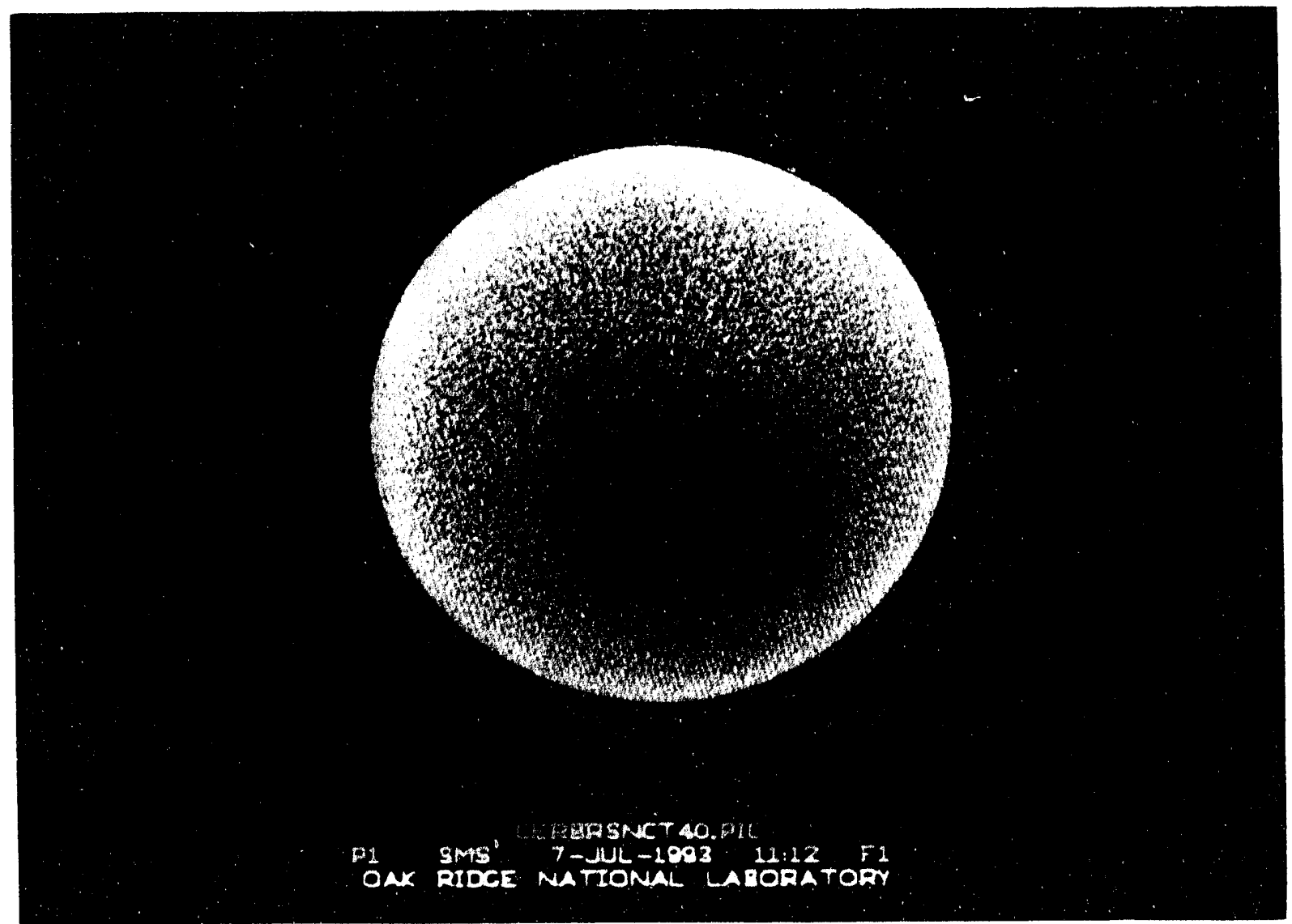

Fig. 15. CT slice $(0.25 \mathrm{~mm}$ thick) of the unfired $30-\mathrm{mm}$-diam gelcast sample with the binder removed.

\section{References}

1. W. A. Simpson, Jr., "Nondestructive Evaluation Development," p. 66 in Ceramic Technology Project Bimonthly Progress Report, Martin Marietta Energy Systems, Inc., Oak Ridge Natl. Lab., February-March 1993.

2. W. T. Yost and J. H. Cantrell, "Materials Characterization Using Acoustic Nonlinearity Parameters and Harmonic Generation: Engineering Materials," Rev. Prog. Quant. Nondest. Eval. 8B, 1669 (1990).

3. P. Li ot al., Proc. IEEE Ultrasonics Symposium, 1113 (1985).

4. W. H. Prosser, "Stress Dependence of Uitrasonic Velocity in Unidirectional Graphite/Epoxy Composites for Longitudinal Waves Propagating Along the Direction of Stress," Rev. Prog. Quant. Nondest. Eval. 8B, 1701 (1990). 


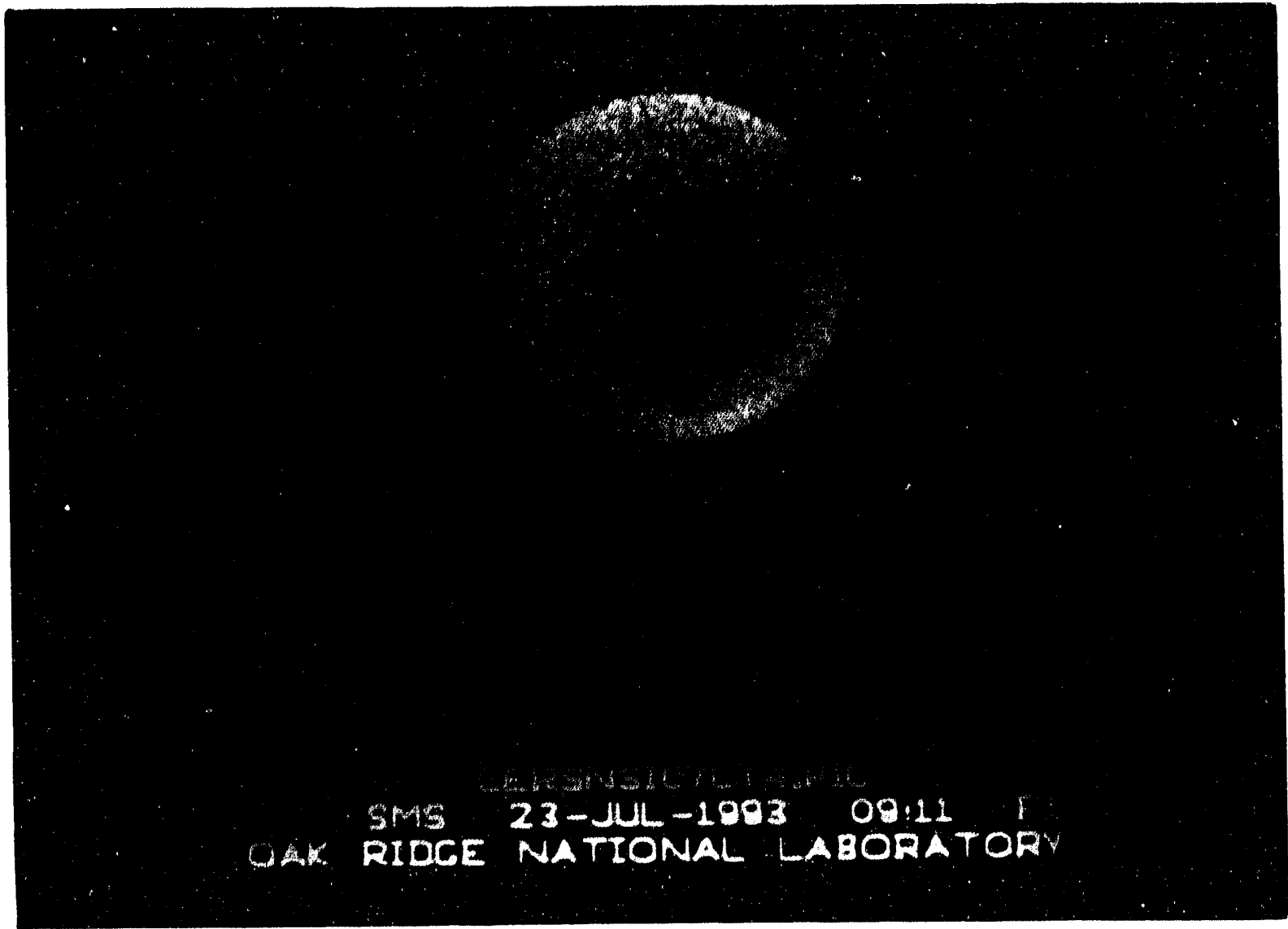

Fig. 16. CT slice (0.25 mm thick) of the SIC sample no. 4.

5. A. Hikata and C. Elbaum, "Generation of Ultrasound Second and Third Harmonics due to Dislocations. I," Phys. Rev. 144(2), 469-77 (1966).

6. A. Hikata, F. A. Sewell, Jr., and C. Elbaum, "Generation of Ultrasonic Second and Third Harmonics due to Dislocations. II," Phys. Rev. 151(2), $442-49$ (1966).

7. B. P. Banner and B. J. Wanamaker, "Nonlinear Acoustic Effects in Rocks and Soil," Rev. Prog. Quant. Nondest. Eval. 9B, 1709 (1990).

8. G. Dace, R. B. Thompson, and O. Buck, "Measurement of the Acoustic Harmonic Generation for Materials Characterization Using Contact Transducers," Rev. Prog. Quant. Nondest. Eval. 11B, 2069-76 (1992).

9. M. A. Breazeale, "Whither Nonlinear Acoustics?," Rev. Prog. Quant. Nondest. Eval. 9B, 1653 (1990).

10. W. A. Simpson, Jr., "Nondestructive Evaluation Development," p. 65 in Ceramic Technology Project Bimonthly Progress Report, Martin Marietta Energy Systems, Inc., Oak Rilge Natl. Lab., August-September, 1992, p. 65. 
YP17510

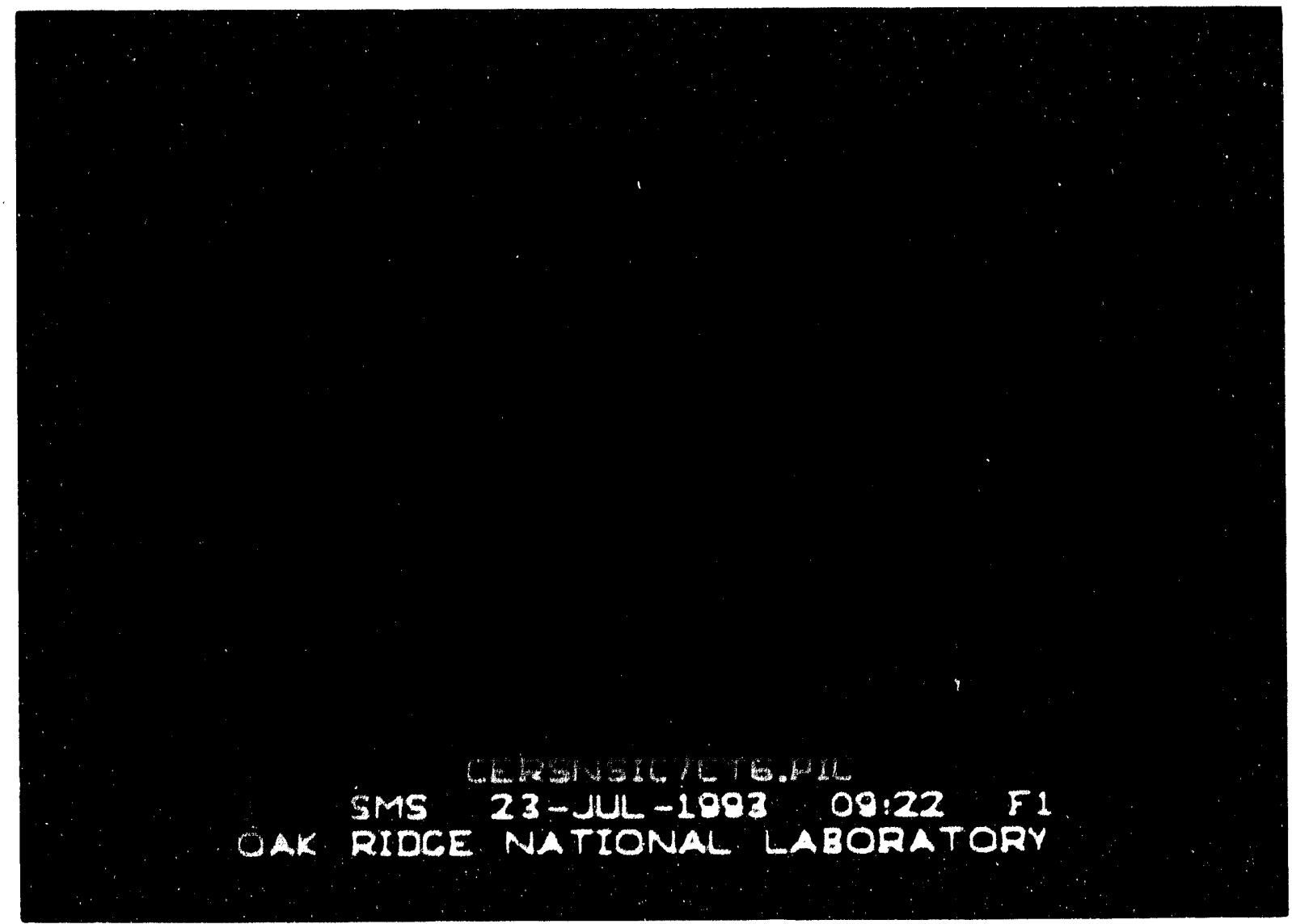

Fig. 17. CT slice (0.25 mm thick) of the SIC sample no. 4 displaced $2 \mathrm{~mm}$ from Fig. 6. 
YP17509

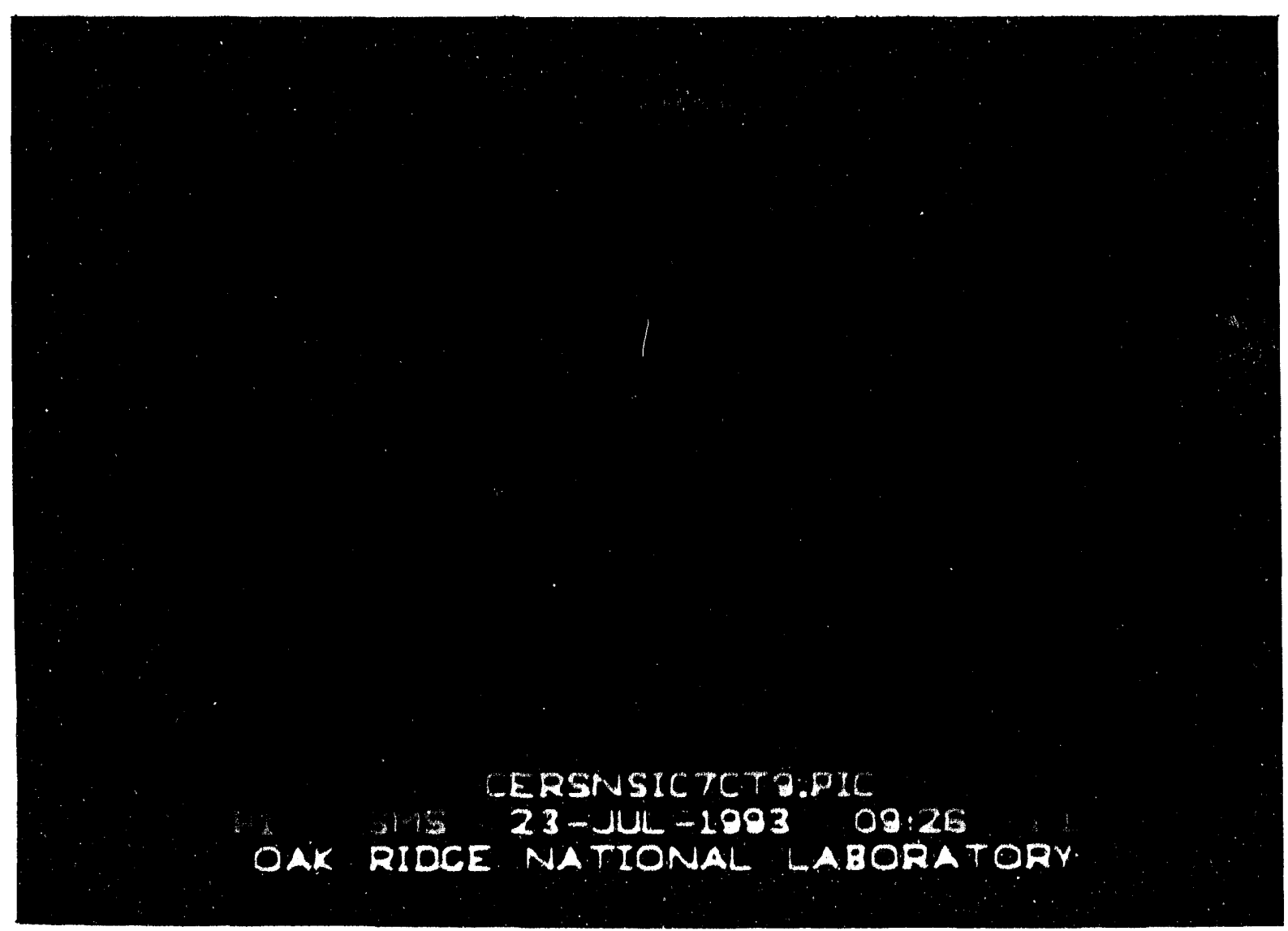

Fig. 18. CT slice (0.25 mm thick) of the fired SIC sample no. 4 dlsplaced $3 \mathrm{~mm}$ from Fig. 7 and $5 \mathrm{~mm}$ from Fig. 6. 
YP17512

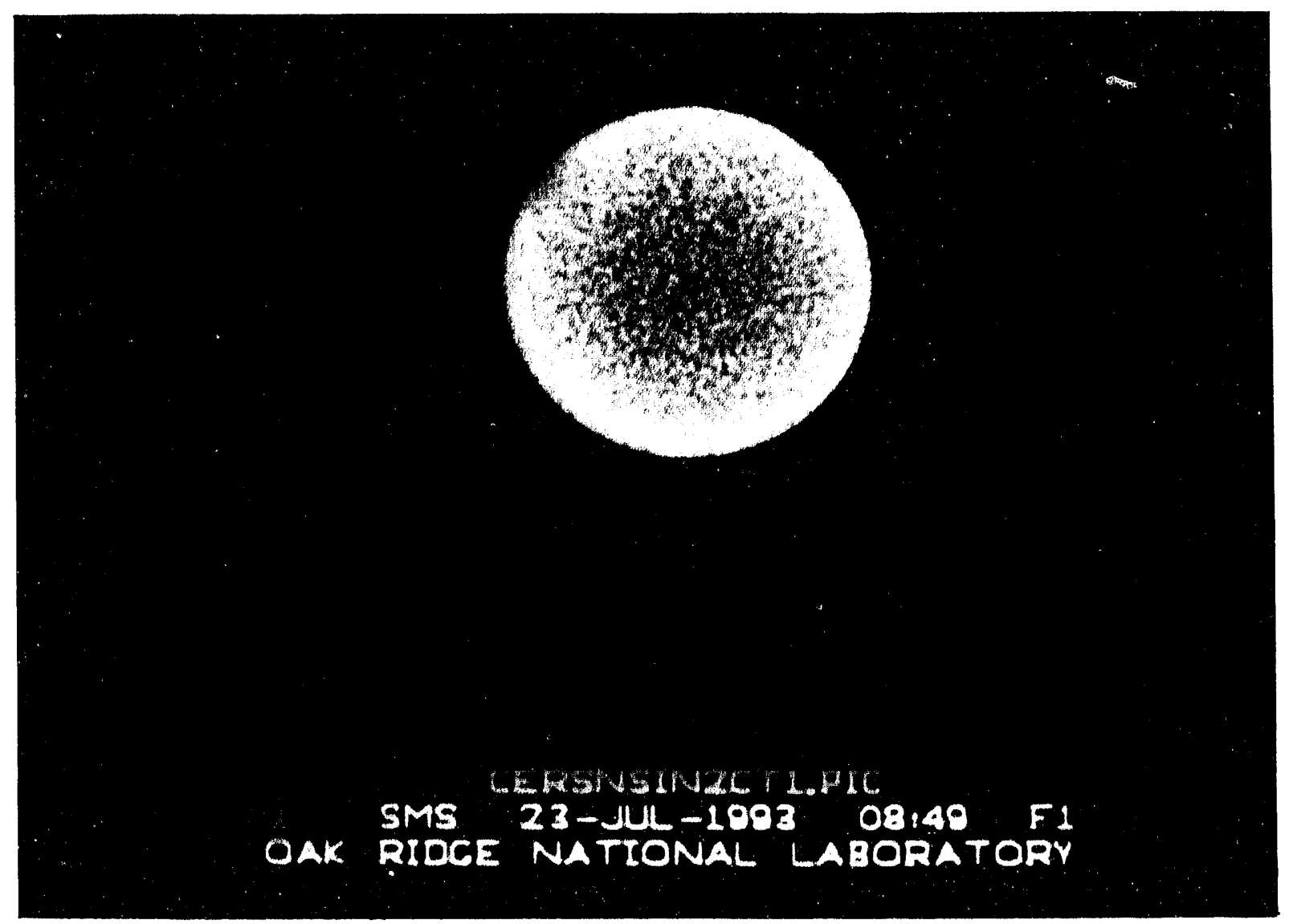

Fig. 19. CT slice $\left(0.25 \mathrm{~mm}\right.$ thick) of the fired $\mathrm{Si}_{3} \mathrm{~N}_{4}$ sample no. 2 . 
X-ray Computed Tomoaraphic Imagina - W. A. Ellingson, T. D. Jacobs, D. L. Holloway, E. A. Sivers (Argonne National Laboratory) in cooperation with J. P. Pollinger and H. C. Yeh (Ceramic Components of Allied-Signal Aerospace Corporation)

\section{Oblective/scope}

The objective of this program is to develop $X$-ray computed tomographic (CT) imaging technology for application to structural ceramic materials. This technique has shown the potential to map short-range $(<5-\mathrm{mm})$ and long-range $(>5-\mathrm{mm})$ density variations (to perhaps $0.5-1 \%$ ), detect and size high- and low-density inclusions, and detect and size (within limits) cracks in green-state and densified ceramics. Use of three dimensional (3-D) CT (volume CT) imaging allows interrogation of the full volume of a component and is noncontacting. It is also relatively insensitive to specimen shape. The current work is to show the reliability of extension of this technology to inspect components with complex shapes, e.g., turbocharger rotors.

\section{Iechnical progress}

The work accomplished during this reporting period has focused on analytical and experimental verification of the reconsdiruction algorithms to be used in the research. We have had a delay in getting the Allied-Signal/Ceramic Components new subcontract in place and thus we have not had any parts produced.

\section{(a) Hardware developments}

We received, setup and installed our new SUN SPARC 10/GX workstation which is dedicated to 3D X-ray CT reconstructions. The workstation was brought on-line and loaded with operational software. A 19" high resolution graphics screen is part of the system as is a CD ROM, 8-mm tape and $3 \mathrm{~Gb}$ external hard drive.

\section{(b) Software}

For large objects such as the ATTAP rotors to be used in this research study, in order to reduce data acquisition times, it becomes advantageous to move the $X$-ray head closer to the 2D detector. This results in a so-called large numerical aperture. A problem (limitation) of the existing 3-D reconstruction code, is that at large numerical apertures, a loss in fidelity of the reconstructions have been shown to be apparent ${ }^{1}$ at the top and bottom of the object. For density analysis, such lack of fidelity could impact the reliability of $X$-ray $C T$ measured density variations. A different 3-D X-ray CT code, the so-called Grangeat Code, may achieve better fidelity at the extremes of the object. This new code was modified this period and ported from the VAX 8700 to the SUN SPARC 10 workstation. Two simulation software packages have been used as inputs to the code to verify the operation. Both codes have been ported to the SUN SPARC 10/GX located at the X-ray CT scanner. The X-ray CT scanner will thus be equipped

\footnotetext{
1 P. Rizo and W. A. Ellingson, "An Initial Comparison Between Two 3D X-ray CT Algorithms for Characterizing Ceramic
} Materials," Proc. Conf. on NDE of Modem Ceramics, Columbus, OH, pp. 121-125. July 1990. 
with not only the new $1024 \times 1024 \times 14$ bit CCD camera, as reported previously, but two reconstruction codes as well. We hope to soon acquire an array processor to connect to the SPARC 10/GX to further speed reconstruction times.

\section{(c) Cemparisen of results with the two 3-codes}

Simulated data sets were used to compare the two reconstruction codes. The simulated data used consisted of a set of 7 spheres of the same radii and density spaced evenly along a vertical axis of rotation. The data was simulated so that the maximum aperture was 20 (half-angle). The aperture at each of the spheres is as noted below in Fig. 1. This simulation was created using two simulation programs. One is called "PHIL4" and the other "LOCPROD".

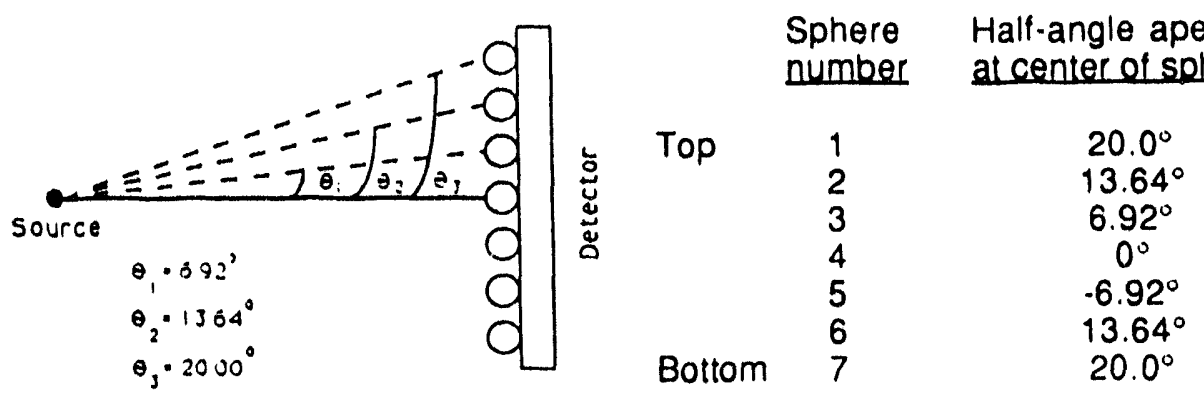

Fig. 1. Schematic diagram showing simulation

After reconstruction of both simulated data sets using both reconstruction codes, axial plots were made which allow the density variation to be determined along the axis of rotation. The density of each sphere of the reconstructed image was compared to the density of the center sphere at an aperture of $0^{\circ}$. By computing the percent difference in density between any sphere and the $0^{\circ}$ aperture sphere we obtained the results shown in Figs. 2 and 3.

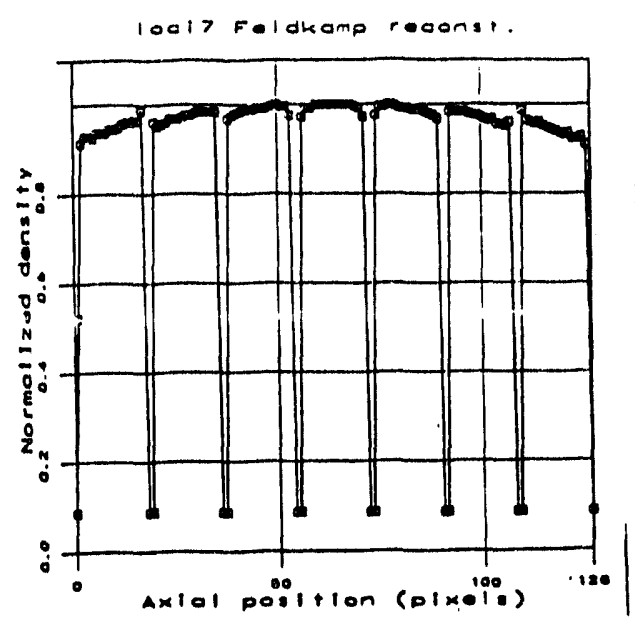

(a)

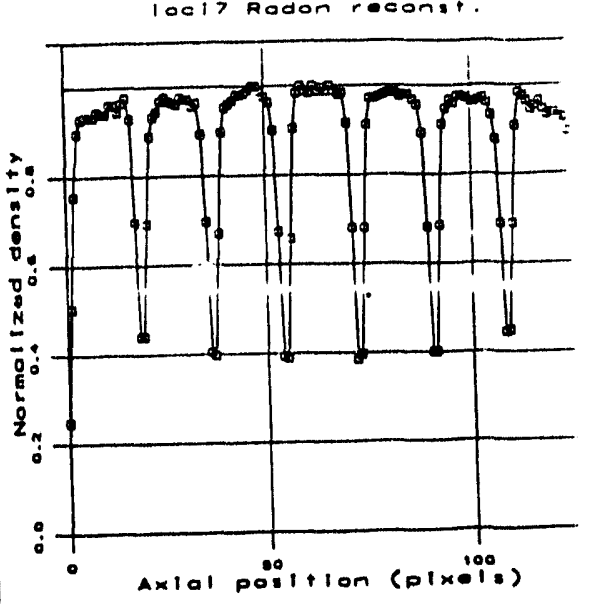

(b)

Fig. 2. "Comparison of axial density plots generated using 7 spheres using LOCPROD simulation with both reconstruction codes (a) Feldkamp, (b) Grangeat 


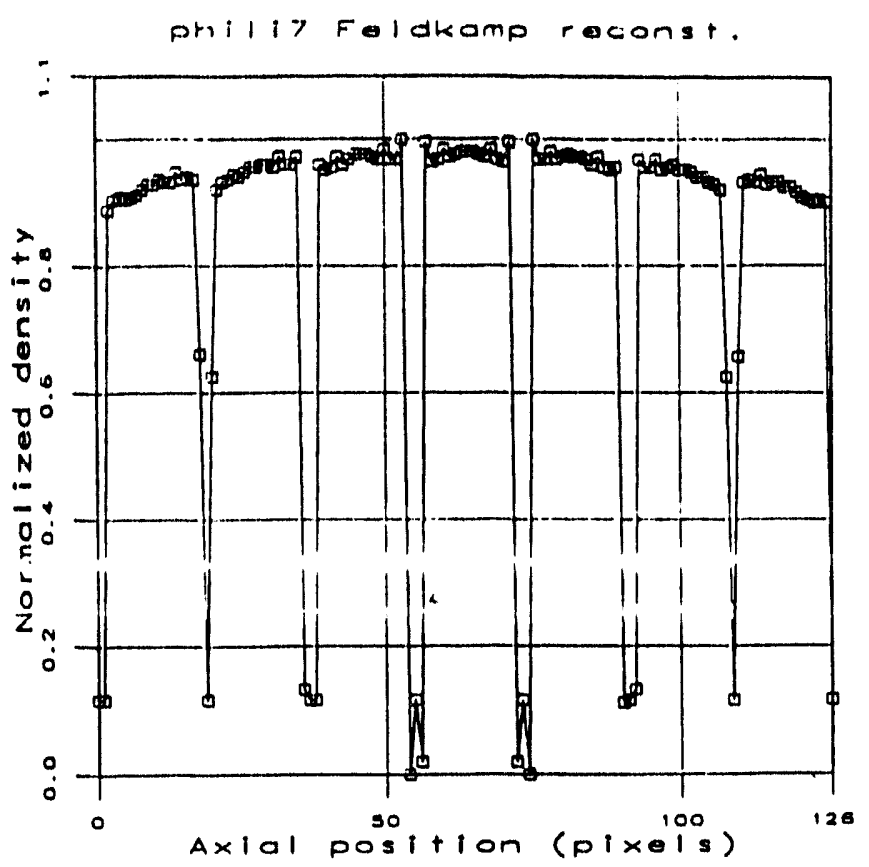

(a)

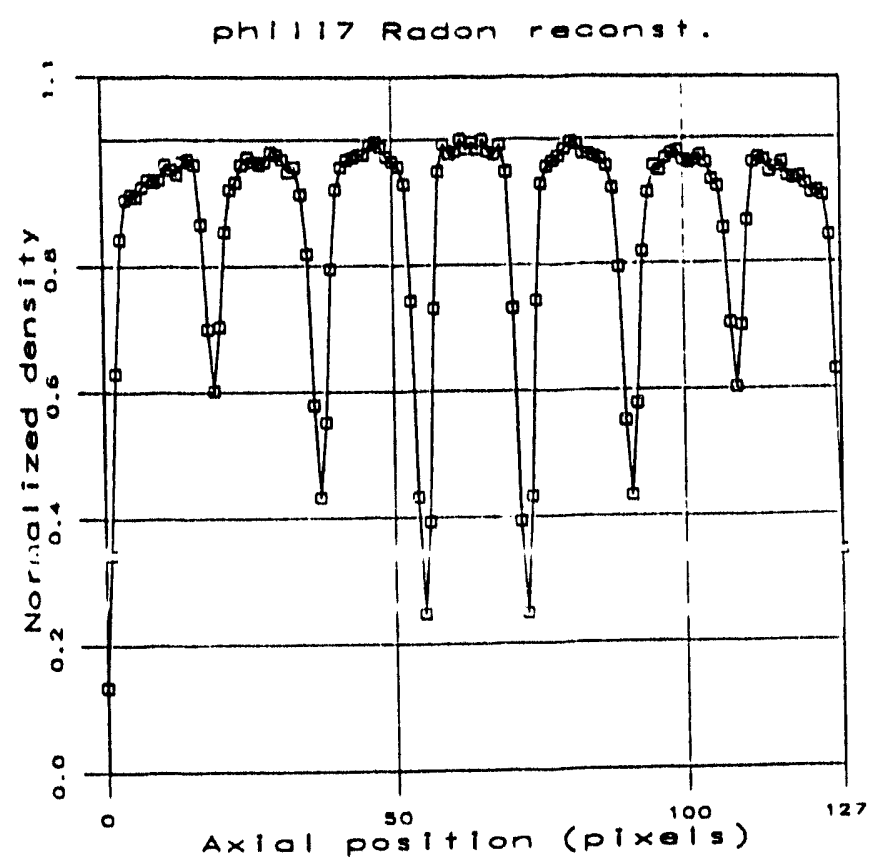

(b)

Fig. 3. Comparison of axial density plots using 7 spheres using PHIL4 simulation code and both reconstruction codes (a) Feldkamp, (b) Grangeat

What is easily discerned is that there is a big difference in the data depending upon which simulation software package is used. The LOCPROD appears to be a better simulation code.

By plotting the density variation as a function of angle (refer to Fig. 1), one obtains the plots shown in Fig. 4. Figure 4 shows that both codes are excellent up to an included angle of $30^{\circ}\left(15^{\circ}\right.$ half-angle). Above a $15^{\circ}$ half-angle there is a slightly higher density variation with the Feldkamp code, but this can be compensated for. The problem with the Grangeat code is that it is very computer memory intensive and thus very slow to obtain results.

Both codes will be evaluated on the density data. 


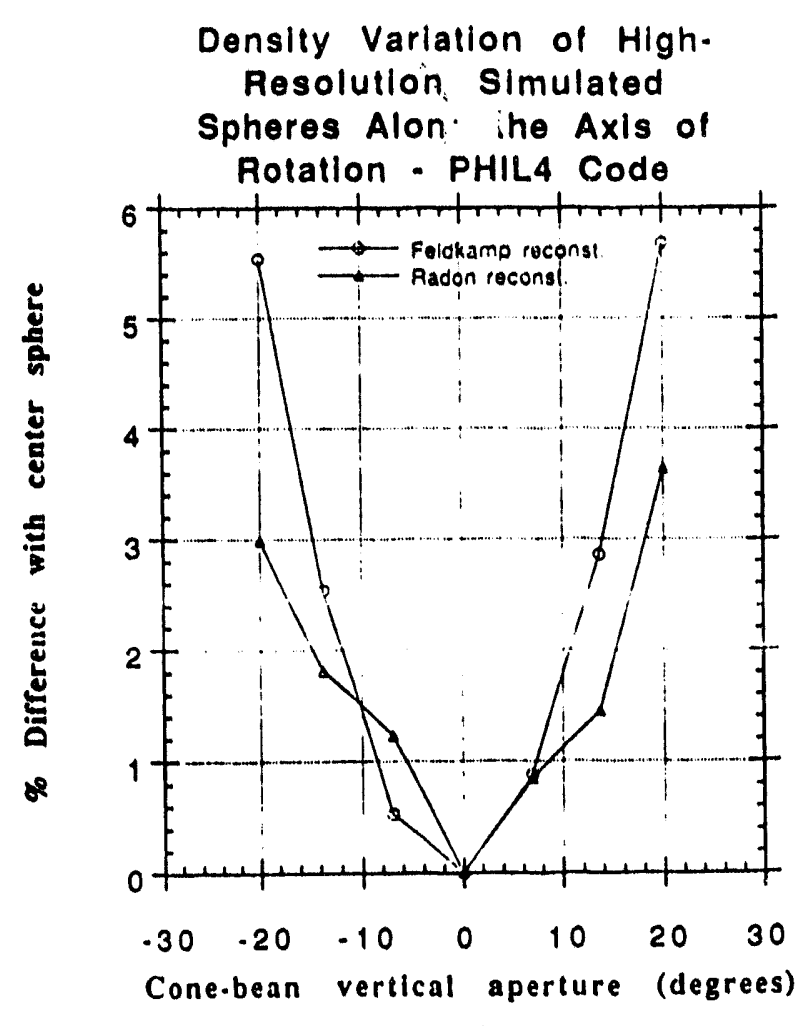

(a)

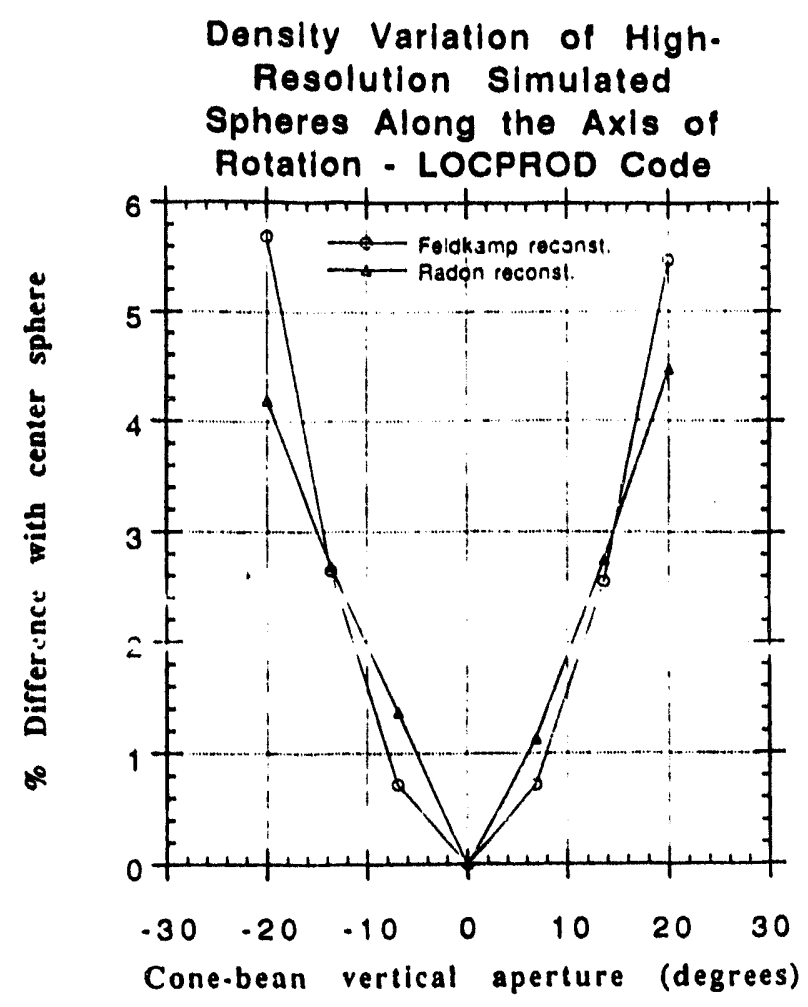

(b)

Fig. 4. Comparison between reconstruction codes and simulation codes.

(a) PHIL 4 code, (b) LOCROD code 
Nuclear Magnetic Resonance Imaging - S.L. Dieckman, O. O. Omatete\#, A.C. Raptis, and W.A. Ellingson, Argonne National Laboratory, \#Materials and Ceramics Division, Oak Ridge National Laboratory, Oak Ridge, TN

\section{Objective/Scope}

The purpose of this work is to evaluate the potentlal of NMR imaging to impact the development and process control of near-net-shape gel-cast ceramic composites. The specific objectives of this work are to determine the utility of NMR imaging for: (1) 3D mapping of polymerization homogeneity: (2) real-time imaging of the polymerization process; (3) nondestructive evaluation of voids and flaws in the resultant components; and (4) measurement of physical properties such as as degree of polymerization, viscosity, and specimen strength via correlation of these properties with measureable NMR parameters $\left(T_{1}, T_{1}\right.$, and $\left.T_{2}\right)$. This work will be performed in conjunction with $\mathrm{Dr}$. Ogbemi O. Omatete from the Materials and Ceramics Division at Oak Ridge National Laboratory.

\section{Iechnical Highlights}

In this reporting period initial gellation studies on a series of methacrylamide-N,N'methylene bisacrylamide (MAM-MBAM) copolymer systems were conducted. These studies were performed to provide a basis set of experimental parameters required for establishing appropriate gellation component concentrations for the NMR studies. These studies have concentrated upon determining the effect of temperature and initiator/catalyst concentrations upon the gellation time. NMR spectroscopic studies on the methacrylamideN,N'-methylene bisacrylamide (MAM-MBAM) copolymer systems were also performed during this period. The purpose of these studies was to provide the basis set of experimental parameters required for further NMR imaging studies. Such parameters include the appropriate pulse repetition rates, variations in chemical shift due to temperature and $\mathrm{pH}$, and expected relaxation rates as a function of polymerization.

${ }^{1} \mathrm{H}$ NMR spectra were acquired on the individual standard MAM-MBAM reagents and on the composite copolymer premix reagents at a magnetic field strength of $7.1 \mathrm{~T}$. Spectra were acquired in using both $\mathrm{H}_{2} \mathrm{O}$ and $\mathrm{D}_{2} \mathrm{O}$ (as the solvent) at ambient temperature and at $35^{\circ} \mathrm{C}$. The composite spectrum of the copolymer premix (13.3 wt \% methacrylamide, 1.6 wt \% N,N'-methylene bisacrylamide, in deionized water) is presented in Fig. 1 . Structural identification of the resultant peaks are indicated.

In addition to the studies of the individual reactants, NMR spectroscopic studies were conducted as a function of the extent of MAM-MBAM polymerization. In these studies, real time ${ }^{1} \mathrm{H}$ NMR spectra of the copolymerization reaction was acquired as a function of reaction time, see Fig. 2. The spectra demonstrate the expected reduction in the methylene and methyl resonances as the polymerization reaction progresses. Additionally. a variation of the spin lattice relaxation rates of the components as a function of reaction 


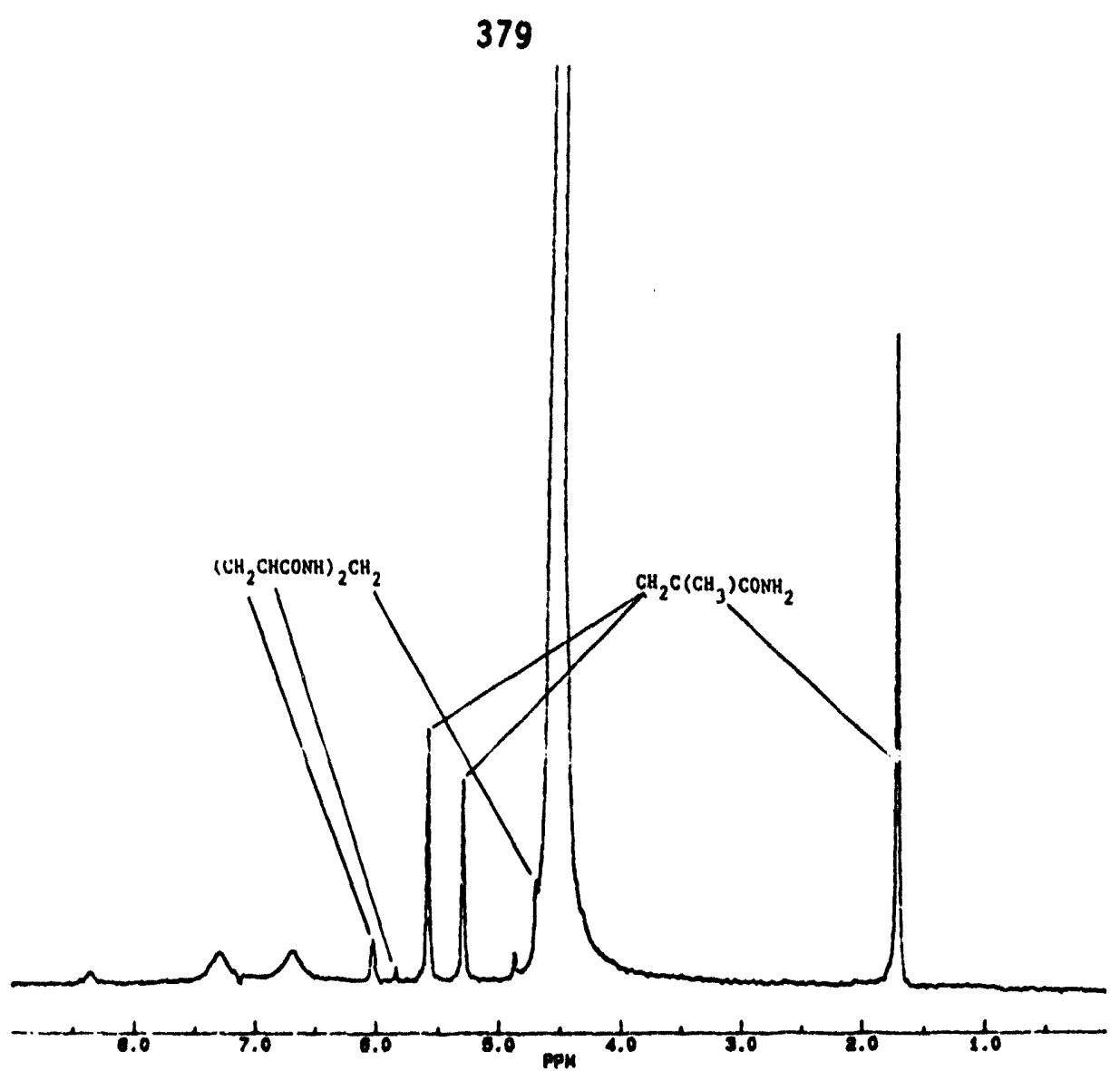

Fig. 1. 1H NMR spectra of the composite spectrum of the copolymer premix (13.3 wt \% methacrylamide, $1.6 \mathrm{wt} \% \mathrm{~N}, \mathrm{~N}^{\prime}$-mathylene bisacrylamide, in deionized water) The peak off scale is from the scivent (ivater).

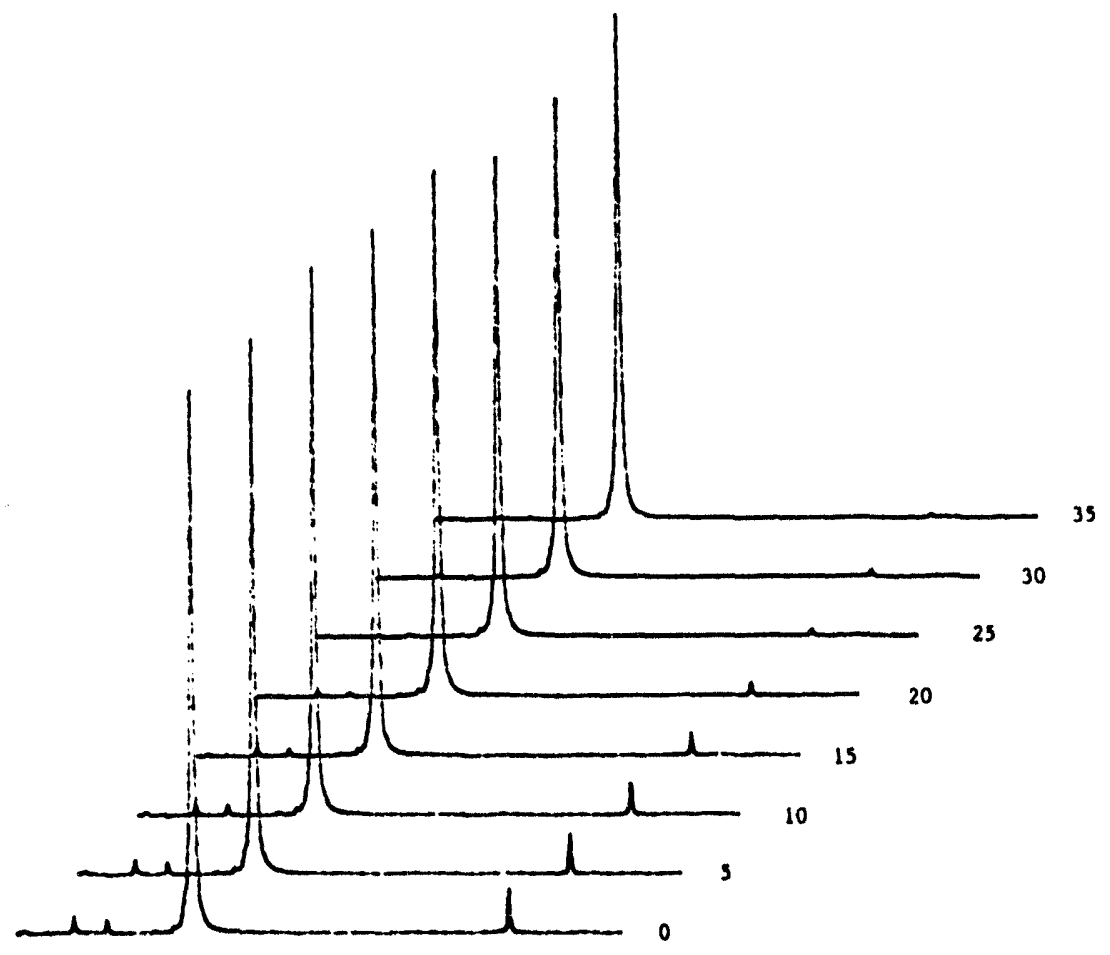

Fig. 2. 1H NMR spectra of the composite spectrum of the MAM-MBAM copolymer reaction as a function reaction time. Spectra acquired at $7.1 \mathrm{~T}$ and at a reaction temperature of $35^{\circ} \mathrm{C}$. 
extent is also expected. In the upcoming reporting period, relaxation studies will be conducted on this system and the methacrylamide-polyethylene glycol (1000) dimethacrylate (MAM-PEG(1000)DMA) copolymer system.

\section{Status of Milestones}

Milestones on schedule

\section{MILESTONESCHEDULE $(3.5,16)$}

Phase 3: $\quad$ Spectroscopy and Imaging of Gel Cast Ceramic Components:

3.5.1.6.11 Complete spectroscopic studies of two gel systems.

Completed $11 / 15 / 93$

3.5.1.6.12 Pertorm initial imaging studies on specimens composed of the most appropriate gel system.

$4 / 15 / 94$

3.5.1.6.13 Complete real-time imaging studies of the gellation process on specimens composed of the most appropriate gel system.

$9 / 15 / 94$

3.5.1.6.14 Report the conclusions of imaging studies of as-cast, prefired, and fired components.

3.5.1.6.15 Submit topical report on application of NMR to gel-cast ceramic processing. 

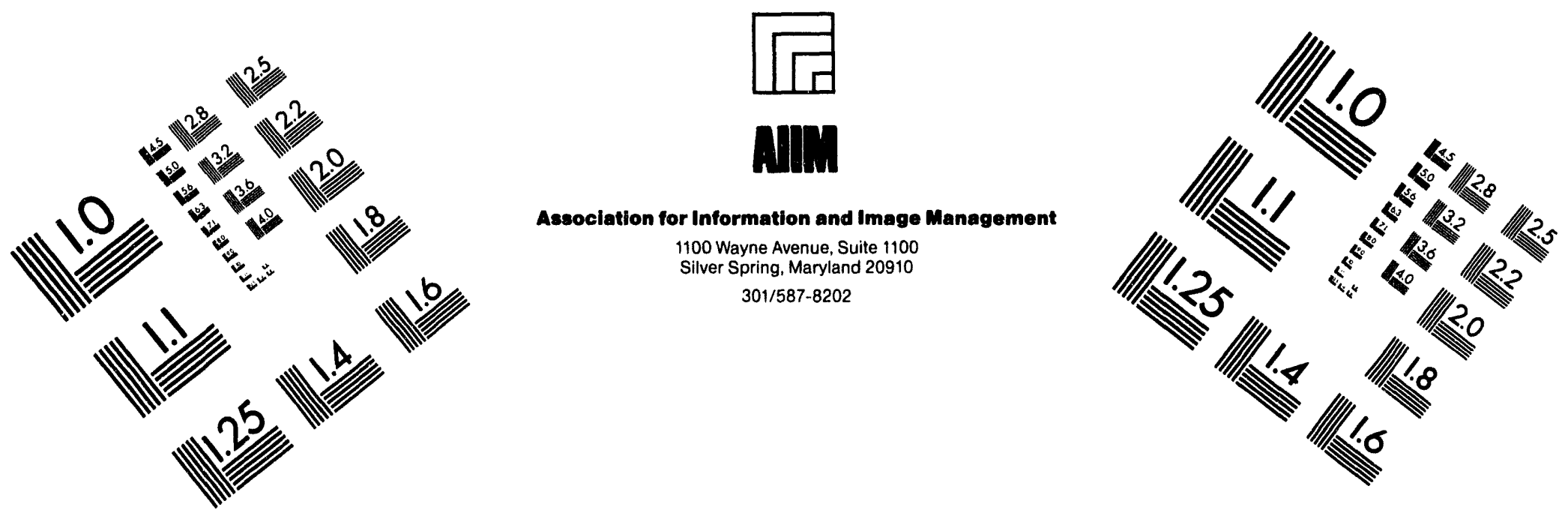

\section{Centimeter}

$\begin{array}{llllllllllllllll}1 & 2 & 3 & 4 & 5 & 6 & 7 & 8 & 9 & 10 & 11 & 12 & 13 & 14 & 15 & \mathrm{~mm}\end{array}$

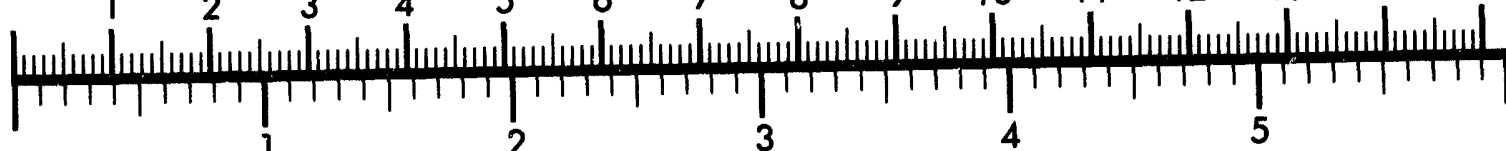
Inches
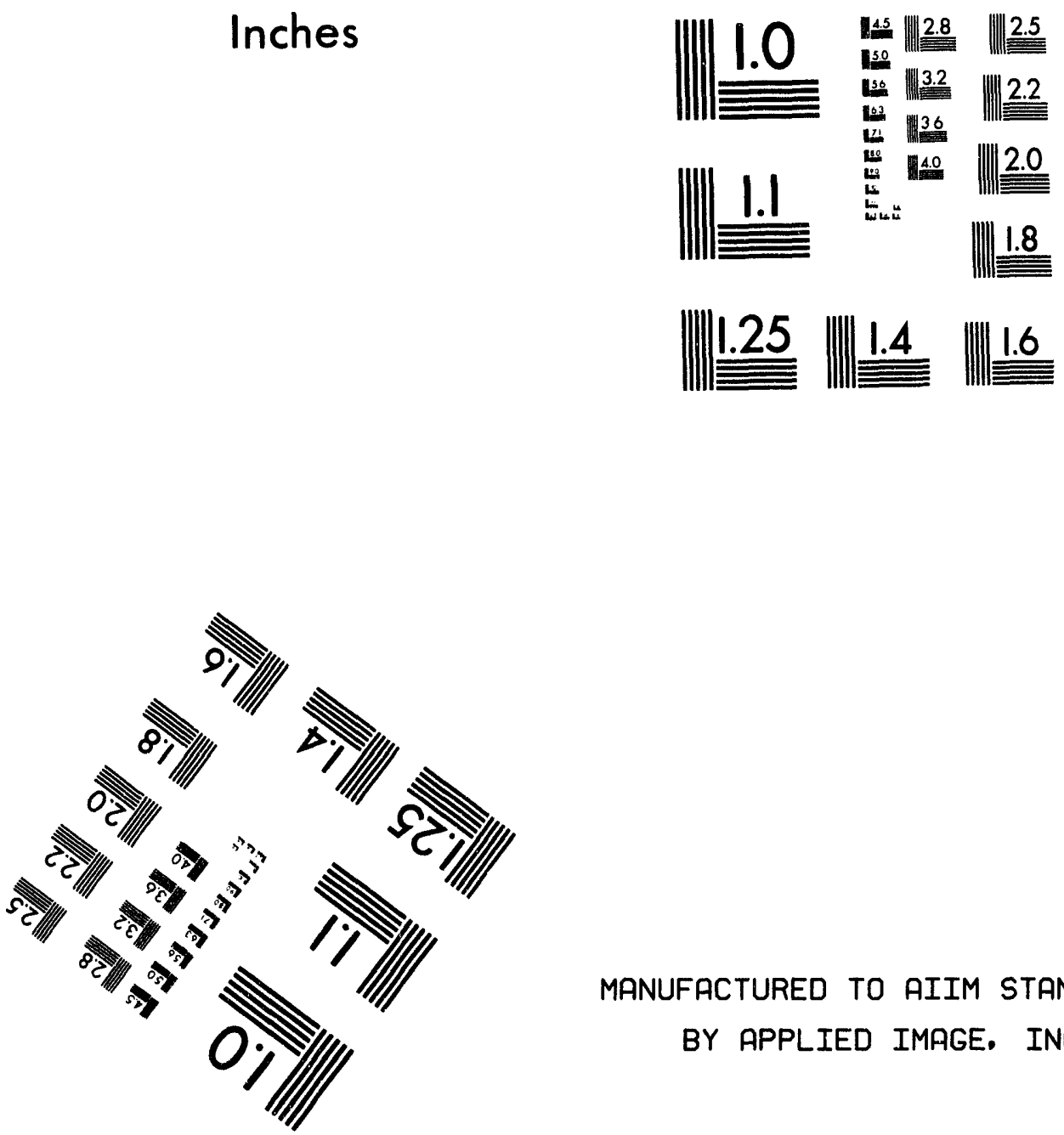

MANUFACTURED TO AIIM STANDARDS

BY APPLIED IMAGE. INC.

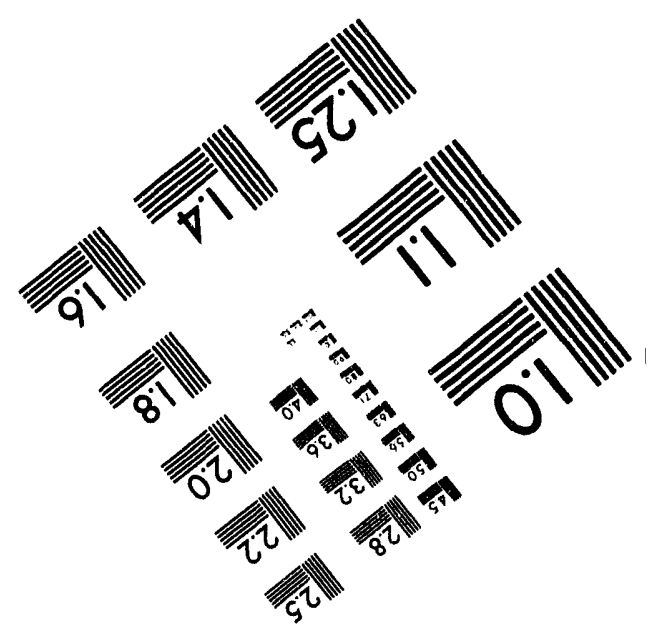



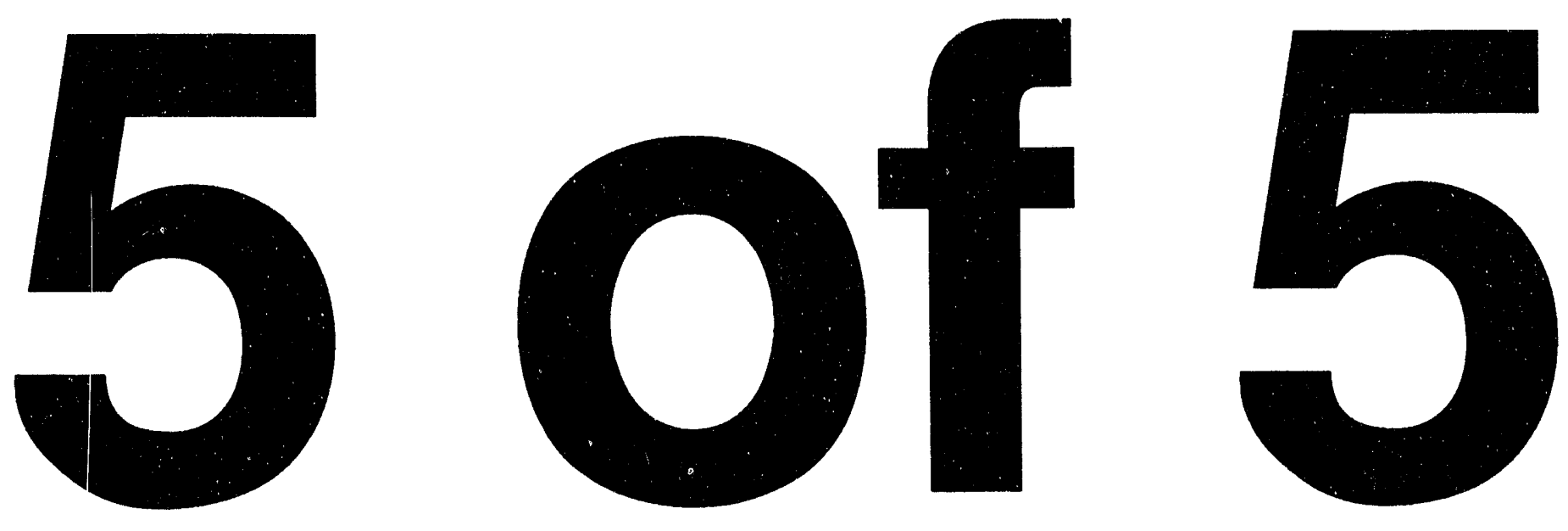
NDE STANDARDS FOR ADVANCED CERAMICS

R. W. McClung (Oak Ridge National Laboratory)

The development of standards is important for the establishment of reliability and acceptance of advanced structural materials. Committee C-28 on Advanced Ceramics is organized in the American Society for Testing and Materials (ASTM) to address this issue. One of the activities of the C-28 committee is nondestructive examination (NDE). The Task Group on NDE (TGNDE) is reviewing existing standards on NDE (primarily developed for metals) to determine potential applicability for ceramics as well as preparing original standards. The use of existing or modified standards is more efficient than the generation of new documents and will ensure the input of a large body of NDE expertise. Close liaison is established with ASTM Committee E-7 on Nondestructive Testing, and documents are in various stages of review, recommendations for modification, and balloting. R. W. McClung is a member of both committees and the official liaison.

Liaison and technical support have been continued between ASTM Committees C-28 and E-7. To date, 31 NDE standards have been reviewed in detail with recommendations made to E-7 for modifications to identified documents. Successful action is complete on 27 documents; the others require action by C-28.

A new draft standard on ceramic reference specimens containing seeded inclusions was prepared based on an earlier-approved ASTM standard C-1212 on fabrication of seeded voids in pressureless sintered ceramics. After an advisory ballot for comments from the TGNDE, the proposed standard was revised and approved for a concurrent subcommittee and committee ballot, which is being conducted at the close of this reporting period. A TGNDE advisory ballot was conducted on a new draft standard for making precise measurements of ultrasonic velocity in advanced ceramics (one application is determination of porosity in ceramics). Approval was obtained for a concurrent subcommittee and committee ballot on this draft standard. However, due to an ASTM error, only the subcommittee ballot was conducted. An advisory ballot was also conducted concurrently for information and technical comments in sub-committee E-7.06 (on ultrasonic nondestructive testing methods). One negative ballot and three sets of comments (with affirmative ballots) were received from the C-28 subcommittee ballot; one set of comments was received from the E-7.06 advisory ballot. Review has begun on the comments and negative ballot for resolution and possible minor modification to the draft standard. A letter and questionnaire were distributed requesting data for "radiographic equivalence factors" from members of the TG and other potential sources but received only minimal response; further action is planned. A TG advisory ballot is planned to obtain comments on the applicability of several new E-7 standards. Other work in progress includes an amplified outline for a draft standard for reference specimens containing laser-drilled holes and a possible standard on determination of porosity in ceramics using ultrasonic velocity. Preparation of a list of facilities and expertise for NDE of advanced ceramics at government laboratories is planned. In Committee E-7, several documents are in progress on radiography, computer tomography, and ultrasonics with relevance for application to advanced ceramics.

A joint tutorial seminar in Committees C-28 and E-7 was organized and presented on June 23, 1993, in Atlanta, Georgia, during the ASTM Committee Week. The purpose of the seminar was to inform members of both committees about fabrication methods, potential for introduction of flaws, and NDE methods with emphasis on application for process control. Arvid Pasto (Oak Ridge National Laboratory) presented "Fabrication of High-Performance Structural Ceramics." R. W. McClung presented "Nondestructive Testing for Process Control and Examination of Advanced Ceramics." 


\subsection{TECHNOLOGY TRANSFER \\ 4.1 TECHNOLOGY TRANSFER}

\subsubsection{Technology Transfer}

\section{Technology Transfer}

D. R. Johnson (Oak Ridge National Laboratory)

Technology transfer in the Ceramic Technology Project is accomplished by a number of mechanisms including the following:

Trade Shows - A portable display describing the program has been built and has been used at numerous national and international trade shows and technical meetings.

Newsletter - A Ceramic Technology Newsletter is published regularly and sent to a large distribution.

Reports - Semiannual technical reports, which include contributions by all participants in the program, are published and sent to a large distribution. Informal bimonthly management and technical reports are distributed to the participants in the program. Open-literature reports are required of all research and development participants.

Direct Assistance - Direct assistance is provided to subcontractors in the program via access to unique characterization and testing facilities at the Oak Ridge National Laboratory.

Workshops - Topical workshops are held on subjects of vital concern to the ceramics community.

International Cooperation - This program is actively involved in and supportive of the cooperative work being done by researchers in West Germany, Sweden, the United States, and, most recently, Japan under an agreement with the International Energy Agency. This effort is ultimately aimed at development of international standards and includes physical, morphological, and micro-structural characterization of ceramic powders and dense ceramic bodies, and mechanical characterization of dense ceramics. 
IEA ANNEX II Management

V. J. Tennery (Oak Ridge National Laboratory)

\section{Objective/scope}

The purpose of this task is to organize, assist, and facilitate international research cooperation on the characterization of advanced structural ceramic materials. A major objective of this research is the evolution of measurement standards. This task, which is managed in the United States by ORNL, now includes a formal IEA Annex agreement identified as Annex II between the United States, Germany, Sweden, and Japan. The original annex included four subtasks: (1) information exchange, (2) ceramic powder characterization, (3) ceramic chemical and physical characterization, and (4) ceramic mechanical property measurements. In the United States, a total of 13 industrial and government laboratories have participated and contributed their resources to this research. The research in Subtasks 2, 3, and 4 is now complete. During CY 1990, agreements were reached for Japan to join the annex and for research in two new subtasks to be initiated. These include Subtask 5, Tensile and Flexural Properties of Ceramics, and Subtask 6, Advanced Ceramic Powder Characterization.

\section{Recent developments}

Mr. Eiji Yamada, Energy Technology and R\&D, International Energy Agency, IEA Representative for Annex II, Paris, France, will no longer be the representative (as of . June 1993). Mr. Masahiro Okuda, Principal Administrator, Energy Technology Collaboration Division, IEA, Paris, is the successor to Mr. Eiji Yamada. He plans to participate in the Executive Committee Meeting in Stuttgart, Germany, on October 6, 1993.

The letter of August 24, 1993, from Mr. Hisao Ogiyama, Alternate IEA Executive Member, informed us of the following changes: Mr. Sadao Mori, NEDO, will be the successor of Mr. Tarasawa, Executive Member, and Dr. Makio Naito, JFCC, will be the successor of Dr. Tsubaki, Technical Leader of Subtask 6.

\section{Proposed future research}

Germany is planning to participate in Subtask 8 (letter to Mr. Schulz dated May 25, 1993, from Drs. Faul and Seitz, KFA, Germany) but not in Subtask 7. (This may, in fact, change later.)

Sweden's letter of May 19,1993, indicated that they are only able to participate in the plan proposed by Japan and not the combination U.S./Japanese plan (Robert Pompe, $\mathrm{SCl}$, Sweden). (This may, in fact, change later.)

Dr. Mizuno, Japan Fine Ceramics Center, reported that at the Japanese Subtask 7 meeting held on June 17, 1993, Japan approved the Japan/U.S. Combination Proposal (telefax of June 18, 1993).

Representatives from Norway (Dr. Jan L. Holm) and Belgium (Dr. J. P. Erauw) were invited to attend the IEA Executive Committee Meeting to be held in Stuttgart on October 6, 1993. 
Subtask 7

An IEA Planning Meeting was held in Cincinnati, Ohio, on April 19, 1993, in conjunction with the American Ceramic Society Meeting. There were 18 attendees including 9 from U.S. industry, 5 representing our international partners, and 4 representing DOE and ORNL. After much discussion of the Japanese and U.S. versions of the proposed research, it was tentatively decided that we would consider a plan that would include both the earlier U.S. strategy and the Japanese strategy proposed at this meeting. The major issue discussed was the logic and procedure to be used for international exchange of silicon nitride billets and flexure specimens. This topic centered on a U.S. and Japanese proposal. The U.S. plan involved the supplying country providing $\mathbf{3 0}$ specimens plus one billet to each other participating country. Japan, on the other hand, proposed that the supplying country provide two billets (60 specimens equivalent) to each receiving country who then returns 30 specimens to the supplying country for fracture and analysis. After much discussion, a U.S./Japan combination plan was prepared with the supplying country providing two billets (60 specimens) and 30 specimens to each receiving country with each receiving country, in turn, machining and returning $\mathbf{3 0}$ of 60 specimens to the supplying country. The silicon nitride materials to be used would be hot isostatically pressed (HIPed) from both ABB Ceramic (Sweden), a U.S. silicon nitride, and a gas-pressure-sintered silicon nitride from Japan. In answer to a question raised on . strain gaging, the Japanese stated they have not discussed the issue of strain gaging and will have to discuss this further with their participating laboratories. Steinbrech (Germany) commented that he felt that strain gaging was necessary. The test fixtures to be used were discussed. Each country will use their own fixtures for specimens of the same dimensions, i.e., $3 \times 4 \times 50 \mathrm{~mm}$ with $20-\mathrm{mm}$ (inner) and $40-\mathrm{mm}$ (outer) spans. Some strain gaging is currently planned for the U.S. specimens.

Bob Schulz discussed the issue of the lack of German participation in Subtask 7. In previous meetings of the Executive Committee, it had been voted that each country had to participate in all subtasks or the country would not participate at all.

It was decided that, if all other countries were ready to commit to Subtask 7 , the amendment to the Annex II could be rewritten to allow nonparticipation by Germany. The amendment will be revised and faxed to the Executive Committee members in time for them to be able to vote on it at the October 6, 1993, meeting in Stuttgart, Germany.

Dr. Tennery then polled each country for their position on conducting Subtask 7. Japan will meet on June 17,1993 , to decide this issue. Sweden has committed to the U.S. plan. However, more discussion in Sweden is required if a combination of the U.S. and Japanese plans is conducted, due to costs. Once DOE approval is given, the United States is ready to start. Tennery will confirm with the participating U.S. laboratories that they agree to the additional work of the combination plans. There was some discussion on the "best technique" (machining) used by each country to produce the important optimum specimen. Each country must identify its "best technique" for specimen machining before starting the work.

Strain gages have been made and received (July 26, 1993) from HiTec Corporation, Westford, Massachusetts, for use in strain gaging a fraction of the flexure bars for the main task.

For the selection of the U.S. silicon nitride to be used in Subtask 7, orders were placed with four suppliers for billets of five different silicon nitride materials for evaluation of the Weibull modulus and characteristic strength under "identical" machining conditions. 
The billets have been received and sent to Chand Kare for machining into $3 \times 4 \times 50-\mathrm{mm}$ flexure specimens. The machining (by Chand Kare Technical Ceramics, Worcester, Massachusetts) was completed, and the flexure specimens were all received (at the High Temperature Materials Laboratory) by September 30, 1993. W. Ellingson of Argonne National Laboratory (ANL) has expressed an interest in characterizing the 4-by $50-\mathrm{mm}$ surfaces of specimens of the five materials using a new laser scanning technique to determine if it can "distinguish" between these silicon nitrides having very different microstructures. One specimen of each material was shipped to ANL for some baseline measurements.

Dr. Seitz's (Germany) letter of September 22, 1993, indicated that there would probably be no direct involvement of German laboratories. Germany would, however, like to participate by perhaps exchanging reports of the work they have already done on ceramic machining with the reports done by participants of Subtask 7. This will be resolved at the IEA Executive Committee Meeting in Stuttgart on October 6, 1993. (The German government later had a problem with this matter.)

Dr. Mizuno's (Japan) letter of August 27, 1993, agreed that Belgium could participate in Subtask 7 but that, in Japan, they could not increase the number of available silicon nitride specimens. Questions were also raised about how the results would be disclosed.

\section{Subtask 8}

The Subtask 8 planning activity is progressing at a rapid pace. Two primary activities under this project were the development of draft procedures for the measurement of secondary properties of powders and compilation of procedures collected from the participants. A number of these procedures developed at the National Institute of Standards and Technology (NIST) are in a very preliminary stage requiring significantly more work to refine them. This task will be initiated shortly. The participants have sent a few procedures for secondary properties measurement to NIST. We have completed a review of these procedures, and a compilation has been prepared. This compilation consists of participants' contributions and NIST-produced procedures, as well as Subtask 6 procedures requiring additional work. These procedures will be discussed at the technical leaders meeting in Stuttgart on October 3, 1993. The revised procedures will be sent to participants for their review and input.

Technical highlights

Subtask 5, Tensile and Flexural Properties of Ceramics

\section{United States}

The draft report for Subtask 5 was completed on June 30, 1993, and sent to the participants for comments on July 15, 1993 (comments were returned by July 30).

The final report for Subtask 5 was completed on September 11, 1993. Twenty copies were sent on September 28, 1993, to Stuttgart, Germany, for Dr. Tennery to distribute at the IEA Executive Committee Meeting in Stuttgart on October 6 (title listed under "Publications"). Also, on September 28, 1993, copies of the Subtasks 5 and 6 reports were sent to R. B. Schulz, T. J. Gross, and J. J. Eberhardt, DOE Headquarters. 


\section{Germany, Sweden, and Japan}

We received from Dr. Sven Karlsson, Swedish Ceramic Institute, the fractographic data sheets of all four materials together with original scanning electron microscopy (SEM) photos of all the GN-10 (United States) and the Kyocera (Japan) specimens, and copies of the ABB (Sweden) and the ESK (German) specimens (April 15, 1993). The fractographic examination of the INSTRON tensile specimens tested at Volvo

Flygmotor $A B$ were included.

The "Report on Mechanical Characterization of Ceramics Within IEA, Subtask V," was received from Dr. Lennart Carlsson, Swedish National Testing and Research Institute, on May 17, 1993. This report is a summary with limited distribution regarding their results on flexure testing of 100 test specimens.

Dr. Seitz's letter of August 23, 1993, indicated that the final report from the Fraunhofer-institut für Werkstoffmechanik (Dr. Hollstein) is finished. The report from Karlsruhe University, Institut für Zuverlässigkeit und Schadenskunde (Professor Munz), will be available soon. When both are ready, Dr. Seitz will provide a copy to Dr. Tennery.

Dr. Pompe's letter of August 18, 1993, indicated that the Subtask 5 work has been completed, and the partial reports had been sent. Dr. Carlsson has sent reports from SCl, Volvo Flygmotor, and SP to ORNL and Germany. No formal report from United Turbine regarding their spin tests has been prepared, but Dr. Carlsson has sent their results to the United States and Germany. He hopes to distribute the radiography and $X$-ray diffraction report from Linköping at the IEA Executive Meeting in Stuttgart on October 6, 1993.

The telefax of August 13,1993, from Dr. Mizuno indicated that he will send the final report to ORNL on the Subtask 5 research soon.

\section{Subtask 6, Advanced Ceramic Powder Characterization}

Major responsibility for this subtask in the United States is at NIST, and a detailed report of progress on this subtask is provided in the section of this report submitted by NIST.

A draft of the Subtask 6 final report was prepared and sent to the technical leaders for their input. Their major contribution to ihis report will be to review the information and add to the discussion of results. In addition, a chapter on summary and conclusions was completed and sent to all participants in Germany, Japan, Sweden, and the United States. Most of the participants have responded with no major comments. Therefore, this chapter will be finalized. Discussions were concluded with the technical leaders on the Subtask 6 draft report distributed by NIST in May 1993. The technical leaders accepted the draft report as presented to them.

The final report on Subtask 6 was completed at NIST and mailed to ORNL for printing (September 10, 1993). In the past, we had discussed the idea of releasing this report in two or three volumes. Since a number of participants suggested to combine Vol. 2, containing data listing, with the main body of the report, we decided to produce the entire report in a single volume. Twenty copies of the Subtask 6 Final Report were sent to Germany from ORNL on September 28, 1993, for distribution by Dr. Malghan at the IEA Executive Committee Meeting (title listed under "Publications").

Dr. Stephen Hsu submitted his resignation from Subtask 6 by letter (September 17, 1993). He will continue to complete any details regarding Subtask 6 . He has recommended that Dr. Subhas Malghan be the new coordinator for Subtask 8. 


\section{Status of milestones}

Milestone 411513 (complete draft of final reports for Subtasks 5 and 6) completed on June 30, 1993.

Milestone 411514 will be discussed at the IEA Executive Committee meeting in Stuttgart, Germany, on October 6, 1993.

\section{Communications/visits/travel}

Dr. Mineo Mizurio, Japan Fine Ceramics Center, Nagoya, Japan, visited ORNL on April 27, 1993, and presented a seminar entitled "Creep Rupture of Silicon Nitride Ceramics Related to the Ceramic Gas Turbine Project in Japan."

V. J. Tennery left Oak Ridge, Tennessee, on September 29, 1993, to attend the IEA Executive Committee Meeting in Stuttgart, Germany, on October 6, 1993. He also attended the conference, "Silicon Nitride 93," at the Max-Planck Institute for Metals Research and visited several German laboratories.

\section{Publications and presentations}

IEA Annex II, Subtask 5 Final Report - "Study of the Flexure and Tensile Strength of a United States Silicon Nitride," by V. J. Tennery, K Breder, M. K. Ferber, and M. G. Jenkins, Oak Ridge National Laboratory, September 1993, 230 p.p.

IEA Annex II, Subtask 6 Final Report - "Development and Testing of Procedures for Characterization of Ceramic Powders," by S. G. Malghan (United States), H. Hausner (Germany), R. Pompe (Sweden), J. Tsubaki (Japan), and S. M. Hsu (United States), Ceramics Division, National institute of Standards and Technology (NIST), U.S. Department of Commerce for the Ceramic Technology Project, managed by the Oak Ridge National Laboratory for the U.S. Department of Energy, September 1993, 594 p.p. 
Characterization of Ceramic Powders

S. G. Malghan, and L. -S. Lum

(National Institute of Standards and Technology)

\section{Objective/Scope}

Ceramics have been successfully employed in engines on a demonstration basis. The successful manufacture and use of ceramics in advanced engines depends on the development of reliable materials that will withstand high, rapidly varying thermal stress loads. Improvement in the characterization of ceramic starting powders is a critical factor in achieving reliable ceramic materials for engine applications. The production and utilization of such powders require characterization methods and property standards for quality assurance.

The objectives of the NIST program are: (1) to assist with the division and distribution of ceramic starting powders for an international round-robin on powder characterization; (2) to provide reliable data on physical (dimensional), chemical and phase characteristics of powders; and (3) to conduct statistical assessment, analysis and modeling of round-robin data. This program is directed toward a critical assessment of powder characterization methodology and toward establishment of a basis for the evaluation of fine powder precursors for ceramic processing. This work will examine and compare by a variety of statistical means the various measurement methodologies employed in the round-robin and the correlations among the various parameters and characteristics evaluated. The results of the roundrobin are expected to provide the basis for identifying measurements for which Standard Reference Materials are needed and to provide property and statistical data which will serve the development of internationally accepted standards.

\section{Technical Progress}

During this period, our progress has been in the following activities: preparation of final report on Subtask 6, development of technical plan for Subtask 8 activities, and continuation of ASTM C28.05 activities.

A draft of the Subtask 6 final report was prepared and sent to technical leaders for their input. The primary input expected from the technical leaders was in the form of data analysis and review of chaptexs. The technical leaders of Subtask 6 accepted the draft in the as-presented form. In the current format, the report contains one volume. The first part consists of summary data, summary statistics, procedures used to collect the data, and conclusions and recommendations. The second part in appendix consists of tabulated data. There are ten chapters.

The first chapter is an introduction to the report consisting of background information on IEA Annex 2, purpose of Subtask 6, and a description of technical program. The second through ninth chapters contain core of the data and procedures on specific surface area, particle size distribution, metallic and nonmetallic chemical 
impurities, major chemical components, halides, phase composition, spectroscopy, and interface chemistry. The tenth chapter contains summary tables, comments, conclusions and recommendations. Each of the technical chapters is organized in the same manner, in which, first the procedure and accompanying comments are presented, followed by statistical data obtained using the previously described procedure. In the procedure description, the key steps are highlighted. The data presentation format is approximately the same for all methods studied, in which, first the mean, minimum, and maximum values for each participant's data are tabulated for a given method of analysis. Followed by this, the data are presented in a graphical format and their summary statistics such as the mean of the laboratory means, repeatability and reproducibility are presented following the graphical presentation. In the calculation of the summary statistics, only the data containing a minimum of two replicates are included. Those data not used in the calculations are clearly identified. All data, irrespective of whether used in the summary statistics or not, are presented in the appendix.

During review of this draft report, Dr. Pompe, Swedish Ceramic Institute, made a suggestion to split this volume into three separate bound volumes on physical properties, bulk chemical properties, and surface chemical properties. One advantage of presenting in the form of three volumes is that the specific reports can be used by only those interested in the subject. However, it adds other problems such as the cost of producing three volumes, and moreover, the three volumes are not truly independent. In addition, consensus opinion of the working group was to combine the data into one single volume. Therefore, the final report was produced as a single volume.

The final report on Subtask 6 was completed at NIST and mailed to Dr. V. Tennery at ORNL in September for printing and distribution. This report will be released at the upcoming IEA Annex 2 Executive Committee Meeting in Stuttgart, Germany, held in conjunction with Silicon Nitride 93 conference. The participants of Subtask 6 should be receiving the report in the next 4 to 6 weeks.

Subtask 8 planning activities are progressing well. A letter requesting procedures and powders was sent to the participants. The purpose of this activity is to obtain procedures from participants to all the methods of powder analysis included in subtask 8 . These procedures will be compiled and efforts will be initiated to develop one procedure for each method of analysis. It is possible that we will get very few procedures from the participants since a large number of procedures included in Subtask 8 are fairly new. At NIST, we have initiated an effort to develop these procedures. At this time, we have developed thirteen draft procedures. These will be combined with all other procedures obtained from the participants. One of the next steps is to develop consensus derived procedures from this compilation. With respect to obtaining powders for Subtask 8 testing, we have had discussions with powder manufacturers in this program. Subsequently, we are now seeking suggestions from the participants. All of this input will be used to reach a decision on powder selection.

In response to our request, we have received only a few procedures from the participants. We expect that we will not be able to receive a 
large number of procedures as in the case of Subtask 6. The primary reason is the lack of availability of well-documented procedures for characterization of secondary properties of ceramic powders.

The methods for powder analysis for a number of secondary properties may be considered to be proprietary information by the participants since they are an integral part of powder processing. These procedures range from as basic as the $\mathrm{pH}$ measurement of slurries to as complex as the measurement of properties of green ceramics. The following is a list of thirteen procedures included in Subtask 8:

1. Deagglomeration by ultrasonication

2. Settling behavior

3. Agglomerates size distribution

4. $\mathrm{pH}$ of slurry

5. Rheology of slurry

6. Sedimentation

7. Casting rate

8. Flow rate of spray dried powders (SDP)

9. Size distribution of SDP

10. Pressing behavior of SDP

11. Density of green body (GB)

12. Porosity of $G B$

13. Moisture and volatiles in $G B$

Preliminary work on a number of these procedures has been initiated at NIST. Significantly more work is required to refine them. This task will be initiated shortly. We have reviewed and evaluated procedures submitted by Subtask 8 participants and a compilation has been prepared. This compilation includes participants contributions, NIST produced procedures, and Subtask 6 procedures requiring additional work. These procedures will be discussed at the technical leaders meeting in Stuttgart. The revised procedures will be sent to participants for their review and input

The IEA Annex 2 Executive Committee meeting is scheduled to meet on October 6, 1993 in Stuttgart, Germany, in conjunction with the Silicon Nitride 93 conference. The technical leaders of Subtask 8 are also meeting at this time to review these procedures and develop technical plans. Some of the major issues to be addressed are powders preparation, procedures tightening, and procedures development. We are going to have two new technical leaders representing Japan and Germany. They are Dr. Naito from JFCC, Japan, and Dr. Nietfeld from H. C. Starck Co., Germany. In addition, there is a possibility that Belgium could become the fourth member of the IEA Subtask 8 program.

In the ASTM C-28.05 activity, two procedures on particle size distribution that had received negative ballots have been revised, and the negative ballots were withdrawn. These procedures will be submitted for concurrent ballot so that a decision can be made prior to the Cocoa Beach C-28 meeting.

\section{Status of Milestones}

On target. 


\section{Publications/Presentations}

S. G. Malghan, "Draft of Subtask 6 Report" distributed to technical leaders.

S. G. Malghan, "Final Draft of Conclusions and Recommendations of Subtask 6" distributed to IEA Subtask 6 participants.

S. G. Malghan and others, "Development and Testing of Procedures for Characterization of Ceramic Powders, IEA Subtask 6 Final Report"

Communications/visits

None 
Ceramic Mechanical Property Test Method Development

George D. Quinn (National Institute of Standards and Technology)

\section{Objective/Scope}

This task is to develop mechanical test method standards in support of the Ceramic Technology for Advanced Heat Engines and Advanced Turbine Technology Applications Programs. The prime DOE contractors and subcontractors will be surveyed to assess their needs and capabilities. Test method development should also consider the general USA structural ceramics community as well as foreign laboratories and companies, but emphasis will be placed on the needs of the DOE community.

Draft recomnendations for practices or procedures shall be developed based upon the needs identified above and circulated within the DOE ceramics heat engine community for review and modification. Round-robins will be conducted as necessary, but shall be well-focussed, limited in scope and not interfere with ongoing IEA round-robins. Procedures developed in this program shall be presented as ATTAP or CTAHE "standard procedures." Alternatively, (and eventually) these will be advanced for final standardization by ASTM or by thas U.S. Army as possible MIL STD's.

\section{Technical Highlights and Results} standards:

Previous work in this project has contributed to the following completed

1. ASTM C- $1 \perp y 8-y 1$ "Dynamic Young's Modulus, Shear Modulus, and Poisson's Ratio for Advanced Ceramics by Sonic Resonance," by S. Gonczy, Allied-Signal; G. Quinn, NIST; and J. Helfinstine, Corning.

2. ASTM C-1161-90 "Standard Test Method for Flexural Strength of Advanced Ceramics at Ambient Temperature," G. Quinn, NIST.

3. ASTM C-1211-92 "Standard Test Method for Flexural Strength of Advanced Ceramic at Elevated Temperature," by G. Quinn in cooperauion with Mr. M. Foley, Norton; Mr. T. Richerson, Allied-Signal; and $\mathrm{Dr}$. M. Ferber, ORNL.

4. MIL HDBK 790 "Fractography and Characterization of Fracture Origins in Advanced Structural Ceramics," with J. Swab and M. Slavin, U. S. Army, ARL.

5. ASTM C-1239-93 "Standard Practice for Reporting Strength Data and Estimating Weibull Distribution Parameters," by S. Duffy, NASA-Lewis; G. Quinn, NIST; and C. Johnson, G.E.

\section{Weibull Analysis}

The draft standard: "Reporting Uniaxial Strength Data and Estimating Weibull Distribution Parameters for Advanced Ceramics, "by S. Duffy, G. Quinn and C. Johnson was submitted for an ASTM Society ballot and was approved in this semiannual period. It has been assigned the designation C-1239. A few minor revisions need to be made to this document, and supplemental ballot and revisions will be undertaken in late 1993 and early 1994 as needed.

Fracture Toughness

Standardization of fracture toughness testing continues. Mr. Jonathan Salem of NASA-Lewis is overall leader of this activity. Professor Isa Bar-on of Worcester Polytechnic Institute is acting as the C-28-E-8 committee liaison. 
This is a potentially contentious topic since very strong preferences and opinions have developed over the years. Much of tive experimental and research work in recent years has focussed on fracture toughness of composites or $R$-curve phenomena.

During this 6 months period, there was intensive work on analyzing the results of the controlled surface flaw round-robin. This VAMAS project started in November 1992 and ended in September 1993. The round-robin is a joint program by NIST and by EMPA, the Swiss Federal Research Laboratory. Mr. Jakob Kübler of EMPA was at NIST during the summer to assist with the analysis.

Twenty-four laboratories in Europe and the United States are agreed to participate and 20 sent results back in the allotted time period (which was extended beyond May 1993 by 5 months!) In the USA, the participants were NASALewis, NIST, and Alfred University. (Carborundum and St. Gobain-Norton were not able to find time to do their work.) The round-robin involved three materials: Norton hot-pressed silicon nitride, grade NC 132; ESK hipped silicon nitride; and EMPA (Swiss) sintered yttria-partially stabilized zirconia. The latter two materials were donated by EMPA. Each participant received 10 specimens of each material with detailed instructions on procedure. It was planned that the exercise would require no more than 1-2 man-weeks of effort per laboratory. This round- robin interfaces nicely with an ongoing round-robin in Europe conducted under the auspices of the European Structural Integrity Society. The latter exercise includes chevron notch (CN), single-edge precracked beam (SEPB), indentation strength (IS) and single-edge notched beam (SENB) methods on similar materials.

Sketchy results from this round-robin have been reported in past bimonthly reports, but now that the round-robin is closed, we can present the principal findings. Figures 1 through 3 illustrate the fracture toughness results. Excellent consistency was obtained for the NC-132 hot-pressed silicon nitride. Al1 20 laboratories reported results. The grand average toughness for 107 accepted specimen outcomes was $4.6 \mathrm{MPa} / \mathrm{m}$ with a standard deviation of only 0.37 . The ESK silicon nitride was more difficult to test, and the average toughness for 105 accepted specimens was $4.95 \mathrm{MPa} / \mathrm{m}$ with a standard deviation of 0.55 . Only 12 laboratories tried the zirconia, which was optional, and eight laboratories obtained accepted results with and average for 42 specimens of $4.42 \mathrm{MPa} / \mathrm{m}$ and a standard deviation of 0.57 . The zirconia posed many problems for the laboratories, and several misinterpreted their fracture surfaces and marked hackle lines as the precrack. This data is shown in Figure 3 but is marked by an " $\mathrm{X}$ " and is not included in the grand average.

In the case of the NC-132, the average is in excellent agreement with chevron notch (CN) and single-edged precracked beam (SEPB) results obtained at NASA-Lewis by Shannon and Salem. A review of over 20 studies that have published fracture toughness values for NC-132 indicates that a value of 4.6 probably is the definitive toughness for this material. The ESK and zirconia results are credible as well, but there is fewer alternative data to compare the results to. A similar outstanding agreement of CSF to CN and SEPB data had been reached earlier in work on sintered $\alpha$ silicon carbide (Carborundum SA) published by Ghosh, Bradt, Kobayashi, Jenkins and Salem at U. Washington.

A stunning conclusion from the round-robin is that the results are not especially sensitive to the details of the precrack size measurement. It is true 


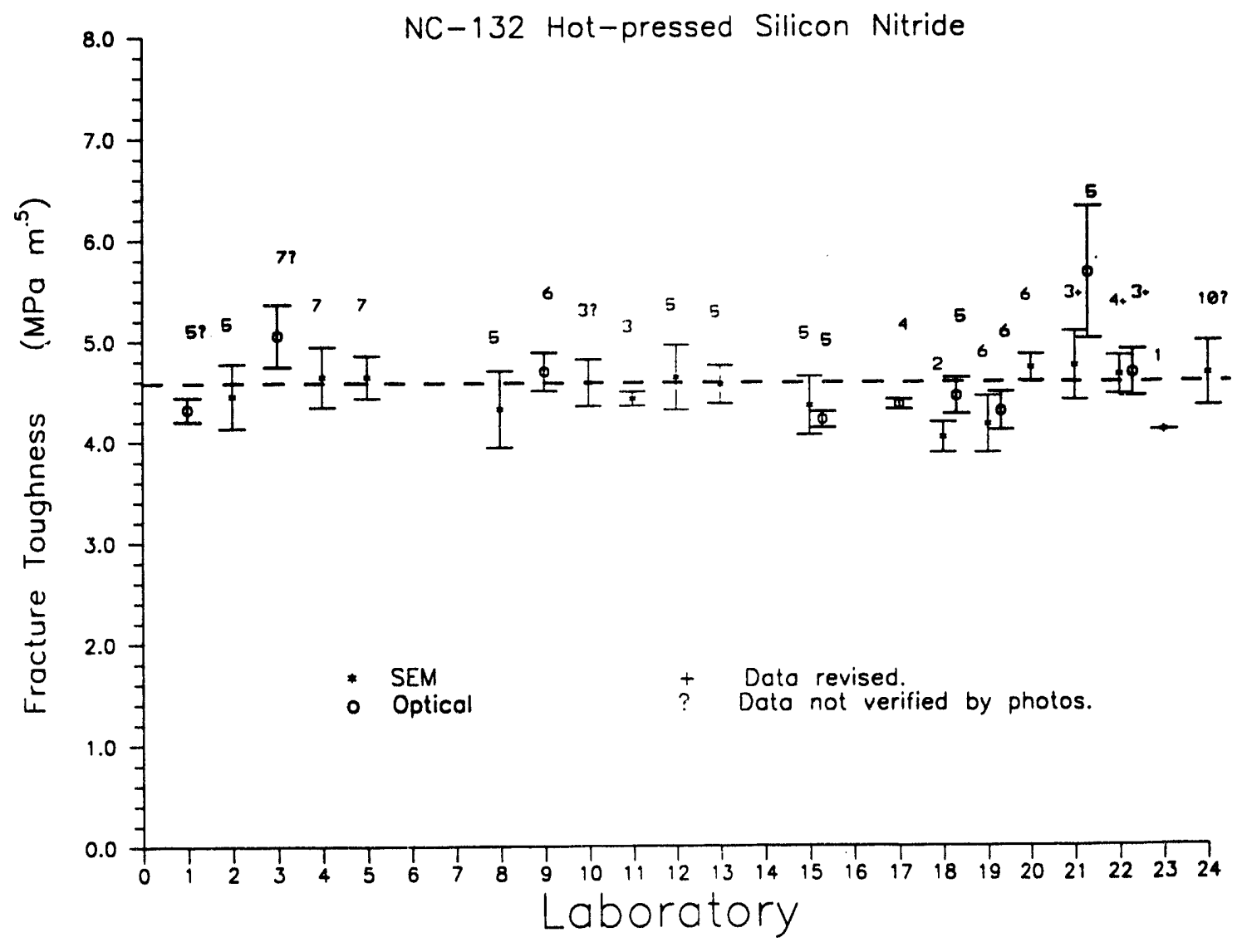

Figure 1. Results of the fracture toughness by the controlled surface flaw method for NC-132 hot-pressed silicon nitride. The average and standard deviation of each laboratories results are shown as well as the number of specimens the laboratory had some success with. Laboratories usually tried either 5 or 10 specimens. The grand average is shown by the dotted line. 


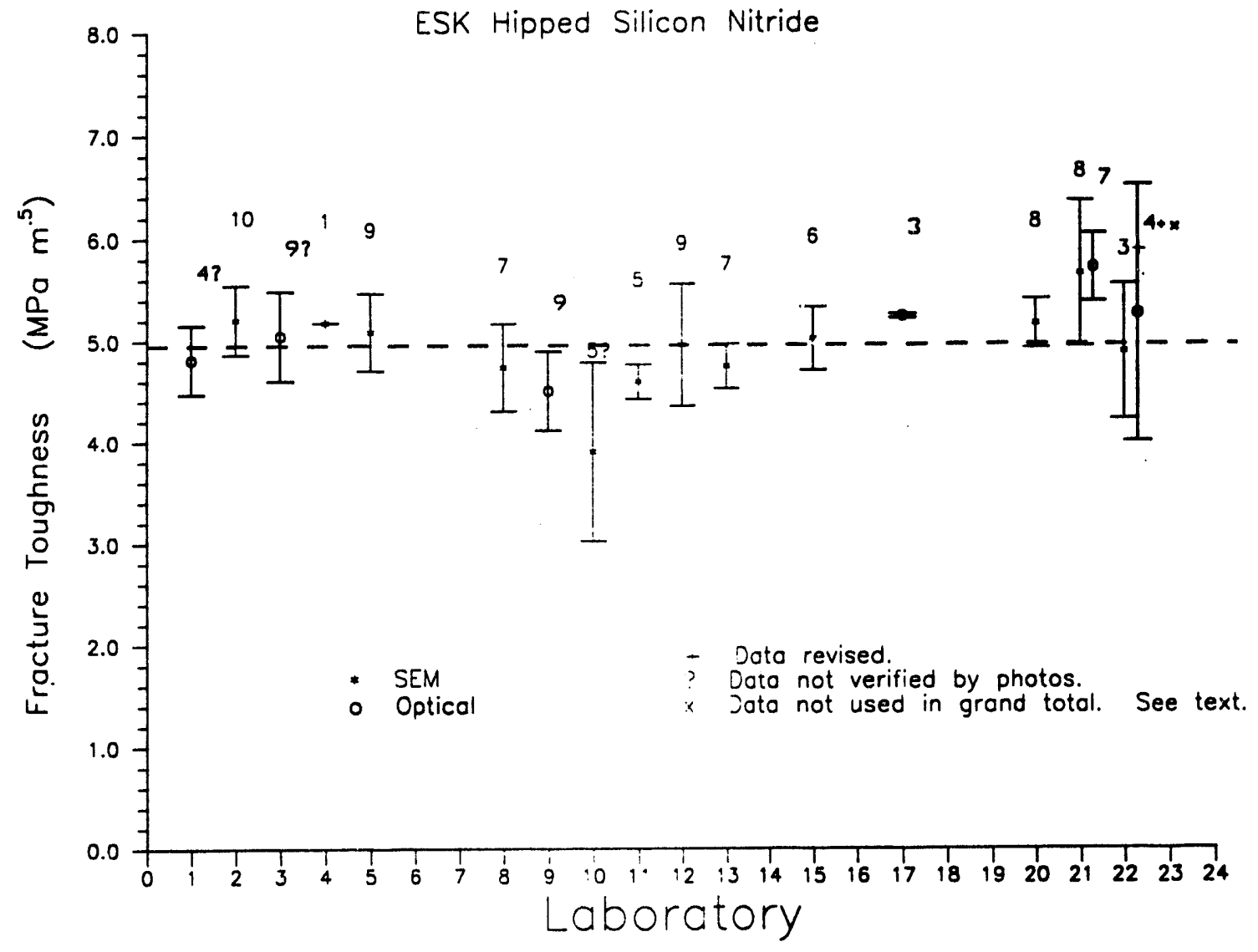

Figure 2. Results for the ESK hipped silicon nitride, which was more difficult than the NC-132. 


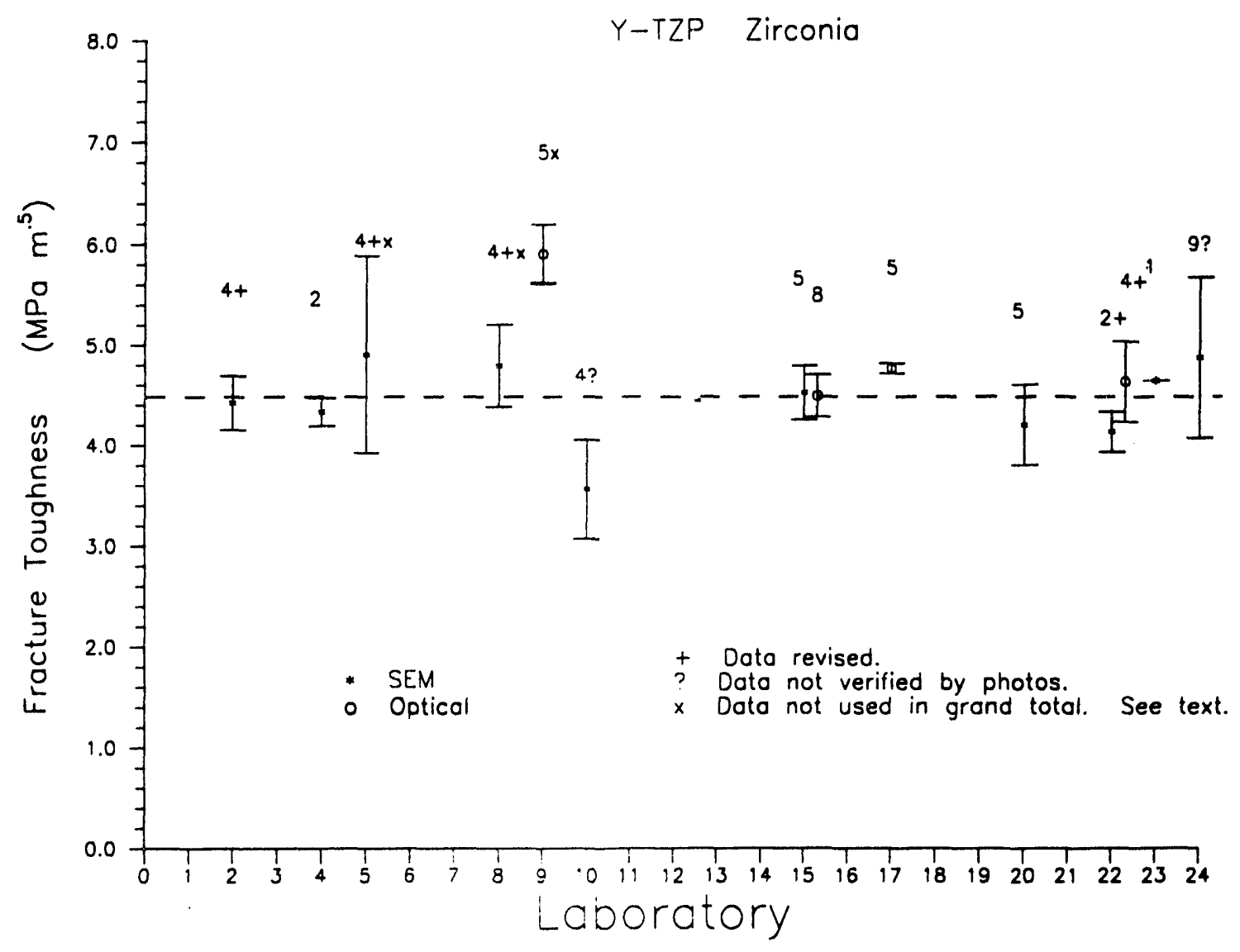

Figure 3. Results for the yttria-stabilized tetragonal zirconia. of 12 laboratories that attempted this material, eight had some measure of success. 
that the participants had different tendencies and inclinations in marking their precracks, but the mitigating influence of the square root dependence of fracture toughness upon the precrack size tended to diminish the scatter. Furthermore, there was a fascinating tendency for the Newman-Raju stress intensity shape factors to partially offset scatter in the crack sizes. That is to say, an overestimate in precrack depth measurement, would be partially offset by a diminishment in the shape factor.

A comprehensive report is in preparation and will be ready for review by the participating laboratories in late November 1993. It will include extensive fractographic analysis. Once the reviews (al1 20 participating laboratories) have been obtained, the final report wil $\perp$ be corrected and made available to any interested party. This should be in January or February of 1994. A condensed version of the report has already been prepared for presentation at the January meeting of the Engineering Ceramics Division in Cocoa Beach. It is scheduled for the afternoon of Thursday, January 13.

The success of this exercise indicates that the method warrants standardization. It was not clear whether this was so at the beginning of the exercise, since there was serious concern over some aspects of the method, such as whether participants could read the precracks properly. There is a new impetus to use this method since a new ASTM standard for metals, E-740, uses a method that is conceptually very similar. The findings of the round-robin exercise will be used to refine the new ceramic fracture toughness standard being developed in ASTM Committees C-28 and E-8. This draft features the controlled surface flaw method, the chevron notch method, and the single-edged precracked beam method.

During this period, a revised draft standard which was prepared by Professor Isa Bar-on of Worcester Polytechnic was reviewed at NIST. A conference call of $1 \frac{1}{2}$ was held with M. Jenkins, J. Salem, I. Bar-on, and G. Quinn to review this document and to discuss the presentation of Professor Bar-on at the Noveinber meeting of $\mathrm{E}-8$ in Houston.

A billet of NC-132 was given by G. Quinn to J. Salem in October to enable NASA-Lewis to coordinate a chevron notch round-robin on this material.

\section{Hardness}

Work continues at NIST on developing hardness standards for advanced ceramics. An internally funded program is attempting to develop two "standard reference materials" for which the hardness is certified by NIST. Parallel to this is an intensive review of the world standards for Vickers and knoop hardness and laboratory work on examining the techniques and errors in measurements.

Hardness testing is in principal very simple, but in practice it is very sensitive to technique. Our original intent was to simply modify current techniques and write a simple standard for advanced ceramics. Unfortunately, it will require a little more work, but the problem should be solvable in the near term. The problem with measuring the hardness of advanced ceramics is that the materials are themselves hard, and the indentations are very small. It is difficult to get a precise or accurate reading of the diagonal length with an ordinary microscope. Operator bias and technique is critical.

It has been decided that work will initially focus on a Knoop standard 
since there are already two related ASTM standards as noted above. We are carefully studying the matter of the apparent shortening of the diagonal lengths due to the limits of resolution of optical microscopes as illustrated in Figure 6. The $7 \lambda / 2 \mathrm{NA}$ correction factor is mandated in the two ASTM standards C-730 and $\mathrm{C}-8459$. but is not used by standards in the rest of the world. The difference in hardness with or without the correction factor is about 100-150 units of most glasses! This has led to wild confusion in the literature with respect to whether the correction factor has or has not been applied. For example, older versions of the Schott Glass catalog list hardness both with and without the factor. The original work which suggested the correction factor was necessary was done in the 1950's, before the advent of scanning electron microscopy. We therefore are measuring indentations with several optical microscopes and with a calibrated scanning electron microscope in order to verify the effect.

During this 6 months period, work on this project shifted back to the NIST internal project to prepare SRM's. The standardization in ASTM Committee C-28 must wait pending the outcome of the SRM effort. A small round-robin was set up and commenced in October. Participants have only 2 weeks in which to measure the hardness of a steel ball, a tungsten carbide disk, and a silicon nitride ball. Eight laboratories are participating: Cerbec, Corning, Osram/Sylvania, ORNL, Wilson, Kennametal, NPL-England, and MPA, Dortmund, Germany. The latter two are world famous leaders in hardness testing.

\section{Fractography}

During this 6 months period, elements of MIL HDBK 790, "Standard Practice for Characterizing Fracture Origins Limiting Defects in Advanced Structural Ceramics" were brought into the ASTM C-28 forum. This work is a collaborative undertaking with NIST and with J. Swab of U. S. Army Research Laboratory (ARL). A list of flaw definitions was introduced into the Terminology Subcommittee, C28.91 and these were balloted in September 1993. Pending the outcome of these ballots, the definitions will be advanced for a Society ballot or will be revised at the C-28 Cocoa Beach meeting.

In the meantime, a fractography round-robin was organized under the auspices of the VAMAS collaboration. This exercise was developed by the US ARL in cooperation with NIST. Emphasis will be on several topics including: the detection and characterization of machining damage, the detection and characterization of material processing related flaws, and fractographic techniques and analysis. The round-robin will include the examination of photos and specimens. The US (ARL) distributed the photos and specimens in May 1993 and the exercise closed out in October. NIST is assisting with the interpretation of these results.

\section{Status of Milestones}

All milestones are on schedule.

\section{Publications/Presentations}

1. ASTM Standard C-1239-93 "Standard Practice for Reporting Strength Data and Estimating Weibull Distribution Parameters," by S. Duffy, NASA-Lewis; G. Quinn, NIST; and C. Johnson, G.E., April 1993. 
2. G. Quinn, "Fracture Toughness of Advanced Ceramics at Room Temperature: A VAMAS Round-Robin," Ceram. Eng. and Sci. Proc., Vol. 14, [7-8] 1993, pp. $92-100$.

3. G. D. Quinn, J. J. Swab, and M. J. Slavin, "Fractography and Characterization of Fracture Origins in Advanced Structural Ceramics, idem, pp. $75-83$.

4. C. R. Brinkman, G. D. Quinn, and R. W. McClung, "Development of ASTM Standards in Support of Advanced Ceramics Development," in Proc. of the ASME Turbo Expo Conference, May 1993. 
ORNL/TM-12674

INTERNAL DISTRIBUTION

Central Research Library (2)

Document Reference Section

Laboratory Records Department (2)

Laboratory Records, ORNL RC

ORNL Patent Section

M\&C Records Office

L. F. Allard, Jr.

L. D. Armstrong

D. L. Balltrip

R. L. Beatty

P. F. Becher

T. M. Besmann

P. J. Blau

E. E. Bloom

K. W. Boling

R. A. Bradley

C. R. Brinkman

V. R. Bullington

R. S. Carlsmith

P. T. Carlson

G. M. Caton

S. J. Chang

D. D. Conger

R. H. Cooper, Jr.

S. A. David

J. H. DeVan

J. L. Ding

M. K. Ferber

W. Fulkerson

R. L. Graves

D. L. Greene

H. W. Hayden, Jr.

E. E. Hoffman

C. R. Hubbard
M. A. Janney

D. R. Johnson (5)

F. W. Jones

R. R. Judkins

M. A. Karnitz

B. L. Keyes

H. D. Kimrey, Jr.

T. G. Kollie

K. C. Liu

E. L. Long, Jr.

W. D. Maniy

R. W. McClung

D. J. McGuire

J. R. Merriman

T. A. Nolan

A. E. Pasto

M. H. Rawl ins

J. L. Rich

C. R. Richmond

J M Robbins

G. V. Rogers, Jr.

M. L. Santella

A. C. Schaffhauser

S. Scott

E. J. Soderstrom

D. P. Stinton

R. W. Swindeman

V. J. Tennery

T. N. Tiegs

J. R. Weir, Jr.

B. H. West

S. G. Winslow

J. M. Wyrick

C. S. Yust 


\section{EXTERNAL DISTRIBUTION}

Pioneering Research Info. Ctr. E.I. Dupont de Nemours \& Co. Inc. Experimental Station P.0. Box 80302 Wilmington DE 19880-0302

Jeffrey Abboud U.S. Advanced Ceramics Assoc. 1600 Wilson Blvd., Suite 1008 Arlington VA 22209

James H. Adair

University of Florida

Materials Science \& Engineering 317 MAE Bldg.

Gainesville FL 32611-2066

Donald F. Adams

University of Wyoming

Mechanical Engineering Department P.0. Box 3295

Laramie WY 82071

Jalees Ahmad

AdTech Systems Research Inc.

Solid Mechanics

1342 N. Fairficld Road

Dayton $\mathrm{OH}$ 45432-2698

Yoshio Akimune

NISSAN Motor Co., Ltd.

Materials Research Laboratory

1 Natsushima-Cho

Yokosuka 237

JAPAN

Mufit Akinc

Iowa State University

322 Spedding Hall

Ames IA 50011

Ilhan A. Aksay

Princeton University

A313 Engineering Quadrangle

Princeton NJ 08544-5263

Richard L. Allor

Ford Motor Company

Materials Systems Reliability

P.0. Box 2053, Room S-2031

Dearborn MI 48121-2053
Joseph E. Amaral

Instron Corporation

Corporate Engineering Office

100 Royale Street

Canton MA 02021

Edward M. Anderson

Aluminum Company of America

$N$. American Industrial Chemical

P.0. Box 300

Bauxite AR 72011

Norman C. Anderson

Ceradyne, Inc.

Ceramic-to-Metal Division

3169 Redhill Avenue

Costa Mesa CA 92626

Don Anson

$\mathrm{BCL}$

Thermal Power Systems

505 King Avenue

Columbus $\mathrm{OH}$ 43201-2693

Thomas Arbanas

G.B.C. Materials Corporation

580 Monastery Drive

Latrobe PA 15650-2698

Frank Armatis

3M Company

Building 60-1N-01

St. Pau1 MN 55144-1000

Everett B. Arnold

Detroit Diesel Corporation

Mechanical Systems Technology

13400 Outer Drive West

Detroit MI 48239-4001

Bertil Aronsson

Sandvik $A B$

S-12680

Stockholm Lerkrogsvagen 19

SWEDEN

Dennis Assanis

University of 111 inois

Dept. of Mechanical Engineering 1206 W. Green Street

Urbana IL 61801 
v. S. Auva

North Carolina A\&T State Univ. Dept. of Mechanical Engineering Greensboro NC 27411

Patrick Badgley

Adiabatics, Inc.

3385 Commerce Drive

Columbus IN 47201

Sunggi Baik

Pohang Institute of Sci. \& Tech.

P.0. Bnx 125

Pohang 790-600

KOREA

John M. Bailey

Consultant

Caterpillar, Inc.

P.0. Box 1875

Peoria IL 61656-1875

Bob Baker

Ceradyne, Inc.

3169 Redhill Avenue

Costa Mesa CA 92626

Frank Baker

Aluminum Company of America

Alcoa Technical Center

Alcoa Center PA 15069

Clifford P. Ballard

AlliedSignal Aerospace Company

Ceramics Program

P.0. Box 1021

Morristown NJ 07962-1021

B. P. Bandyopadhyay

University of North Dakota

Mechanical Engineering Department

Grand Forks ND 58202-8359

P. M. Barnard

Ruston Gas Turbines Limited

P.0. Box 1

Lincoln LN2 5DJ

ENGLAND
Harold N. Barr

Hittman Corporation

9190 Red Branch Road

Columbia MD 21045

Renald D. Bartoe

Vesuvius McDanel

510 Ninth Avenue

Box 560

Beaver Falls PA 15010-0560

David L. Baty

Babcock \& Wilcox - LRC

P.0. Box 11165

Lynchburg VA 24506-1165

Donald F. Baxter, Jr.

ASM International

Advanced Materials \& Processes

Materials Park OH 44073-0002

M. Brad Beardsley

Caterpillar Inc.

Technical Center Bldg. E

P.0. Box 1875

Peoria IL 61656-1875

John C. Bell

Shell Research Limited

Thornton Research Centre

P.0. Box 1

Chester $\mathrm{CH} 13 \mathrm{SH}$

ENGLAND

M. Bentele

Xamag, Inc.

259 Melville Avenue

Fairfield CT 06430

Larry D. Bentsen

BFGoodrich Company

R\&D Center

9921 Brecksville Road

Brecksville OH 44141

Joseph C. Bentz

Enceratec, Inc.

810 Brown Street

Columbus IN 47201 
Louis Beregszazi

Defiance Precision Products

P.0. Drawer 428

Defiance $\mathrm{OH} 43512$

Tom Bernecki

Northwestern University

1801 Maple Avenue

Evanston IL 60201-3135

Charles F. Bersch

Institute for Defense Analyses

$1801 \mathrm{~N}$. Beauregard Street,

Alexandria VA 22311

Ram Bhatt

NASA Lewis Research Center

21000 Brookpark Road

$\mathrm{Clevel}$ and $\mathrm{OH} 44135$

Deane I. Biehler

Caterpillar Inc.

Engineering Research Materials

P.0. Box 1875 , B1dg. E

Peoria IL 61656-1875

John W. Bjerklie

Consolidated Natural Gas Service

Co. Inc.

Research Department

Pittsburgh PA 15222-3199

William D. Bjorndahl

TRW, Inc.

One Space Park, MS:R6-2188

Building 01, Room 2040

Redondo Beach CA 90278

Keith A. Blakely

Advanced Refractory Technologies, Inc.

699 Hertel Avenue

Buffalo NY 14207

Edward G. Bl anchard

Netzsch Inc.

119 Pickering Way

Exton PA 19341
Bruce Boardman

Deere and Company Technical ctr. 3300 River Drive

Moline IL 61265

Russel1 Bockstedt

Hoechst Celanese Corporation

150 JFK Parkway

Short Hills NJ 07078

M. Boehmer

DLR German Aerospace Research

Estab.

Postfach 906058

D-5000 Koln 90

GERMANY

Lawrence P. Boesch

EER Systems Corp.

1593 Spring Hill Road

Vienna VA 22182-2239

Donald H. Boone

Boone \& Associates

2412 Cascade Drive

Walnut Creek CA 94598-4313

Tom Booth

AlliedSignal, Inc.

AiResearch Los Angeles Division

2525 West 190th Street

Torrance CA 90509-2960

Tibor Bornemisza

Sundstrand Power Systems

4400 Ruffin Road

San Diego CA 92186-5757

J.A.M. Boulet

University of Tennessee

Engineering Science and Mechanics

Knoxville TN 37996-2030

H. Kent Bowen

Massachusetts Institute of Technology

77 Massachusetts Ave., Rm E40-434

Cambridge MA 02139 
Leslie J. Bowen

Materials Systems

53 Hillcrest Road

Concord MA 01742

Steven C. Boyce

Air Force Office of Scientific

Research

AFOSR/NA B1dg. 410

Bolling AFB DC 20332-6448

Gary L. Boyd

Ceramic Engineering Consulting

328 Sneath Way

Alpine CA 91901

Steve Bradley

UOP Research Center

50 E. Algonquin Road

Des Plaines IL 60017-6187

Michael C. Brands

Cummins Engine Company, Inc.

P.0. Box 3005, Mail Code 50179

Columbus IN 47201

Raymond J. Bratton

Westinghouse Science \& Technology

1310 Beulah Road

Pittsburgh PA 15235

John J. Brennan

United Technologies Corporation

Silver Lane, MS:24

East Hartford CT 06108

Jeff D. Bright

Ceramatec, Inc.

2425 South 900 West

Salt Lake City UT 84108

Terrence K. Brog

Golden Technologies Company

4545 Mc Intyre Street

Golden CO 80403

Gunnar Broman

317 Fairlane Drive

Spartanburg SC 29302
Al Brown

High-Tech Materials Alert

P.0. Box 882

Dayton NJ 08810

Jesse J. Brown

VPI \& SU

Ctr. for Advanced Ceram Materials

B1acksburg VA 24061-0256

Sherman D. Brown

University of Illinois

Materials Science and Engineering 105 South Goodwin Avenue

Urbana IL 6180]

S. L. Bruner

Ceramatec, Inc.

2425 South 900 West

Salt Lake City UT 84119

Walter Bryzik

U.S. Army Tank Automotive Command R\&D Center, Propulsion Systems

Warren MI 48397-5000

S. J. Burden

2572 Devonwood

Troy MI 48098

Curt V. Burkl and

AMERCOM, Inc.

8928 Fullbright Avenue

Chatsworth CA 91311

Bill Bustamante

AMERCOM, Inc.

8928 Fullbright Avenue

Chatsworth CA 91311

Oral Buyukozturk

Massachusetts Institute of Technology

77 Massachusetts Ave., Room 1-280

Cambridge MA 02139

David A. Caillet

Ethyl Corporation

451 Florida Street

Baton Rouge La 70801 
Frederick J. Calnan

Heany Industries, Inc.

249 Briarwood Lane

Scottsville NY 14546

Roger Cannon

Rutgers University

P.0. Box 909

Piscataway NJ 08855-0909

Scott Cannon

P.0. Box 567254

Atlanta GA 30356

Harry W. Carpenter

1844 Fuerte Street

Fallbrook CA 92028

David Carruthers

Kyocera Industrial Ceramics Company

P.0. Box 2279

Vancouver WA 98668-2279

Calvin H. Carter, Jr. Cree Research, Inc. 2810 Meridian Parkway

Durham NC 27713

J. David Casey

35 Atlant is Street

West Roxbury MA 02132

Jere G. Castor

J. C. Enterprise

5078 N. 83rd Street

Scottsdale AZ 85250

James D. Cawley

Case Western Reserve University

Materials Science \& Engineering

Cleveland $\mathrm{OH} 44106$

Thomas C. Chadwick

Den-Mat Corporation

P.0. Box 1729

Santa Maria CA 93456
Ronald H. Chand

Chand Kare Technical Ceramics

2 Coppage Drive

Worcester MA 01603

Robert E. Chaney

EG\&G Idaho, Inc.

Idaho National Engineering Lab

P.0. Box 1625

Idaho Falls ID 83415-3525

Frank C. Chang

U.S. Army Materials Technology

AMTL-EMM

405 Arsenal Street

Watertown MA 02172

Nam S. Chang

Chrysler Corporation

12000 Chrysler Drive

Highland Park MI 48288-0001

Robert M. Chapman

AlliedSignal Aerospace Company

1001 Pennsylvania Avenue, N.W.

Suite 700 South

Washington DC 20004

William Chapman

Williams International Corp.

2280 W. Maple Road

Walled Lake MI 48390-0200

Ching-Fong Chen

LECO Corporation

3000 Lakeview Avenue

St. Joseph MI 49085

Frank Childs

EG\&G Idaho, Inc.

Idaho National Engineering Lab

P.0. Box 1625

Idaho Falls ID 83415-3527

William J. Chmura

Torrington Company

59 Field Street

Torrington CT 06790-4942 
Tsu-Wei Chou

University of Delaware

201 Spencer Laboratory

Newark DE 19716

R. J. Christopher

Ricardo Consulting Engineers

Bridge Works

Shoreham-By-Sea W. Sussex BN435FG ENGLAND

Joel P. Clark

Massachusetts Institute of

Technology

Room 8-409

Cambridge MA 02139

Giorgio Clarotti

Commission of the European Comm

DGXII-C3, M075, 1-53;

200 Rue de la Loi

B-1049 Brussels

BELGIUM

W. J. Clegg

ICI Advanced Materials

P.0. Box 11, The Heath

Runcorn Cheshire WA7 4QE

ENGLAND

Joseph Cleveland

GTE Products Corporation

Hawes Street

Towanda PA 18848-0504

Gloria M. Collins

ASTM

1916 Race Street

Philadelphia PA 19103

William C. Connors

Sundstrand Aviation Operations

Materials Science \& Engineering

4747 Harrison Avenue

Rockford IL 61125-7002

John A. Coppola

Carborundum Company

Niagara Falls R\&D Center

P.0. Box 832

Niagara Falls NY 14302
Normand D. Corbin

Norton Company

Advanced Ceramics

Goddard Road

Northboro MA 01532-1545

Douglas Corey

AlliedSignal, Inc.

2525 West 190th Street, MS:T52

Torrance CA 90504-6099

Keith P. Costello

Chand/Kare Technical Ceramics

2 Coppage Drive

Worcester MA 01603-1252

Ed L. Courtright

Pacific Northwest Laboratory

MS :K3-59

Richland WA 99352

Anna Cox

Mitchel1 Market Reports

P.0. Box 23

Monmouth Gwent NP5 4YG

UNITED KINGDOM

J. Hesley Cox

BIRL

1801 Maple Avenue

Evanston IL 60201-3135

Art Cozens

Instron Corporation

3414 Snowden Avenue

Long Beach CA 90808

Mark Crawford

New Technology Week

4604 Monterey Drive

Annandale VA 22003

Richard A. Cree

Markets \& Products, Inc.

P.0. Box 14328

Columbus $\mathrm{OH}$ 43214-0328

Les Crittenden

Vesuvius McDanel

Box 560

Beaver Falls PA 15010 
William J. Croft

U.S. Army Materials Technology

405 Arsenal Street

Watertown MA 02172

M. J. Cronin

Mechanical Technology, Inc.

968 Albany-Shaker Road

Latham NY 12110

Gary M. Crosbie

Ford Motor Company

1430 Culver Avenue

S-2079, SRL Building

Dearborn MI 48121-4036

Floyd W. Crouse, Jr.

U.S. Department of Energy

Morgantown Energy Technology Ctr P.0. Box 880

Morgantown WV 26505

John Cuccio

AlliedSignal Engines

P. 0. Box 52180, MS: $1302-2 Q$

Phoenix AZ 85072-2180

Raymond A. Cutler

Ceramatec, Inc.

2425 South 900 West

Salt Lake City UT 84119

Stephen C. Danforth

Rutgers University

P.0. Box 909

Piscataway NJ 08855-0909

Sankar Das Gupta

Electrofuel Manufacturing Co.

9 Hanna Avenue

Toronto Ontario MGK-1W8

CANADA

Frank Davis

AlliedSignal Aerospace Company

7550 Lucerne Drive, \#203

Middleburg Heights $\mathrm{OH} 44130$
Robert F. Davis

North Carolina State University

Materials Engineering Department

P.0. Box 7907

Raleigh NC 27695

Thomas DeAngel is

Carborundum Company

Niagara Falls R\&D Center

P.0. Box 832

Niagara Falls NY 14302

George DeBell

Ford Motor Company

Material Systems Reliability

P.0. Box 2053, Room S-2023

Dearborn, MI 48121-2053

Michael DeLuca

RSA Research Group

1534 Claas Ave.

Holbrook NY 11741

Gerald L. DePoorter

Colorado School of Mines

Metallurgical \& Materials Engr

Golden CO 80401

J. F. DeRidder

Omni Electro Motive, Inc.

12 Seely Hill Road

Newfield NY 14867

Nick C. Dellow

Materials Technology Publications

40 Sotheron Road

Watford Herts WD1 2QA

UNITED KINGDOM

L. R. Dharani

University of Missouri-Rolla

224 M.E.

Rolla MO 65401

Douglas A. Dickerson

Union Carbide Specialty Powders

1555 Main Street

Indianapol is IN 46224 
John Dodsworth

Vesuvius Research \& Development

Technical Ceramics Group

Box 560

Beaver Falls PA 15010

\section{B. Dogan \\ Institut fur Werkstofforschung \\ GKSS-Forschungszentrum Geesthacht \\ Max-Planck-Strasse \\ D-2054 Geesthacht \\ GERMANY \\ Jean-Marie Drapier \\ FN Moteurs S.A. \\ Material and Processing \\ B-4041 Milmort (Herstal) \\ BELGIUM}

Kenneth C. Dreitlein

United Technologies Research Ctr

Silver Lane

East Hartford CT 06108

Robin A.L. Drew

McGill University

3450 University Street

Montreal Quebec H3A 2A7

CANADA

Winston H. Duckworth

$\mathrm{BCL}$

Columbus Division

505 riing Avenue

Columblis $\mathrm{OH}$ 43201-2693

Bill Durako

Sundstrand Aviation Operations

P.0. Box 7002

Rockford IL 61125-7002

Ernest J. Duwell

3M Abrasive Systems Division

3M Center

St. Paul MN 55144-1000

Chuck J. Dziedzic

Coors Ceramics Company

17750 West 32nd Avenue

Golden CO 80401
Robert J. Eagan

Sandia National Laboratories

Engineered Materials \& Processes P.0. Box 5800

Albuquerque NM 87185-5800

Jeffrey Eagleson

Lanxide Corporation

1001 Connecticut Avenue, N.W.

Washington DC 20036

Harry E. Eaton

United Technologies Corporation

Silver Lane

East Hartford CT 06108

Harvil1 C. Eaton

Louisiana State University

240 Thomas Boyd Hall

Baton Rouge LA 70803

Christopher A. Ebel

Carborundum Company

Technology Division

P.0. Box 832

Niagara Falls NY 14302-0832

J. J. Eberhardt

U.S. Department of Energy

Office of Transportation Matrl's

CE-34, Forrestal Building

Washington DC 20585

Jim Edler

Eaton Corporation

26201 Northwestern Highway

P.0. Box 766

Southfield MI 48037

G. A. Eisman

Dow Chemical Company

Ceramics and Advanced Materials

52 Building

Midl and MI 48667

William A. Ellingson

Argonne National Laboratory

Energy Technology Division

$9700 \mathrm{~S}$. Cass Avenue

Argonne IL 60439 
William S. Ellis Machined Ceramics 629 N. Graham Street Bowling Green KY 42101

Glen B. Engle

Nuclear \& Aerospace Materials 16716 Martincoit Road

Poway CA 92064

Jeff Epstein

Carimic Technologies, Inc. 12739 Ashford Knoll

Houston TX 77082

Kenneth A. Epstein

Dow Chemical Company

2030 Building

Midland MI 48674

Art Erdemir

Argonne National Laboratory

9700 S. Cass Avenue

Argonne IL 60439

E. M. Erwin

Lubrizol Corporation

1819 East 225th Street

Euclid $\mathrm{OH} 44117$

John N. Eustis

U.S. Department of Energy

Industrial Energy Efficiency Div CE-221, Forrestal Building

Washington DC 20585

W. L. Everitt

Kyocera International, Inc.

8611 Balboa Avenue

San Diego CA 92123

Gordon Q. Evison

332 S. Michigan Avenue

Suite 1730

Chicago IL 60604

John W. Fairbanks

U.S. Department of Energy

Office of Propulsion Systems

CE-322, Forrestal Building

Washington DC 20595
Tim Fawcett

Dow Chemical Company

Advanced Ceramics Laboratory

1776 Building

Midland MI 48674

Robert H. Fawley

Sundstrand Power Systems

Div. of Sundstrand Corporation

P.0. Box 85757

San Diego CA 92186-5757

John J. Fedorchak

GTE Products Corporation

Hawes Street

Towanda PA 18848-0504

Jeff T. Fenton

Vista Chemical Company

900 Threadneedle

Houston TX 77079

Larry Ferrel1

Babcock \& Wilcox

01d Forest Road

Lynchburg VA 24505

Raymond R. Fessler

BIRL

1801 Maple Avenue

Evanston IL 60201

Ross F. Firestone

Ross Firestone Company

188 Mary Street

Winnetka IL 60093-1520

Sharon L. Fletcher

Arthur D. Little, Inc.

15 Acorn Park

Cambridge MA 02140-2390

Thomas F. Foltz

Textron Specialty Materials

2 Industrial Avenue

Lowel1 MA 01851

Renee G. Ford

Materials and Processing Report

P.0. Box 72

Harrison NY 10528 
John Formica

Supermaterials

2020 Lakeside Avenue

Cleveland $\mathrm{OH} 44114$

Edwin Frame

Southwest Research Institute

P.0. Drawer 28510

San Antonio TX 78284

Armanet Francois

French Scientific Mission

4101 Reservoir Road, N.W.

Washington DC 20007-2176

R. G. Frank

Technology Assessment Group 10793 Bentley Pass Lane

Lovel and $\mathrm{OH} 45140$

David J. Franus

Forecast International

22 Commerce Road

Newtown CT 06470

Marc R. Freedman

NASA Lewis Research Center

21000 Brookpark Road, MS:49-3

Cleveland $\mathrm{OH} 44135$

Douglas Freitag

LTV Missiles Division

P.0. Box 650003, MS:WT-21

Dallas TX 75265

Brian R.T. Frost

Argonne National Laboratory

9700 S. Cass Avenue, B1dg. 900

Argonne IL 60439

Lawrence R. Frost

Instron Corporation

100 Royall Street

Canton MA 02021

George A. Fryburg

Norton/TRW Ceramics

7A-4 Raymond Avenue

Salem NH 03079
Xiren $\mathrm{Fu}$

Shanghai Instituie of Ceramics

1295 Ding-xi Road

Shanghat 200050

CHINA

J. P. Gallagicien

University of Dayton Research

Institute

300 College Park, JPC-250

Dayton $\mathrm{OH}$ 45469-0120

Garry Garvey

Golden Technologies Company Inc.

4545 McIntyre Street

Golden CO 80403

Joy A. Garwood

Norton Company

Advanced Ceramics

Goddard Road

Northboro MA 01532-1545

Richard Gates

NIST

Materials Bldg., A-256

Gaithersburg MD 20899

L. J. Gauckler

ETH-Zurich

Sonneggstrasse 5

CH-8092 Zurich 8092

SWITZERLAND

George E. Gazza

U.S. Army Materials Technology

Ceramics Research Division

405 Arsenal Street

Watertown MA 02172-0001

D. Gerster

CEA-DCOM

33 Rue De La Federation

Paris 75015

FRANCE

John Ghinazzi

Coors Technical Ceramics Company 1100 Commerce Park Drive

Oak Ridge TN 37830 
Robert Giddings

General Electric Company

P. 0. Box 8

Schenectady NY 12301

\section{A. M. Glaeser University of California Lawrence Berkeley Laboratory Hearst Mining Building Berkeley CA 94720}

Joseph W. Glatz

Naval Air Propulsion Center Systems Engineering Division P.0. Box 7176, PE24

Trenton NJ 08628

W. M. Goldberger

Superior Graphite Company R\&D

2175 E. Broad Street

Columbus $\mathrm{OH} 43209$

Allan E. Goldman U.S. Graphite, Inc. 907 W. Outer Drive

Oak Ridge TN 37830

Stephen T. Gonczy

Allied Signal Research

P.0. Box 5016

Des Plaines IL 60017

Jeffrey M. Gonzales

GTE Products Corporation

Hawes Street

Towanda PA 18848-0504

Robert J. Gottschall

U.S. Department of Energy

ER-131, MS:G-236

Washington DC 20545

Earl Graham

Cleveland State University

Dept. of Chemical Engineering

Euclid Avenue at East 24th Street

Cleveland $\mathrm{OH} 44115$
John W. Graham

Astro Met, Inc.

9974 Springfield Pike

Cincinnati $\mathrm{OH} \mathbf{4 5 2 1 5}$

G. A. Graves

$U$. of Dayton Research Institute

300 College Park

Dayton $\mathrm{OH}$ 45469-0001

Robert E. Green, Jr.

Johns Hopkins University

Materials Science and Engineering

Baltimore MD 21218

Alex A. Greiner

P1int \& Partners

Oaklands Park

Wokingham Berkshire RG11 2FD

UNITED KINGDOM

Lance Groseclose

General Motors Corporation

Allison Gas Turbine Division

P.0. Box 420, MS:W-5

Indianapolis IN 46206

Thomas J. Gross

U.S. Department of Energy

Transportation Technologies

CE-30, Forrestal Building

Washington DC 20585

Mark F. Gruninger

Union Carbide Corporation

Specialty Powder Business

1555 Main Street

Indianapolis IN 46224

Ernst Guge 1

Cremer Forschungs inst itut

GmbH\&CO.KG

Deslauer Strasse 35

D-8633 Roedental 8633

GERMANY

Donald L. Guile

Corning Glass Works

SP-DV-1-9

Corning NY 14831 
John P. Gyekenyesi

NASA Lewis Research Center

21000 Brookpark Road, MS:6-1

Cleveland $\mathrm{OH} 44135$

Nabil S. Hakim

Detroit Diese1 Corporation

13400 Outer Drive West

Detroit MI 4823s

Philip J. Haley

General Motors Corporation

P.0. Box 420, MS:T12A

Indianapol is IN 46236

Judith Hall

Fiber Materials, Inc.

Biddeford Industrial Park

5 Morin Street

Biddeford ME 04005

Y. Hamano

Kyocera Industrial Ceramics Corp.

5713 E. Fourth Plain Blvd.

Vancouver WA 98661-6857

Y. Harada

IIT Research Institute

10 West 35th Street

Chicago IL 60616

R. A. Harmon

25 Schalren Drive

Latham NY 12110

Norman H. Harris

Hughes Aircraft Company

P.0. Box 800520

Saugus CA $91380-0520$

Alan M. Hart

Dow Chemical Company

1776 Building

Midland MI 48674

Pat E. Hart

Battelle Pacific Northwest Labs

Ceramics and Polymers Development

P.0. Box 999

Richland WA 99352
Stephen D. Hartline

Norton Company

Advanced Ceramics

Goddard Road

Northboro MA 01532-1545

Michael H. Haselkorn

Caterpillar Inc.

Technical Center, Building $E$

P.0. Box 1875

Peoria IL 61656-1875

N. B. Havewala

Corning Inc.

SP-PR-11

Corning NY 14831

John Haygarth

Teledyne WAA Chang Albany

P.0. Box 460

Albany OR 97321

Norman L. Hecht

$U$. of Dayton Research Institute 300 College Park

Dayton $\mathrm{OH}$ 45469-0172

Peter W. Heitman

General Motors Corporation

P.0. Box 420, MS:W-5

Indianapol is IN 46206-0420

Robert W. Hendricks

VPI \& SU

210 Holden Hall

B1acksburg VA 24061-0237

Wynne Henley

Hertel Cutting Technologies Inc.

1000 Clearview Court

Oak Ridge TN 37830

Thomas L. Henson

GTE Products Corporation

Chemical \& Metallurgical Division

Hawes Street

Towanda PA 18848 
Thomas P. Herbell

NASA Lewis Research Center

21000 Brookpark Road, MS:49-3

Cleveland $\mathrm{OH} 44135$

Marlene Heroux

Rolls-Royce, Inc.

2849 Paces Ferry Road, Suite 450

Atlanta GA 30339-3769

Robert L. Hershey

Science Management Corporation

1255 New Hampshire Ave., N.W.

Suite 1033

Washington DC 20036

Hendrik Heystek

Bureau of Mines

Tuscaloosa Research Center

P.0. Box L

University $\mathrm{AL} 35486$

Robert V. Hillery

GE Aircraft Engines

One Neumann Way, M.D. 485

Cincinnati $\mathrm{OH} 45215$

Arthur Hindman

Instron Corporation

100 Royall Street

Canton MA 02021

Hans Erich Hintermann

CSEM

Rue Breguet 2

Neuchatel 2000

SWITZERLAND

Shinichi Hirano

Mazda R\&D of North America, Inc. 1203 Woodridge Avenue

Ann Arbor MI 48105

Tommy Hiraoka

NGK Locke, Inc.

1000 Town Center

Southfield MI 48075
Fu H. Ho

General Atomics

P.0. Box 85608

San Diego CA 92186-9784

John M. Hobday

U.S. Department of Energy

Morgantown Energy Technology Ctr

P.0. Box 880

Morgantown WV 26507

Clarence Hoenig

Lawrence Livermore National Lab

P.0. Box 808, Mail Code L-369

Livermore CA 94550

Thomas Hollstein

Fraunhofer-Institut fur

Werkstoffmechanik

Wohlerstrabe 11

79108 Freiburg

GERMANY

Richard Holt

National Research Council Canada

Structures and Materials Lab

Ottawa Ontario KIA OR6

CANADA

Michael Horgan

Materials Engineering Magazine

1100 Superior Avenue

$\mathrm{Clevel}$ and $\mathrm{OH} 44114$

Woodie Howe

Coors Technical Ceramics Company

1100 Commerce Park Drive

Oak Ridge TN 37830

Stephen M. Hsu

NIST

Gaithersburg MD 20899

Hann S. Huang

Argonne National Laboratory

9700 S. Cass Avenue

Argonne IL 60439-4815 
Gene Huber

Precision Ferrites \& Ceramics

5576 Corporate Drive

Cypress CA 90630

Harold A. Huckins

Princeton Advanced Technology

4 Bertram Place

Hilton Head SC 29928

Fred R. Huettic

Advanced Magnetics Inc.

45 Corey Lane

Mendham NJ 07945

Brian K. Humphrey

Lubrizol Petroleum Chemicals Co.

3000 Town Center, Suite 1340

Southfield MI 48075-1201

Robert M. Humrick

Dylon Ceramic Technologies

3100 Edgehill Road

Cleveland Heights $\mathrm{OH} \mathbf{4 4 1 1 8}$

Lorretta Inglehart

National Science Foundation

Division of Materials Research

1800 "G" Street, N.W., Room 408

Washington DC 20550

Michael S. Inoue

Kyocera International, Inc.

8611 Balboa Avenue

San Diego CA 92123-1580

Joseph C. Jackson

U.S. Advanced Ceramics Assoc.

1600 Wilson Blvd., Suite 1008

Arlington VA 22209

Osama Jadaan

U. of Wiscons in-Platteville

1 University Plaza

Platteville WI 53818

Said Jahanmir

NIST

Materials B1dg., Room A-237

Gaithersburg MD 20899
Curtis A. Johnson

General Electric Company

P.0. Box 8

Schenectady NY 12301

Sylvia Johnson

SRI International

333 Ravenswood Avenue

Menlo Park CA 94025

Thomas A. Johnson

Lanxide Corporation

P.0. Box 6077

Newark DE 19714-6077

W. S. Johnson

Indiana University

One City Centre, Suite 200

Bloomington IN 47405

Walter F. Jones

Air Force Office of Scientific

Research

Bolling Air Force Base

Washington DC 20332-6448

Jill E. Jonkouski

U.S. Department of Energy

9800 S. Cass Avenue

Argonne IL 60439-4899

L. A. Joo

Great Lakes Research Corporation

P.0. Box 1031

Elizabethton TN 37643

A. David Joseph

SPX Corporation

700 Terrace Point

Muskegon MI 49443

Adam Jostsons

Australian Nuclear Science \&

Technology

New Illawarra Road

Lucas Heights New South Wales

AUSTRALIA 
Matthew K. Juneau Ethyl Corporation 451 Florida Street Baton Rouge LA 70801

Hartmut Kainer Didier-Werke AG

Anlagentechnik Wiesbaden D-62 Wiesbaden GERMANY

Tom Kalamasz Norton/TRW Ceramics 7A-4 Raymond Avenue Salem NH 03079

Lyle R. Kallenbach Phillips Petroleum Mail Drop:123AL

Bartlesville OK 74004

Nick Kamiya

Kyocera Industrial Ceramics Corp. 25 Northwest Point Blvd., \#450

Elk Grove Village IL 60007

Roy Kamo

Adiabatics, Inc.

3385 Commerce Park Drive

Columbus IN 47201

Chih-Chun Kao

Industrial Technology Research Institute

195 Chung-Hsing Road, Sec. 4 Chutung Hsinchu 31015 R.O.C.

TAIWAN

Keith R. Karasek

AlliedSignal Aerospace Company

$50 \mathrm{E}$. Algonquin Road

Des Plaines IL 60017-5016

Martha R. Kass

U.S. Department of Energy

Oak Ridge Operations

Building 4500N, MS: 6269

Oak Ridge TN 37831-6269
Robert E. Kasse1

Ceradyne, Inc.

3169 Redhill Avenue

Costa Mesa CA 92626

All an Katz

Wright Laboratory

Metals and Ceramics Division

Wright-Patterson AFB OH 45433

R. Nathan Katz

Worcester Polytechnic Institute

100 Institute Road

Worcester MA 01609

Tony Kaushal

Detroit Diesel Corporation

13400 Outer Drive, West

Detroit MI 48239-4001

Ted Kawaguchi

Tokaf Carbon America, Inc.

375 Park Avenue, Suite 3802

New York NY 10152

Noritsugu Kawashima

TOSHIBA Corporation

4-1 Uki shima-Cho

Kawasaki-Ku Kawasaki 210

JAPAN

Lisa Kempfer

Penton Publishing

1100 Superior Avenue

Clevel and $\mathrm{OH}$ 44114-2543

Frederick L. Kennard, III

AC Rochester

1300 N. Dort Highway

Flint MI 48556

David 0. Kennedy

Lester B. Knight Cast Metals Inc.

549 W. Randolph Street

Chicago IL 60661

George Keros

Photon Physics

3175 Penobscot Building

Detroit MI 48226 
Pramod K. Khandelwal

General Motors Corporation Allison Gas Turbine Division P.0. Box 420, MS:W05 Indianapol is IN 46206

Jim R. Kidwell

AlliedSignal Engines

P.0. Box 52180

Phoenix AZ 85072-2180

Shin Kim

Korea Institute of Machinery \& Metals

66 Sangnam-dong, Changwon

Kyungnam 641-010

KOREA

W. C. King

Mack Truck, Z-41

1999 Pennsylvania Avneue

Hagerstown MD 21740

Carol Kirkpatrick

MSE, Inc.

P.0. Box 3767

Butte MT 59702

Tony Kirn

Caterpillar Inc.

Defense Products Department, JB7

Peoria IL 61629

James D. Kiser

NASA Lewis Research Center

21000 Brookpark Road, MS:49-3

Clevel and $\mathrm{OH} 44135$

Max Klein

900 24th Street, N.W., Unit G

Washington DC 20037

Richard N. Kleiner

Golden Technologies Company

4545 McIntyre Street

Golden $\mathrm{CO} 80403$

Stanley J. Klima

NASA Lewis Research Center

21000 Brookpark Road, MS:6-1

$\mathrm{Clevel}$ and $\mathrm{OH} 44135$
Albert S. Kobayashi

University of Washington

Mechanical Engineering Department

Mat1 Stop:FU10

Seattle WA 98195

Shigeki Kobayashi

Toyota Central Research Labs

Nagakute Aichi 480-11

JAPAN

Richard A. Kole

Z-Tech Corporation

8 Dow Road

Bow NH 03304

E. Kostiner

University of Connecticut

Chemistry Department, U-60

Storrs CT 06269-2060

Joseph A. Kovach

Eaton Corporation

32500 Chardon Road

Willoughby Hills OH 44094

Kenneth A. Kovaly

Technical Insights Inc.

P.0. Box 1304

Fort Lee NJ 07024-9967

Ralph G. Kraft

Spraying Systems Company

North Avenue at Schmale Road

Wheaton IL 60189-7900

Arthur Kranish

Trends Publishing Inc.

1079 National Press Building Washington DC 20045

A. S. Krieger

Radiation Science, Inc.

P.0. Box 293

Belmont MA 02178 
Pleter Krijgsman

Ceramic Design International

Holding B.V.

P.0. Box 68

Hattem 8050-AB

THE NETHERLANDS

Waltraud M. Kriven

University of 111 inots

105 S. Goodwin Avenue

Urbana IL 61801

Edward J. Kube1, Jr.

ASM International

Advanced Materials \& Processes

Materials Park OH 44073

Dave Kupperman

Argonne National Laboratory

9700 S. Cass Avenue

Argonne IL 60439

Oh-Hun Kwon

North Company

Advanced Ceramics

Goddard Road

Northboro MA 01532-1545

W. J. Lackey

GTRI

Materials Science and Tech. Lab

Atlanta GA 30332

Jai Lala

Tenmat Ltd.

40 Somers Road

Rugby Warwickshire CV22 7DH

ENGLAND

Hari S. Lamba

General Motors Corporation

9301 West 55th Street

LaGrange. IL 60525

Richard L. Landingham

Lawrence Livermore National Lab

P.0. Box 808, L-369

Livermore CA 94550
James Lankford

Southwest Research Institute

6220 Culebra Road

San Antonio TX 78228-0510

Stanley B. Lasday

Business News Publishing Co.

1910 Cochran Road, Suite 630

Pittsburgh PA 15220

S. K. Lau

Carborundum Company

Technology Division

P.0. Box 832, B-100

Niagara Falls NY 14302

Edward A. Lauder

Advanced Composite Materials Corp

1525 S. Buncombe Road

Greer SC 29651-9208

J. Lawrence Lauderdale

Babcock \& Wilcox

1850 "K" Street, Suite 950

Washington DC 20006

Jean F. LeCostaouec

Textron Specialty Materials

2 Industrial Avenue

Lowel1 MA 01851

Benson P. Lee

Interscience, Inc.

9718 Lake Shore Boulevard

Cleveland $\mathrm{OH} 44108$

Burtrand I. Lee

Clemson University

01 in $\mathrm{Hall}$

Clemson SC 29634-0907

June-Gunn Lee

KIST

P.0. Box 131, Cheong-Ryang

Seoul 130-650

KOREA 
Ran-Rong Lee

Ceramics Process Systems

Corporation

155 Fortune Boulevard

Mildford MA 01757

Stan Levine

NASA Lewis Research Center

21000 Brookpark Road, MS:49-3

Cleveland $\mathrm{OH} 44135$

Ai-Kang Li

Materials Research Labs., ITRI

195-5 Chung-Hsing Road, Sec. 4

Chutung Hsinchu 31015 R.O.C.

TAIWAN

Winston W. Liang

Hong Kong Industrial Technology Centre

78 Tat Chee Avenue

4/F, HKPC Building -- Kowloon

HONG KONG

Robert Licht

Norton Company

Advanced Ceramics

Goddard Road

Northboro MA 01532-1545

E. Lilley

Norton Company

Advanced Ceramics

Goddard Road

Northboro MA 01532-1545

Chih-Kuang Lin

National Central University

Dept. of Mechanical Engineering

Chung-Li 32054

TAIWAN

Laura J. Lindberg

AlliedSignal Aerospace Company

Garrett Fluid Systems Division

P.0. Box 22200

Tempe AZ 85284-2200
Hans A. Lindner

Cremer Forschungsinstitut

GmbH\&Co.KG

Oeslauer Strasse 35

D-8633 Rodental 8866

GERMANY

Ronald E. Loehman

Sandia National Laboratories

Chemistry \& Ceramics Dept. 1840

P.0. Box 5800

Albuquerque NM 87185

Jeffrey C. Logas

Winona State University

115 Pasteur Hall

Winona MN 55987

Bill Long

Babcock \& Wilcox

P.0. Box 11165

Lynchburg VA 24506

L. A. Lott

EG\&G Idaho, Inc.

Idaho National Engineering Lab

P.0. Box 1625

Idaho Falls ID 83415-2209

Raouf 0. Loutfy

MER Corporation

7960 S. Kolb Road

Tucson AZ 85706

Gordon R. Love

Aluminum Company of America

Alcoa Technical Center

Alcoa Center PA 15960

Lydia Luckevich

Ortech International

2395 Speakman Drive

Mississauga Ontario L5K 183

CANADA

James W. MacBeth

Carborundum Company

Structural Ceramics Division

P.0. Box 1054

Niagara Falls NY 14302 
H. MacLaren

General Electric Company

1000 Western Avenue

Lynn MA 01910

George Maczura

Aluminum Company of America

3450 Park Lane Drive

Pittsburgh PA 15275-1119

David Maginnis

Tinker AFB

OC-ALC/LIIRE

Tinker AFB OK 73145-5989

Frank Maginnis

Aspen Research, Inc.

220 Industrial Boulevard

Moore OK 73160

Tai-il Mah

Universal Energy Systems, Inc.

4401 Dayton-Xenia Road

Dayton $\mathrm{OH} .45432$

Kenneth M. Maillar

Barbour Stockwell Company

83 Linskey Way

Cambridge MA 02142

S. G. Malghan

NIST

I-270 \& Clopper Road

Gaithersburg MD 20899

Lars Malmrup

United Turbine $A B$

Box 13027

Malmo S-200 44

SWEDEN

John Mangels

Ceradyne, Inc.

3169 Redhill Avenue

Costa Mesa CA 92626

Murli Manghnani

University of Hawaii

2525 Correa Road

Honolulu HI 96822
Russe11 V. Mann

Matec Applied Sciences, Inc.

75 South Street

Hopkinton MA 01748

William R. Manning

Champion Aviation Products Div

P.0. Box 686

Liberty SC 29657

Ken Marnoch

Amercom, Inc.

8928 Fuilbright Avenue

Chatsworth CA 91311

Robert A. Marra

Aluminum Company of America

Alcoa Technical Center

Alcoa Center PA 15069

Chauncey L. Martin

3M Company

3M Center, Building $\cdot 60-1 N-01$

St. Paul MN 55144

Steve C. Martin

Advanced Rerilactory Technologies

699 Hertel Avenue

Buffalo NY 14207

Kelly J. Mather

William International Corporation

2280 W. Maple Road

Walled Lake MI 48088

James P. Mathers

3M Company

3M Center, B1dg. 201-3N-06

St. Paut MN 55144

Ron Mayville

Arthur D. Little, Inc.

15-163 Acorn Park

Cambridge MA 02140

F. N. Mazadarany

General Electric Company

Bldg. K-1, Room MB-159

P.0. Box 8

Schenectady NY 12301 
James W. McCauley

Alfred University

Binns-Merrill $\mathrm{Hall}$

Alfred NY 14802

Louis R. McCreight

2763 San Ramon Drive

Rancho Palos Verdes CA 90274

Col in F. McDonald

McDonald Thermal Engineering

1730 Castellana Road

La Jolla CA 92037

B. J. McEntire

Norton Advanced Ceramics

10 Airport Park Road

East Granby CT 06026

Chuck McFadden

Coors Ceramics Company

600 9th Street

Golden CO 80401

Thomas D. McGee

Iowa State University

110 Engineering Annex

Ames IA 50011

Carol McGill

Corning Inc.

Sullivan Park, FR-02-08

Corning NY 14831

James McLaughl in

Sundstrand Power Systems

4400 Ruffin Road

P.0. Box 85757

San Diego CA 92186-5757

Matt McMonigle

U.S. Department of Energy

Improved Energy Productivity

CE-231, Forrestal Building

Washington DC 20585

J. C. McVickers

AlliedSignal Engines

P.0. Box 52180, MS:9317-2

Phoenix AZ 85072-2180
D. B. Meadowcroft

"Jura," The Ridgeway

oxshott

Leatherhead Surrey KT22 OLG

UNITED KINGDOM

Joseph J. Meind 1

Reynolds International, Inc.

6603 W. Broad Street

P.0. Box 27002

Richmond VA 23261-7003

Michael D. Meiser

AlliedSignal, Inc.

Ceramic Components

P.0. Box 2960, MS:T21

Torrance CA 90509-2960

George Messenger

National Research Council of Canada

Building M-7

Ottawa Ontario K1A OR6

CANADA

D. Messier

U.S. Army Materials Technology

SLCMT-EMC

405 Arsenal Street

Watertown MA 02172-0001

Arthur G. Metcalfe

Arthur G. Metcalfe and

Associates, Inc.

2108 East 24 th Street

National City CA 91950

R. Metselaar

Eindhoven University

P.0. Box 513

Endhoven 5600 MB

THE NETHERLANDS

David J. Michael

Harbison-Walker Refractories Co.

P.0. Box 98037

Pittsburgh PA 15227 
Ken Michaels

Chrysler Motors Corporation

P.0. Box 1118, CIMS:418-17-09

Detroit MI 48288

Bernd Michel

Institute of Mechanics

P.0. Box 408

D-9010 Chemnitz

GERMANY

D. E. Miles

Commission of the European Comm.

rue de la Loi 200

B-1049 Brussels

BELGIUM

Carl E. Miller

AC Rochester

1300 N. Dort Highway, MS:32-31

Flint MI 48556

Charles W. Miller, Jr.

Centorr Furnaces/Vacuum

Industries

542 Amherst Street

Nashua NH 03063

R. Minimmi

Enichem America

2000 Cornwall Road

Monmouth Junction NJ 08852

Michele V. Mitchell

AlliedSignal, Inc.

Ceramic Components

P.0. Box 2960, MS:T21

Torrance CA 90509-2960

Howard Mizuhara

WESGO

477 Harbor Boulevard

Belmont CA 94002

Helen Moeller

Babcock \& Wilcox

P.0. Box 11165

Lynchburg VA 24506-1165
Francois R. Mollard

Concurrent Technologies Corp.

1450 Scalp Avenue

Johnstown PA 15904-3374

Phil Mooney

Panemetrics

221 Crescent Street

Waltham MA 02254

Geoffrey $P$. Morris

3M Company

3M Traffic Control Materials

Bldg. 209-BW-10, 3M Center

St. Pau1 MN 55144-1000

Jay A. Morrison

Rolls-Royce, Inc.

2849 Paces Ferry Road, Suite 450

Atlanta GA 30339-3769

Joel P. Moskowitz

Ceradyne, Inc.

3169 Redhill Avenue

Costa Mesa CA 92626

Brij Moudgil

University of Florida

Material Science \& Engineering

Gainesville FL $3 \check{c} 611$

Christoph J. Mueller

Sprechsaal Publishing Group

P.0. Box 2962, Mauer 2

D-8630 Coburg

GERMANY

Thomas W. Mullan

Vapor Technologies Inc.

345 Route 17 South

Upper Saddle River NJ 07458

M. K. Murthy

MkM Consultants International

10 Avoca Avenue, Unit 1906

Toronto Ontario M4T 2B7

CANADA 
David L. Mustoe

Custom Technical Ceramics

8041 West I-70 Service Rd. Unit 6 Arvada CO 80002

Curtis V. Nakaishi

U.S. Department of Energy

Morgantown Energy Technology Ctr.

P.0. Box 880

Morgantown WV 26507-0880

Yoshio Nakamura

Faicera Research Institute

3-11-12 Misono

Sagamihara, Tokyo

JAPAN

Stefan Nann

Roland Berger \& Partner GmbH

Georg-Glock-Str. 3

40474 Dusseldorf

GERMANY

K. S. Narasimhan

Hoeganaes Corporation

River Road

Riverton NJ 08077

Robert Naum

Applied Resources, Inc.

P.0. Box 241

Pittsford NY 14534

Malcolm Naylor

Cummins Engine Company, Inc.

P.0. Box 3005, Mail Code 50183

Columbus IN 47202-3005

Fred A. Nichols

Argonne National Laboratory

9700 S. Cass Avenue

Argonne IL 60439

H. Nickel

Forschungszentrum Juelich (KFA)

Postfach 1913

D-5170 Juelich

GERMANY
Dale E. Niesz

Rutgers University

Center for Ceramic Research

P.0. Box 909

Piscataway NJ 08855-0909

Paul W. Niskanen

Lanxide Corporation

P.0. Box 6077

Newark DE 19714-6077

David M. Nissley

United Technologies Corporation

Pratt \& Whitney Aircraft

400 Main Street, MS:163-10

East Hartford CT 06108

Bruce E. Novich

Ceramics Process Systems Corp.

155 Fortune Boulevard

Milford MA 01757

Daniel Oblas

50 Meadowbrook Drive

Bedford MA 01730

Don Ohanehi

Magnetic Bearings, Inc.

1908 Sussex Road

B1acksburg VA 24060

Robert Orenstein

General Electric Company

55-112, River Road

Schenectady NY 12345

Norb Osborn

Aerodyne Dallas

151 Regal Row, Suite 120

Dallas TX 75247

Richard Palicka

Cercom, Inc.

1960 Watson Way

Vista CA 92083

Muktesh Paliwal

GTE Products Corporation

Hawes Street

Towanda PA 18848 
Joseph E. Palko

General Electric Company

779 Trottingham Drive

Schenectady NY 12309

Joseph N. Panzarino

Saint-Gobain/Norton Industrial

Ceramics

Northboro Research Center

Goddard Road

Northboro MA 01532-1545

Pellegrino Papa

Corning Inc.

MP-WX-02-1

Corning NY 14831

Terry Paquet

Boride Products Inc.

2879 Aero Park Drive

Traverse City MI 49684

E. Beth Pardue

MPC

8297 Williams Ferry Road

Lenior City TN 37771

Soon C. Park

3M Company

Building 142-4N-02

P.0. Box 2963

St. Paul MN 55144

Harmut Paschke

Schott Glaswerke

Christoph-Dorner-Strasse 29

D-8300 Landshut

GERMANY

James W. Patten

Cummins Engine Company, Inc.

P.0. Box 3005, Mail Code 50183

Columbus IN 47202-3005

Robert A. Penty

Eastman Kodak Company

1669 Lake Avenue

Rochester NY 14652-5150
Robert W. Pepper

Textron Specialty Materials

2 Industrial Avenue

Lowe11 MA 01851

Peter Perdue

Detroit Diesel Corporation

13400 Outer Drive West,

Speed Code L-04

Detroit MI 48239-4001

John J. Petrovic

Los Alamos National Laboratory

Group MST-4, MS:G771

Los Alamos NM 87545

Frederick S. Pettit

University of Pittsburgh

Pittsburgh PA 15261

Ben A. Phillips

Phillips Engineering Company

721 Pleasant Street

St. Joseph MI 49085

Richard C. Phoenix

Ohmtek, Inc.

2160 Liberty Drive

Niagara Falls NY 14302

Bruce J. Pletka

Michigan Technological University

Metallurgical \& Materials Engr.

Houghton MI 49931

John P. Pollinger

AlliedSignal, Inc.

Ceramic Components

P.0. Box 2960, MS:T21

Torrance CA $90508-2960$

P. Popper

High Tech Ceramics International Journal

22 Pembroke Drive - Westlands

Newcastle-under-Lyme

Staffs ST5 2JN

ENGLAND 
F. Porz

Universitat Karlsruhe

Institut fur Keramik Im

Maschinendau

Postfach 6980

D-76128 Karlsruhe

GERMANY

Harry L. Potma

Royal Netherlands Embassy

Science and Technology

4200 Linnean Avenue, N.W.

Washington DC 20008

Bob R. Powell

North American Operations

Metallurgy Department

Box 9055

Warren MI 48090-9055

Stephen C. Pred

ICD Group, Inc.

1100 Valley Brook Avenue

Lyndhurst NJ 07071

Karl M. Prewo

United Technologies Research Ctr.

411 Silver Lane, MS:24

East Hartford CT 06108

Peter E. Price

Industrial Materials Technology

P.0. Box 9565

Andover MA 01810

Vimal K. Pujari

Norton Company

Advanced Ceramics

Goddard Road

Northboro MA 01532-1545

George Quinn

NIST

Ceramics Division, B1dg. 223

Gaithersburg MD 20899

Ramas V. Raman

Ceracon, Inc.

1101 N. Market Boulevard, Suite 9 Sacramento CA 95834
Charles F. Rapp

Owens Corning Fiberglass

2790 Columbus Road

Granville OH 43023-1200

Dennis W. Readey

Colorado School of Mines

Metallurgy and Materials Engr.

Golden CO 80401

Wilfred J. Rebello

PAR Enterprises, Inc.

12601 Clifton Hunt Lane

Clifton VA 22024

Harold Rechter

Chicago Fire Brick Company

$7531 \mathrm{~S}$. Ashl and Avenue

Chicago IL 60620

Robert R. Reeber

U.S. Army Research office

P.0. Box 12211

Research Triangle Park NC 27709

K. L. Reifsnider

VPI \& SU

Engineering Science and Mechanics

Blacksburg VA 24061

Paul E. Rempes

McDonneli Douglass Aircraft Co.

P.0. Box 516, Mail Code:0642263

St. Louis MO 63166-0516

Gopal S. Revankar

John Deere Company

3300 River Drive

Moline IL 61265

K. Y. Rhee

Rutgers University

P.0. Box 909

Piscataway NJ 08854

James Rhodes

Advanced Composite Materials Corp 1525 S. Buncombe Road

Greer SC 29651 
Roy W. Rice

W. R. Grace and Company

7379 Route 32

Columbia MD 21044

David W. Richerson

2093 E. Delmont Drive

Salt Lake City UT 84117

Tomas Richter

J. H. France Refractories

1944 Clarence Road

Snow Shoe PA 16874

Michel Rigaud

Ecole Polytechnique

Campus Universite De Montreal

P.0. Box 6079, Station A

Montrea1, P.Q. Quebec H3C $3 A 7$

CANADA

Barry Ringstrom

Superior Graphite Company

770 01d Roswell PI., Suite I-300

Roswell GA 30076-1647

John E. Ritter

University of Massachusetts

Mechanical Engineering Department

Amherst MA 01003

Frank L. Roberge

AlliedSignal Engines

P.0. Box 52180

Phoenix AZ 85072-2180

W. Eric Roberts

Advanced Ceramic Technology, Inc. 990 "F" Enterprise Street

Orange CA 92667

Y. G. Roman

TNO TPD Keramick

P.0. Box 595

Einhoven 5600 AN

HOLLAND

Michael Rossetti

Arthur D. Little, Inc.

15 Acorn Park

Cambridge MA 01240
Barry Rossing

Lanxide Corporation

P.0. Box 6077

Newark DE 19714-6077

Steven L. Rotz

Lubrizol Corporation

29400 Lakeland Boulevard

Wickliffe $\mathrm{OH} 44092$

Robert Ruh

Wright Laboratory

WL/MLLM

Wright-Patterson AFB OH 45433

Robert J. Russe11

17 Highgate Road

Framingham MA 01701

Jon A. Salem

NASA Lewis Research Center

21000 Brookpark Road

Clevel and $\mathrm{OH} 44135$

W. A. Sanders

NASA Lewis Research Center

21000 Brookpark Road, MS:49-3

Clevel and $\mathrm{OH} 44135$

J. Sankar

North Carolina A\&T State Univ.

Dept. of Mechanical Engineering

Greensboro NC 27406

Yasushi Sato

NGK Spark Plugs (U.S.A.), Inc.

1200 Business Center Drive, \#300

Mt. Prospect IL 60056

Maxine L. Savitz

AlliedSignal, Inc.

Ceramic Components

P.0. Box 2960, MS:T21

Torrance CA 90509-2960

Ashok Saxena

GTRI

Materials Engineering

At lanta GA 30332-0245 
David W. Scanlon

Instron Corporation 100 Royal1 Street

Canton MA 02021

Charles A. Schacht

Schacht Consulting Services

12 Holl and Road

Pittsburgh PA 15235

Robert E. Schafrik

National Materials Advisory Board 2101 Constitution Ave., N.W.

Washington DC 20418

James Schienle

AlliedSignal Engines

P.0. Box 52180, MS: $1302-2 P$

Phoenix AZ 85072-2180

John C. Schneider

San Juan Technologies, Inc.

3210 Arena Road

Colorado Springs CO 80921-1503

Gary Schnittgrund

Rocketdyne, BA05

6633 Canoga Avenue

Canoga Park CA 91303

Mark Schomp

Lonza, Inc.

17-17 Route 208

Fair Lann NJ 07410

Joop Schoonman

Delft University of Technology

P.0. Box 5045

2600 GA Delft

THE NETHERLANDS

Robert B. Schulz

U.S. Department of Energy

Office of Transportation Matris.

CE-34, Forrestal Building

Washington DC 20585

Murray A. Schwartz

Materials Technology Consulting

30 Orchard Way, North

Potomac MD 20854
Peter Schwarzkopf

SRI International

333 Ravenswood Avenue

Menlo Park CA 94025

William T. Schwessinger

Multi-Arc Scientific Coatings

1064 Chicago Road

Troy MI 48083-4297

W. D. Scott

University of Washington

Materials Science Department

Mail Stop:FB10

Seattle WA 98195

Nancy Scoville

Thermo Electron Technologies

P.0. Box 9046

Wal tham MA 02254-9046

Thomas M. Sebestyen

U.S. Department of Energy

Advanced Propulsion Division

CE-322, Forrestal Building

Washington DC 20585

Brian Seegmiller

Coors Ceramics Company

600 9th Street

Golden CO 80401

T. B. Selover

AICRE/DIPPR

3575 Traver Road

Shaker Heights $\mathrm{OH} 44122$

Charles E. Semler

Semler Materials Services

4160 Mumford Court

Columbus $\mathrm{OH} 43220$

Thomas Service

Service Engineering Laboratory

324 Wells Street

Greenfield MA 01301

Kish Seth

Ethyl Corporation

P.0. Box 341

Baton F...! IA 70821 
Karleen Seybold

AlliedSignal Engines

P.0. Box 52180

Phoenix AZ 85072-2180

William J. Shack

Argonne National Laboratory

9700 S. Cass Avenue, B1dg. 212

Argonne IL 60439

Peter T.B. Shaffer

Technical Ceramics Laboratories, $4045 \mathrm{Nine} / \mathrm{McF}$ arl and Drive

Alpharetta GA 30201

Richard K. Shaltens

NASA Lewis Research Center

21000 Brookpark Road, MS:302-2

Clevel and $\mathrm{OH} 44135$

Robert S. Shane

1904 NW 22nd Street

Stuart FL 34994-9270

Ravi Shankar

Chromalloy

Research and Technology Division

Blaisdell Road

Orangeburg NY 10962

Terence Sheehan

Alpex Wheel Company

727 Berkley Street

New Milford NJ 07646

Dinesh K. Shetty

University of Utah

Materials Science and Engineering

Salt Lake City UT 84112

Masahide Shimizu

New Ceramics Association

Shirasagi 2-13-1-208, Nakano-ku

Tokyo 165

JAPAN

Thomas Shreves

American Ceramic Society, Inc.

735 Ceramic Place

Westerville $\mathrm{OH}$ 43081-8720
Jack D. Sibold

Coors Ceramics Company

4545 McIntyre Street

Golden $\mathrm{CO} 80403$

Johann Siebels

Volkswagen AG

Werkstofftechnologie

Postfach 3180

Wolfsburg 1

GERMANY

George H. Siegel

Point North Associates, Inc.

P.0. Box 907

Madison NJ 07940

Richard Silberglitt

FM Technologies, Inc.

10529-B Braddock Road

Fairfax VA 22032

Mary Silverberg

Norton Company

Goddard Road

Northboro MA 01532-1545

Gurpreet Singh

Department of the Navy

Code 56×31

Washington DC 20362-5101

Maurice J. Sinnott

University of Michigan

5106 IST Building

Ann Arbor MI 48109-2099

John Skildum

3M Company

3M Center

Building 224-2S-25

St. Paul MN 55144

Richard H. Smoak

Smoak \& Associates

3554 Hollyslope Road

Altadena CA 91001-3923 
Jay R. Smyth

AlliedSignal Engines

111 S. 34th Street, MS:503-412

Phoenix AZ 85034

Rafal A. Sobotowski

British Petroleum Company

Technical Center, Broadway

3092 Broadway Avenue

Clevel and $\mathrm{OH} 44115$

S. Somiya

Nishi Tokyo University

3-7-19 Seijo, Setagaya

Tokyo 157

JAPAN

Boyd W. Sorenson

DuPont Lanxide Composites

1300 Marrows Road

Newark DE 19711

Charles A. Sorrell

U.S. Department of Energy

Advanced Industrial Concepts

CE-232, Forrestal Building

Washington DC 20585

C. Spencer

EA Technology

Capenhurst Chester CH1 6ES

UNITED KINGDOM

Allen Spizzo

Hercules Inc.

Hercules Plaza

Wilmington DE 19894

Richard M. Spriggs

Alfred University

Center for Advanced Ceramic

Technology

Alfred NY 14802

Charles Spuckler

NASA Lewis Research Center 21000 Brookpark Road, MS:5-11

Cleveland $\mathrm{OH}$ 44135-3191
M. Srinivasan

Material Solutions

P.0. Box 663

Grand Island NY 14702-0663

Gordon L. Starr

Cummins Engine Company, Inc.

P.0. Box 3005, Mail Code:50182

Columbus IN 47202-3005

Tom Stillwagon

AlliedSignal, Inc.

Ceramic Components

P.0. Box 2960, MS:T21

Torrance CA 90509-2960

H. M. Stoller

TPL Inc.

3754 Hawkins, N.E.

Albuquerque NM 87109

Paul D. Stone

Dow Chemical USA

1776 "Eye" Street, N.W., \#575

Washington DC 20006

F. W. Stringer

Aero \& Industrial Technology Ltd.

P.0. Box 46, Wood Top

Burnley Lancashire BB11 4BX

UNITED KINGDOM

Thomas N. Strom

NASA Lewis Research Center

21000 Brookpark Road, MS:86-6

Clevel and $\mathrm{OH} 44135$

M. F. Stroosnijder

Institute for Advanced Materials

Joint Research Centre

21020 Ispra (VA)

ITALY

Karsten Styhr

30604 Ganado Drive

Rancho Palos Verdes CA 90274

T. S. Sudarshan

Materials Modification, Inc.

2929-P1 Eskridge Center

Fairfax VA 22031 
M. J. Sundaresan

University of Miami

P.0. Box 248294

Coral Gables FL 33124

Patrick L. Sutton

U.S. Department of Energy

Office of Propulsion Systems

CE-322, Forrestal Building

Washington DC 20585

Willard H. Sutton

United Technologies Corporation

Silver Lane, MS:24

East Hartford CT 06108

J. J. Swab

U.S. Army Materials Technology

Ceramics Research Division,

SLCMT-EMC

405 Arsenal Street

Watertown MA 02172

Robert E. Swanson

Metalworking Technology, Inc.

1450 Scalp Avenue

Johnstown PA 15904

Steve Szaruga

Air Force Wright Aeronautical Lab WL/MLBC

Wright-Patterson AFB OH 45433-6533

Yo Tajima

NGK Spark Plug Company

2808 Iwasaki

Komaki-shi Aichi-ken 485

JAPAN

Fred Teeter

5 Tralee Terrace

East Amherst NY 14051

Monika 0. Ten Eyck

Carborundum Company

Technology Division

P.0. Box 832

Niagara Falls NY 14302
David F. Thompson

Corning Glass Works

SP-DV-02-1

Corning NY 14831

Merle L. Thorpe

Hobart Tafa Technologies, Inc.

20 Ridge Road

Concord NH 03301-3010

T. Y. Tien

University of Michigan

Materials Science and Engineering

Dow Building

Ann Arbor MI 481C3

D. M. Tracey

Norton Company

Advanced Ceramics

Goddard Road

Northboro MA 01532-1545

L. J. Troste1, Jr.

Box 199

Princeton MA 01541

W. T. Tucker

General Electric Company

P.0. Box 8, B1dg. K1-4C35

Schenectady NY 12301

Masanori Ueki

Nippon Steel Corporation

1618 Ida

Nakahara-Ku Kawasaki 211

JAPAN

Filippo M. Ugolini

ATA Studio

Via Degli Scipioni, 268A

ROMA, 00192

ITALY

Donald L. Vaccari

General Motors Corporation

Allison Gas Turbines

P.0. Box 420, Speed Code S49

Indianapol is IN 46206-0420 
Carl F. Van Conant Boride Products, Inc. 2879 Aero Park Drive Traverse City MI 49684

Marcel H. Van De Voorde Commission of the European Comm. P.0. Box 2

1755 ZG Petten

THE NETHERLANDS

0. Van Der Biest

Katholieke Universiteit Leuven

Dept. Metaalkunde en Toegepaste

de Croylaan 2

B-3030 Leuven

BELGIUM

Michael Vannier

Washington University, St. Louis 510 S. Kings Highway

St. Louis MO 63110

Stan Venkatesan

Southern Coke \& Coal Corporation P.0. Box 52383

Knoxville TN 37950

V. Venkateswaran

Carborundum Company

Niagara Falls R\&D Center

P.0. Box 832

Niagara Falls NY 14302

Dennis Viechnicki

U.S. Army Materials Technology

405 Arsenal Street

Watertown MA 02172-0001

Ted Vojnovich

U.S. Department of Energy, ST-311

Office of Energy Research, 3F077P

Washington DC 20585

John D. Volt

E.I. Dupont de Nemours \& Co. Inc.

P.0. Box 80262

Wilminaton DE 19880
John B. Wachtman

Rutgers University

P.0. Box 909

Piscataway NJ 08855

Shigetaka Wada

Toyota Central Research Labs

Nagakute Aichi 480-11

JAPAN

Janet Wade

AlliedSignal Engines

P.0. Box 52180, MS:1303-2

Phoenix AZ 85072-2180

Richard L. Wagner

Ceramic Technologies, Inc.

537 Turtle Creek South Dr., \#24D

Indianapol is IN 46227

J. Bruce Wagner, Jr.

Arizona State University

Center for Solid State Science

Tempe AZ 85287-1704

Daniel J. Wahlen

Kohler, Co.

$444 \mathrm{Highl}$ and Drive

Kohler WI 53044

Ingrid Wahlgren

Royal Institute of Technology

Studsvik Library

S-611 82 Nykoping

SWEDEN

Ron H. Walecki

AlliedSignal, Inc.

Ceramic Components

P.0. Box 2960, MS:T21

Torrance CA 90509-2960

Michael S. Walsh

Vapor Technologies Inc.

2100 Central Averiue

Boulder CO 80301 
Chien-Min Wang

Industrial Technology Research Institute

195 Chung-Hsing Road, Sec. 4

Chutung Hsinchu 31015 R.O.C.

TAIWAN

Robert M. Washburn

ASMT

11203 Colima Road

Whittier CA 90604

Gerald Q. Weaver

Carborundum Specialty Products

42 Linus Allain Avenue

Gardner MA 01440-2478

Kevin Webber

Toyota Technical Center, U.S.A. 1410 Woodridge, RR7

Ann Arbor MI 48105

Karen E. Weber

Detroit Diesel Corporation

13400 Outer Drive West

Detroit MI 48239-4001

James $K$. Weddell

Du Pont Lanxide Composites Inc.

P.0. Box 6100

Newark DE 19714-6100

R. W. Weeks

Argonne National Laboratory

MCT-212

9700 S. Cass Avenue

Argonne IL 60439

Ludwig Weiler

ASEA Brown Boveri AG

Eppelheimer Str. 82

D-6900 Heidelberg

GERMANY

James Wesse 1

Dow Corning Corporation

1800 "M" Street, N.W., \#325 South

Washington DC 20036
Robert D. West

Therm Advanced Ceramics

P. 0. Box 220

Ithaca NY 14851

Thomas J. Whalen

Ford Research Laboratory

1845 Cypress Point Court

Ann Arbor MI 48108

Ian A. White

Hoeganaes Corporation

River Road

Riverton NJ 08077

Sheldon M. Wiederhorn

NIST

Building 223, Room A329

Gaithersburg MD 20899

John F. Wight

Alfred University

McMahon Building

Alfred NY 14802

D. S. Wilkinson

McMaster University

1280 Main Street, West

Hamilton Ontario L8S 4 L7

CANADA

James C. Williams

General Electric Company

Engineering Materials Technology

One Neumann Way, Mail Drop:H85

Cincinnati $\mathrm{OH}$ 45215-6301

Steve J. Williams

RCG Hagler Bailly, Inc.

1530 Wilson Boulevard, Suite 900

Arlington VA 22209-2406

Thomas A. Williams

National Renewable Energy Lab

1617 Cole Boulevard

Golden CO 80401 
Craig A. Willkens

Norton Company

Advanced Ceramics

Goddard Road

Northboro MA 01532-1545

Roger R. Wills

TRW, Inc.

Valve Division

1455 East 185th Street

Cleveland $\mathrm{OH} 44110$

David Gordon Wilson

Massachusetts Institute of

Technology

77 Massachusetts Ave., Room 3-455

Cambridge MA 02139

Matthew F. Winkler

Seaworthy Systems, Inc.

P.0. Box 965

Essex CT 06426

Gerhard Winter

Hermann C. Starck Berlin GmbH

P.0. Box 2540

D-3380 Gos lar 3380

GERMANY

W. L. Winterbottom

Ford Motor Company

MD 2313 SRL

P.0. Box 2053

Dearborn MI 48121-2053

William T. Wintucky

NASA Lewis Research Center

Terrestrial Propulsion Office

21000 Brookpark Road, MS:86-6

Cleveland $\mathrm{OH} 44135$

Thomas J. Wissing

Eaton Corporation

Engineering and Research Center

P.0. Box 766

Southfield MI 48037
James C. Withers

MER Corporation

7960 S. Kolb Road

Building $F$

Tucson AZ 85706

Dale E. Wittmer

Southern Illinois University

Mechanical Engineering Department

Carbondale IL 62901

Warren W. Wolf

Owens Corning Fiberglass

2790 Columbus Road, Route 16

Granville OH 43023

Egon E. Wolff

Caterpillar Inc.

Technical Center

P.0. Box 1875

Peoria IL 61656-1875

George W. Wolter

Howmet Turbine Components Corp.

Technical Center

699 Benston Road

Whitehall MI 49461

James C. Wood

NASA Lewis Research Center

21000 Brookpark Road, MS:86-6

$\mathrm{Clevel}$ and $\mathrm{OH} 44135$

Marrill Wood

LECO Corporation

P.0. Box 211688

Augusta GA 30917-1688

Wayne L. Worrell

University of Pennsylvania

3231 Walnut Street

Philadelphia PA 19104

John F. Wosinski

Corning Inc.

ME-2 E-5 H8

Corning NY 14830 
Ian G. Wright

$B C L$

$505 \mathrm{King}$ Avenue

Columbus $\mathrm{OH} 43201$

Ruth Wroe

ERDC

Capenhurst Chester CH1 6ES

ENGLAND

Bernard J. Wrona

Advanced Composite Materials Corp

1525 S. Buncombe Road

Greer SC 29651

Carl C. M. Wu

Naval Research Laboratory

Ceramic Branch, Code 6373

Washington DC 20375

John C. Wurst

$U$. of Dayton Research Institute

300 College Park

Dayton $\mathrm{OH}$ 45469-0101

Neil Wyant

ARCH Development Corp.

9700 S. Cass Avenue, B1dg. 202

Argonne IL 60439

Roy Yamamoto

Texaco Inc.

P.0. Box 509

Beacon NY 12508-0509

John Yamanis

AlliedSignal Aerospace Company

P.0. Box 1021

Morristown NJ 07962-1021

Harry C. Yeh

AlliedSignal, Inc.

Ceramic Components

P.0. Box 2960, MS:T21

Torrance CA 90509-2960

Hiroshi Yokoyama

Hitachi Research Lab

$4026 \mathrm{Kuji}$-Cho

Hitachi-shi Ibaraki 319-12

JAPAN
Thomas M. Yonushonis

Cummins Engine Company, Inc.

P.0. Box 3005, Mail code 50183

Columbus IN 47202-3005

Thomas J. Yost

Corning Inc.

Technical Products Div., 21-1-2

Corning NY 14831

Jong Yung

Sundstrand Aviation Operations

4747 Harrison Avenue

Rockford IL 61125

A. L. Zadoks

Caterpillar Inc.

Technical Center, Building L

P.0. Box 1875

Peoria IL 61656-1875

Avi Zangvil

University of Illinois

104 S. Goodwin Avenue

Urbana IL 61801

Charles H. Zenuk

Transtech

1340 N. Via Ronda Oeste

Tucson AZ 85715-4830

Carl Zweben

General Electric Company

P.0. Box 8555, VFSC/V4019

Philadelphia PA 19101

Department of Energy

Oak Ridge Operations Office

Assistant Manager for Eviergy

Research and Development

P.0. Box 2001

Oak Ridge, TN 37831-8600

Department of Energy (2)

Office of Scientific and Technical Information

Office of Information Services

P.0. Box 62

Oak Ridge, TN 37831

For distribution by microfiche

as shown in DOE/OSTI-4500,

Distribution Category UC-332

(Ceramics/Advanced Materials). 

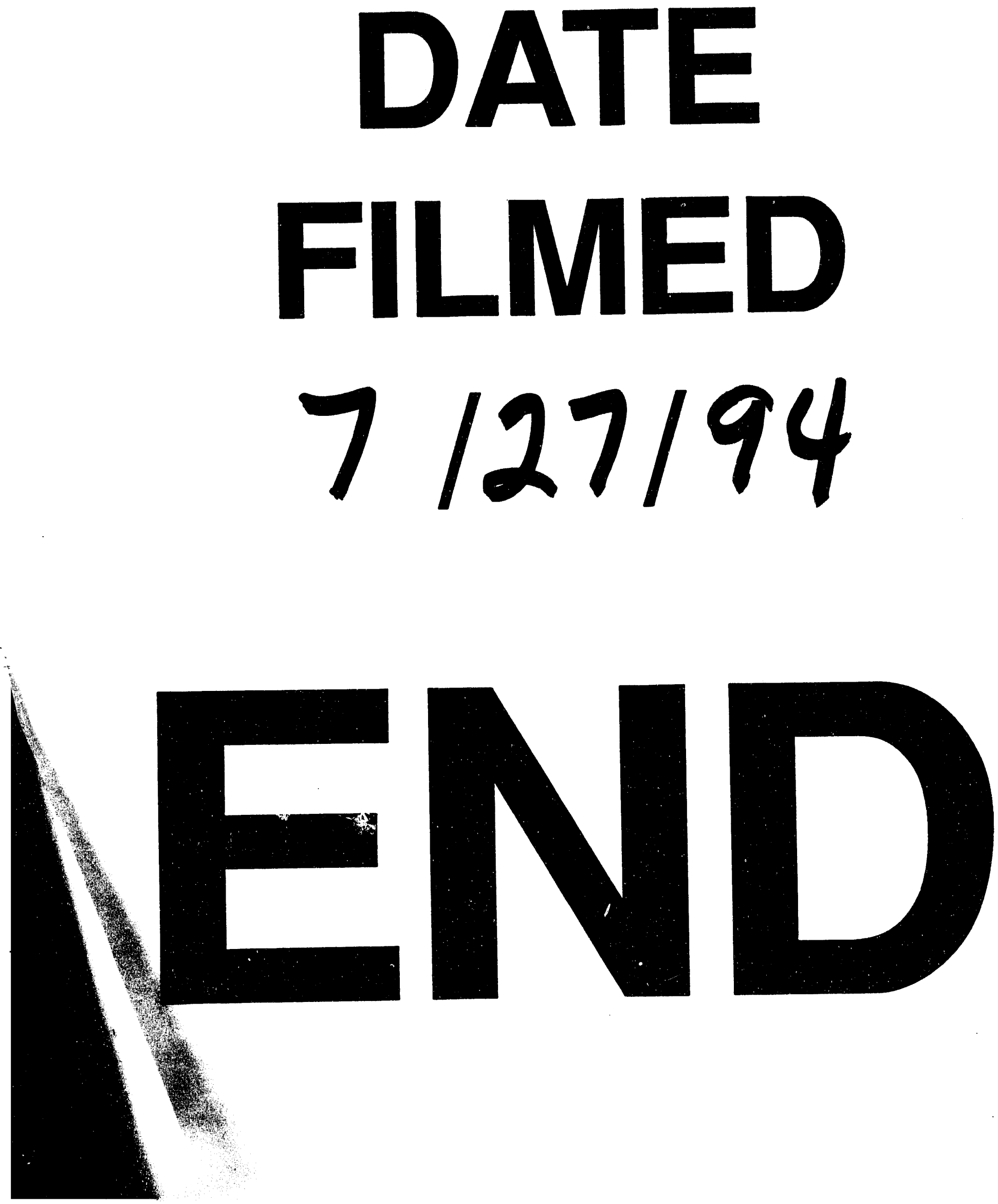
